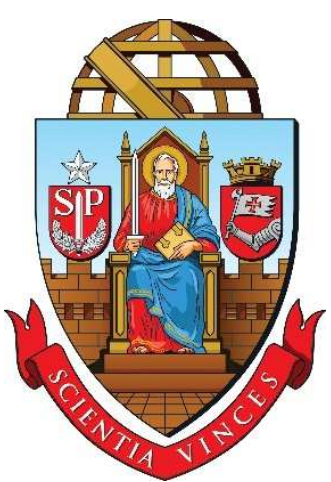

UNIVERSIDADE DE SÃO PAULO

INSTITUTO DE QUÍMICA DE SÃO CARLOS

Estudo da ocorrência de reações de bio-oxidação dos esteroides progesterona e 17a-etinilestradiol por fungos de ambiente marinho

Samuel Filipe Cardoso de Paula 
Samuel Filipe Cardoso de Paula

\section{Estudo da ocorrência de reações de bio-oxidação dos esteroides progesterona e 17a-etinilestradiol por fungos de ambiente marinho}

Dissertação apresentada ao Instituto de Química de São Carlos da Universidade de São Paulo para obtenção do título de Mestre em Ciências.

Área de concentração: Química Orgânica e Biológica.

Orientador: Prof. Dr. André Luiz Meleiro Porto.

\section{Exemplar revisado}

$\mathrm{O}$ exemplar original encontra-se em acervo reservado na Biblioteca do IQSC-USP

São Carlos 
Autorizo a reprodução e divulgação total ou parcial deste trabalho, por qualquer meio convencional ou eletrônico para fins de estudo e pesquisa, desde que citada a fonte.

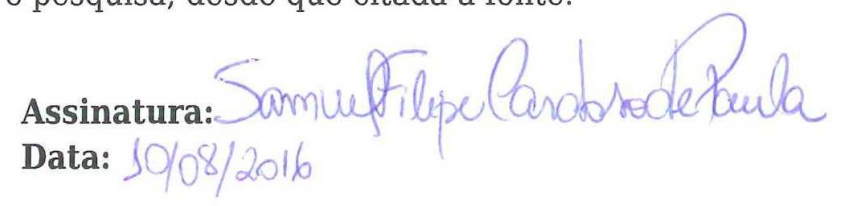

De Paula, Samuel Filipe Cardoso

Estudo da ocorrência de reações de bio-oxidação dos esteroides Progesterona e 17 alfa-Etinilestradiol por fungos de ambiente marinho / Samuel Filipe Cardoso De Paula. - São Carlos, 2016. $277 \mathrm{f}$.

Dissertação (Mestrado em Química Orgânica e Biológica) - Instituto de Química de São Carlos / Universidade de São Paulo, 2016.

Edição revisada

Orientador: Prof. Dr. André Luiz Meleiro Porto

1. Biotransformação. 2. Fungos Marinhos. 3. Progesterona. 4.17 alfaEtinilestradiol. 5. Bio-oxidação. I. Título.

$$
\begin{aligned}
& \text { Referências Bibliográficas } \\
& \text { conferidas pelo SBZIIQSC }
\end{aligned}
$$




\section{AGRADECIMENTOS}

A Deus: pelo Seu perdão, graça, amizade, proteção, força em meio às lutas e dificuldades e pelas bênçãos derramadas no âmbito profissional, social e pessoal. Não apenas grato a Ele por essas dádivas recebidas durante o período de desenvolvimento deste trabalho, mas por toda uma vida.

Aos meus pais, Getúlio e Regina, e à minha irmã Taynã pelo amor e carinho recebidos. Pela compreensão e apoio dedicados durante a construção deste trabalho, que se deu à longa distância de minha terra, meu lar.

Ao Prof. Dr. André Luiz Meleiro Porto pela orientação profissional e acadêmica prestada para o desenvolvimento deste trabalho.

Ao Conselho Nacional de Desenvolvimento Científico e Tecnológico (CNPq) pela bolsa de mestrado concedida.

À Fundação de Amparo à Pesquisa do Estado de São Paulo (FAPESP) pelo auxílio à pesquisa prestado.

Ao Instituto de Química de São Carlos (IQSC) da Universidade de São Paulo pela infraestrutura necessária para o desenvolvimento deste trabalho.

Aos técnicos Marília Peret e João Pedro Lima pelo auxílio prestado e amizade construída.

Aos colegas de pós-graduação do Laboratório de Química Orgânica e Biocatálise que comigo conviveram durante a execução deste trabalho: Sandra Ribeiro (in memorian), Irlon Maciel, Natália Alvarenga, David Quintero, William Birolli, Darlisson de Alexandria, Iara Matos, Rafaely Lima, Charlene Anjos, Juliana Scramin, Juliana Barreiro e Paulo Soares. Faço também menção aos alunos de Iniciação Cientifica do Laboratório: Eloá Borges, Bia Anjos, Aline Morais, Graciele Neves, Muriel Thaiara, Leonardo Totti, Marylyn Arai e Lucas Casari. Grato pela convivência e pelas sugestões dadas. 
À Edvânia Fernandes e Jhenifer Santos pela amizade e por sempre cuidar do nosso ambiente de trabalho e pesquisa.

A Central de Análises Químicas Instrumentais (CAQI) do IQSC pelas análises executadas para caracterizações dos compostos obtidos neste trabalho.

Ao Prof. Dr. Isac George Rosset do Departamento de Engenharias e Exatas da Universidade Federal do Paraná - Setor Palotina, pelos estudos teóricos realizados.

Aos componentes da comissão julgadora desta dissertação pelas sugestões dadas para aprimoramento deste trabalho: Prof ${ }^{\mathrm{a}}$. Dr ${ }^{\mathrm{a}}$. Ângela Regina Araújo do Instituto de Química de Araraquara - Universidade Estadual Paulista Júlio Mesquita Filho (IQAr-UNESP) e Prof. Dr. Paulo Cézar Vieira do Departamento de Química da Universidade Federal de São Carlos (DQUFSCar).

Aos amigos da Região Metropolitana de Belo Horizonte e de Almenara, no Vale do Jequitinhonha (Minas Gerais), que ficaram distantes geograficamente, mas, que torceram, oraram, me apoiaram e incentivaram a trilhar esse caminho. Grato também aos meus novos amigos feitos em São Carlos e região. Todos me incentivaram, concederam sua amizade e pude compartilhar momentos de alegria, risos e descontração. Contudo, faço menção especial aos casais Eduardo e Heliny Máximo, Walcyr e Maria Helena Tedeschi e ao senhor Waldeci Albino. Faço menção especial a estes porque, além da amizade e das alegrias compartilhadas, demonstraram interesse e preocupação com minha pessoa em face das minhas angústias, meus sofrimentos, meus conflitos que outrora, pouco foram percebidos por quem convivi. Em face disso, esses me ouviram sem julgamentos, sem censura e sempre me deram uma palavra de ânimo e conforto. A esses fica aqui meu singelo muito obrigado e poder encerrar esse trabalho devo muito a vocês.

Aos demais docentes, funcionários efetivos, terceirizados e discentes do IQSC e da USP de São Carlos pelas sugestões dicas e convivência.

E a todos que de forma indireta puderam trazer boas contribuições para execução deste trabalho. 
"Creia, experimente e saberás."

Siegfreud Júlio Schwantes - Colunas do Caráter 


\section{RESUMO}

Neste trabalho foram realizados estudos de reações de bio-oxidação dos esteroides progesterona e $17 \alpha$-etinilestradiol por fungos de ambiente marinho. Para a progesterona foi feita uma triagem de reações com os caldos enzimáticos e as massas miceliais dos fungos Aspergillus sydowii CBMAI 934, Aspergillus sydowii CBMAI 935, Penicilium oxalicum CBMAI 1185 e Penicilium citrinum CBMAI 1186. Para as reações envolvendo os fungos A. sydowii CBMAI 935, $P$. oxalicum CBMAI 1185 e P. citrinum CBMAI 1186 os produtos majoritários observados foram os metabólitos testosterona e testololactona, produtos de oxidação da progesterona promovida por enzimas do tipo Baeyer-Villiger monoxigenases. Para as reações envolvendo o fungo $A$. sydowii CBMAI 934 foram observados produtos de hidroxilação da progesterona em carbonos do núcleo esteroidal não ativados eletronicamente, sendo produtos de oxidação da progesterona promovida por enzimas do citocromo P-450. Da triagem foram selecionados os fungos $A$. sydowii CBMAI 934 e A. sydowii CBMAI 935 para executar reações de bio-oxidação em quintuplicatas $\left(32^{\circ} \mathrm{C}, 130 \mathrm{rpm}, \mathrm{pH} 7,4\right)$ utilizando o caldo enzimático e a massa micelial para isolamento e caracterizações espectroscópicas (RMN, EMAR e IV) e polarimétricas dos produtos majoritários. Após 14 dias de reação com o caldo enzimático do fungo A. sydowii CBMAI 934 foi isolado a 7,15-di-hidroxiprogesterona com $13 \%$ de rendimento em massa. Contudo não foi possível determinar com exatidão a configuração relativa dos grupos hidroxilas. Já para a reação com a massa micelial do fungo A. sydowii CBMAI 934 após 14 dias de reação foi isolado o produto $15 \beta$-hidroxiprogesterona com $58 \%$ de rendimento em massa. Após 7 dias de reação com o caldo enzimático do fungo A. sydowii CBMAI 935 foram isolados os produtos testosterona e testololactona com rendimentos em massa de $24 \%$ e $36 \%$, respectivamente. A testololactona também foi isolada da reação com a massa micelial do fungo A. sydowii CBMAI 935 após 7 dias com rendimento em massa de 87\%. Para o 17 $\alpha$ etinilestradiol foi feita uma triagem com os mesmos fungos utilizados na triagem das reações com a progesterona, exceto com o fungo A. sydowii CBMAI 934. Após 7 dias de reação e nas mesmas condições das reações com a progesterona, não foram observados produtos de biotransformação do 17a-etinilestradiol. Este estudo envolvendo a bio-oxidação da progesterona mostra o potencial de biotransformação de fármacos esteroidais no meio ambiente.

Palavras Chave: biotransformação, fungos marinhos, progesterona, 17 $\alpha$-etinilestradiol, biooxidação. 


\begin{abstract}
In this work was performed bio-oxidation studies of steroids progesterone and $17 \alpha-$ ethynylestradiol by marine-derived fungi. For progesterone was performed a reactions screening with culture broth and micelia from Aspergillus sydowii CBMAI 934, Aspergillus sydowii CBMAI 935, Penicilium oxalicum CBMAI 1185 e Penicilium citrinum CBMAI 1186. For reactions using A. sydowii CBMAI 935, P. oxalicum CBMAI 1185 e P. citrinum CBMAI 1186 the majoritarian products obtained were testosterone and testololactone, products from progesterone oxidation by Baeyer-Villiger mono-oxygenases enzymes. For reactions using $A$. sydowii CBMAI 934 was observed hydroxylation products from progesterone in carbons of progesterone by eletronic factors. The enzymes than promoted the hydroxylation of the progesterone were of citochrome P-450 group. From screening was selected A. sydowii CBMAI 934 and $A$. sydowii CBMAI 935 for quintuplicate bio-oxydations $\left(32^{\circ} \mathrm{C}, 130 \mathrm{rpm}, \mathrm{pH} 7,4\right)$ using the culture broth and micelia for isolation and spectroscopicals caracterizations (NMR, HRMS and IR) and polarimetrics of majoritary products. After 14 days, the reaction with culture broth from A. sydowii CBMAI 934 was isolated 7,15-dihydroxyprogesterone with 13\% yield. But, the configurations of hydroxy groups were not possible to determine. Already for reaction with micelia from A. sydowii CBMAI 934 was isolated 15ß-hydroxyprogesterone with 58\% yield. After 7 days the reaction with culture broth from A. sydowii CBMAI 935 was isolated the testosterone and testololactone with $24 \%$ and $36 \%$ yields, respectively. The Testololactone also was isolated from reaction with micelia from A. sydowii CBMAI 935 after 7 days with $87 \%$ yield. For $17 \alpha$-ethynylestradiol was performed a screening with same fungi used in reaction screening with Progesterone, except the A. sydowii CBMAI 934. After 7 days in same condictions of reactions with Progesterone, It was not observed products from $17 \alpha-$ ethynylestradiol. This study involving the bio-oxidation from Progesterone showed the potential of biontrasnformations steroidal drugs in environment.
\end{abstract}

Keywords: biotransformation, progesterone, 17 $\alpha$-ethynylestradiol, marine-derived fungi, biooxidation 


\section{LISTA DE FIGURAS}

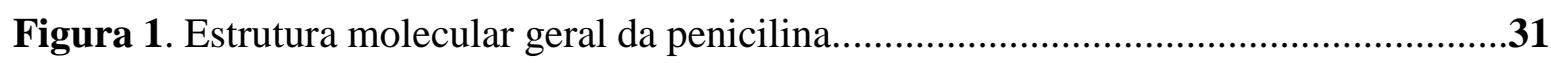

Figura 2. Fluxograma para a produção industrial da penicilina..........................................32

Figura 3. Estruturas químicas de cofatores: (A) $\mathrm{NAD}^{+}$, (B) flavina e (C) vitamina $\mathrm{B} 12 \ldots . .35$

Figura 4. Classificação das oxidorredutases................................................................36

Figura 5. Estrutura químicas de cofatores: (A) NADPH, (B) FADH...................................37

Figura 6. Ilustração geral do mecanismo de oxidação por enzimas do citocromo P-450.......40

Figura 7. Estrutura química do cofator FMN .........................................................41

Figura 8. Representações dos esqueletos estruturais dos esteroides..................................46

Figura 9. Orientações espaciais dos hidrogênios ligados aos carbonos da junções dos anéis B,C e D do núcleo tetracíclico de esteroides.......................................................................47

Figura 10. Conformações espaciais dos esteroides: (A) de tipo $\alpha$, (B) de tipo $\beta \ldots \ldots \ldots \ldots \ldots \ldots . . . . .47$

Figura 11. Hormônios sexuais femininos do tipo estrogênios...............................................48

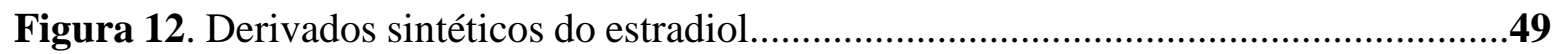

Figura 13. Principais anticoncepcionais progestógenos...................................................49

Figura 14. Fórmula estrutural da cortisona......................................................................50

Figura 15. Fármacos esteroidais para biotransformação com fungos de ambiente marinho..60

Figura 16. Preparo dos meios de cultura sólido para cultivo das cepas dos fungos deste trabalho.

Figura 17. Preparo dos meios de cultura líquidos para cultivo das cepas dos fungos deste trabalho. .66

Figura 18. Ilustração das etapas de inoculação e cultivo dos fungos em meio líquido. .67

Figura 19. Procedimento de avaliação do crescimento do fungo A. sydowii CBMAI 934 na presença de DMSO.

Figura 20. Procedimento de biotransformação dos substratos com a massa micelial. .70

Figura 21. Etapas do procedimento de monitoramento da biotransformação dos substratos com a massa micelial fúngica. 
Figura 22. Etapas do procedimento de biotransformação dos substratos com o caldo enzimático

Figura 23. Etapas do procedimento de monitoramento da biotransformação dos substratos com o caldo enzumático

Figura 24. Procedimento de extração das reações de biotransformação com a massa micelial.

Figura 25. Procedimento de concentração da fase orgânica obtida da extração das reações de biotransformação com a massa micelial .76

Figura 26. Procedimento de extração das reações de biotransformação com o caldo enzimático. .78

Figura 27. Procedimento de concentração da fase orgânica obtida da extração das reações de biotransformação com o caldo enzimático. 79

Figura 28. Procedimento de separação, isolamento e purificação dos produtos de biotransformação contidos nos extratos obtidos das reações com os fungos de ambiente marinho.

.80

Figura 29. Procedimento de isolamento dos produtos de biotransformação dos esteroides contidos nos extratos obtidos das reações com os fungos de ambiente marinho.

Figura 30. Estruturas de esteroides encontrados em água determinados por GOMES et al. (2013), utilizando cromatografia gasosa bidimensional acoplada a espectroscopia de massas (CGxCG-EM) 88

Figura 31. Cromatogramas obtidos dos padrões de esteroides por CG-EM. .89

Figura 32. Cromatogramas obtidos dos extratos dos caldos enzimáticos na ausência dos esteroides após 14 dias de agitação.....

Figura 33. Espectros de massas $(70 \mathrm{eV})$ : $(\mathrm{A})$ experimental para composto $t_{\mathrm{R}}=7,75$ minutos, (B) pirrol[1,2-a]pirazina-1,4-diona,hexa-hidro-3-(2-metilpropil) (similaridade 62\%, biblioteca NIST107), (C) experimental composto $t_{R}=4,77$ minutos, (D) 1-tridecanol (similaridade 96\%, biblioteca NIST21), (E) experimental para composto $t_{R}=10,00$ minutos, (F) 1-triacontanol (similaridade 85\%, biblioteca NIST05s). .94

Figura 34. Cromatogramas obtidos dos extratos dos meios com massa micelial na ausência dos esteroides após 14 dias de agitação. 
Figura 35. Espectros de massas $(70 \mathrm{eV})$ : (A) experimental para composto $t_{\mathrm{R}}=4,60$ minutos (fungo A. sydowii CBMAI 934), (B) 1-trideceno (similaridade 95\%, biblioteca NIST21), (C) experimental composto $t_{R}=7,87$ minutos (fungo A. sydowii CBMAI 934), (D) ácido 1pentadecanoico (similaridade 92\%, biblioteca WILEY 8), (E) experimental para composto $t_{R}$ = 8,73 minutos (fungo A. sydowii CBMAI 934), (F) ácido 9,12 (Z,Z) octadienoico (similaridade $85 \%$, biblioteca NIST05s). (G) experimental para composto $t_{R}=13,24$ minutos (fungo A.sydowii CBMAI 934), (H) antiaergosta-1,5,7,9,22-pentaeno (similaridade 63\%, biblioteca NIST05), (I) experimental composto $t_{R}=15,14$ minutos (fungo A. sydowii CBMAI 934), (J) 5,9(11)androstatrieno,3-hidroxi-17-oxo (similaridade 63\%, biblioteca NIST 05), (K) experiemntal para composto $t_{R}=15,61$ minutos. (fungo A. sydowii CBMAI 934), (L) Ergosterol (similaridade 86\%, biblioteca NIST05).

Figura 36. Cromatogramas obtidos da análise dos extratos em acetato de etila provenientes das triagens das reações de biotransformação da progesterona com os caldos enzimáticos dos fungos empregados neste trabalho após 7 dias de reação.

Figura 37. Espectros de massas $(70 \mathrm{eV})$ : (A) experimental para composto $t_{\mathrm{R}}=11,50$ minutos (fungo A. sydowii CBMAI 935), (B) testosterona (similaridade 85\% biblioteca WILEY 8, (C) experimental para o composto $\mathrm{t}_{\mathrm{R}}=14,36$ minutos (fungo A. sydowii CBMAI 935), (D) testololactona (similaridade $83 \%$, biblioteca NIST107).

Figura 38. Espectros de massas (70 eV): (A) experimental para composto $t_{\mathrm{R}}=13,44$ minutos (fungo A. sydowii CBMAI 934), (B) 11 $\alpha$-hidroxiprogesterona (similaridade 65\%, biblioteca NIST21)...... .101

Figura 39. Cromatogramas obtidos das análises dos extratos em acetato de etila provenientes das triagens das reações de biotransformação da progesterona com os caldos enzimáticos dos fungos empregados neste trabalho após 14 dias de reação.

Figura 40. Espectros de massas $(70 \mathrm{eV})$ : (A) experimental para composto $t_{\mathrm{R}}=12,74$ minutos (fungo A. sydowii CBMAI 934), (B) 63-hidroxiprogesterona (similaridade $77 \%$ biblioteca NIST05)...... 103

Figura 41. Cromatogramas obtidos das análises dos extratos em acetato de etila provenientes das triagens das reações de biotransformação da progesterona com os micélios dos fungos empregados neste trabalho após 7 dias de reação.....

.104

Figura 42. Espectros de massas (70 eV): (A) experimental para composto $t_{R}=15,29$ minutos (fungo A. sydowii CBMAI 934), (B) 63-hidroximetanodienona (similaridade 66\% biblioteca NIST05)...... .105

Figura 43. Cromatogramas obtidos das análises dos extratos em acetato de etila provenientes das triagens das reações de biotransformação da progesterona com os micélios dos fungos empregados neste trabalho após 14 dias de reação. 
Figura 44. Espectros de massas $(70 \mathrm{eV})$ : (A) experimental para composto $t_{\mathrm{R}}=9,00$ minutos (fungo P.citrinumi CBMAI 1186), (B) ácido 1-octadecanoico (similaridade 91\% biblioteca NIST05)......

Figura 45. Estrutura molecular do Cortisol.

Figura 46. Cromatograma obtido por CG-EM do extrato em acetato de etila obtido da biotransformação da progesterona pelo caldo enzimático proveniente do fungo A. sydowii CBMAI 934.

Figura 47. Espectros de massas $(70 \mathrm{eV})$ : $(\mathrm{A})$ experimental para composto $\mathrm{t}_{\mathrm{R}}=14,68$ minutos (B) $15 \beta$-hidroxiprogesterona (similaridade $81 \%$ biblioteca NIST05). 111

Figura 48. Análise das frações obtidas por CG-EM após separação por cromatografia em coluna dos metabólitos majoritários presentes no extrato da biotransformação da progesterona com caldo enzimático do fungo A. sydowii CBMAI 934.

Figura 49. Espectros de massas $(70 \mathrm{eV})$ : $(\mathrm{A})$ experimental para composto $t_{\mathrm{R}}=14,74$ minutos (frações 67-68), (B) experimental para composto $t_{R}=14,74$ minutos (frações 69-73), (C) 15ßhidroxiprogesterona (similaridade $82 \%$ biblioteca NIST05).

Figura 50. Cromatograma obtido por CG-EM do extrato em acetato de etila obtido da biotransformação da progesterona pela massa micelial do fungo A. sydowii CBMAI 934...114

Figura 51. Espectros de massas (70 eV): (A) experimental para composto $t_{R}=14,68$ minutos, (B) $7 \alpha, 11 \alpha$-di-hidroxiprogesterona (similaridade: 64\%, biblioteca NIST07). (C) experimental para o composto com $t_{R}=17,74$ minutos (fração 69-73), (D) $16 \alpha, 17 \alpha$-epoxiprogesterona (similaridade $73 \%$ biblioteca NIST07).

.116

Figura 52. Análise das frações obtidas por CG-EM após separação por cromatografia em coluna dos metabólitos majoritários presentes no extrato obtido da biotransformação da progesterona com a massa micelial do fungo A. sydowii CBMAI 934......

Figura 53. Espectros de massas $(70 \mathrm{eV})$ : (A) experimental para composto $t_{\mathrm{R}}=15,01$ minutos (frações 86-121), (B) $7 \alpha, 11 \alpha$ di-hidroxiprogesterona (similaridade 70\%, biblioteca NIST107) .119

Figura 54. Cromatograma obtido por CG-EM do extrato em acetato de etila da biotransformação da progesterona pelo caldo enzimático proveniente do fungo A. sydowii CBMAI 935.

Figura 55. Análise das frações obtidas por CG-EM após separação por cromatografia em coluna dos metabólitos majoritários presentes no extrato da biotransformação da progesterona com o caldo enzimático do fungo A. sydowii CBMAI 935.

Figura 56. Espectros de massas $(70 \mathrm{eV})$ : (A) experimental para composto $t_{\mathrm{R}}=11,53$ minutos (frações 29-35), (B) testosterona (similaridade 93\%, biblioteca NIST21). 
Figura 57. Espectros de massas $(70 \mathrm{eV})$ : (A) experimental para composto $t_{\mathrm{R}}=14,36$ minutos (frações 47-59), (B) testololactona (similaridade 82\%, biblioteca NIST107).

Figura 58. Cromatograma obtido por CG-EM do extrato em acetato de etila da biotransformação da progesterona pela massa micelial do fungo A. sydowii CBMAI 935...124

Figura 59. Análise das frações obtidas por CG-EM após separação por cromatografia em coluna dos metabólitos majoritários presentes no extrato obtido da biotransformação da progesterona com a massa micelial do fungo A sydowii CBMAI 935 126

Figura 60. Estruturas químicas para a progesterona: (A) planar, (B) tridimensional. 131

Figura 61. Espectros de $\mathrm{RMN}$ de ${ }^{13} \mathrm{C}\left(100 \mathrm{MHz}, \mathrm{CDCl}_{3}\right)$ : (A) progesterona; (B) produto dihidroxilado isolado da reação com o caldo enzimático do fungo A. sydowii CBMAI 934....133

Figura 62. Estruturas químicas dos possíveis estereoisômeros de produtos di-hidroxilados da

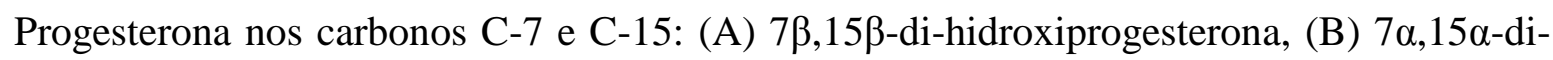
hidroxiprogesterona, (C) $7 \beta, 15 \alpha$-di-hidroxiprogesterona $\quad$ (D) $7 \alpha, 15 \beta$-dihidroxiprogesterona.

Figura 63. Estruturas químicas tridimensionais de dois possíveis estereoisômeros de produtos di-hidroxilados da progesterona nos carbonos C-7 e C-15: (A) 7 $\beta, 15 \beta$-dihidroxiprogesterona, (B) $7 \alpha, 15 \beta$-di-hidroxiprogesterona.

Figura 64. Espectros de RMN de HSQC (125 MHz E $500 \mathrm{MHz}, \mathrm{CDCl}_{3}$ ) ampliados: (A) progesterona; (B) produto di-hidroxilado isolado da reação com o caldo enzimático do fungo A.sydowii CBMAI 934.

Figura 65. Espectros de RMN de HSQC (125 MHz E $500 \mathrm{MHz}, \mathrm{CDCl}_{3}$ ) completos: (A) progesterona; (B) produto di-hidroxilado isolado da reação com o caldo enzimático do fungo A.sydowii CBMAI 934. 138

Figura 66. Algumas correlações $J_{\mathrm{HC}}$ observadas nos espectros de HMBC do produto dihidroxilado isolado da reação com o caldo enzimático do fungo A. sydowii CBMAI 934 (A) $J_{\mathrm{H} 7-\mathrm{C}},(\mathrm{B}) J_{\mathrm{H}-\mathrm{C} 7},(\mathrm{C}) J_{\mathrm{H}-\mathrm{C} 15}$, (D) $J_{\mathrm{H} 15-\mathrm{C}}$

Figura 67. Ampliação do espectro de RMN de $\mathrm{HMBC}\left(125 \mathrm{MHz}\right.$ e $\left.500 \mathrm{MHz}, \mathrm{CDCl}_{3}\right)$ do produto di-hidroxilado isolado da reação com o caldo enzimático do fungo A.sydowii CBMAI 934.

Figura 68. Algumas correlações $J_{\mathrm{HH}}$ observadas nos espectros de COSY do produto dihidroxilado isolado da reação com o caldo enzimático do fungo A. sydowii CBMAI 934: (A) $J_{\mathrm{H} 7-\mathrm{H}},(\mathrm{B}) J_{\mathrm{H} 15 \alpha-\mathrm{H}}$

Figura 69. Ampliação do espectro de $\mathrm{RMN}$ de $\mathrm{COSY}\left(400 \mathrm{MHz}, \mathrm{CDCl}_{3}\right.$ ) do produto dihidroxilado isolado da reação com o caldo enzimático do fungo A. sydowii CBMAI 934. 
Figura 70. Modelos para reconhecimento de sinais de ${ }^{1} \mathrm{H}$ em espectros de $\mathrm{RMN}$ de esteroides: (A) H-7, (B) H-15.

Figura 71. Sinais de multipletos de hidrogênios $\mathrm{H}-7$ obtidos de espectros de $\mathrm{RMN}$ de ${ }^{1} \mathrm{H}$ (400 $\mathrm{MHz}, \mathrm{CDCl}_{3}$ ): (A) progesterona (B) produto di-hidroxilado isolado da reação com o caldo enzimático do fungo $A$. sydowii CBMAI 934.

Figura 72. Algumas possíveis correlações $J_{\mathrm{HH}}$ da Progesterona obtidas a partir das constantes de acoplamentos calculdas dos sinais dos hidrogênios H-7: (A) $J_{\mathrm{H} 7 \alpha-\mathrm{H}}$, (B) $J_{\mathrm{H} 7 \beta-\mathrm{H}} \cdots$

Figura 73. Algumas possíveis correlações $J_{\mathrm{HH}}$ do produto di-hidroxilado obtidas a partir das constantes de acoplamentos calculdas dos sinais dos hidrogênios H-7: (A) $J_{\mathrm{H} 7 \alpha-\mathrm{H}}$, (B) $J_{\mathrm{H} 7 \beta-}$

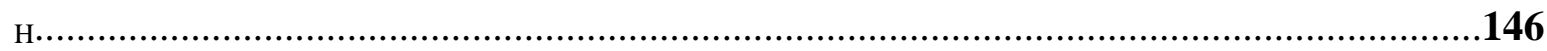

Figura 74. Sinais de multipletos de hidrogênios $\mathrm{H}-15$ obtidos de espectros de $\mathrm{RMN}$ de ${ }^{1} \mathrm{H}$ (400 MHz, $\mathrm{CDCl}_{3}$ ): (A) progesterona (B) produto di-hidroxilado isolado da reação com o caldo enzimático do fungo A.sydowii CBMAI 934.

Figura 75. Espectros de IV: (A) progesterona (B) produto di-hidroxilado isolado da reação com o caldo enzimático do fungo A.sydowii CBMAI 934.

Figura 76. Espectro de massas de alta resolução modo positivo $\left(\mathrm{H}^{+}\right)$do produto dihidroxilado isolado da reação com o caldo enzimático do fungo A.sydowii CBMAI 934.....152

Figura 77. Estruturas químicas planas e tridimensionais: (A) 15 $\beta$-hidroxiprogesterona, (B) $15 \alpha$-hidroxiprogesterona.

Figura 78. Espectros de $\mathrm{RMN}$ de ${ }^{13} \mathrm{C}\left(\mathrm{CDCl}_{3}\right)$ : (a) progesterona $(100 \mathrm{MHz})$; (b) $15 \beta$ hidroxiprogesterona obtida da reação com a massa micelial do fungo A. sydowii CBMAI 935 (125 MHz). 157

Figura 79. Espectros de RMN de $\mathrm{HSQC}\left(\mathrm{CDCl}_{3}\right)$ ampliados: (A) progesterona (125 $\mathrm{MHz}$ e $500 \mathrm{MHz}$ ); (B) 15ß-hidroxiprogesterona (100 MHz e $400 \mathrm{MHz}$ ).

Figura 80. Espectros de RMN de HSQC $\left(\mathrm{CDCl}_{3}\right)$ completos: (A) progesterona $(125 \mathrm{MHz}$ e $500 \mathrm{MHz}$ ); (B) 15 $\beta$-hidroxiprogesterona (100 MHz e $400 \mathrm{MHz}$ )....

Figura 81. Algumas correlações $J_{\mathrm{HC}}$ observadas nos espectros de $\mathrm{HMBC}$ da $15 \beta$ hidroxiprogesterona: (A) $J_{\mathrm{H}-\mathrm{C} 2}$, (B) $J_{\mathrm{H}-\mathrm{C} 15}$, (C) $J_{\mathrm{H}-\mathrm{C} 16}$, (D) $J_{\mathrm{H} 15 \alpha-\mathrm{C}}$.

Figura 82. Espectros de RMN de $\mathrm{HMBC}$ ampliado (100 $\mathrm{MHz}$ e $\left.400 \mathrm{MHz} \mathrm{CDCl}_{3}\right)$ da $15 \beta$ hidroxiprogesterona.

Figura 83. Algumas correlações $J_{\mathrm{HH}}$ observadas nos espectros de COSY da $15 \beta$ hidroxiprogesterona envolvendo o hidrogênio $\mathrm{H}-15 \alpha$

Figura 84. Espectros de RMN de COSY ampliado (400 $\mathrm{MHz}, \mathrm{CDCl}_{3}$ ) da $15 \beta$ hidroxiprogesterona. 
Figura 85. Sinais de multipletos de hidrogênios $\mathrm{H}-15$ obtidos de espectros de $\mathrm{RMN}$ de ${ }^{1} \mathrm{H}$ (400 MHz, $\mathrm{CDCl}_{3}$ ): (A) progesterona (B) $\mathrm{H}-15 \alpha$ da $15 \beta$-hidroxiprogesterona....................164

Figura 86. Espectros de IV: (A) progestesterona (B) $15 \beta$-hidroxiprogesterona.................168

Figura 87. Espectro de massas de alta resolução modo positivo $\left(\mathrm{H}^{+}\right)$da $15 \beta-$ hidroxiprogesterona isolada da reação da progesterona com a massa micelial do fungo $A$.

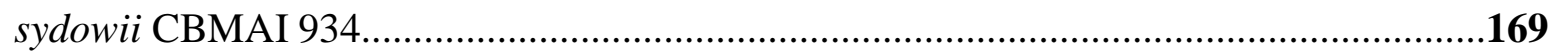

Figura 88. Estruturas químicas para a testosterona: (A) planar, (B) tridimensional...........173

Figura 89. Espectros de $\mathrm{RMN}$ de ${ }^{13} \mathrm{C}\left(100 \mathrm{MHz}, \mathrm{CDCl}_{3}\right)$ : (A) progesterona, (B)

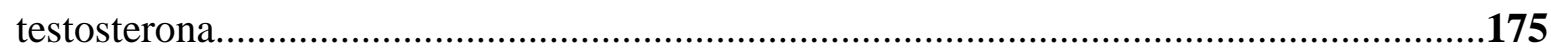

Figura 90. Espectros de RMN de HSQC $\left(\mathrm{CDCl}_{3}\right)$ ampliados: (A) progesterona $(125 \mathrm{MHz}$ e

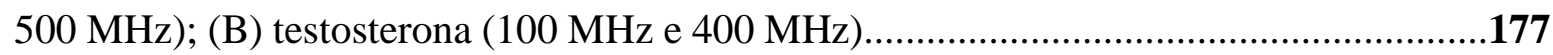

Figura 91. Espectros de RMN de HSQC $\left(\mathrm{CDCl}_{3}\right)$ completos: (A) progesterona (125 $\mathrm{MHz}$ e

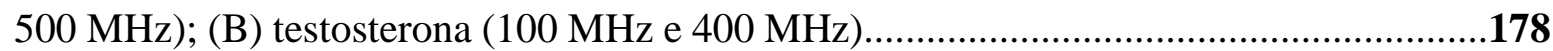

Figura 92. Algumas correlações $J_{\mathrm{HC}}$ observadas nos espectros de HMBC (100 MHz e 400

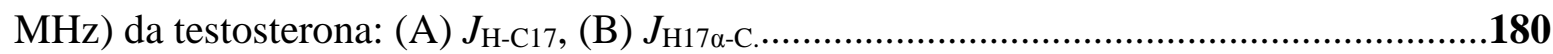

Figura 93. Espectros de RMN de HMBC ampliado (100 $\mathrm{MHz}$ e $400 \mathrm{MHz} \mathrm{CDCl}_{3}$ ) da testosterona.

Figura 94. Algumas correlações $J_{\mathrm{HH}}$ observadas nos espectros de COSY envolvendo o hidrogênio $\mathrm{H}-17 \alpha$ no anel D do núcleo dos esteroides: (A) progesterona, (B) testosterona isolda da reação com o caldo enzimático do fungo A. sydowii CBMAI 935, (C) "acoplamento W" entre H-18 e H-17 $\alpha$ na Progesterona, (D) "acoplamento W" entre H-18 e H-14 $\alpha$ na testosterona.

Figura 95. Espectros de RMN de COSY ampliados: (A) progesterona (500 $\mathrm{MHz}, \mathrm{CDCl}_{3}$ ), (B) testosterona isolada da reação com o caldo enzimático do fungo A. sydowii CBMAI 935 (400 MHz, $\left.\mathrm{CDCl}_{3}\right)$.

Figura 96. Espectros de $\mathrm{RMN}$ de ${ }^{1} \mathrm{H}\left(400 \mathrm{MHz}, \mathrm{CDCl}_{3}\right)$ ampliados: (A) progesterona, (B) testosterona isolada da reação com o caldo enzimático do fungo A. sydowii CBMAI 935..185

Figura 97. Comparação dos perfis de multiplicidade para o hidrogênio H-17 $\alpha$ do núcleo esteroidal: (A) modelo proposto por Kirk, et al. (1990) $)^{75}$, (B) multipleto para a progesterona, (C) multipleto para a testosterona isolada da reação com o caldo enzimático do fungo $A$. sydowii CBMAI 935.

Figura 98. Espectros de IV: (A) progestesterona (B) testosterona isolada da reação com o caldo enzimático do fungo A.sydowii CBMAI 935.

Figura 99. Espectro de IV para a testosterona. 
Figura 100. Estruturas químicas para a testololactona: (A) planar, (B) tridimensional......193

Figura 101. Espectros de $\mathrm{RMN}$ de ${ }^{13} \mathrm{C}$ : (A) progesterona (100 $\mathrm{MHz}, \mathrm{CDCl}_{3}$ ), (B)

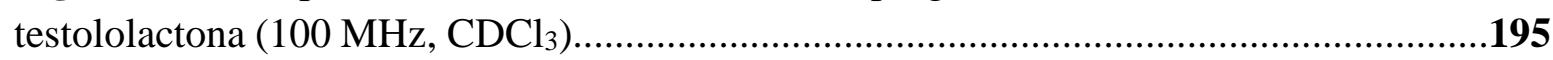

Figura 102. Espectros de $\mathrm{RMN}$ de $\mathrm{HSQC}\left(\mathrm{CDCl}_{3}\right)$ ampliados: $(\mathrm{A})$ progesterona $(125 \mathrm{MHz}$ e $500 \mathrm{MHz})$; (B) testololactona (100 MHz e $400 \mathrm{MHz})$..................................................197

Figura 103. Espectros de RMN de HSQC $\left(\mathrm{CDCl}_{3}\right)$ completos: (A) progesterona $(125 \mathrm{MHz}$ e $500 \mathrm{MHz})$; (B) testololactona (100 MHz e $400 \mathrm{MHz})$...

Figura 104. Correlações $J_{\mathrm{HC}}$ observadas nos espectros de $\mathrm{HMBC}$ no anel D do núcleo esteroidal: (A) $J_{\mathrm{H}-\mathrm{C} 13}$ na progesterona (B) $J_{\mathrm{H}-\mathrm{C} 13}$ na testololactona, (C) $J_{\mathrm{H}-\mathrm{C} 17}$ na progesterona, (D) $J_{\mathrm{H}-\mathrm{C} 17}$ na testololactona.

200

Figura 105. Espectros de RMN de HMBC (100 MHz e $400 \mathrm{MHz}$ ) ampliados: (A) progesterona; (B) testololactona.............................................................................201

Figura 106. Algumas correlações $J_{\mathrm{HH}}$ observadas nos espectros de COSY envolvendo o hidrogênio $\mathrm{H}-17 \alpha$ no anel $\mathrm{D}$ do núcleo dos esteroides: (A) progesterona, (B) testololactona.

Figura 107. Espectros de RMN de COSY ampliados: (A) progesterona (500 $\mathrm{MHz}, \mathrm{CDCl}_{3}$ ), (B) testololactona isolada da reação com o caldo enzimático do fungo A. sydowii CBMAI $935\left(400 \mathrm{MHz}, \mathrm{CDCl}_{3}\right)$.

Figura 108. Espectros de $\mathrm{RMN}$ de ${ }^{1} \mathrm{H}\left(\mathrm{CDCl}_{3}\right)$ ampliados: (A) progesterona (400 MHz), (B) testololactona. 205

Figura 109. Modelos de perfis de multiplicidade propostos por Kirk, et al. (1990) para reconhecimento de sinais de ${ }^{1} \mathrm{H}$ em espectros de RMN: (A) H-14 $\alpha$, (B) H-15 e (C) H-16....206

Figura 110. Multipletos obtidos do espectro de RMN de ${ }^{1} \mathrm{H}$ dos hidrogênios $\mathrm{H}-16 \alpha$ e H-16ß: (A) progesterona (400 MHz, $\mathrm{CDCl}_{3}$ ), (B) testololactona 207

Figura 111. Orientações espaciais dos hidrogênios H-15 e H-16 no anel D do núcleo esteroidal: (A) progestesrona. (B) testololactona...... .209

Figura 112. Espectros de IV: (A) progestesterona (B) testololactona. 211

Figura 113. Espectro de massas de alta resolução modo positivo $\left(\mathrm{H}^{+}\right)$da testololactona..212

Figura 114. Espectros de massas $(70 \mathrm{eV})$ : $(\mathrm{A})$ experimental para composto $t_{R}=13,23$ minutos (B) octacosa-hidro-2H-di-ciclo-deca[c,J][1]oxa-ciclo-tetradecino (similaridade: $69 \%$, biblioteca NIST07)

Figura 115. Estrutura cristalina da enzima Cetoesteroide monoxigenase EC1.14.13.54...219

Figura 116. Estrutura cristalina da Testosterona $17 \beta$-desidrogenase EC.1.1.1.64. 
Figura 117. Análises cromatográficas da conversão da testosterona em testololactona pelo caldo enzimático do fungo $A$. sydowii CBMAI 935.

Figura 118. Estrutura terciária da enzima esteroide $15 \beta$-monoxigenase EC 1.14.15.8 determinada computacionalmente: (A) estrutura geral (B) progesterona ancorada ao sítio ativo da enzima.

Figura 119. Cromatogramas obtidos da análise dos extratos em acetato de etila provenientes das triagens das reações de biotransformação do 17 $\alpha$-etinilestradiol com os caldos enzimáticos dos fungos empregados neste trabalho após 7 dias de reação.

Figura 120. Espectros de massas: $(70 \mathrm{eV})$ : $(\mathrm{A})$ experimental para o composto de $t_{\mathrm{R}}=11,93$ minutos (fungo A. sydowii CBMAI 935), (B) 9(1H)fenantrona,23,4,4a-tetra-hidro-1 $\alpha, 4 \mathrm{a} . \beta$ dimetil (similaridade 56\%, biblioteca WILEY 8), (C) experimental para o composto de $t_{\mathrm{R}}=$ 7,45 minutos (fungo $P$. oxalicum CBMAI 1185), (D) bis(2-etil-hexil)ftalato (similaridade 96\%, biblioteca NIST05), (E) experimental para o composto de $t_{\mathrm{R}}=7,45$ minutos (fungo $P$. oxalicum CBMAI 1185), (F) ácido pentadecanoico (similaridade 90\%, biblioteca NIST21) 231

Figura 121. Cromatogramas obtidos da análise dos extratos em acetato de etila provenientes das triagens das reações de biotransformação do $17 \alpha$-etinilestradiol com a massa micelial dos fungos empregados neste trabalho após 7 dias de reação. 


\section{LISTA DE ESQUEMAS}

Esquema 1. Biotransformação do lapachol utilizando o fungo C. lunata. 34

Esquema 2. Mecanismo geral de oxidação biocatalítica promovida por monoxigenase. 37

Esquema 3. Exemplos gerais de reações catalisadas por monoxigenases e seus respectivos cofatores. 38

Esquema 4. Biotransformação da herbicina A catalisada pelo fungo de ambiente marinho Eupenicillium sp.

Esquema 5. Resolução enzimática do benzil-glicidil-eter catalisada pelo fungo A. sydowii CBMAI 935.

Esquema 6. Reações de biodegradação de pesticidas utilizando o fungo A. sydowii CBMAI 935: (A) clorpirifós, (B) profenofós, (C) metilparation.

Esquema 7. Biotransformação de produtos naturais utilizando fungos de origem marinha: (A) (-)-ambrox ${ }^{\circledR}$, (B) sclareol e (C) sclareolide.

Esquema 8. Formas da vitamina D e seus respectivos esteroides precursores: (A) fotólise do ergosterol originando a vitamina $\mathrm{D}_{2}$ (ergocalciferol), (B) fotólise do 7-desidrocolesterol originando a vitamina $\mathrm{D}_{3}$ (colecalciferol).

Esquema 9. Biotransformação da progesterona catalisada pelo fungo $R$. nigricans. .51

Esquema 10. Biotransformação da 6-metil-cortisona catalisada pelo fungo $C$. lunata. . .51

Esquema 11. Biotransformação da progesterona catalisada pelo fungo S. argenteolus produzindo 16 $\alpha$-Hidroxiprogesterona, intermediária na produção da Triancinolona......

Esquema 12. Biotransformação da cortexolona para a produção de hidrocortisona e predinisolona utilizando microrganismos provenientes do solo.

Esquema 13. Biotransformação da corticosterona catalisada pelo fungo $S$. affinis...... .53

Esquema 14. Obtenção da progesterona a partir da 3-metoxiandrosta-3,5-dien-17-ona por via sintética. .55

Esquema 15. Reações enzimáticas empregando fungos de ambiente marinho: (A) redução de (1E,4E)-1,5-difenilpenta-1,4-dien-3-ona catalisada pelo fungo Penicillium citrinum CBMAI 1186, (B) biotransformação de fenilacetonitrilas catalisada pelo fungo Aspergillus sydowii CBMAI 934. .58

Esquema 16. Biotransformação da progesterona utilizando o fungo Syncephalastrum sp..153 
Esquema 17. Biotransformação da progesterona utilizando o fungo Didymosphaeria igniaria $\mathrm{KCH} 6670$.

Esquema 18. Biotransformação da progesterona utilizando a bactéria B. megaterium com injeção de ar..

Esquema 19. Biotransformação da progesterona utilizando a bactéria $B$. megaterium sem injeção de ar..

Esquema 20. Biotransformação da progesterona pelo fungo P.simplicissimum. 190

Esquema 21. Biotransformação da progesterona pelo fungo A. tamarii. 191

Esquema 22. Biotransformação da progesterona por esporos do fungo A. ochraceus..... 191

Esquema 23. Biotransformação da progesterona pelo fungo P.notatum KCH 904. 214

Esquema 24. Biotransformação da progesterona pelo fungo P. citreo-viride A.C.C.C. 0402.

Esquema 25. Biotransformação da progesterona pelo caldo enzimático do fungo A. sydowii CBMAI 934.

Esquema 26. Biotransformação da progesterona pela masssa micelial do fungo A. sydowii CBMAI 934.

Esquema 27. Biotransformação da progesterona pelo caldo enzimático do fungo A. sydowii CBMAI 935.

Esquema 28. Biotransformação da progesterona pela massa micelial do fungo A. sydowii CBMAI 935.

Esquema 29. Rota de biotransformação da progesterona por cepas de $P$. simplicissimum WY134-2.

Esquema 30. Mecanismo enzimático de oxidação de Baeyer-Villiger utilizando ciclohexanona como substrato. .220

Esquema 31. Mecanismo enzimático de hidrólise de éster catalisada por esterase. .221

Esquema 32. Mecanismos de desidrogenação de álcoois desidrogenase: (A) Mecanismo por perda de próton de anel pirrólico de histidina, (B) mecanismo por sistema de zinco pentacoordenado.

Esquema 33. Obtenção da $2 \beta$-hidroxiprogesterona e $15 \beta$-hidroxiprogesterona utilizando a enzima CYP6A1...

Esquema 34. Obtenção da 15 $\beta$-hidroxiprogesterona utilizando a enzima esteroide $15 \beta$ monoxigenase EC 1.14.15.8 na presença de megarredoxina reduzida. 
Esquema 35. Biotransformação do $17 \alpha$-etinilestradiol utilizando a enzima P-450 $0_{\mathrm{NF}}$ e NADPH.

Esquema 36. Rotas envolvidas no metabolismo do $17 \alpha$-etinilestradiol em humanos. As rotas mais proeminentes são indicadas com setas cheias. 


\section{LISTA DE TABELAS}

Tabela 1. Biotransformação da cortexolona catalisada por fungos para obtenção da Hidrocortisona e catalisada por bactérias para obtenção da prednisolona.

Tabela 2. Linhagens de fungos de ambiente marinho utilizadas na biotransformação dos esteroides propostos.

Tabela 3. Descrição dos fungos cultivados em meio de cultura de extrato de malte utilizados nas biotransformações dos fármacos esteroidais progesterona e $17 \alpha$-etinilestradiol.....

Tabela 4. Solubilidade dos esteroides progesterona e 17 $\alpha$-etinilestradiol em DMSO. .86

Tabela 5. Dissolução dos esteroides progesterona e $17 \alpha$-etinilestradiol em acetato de etila.

Tabela 6. Avaliação do crescimento do fungo A. sydowii CBMAI 934 na presença de DMSO $\left(32{ }^{\circ} \mathrm{C}, \mathrm{pH} 7,4,120 \mathrm{rpm}, 14\right.$ dias $)$.

Tabela 7. Meios reacionais selecionados utilizando caldos enzimáticos e micélios provenientes de fungos de ambiente marinho dos gêneros Aspergillus e Penicilium para isolamento e caracterização dos produtos de biotransformação da progesterona. 108

Tabela 8. Possíveis produtos de biotransformação da progesterona após reações em quintuplicatas com o caldo enzimático proveninente do fungo A. sydowii CBMAI 934......110

Tabela 9. Frações obtidas na separação cromatográfica do extrato obtido após a biotransformação da progesterona pelo caldo enzimático do fungo A. sydowii CBMAI 935 após 14 dias de reação.

Tabela 10. Valores de massa micelial úmida e seca do fungo A. sydowii CBMAI 934 após 14 dias da reação de biotransformação da progesterona.

Tabela 11. Possíveis produtos de biotransformação da progesterona após reações em quintuplicatas com a massa micelial proveninente do fungo A. sydowii CBMAI 934.

Tabela 12. Frações obtidas na separação cromatográfica do extrato obtido da progesterona frente a biotransformação com a massa micelial do fungo A. sydowii CBMAI 935.

Tabela 13. Possíveis produtos de biotransformação da progesterona após reações em quintuplicatas com o caldo enzimático do fungo A. sydowii CBMAI 935.

Tabela 14. Frações obtidas na separação cromatográfica do extrato obtido da progesterona frente a biotransformação com o caldo enzimático do fungo A. sydowii CBMAI 935.

Tabela 15. Valores de massa micelial úmida e seca do fungo A. sydowii CBMAI 934 após 14 dias da reação de biotransformação da progesterona.

Tabela 16. Possíveis produtos de biotransformação da progesterona após reações em quintuplicatas com a massa micelial do fungo A. sydowii CBMAI 935. 125

Tabela 17. Frações obtidas na separação cromatográfica do extrato da biotransformação da progesterona com a massa micelial do fungo A. sydowii CBMAI 935. 
Tabela 18. Valores de rotação óptica para a progesterona.

Tabela 19. Valores das bandas vibracionais obtidas por IV para a progesterona.

Tabela 20. Valores de deslocamentos químicos (ppm) de $\operatorname{RMN}\left({ }^{13} \mathrm{C}\right.$ e $\left.{ }^{1} \mathrm{H}\right)$ para a progesterona.

Tabela 21. Valores de deslocamentos químicos (ppm) de $\mathrm{RMN}\left({ }^{13} \mathrm{C}\right.$ e $\left.{ }^{1} \mathrm{H}\right)$ para os estereoisômeros $7 \beta, 15 \beta$-di-hidroxiprogesterona, $7 \alpha, 15 \beta$-di-hidroxiprogesterona.

Tabela 22. Constantes de acoplamento $(J)$ obtidas experimentalmente para os hidrogênios $\mathrm{H}-7 \alpha$ e $\mathrm{H}-7 \beta$ da progesterona.

Tabela 23. Constantes de acoplamento $(J)$ obtidas experimentalmente para o hidrogênio $\mathrm{H}$ 7 do produto di-hidroxilado isolado da reação com o caldo enzimático do fungo A. sydowii CBMAI 934

Tabela 24. Valores de deslocamentos químicos (ppm) de $\mathrm{RMN}\left({ }^{13} \mathrm{C}\right.$ e $\left.{ }^{1} \mathrm{H}\right)$ teóricos comparativos com os dados experimentais para os isômeros do produto di-hidroxilado isolado da reação com o caldo enzimático do fungo A. sydowii CBMAI 934.

Tabela 25. Valores das bandas vibracionais obtidas por IV para o produto di-hidroxilado isolado da reação com o caldo enzimático do fungo A. sydowii CBMAI 934.

Tabela 26. Valores de rotação óptica para os isômeros di-hidroxilados de configuração $7 \beta, 15 \beta, 7 \alpha, 15 \beta$ e obtido experimentalmente do produto di-hidroxilado isolado da reação com o caldo enzimático do fungo A.sydowii CBMAI 934.

153

Tabela 27. Valores de deslocamentos químicos (ppm) de $\mathrm{RMN}\left({ }^{13} \mathrm{C}\right.$ e $\left.{ }^{1} \mathrm{H}\right)$ para os estereoisômeros $15 \alpha$-hidroxiprogesterona e 15 $\beta$-hidroxiprogesterona.

Tabela 28. Constantes de acoplamento $(J)$ obtidas experimentalmente para o hidrogênio H$15 \alpha$ da $15 \beta$-hidroxiprogesterona..

Tabela 29. Valores de deslocamentos químicos (ppm) de $\mathrm{RMN}\left({ }^{13} \mathrm{C}\right.$ e $\left.{ }^{1} \mathrm{H}\right)$ teóricos e experimentais para os isômeros 15-hidroxiprogesterona.

Tabela 30. Valores das bandas vibracionais obtidas por IV para o produto $15 \beta$ hidroxiprogesterona isolado da reação com o micéilo do fungo A. sydowii CBMAI 934.

Tabela 31. Valores de rotação óptica para a 15 $\beta$-hidroxiprogesterona. 170

Tabela 32. Valores de deslocamentos químicos (ppm) de $\operatorname{RMN}\left({ }^{13} \mathrm{C}\right.$ e $\left.{ }^{1} \mathrm{H}\right)$ para a testosterona.

Tabela 33. Valores das bandas vibracionais obtidas por Espectroscopia no IV para a testosterona isolada da reação com o caldo enzimático do fungo A. sydowii CBMAI 935.

Tabela 34. Valores de rotação óptica para a testosterona isolada da reação com o caldo enzimático do fungo A. sydowii CBMAI 935. 
Tabela 35. Valores de deslocamentos químicos (ppm) de $\mathrm{RMN}\left({ }^{13} \mathrm{C}\right.$ e $\left.{ }^{1} \mathrm{H}\right)$ para a testololactona..

Tabela 36. Constantes de acoplamento $(J)$ encontradas experimentalmente para o hidrogênio $\mathrm{H}-16 \alpha$ da progesterona e da testololactona.

Tabela 37. Constantes de acoplamento $(J)$ encontradas experimentalmente para o hidrogênio $\mathrm{H}-16 \beta$ da progesterona e da testololactona. .208

Tabela 38. Valores das bandas vibracionais obtidas por Espectroscopia no IV para a testosterona isolada da reação com o caldo enzimático do fungo A.sydowii CBMAI 935...210

Tabela 39. Valores de rotação óptica para a testololactona .213 


\section{LISTA DE ABREVIATURAS, SIGLAS, SÍMBOLOS E FÓRMULAS}

\begin{tabular}{|c|c|}
\hline AcOEt & acetato de etila \\
\hline Asp & ácido aspártico \\
\hline${ }^{\circ} \mathrm{C}$ & grau Célsius \\
\hline${ }^{\circ} \mathrm{C} / \mathrm{min}$ & grau Célsius por minuto \\
\hline${ }^{13} \mathrm{C}$ & Carbono 13 \\
\hline c & Conversão \\
\hline $\mathrm{CaCl}_{2} \cdot 2 \mathrm{H}_{2} \mathrm{O}$ & cloreto de cálcio diidratado \\
\hline CAQI & Central de Análises Químicas e Instrumentais \\
\hline CBMAI & Coleção Brasileira de Microrganismos de Ambiente e Indústria \\
\hline $\mathrm{CC}$ & Cromatografia em Coluna \\
\hline $\mathrm{CCD}$ & Cromatografia em Camada Delgada \\
\hline $\mathrm{CDCl}_{3}$ & clorofórmio deuterado \\
\hline CG-EM & Cromatografia à Gás acoplada à Espectrometria de Massas \\
\hline CGxCG-EM & $\begin{array}{l}\text { Cromatografia à Gás bidimensional acoplada à Espectrometria de } \\
\text { Massas }\end{array}$ \\
\hline $\mathrm{cm}$ & Centímetro \\
\hline $\mathrm{cm} / \mathrm{min}$ & centímetro por minutos \\
\hline $\mathrm{cm} / \mathrm{seg}$ & centímetro por segundo \\
\hline CNTP & Condições Normais de Temperatura e Pressão \\
\hline COSY & Correlation Spectroscopy \\
\hline Cys & Cisteína \\
\hline Deg & giro em graus do desvio da luz plano polarizda \\
\hline DMF & $N, N$-dimetil-formamida \\
\hline DMSO & dimetil-sulfóxido \\
\hline EM & Espectrometria de Massas \\
\hline EMAR & Espectrometria de Massas de Alta Resolução \\
\hline EPA & $\begin{array}{l}\text { United States Environmental Protection Agency - Agência de } \\
\text { Proteção Ambiental dos Estados Unidos }\end{array}$ \\
\hline ETE & Estação de Tratamento de Esgoto \\
\hline $\mathrm{eV}$ & Eltronvolt \\
\hline FAD e FADH & flavina-adenina dinucleotídeo \\
\hline $\mathrm{Fe}^{2+}$ & íon ferroso \\
\hline $\mathrm{Fe}^{3+}$ & íon férrico \\
\hline FMN & flavina mononucleotideo \\
\hline$g / L$ & grama por litro \\
\hline $\mathrm{g} / 100 \mathrm{~mL}$ & grama por cem mililitros \\
\hline $\mathrm{g} / \mathrm{mol}$ & grama por mol \\
\hline Glu & ácido glutâmico \\
\hline${ }^{1} \mathrm{H}$ & Próton \\
\hline $\mathrm{H}_{3} \mathrm{BO}_{3}$ & ácido bórico \\
\hline $\mathrm{HClO}_{4}$ & ácido perclórico \\
\hline $\mathrm{He}$ & Hélio \\
\hline
\end{tabular}




\begin{tabular}{|c|c|}
\hline His & Histidina \\
\hline HIV & $\begin{array}{l}\text { Human Immounodeficiency Virus -Vírus da Imunodeficiência } \\
\text { Humana }\end{array}$ \\
\hline HMBC & Heteronuclear Multiple-Bond Correlation Spectroscopy \\
\hline HSQC & Heteronuclear Single-Quantum correlation Spectroscopy \\
\hline $\mathrm{Hz}$ & Hertz \\
\hline IBGE & Instituo Brasileiro de Geografia e Estatística \\
\hline IE & Impacto Eletrônico \\
\hline IQSC & Instituto de Química de São Carlos \\
\hline IUBMB & $\begin{array}{l}\text { International Union of Biochemistry and Molecular Biology - União } \\
\text { Internacional de Bioquímica e Biologia Molecular }\end{array}$ \\
\hline IUPAC & $\begin{array}{l}\text { International Union of Pure and Applied Chemistry - União } \\
\text { Internacional de Química Pura e Aplicada }\end{array}$ \\
\hline IV & Infravermelho \\
\hline$J$ & Constante de acoplamento \\
\hline$J_{\mathrm{HC}}$ & Acoplamento Hidrogênio-Carbono \\
\hline${ }^{2} J_{\mathrm{HC}}$ & Acoplamento Hidrogênio-Carbono a duas ligações \\
\hline${ }^{3} J_{\mathrm{HC}}$ & Acoplamento Hidrogênio-Carbono a três ligações \\
\hline${ }^{4} J_{\mathrm{HC}}$ & Acoplamento Hidrogênio-Carbono a quatro ligações \\
\hline$J_{\mathrm{HH}}$ & Acoplamento Hidrogênio-Hidrogênio \\
\hline${ }^{2} J_{\mathrm{HH}}$ & Acoplamento Hidrogênio-Hidrogênio a duas ligações \\
\hline${ }^{3} J_{\mathrm{HH}}$ & Acoplamento Hidrogênio-Hidrogênio a três ligações \\
\hline${ }^{4} J_{\mathrm{HH}}$ & Acoplamento Hidrogênio-Hidrogênio a quatro ligações \\
\hline $\mathrm{KBr}$ & brometo de potássio \\
\hline $\mathrm{KCl}$ & cloreto de potássio \\
\hline $\mathrm{kDa}$ & kiloDalton \\
\hline $\mathrm{Kgf} / \mathrm{cm}^{2}$ & kilogramaforça por centímetro quadrado \\
\hline $\mathrm{KH}$ & hidreto de potássio \\
\hline $\mathrm{kPa}$ & kiloPascal \\
\hline $\mathrm{m}$ & Metro \\
\hline$m-\mathrm{CH}_{3}$ & meta-metil \\
\hline$m / z$ & relação massa/carga \\
\hline $\mathrm{Me}$ & Metil \\
\hline Met & Metionina \\
\hline $\mathrm{mg}$ & Miligrama \\
\hline $\mathrm{mg} / \mathrm{mL}$ & miligrama por mililitro \\
\hline $\mathrm{MgCl}_{2} \cdot 6 \mathrm{H}_{2} \mathrm{O}$ & cloreto de magnésio hexaidratado \\
\hline $\mathrm{MHz}$ & Mega Hertz \\
\hline $\mathrm{mL}$ & Mililitro \\
\hline $\mathrm{mL} / \mathrm{min}$ & mililitro por minuto \\
\hline $\mathrm{mm}$ & Milímetro \\
\hline $\mathrm{Na}_{2} \mathrm{SO}_{4}$ & sulfato de sódio anidro \\
\hline $\mathrm{NaBH}_{4}$ & boridreto de sódio \\
\hline $\mathrm{NaCl}$ & cloreto de sódio \\
\hline NAD e NADH & nicotinamida-adenina dinucleotídeo \\
\hline
\end{tabular}




\begin{tabular}{ll}
$\mathrm{NADP}$ e NADPH & fosfato de nicotinamida-adenina dinucleotídeo \\
$\mathrm{NaH}_{2} \mathrm{PO}_{4}$ & fosfato de sódio monobásico anidro \\
$\mathrm{NaHCO}_{3}$ & bicarbonato de sódio anidro \\
$\mathrm{nm}$ & Nanômetro \\
$\mathrm{NOESY}$ & Nuclear Overhauser Effect Spectroscopy \\
$o-\mathrm{CH}_{3}$ & orto-metil \\
$p-\mathrm{CH}_{3}$ & para-metil \\
$\mathrm{pH}$ & potencial hidrogeniônico \\
$\mathrm{ppm}$ & partes por milhão \\
$\mathrm{Pr} 2 \mathrm{NH} / \mathrm{POCl}_{3}$ & cloreto de fosforila em di-isopropil-amina \\
$\mathrm{r}$ & Rendimento \\
$\mathrm{RMN}$ & Ressonância Magnética Nuclear \\
$\mathrm{rpm}$ & rotações por minuto \\
$\mathrm{Ser}$ & Serina \\
$\mathrm{SrCl}$ & \\
$\mathrm{t}-\mathrm{BuOK}$ & cloreto de estrôncio hexaidratado \\
$\mathrm{Thr}$ & terc-butóxido de potássio \\
$\mathrm{TMS}$ & Treonina \\
$\mathrm{t}_{\mathrm{R}}$ & tetra-metilsilano \\
$\mathrm{Trp}$ & tempo de retenção \\
$\mathrm{USP}$ & Triptofano \\
$\mathrm{UV}$ & Universidade de São Paulo \\
$\mathrm{Zn}{ }^{2+}$ & Ultra-violeta \\
$\alpha_{\mathrm{D}}$ & íon Zinco (II) \\
$\delta$ & rotação óptica \\
$\lambda$ & deslocamento químico \\
$\nu_{\mathrm{máx}}$ & comprimento de onda \\
$\mu \mathrm{g}$ & número de onda máximo \\
$\mu \mathrm{L}$ & Micrograma \\
$\mu \mathrm{gg} / \mathrm{mL}$ & Microlitro \\
$\mu \mathrm{m}$ & micrograma por mililitro \\
$\phi$ & Micrômetro \\
& Diâmetro \\
\hline &
\end{tabular}


A. INTRODUÇÃO ............................................................................................................................30

A.1 BIOCATÁLISE E BIOTRANSFORMAÇÃO..................................................................30

A.2 OXIDORREDUTASES............................................................................................................34

A.2.1 OXIGENASES ..........................................................................................................................36

A.2.2 MONOXIGENASES ...............................................................................................................37

A.2.3 MONOXIGENASES DO CITOCROMO P-450 ............................................................39

A.3 EMPREGO DE MICRORGANISMOS EM PROCESSOS DE BIOTRANSFORMAÇÃ $O$.........................................................................................................42

A.4 ESTEROIDES E REAÇÕES DE BIOTRANSFORMAÇÃO .........................................46

A.5 ESTEROIDES E AS QUESTÕES AMBIENTAIS...........................................................56

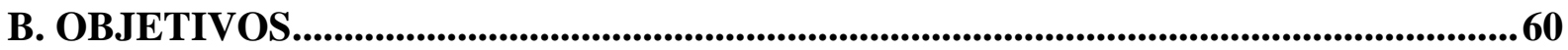

B.1 OBJETIVO GERAL .............................................................................................................60

B.2 OBJETIVOS ESPECÍFICOS ........................................................................................60

C. MATERIAIS E MÉTODOS ..............................................................................62

C.1 COMPOSTOS ESTEROIDAIS PARA BIOTRANSFORMAÇÃO .............................62

C.2 TESTES DE DISSOLUÇÃO DOS ESTEROIDES ...........................................................62

C.3 DESENVOLVIMENTO E OTIMIZAÇÃO DA METODOLOGIA DE ANÁLISE DOS ESTEROIDES POR CG-EM ........................................................................................63

C.4 MICRORGANISMOS PARA BIOTRANSFORMAÇÃO ..............................................63

C.5 PREPARO DOS MEIOS DE CULTURA ...........................................................................64

C.6 INÓCULOS DOS FUNGOS ..........................................................................................66

C.7 AVALIAÇÃO DO CRESCIMENTO DOS FUNGOS NA PRESENÇA DE DIMETIL-SULFÓXIDO ...................................................................................................67

C.8 REAÇÕES DE BIOTRANSFORMAÇÃO DOS ESTEROIDES....................................69

C.8.1 REAÇÕES COM A MASSA MICELIAL........................................................................69

C.8.2 REAÇÕES COM O CALDO ENZIMÁTICO...............................................................71

C.9 PREPARO DOS EXTRATOS APÓS A BIOTRANSFORMAÇÃO DOS

ESTEROIDES..............................................................................................................................74

C.9.1 EXTRAÇÃO DAS REAÇÕES COM A MASSA MICELIAL....................................74 
C.10 SEPARAÇÃO E PURIFICAÇÃO DOS PRODUTOS DE

BIOTRANSFORMAÇÃO PELOS FUNGOS DE AMBIENTE MARINHO

C.11 CARACTERIZAÇÃO DOS SUBSTRATOS E PRODUTOS DE

BIOTRANSFORMAÇÃ̃O DOS ESTEROIDES

C.11.1 CARACTERIZAÇÃO POR ESPECTROSCOPIA NO INFRAVERMELHO ....83

C.11.2 CARACTERIZAÇÃO POR ESPECTROSCOPIA DE RESSONÂNCIA

MAGNÉTICA NUCLEAR 83

C.11.4 DETERMINAÇÃO DA ROTAÇÃO ÓPTICA POR POLARIMETRIA .84

D. RESULTADOS E DISCUSSÃO.. .86

D.1. TESTES DE DISSOLUÇÃO DOS ESTEROIDES .86

D.2 DESENVOLVIMENTO E OTIMIZAÇÃO DA METODOLOGIA DE ANÁLISE DOS ESTEROIDES POR CG-EM..

D.3 AVALIAÇÃO DO CRESCIMENTO DOS FUNGOS NA PRESENÇA DE DIMETIL-SULFÓXIDO

D.4. MONITORAMENTO DOS MEIOS REACIONAIS NA AUSÊNCIA DOS ESTEROIDES. .91

D.5 REAÇÕES DE BIOTRANSFORMAÇÃO DA PROGESTERONA .98

D.5.1. REAÇÕES COM OS CALDOS ENZIMÁTICOS - TRIAGEM .99

D.5.2 REAÇÕES COM OS MICÉLIOS - TRIAGEM 104

D.5.3 BIOTRANSFORMAÇÕES EM QUINTUPLICATAS 109

D.5.3.1 Reação de biotransformação da progesterona com o caldo enzimático do fungo A. sydowii CBMAI 934

D.5.3.2 Purificação e isolamento dos produtos de biotransformação da progesterona com o caldo enzimático do fungo $A$. sydowii CBMAI 934.

D.5.3.3 Reação de biotransformação da progesterona com a massa micelial do fungo $A$. sydowii CBMAI 934

D.5.3.4 Purificação e isolamento dos produtos da biotransformação da progesterona com a massa micelial do fungo $A$. sydowii CBMAI 934.

D.5.3.5 Reação de biotransformação da progesterona com o caldo enzimático do fungo

A. sydowii CBMAI 935

D.5.3.6 Purificação e isolamento dos produtos de biotransformação da progesterona com o caldo enzimático do fungo $A$. sydowii CBMAI 935.

D.5.3.7 Reação de biotransformação da progesterona com o micélio do fungo $A$. sydowii 
D.5.3.8 Purificação e isolamento dos produtos de biotransformação da progesterona com a massa micelial do fungo $A$. sydowii CBMAI 935.

\section{D.5.4 CARACTERIZAÇÃO POR TÉCNICAS ESPECTROSCÓPICAS DOS} COMPOSTOS ISOLADOS

D.5.4.1 Caracterização do produto 7,15-di-hidroxiprogesterona isolado da reação com o caldo enzimático do fungo $A$. sydowi $\mathrm{CBMAI} 934\left(14\right.$ dias, $\left.32^{\circ} \mathrm{C}, 130 \mathrm{rpm}\right)$

D.5.4.2 Caracterização da $15 \beta$-hidroxiprogesterona isolada da reação com a massa micelial do fungo $A$. sydowii CBMAI 934 (14 dias, $\left.32^{\circ} \mathrm{C}, 130 \mathrm{rpm}\right)$

D.5.4.3 Caracterização da testosterona obtida da reação com o caldo enzimático do fungo $A$. sydowii CBMAI 935 ( 7 dias, $32^{\circ} \mathrm{C}, 130$ rpm).

D.5.4.4 Caracterização da testololactona obtida das reações com o caldo enzimático e com a massa micelial do futgo $A$. sydowii CBMAI $935\left(7\right.$ dias, $\left.32^{\circ} \mathrm{C}, 130 \mathrm{rpm}\right)$.............192

D.5.5 MECANISMOS ENZIMÁTICOS DE BIOTRASNFORMAÇÃO DA PROGESTERONA PARA OBTENÇÃO DOS COMPOSTOS DESCRITOS.

D.5.5.1 Obtenção da testosterona e testololactona.

D.5.5.2 Obtenção dos compostos 15 $\beta$-hidroxiprogesterona e da 7,15 di-

hidroxiprogesterona

D.6 BIOTRANSFORMAÇÃO DO 17 $\alpha$-ETINILESTRADIOL 228

D.6.1 MONITORAMENTO DOS MEIOS REACIONAIS (CALDO ENZIMÁTICO E MASSA MICELIAL) NA PRESENÇA DO 17 $\alpha$-ETINILESTRADIOL........................229

E. CONCLUSÕES .235

F. PERSPECTIVAS 237

G. REFERÊNCIAS 238

ANEXOS 249 


\section{A. INTRODUÇÃO}

\section{A.1 BIOCATÁLISE E BIOTRANSFORMAÇÃO}

A Biocatálise consiste no emprego de catalisadores naturais, as enzimas, para a realização de reações químicas em substratos xenobióticos ao sistema biológico em que são empregados ${ }^{1}$. Os sistemas biológicos em que processos biocatalíticos podem ser executados são: células intactas de microrganismos por serem as fontes das enzimas (fungos, bactérias, animais, vegetais), as enzimas isoladas, imobilizadas ou até mesmo uma mistura das mesmas que podem ser obtidas de caldos enzimáticos produzidos por fungos e bactérias em crescimento.

O uso de biocatalisadores em reações químicas está intrinsicamente ligado aos princípios da Química Verde, pois tais catalisadores são biodegradáveis e de fontes renováveis. Além disso, as condições de reação são brandas, pois a temperatura e pressão empregados são bem próximos da CNTP e, ocorrem em meio neutro ou levemente alcalino ou ácido. Por fim, o solvente utilizado no meio reacional é a água, o que torna processos biocatalíticos menos agressivos ao meio ambiente ${ }^{2}$.

Há dois grandes grupos principais de reações biocatalíticas:

a) reações de biodegradação, que consistem na fragmentação enzimática da molécula de um substrato xenobiótico geralmente produzindo substâncias de estruturas moleculares mais simples $^{3}$;

b) reações de biotransformação, que são transformações da molécula do substrato xenobiótico, em outra(s) substância(s) recuperável(is) com propriedade(s) química(s) e física(s) diferente(s) da substância biotransformada, sem necessariamente ocorrer a fragmentação da molécula do reagente ${ }^{4}$.

As modificações moleculares do reagente ou substrato no processo de biotransformação podem ocorrer em dois estágios denominados Fase I e Fase II. As reações de Fase I basicamente são reações de funcionalização, gerando grupos polares nas moléculas dos compostos xenobióticos (-OH, $\left.-\mathrm{NH}_{2},-\mathrm{COOH}\right)$, o que diminui a lipofilicidade dos compostos. Estas reações compreendem oxidações, reduções e hidrólises ${ }^{5}$. Já as reações de Fase II são reações de conjugação em que são adicionadas moléculas de carboidratos, aminoácidos, peptídeos, grupos sulfatos, dentre outros. Estas reações, promovidas nos sistemas metabólicos de mamíferos, ocasionam a perda da atividade biológica do composto, bem como facilitar a sua eliminação ou excreção ${ }^{5}$. 
São muitas as vantagens do emprego da biotransformação em reações químicas. Podem ser destacadas as seguintes ${ }^{6,7}$ :

a) obtenção de produtos com alta quimio, regio e enantiosseletividade, o que torna a biocatálise uma tecnologia quiral;

b) são processos que possuem altos rendimentos de conversão de substratos em produtos em condições CNTP;

c) um catalisador pode ser empregado em vários tipos de reações, dada a sua promiscuidade enzimática que é a capacidade de uma enzima atuar estereosseletivamente sobre diversos $\operatorname{substratos}^{8}$;

d) os processos biocatalíticos podem ser utilizados sem ferir princípios de bioética, quando são empregados microrganismos não patogênicos ou enzimas isoladas sem que tragam prejuízos à saúde humana e ao meio ambiente;

e) obtenção de novas moléculas biologicamente ativas a partir de outras que possuam ou não atividade biológica;

f) obtenção de produtos com alto grau de pureza enantiomérica a partir de misturas racêmicas ou substratos aquirais;

g) formação de metabólitos quirais a partir de substratos aquirais;

h) redução de etapas de obtenção dos produtos desejados;

i) correlação entre processos metabólicos in vivo e in vitro;

j) os processos biocatalíticos são considerados processos químicos naturais, pois são promovidos por enzimas ou cofatores de origem natural.

Dadas inúmeras vantagens aqui descritas, a biotransformação tem sido bastante empregada na indústria, especialmente na produção de fármacos ${ }^{9}$. Um clássico exemplo é a produção industrial do antibiótico penicilina (Figura 1) como mostra a Figura 2.

Figura 1. Estrutura molecular geral da penicilina.<smiles>[R]C(=O)N[C@H]1C(=O)N2[C@@H]1SC(C)(C)[C@H]2C(=O)O</smiles> 
Figura 2. Fluxograma para a produção industrial da penicilina ${ }^{10}$.

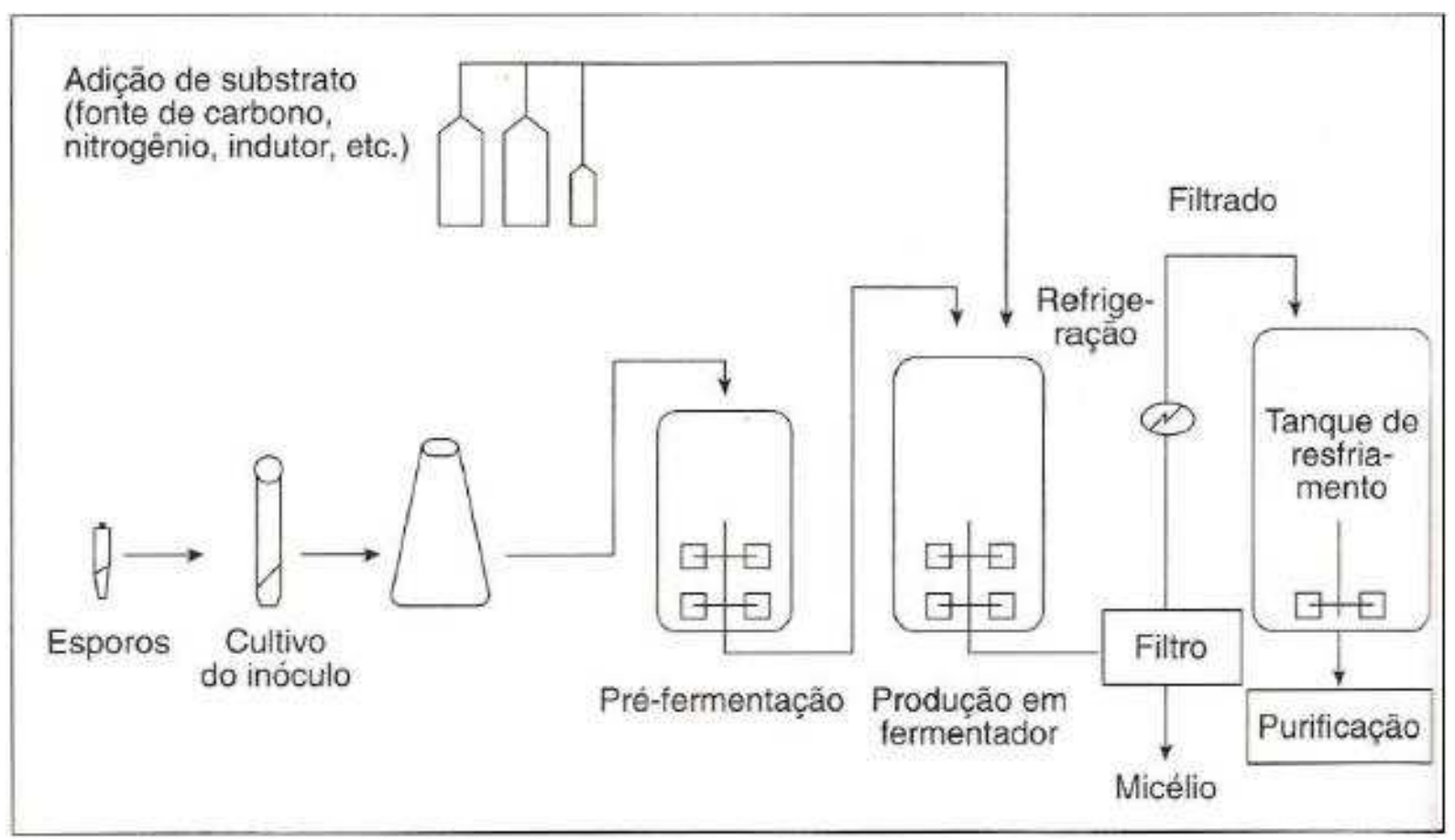

Fonte: SATO, S. Produção de antibióticos In: LIMA U.A. et al. Biotecnologia industrial. $1^{\text {a }}$ Ed. São Paulo: Edgard Blücher, 2001, v.3 p.114 10

A penicilina é produzida utilizando processos submersos em fermentadores de 40.000 200.000 litros. Devido as dificuldades de aeração tanques maiores não são empregados. O processo fermentativo é aeróbio e as cepas utilizadas normalmente são do fungo Penicilium chrysogenum e o inóculo se inicia utilizando esporos liofilizados. Devido à grande variabilidade de cepas de alta produção é necessária manutenção cuidadosa das mesmas. A concentração de esporos mais adequada é de $5 \times 10^{3}$ esporos/ $\mathrm{mL}$ e a formação de agregados, denominados "pellets" são cruciais para o rendimento do processo. Para se conseguir uma velocidade ótima de formação de penicilina, os "pellets" não devem crescer como bolas compactas, e sim, em formas soltas ${ }^{10}$.

Depois de várias etapas de crescimento, o cultivo de produção está preparado. Na fermentação típica da penicilina há uma fase de crescimento de mais ou menos 40 horas, com um tempo de duplicação de 6 horas e nesse estágio a maior parte da massa celular se forma. A baixa aeração no cultivo em crescimento é crítica, porque o aumento da viscosidade dificulta a transferência de oxigênio. Isto pode ser resolvido por alterações na engenharia do fermentador ou pela utilização de mutantes que desenvolvam menor viscosidade. Após a fase de crescimento, o cultivo chega à fase real de produção de penicilina. Em casos de alta produção da penicilina o crescimento reduz-se fortemente. Alimentando o meio com diferentes componentes, a fase de produção pode se estender de 120-160 horas ${ }^{10}$. 
A composição do meio de cultivo pode variar, dependendo da cepa, e geralmente, consiste em: água de milho (4-5\% peso seco), que nos processos atuais podem ser substituídos por outras fontes de carbono (como lactose); uma fonte de nitrogênio adicional como a farinha de soja, o extrato de levedura ou soro de leite e vários tampões ${ }^{10}$.

$\mathrm{O}$ pH é mantido constantemente a 6,5 no fermentador principal e por volta de 0,5 a $0,8 \%$ do total do substrato (fonte de carbono, nitrogênio, indutor, precursor, etc) é constituído de ácido fenilacético, como precursor). Os processos com alimentação de glicose ou melaço são bem-sucedidos. A produção se dá por batelada, pois, não se consegue ajustar a velocidade de utilização do açúcar e o fornecimento de oxigênio em um processo contínuo ${ }^{10}$.

A penicilina é excretada no meio de cultivo e menos de $1 \%$ permanece fixada no micélio. Após separação do micélio por filtração, é realizada a recuperação do produto por meio de duas etapas de extração contínua em contracorrente do caldo de fermentação com acetato de amila, acetato de butila ou metil-isobutil-cetona a $0-3^{\circ} \mathrm{C}$ e $\mathrm{pH} 2,5-3,0$. O rendimento total do processo é ao redor de $90 \%{ }^{10}$.

Considerando que normalmente são complexas e altamente funcionalizadas as estruturas químicas das moléculas dos fármacos, as obtenções destes compostos exclusivamente por métodos clássicos de síntese química podem requerer o emprego de muitas etapas de reação, aumentando o tempo do processo. Além disso, pode ocorrer a geração de resíduos e subprodutos de diferentes tipos e em grande quantidade, o que acarreta o aumento dos custos de produção de tais fármacos. A biotransformação empregada na produção de fármacos reduz tempo para a obtenção dos produtos, os custos e pode ser ambientalmente correta.

Otten e Rosazza (1979) ${ }^{11}$ observaram que o lapachol, um antimalárico, antibiótico e antitumoral quando biotransformado pelo fungo Curvularia lunata produz o metabólito desidro- $\alpha$-lapachona com rendimento de $50 \%$ em uma única etapa. Este composto é um fármaco que possui atividades antitumoral e antibacteriana (Esquema 1). Este é um típico exemplo da obtenção de fármacos por biotransformação. 
Esquema 1. Biotransformação do lapachol utilizando o fungo C. lunata. ${ }^{11}$<smiles>C=CC1=C(O)C(=O)c2ccccc2C1=O</smiles>

lapachol<smiles>CC1(C)C=CC2=C(O1)C(=O)c1ccccc1C2=O</smiles>

desidro- $\alpha$-lapachona

Fonte: Adaptação de OTTEN, S. e ROSAZZA, J.P., Microbial transformations of natural antitumor agentes: conversion of lapachol to dehydro-alpha-lapachone by Curvularia lunata. Applied and Environmental Microbiology v. 38. n. 3, p.312, 1979.

As reações de Fase I que despertam interesse na biotransformação de fármacos são aquelas que promovem a possível oxidação de uma molécula tornando-a mais polar, o que favorece a sua atuação como medicamento ${ }^{12}$. Dentre as enzimas que são capazes de promover a oxidação de compostos, as oxidorredutases são as principais enzimas que executam essa função.

\section{A.2 OXIDORREDUTASES}

As oxidorredutases são enzimas que em sua maioria são intracelulares, podendo ser encontradas em praticamente todos os seres vivos. Tais enzimas catalisam tanto reações de oxidação quanto de redução por transferência de elétrons com o auxílio de cofatores ${ }^{13}$. Estas substâncias, os cofatores, não possuem natureza proteica e podem ser de natureza inorgânica como íons metálicos $\left(\mathrm{Fe}^{2+}, \mathrm{Mg}^{2+}, \mathrm{Zn}^{2+}, \mathrm{Ca}^{2+}, \mathrm{K}^{+}\right)$. Eles também podem ser uma molécula orgânica, como a nicotinamida-adenina dinucleotídeo $\left(\mathrm{NAD}^{+}\right)$, a flavina ou um complexo metálico, como a vitamina B12 (Figura 3). Quando se trata de um complexo metálico, o cofator é denominado coenzima ${ }^{14}$. 
Figura 3. Estruturas químicas de cofatores: (A) $\mathrm{NAD}^{+}$, (B) flavina e (C) vitamina $\mathrm{B} 12^{14}$.

(A)<smiles>NC(=O)c1ccc[n+]([C@@H]2O[C@H](OP(=O)([O-])[O-])[C@@H](O)[C@H]2O)c1</smiles>

(B)<smiles>Cc1cc2nc3c(=O)[nH]c(=O)nc-3[nH]c2cc1C</smiles>

(C)

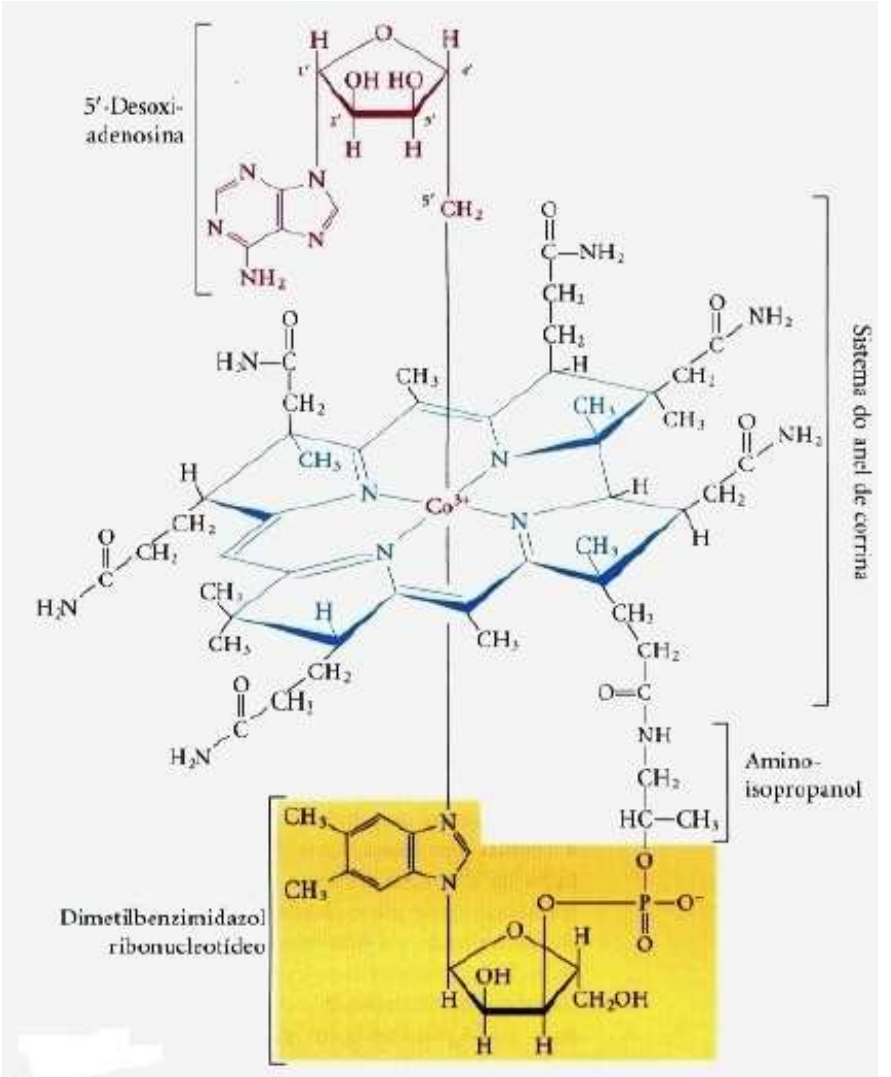

Fonte: Adaptação de NELSON, D.L. e COX, M.M., Lehninger: Princípios de Bioquímica. Tradução de Fabiana Horn et al. $5^{a}$ Ed. Porto Alegre: Artmed, 2011, p.475

Um cofator é denominado grupo prostético quando se liga fortemente a uma enzima por interações intermoleculares ou por ligações covalentes. Uma enzima completa com sua coenzima e cataliticamente ativa é denominada holoenzima e a parte proteica é denominada apoenzima ou apoproteína ${ }^{14}$.

De acordo com os cofatores necessários ou com a natureza dos substratos, as oxidorredutases podem ser classificadas em três grandes grupos: oxigenases, oxidases e peroxidases (Figura 4$)^{15}$. Neste trabalho, será discorrido sobre o grupo das oxigenases, pois são enzimas que catalisam reações de bio-oxidação em diversos produtos naturais, como por exemplo, nos hormônios esteroidais. 
Figura 4. Classificação das oxidorredutases ${ }^{16}$.

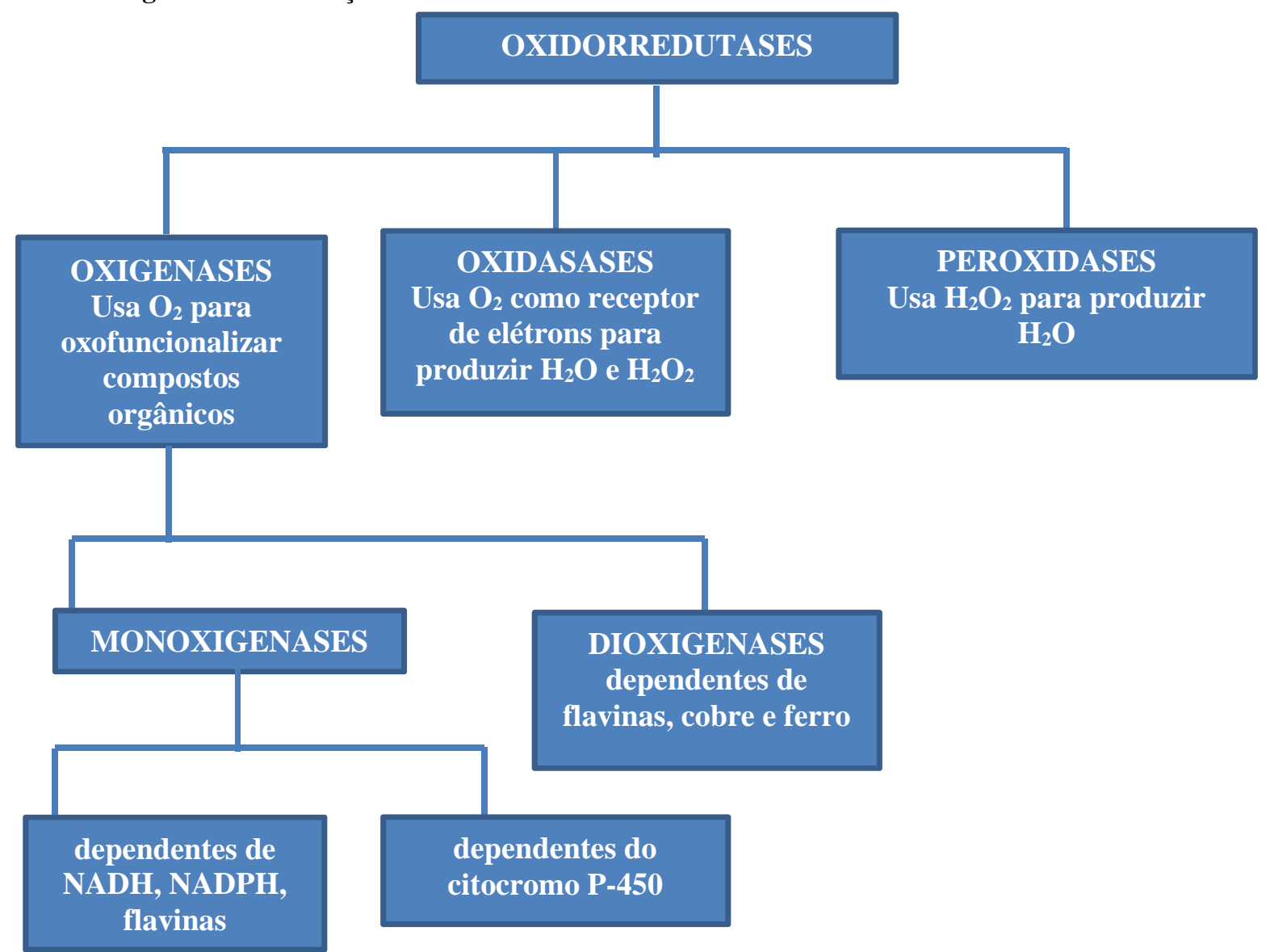

Fonte: Adaptação de MARTINS, M.P., Resolução cinética de haloidrinas racêmicas com a lipase B de Candida antarctica e biotransformação de produtos naturais por micro-organismos. 2012. 170f. Tese (Doutorado em Ciências: Físico-Química) - Instituto de Química de São Carlos, Universidade de São Paulo, São Carlos, 2012, p. 42.

\section{A.2.1 OXIGENASES}

As oxigenases catalisam reações que fazem introdução específica de átomos de oxigênio, provenientes do $\mathrm{O}_{2}$, na molécula do substrato em condições brandas. Elas permitem executar reações de oxofuncionalização, ativando especialmente ligações C-H da molécula do substrato $^{17}$. Quanto ao número de átomos de oxigênio introduzidos no substrato, as oxigenases são divididas em monoxigenases, quando introduzem um átomo de oxigênio e dioxigenases, quando introduzem dois átomos de oxigênio ${ }^{15}$. 


\section{A.2.2 MONOXIGENASES}

O mecanismo geral das reações envolvendo monoxigenases apresenta que a forma de ativação do oxigênio é sempre a mesma: um átomo da molécula de oxigênio é transferido para o substrato, o outro átomo de oxigênio é reduzido para formar uma molécula de água, sendo a transferência eletrônica intermediada pelo cofator e este também é fonte de íon hidreto $(\text { Esquema } 2)^{18}$.

Esquema 2. Mecansismo geral de oxidação biocatalítica promovida por monoxigenase ${ }^{18}$.

$$
\text { Substrato }+\mathrm{O}-\mathrm{O}+\mathrm{H}^{+} \quad \underset{\text { monoxigenase }}{\text { Cofator- } \mathrm{H}} \text { Substrato-O }+ \text { Cofator }+\mathrm{H}_{2} \mathrm{O}
$$

As monoxigenases podem catalisar vários tipos de reações de oxidação dependendo do grupo prostético da enzima. Algumas são dependentes de cofatores NADH, NADPH (fosfato de nicotinamida adenina dinucleotídeo - Figura 5A), flavina e FADH (flavina-adenina dinucleotídeo, FADH - Figura 5B), outras são dependentes do citocromo P-450. O Esquema 3 apresenta exemplos de reações que são catalisadas por monoxienases e os cofatores envolvidos.

Figura 5: Estrutura químicas de cofatores: (A) NADPH, (B) FADH<smiles>NC(=O)c1ccc[n+]([C@@H]2O[C@H](COP(=O)(O)OP(=O)([O-])OC[C@H]3O[C@@H](n4cnc5c(N)ncnc54)[C@H](O[P+](=O)([O-])[O-])[C@@H]3O)[C@@H](O)[C@H]2O)c1</smiles><smiles>Cc1cc2nc3c(=O)[nH]c(=O)nc-3n(C[C@H](O)[C@H](O)[C@H](O)COP(=O)(O)OP(=O)(O)O)c2cc1C</smiles> 
Esquema 3. Exemplos gerais de reações catalisadas por monoxigenases e seus respectivos cofatores.

(A) Oxidação de Baeyer-Villiger (Conversão de cetonas a ésteres ou lactonas) ${ }^{19}$<smiles>O=C1CCCCC1</smiles>

(B) Epoxidação de alcenos $^{20}$<smiles>C/C=C\c1ccccc1</smiles>

(C) Hidroxilação de aromáticos ${ }^{21}$<smiles>Nc1cc(C(=O)O)ccc1O</smiles>

(D) Dimerização 22<smiles>C/C=C/c1ccc(O)c(OC)c1</smiles>

(E) Oxidação de fenois substrituídos a hidroxibenzaldeídos ${ }^{23}$<smiles>COCc1ccc(O)c(O)c1</smiles>

Fontes: (A) aAdaptação de KAMERBEEK, N.M. et al., Baeyer Villiger Monooxygenases, an Emerging Family of Flavin-Dependent Biocatalysts. Advanced Synthesi Catalysis v.345, n.6-7, p. 669, 2003.

(B) Adaptação de ARCHELAS, A., FURSTOSS, R., Synthesis of Enantiopure Epoxides Through Biocatalytic Approaches. Annual Review of Microbiology, v.51, n.1, p.494, 1997

(E) Adaptação de VAN DEN HEUVEL, R.H.H. et al. Vanillyl -alcohol oxidadase, a tasteful biocatalyst. Journal of Molecular Catalysis B: Enzymatic. v.11, p. 186, 2001. 


\section{A.2.3 MONOXIGENASES DO CITOCROMO P-450}

Nas biotransformações de fármacos, as monoxigenases que metabolizam esses compostos são as do sistema hepático do citocromo P-450. Essas enzimas do citocromo P-450 são proteínas complexas e a sua constituição estrutural é basicamente uma porfirina que complexa um íon de Ferro, e, uma cadeia polipeptídica de 45 a 55 kDa. O Ferro é hexavalente e encontra-se ligado à porfirina por quatro ligações planares com os átomos de nitrogênio de seus aneis pirrólicos, podendo estar ou no estado férrico $\left(\mathrm{Fe}^{3+}\right)$ ou no estado ferroso $\left(\mathrm{Fe}^{2+}\right)$. A maior parte dos citocromos P-450 se apresenta na configuração hexa-coordenada (ferro-heme, $\mathrm{Fe}^{3+}$, inativo). Uma quinta ligação do tipo coordenada é feita com o grupo tiolato ( $\left.\mathrm{S}^{-}\right)$da cisteína da cadeia polipeptídica, prendendo assim o grupo heme na apoproteína ${ }^{24}$.

Um mecanismo de oxidação por enzimas do citocromo P-450 (monoxigenases) foi descrito por Urlacher et al. (2004) ${ }^{24}$ e está representado na Figura 6 de acordo com Ener et al. $(2010)^{25}$. Na equação geral, um átomo de oxigênio do $\mathrm{O}_{2}$ é reduzido a água, enquanto o outro é incorporado ao substrato $(\mathrm{R}-\mathrm{H})$, tornando-o mais reativo e hidrossolúvel, sendo o cofator NADPH o doador de equivalentes de redução (um íon hidreto) ${ }^{25}$. 
Figura 6. Ilustração geral do mecanismo de oxidação por enzimas do citocromo P-450²5

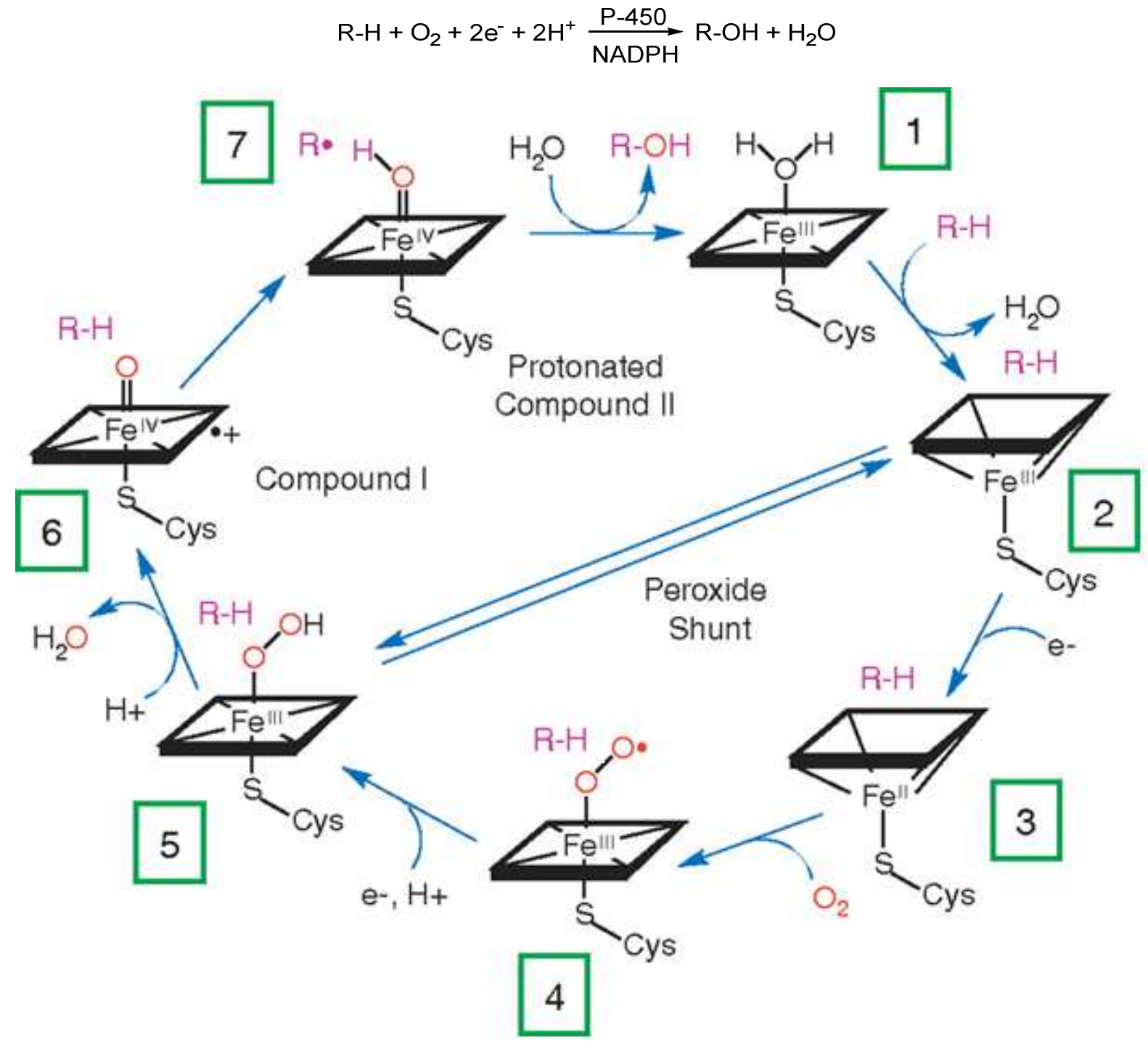

Compound I: Composto I

Protonated Compound II: Composto protonado II

Peroxide Shunt: Atalho por peróxido

Fonte: Adaptação de ENER, M.E. et al. Photooxidation of cytochrome P450-BM3, Proceedings of the National Academy of Sciences of the United States of America, 2010, v.107, n.44, p.18783.

O Ferro ligado ao Enxofre da cisteína se mantém normalmente no estado férrico $\left(\mathrm{Fe}^{3+}\right)$. Quando o átomo de $\mathrm{Fe}^{3+}$ é reduzido a $\mathrm{Fe}^{2+}$ a molécula pode ligar-se, por exemplo, ao monóxido de carbono e passar a absorver luz no comprimento de onda de $450 \mathrm{~nm}^{26}$, daí decorrendo a denominação P-450, ou pigmento que absorve luz a $450 \mathrm{~nm}$. O ciclo catalítico inicia-se com uma molécula de água se ligando ao centro coordenação, no estado férrico gerando uma configuração hexa-coordenada do complexo ferro-heme (Figura 6 - etapa 1), ou no estado 
ferroso com o oxigênio molecular, sendo esta última reação a que normalmente acontece durante a fase I da biotransformação de fármacos ${ }^{27,28,29}$.

O substrato liga-se diretamente ao grupo ferro-heme do citocromo P-450 substituindo a molécula de água no centro de coordenação (Figura 6 - etapa 2), porém não consegue interagir diretamente com o NADPH ou o NADH. No retículo endoplasmático um elétron é doado do NADPH para o citocromo P-450 via uma flavoproteína conhecida como NADPH-citocromo P450 redutase, havendo redução do ferro do grupo heme do estado férrico $\left(\mathrm{Fe}^{3+}\right)$ para o estado ferroso $\left(\mathrm{Fe}^{2+}\right.$ ), (Figura 6 - etapa 3). O citocromo P-450 recebe somente um elétron de cada vez, o que só é possível devido à presença de 2 grupos flavina na estrutura da redutase, um FMN (flavina mononucleotídio - Figura 7) e um FAD. O Oxigênio pode então se ligar diretamente ao citocromo P-450 no estado ferroso, oxidando o ferro ao estado férrico. Contudo, o substrato não se liga diretamente ao centro de coordenação do grupo ferro-heme (Figura 6 - etapa 4). O oxigênio ligado ao complexo então recebe um segundo elétron do NADPH redutase ou do citocromo b5, via NADH-citocromo b5 redutase (Figura 6 - etapa 5). Após a entrada desse segundo elétron ocorre decomposição do complexo com a saída de uma molécula de água (Figura 6 - etapa 6) e um átomo de Oxigênio permanece ligado ao Ferro por uma ligação dupla. Um íon hidreto proveniente do substrato é transferido ao átomo de oxigênio remanescente do complexo (Figura 6 - etapa 7), e posteriormente o complexo é decomposto com a liberação do substrato oxidado e com uma molécula de água se ligando ao centro de coordenação do complexo, reiniciando assim o ciclo catalítico. Na mitocôndria, a ferrodoxina e a ferrodoxinaredutase são as proteínas responsáveis pela transferência dos elétrons ${ }^{24}$.

Figura 7. Estrutura química do cofator FMN<smiles>Cc1cc2nc3c(=O)[nH]c(=O)nc-3n(C[C@H](O)[C@H](O)[C@H](O)COP(=O)(O)O)c2cc1C</smiles> 


\section{A.3 EMPREGO DE MICRORGANISMOS EM PROCESSOS DE BIOTRANSFORMAÇÃO}

Para o desenvolvimento de processos biotecnológicos tem sido realizadas triagens de microrganismos como novas fontes de enzimas. Em geral, essas triagens são promovidas por linhagens de fungos e bactérias provenientes de ecossistemas específicos, como o ambiente marinho. As enzimas provenientes destes microrganismos possuem suas propriedades bioquímicas influenciadas pelas condições ambientais do ecossistema marinho como a acidez, alcalinidade, temperatura, salinidade. Uma vez que tais condições do ambiente marinho são alteradas, as propriedades destas enzimas também podem ser afetadas frente às reações bioquímicas que são catalisadas nos seus sistemas biológicos. Sendo assim, esses fungos se constituem fontes importantes de enzimas que podem ser promissoras em reações de biooxidação ${ }^{30,31}$. Assim, o desenvolvimento crescente de trabalhos com culturas in vitro de células de fungos filamentosos é devido ao potencial biotecnológico de interesse industrial, como por exemplo, a biotransformação de fármacos e a biodegradação de agroquímicos.

Setenta e cinco por cento da superfície terrestre é coberta pelos oceanos. Este ecossistema abriga uma enorme biodiversidade compreendendo desde os microrganismos mais simples como fungos, bactérias até seres vivos superiores como grandes peixes, cetáceos e vastas colônias de corais e esponjas. Estima-se que $3,67 \times 10^{30}$ é o total de microrganismos que vivem em ambiente marinho ${ }^{32,33}$. Pode-se perceber que a partir desta rica biodiversidade, $\mathrm{o}$ ambiente marinho pode ser fonte de uma alta variedade de potenciais biocatalisadores de reações de interesse econômico e científico.

Em geral, os fungos de ambiente marinho estão associados a outros seres vivos como esponjas, peixes, cnidários e algas. Basicamente podemos dividir os microrganismos em dois grandes grupos quanto á sua origem ${ }^{34,35}$ :

a) "obrigatórios" que são aqueles que se desenvolvem exclusivamente nos mares;

b) "facultativos" que são encontrados tanto em ambientes marinhos, quanto em ambientes continentais.

Existem alguns trabalhos na literatura que relatam a biotransformação de compostos químicos utilizando fungos de ambiente marinho. O fungo Eupenicillium sp., isolado da esponja marinha Axinella sp., foi utilizado na biotransformação da herbimicina A, um fármaco antitumoral. Os resultados mostraram que a herbimicina A, inicialmente insolúvel em água, foi transformada em herbimicina $\mathrm{C}$ e 11-hidroxi-(11-demetoxi)-herbimicina $\mathrm{C}$ via reação de 
desmetilação. Ambos os metabólitos são mais solúveis em água ${ }^{32}$ (Esquema 4). Assim, a atividade catalítica em xenobióticos pelas enzimas do tipo citocromo P-450 foram também encontrados em organismos marinhos. $\mathrm{sp}^{32}$.

Esquema 4. Biotransformação da Herbicina A catalisada pelo fungo de ambiente marinho Eupenicillium

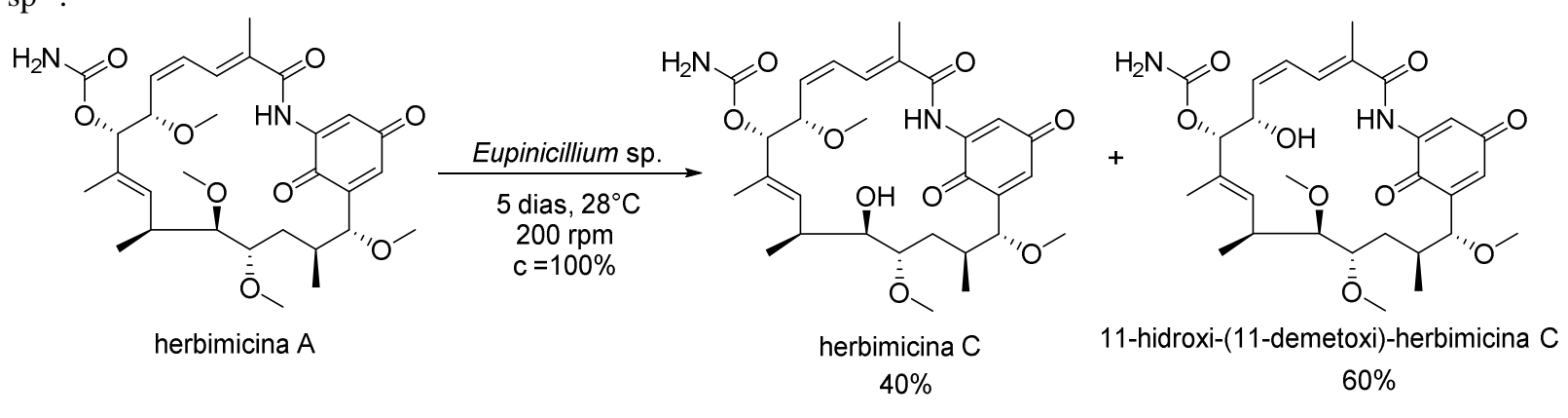

Fonte: Adaptação de XIE, L. et al., Microbial biotransformation of water-insoluble herbimycin A to 11-hydroxy(11-demethoxy)-herbimycin C by Eupenicillium sp. Journal of Molecular Catalysis B: Enzymatic, v.62, n.1 p.77, 2010.

Martins et al. (2010) ${ }^{36}$ mostraram que o fungo Aspergillus sydowii CBMAI 935 foi capaz de promover a resolução enzimática do benzil-glicidil-éter (( \pm$)$-2(benziloximetil)oxirano levando à formação do $(R)$-2-(benziloximetil)oxirano e do $(R)$-2(benziloxi)propano-1,2-diol, com boas conversões, sendo constatado que o enantiômero $(S)$ do substrato é que sofreu a reação de hidrólise catalítica levando ao produto diol (Esquema 5). As enzimas resposáveis por esta catálise são epóxido-hidrolases. Os autores também concluíram que a reação de hidrólise ocorreu quando o fungo foi cultivado na presença de água do mar artificial.

Esquema 5. Resolução enzimática do benzil-glicidil-eter catalisada pelo fungo A. sydowii CBMAI $935^{36}$

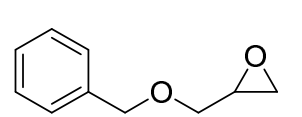

(士)-2-(benziloximetil)oxirano

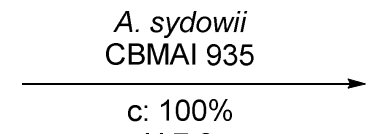

$\mathrm{pH} 7,0$ $0,1 \mathrm{M}$

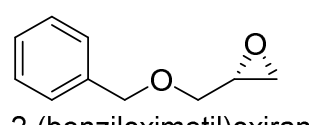

(R)-2-(benziloximetil)oxirano ee $24-46 \%$

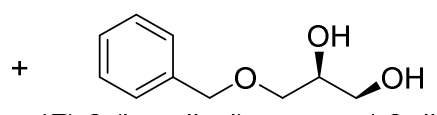

(R)-2-(benziloxi)propano-1,2-diol $e e<10 \%$

Fonte: Adaptação de MARTINS, M.P. et al., Marine Fungi Aspergillus sydowii and Trichoderma sp. Catalyze the Hydrolysis of Benzyl Glycidil Ether. Marine Biotechnology, v.13, n.2, p. 317, 2010.

Há também o interesse científico do emprego de microrganismos de ambiente marinho em reações de biodegradação de agroquímicos, visto que o mar é o destino final de muitos produtos utilizados na cultura de diversos produtos. Foi observado que o fungo A. sydowii 
CBMAI 935 foi capaz de biodegradar os pesticidas profenofós, clorpirifós e metilparation, empregados como pesticidas em culturas agrícolas. Os produtos observados são do tipo fenol e fosfotionato $^{37,38,39}$ (Esquema 6).

Esquema 6. Reações de biodegradação de pesticidas utilizando o fungo A. sydowii CBMAI 935: (A) clorpirifós, (B) profenofós, (C) metilparation ${ }^{37,38,39}$.

(A)

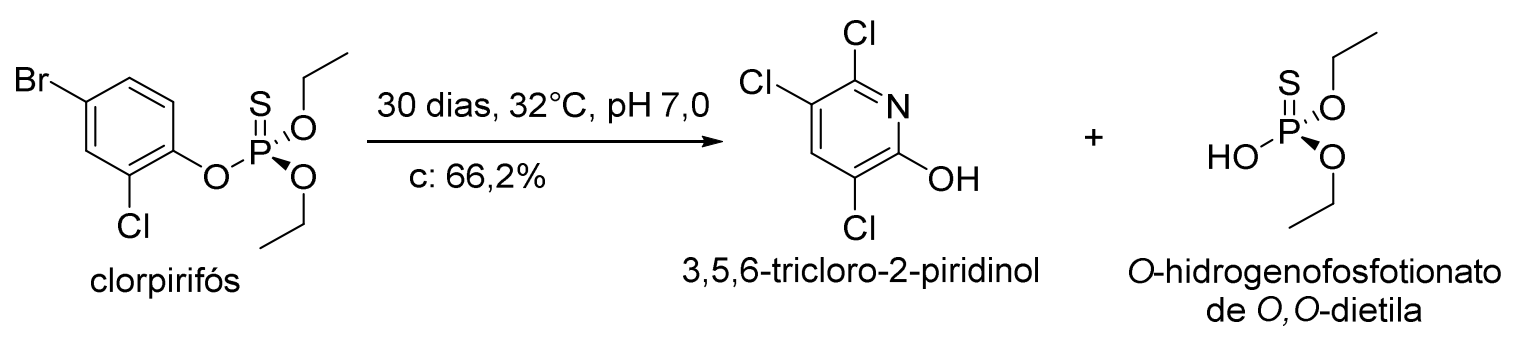

(B)

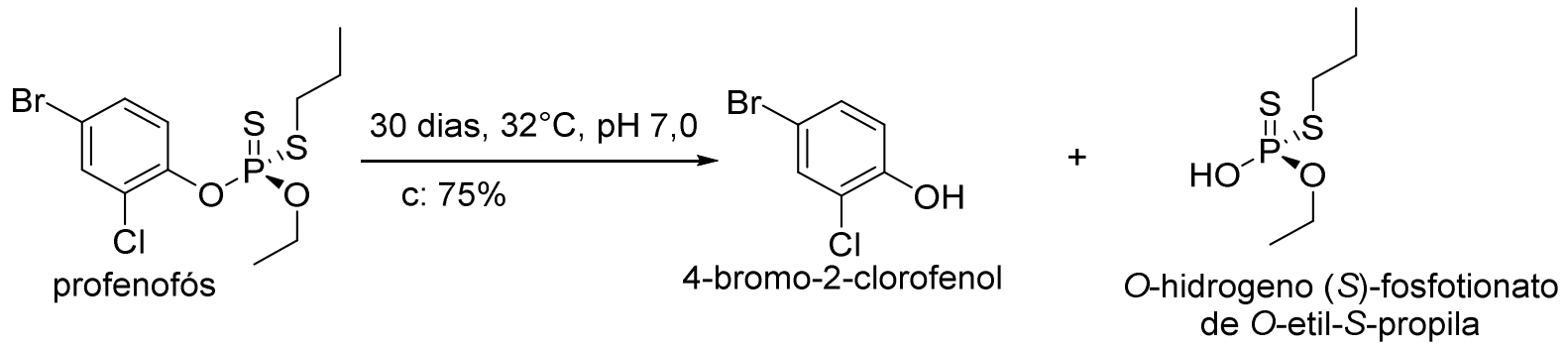

(C)

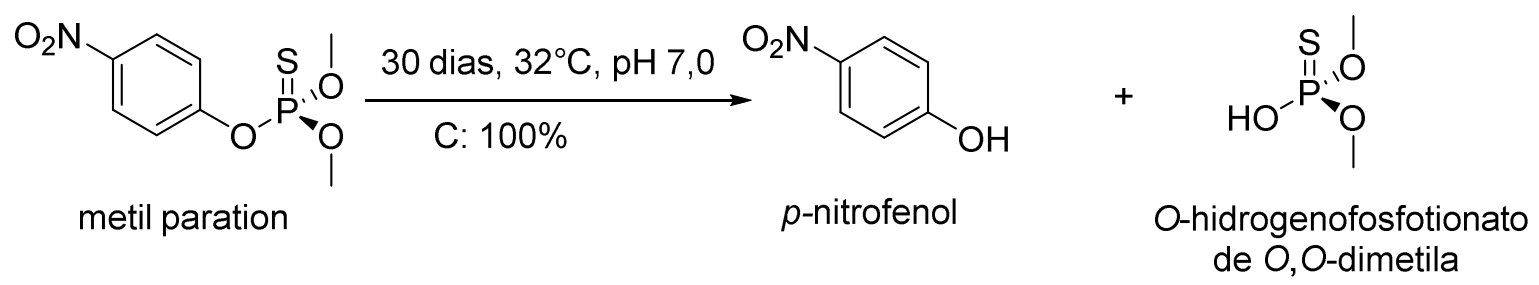

Fontes: (A) Adaptação de SILVA, N.A., et al. Biodegradation of the Organophosphate Pesticide. In: PATIL, Y.B. e RAO, P., Applied Bioremediation - Active and Active Approaches. Rijeka: InTech, 2013, p.151.

(B), (C) Adaptações de SILVA, N.A., Biodegradação dos pesticidas clorpirifós, metil-paration e profenofós por fungos de origem marinha. 2013. 161f. Dissertação (Mestrado em Ciências: Química Orgânica e Biológica) - Instituto de Química de São Carlos, Universidade de São Paulo, São Carlos, 2013, p.93

Há o interesse no estudo de biotransformação de produtos de origem natural, de estrutura química complexa contendo esqueleto carbônico policíclico condensado. Os compostos (-)ambrox ${ }^{\circledR},(-)$-sclareol e (-)-sclareolide, quando submetidos à presença de fungos de ambiente marinho, sofreram reações de hidroxilação, gerando núcleos decalínicos mais polares ${ }^{16,40}$ (Esquema 7). 
Esquema 7. Biotransformação de produtos naturais utilizando fungos de origem marinha:

(A) (-)-ambrox ${ }^{\circledR},(\mathrm{B})$ sclareol e (C) sclareolide. ${ }^{16,40}$

(A)

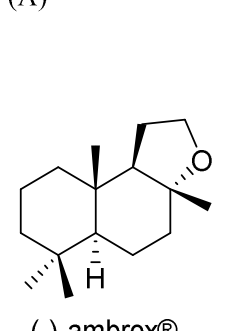

$(-)$-ambrox®

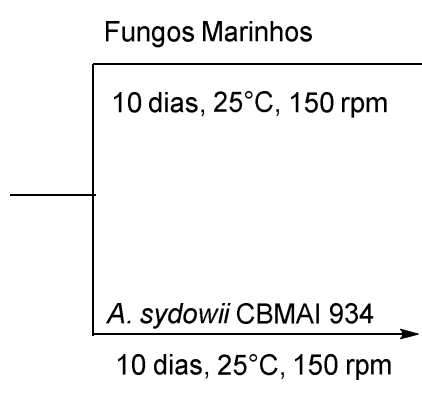

0 dias, $25^{\circ} \mathrm{C}, 150 \mathrm{rpm}$

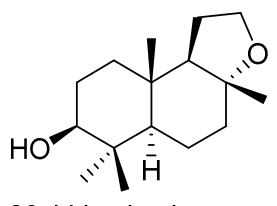

3 $\beta$-hidroxiambrox

Bostryopharia sp.CBMAl $1197(r=17 \%)$

Eutypella sp. CBMAI $1196(r=11 \%)$

(B)

\section{$1 \beta$-hidroxiambrox $(r=44 \%)$}

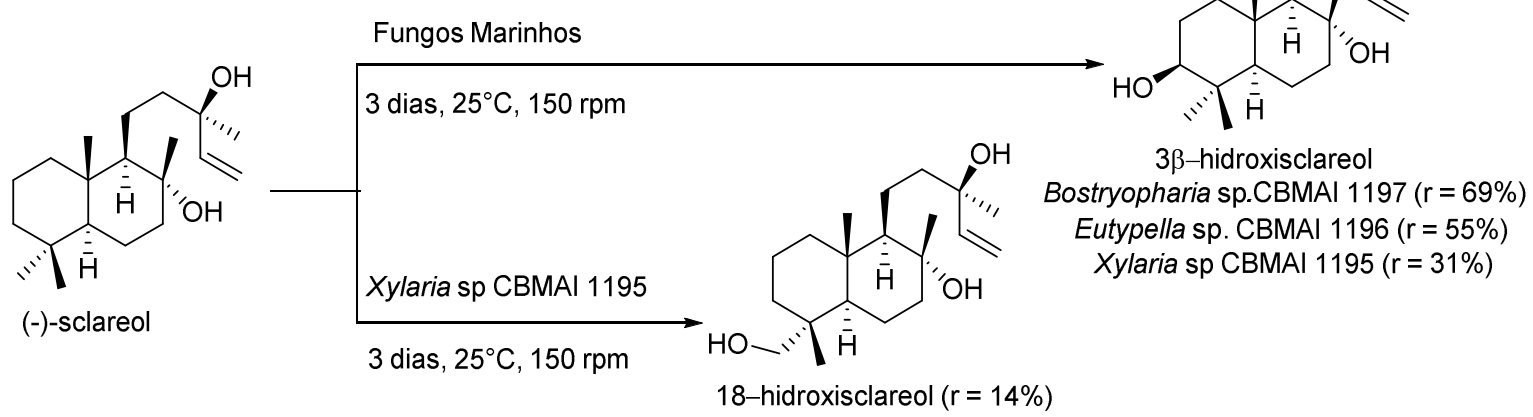

(C)

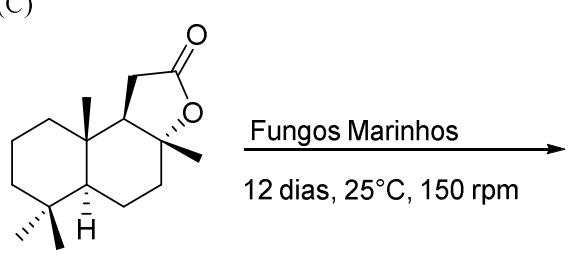

$(-)$-sclareolide

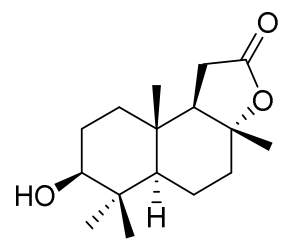

3ß-hidroxisclareolide

Bostryopharia sp.CBMAI $1197(r=34 \%)$

Eutypella sp. CBMAI $1196(r=7 \%)$

Como pode ser observado, os produtos naturais (-)-ambrox ${ }^{\circledR},(-)$-sclareol e (-)sclareolide apresentam núcleo estrutural policíclico condensado assim como os esteroides, embora o núcleo básico estrutural desses produtos naturais em questão seja do tipo decalina. Sendo assim, tomando por base a capacidade de fungos de ambiente marinho promoverem a biotransformação dos produtos naturais referidos, suscitou-se o interesse na capacidade destes microrganismos promoverem a biotransformação de fármacos esteroidais por serem produtos de origem natural contendo núcleos policíclicos condensados. 


\section{A.4 ESTEROIDES E REAÇÕES DE BIOTRANSFORMAÇÃO}

Esteroides são compostos orgânicos cujas moléculas possuem um esqueleto estrutural básico tetracíclico arranjado como no ciclopenta[a]fenantreno (Figura 8A), que pode ser completamente ou parcialmente reduzido. Seguindo convenção determinada em $1971^{41}$ e resvisada em $1989^{41}$ pela Comissão de Nomenclatura em Bioquímica formada pela União Internacional de Química Pura e Aplicada (IUPAC em inglês: International Union of Pure and Applied Chemistry) e pela União Internacional de Bioquímica e Biologia Molecular (IUBMB em inglês: International Union of Biochemistry and Molecular Biology) os anéis do núcleo tetracíclico, como mostra a Figura 8, são denominados pelas letras maiúsculas A,B,C e D, da esquerda para a direita. A numeração dos átomos de carbono do núcleo tetracíclico é feita tomando por referência o núcleo de gonano (Figura $8 \mathrm{~B})^{41}$.

A grande maioria dos esteroides também podem ter um ou dois grupos metilas ligados aos carbonos 10 e 13 do esqueleto estrutural, sendo os carbonos metílicos numerados como 19 e 18 respectivamente como no 10,13-dimetil-gonano ${ }^{41}$ (Figura 8C) .

Figura 8. Representações dos esqueletos estruturais dos esteroides.

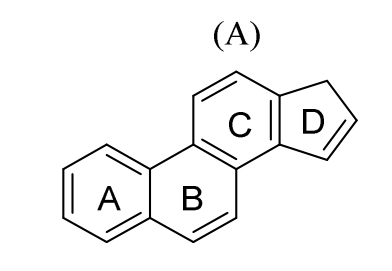

ciclo-penta[a]fenantreno

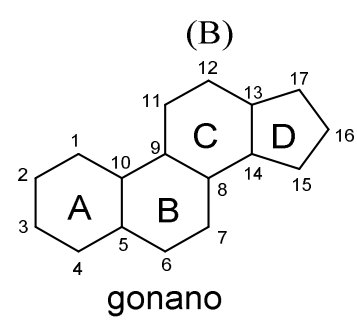

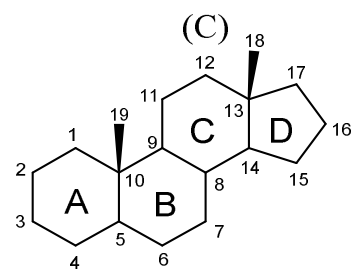

10,13-dimetil-gonano

Quanto à orientação dos substituintes ligados ao núcleo esteroidal, eles podem assumir as seguintes orientações especiais, tomando como referência a conformação planar do núcleo esteroidal: $\alpha$ quando o sentido da ligação é para dentro do plano em que se encontram os anéis do núcleo esteroidal e $\beta$, quando o sentido da ligação é para fora do plano em que se encontram os aneis do núcleo esteroidal. Os hidrogênios ligados aos carbonos C-8, C-9, C-14 que estão nas junções dos anéis $\mathrm{B}, \mathrm{C}$ e $\mathrm{D}$ do núcleo tetracíclico assumem as seguintes orientações espaciais: $8 \beta, 9 \alpha, 14 \alpha$ (Figura 9). Espacialmente, os esteroides podem assumir duas conformações: de tipo $\alpha$ ou de tipo $\beta$. A forma de reconhecer a conformação do esteroide é pela orientação do hidrogênio ligado ao carbono C-5 ${ }^{41}$ (Figura 10). 
Figura 9. Orientações espaciais dos hidrogênios ligados aos carbonos da junções dos anésis B,C e D do núcleo tetracíclico de esteroides.

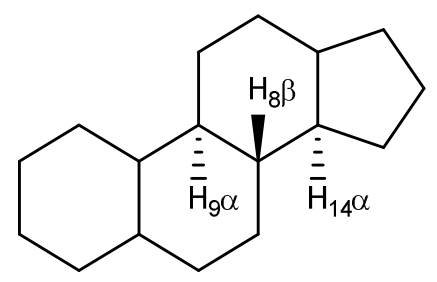

Figura 10. Conformações espaciais dos esteroides: (A) de tipo $\alpha$, (B) de tipo $\beta$

(A)

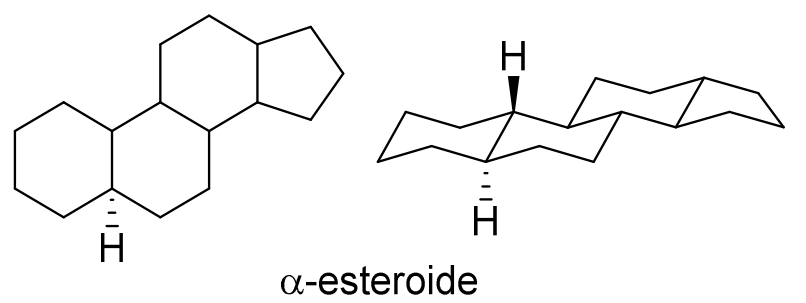

(Fusão trans do anel $\mathrm{AB}$ )
(B)<smiles>C1CCC2CCC3CCCC3C2CC1</smiles><smiles>C1CCC2CCCC(C1)CCC2</smiles>

(Fusão cis do anel $A B$ )

Um composto que é classificado como como fármaco esteroidal, apesar de não possuir o esqueleto estrutural típico, é a vitamina $\mathrm{D}$, encontrada de duas formas ${ }^{41}$ :

a) vitamina $D_{2}$ denominada ergocalciferol, derivada do esteroide ergosterol (Esquema $8 \mathrm{~A})$;

b) vitamina $\mathrm{D}_{3}$ denominada colecalciferol, derivada do esteroide colesta-5,7-dien-3 $\beta$-ol (7-desidrocolesterol) (Esquema 8B).

As formas de vitamina D se originam de seus respectivos esteroides através de uma fotólise da ligação C-C, seguida de desidrogenação, entre os carbonos C-9 e C-10 do anel B do estreróide precursor (Esquema 8). Essa fotólise explica a capacidade de o organismo humano sintetizar as formas de vitamina D. Como é sabido as formas de vitamina D têm sua importância na absorção de cálcio pelo organismo e em função da fotólise da ligação entre os carbonos e C9 e C-10 que se recomenda a exposição à luz solar tanto para pacientes com deficiência de cálcio no organismo, quanto para indivíduos sadios como medida preventiva e de estilo de vida. 
Esquema 8. Formas da vitamina D e seus respectivos esteroides precursores: (A) fotólise do ergosterol originando a vitamina $\mathrm{D}_{2}$ (ergocalciferol), (B) fotólise do 7-desidrocolesterol originando a vitamina $\mathrm{D}_{3}$ (colecalciferol).<smiles>CC(C)[C@H](C)/C=C/[C@H](C)[C@H]1CC[C@H]2C3=CC=C4C[C@@H](O)CC[C@]4(C)C3CC[C@]21C</smiles>
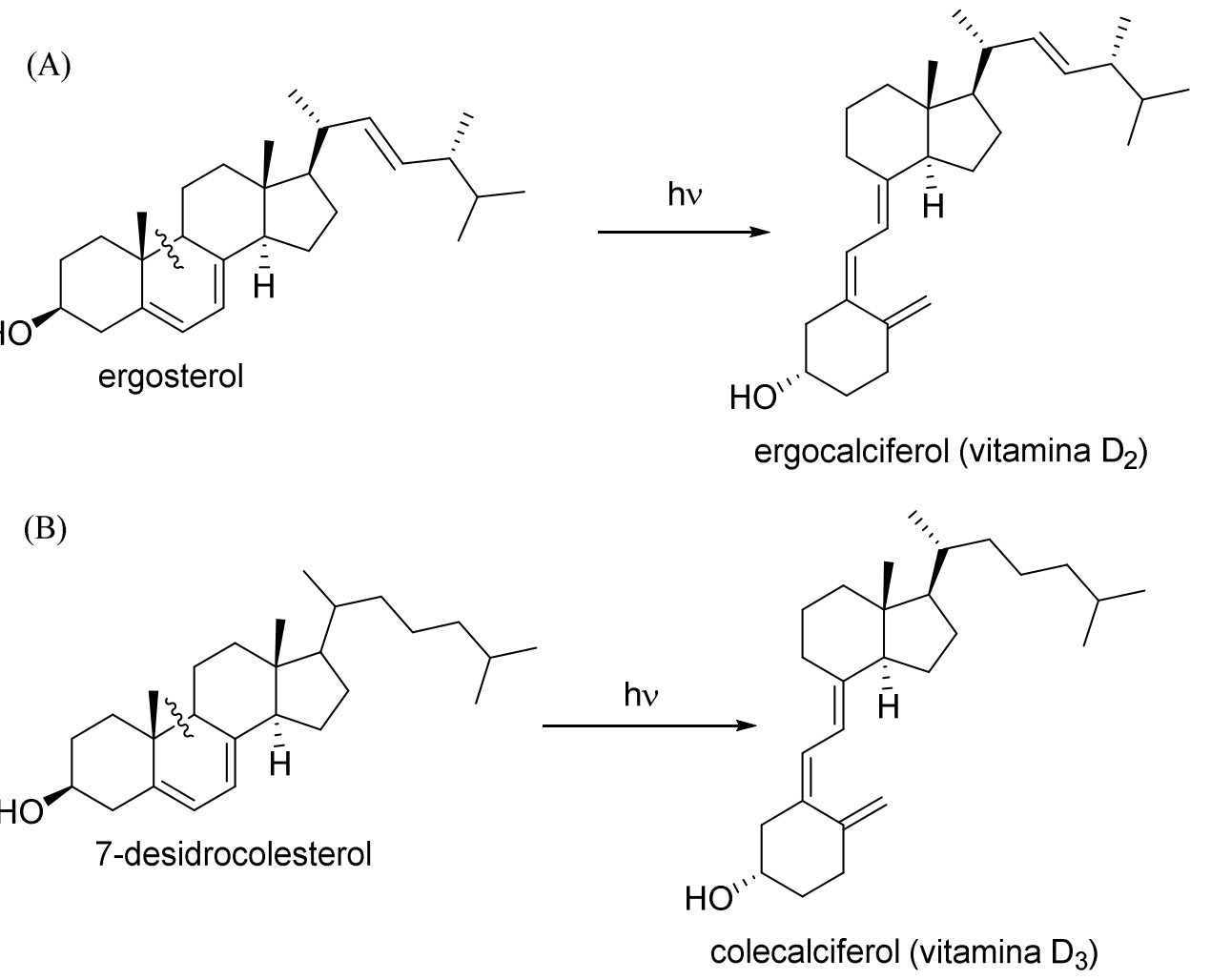

Dentre os diferentes tipos de esteroides e atividades biológicas que desempenham, temos os estrogênios, que são hormônios sexuais estimulantes dos caracteres femininos e são produzidos nos ovários ${ }^{42}$. Os principais estrogênios são a estrona, o estradiol e o estriol (Figura 11).

Figura 11. Hormônios sexuais femininos do tipo estrogênios<smiles>C[C@]12CCC3c4ccc(O)cc4CC[C@H]3[C@@H]1CCC(=O)[C@]2(C)CCCO</smiles>

Derivados sintéticos de estrogênios, 17 $\alpha$-etinilestradiol e mestranol (Figura 12) são bastante empregados como inibidores do processo de ovulação, sendo o princípio ativo de muitos contraceptivos. Além disso, estes fármacos também são administrados no controle de 
sintomas que envolvem a menopausa, no tratamento de distúrbios fisiológicos, câncer de próstata e de mama, de infertilidade e auxílio no controle do ciclo menstrual ${ }^{43}$.

Figura 12. Derivados sintéticos do estradiol<smiles>C#C[C@]1(O)CC[C@H]2[C@H]3CCc4cc(O)ccc4[C@@H]3CC[C@@]2(C)[C@]1(C)O</smiles>

Outros fármacos que também são utilizados como anticoncepcionais são os progestógenos como a progesterona, noretindrona, norgestimato, acetato de medroxiprogesterona, levonorgestrel e desogestrel ${ }^{44}$ (Figura 13).

Figura 13. Principais anticoncepcionais progestógenos ${ }^{44}$.

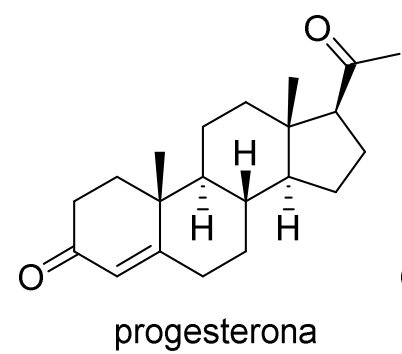

(c)

acetato de medroxiprogesterona

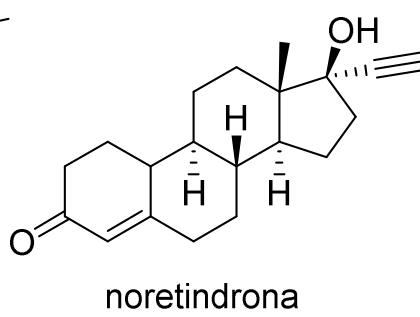<smiles>C#C[C@]1(O)CC[C@H]2[C@@H]3CCC4=CC(=O)CCC4[C@@H]3CC[C@]21CC</smiles>

levonorgestrel<smiles>C#C[C@]1(O)CC[C@H]2[C@H]3CCC4=C/C(=N/O)CCC4[C@@H]3CC[C@]21CC</smiles>

norgestimato

desogestrel

Desde a descoberta da atividade anti-inflamatória da cortisona em 1949 (Figura 14), que rendeu o Prêmio Nobel de Medicina (1950) para Kendall, Reichstein e Hench ${ }^{45}$, os hormônios esteroidais e seus derivados têm sido utilizados com diversas aplicações terapêuticas. Além das estabelecidas aplicações como imunossupressores, anti-inflamatórias, antirreumáticas, progestacionais, diuréticas, sedativas, anabolizantes e anticoncepcionais, as recentes aplicações dos esteroides incluem o tratamento de algumas formas de câncer, osteoporose, HIV, entre outras. Em 2010, os esteroides representaram um dos setores mais rentáveis da indústria 
farmacêutica, com mercado mundial com cerca de 10 bilhões de dólares e produção anual que excedeu 1.000 .000 de toneladas ${ }^{46}$.

Figura 14. Fórmula estrutural da cortisona.

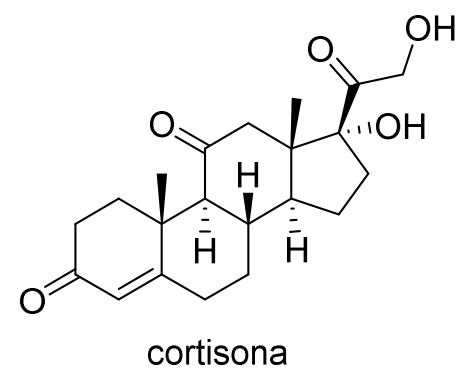

Até o início da década de 1950 as rotas sintéticas disponíveis para obtenção de derivados de esteroides possuíam várias etapas e apresentavam alguns problemas, como a introdução de uma hidroxila no carbono C-11 do esqueleto estrutural. Essa introdução é necessária para a atividade do fármaco. A hidroxilação enzimática de esteroides na posição C-11 é catalisada por monoxigenases do citrocromo P-450 presente em diversas linhagens microbianas ${ }^{46}$.

Microrganismos que catalisam reações de hidroxilação, hidrogenação, desidrohalogenação e quebra de ligações $\mathrm{C}-\mathrm{C}$ de esteroides foram identificados e representam as mais importantes aplicações de biotransformações de esteroides em processos industriais. Avanços na otimização e elaboração de processos biocatalíticos de biotransformação de esteroides foram obtidos principalmente através do isolamento de novos microrganismos capazes de realizar transformações de interesse industrial.

Por exemplo, Žnidaršič-Plazl e Plazl $(2010)^{46}$ utilizaram o fungo Rhizopus nigricans com o objetivo de melhorar o desempenho da reação de $11 \alpha$-hidroxilação da progesterona, que produz a $11 \alpha$-hidroxiprogesterona (Esquema 9). Esta etapa de hidroxilação da progesterona é fundamental na produção da cortisona. Várias questões foram abordadas no trabalho relacionando a forma de melhorar a produtividade do processo, incluindo imobilização do biocatalisador, a solubilidade do substrato e o desenvolvimento de um processo de reação contínua. Após estudos de morfologia do fungo R. nigricans alguns "pellets" (colônias esféricas de células fúngicas) contendo as células foram obtidas, o que permitiu seu processo contínuo de biotransformação. A baixa solubilidade do esteroide foi minimizada pela adição de solventes orgânicos ( $N, N$-dimetil-formamida, dimetil-sufóxido) ou $\beta$-ciclo-dextrina. A extração do produto biotransformado foi facilitada via fase líquida contínua com dispositivo de microcanal $^{46}$. 
Esquema 9. Biotransformação da progesterona catalisada pelo fungo R. nigricans ${ }^{46}$.<smiles>CC(=O)[C@H]1CC[C@H]2[C@@H]3CCC4=CC(=O)CC[C@]4(C)[C@H]3CC[C@]12C</smiles>

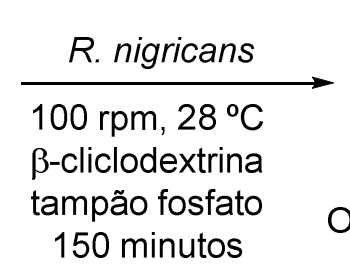

150 minutos

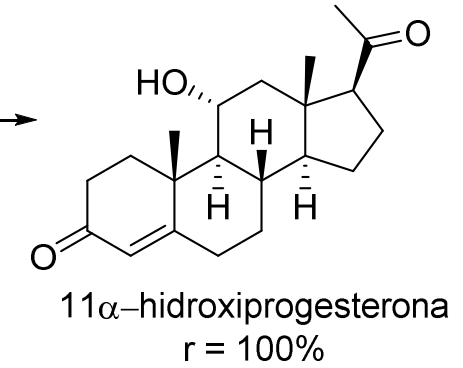

Um dos principais usos industriais de obtenção de esteroides é a $\beta$-hidroxilação da cortexolona um derivado da progesterona, para originar a hidrocortisona, um corticosteroide com atividade anti-inflamatória. Nesse processo, foram utilizados o fungo Curvularia lunata ${ }^{47}$ (Esquema 10).

Esquema 10. Biotransformação da cortexolona catalisada pelo fungo C. lunata ${ }^{47}$.

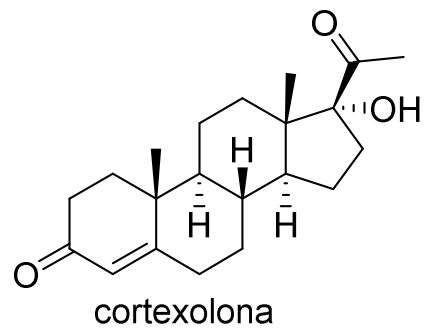

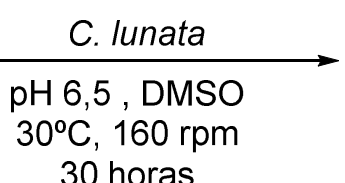

30 horas<smiles>CC(=O)[C@]1(O)CC[C@H]2[C@@H]3CCC4=CC(=O)CC[C@]4(C)[C@H]3[C@@H](O)C[C@]21C</smiles>

$11 \beta$-cortexolona ou hidrocortisona $r=60 \%$

Fonte: Adaptação de SONOMOTO, K. et. al 11ß-Hydroxyltion of cortexolone (Reichstein Compound S) to hydrocortisone by Curvularia lunata Entrapped in Photo-Cross-Linked Resin Gels. Applied and Environmental Microbiology, February 1983, vol. 45, n.2, p.437.

Outros exemplos de hidroxilações são descritos na literatura como o uso do fungo Streptomyces argenteolus para obtenção da 16 $\alpha$-hidroxiprogesterona, através da reação de hidroxilação da progesterona. Esta reação é importante, pois, o produto hidroxilado obtido é um precursor para obtenção da triancinolona, um dos fármacos anti-inflamatórias mais eficientes $^{48}$ (Esquema 11). 
Esquema 11. Biotransformação da progesterona catalisada pelo fungo S. argenteolus produzindo 16 $\alpha$ hidroxiprogesterona, intermediária na produção da triancinolona ${ }^{48}$.<smiles>CC(=O)C1CCC2C3CC(O)C4=CC(=O)CCC4(C)C3CCC12C</smiles>

progesterona

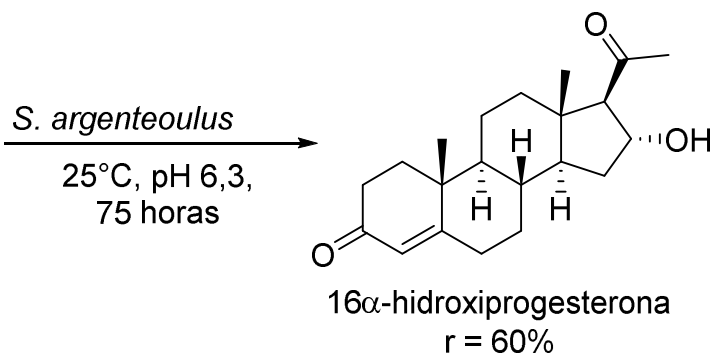

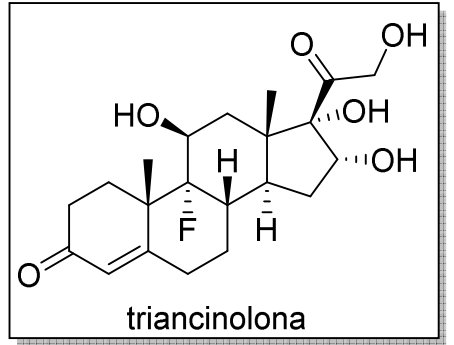

Manosroi, Abe e Manosroi (1999) ${ }^{49}$ estudaram a biotrasnformação da cortexolona utilizando os fungos das espécies C. lunata e Cunninghamella blakesleeana para obtenção da hidrocortisona. Também foi estudada a biotransformação desse substrato utilizando bactérias das espécies Bacillus sphaericus e Nocardioides simplex para obtenção da prednisolona (Esquema 12). O melhor resultado obtido para a hidrocortisona foi com o fungo $C$. blakesleeana, enquanto a bactéria $N$. simplex foi a mais eficiente para a produção de prednisolona (Tabela 1$)^{49}$.

Esquema 12. Biotransformação da cortexolona para a produção de hidrocortisona e predinisolona utilizando microrganismos provenientes do solo $^{49}$.

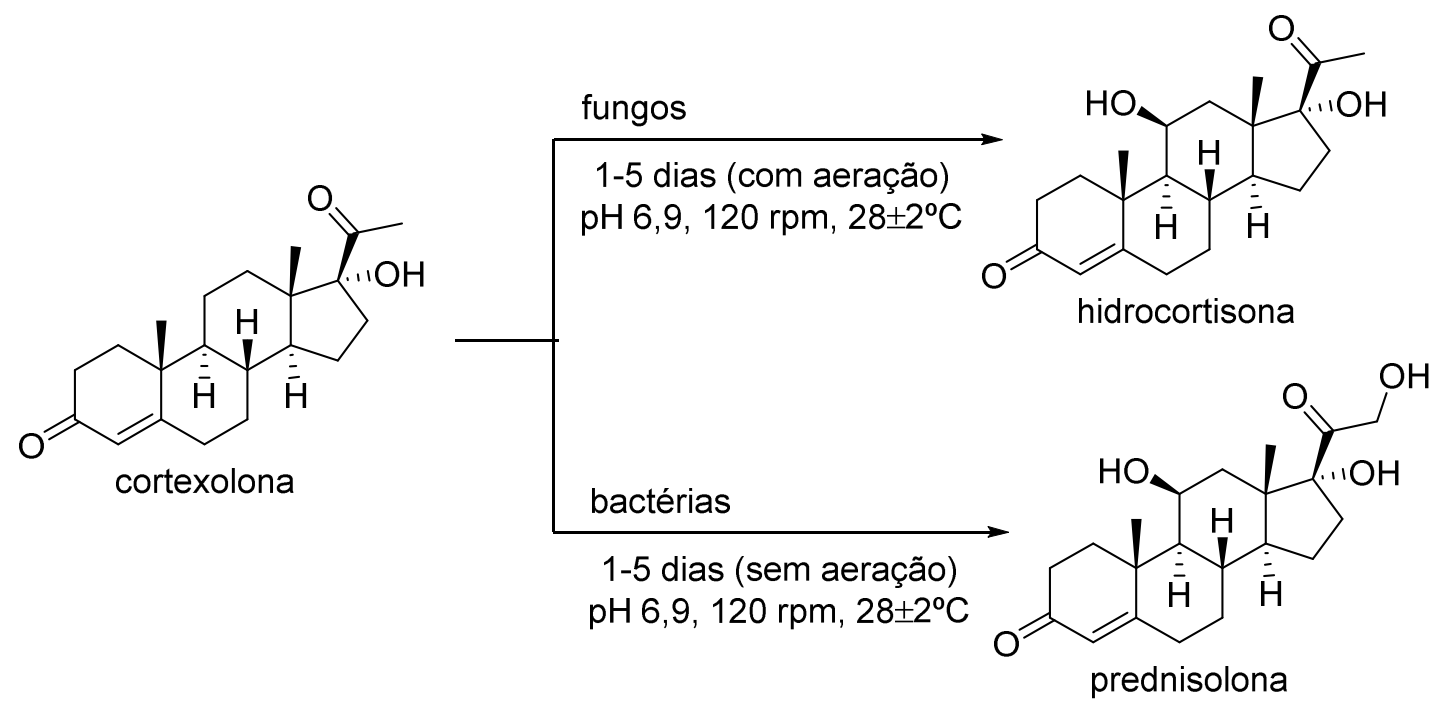


Tabela 1. Biotransformação da cortexolona catalisada por fungos para obtenção da hidrocortisona e catalisada por bactérias para obtenção da prednisolona ${ }^{49}$.

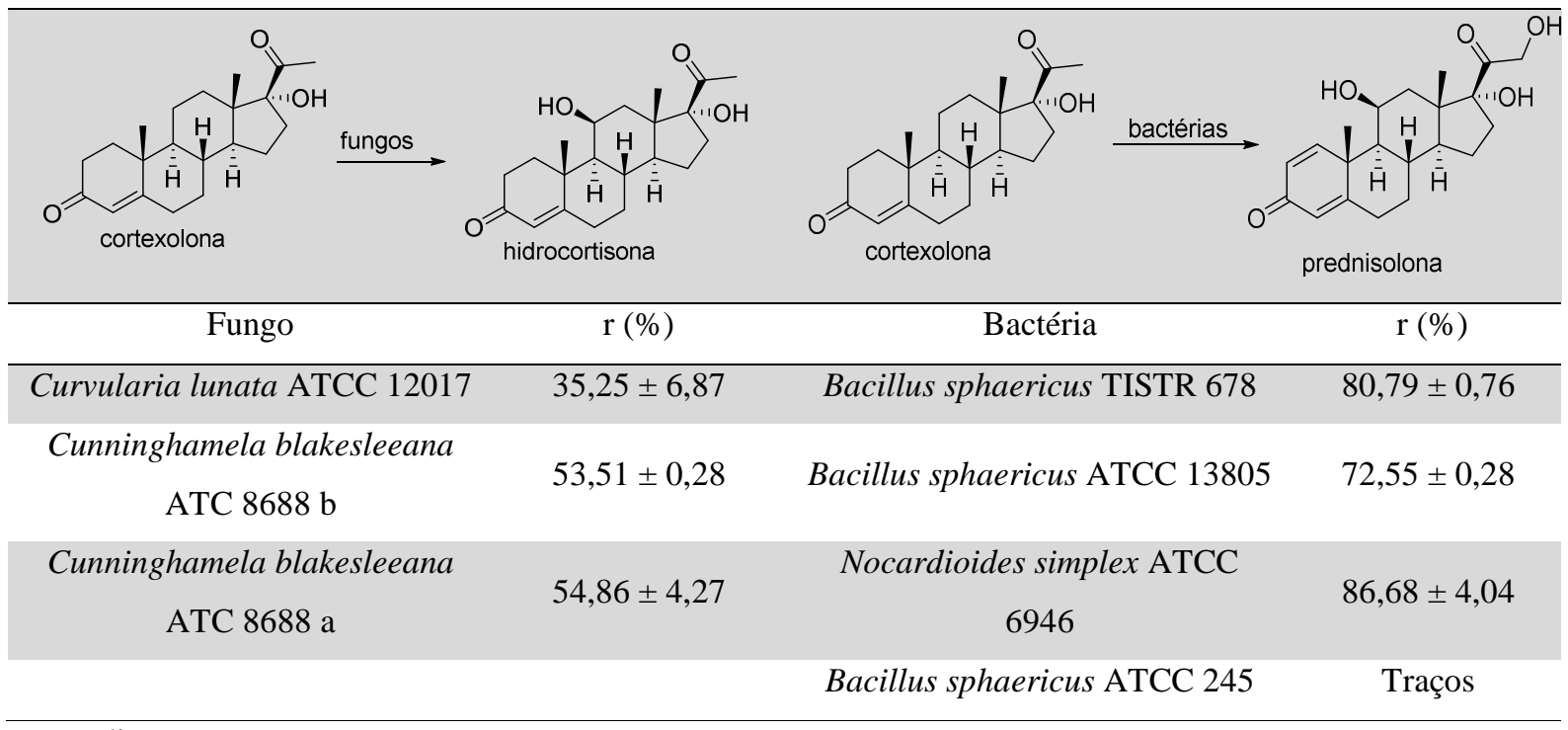

$\mathrm{r}=$ rendimento

Como outrora já foi descrito, fármacos esteroidais quando são biotransformados têm a sua eficácia terapêutica melhorada. Um exemplo é a biotransformação da 6-metil-cortisona através da reação de desidrogenação deste esteroide, formando uma ligação dupla na posição 1,2 do núcleo esteroidal utilizando o fungo Septomyxia affinis ${ }^{50}$ (Esquema 13). Inclusive a utilização de linhagens de Arthrobacter (Corynebacterium) simplex, Bacillus sphaericus e Bacterium cyclooxydans já foi aplicada em escala industrial na biotransformação deste esteroide pela indústria farmacêutica Schering ${ }^{51}$.

Esquema 13. Biotransformação da 6-metil-cortisona catalisada pelo fungo S. affinis ${ }^{50}$.

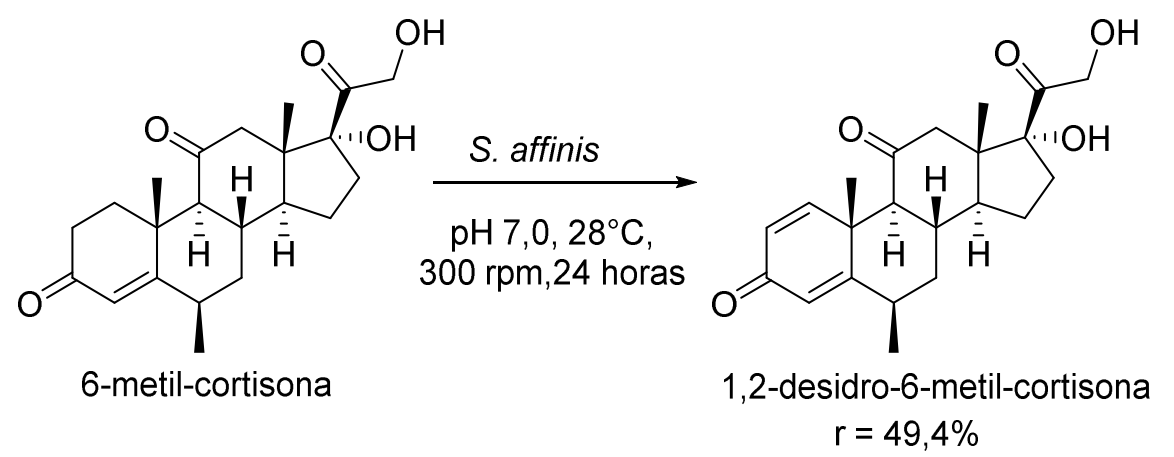

A produção de esteroides por biotransformação em escala industrial tem como primeira etapa o desenvolvimento de um inóculo que é feito em um fermentador que normalmente é de aço inoxidável, aerado e com agitação. O microrganismo cresce em um período de 17 - 48 horas em meio de cultura especialmente selecionado para um bom rendimento até que se consiga uma concentração desejada de células ativas ${ }^{4}$. 
O meio de cultura deve ser composto de uma quantidade mínima de nutrientes de modo que permita maior facilidade de extração e purificação do produto de biotransformação. Uma faixa de temperatura de $27-37^{\circ} \mathrm{C}$ é ótima para a produção das enzimas desejadas que promovem a biotransformação do substrato. Após o crescimento do microrganismo, o substrato é adicionado em uma faixa de concentração de 1 - $20 \mathrm{~g} / \mathrm{L}$ e a biotransformação é feita em condições semelhantes até que se alcance um máximo de produto, normalmente numa faixa de pH neutro ${ }^{4}$.

Os esteroides são insolúveis em água e para adição desses substratos ao meio reacional é feita a dissolução em um solvente apropriado como propilenoglicol, metanol, etanol, acetona, dimetil-sulfóxido (DMSO), N,N-dimetil-formamida (DMF) em concentração que não seja muito agressivo ao microrganismo. A solução do substrato é adicionada lentamente e em pequenas quantidades. Logo após a adição, é feita a agitação vigorosa do meio reacional para máxima eficiência do processo, permitindo uma maior superfície de contato entre o substrato e o microrganismo. O tempo desejável de biotransformação do substrato é de 24 - 48 horas ${ }^{4}$.

Após o processo de biotransformação do substrato, o(s) produto(s) obtido(s) é (são) recuperado(s) por filtração do meio de cultura, separando-o do micélio. A extração do(s) produto(s) é feita utilizando um solvente imiscível em água como, diclorometano ou acetato de etila. Este último é o solvente mais recomendado por ser um solvente menos tóxico e mais ambientalmente correto em relação aos solventes halogenados. O solvente é evaporado e o esteroide é separado como sólido ou como um óleo. Em seguida é submetido à diversas cristalizações para obtenção de um produto puro ${ }^{4}$.

A obtenção de esteroides a partir de outros esteroides por biotransformação traz como vantagem a execução direta da reação em um único frasco ou reator e em poucas ou até mesmo em uma única etapa. Quando possível, esta técnica pode substituir métodos sintéticos que necessitam de várias etapas de reação e gasto de energia.

A obtenção da progesterona a partir da 3-metoxiandrosta-3,5-dien-17-ona requer seis etapas reacionais e vários reagentes. Ainda não há uma rota de obtenção da progesterona por via biossintética a partir da 3-metoxiandrosta-3,5-dien-17-ona (Esquema 14) ${ }^{52}$. É bem possível que se um processo de biotransformação deste esteroide for desenvolvido e que se obtenha como produto a progesterona, a rota sintética clássica poderá deixar de ser utilizada. 
Esquema 14. Obtenção da progesterona a partir da 3-metoxiandrosta-3,5-dien-17-ona por via sintética. ${ }^{52}$

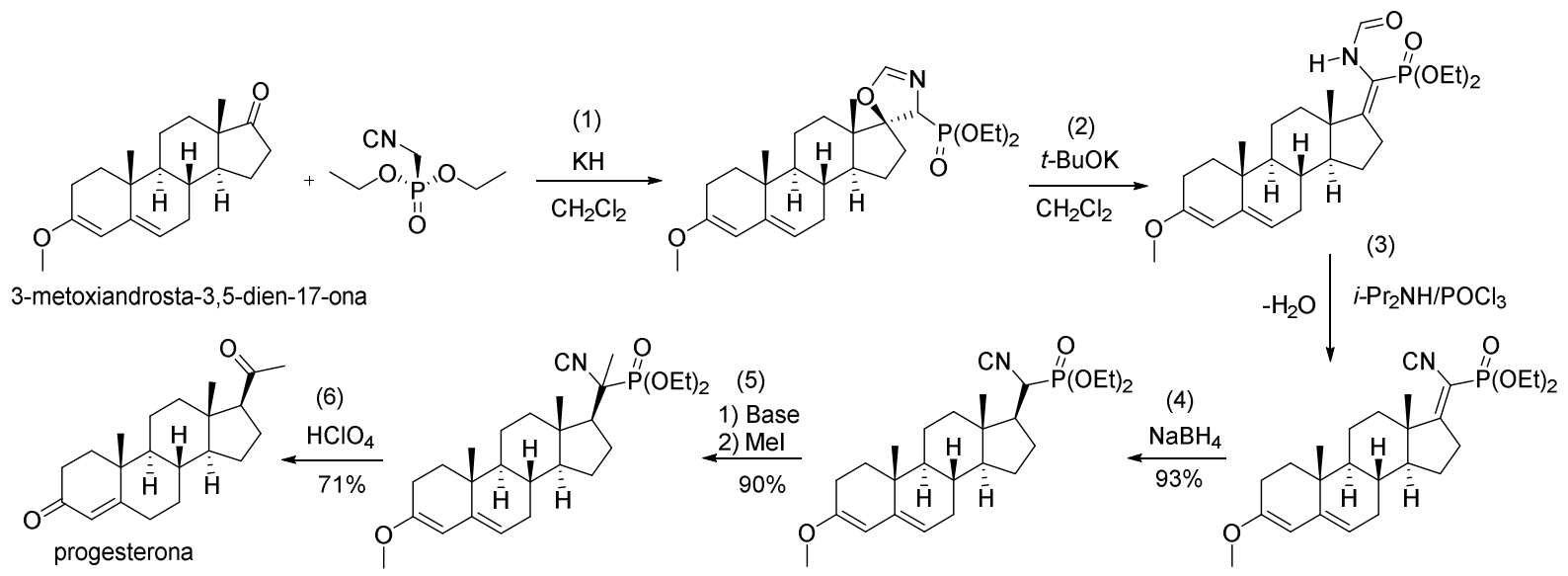

Fonte: Adaptação de STOELWINDER, J, VAN ZOEST, W.J., VAN LEUSEN, Chemistry of N,P-acetals: application to synthesis of 20-ketosteroids. Journal of Organic Chemistry, 1992, vol. 47, nº 8, p.2250. Copyright (C) 1992 American Chemical Society.

Segundo Stoelwinder et al. (1992) ${ }^{52}$ utilizando diclorometano como solvente e na presença de hidreto de potássio $(\mathrm{KH})$ a 3-metoxiandrosta-3,5-dien-17-ona reage com a dietil(isocianometil)fosfonato, ânion da 2-(dietilfosfono)-propionitrila, proporcionando a obtenção de um esteroide do tipo 2-oxazolina (Esquema 14 - etapa 1). Posteriormente é feita a abertura eletrocíclica do anel oxazolínico com terc-butóxido de potássio (t-BuOK) obtendo-se um esteroide do tipo [(dietilfosfono)formamidometileno] (Esquema 14 - etapa 2). Uma desidratação do esteroide obtido é feita usando cloreto de fosforila em di-isopropil-amina ( $i$ $\operatorname{Pr}_{2} \mathrm{NH} / \mathrm{POCl}_{3}$ ) dando um esteroide (E)-17-[(dietilfosfono)isocianometileno)] (Esquema 14 etapa 3). Efetua-se uma redução da dupla ligação do carbono C-17 com boridreto de sódio $\left(\mathrm{NaBH}_{4}\right)($ Esquema 14 - etapa 4) seguida de uma metilação no carbono C-20 em meio básico (Esquema 14 - etapa 5). Por fim é efetuada uma hidrólise do esteroide metilado na presença de ácido perclórico $\left(\mathrm{HClO}_{4}\right)$ obtendo-se então a progesterona (Esquema 14 - etapa 6). 


\section{A.5 ESTEROIDES E AS QUESTÕES AMBIENTAIS}

Os anticoncepcionais ou contraceptivos orais utilizados no controle de natalidade foram aprovados na década de 1960 nos Estados Unidos. No contexto brasileiro, em 2006 o IBGE estimou que $25 \%$ das mulheres utilizavam algum contraceptivo oral ${ }^{53}$. Dessa estatística, podese ter uma ideia do descarte inadequado de contraceptivos no meio ambiente, especialmente nos corpos d'água.

Um dos principais problemas ambientais atualmente, e que se tornou uma preocupação crescente em todo o mundo, é a presença de compostos desreguladores endócrinos e produtos farmacêuticos e seus metabólitos nas estações de tratamento de esgoto (ETEs). Os produtos farmacêuticos e seus metabólitos são micropoluentes orgânicos. As principais fontes destes compostos no ambiente aquático são provenientes de despejo de efluentes tratados nas ETEs, bem como o despejo de esgoto bruto. Concentrações típicas desses compostos nas águas estão no intervalo de nano- a microgramas por litro e, devido à sua presença contínua e persistente são chamados de "pseudopersistentes" propriedades físico-químicas persistentes, são lipofílicos, bio-acumulativos e têm baixa pressão de vapor, facilitando desta forma a sua dispersão no meio ambiente ${ }^{43}$.

Apesar da ocorrência, destino e toxicidade de fármacos nesses ambientes serem estudados há mais de 10 anos, o efeito dessas misturas complexas de poluentes (bioativos) em organismos aquáticos não é compreendido. Estudos precisos são essenciais para avaliar a toxicidade e os riscos causados por estes poluentes. Em relação aos fármacos, por exemplo, estes estudos são muito complexos, pois mesmo obtendo informações sobre prescrição e vendas, estas não são suficientes para predizer as suas concentrações ambientais, pois muitos são metabolizados no meio ambiente em novos derivados que também devem ter propriedades nos organismos vivos, porém desconhecidos cientificamente. Inclusive, muitos fármacos são vendidos sem receitas, como os analgésicos e anti-inflamatórios, os quais são encontrados em concentrações muito elevadas no meio ambiente. Além disso, pouco é conhecido sobre seus efeitos na combinação com outros poluentes encontrados em efluentes, tais como hormônios, pesticidas, metais, etc ${ }^{55}$.

Os principais mecanismos de atenuação destes compostos no meio ambiente são a fotólise (processo abiótico que depende da intensidade da luz) e a biotransformação (dependente da atividade microbiana), sendo esta última a mais importante, principalmente em rios turvos e profundos ou bastante poluídos ${ }^{56}$. 
Os micropoluentes orgânicos, provenientes de fármacos, são encontrados principalmente na urina e os mais comuns são os hormônios esteroidais. É conhecido que hormônios naturais e sintéticos, que são liberados no meio ambiente prejudicam o balanço hormonal em peixes, afetando a fertilidade. Ainda, a avaliação dos riscos causados por diversos produtos farmacêuticos é muito pouco conhecida em humanos. Essas substâncias são destinadas a exercer atividades biológicas específicas e, portanto, é importante avaliar o seu destino ambiental e seus possíveis efeitos ${ }^{57}$.

Os fármacos, como já mencionado, são absorvidos pelo organismo, sofrendo diversas reações metabólicas. Uma quantidade significativa dessas substâncias, tanto a original quanto os metabólitos formados, são lançados no meio ambiente. Estudos mostram alterações na fertilidade de animais e até em humanos, possivelmente devido à presença destes micropoluentes (desreguladores endócrinos) em águas superficiais e subterrâneas ${ }^{56,57}$. Essas substâncias causam problemas de esterilização ou feminilização em peixes. No homem pode ainda induzir doenças como câncer de mama, útero e próstata, desenvolvimento sexual anormal, redução da fertilidade masculina, aumento da incidência de ovário policístico, alteração de glândulas tireoides, distúrbios nas funções dos ovários, na fertilização e gravidez.

Desde 1996, o Departamento de Pesquisa e Desenvolvimento da Agência de Proteção Ambiental dos Estados Unidos (em inglês: United States Environmental Protection Agency $E P A)$ tem considerado a problemática dos desreguladores endócrinos como uma das seis áreas de pesquisa mais importantes ${ }^{57,59}$. Além disso, diversas pesquisas realizadas na Europa têm demonstrado uma preocupação com a presença de fármacos no meio ambiente, especialmente nas águas fluviais e marinhas ${ }^{57}$.

O estrogênio sintético, 17 $\alpha$-etinilestradiol, vêm sendo detectado em efluentes de estações de tratamento de esgoto e em águas superficiais e subterrâneas. O 17 $\alpha$-etinilestradiol é um dos hormônios esteroidais sintéticos mais utilizados em pílulas anticoncepcionais (30-50 $\mu \mathrm{g}$ por pílula) e em terapia de reposição hormonal e, devido ao seu alto potencial estrogênico, tem sido classificado como o principal composto sintético responsável em provocar alterações endócrinas em organismos presentes em águas superficiais. O aumento crescente das concentrações desta substância no ambiente, além de outros fármacos hormonais como mestranol é devido, além da excreção pelos seres humanos, também pela descarga de uma grande quantidade de medicamentos expirados (não utilizados) advindos de domicílios, resíduos hospitalares e de indústrias farmacêuticas ${ }^{43}$.

Em face da obtenção de esteroides em escala industrial por biotransformação, os mares serem o destino final de fármacos disponibilizados de maneira inadequada em corpos d'água, 
propôs-se neste trabalho investigar a biotransformação de fármacos esteroidais por fungos de ambiente marinho a fim de verificar a possibilidade de biossíntese de esteroides a partir de hormônios conhecidos, como potencial de implantação destes fungos na produção comercial de novos esteroides e, compreender ou inferir sobre a biotransformação natural de esteroides nesse ecossistema. Assim este trabalho objetivou um estudo de biotransformação de fármacos esteroidais visando sustentabilidade e uma noção da compreensão da biotransformação natural de esteroides no meio ambiente.

O Laboratório de Química Orgânica e Biocatálise do Instituto de Química de São Carlos (IQSC - USP) promove reações enzimáticas empregando células íntegras de microrganismos de ambiente marinho isolados do Litoral Norte do Estado de São Paulo. Vários tipos de reações já foram realizadas, como a redução de cetonas proquirais ${ }^{60,63}$ (Esquema 15A), hidrólises de nitrilas ${ }^{61,62}$ (Esquema 15B) e epóxidos ${ }^{36}$ (Esquema 5) e a biodegradação de pesticidas $^{37,38,39}$ (Esquema 6).

Esquema 15. Reações enzimáticas empregando fungos de ambiente marinho: (A) redução de $(1 E, 4 E)$ 1,5-difenilpenta-1,4-dien-3-ona catalisada pelo fungo Penicillium citrinum CBMAI $1186^{60}$, (B) biotransformação de fenilacetonitrilas catalisada pelo fungo Aspergillus sydowii CBMAI 934 ${ }^{61,62}$.

(A)<smiles>O=C(/C=C/c1ccccc1)/C=C/c1ccccc1</smiles>

Penicillium citrinum

$32^{\circ} \mathrm{C}, 132 \mathrm{rpm}$ 6 dias
$\mathrm{c}=90 \%$

(B)

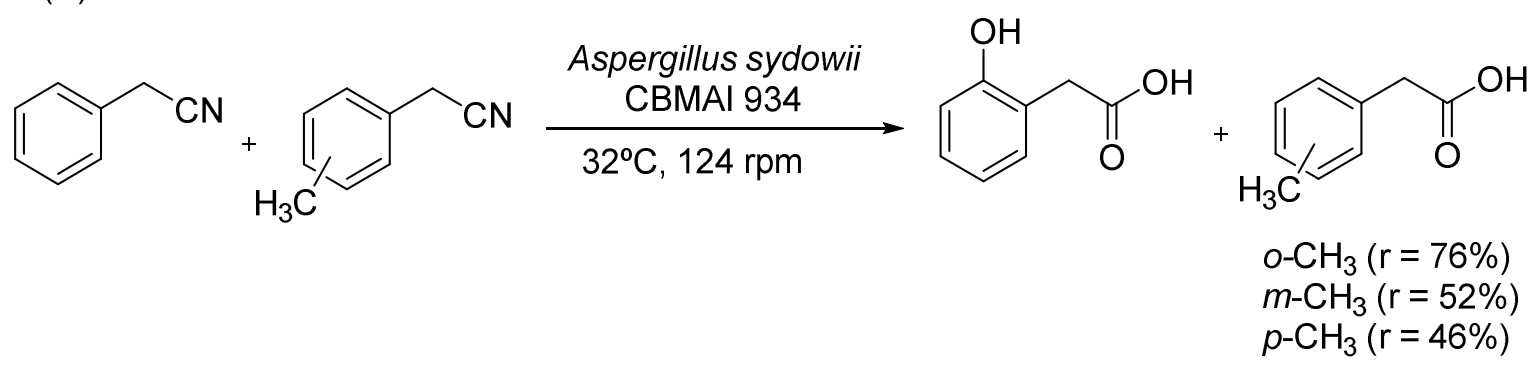

Fontes: (A) Adaptação de FERREIRA, I.M., et al., Chemoselective biohydrogenation of $\alpha, \beta-$ and $\alpha, \beta, \gamma, \delta$ unsaturated ketones by the marine-derived fungus Penicillium citrinum CBMAI 1186 in a biphasic system. Journal of Molecular Catalysis B: Enzymatic, 2015, v.115, p.61.

(B) Adaptação de BIROLLI, W.G. et al. Biocatalysis and biotransformation in Brazil: An overview, Biotechnology Advances, 2015, v.33, n.5, p.505.

Não foram encontradas muitas referências na literatura envolvendo a utilização de microrganismos coletados de ambientes marinhos, o que revela o potencial de investigação 
científica no emprego destes microrganismos em Biocatálise. Por sua vez, não são encontradas referências frente à biotransformação de esteroides empregando fungos desse ecossistema.

Tendo em consideração a inovação do emprego de fungos de ambiente marinho em Biocatálise, o conhecimento adquirido decorrente deste trabalho pode ser precursor para a obtenção comercial e/ou industrial de fármacos esteroidais empregando fungos ainda não utilizados nesse tipo de biotransformação, sendo assim, uma relevância deste estudo. Este trabalho traz também contribuições para área ambiental, uma vez que o conhecimento obtido pode servir de base para inferir sobre os impactos ambientais relacionados à biotransformação natural de esteroides em ambiente marinho. Como já foi comentado, esteroides são por vezes descartados no ambiente de maneira inadequada e os mares são o destino final da deposição destes compostos e seus metabólitos e pouco tem sido pesquisado sobre como a natureza modifica esta classe de compostos. 


\section{B. OBJETIVOS}

\section{B.1 OBJETIVO GERAL}

Realizar a biotransformação de fármacos esteroidais (progesterona e 17 $\alpha$-etinilestradiol Figura 15) utilizando fungos de ambiente marinho com intuito de verificar os metabólitos produzidos destes substratos.

Figura 15. Fármacos esteroidais para biotransformação com fungos de ambiente marinho

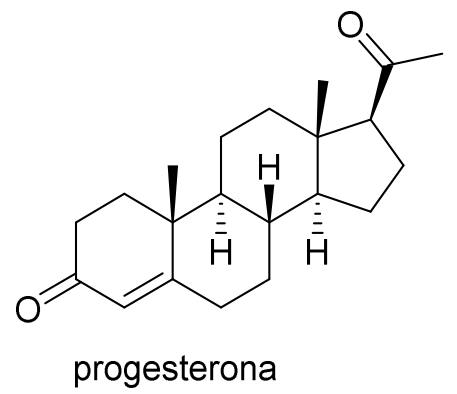<smiles>C#C[C@]1(O)CC[C@H]2[C@H]3CCc4cc(O)ccc4[C@H]3CC[C@]21C</smiles>

\section{B.2 OBJETIVOS ESPECÍFICOS}

a) Fazer uma triagem da biotransformação dos fármacos propostos utilizando a linhagens de fungos de ambiente marinho (Tabela 2), catalogadas na Coleção Brasileira de Microrganismos de Ambiente e Indústria (CBMAI), efetuando reações com a massa micelial e com o caldo enzimático.

Tabela 2. Linhagens de fungos de ambiente marinho utilizadas na biotransformação dose esteroides propostos.

\begin{tabular}{cc}
\hline Linhagens de fungos & Código CBMAI \\
\hline Aspergillus sydowii & 934 \\
Aspergillus sydowii & 935 \\
Penicilium oxalicum & 1185 \\
Penicilium citrinum & 1186 \\
\hline
\end{tabular}

b) Selecionar o(s) fungo(s) e o(s) caldo(s) enzimático(s) que apresentar(em) o melhor perfil de biotransformação e efetuá-la(s) em replicata utilizando os fármacos propostos. 
c) Isolar os metabólitos obtidos das reações em replicata utilizando cromatografia em coluna (CC) monitorada por cromatografia em camada delgada (CCD).

d) Caracterizar os metabólitos obtidos das biotransformações utilizando técnicas de: polarimetria, cromatografia a gás - espectrometria de massas (CG-EM), espectrometria de massas de alta resolução (EMAR) quando necessário, espectroscopias no infravermelho (IV), de ressonância magnética nuclear de hidrogênio, carbono e bidimensionais (RMN de ${ }^{1} \mathrm{H},{ }^{13} \mathrm{C}, \mathrm{COSY}, \mathrm{HSQC}, \mathrm{HMBC}$ ). 


\section{MATERIAIS E MÉTODOS}

Neste tópico são apresentadas as técnicas e as metodologias que foram necessárias para o desenvolvimento do trabalho.

\section{C.1 COMPOSTOS ESTEROIDAIS PARA BIOTRANSFORMAÇÃO}

Os compostos deste trabalho (Figura 15) foram selecionados por serem os principais representantes das classes de esteroides abordadas neste trabalho, são bem conhecidos e consumidos como fármacos e seus custos de aquisição em relação a outros fármacos das respectivas classes são mais baixos:

a) progesterona: é um esteroide natural encontrado em fêmeas de mamíferos por ser um representante dos progestógenos e utilizada como precursor de conhecidos anticoncepcionais como norentindrona, norgestimato, acetato de medroxiprogesterona, levonorgestrel, desogestrel (Figura 13);

b) 17a-etinilestradiol: por ser um derivado sintético do estradiol. Além disso é um representante dos estrógenos e também é utilizado como precursor de contraceptivos como estrona, estradiol, estriol (Figura 11) e estranol (Figura 12).

\section{C.2 TESTES DE DISSOLUÇÃO DOS ESTEROIDES}

a) Teste de dissolução em dimetil-sulfóxido (DMSO). Foi verificada a dissolução dos substratos em DMSO para verificar a utilização deste solvente na dissolução dos substratos a serem introduzidos no meio reacional. Em um frasco do tipo Ependorff foi adicionado 1,0 mg do substrato (progesterona ou 17 $\alpha$-etinilestradiol) e adicionado com uma micropipeta, $20 \mu \mathrm{L}$ de DMSO. As amostras foram homogeneizadas com um agitador Vortex e verificado se houve dissolução.

b) Teste de dissolução em acetato de etila. Foi testada a dissolução dos substratos neste solvente com o objetivo de estipular a possibilidade de utilizá-lo nas soluções tanto dos padrões dos substratos, quanto das que contivessem os metabólitos que fossem analisados por CG-EM. Em um frasco do tipo Ependorff foi adicionado 1,0 $\mathrm{mg}$ do substrato (progesterona ou $17 \alpha-$ etinilestradiol) e dissolvidos em 1,0 mL de acetato de etila. As amostras foram homogeneizadas com um agitador Vortex e verificado se houve dissolução. 


\section{C.3 DESENVOLVIMENTO E OTIMIZAÇÃo DA METODOLOGIA DE ANÁLISE DOS ESTEROIDES POR CG-EM}

Foram preparadas soluções padrões dos substratos (progesterona, 17 $\alpha$-etinilestradiol) com concentrações de 1,0 mg/mL em acetato de etila e analisadas em CG-EM a fim de se desenvolver um método de análise cromatográfica dos extratos das reações e estabelecer o tempo de retenção dos compostos.

Foi feita uma revisão bibliográfica a fim de verificar qual o método analítico mais adequando para análise de CG-EM. Uma vez escolhido o método, foram feitas as devidas adaptações de acordo com o equipamento. Foi utilizado um cromatógrafo a gás Shimadzu/GC2010 equipado com auto injetor Shimadzu/AOC-5000 e detector de massas (Shimadzu MS2010 plus) com impacto de elétrons (IE, $70 \mathrm{eV}$ ). $\mathrm{O}$ forno do cromatógrafo a gás foi equipado com uma coluna de sílica fundida DB-5 (J\&W Scientific, $30 \mathrm{~m}$ x 0,25 mm x 0,25 $\mu \mathrm{m}$ ).

As condições cromatográficas utilizadas foram: gás carreador $\mathrm{He}$, temperatura de injeção de $250^{\circ} \mathrm{C}$, razão de Split 5.0. Coluna DB-5 ms de dimensões 30m x 0,25 mm x 0,25 $\mu \mathrm{m}$, rampa de temperatura: $120^{\circ} \mathrm{C}$ por 1 minuto, taxa de aquecimento $20^{\circ} \mathrm{C} / \mathrm{min}$ por 15 minutos, pressão de $73,8 \mathrm{kPa}$, fluxo de $6,6 \mathrm{~mL} / \mathrm{min}$, velocidade linear de $36,1 \mathrm{~cm} / \mathrm{seg}$, tempo de análise de 25 minutos.

\section{C.4 MICRORGANISMOS PARA BIOTRANSFORMAÇÃO}

Neste trabalho as linhagens de fungos utilizadas foram coletadas de esponjas marinhas do Litoral Norte do Estado de São Paulo e isolados pelos grupos de pesquisa do Prof. Dr. Roberto G.S. Berlink do Departamento de Físico-Química do Instituto de Química de São Carlos - Universidade de São Paulo e da Prof ${ }^{a}$. Dr ${ }^{\mathrm{a}}$. Mirna H.R. Seleghim do Departamento de Ecologia e Biologia Evolutiva da Universidade Federal de São Carlos. A Tabela 3 apresenta uma descrição das linhagens de microrganismos utilizados neste estudo. 
Tabela 3. Descrição dos fungos cultivados em meio de cultura de extrato de malte utilizados nas biotransformações dos fármacos esteroidais progesterona e $17 \alpha$-etinilestradiol.

\begin{tabular}{|c|c|c|}
\hline Linhagem de fungos & Imagem* & Descrição \\
\hline Aspergillus sydowii CBMAI 934 & & $\begin{array}{l}\text { Fungo verde musgo bem escuro, } \\
\text { com bordas esbranquiçadas com } \\
\text { crescimento bem volumoso das } \\
\text { colônias. }\end{array}$ \\
\hline Aspergillus sydowii CBMAI 935 & & $\begin{array}{l}\text { Fungo verde-limão brilhante } \\
\text { como bordas esbranquiçadas com } \\
\text { modo de crescimento arbóreo e } \\
\text { volumoso das colônias. }\end{array}$ \\
\hline Penicilium oxalicum CBMAI 1185 & & $\begin{array}{l}\text { Fungo azul-esverdeado opaco } \\
\text { com bordas esbranquiçadas. } \\
\text { Crescimento não muito intenso ou } \\
\text { volumoso das colônias. }\end{array}$ \\
\hline Penicilium oxalicum CBMAI 1186 & & $\begin{array}{l}\text { Fungo verde-mar com bordas } \\
\text { esbranquiçadas. Crescimento não } \\
\text { muito intenso ou volumoso das } \\
\text { colônias. }\end{array}$ \\
\hline
\end{tabular}

*autoria própria

\section{C.5 PREPARO DOS MEIOS DE CULTURA}

a) Meio sólido - o meio de cultura foi preparado dissolvendo em água os seguintes constituintes na composição: extrato de malte $(20 \mathrm{~g} / \mathrm{L})$, cloreto de cálcio diidratado $\left(\mathrm{CaCl}_{2} \cdot 2 \mathrm{H}_{2} \mathrm{O}-1,36 \mathrm{~g} / \mathrm{L}\right)$, cloreto de potássio $(\mathrm{KCl}-0,68 \mathrm{~g} / \mathrm{L})$, cloreto de magnésio hexaidratado $\left(\mathrm{MgCl}_{2} \cdot 6 \mathrm{H}_{2} \mathrm{O}-9,68 \mathrm{~g} / \mathrm{L}\right)$, cloreto de sódio $(\mathrm{NaCl}-30 \mathrm{~g} / \mathrm{L})$, fosfato de sódio monobásico anidro $\left(\mathrm{NaH}_{2} \mathrm{PO}_{4}-1,4 \times 10^{-4} \mathrm{~g} / \mathrm{L}\right)$, sulfato de sódio anidro $\left(\mathrm{Na}_{2} \mathrm{SO}_{4}-3,47 \mathrm{~g} / \mathrm{L}\right)$, bicarbonato de sódio anidro $\left(\mathrm{NaHCO}_{3}-0,17 \mathrm{~g} / \mathrm{L}\right)$, brometo de potássio $(\mathrm{KBr}-0,10 \mathrm{~g} / \mathrm{L})$, cloreto de estrôncio 
hexaidratado $\left(\mathrm{SrCl}_{2} .6 \mathrm{H}_{2} \mathrm{O}-0,04 \mathrm{~g} / \mathrm{L}\right)$, ácido bórico $\left(\mathrm{H}_{3} \mathrm{BO}_{4}\right.$ - 0,03 g/L). Após a dissolução dos constituintes foi acertado o pH do meio em 7,0 e adicionado ágar (20g/L).

$\mathrm{O}$ meio de cultura preparado foi esterilizado em autoclave vertical à temperatura de $120^{\circ} \mathrm{C}$ e pressão de $1,0 \mathrm{Kgf} / \mathrm{cm}^{2}$ por 20 minutos e distribuídos em placas de Petri em uma câmara de fluxo laminar. Após o resfriamento e a solidificação dos meios, nas placas, estas foram lacradas e acondicionados em estufa por $32^{\circ} \mathrm{C}$ por 24 horas com o objetivo de verificar se houve contaminação aparente em todo o processo de preparo. Uma vez não verificada a contaminação, as placas foram estocadas em geladeira por $4^{\circ} \mathrm{C}$ por até um mês para o cultivo das cepas dos fungos. Esta composição do meio foi definida para simular o ambiente marinho, ecossistema de origem dos fungos utilizados nesta pesquisa e que permitisse um bom crescimento dos fungos em estufa a $32^{\circ} \mathrm{C}$ por 5 dias baseando em cultivos realizados por outros pesquisadores do Laboratório de Química Orgânica e Biocatálise. A Figura 16 ilustra as etapas para o preparo dos meios de cultura sólido para cultivo dos fungos.

Figura 16. Preparo dos meios de cultura sólido para cultivo das cepas dos fungos deste trabalho.

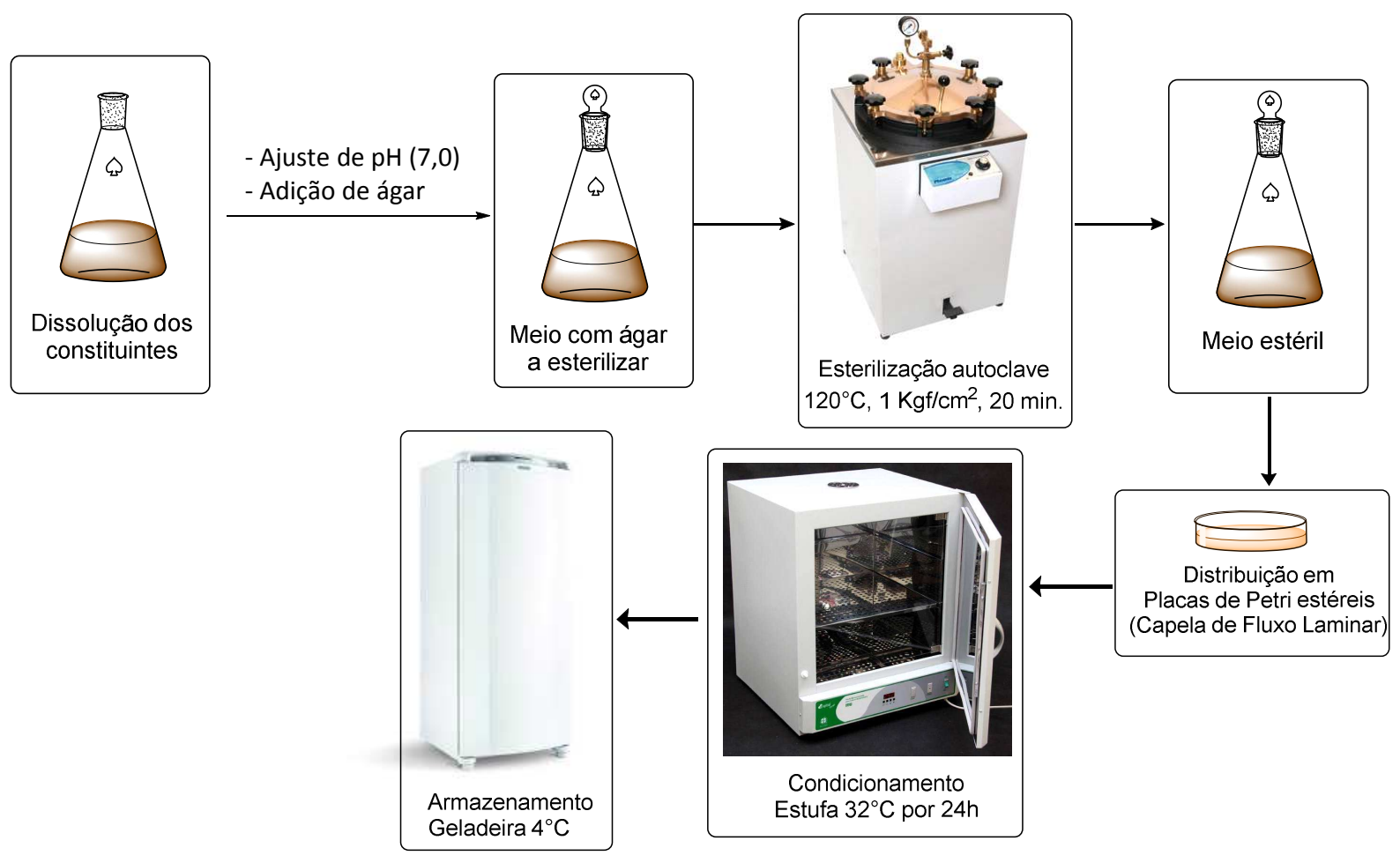

b) Meio líquido: o meio de cultura foi preparado dissolvendo em água os mesmos constituintes nas mesmas concentrações do meio de cultura sólido. Contudo, não foi adicionado o ágar e o pH do meio foi acertado em 7,4 que é o valor mais utilizado em processos fermentativos industriais ${ }^{4}$ e é um valor de condição reacional branda. Foram adicionados 100 
$\mathrm{mL}$ do meio preparado em frascos Erlenmeyer de $250 \mathrm{~mL}$ com tampa de algodão e esterilizados em autoclave vertical nas mesmas condições do preparo do meio de cultura sólido. Após o resfriamento dos meios em uma câmara de fluxo laminar foram feitos os inóculos dos fungos cultivados em meios sólidos para crescimento e cultivo da massa micelial. A Figura 17 ilustra preparo dos meios de cultura líquido para o cultivo e o crescimento da massa micelial dos fungos.

Figura 17. Preparo dos meios de cultura líquidos para cultivo das cepas dos fungos deste trabalho.

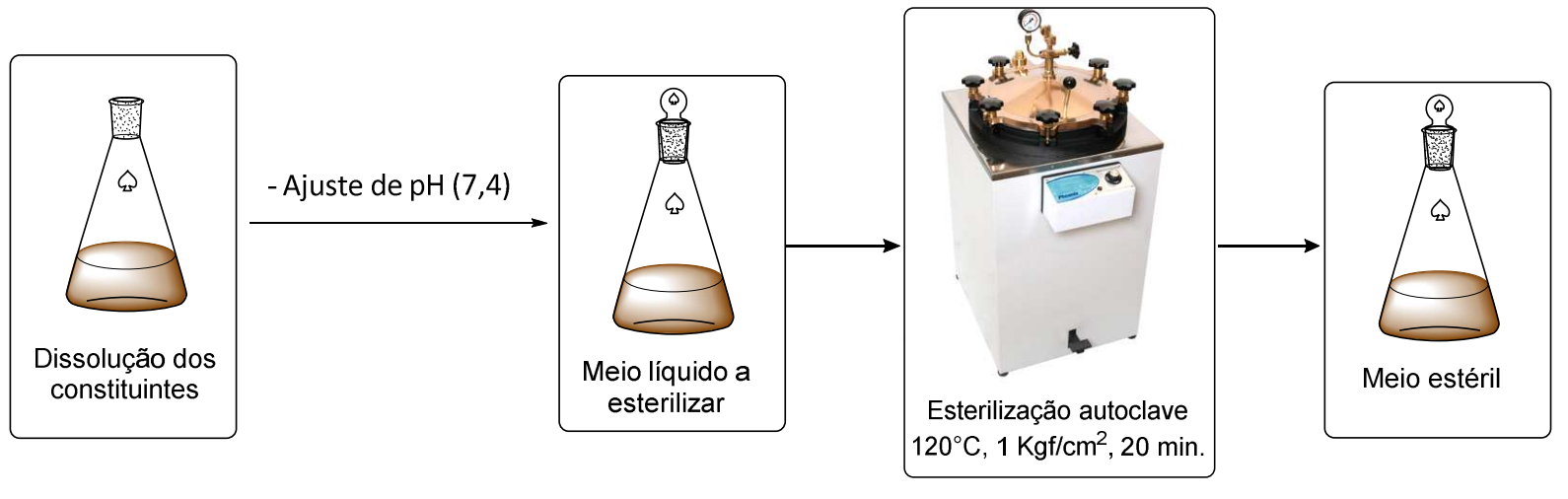

\section{C.6 INÓCULOS DOS FUNGOS}

Os esporos dos fungos provenientes de cepas estoques do Laboratório de Química Orgânica e Biocatálise foram inoculados na superfície dos meios de cultura sólido contidos em placa de Petri. Os fungos foram cultivados em estufa à temperatura de $32^{\circ} \mathrm{C}$, por 5 dias que foi o tempo suficiente em que os esporos e micélios levaram para crescer por toda a superfície do meio de cultura. Após isso, 7 fragmentos de meio sólido contendo os micélios $(0,5 \mathrm{~cm}$ de diâmetro) foram retirados com o auxílio de um cortador radial e inoculados em $100 \mathrm{~mL}$ de meio de cultura líquido estéril em um frasco Erlenmeyer de $250 \mathrm{~mL}$. Os frascos contendo os inóculos foram acondicionados em um agitador orbitalar à temperatura de $32^{\circ} \mathrm{C}$, rotação de $130 \mathrm{rpm}$ promovendo assim o crescimento da massa micelial por 5 dias. A Figura 18 ilustra as etapas de inoculação e cultivo dos fungos. 
Figura 18. Ilustração das etapas de inoculação e cultivo dos fungos em meio líquido.

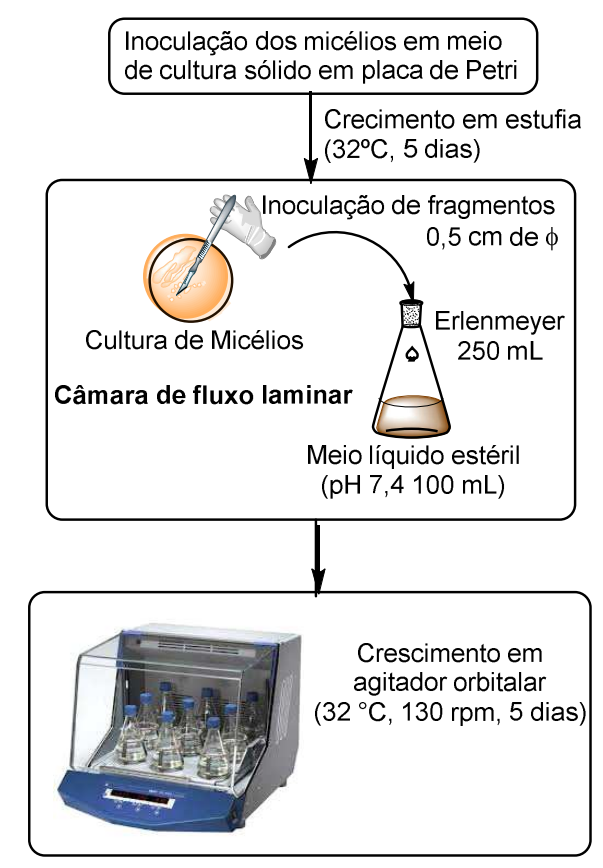

\section{C.7 AVALIAÇÃO DO CRESCIMENTO DOS FUNGOS NA PRESENÇA DE DIMETIL- SULFÓXIDO}

Foi escolhido o fungo A. sydowii CBMAI 934 para avaliar o crescimento da massa micelial na presença de DMSO como solvente dispersante dos substratos por apresentar um bom crescimento tanto em meio sólido, quanto em meio líquido. Em estudos de biotransformação é importante que o fungo apresente um bom crescimento, bem como produzir uma elevada quantidade de massa micelial para ser utilizada nas reações sem que algum composto adicionado ao sistema prejudique o crescimento do fungo ou interfira nas reações biocatalíticas.

Realizou-se o inóculo do fungo A. sydowii CBMAI 934 a partir de uma cultura de estoque com o auxílio de uma alça de inoculação e seu crescimento foi mantido em meio sólido, à temperatura de $32^{\circ} \mathrm{C}$ em estufa por 5 dias.

Sete fragmentos de meio sólido contendo os micélios $(0,5 \mathrm{~cm}$ de diâmetro) foram retirados com auxílio de um cortador radial e inoculados em $100 \mathrm{~mL}$ de meio de cultura líquido contidos em frascos Erlenmeyer de $250 \mathrm{~mL}$ e mantido o crescimento em agitador orbitalar à temperatura de $32^{\circ} \mathrm{C}$ e rotação de $130 \mathrm{rpm}$ por 5 dias. Foram utilizados seis frascos Erlenmeyer de $250 \mathrm{~mL}$. Após esse período, os meios contendo os micélios foram filtrados em funil de Büchner separando a massa micelial do caldo. De cada massa micelial obtida foram tomados 
3,0 g de massa micelial e essa quantidade foi transferida para frascos Erlenmeyer de $250 \mathrm{~mL}$ contendo $100 \mathrm{~mL}$ de meio de cultura líquido estéril.

Aos frascos Erlenmeyer contendo os micélios foram adicionados os seguintes volumes de DMSO: 0,5 mL; 1,0 mL; 2,0 mL; 3,0 mL e 4,0 mL. Em um frasco Erlenmeyer contendo os micélios não foi adicionado o DMSO para servir de experimento controle. Os frascos contendo os micélios foram condicionados em agitador orbitalar à temperatura de $32^{\circ} \mathrm{C}$ e rotação de 130 rpm por 14 dias. Ao final desse período, os meios contento os micélios foram filtrados a vácuo com um funil de Büchner. Em cada material retido foi medida a massa micelial úmida para verificar se houve crescimento da massa micelial durante o período de cultivo na presença do DMSO e retirada uma pequena alíquota da qual fez-se um repique em meios sólidos estéreis e então, mantidos em estufa a $32^{\circ} \mathrm{C}$ por 5 dias com o objetivo de verificar se os micélios estavam vivos durante o período de cultivo. A Figura 19 ilustra o processo de crescimento do fungo $A$. sydowii CBMAI 934 na presença de DMSO.

Figura 19. Procedimento de avaliação do crescimento do fungo A. sydowii CBMAI 934 na presença de DMSO.

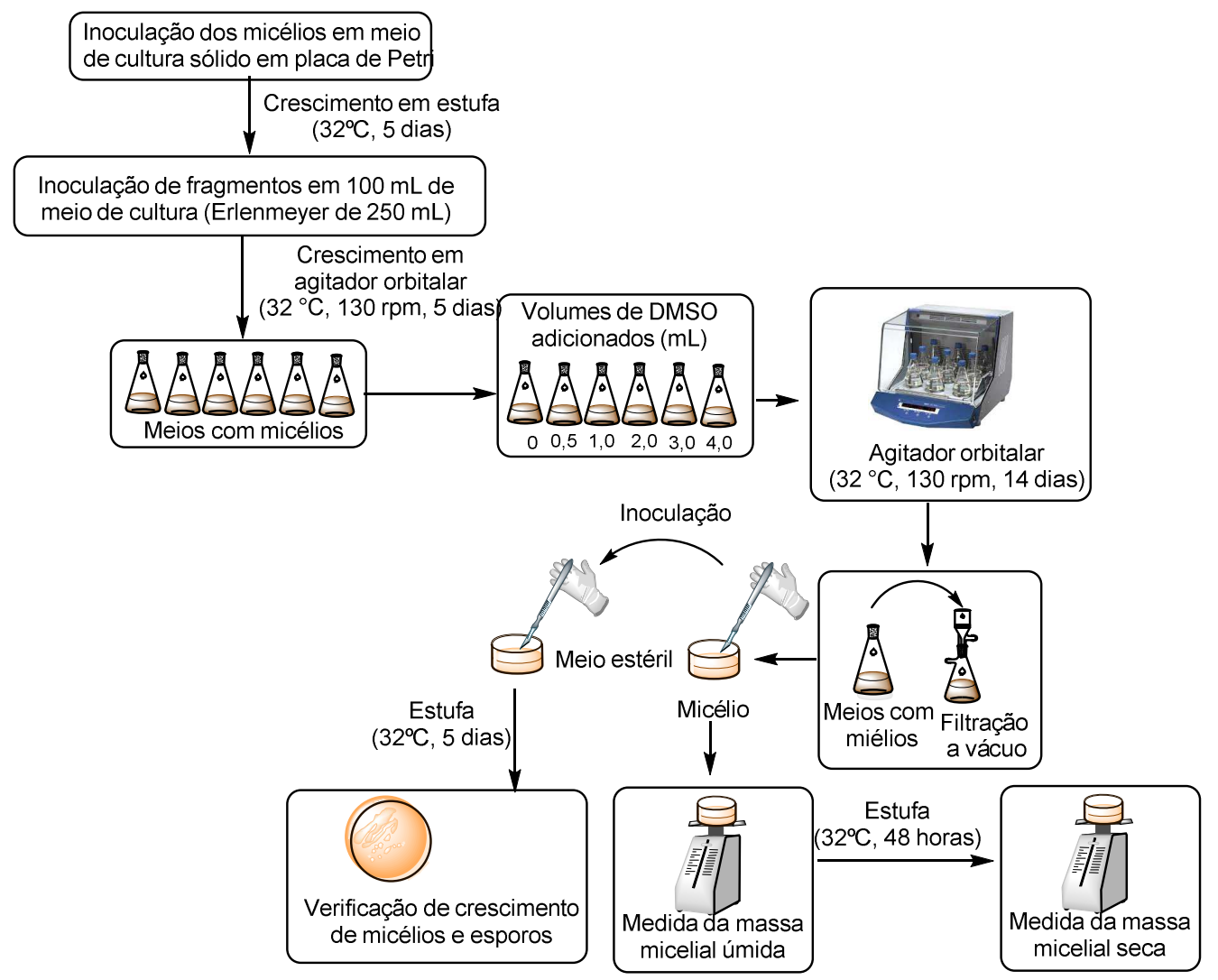

Os materiais e vidrarias que foram utilizados na manipulação de microrganismos foram esterilizados em autoclave. A manipulação dos microrganismos foi feita em uma câmara de fluxo laminar, marca Veco, a fim de se evitar contaminação por outros microrganismos. 


\section{C.8 REAÇÕES DE BIOTRANSFORMAÇÃO DOS ESTEROIDES}

Os procedimentos descritos a seguir foram referentes à triagem da biotransformação dos fármacos (Figura 15) utilizando a massa micelial e o caldo enzimático das linhagens de fungos de ambiente marinho (Tabelas 2 e 3). O objetivo foi selecionar o(s) melhor(es) fungo(s) que apresentar(em) o melhor(es) perfil(s) de biotransformação a partir das análises por CG-EM de alíquotas obtidas das amostras das triagens e então executar reações em quintuplicatas com os fungos selecionados para o isolamento dos produtos

Foi determinado como critérios de perfil de biotransformação a variedade de produtos obtidos. As reações em quintuplicatas foram realizadas seguindo os mesmos procedimentos descritos a seguir com o objetivo de se obter quantidades suficientes dos principais metabólitos produzidos pelas reações para isolamento, purificação por CC e caracterização por técnicas espectroscópicas.

\section{C.8.1 REAÇÕES COM A MASSA MICELIAL}

Após o cultivo dos fungos em meio líquido, o meio contendo os micélios foram filtrados em funil de Büchner. Foram pesados 3,0 g. de massa micelial a qual foi transferida para frascos Erlenmeyer de $250 \mathrm{~mL}$ contendo $100 \mathrm{~mL}$ de meio de cultura líquido de extrato de malte. A este frasco foi adicionado $1,0 \mathrm{~mL}$ de solução do esteroide $(50 \mathrm{mg} / \mathrm{mL})$ em DMSO. Foi feito para cada fungo um experimento em que não foi adicionado o substrato com o objetivo de verificar os metabólitos produzidos pelo próprio fungo na ausência dos esteroides nas condições de reação estabelecidas.

Os frascos com as reações foram mantidos em agitador orbitalar à temperatura de $32^{\circ} \mathrm{C}$ e rotação de 130 rpm por 7 dias. Se até este período foi observada biotransformação, mantevese o monitoramento da reação por mais 7 dias totalizando 14 dias de reação (Figura 20). 
Figura 20. Procedimento de biotransformação dos substratos com a massa micelial.

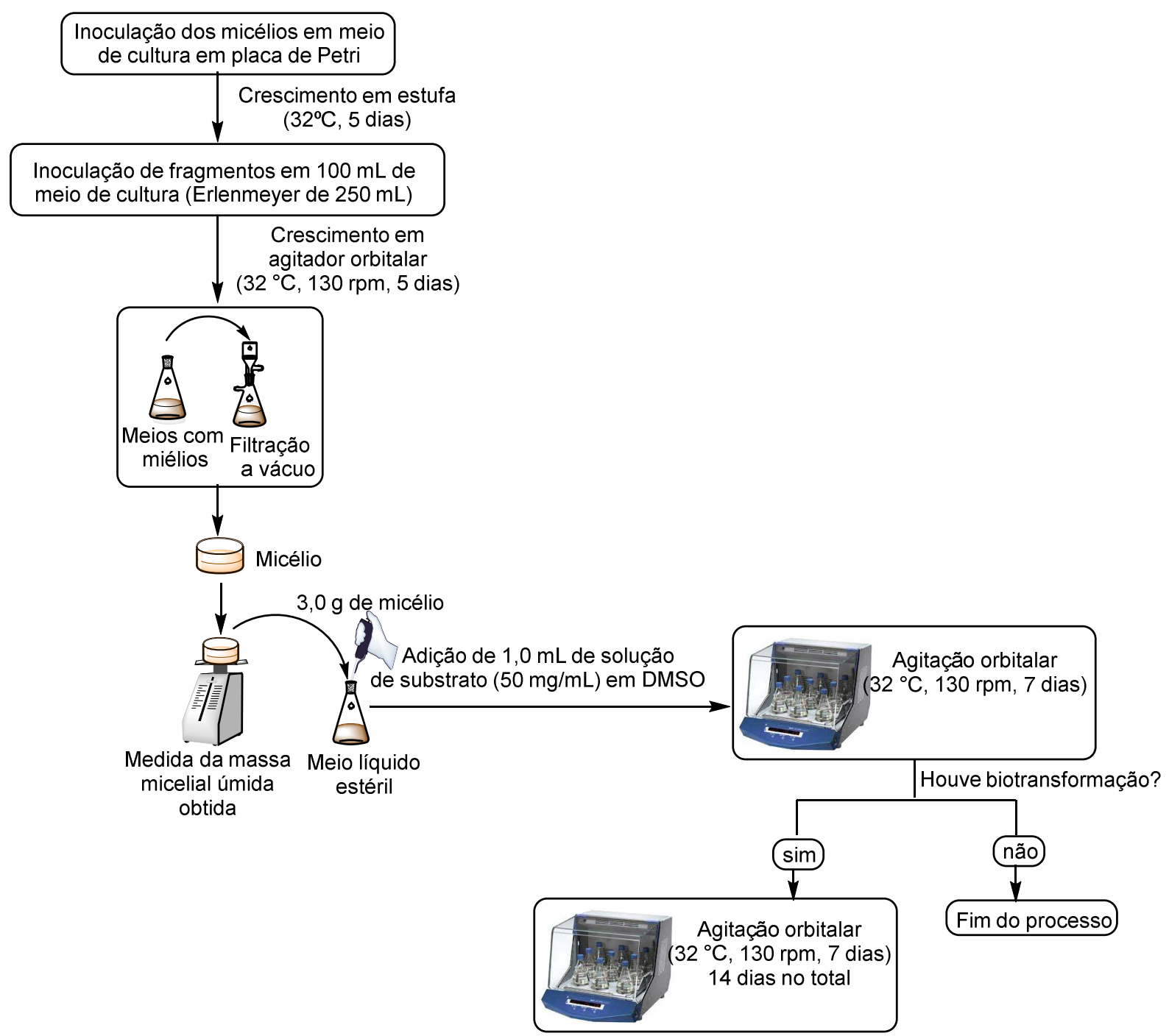

As reações foram monitoradas coletando-se 2,0 mL de amostra que foi transferida para um tubo Falcon de $13 \mathrm{~mL}$. A este frasco foi adicionado 2,0 $\mathrm{mL}$ de acetato de etila (AcOEt) e foi executada uma microextração agitando o frasco por 2,0 minutos com o auxílio de um Vortex. O frasco foi centrifugado a $6000 \mathrm{rpm}$ por $6 \mathrm{~min}$. Foi coletada a fase orgânica no tubo Falcon e esta foi filtrada na presença de $\mathrm{Na}_{2} \mathrm{SO}_{4}$ anidro. $\mathrm{O}$ filtrado foi coletado em um frasco vial de $1500 \mu \mathrm{L}$. Após estes processos de extração foram feitas análises cromatográficas (CGEM e CCD) dos extratos obtidos (Figura 21). 
Figura 21. Etapas do procedimento de monitoramento da biotransformação dos substratos com a massa micelial fúngica.

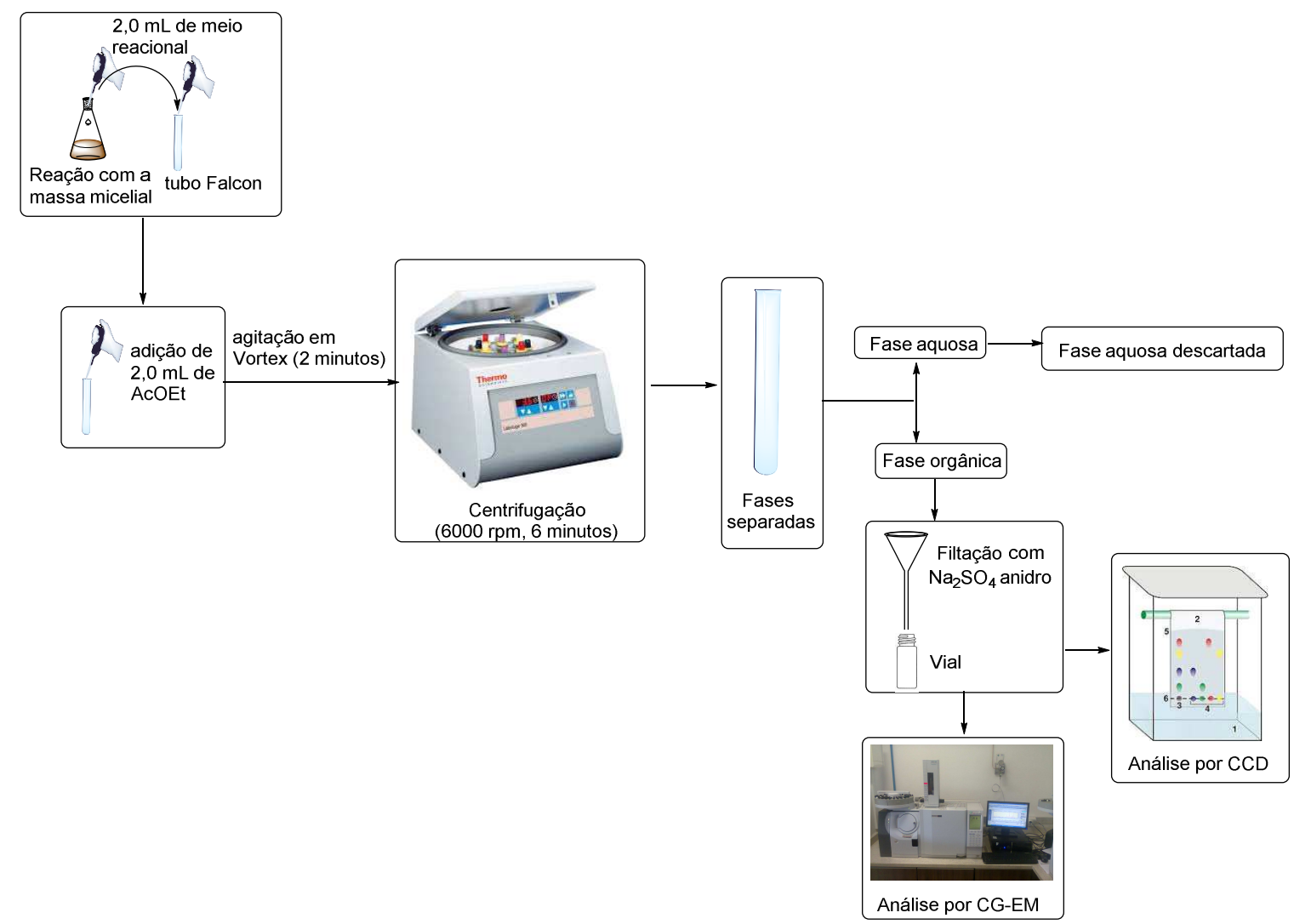

O uso das técnicas cromatográficas teve como objetivo analisar o perfil da biotransformação, verificando qualitativamente a formação de produtos (CCD) e obter informações prévias de possíveis produtos do processo de biotransformação (CG-EM). Essas análises foram feitas mediante a comparação com as soluções dos padrões dos substratos e os seus respectivos espectros de massas.

\section{C.8.2 REAÇÕES COM O CALDO ENZIMÁTICO}

Os caldos enzimáticos dos fungos obtidos da filtração dos meios foram transferidos para frascos Erlenmeyer de $250 \mathrm{~mL}$ estéreis e a cada um destes frascos foi adicionado $1,0 \mathrm{~mL}$ de solução do esteroide $(50 \mathrm{mg} / \mathrm{mL})$ em DMSO. Foi feito para cada caldo enzimático um experimento em que não foi adicionado o substrato com o objetivo de verificar os metabólitos contidos no caldo enzimático produzidos pelo próprio fungo na ausência dos esteroides nas condições de reações estabelecidas. 
Os frascos com as reações foram mantidos em agitador orbitalar à temperatura de $32^{\circ} \mathrm{C}$ e rotação de $130 \mathrm{rpm}$ por 7 dias. Se até este período foi observada biotransformação, mantevese o monitoramento da reação por mais 7 dias totalizando 14 dias de reação (Figura 22).

Figura 22. Etapas do procedimento de biotransformação dos substratos com o caldo enzimático.

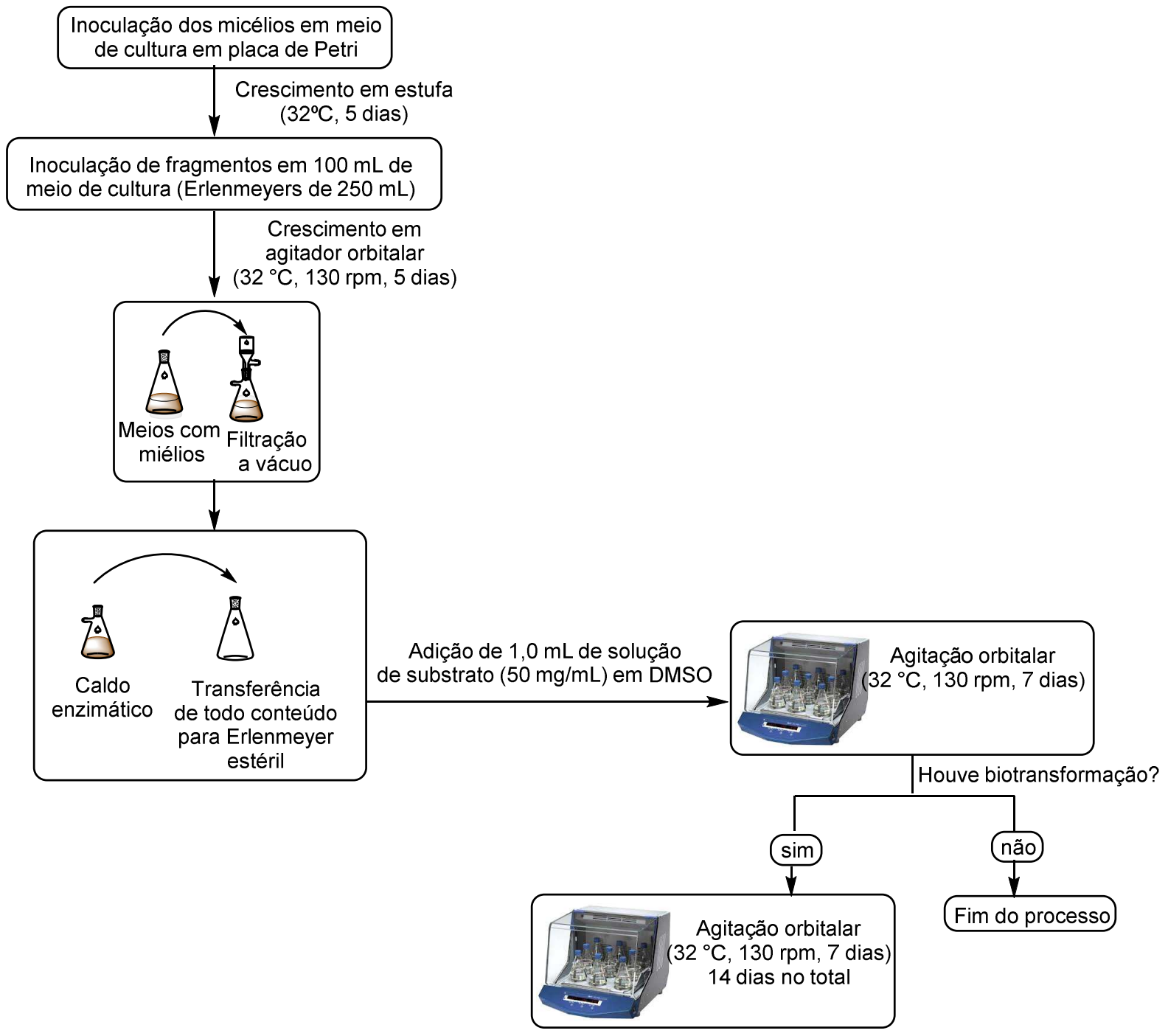

As reações foram monitoradas coletando-se $2,0 \mathrm{~mL}$ de amostra que foi transferida para um tubo Falcon de $13 \mathrm{~mL}$. A este frasco foi adicionado 2,0 $\mathrm{mL}$ de acetato de etila (AcOEt) e foi executada uma microextração agitando o frasco por 2,0 minutos com o auxílio de um agitador Vortex. O frasco foi centrifugado a $6000 \mathrm{rpm}$ por 6 minutos. Foi coletada a fase orgânica no tubo Falcon e esta foi filtrada na presença de $\mathrm{Na}_{2} \mathrm{SO}_{4}$ anidro. O filtrado foi coletado em um frasco vial de $1500 \mu \mathrm{L}$. Após estes processos de extração foram feitas análises cromatográficas (CG-EM e CCD) dos extratos obtidos (Figura 23). 
Figura 23. Etapas do procedimento de monitoramento da biotransformação dos substratos com o caldo enzumático.

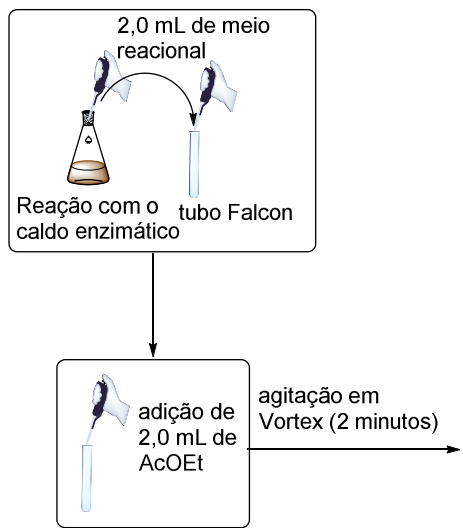

O uso das técnicas cromatográficas tevem como objetivo analisar o perfil da biotransformação, verificando qualitativamente a formação de produtos (CCD) e obter informações prévias de possíveis produtos do processo de biotransformação (CG-EM). Essas análises foram feitas mediante a comparação com as soluções dos padrões dos substratos e seus respectivos espectros de massas. 


\section{C.9 PREPARO DOS EXTRATOS APÓS A BIOTRANSFORMAÇÃO DOS ESTEROIDES}

\section{C.9.1 EXTRAÇÃO DAS REAÇÕES COM A MASSA MICELIAL}

Após o tempo de execução das reações em quintuplicatas, os meios em que se processaram as biotransformações com a massa micelial foram filtrados em funil de Büchner a vácuo. Os micélios retidos no papel de filtro foram transferidos para um frasco Erlenmeyer de $1000 \mathrm{~mL}$ onde foram suspendidos em água e feitas as extrações com $150 \mathrm{~mL}$ de acetato de etila em agitação por 30 min. Os caldos enzimáticos obtidos da filtração foram transferidos para outro frasco Erlenmeyer de $1000 \mathrm{~mL}$ onde foram feitas as extrações com $150 \mathrm{~mL}$ de acetato de etila.

Após a agitação, o conteúdo do frasco Erlenmeyer contendo os micélios foi filtrado em funil de Buchner a vácuo. A massa micelial retida no funil foi submetida a extração por mais duas vezes e o filtrado foi transferido para um funil de separação. A fase aquosa foi utilizada para suspensão da massa micelial nas duas extrações subsequentes e a fase orgânica foi encaminhada para filtração e concentração em rotaevaporador (Figura 25). Ao final de todo o processo de extração, a massa micelial remanescente teve sua massa úmida medida, e depois, condicionada em estufa a $32^{\circ} \mathrm{C}$ por 48 horas e, posteriormente, medida a sua massa micelial seca. A massa fúngica obtida foi esterilizada em autoclave vertical à temperatura de $120{ }^{\circ} \mathrm{C} \mathrm{e}$ pressão de $1,0 \mathrm{Kgf} / \mathrm{cm}^{2}$ por 20 minutos para o devido descarte.

Após agitação o conteúdo do frasco Erlenmeyer contendo o caldo enzimático foi transferido para um funil onde foi feita a separação das fases. A faes aquosa foi submetida a extração por mais duas vezes e a fase orgânica foi reunida com a fase orgânica obtida da extração do micélio e encaminhada para filtração e concentração em rotaevaporador. Ao final de todo o processo de extração a fase aquosa foi devidamente descartada (Figura 24). 
Figura 24. Procedimento de extração das reações de biotransformação com a massa micelial.

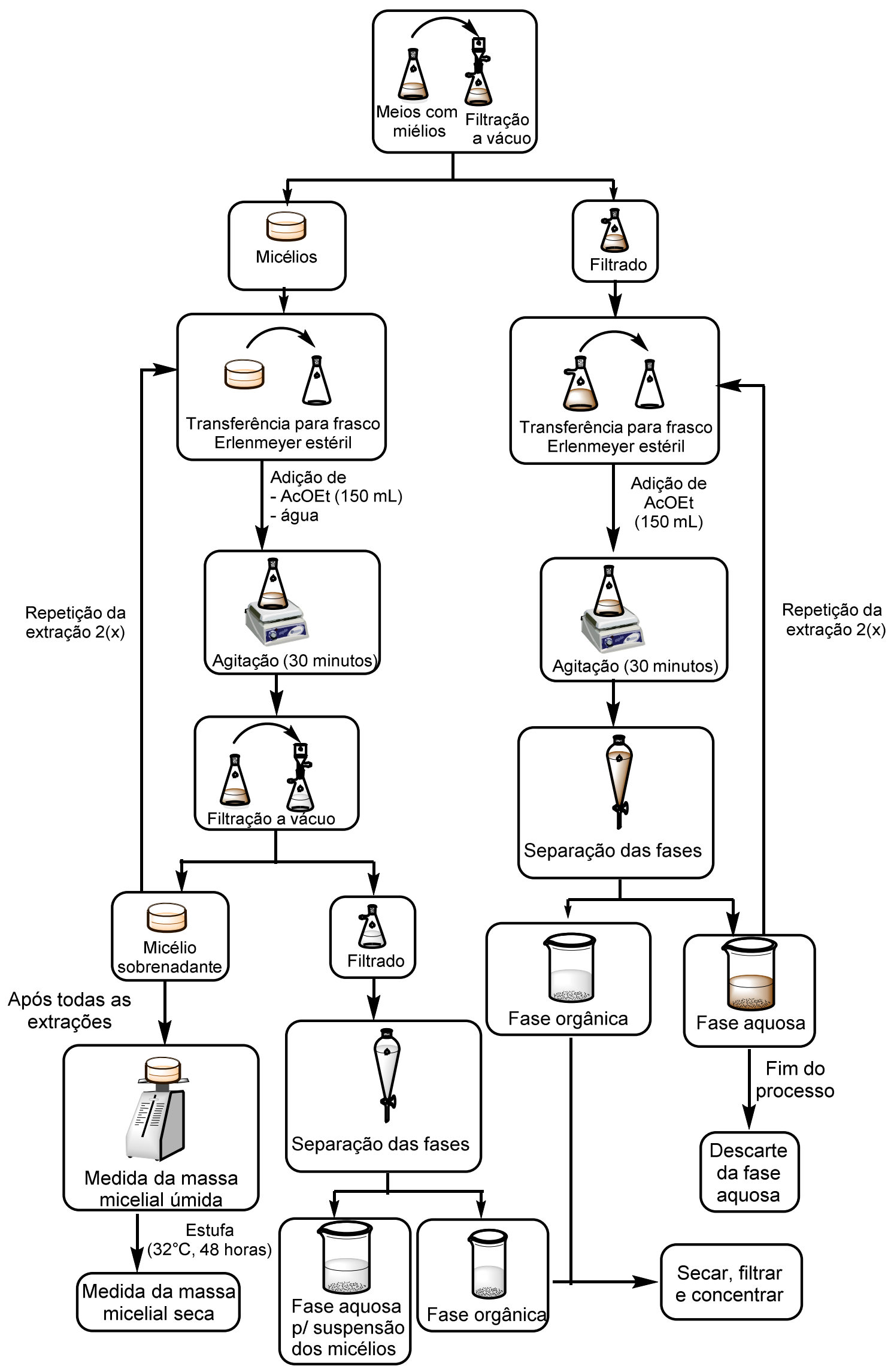


À fase orgânica foi adicionado sulfato de sódio anidro $\left(\mathrm{Na}_{2} \mathrm{SO}_{4}\right)$. Em seguida, fez-se uma filtração e o filtrado foi concentrado até $10 \mathrm{~mL}$ em um rotaevaporador a baixa pressão. Do extrato concentrado foi retirado uma alíquota de $0,3 \mathrm{~mL}$ e diluída 5 vezes em acetato de etila para as análises cromatográficas (CCD e CG-EM). O extrato concentrado foi transferido para um "frasco de penicilina" e este adaptado ao rotaevaporador e, à baixa pressão, o solvente remanescente foi evaporado e obtido o extrato seco para posterior purificação dos metabólitos de biotransformação (Figura 25).

Figura 25. Procedimento de concentração da fase orgânica obtida da extração das reações de biotransformação com a massa micelial.

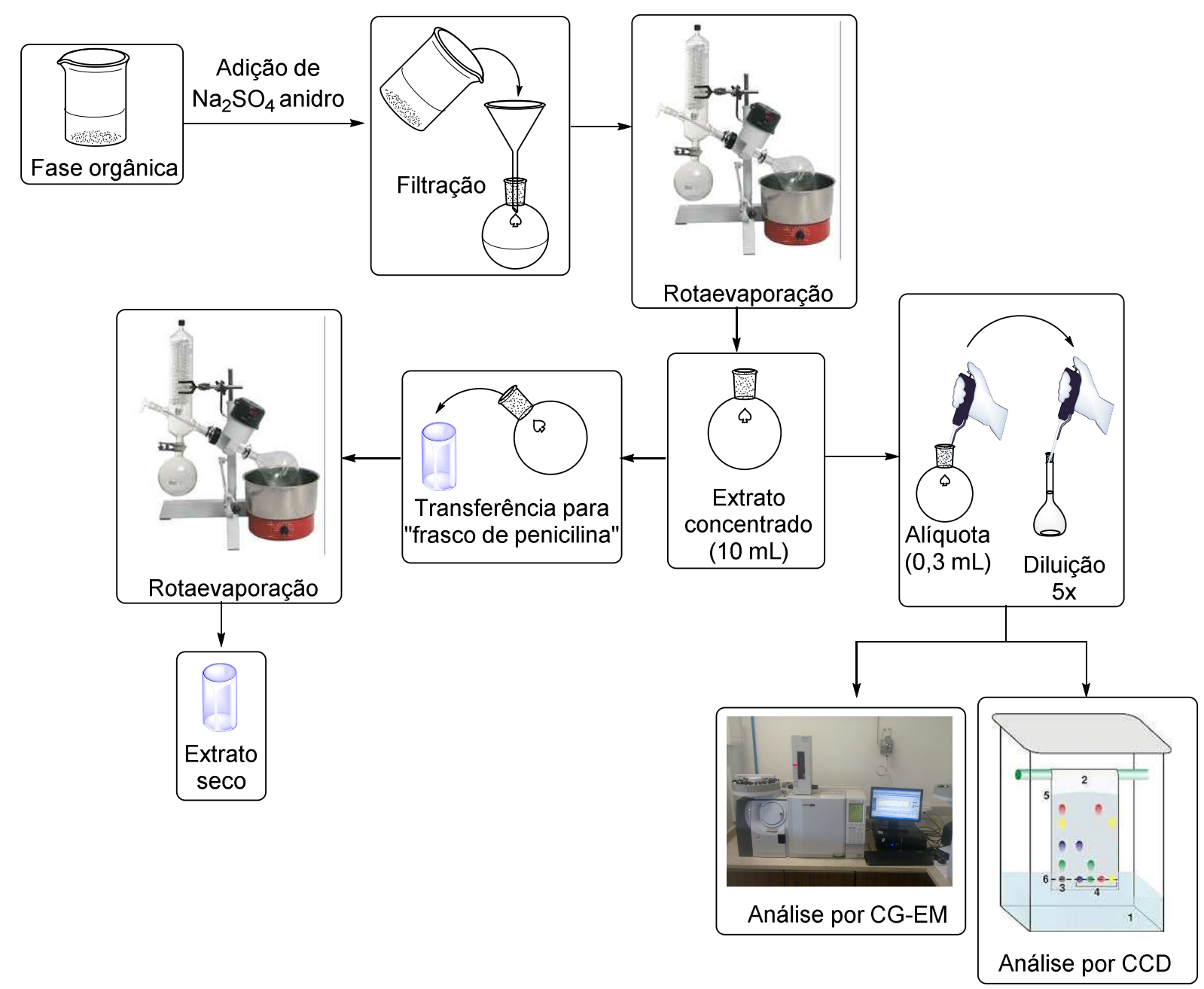

O uso das técnicas cromatográficas teve como objetivo analisar e obter informações prévias dos produtos do processo de biotransformação (CG-EM). Essas análises foram feitas mediante a comparação com as soluções dos padrões dos substratos e com o controle do meio reacional utilizando a massa micelial ou o caldo enzimático na ausência dos esteroides. 


\section{C.9.2 EXTRAÇÃO DAS REAÇÕES COM O CALDO ENZIMÁTICO}

Durante o processo de biotransformação utilizando o caldo enzimático foram observadas a presença de poucos "pellets" dos fungos no meio reacional. O processo de filtração dos meios contendo as massas miceliais dos fungos cultivados para as reações de biotransformação não foi capaz de reter a totalidade das células dos fungos. Visualmente não foi possível verificar a presença de "pellets" ou colônias de fungos no caldo enzimático logo após a filtração. Sendo assim, algumas células passam pelo processo de filtração e como consequência, as células se multiplicam durante o período de reação, formando colônias. Desse modo, o procedimento de extração dos meios reacionais utilizando o caldo enzimático é semelhante ao procedimento de extração dos meios reacionais utilizando a massa mielial.

Após tempo de execução das reações em quintuplicatas, os meios em que se processaram as biotransformações com o caldo enzimático foram reunidos em um frasco Erlenmeyer de $1000 \mathrm{~mL}$ e foram feitas as extrações com $150 \mathrm{~mL}$ de acetato de etila em agitação magnética por 30 minutos.

Após a agitação, o conteúdo do frasco Erlenmeyer foi filtrado em funil de Büchner a vácuo. O filtrado foi transferido para um funil de separação. A fase aquosa foi reunida aos "pellets" retidos no papel de filtro durante a filtração e então repetido o processo de extração por mais duas vezes. A fase orgânica foi encaminhada para filtração e concentração (Figura 26). Ao final de todo o processo de extração, a fase aquosa foi devidamente descartada e os “pellets" foram esterilizados em autoclave vertical à temperatura de $120^{\circ} \mathrm{C}$ e pressão de 1,0 $\mathrm{Kgf} / \mathrm{cm}^{2}$ por 20 minutos para o devido descarte (Figura 26). 
Figura 26. Procedimento de extração das reações de biotransformação com o caldo enzimático.

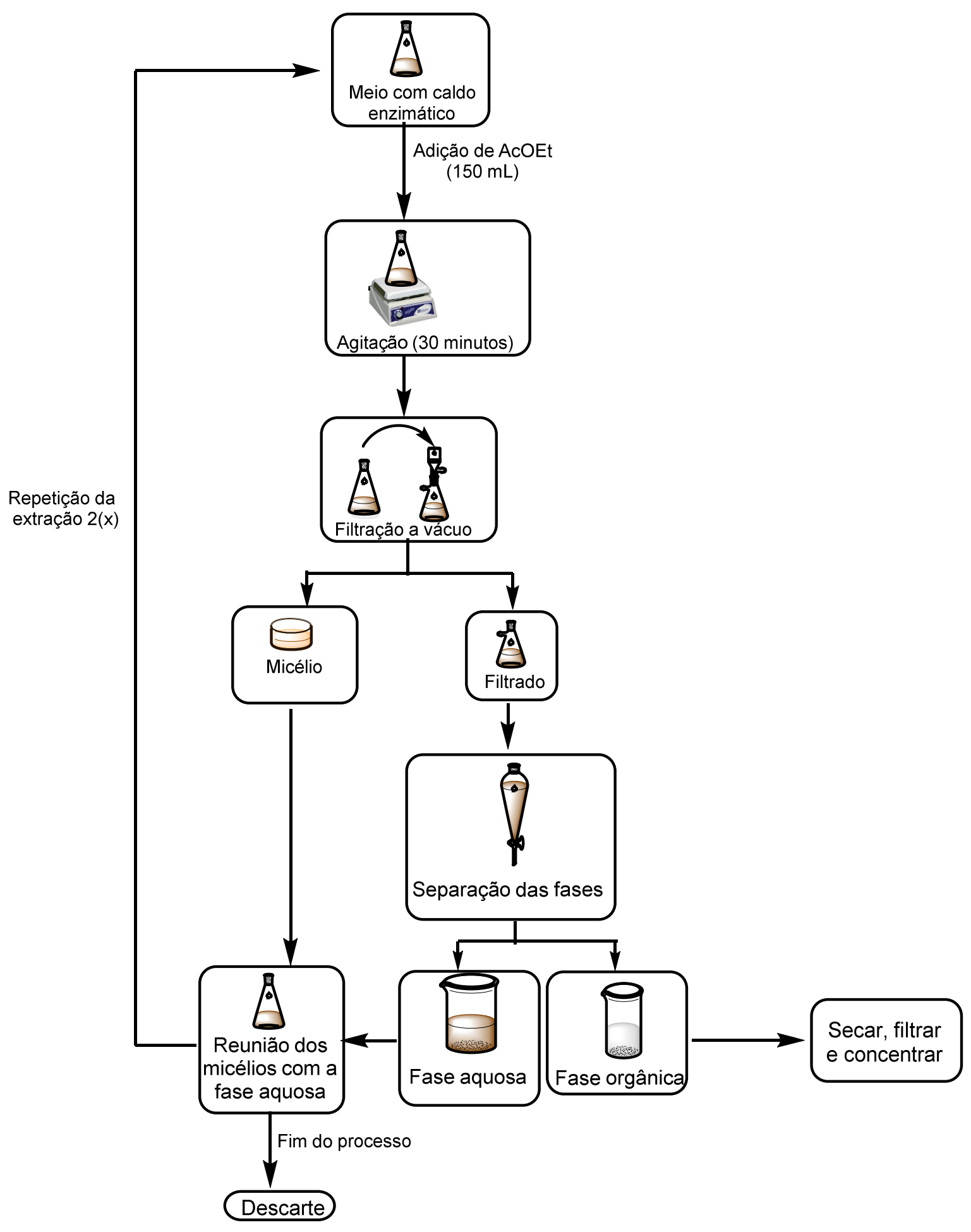

À fase orgânica foi adicionado sulfato de sódio anidro $\left(\mathrm{Na}_{2} \mathrm{SO}_{4}\right)$. Em seguida, fez-se uma filtração e o filtrado foi concentrado até $10 \mathrm{~mL}$ em um rotaevaporador a baixa pressão. Do extrato concentrado foi retirado uma alíquota de $0,3 \mathrm{~mL}$ e diluída 5 vezes em acetato de etila para as análises cromatográficas (CCD e CG-EM). O extrato concentrado foi transferido para 
um "frasco de penicilina"e este adaptado ao rotaevaporador e, à baixa pressão, o solvente remanescente foi evaporado e obtido o extrato seco (Figura 27).

Figura 27. Procedimento de concentração da fase orgânica obtida da extração das reações de biotransformação com o caldo enzimático.

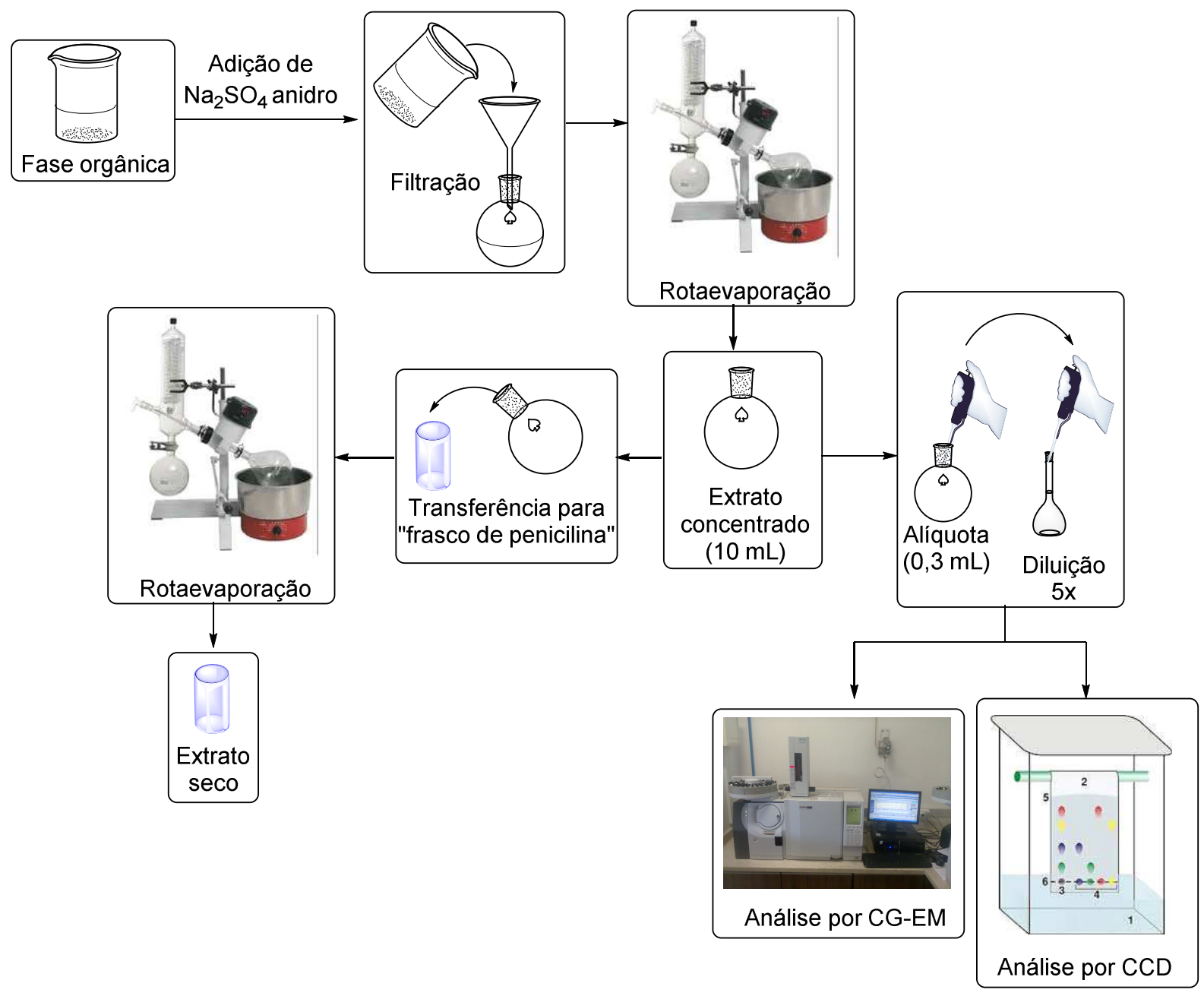

O uso das técnicas cromatográficas teve como objetivo obter informações prévias dos possíveis produtos do processo de biotransformação (CG-EM). Essas análises foram feitas mediante a comparação com as soluções dos padrões dos substratos e com o controle do meio reacional utilizando a massa micelial e o caldo enzimático na ausência dos esteroides bem como pelas análises dos espectros de massas. Em todas as análises de CCD as placas cromatográficas foram reveladas em uma câmara de radiação ultra-violeta (UV) utilizando lâmpada de $250 \mathrm{~nm}$ e utilizando solução de ácido fosfomolibídico $7 \%$ em etanol. 


\section{C.10 SEPARAÇÃO E PURIFICAÇÃO DOS PRODUTOS DE BIOTRANSFORMAÇÃO PELOS FUNGOS DE AMBIENTE MARINHO}

Após os processos de extração dos meios reacionais utilizando a massa micelial e o caldo enzimático procedeu-se às etapas de purificação dos metabólitos obtidos pela biotransformação.

Aos extratos secos obtidos foi adicionada uma quantidade mínima de acetato de etila para dissolução. Com as soluções obtidas, foram feitos os estudos de gradientes de eluição por CCD, utilizando misturas dos solventes n-hexano e acetato de etila com proporções variáveis entre os solventes. O objetivo deste estudo foi determinar a menor polaridade do eluente a ser utilizada para iniciar o processo de eluição por cromatografia em coluna e a maior polaridade para finalizar o processo cromatográfico. Os produtos foram purificados por cromatografia em coluna utilizando como fase estacionária sílica gel de porosidade de 230-400 mesh (Figura 28).

Figura 28. Procedimento de separação, isolamento e purificação dos produtos de biotransformação contidos nos extratos obtidos das reações com os fungos de ambiente marinho.

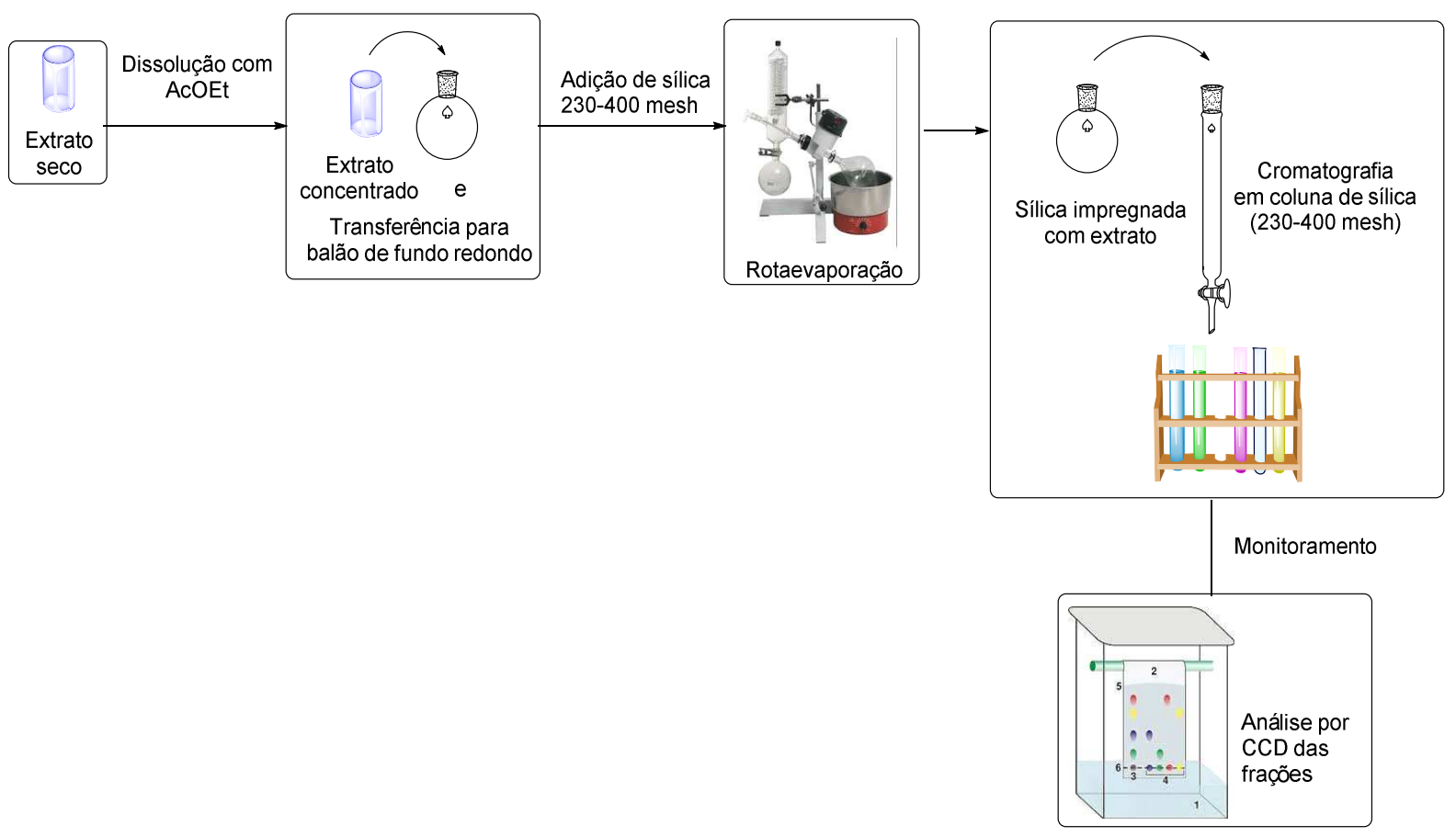

O processo de purificação foi monitorado por CCD a fim de se verificar os possíveis grupos de frações semelhantes a serem reunidas. Uma vez determinados estes grupos, foram tomadas alíquotas de cada fração do mesmo grupo e reunidas essas alíquotas em um pequeno "frasco de penicilina" de 5,0 mL. Com uma micropipeta de $1000 \mu \mathrm{L}$ foram tomados $300 \mu \mathrm{L}$ 
deste frasco e diluídos para $1500 \mu \mathrm{L}$ com acetato de etila em um frasco vial de mesma capacidade para análise por CG-EM a fim de se verificar se o grupo de frações determinado continha apenas, um único produto, confirmando assim o isolamento do metabólito. Caso o metabólito tenha sido isolado, as frações em que este composto estava presente foram reunidas em um balão de fundo redondo e evaporado o solvente em um rotaevaporador giratório até uma quantidade mínima de líquido. Este líquido foi transferido para "frascos de penicilina" onde foi finalizada a evaporação do solvente adaptando o frasco a um rotaevaporador, obtendo assim o metabólito isolado (Figura 29). Foi medida a massa do metabólito isolado para determinação do rendimento do processo. 
Figura 29. Procedimento de isolamento dos produtos de biotransformação dos esteroides contidos nos extratos obtidos das reações com os fungos de ambiente marinho.

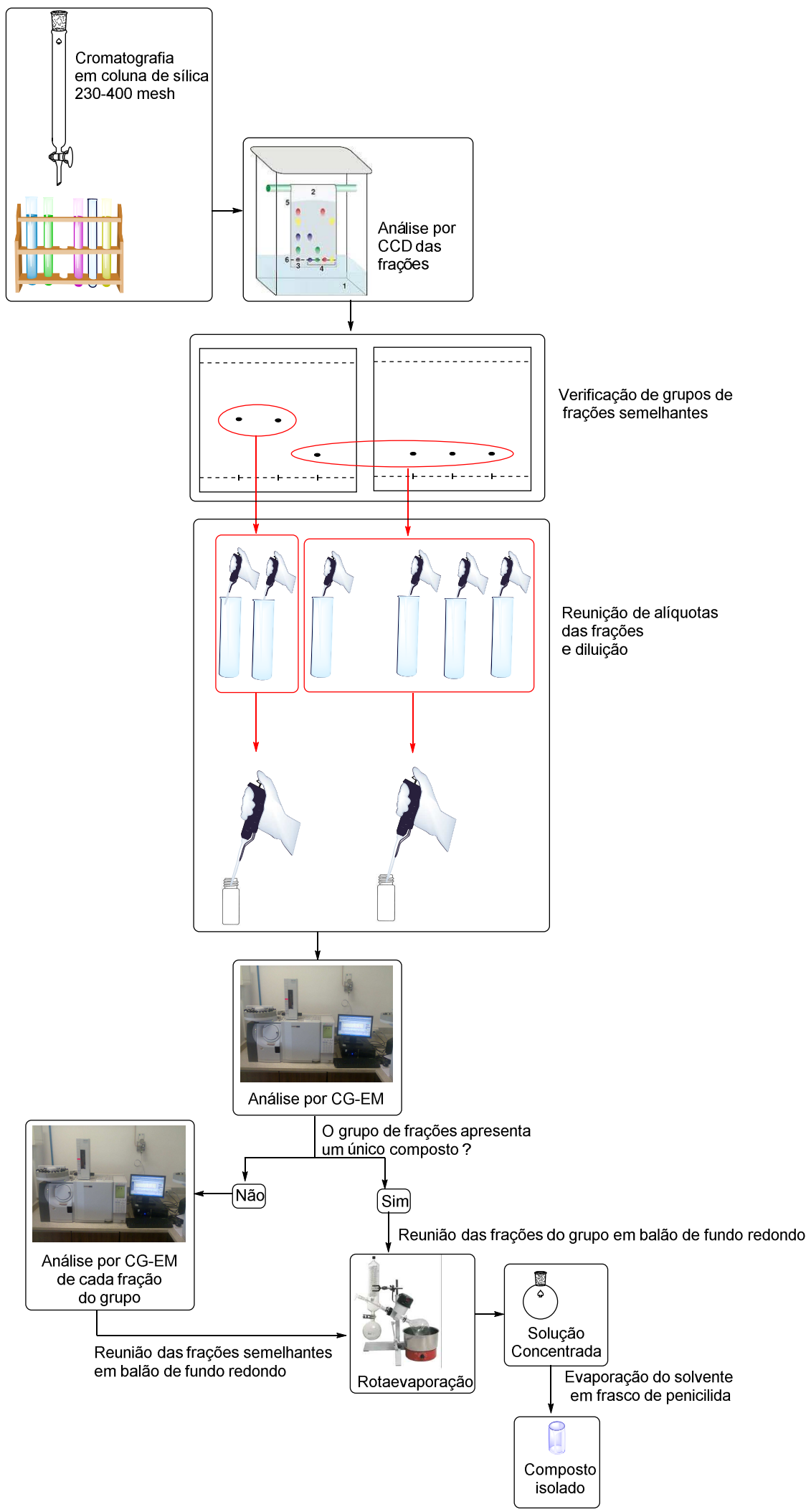




\section{C.11 CARACTERIZAÇÃo DOS SUBSTRATOS E PRODUTOS DE BIOTRANSFORMAÇÃO DOS ESTEROIDES}

\section{C.11.1 CARACTERIZAÇÃO POR ESPECTROSCOPIA NO INFRAVERMELHO}

Foi feita a mistura tanto do substrato quanto dos produtos em $\mathrm{KBr}$ sólido previamente seco em estufa a $100^{\circ} \mathrm{C}$ por 24 horas, utilizando um grau e pistilo de ágata. Essa solução sólida obtida foi submetida a alta pressão, obtendo uma pastilha de $1,0 \mathrm{~cm}$ de diâmetro. Foi feita a análise no Espectrômetro de Infravermelho (IV) com Transformada de Fourier - Marca Shimadzu - modelo IRAffinity 1 na faixa de 450 a $4000 \mathrm{~cm}^{-1}$. O objetivo desta análise consistiu em identificar os grupos funcionais presentes tanto no substrato, quanto no produto através das bandas características que cada grupo funcional apresenta no espectro de IV, confirmando assim a ocorrência da reação de biotransformação.

\section{C.11.2 CARACTERIZAÇÃo POR ESPECTROSCOPIA DE RESSONÂNCIA MAGNÉTICA NUCLEAR}

Os substratos que sofreram biotransformação e os metabólitos obtidos foram dissolvidos em clorofórmio deuterado $\left(\mathrm{CDCl}_{3}\right)$, sendo utilizados de 10 a $20 \mathrm{mg}$ dos compostos para dissolução. As soluções foram submetidas às análises de Ressonância Magnética Nuclear $(\mathrm{RMN})$ de ${ }^{1} \mathrm{H}(400$ e $500 \mathrm{MHz}),{ }^{13} \mathrm{C}(100$ e $125 \mathrm{MHz})$ e também em técnicas bidimensionais (COSY, HSQC e HMBC) nos Espectrômetros com Transformada de Fourier marca Agilent Technologies: modelo 500/54 premium shielded (500 MHz) e modelo 400/54 premium shielded (400 MHz). A faixa de deslocamento químico dos sinais de ${ }^{1} \mathrm{H}$ foi de 0 a 15 ppm e a faixa dos sinais de ${ }^{13} \mathrm{C}$ foi de 0 a $230 \mathrm{ppm}$. Os sinais de referência para os núcleos de ${ }^{1} \mathrm{H}$ e ${ }^{13} \mathrm{C}$ nos espectros obtidos foram relativos ao padrão interno tetrametil-silano (TMS). O objetivo desta análise foi a elucidação estrutural comparativa dos metabólitos com os substratos. 


\section{C.11.3 CARACTERIZAÇÃO POR ESPECTROMETRIA DE MASSAS DE ALTA RESOLUÇÃO}

Os metabólitos obtidos cujas informações na literatura para elucidação estrutrural foram bastante restritas ou cuja similaridade entre os espectros de massas obtidos experimentalmente por CG-EM e os fornecidos pelas bibliotecas foram inferiores à 90\% foram dissolvidos em acetonitrila grau espectroscópico com $0,1 \%$ de ácido fórmico na concentração de $2 \mu \mathrm{g} / \mathrm{mL}$ e submetidos para análise por Espectrometria de Massas de Alta Resolução (EMAR) por inserção direta e ionização por eletrospray no espectrômetro de marca Termo Scientific - modelo LTQ Velos. A faixa de leitura dos picos foi de $m / z$ 80,00 a 400,00. O objetivo desta análise foi a elucidação estrutural complementar dos compostos pela fragmentação das moléculas dos compostos.

\section{C.11.4 DETERMINAÇÃO DA ROTAÇÃO ÓPTICA POR POLARIMETRIA}

Os substratos biotransformados e seus respectivos metabólitos foram dissolvidos em clorofórmio grau espectroscópico nas concentrações determinadas pelas referências da literatura em g/100 mL. A rotação óptica dessas soluções forma medidas utilizando cela de caminho ótico de 1,0 cm e volume de 2,0 mL em um polarímetro marca Jasco - modelo P-2000 equipado com lâmpada de sódio $(\lambda=589 \mathrm{~nm})$. O objetivo dessa análise é verificar o desvio da luz plano polarizada pelos compostos, uma vez que tanto os substratos, quanto os produtos são substâncias quirais.

As caracterizações espectroscópicas e a determinações polarimétricas dos compostos foram feitas em equipamentos alocados na Central de Análises Químicas e Instrumentais (CAQI) do Instituto de Química de São Carlos.

\section{C.12 REAGENTES E OUTROS EQUIPAMENTOS}

a) Reagentes: ágar (marca KASVI), extrato de malte (marca KASVI), progesterona (marca Sigma-Aldrich), 17 $\alpha$-etinilestradiol (marca Sigma-Aldrich), acetato de etila (P.A.A.C.S. - marca Synth), n-hexano (P.A.A.C.S. - marca Synth), DMSO ( P.A.A.C.S. - marca TEDIA), clorofórmio grau espectroscópico (marca J.T. Backer), clorofórmio deuterado (marca Cambridge Isotopes Laboratories Inc.), acetonitrila grau espectroscópico (marca Panreac), 
ácido fórmico (P.A.A.C.S. - marca Synth), metanol (P.A.A.C.S. -marca Synth) $\mathrm{CaCl}_{2} \cdot 2 \mathrm{H}_{2} \mathrm{O}$ (P.A. - marca Synth), KCl (P.A. - marca -Synth), NaCl (P.A. - marca LS Chemicals), $\mathrm{MgCl}_{2} .6 \mathrm{H}_{2} \mathrm{O}$ (P.A. - marca Synth), $\mathrm{NaH}_{2} \mathrm{PO}_{4}$ (P.A. - marca Merck), $\mathrm{Na}_{2} \mathrm{SO}_{4}$ (P.A. - marca Synth), $\mathrm{NaHCO}_{3}$ (P.A. - marca Synth), $\mathrm{KBr}$ (P.A.A.C.S. - marca Synth), $\mathrm{SrCl}_{2} 6 \mathrm{H}_{2} \mathrm{O}$ (P.A.A.C.S. - marca J.T.Backer), $\mathrm{H}_{3} \mathrm{BO}_{4}$ (P.A.A.C.S.- marca Synth), ácido fosfomolibídico (P.A. - marca Qhemis)

b) Outros equipamentos: pHmetro - marca Qualxtron, balança analítica - marca Shimadzu modelo AY220, balança semi-analítica -marca AND modelo EK - 410i, centrífuga - marca Hermle modelo Z200A, rotaevaporador - marca Fisatom modelo 801 equipado com banho termostatizado - marca Tecnal modelo TE2005 e bomba de vácuo - marca BOC Edwards e banho maria - marca Fisatom, estufa incubadora B.O.D. - marca Nova Ética modelo 411D, estufa - marca Nova Ética, câmara de fluxo laminar - marca VECO, autoclave vertical - marca Phoenix, agitador magnético - marca Stuart modelo stir CB161, agitador orbitalar marca Lab companion modelo SI 600R, bomba a vácuo - marca Marte modelo 161. 


\section{RESULTADOS E DISCUSSÃO}

\section{D.1. TESTES DE DISSOLUÇÃO DOS ESTEROIDES}

O teste de dissolução consistiu em estipular a quantidade adequada de solvente a ser empregada na adição do substrato ao meio reacional (DMSO) e extração dos compostos (acetato de etila).

$\mathrm{Na}$ adição do substrato ao meio reacional foi determinado adicionar $50 \mathrm{mg}$ de substrato (progesterona ou 17 $\alpha$-etinilestradiol) ao frasco Erlenmeyer de $250 \mathrm{~mL}$. Então buscou-se avaliar a possibilidade de preparar uma solução do esteroide a ser biotransformado em DMSO na concentração de $50 \mathrm{mg} / \mathrm{mL}$.

$\mathrm{Na}$ extração dos compostos do meio reacional com acetato de etila foi determinado executar uma extração em triplicata adicionando ao meio reacional $30 \mathrm{~mL}$ de acetato de etila em cada replicata, totalizando o uso de $90 \mathrm{~mL}$ de solvente por frasco Erlenmeyer em cada extração. Como foi determinado adicionar $50 \mathrm{mg}$ de substrato ao meio reacional, a concentração de esteroide em acetato de etila adequada para a utilização de $90 \mathrm{~mL}$ de solvente por extração foi de $0,56 \mathrm{mg} / \mathrm{mL}$. Contudo, considerando que os produtos de biotransformação foram da mesma classe dos substratos, porém com solubilidades diferentes, foi verificado se os compostos a serem biotransformados se dissolviam na concentração de $1,0 \mathrm{mg} / \mathrm{mL}$, o que permitiu estipular se $90 \mathrm{~mL}$ era a quatidade adequada de acetato de etila a ser utilizada nas extrações por meio reacional de modo que fosse possível extrair com boa eficiência tanto o substrato, quanto os produtos de biotransformação.

a) Teste de dissolução em dimetil-sulfóxido. A Tabela 4 apresenta os resultados dos testes de dissolução dos esteroides progesterona e 17 $\alpha$-etinilestradiol em DMSO com o objetivo de verificar a viabilidade do uso deste solvente para dissolução dos substratos a serem introduzidas ao meio reacional.

Tabela 4. Solubilidade dos esteroides progesterona e 17 $\alpha$-etinilestradiol em DMSO.

\begin{tabular}{cccc}
\hline Esteroide & Massa $(\mathrm{mg})$ & Volume $(\mu \mathrm{L})$ & Dissolução \\
\hline progesterona & 1,0 & 20 & solúvel \\
$17 \alpha$-etinilestradiol & 1,0 & 20 & solúvel \\
\hline
\end{tabular}

Como a Tabela 4 apresentou os dois esteroides se dissolveram em DMSO na concentração proposta. Em biocatálise tem sido observado que o DMSO, dentro de uma 
determinada quantidade, não é tóxico ou prejudicial ao crescimento dos fungos e é um bom dispersante dos substratos em meio reacional, se porventura não sejam solúveis em água ${ }^{4,60,63,64}$.

b) Teste de dissolução dos esteroides em acetato de etila. A Tabela 5 apresenta os resultados dos testes de dissolução dos esteroides progesterona e 17 $\alpha$-etinilestradiol em acetato de etila com o objetivo de verificar a viabilidade do uso deste solvente na extração dos produtos de biotransformação.

Tabela 5. Dissolução dos esteroides progesterona e $17 \alpha$-etinilestradiol em acetato de etila.

\begin{tabular}{cccc}
\hline Esteroide & Massa $(\mathrm{mg})$ & Volume $(\mathrm{mL})$ & Dissolução \\
\hline progesterona & 1,0 & 1,0 & solúvel \\
$17 \alpha$-etinilestradiol & 1,0 & 1,0 & solúvel \\
\hline
\end{tabular}

Como a Tabela 5 apresentou os dois esteroides se dissolveram em em acetato de etila na concentração proposta. O uso deste solvente para extração de metabólitos de biotransformação, como já descrito na introdução, é preferível por ser um solvente menos tóxico em relação aos solventes halogenados ${ }^{4}$ e também por possuir baixo custo e de fácil recuperação por evaporação.

\section{D.2 DESENVOLVIMENTO E OTIMIZAÇÃO DA METODOLOGIA DE ANÁLISE DOS ESTEROIDES POR CG-EM}

Existem várias técnicas analíticas instrumentais aplicadas a compostos orgânicos. Utilizar a CG-EM seria interessante para a análise de esteroides por permitir a identificação prévia dos metabólitos de biotransformação, bem como dos possíveis compostos formados pelo metabolismo do próprio microrganismo dentro das condições experimentais deste estudo. A identificação destes compostos é possível através da comparação dos espectros de massas fornecidos pelos analitos com os espectros armazenados em uma biblioteca. Porém, muitas metodologias das análisse de esteroides por cromatografia a gás requerem a derivatização dos analitos. Executar esse procedimento neste estudo não seria adequado por estar na fase inicial onde demandaria uma etapa adicional frente as triagens a serem realizadas.

No entanto, Gomes et al. (2013) ${ }^{65}$ executaram determinações de contaminantes em água por Cromatografia a Gás Bidimensional acoplada a Espectrometria de Massas (CGxCG-EM). Dentre os contaminantes foram encontrados vários esteroides: estrona, estradiol, 17 $\alpha$ etinilestradiol, mestranol metandrostenolona, androstenediona, mesterolona, metandriol, mestanalona (Figura 30). A metodologia cromatográfica utilizada não requereu o emprego de 
agentes de derivatização. De posse das informações das condições cromatográficas contidas na bibliografia citada, foram feitas as análises cromatográficas, dos padrões dos esteroides, com as condições cromatográficas adaptadas da literatura ${ }^{65}$ (Figura 31). Foram preparadas soluções padrões dos esteroides progesterona e $17 \alpha$-etinilestradiol com concentrações de $1,0 \mathrm{mg} / \mathrm{mL}$ em acetato de etila e analisados por CG-EM, tendo estabelecido assim o tempo de retenção destes compostos como mostra a Figura 31.

Figura 30. Estruturas de esteroides encontrados em água determinados por GOMES et al. $(2013)^{65}$, utilizando cromatografia a gás bidimensional acoplada à espectroscopia de massas (CGxCG-EM).

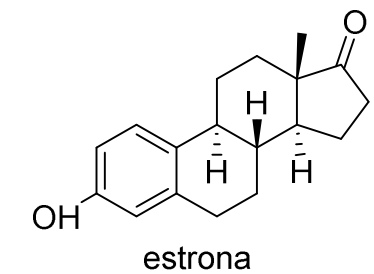

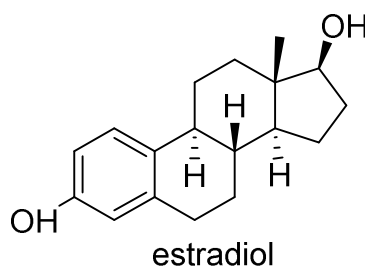

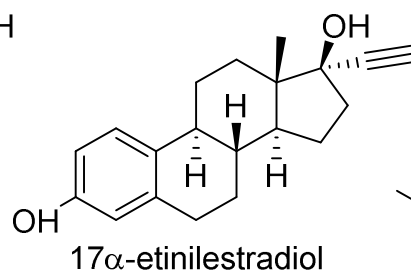<smiles>C#C[C@]1(O)CC[C@H]2[C@H]3CCc4cc(OC)ccc4[C@@H]3CC[C@@]21C</smiles><smiles>CC12C=CC(=O)C=C1CCC1C2CCC2(C)C1CC[C@H]2O</smiles>

metandrostenolona<smiles>CC12CCC3C(CCC4=CC(=O)CCC43C)C1CCC2=O</smiles>

androstenediona

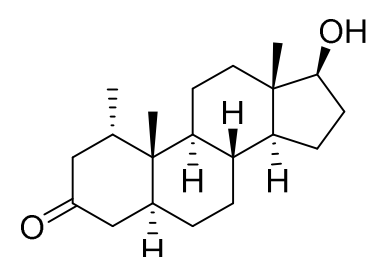

$\overline{\mathrm{H}}$ mesterolona

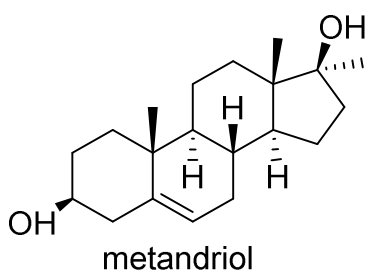<smiles>C[C@H]1CC[C@H]2[C@@H]3CC[C@H]4CC(=O)CC[C@]4(C)[C@H]3CC[C@]2(C)O1</smiles> 
Figura 31. Cromatogramas obtidos dos padrões de esteroides por CG-EM.

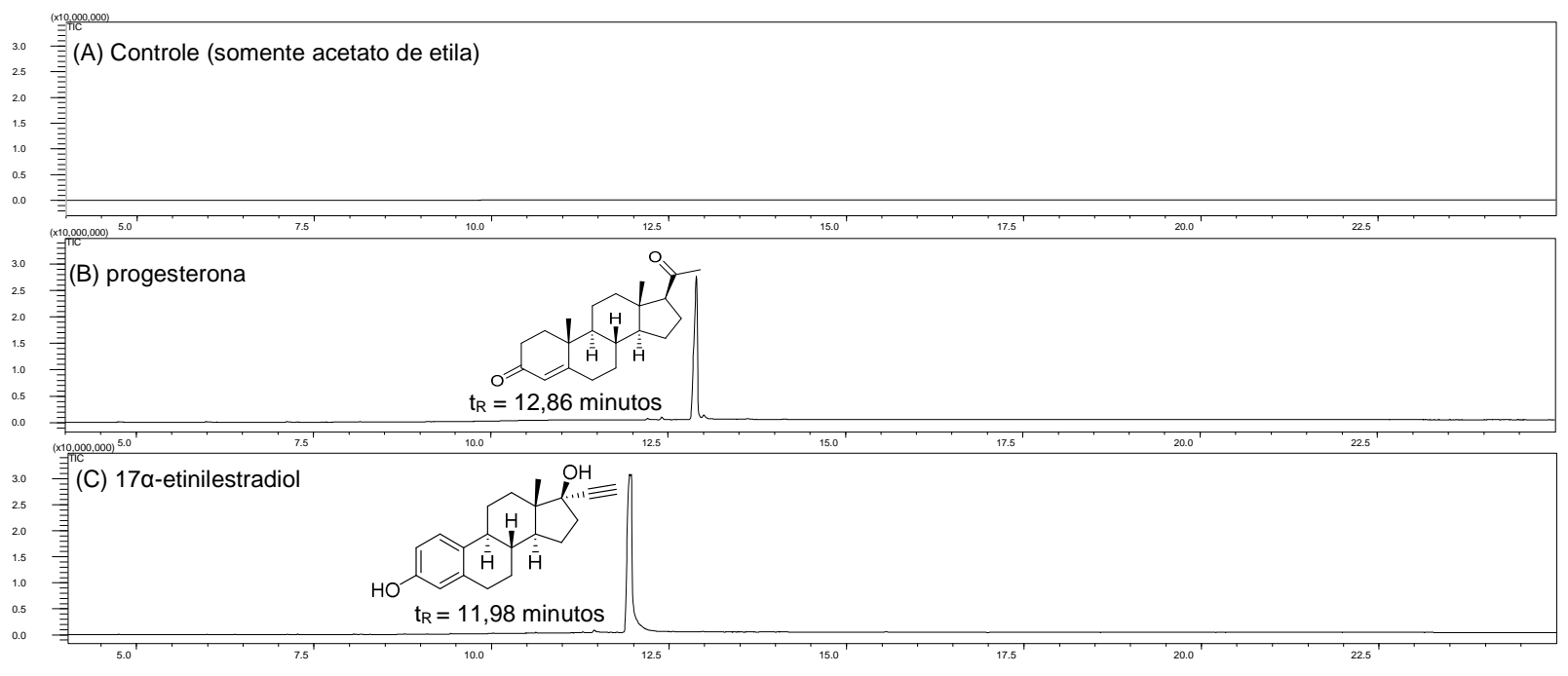

Condições cromatográficas: gás carreador He, temperatura de injeção de $250^{\circ} \mathrm{C}$, razão de Split 5.0. Coluna DB$5 \mathrm{~ms}$ (cadeia polimérica com 5\% de fenil e 95\% dimetil-arilenosiloxano) de dimensões $30 \mathrm{~m}$ x 0,25 mm x 0,25 $\mu \mathrm{m}$, rampa de temperatura: $120^{\circ} \mathrm{C}$ por $1 \mathrm{~min}$, taxa de aquecimento $20^{\circ} \mathrm{C} / \mathrm{min}$ por $15 \mathrm{~min}$, pressão de $73,8 \mathrm{kPa}$, fluxo de $6,6 \mathrm{~mL} / \mathrm{min}$, velocidade linear de $36,1 \mathrm{~cm} / \mathrm{seg}$, tempo de análise de 25 minutos.

Como pode ser observado na Figura 31 nessas condições foi possível obter um bom perfil cromatográfico com boas respostas para os padrões da progesterona e do $17 \alpha-$ etinilestradiol. Assim, em todas as análises após a identificação dos compostos, houve um tempo de retenção suficiente para identificar os produtos antes e após o tempo de retenção do respectivo padrão.

Decorrente dessas discussões preliminares, foi decidido que as condições cromatográficas enfim determinadas possibilitaram obter bons cromatogramas para os padrões. Portanto, estas condições foram as utilizadas para as análises cromatográficas das biotransformações dos esteroides propostos neste trabalho com os fungos de ambiente marinho.

\section{D.3 AVALIAÇÃO DO CRESCIMENTO DOS FUNGOS NA PRESENÇA DE DIMETIL- SULFÓXIDO}

A Tabela 6 apresenta os resultados relativos a avaliação do crescimento do fungo $A$. sydowii CBMAI 934 na presença de DMSO. Este fungo foi utilizado como referência para verificar a utilização deste solvente como dispersante do substrato nos meios reacionais sem trazer prejuízo ao crescimento do fungo ou interferência às reações de biotransformação. 
Tabela 6. Avaliação do crescimento do fungo A. sydowii CBMAI 934 na presença de DMSO $\left(32^{\circ} \mathrm{C}, \mathrm{pH}\right.$ 7,4, $120 \mathrm{rpm}, 14$ dias).

\begin{tabular}{|c|c|c|c|c|}
\hline $\begin{array}{l}\text { Volume de } \\
\text { DMSO (mL) }\end{array}$ & $\begin{array}{l}\text { Massa úmida } \\
\text { inicial }(\mathrm{g})\end{array}$ & $\begin{array}{c}\text { Massa úmida final } \\
(\mathrm{g})\end{array}$ & Massa seca $(\mathrm{g})$ & $\begin{array}{c}\text { Repiques em meio sólido } \\
\left.\text { (5 dias } 32^{\circ} \mathrm{C}\right)\end{array}$ \\
\hline 0,0 & 3,00 & 2,72 & 0,79 & \\
\hline 0,5 & 3,00 & 3,24 & 0,98 & \\
\hline 1,0 & 3,00 & 3,50 & 0,89 & \\
\hline 2,0 & 3,00 & 3,60 & 0,97 & \\
\hline 3,0 & 3,00 & 3,23 & 1,20 & \\
\hline 4,0 & 3,00 & 3,40 & 0,97 & \\
\hline
\end{tabular}

Como a Tabela 6 apresentou a adição de DMSO nas quantidades listadas não interferiu no crescimento do fungo. Comparando com o experimento em que não foi adicionado o solvente, pôde-se perceber que em todos os casos houve um incremento de massa micelial em relação a massa inicial. Isso levou a sugerir que de certa forma o DMSO estimulou o 
crescimento da massa micelial fúngica por ser fonte de carbono e enxofre. Também se observou que em todos os repiques dos meios reacionais apresentaram crescimento de micélios e esporos. Isso possibilitou concluir que o DMSO, nas quantidades adicionadas, não foi tóxico ao fungo e este se mantve ativo em sua presença. Deste modo, definiu-se utilizar do DMSO como solvente dispersante dos substratos no meio reacional, tendo definido adicionar 1,0 mL deste solvente ao meio reacional contendo ou não o substrato a ser biotransformado.

\section{D.4. MONITORAMENTO DOS MEIOS REACIONAIS NA AUSÊNCIA DOS ESTEROIDES}

O objetivo de fazer o monitoramento dos meios reacionais na ausência dos esteroides

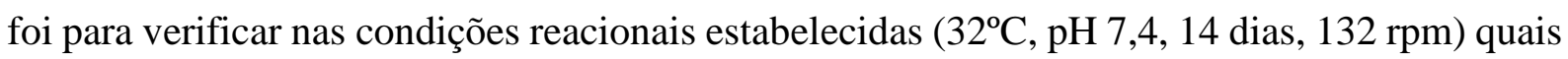
eram os metabólitos produzidos pelos fungos podendo diferenciá-los dos metabólitos produzidos pela biotransformação do substrato ou por indução da presença deste.

A Figura 32 apresenta os cromatogramas obtidos das análises por CG-EM dos extratos com acetato de etila provenientes dos caldos enzimáticos dos fungos utilizados neste estudo, na ausência dos esteroides após 14 dias de agitação, tempo limite definido para a ocorrência das reações de biotransformação. 
Figura 32. Cromatogramas obtidos dos extratos dos caldos enzimáticos na ausência dos esteroides após 14 dias de agitação.
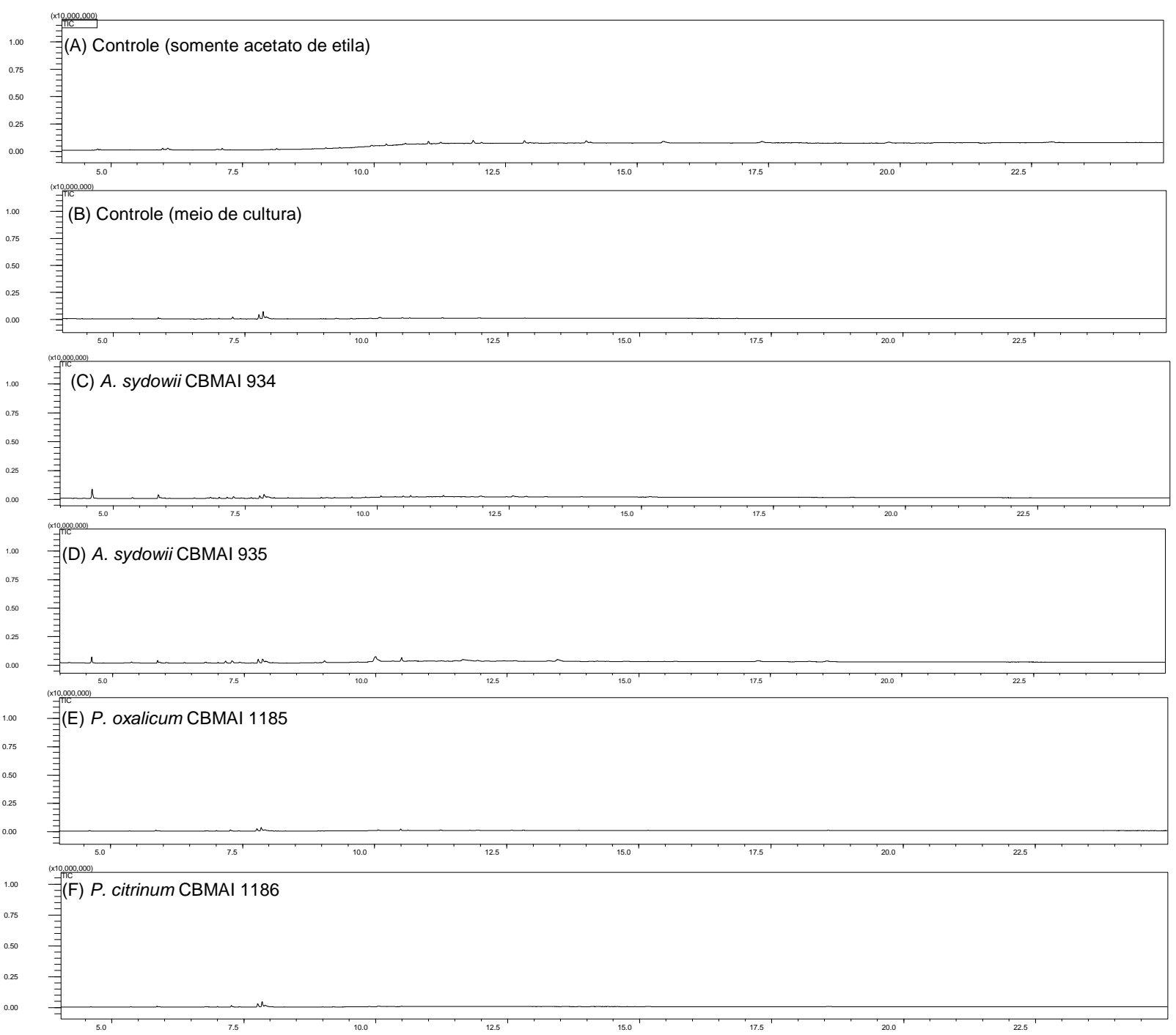

Como pôde ser observado nos cromatogramas da Figura 32, os extratos dos caldos enzimáticos em acetato de etila não apresentaram quantidades de metabólitos que sejam muito significativas na faixa de intensidade a ser considerada para análise dos picos das substâncias envolvidas nos processos enzimáticos $\left(1,2 \times 10^{7} \mathrm{TIC}\right)$. No entanto, alguns sinais podem ser observados:

a) em todos os cromatogramas, incluindo o do controle do meio de cultura, foi observado um pequeno sinal com $t_{\mathrm{R}}=7,75$ minutos que forneceu um espectro de massas com $90 \%$ de similaridade ao espectro de massas do pirrol[1,2-a]pirazina-1,4-diona,hexa-hidro-3-(2metilpropil) de acordo com a biblioteca NIST05 (Figuras 33A e 33B);

b) nos cromatogramas das Figuras $32 \mathrm{C}$ e $32 \mathrm{D}$ foram observados um pico com $t_{R}=4,77$ minutos que forneceu um espectro de massas com $96 \%$ de similaridade ao espectro de massas 
do $n$-tridecanol de acordo com a biblioteca NIST21 (Figuras 33C e 33D), o que levou a sugerir que este álcool de cadeia longa é um metabólito produzido pelas linhagens dos fungos $A$. sydowii CBMAI 934 e A. sydowii CBMAI 935;

c) por fim nos cromatograma da Figura 32D foi observado um sinal de $t_{R}=10,00$ minutos que forneceu um espectro de massas com $85 \%$ de similaridade ao espectro de massas do $n$ triacontanol de acordo com a biblioteca NIST05s (Figuras 33E e 33F), que levou a sugerir que este álcool de cadeia longa poderia ser um metabólito produzido pelo fungo A. sydowii CBMAI 935. 
Figura 33*. Espectros de massas (70 eV): (A) experimental para composto $t_{R}=7,75$ minutos, (B) pirrol[1,2a]pirazina-1,4-diona,hexa-hidro-3-(2-metilpropil) (similaridade 62\%, biblioteca NIST107), (C) experimental composto $t_{R}=4,77$ minutos, (D) 1-tridecanol (similaridade 96\%, biblioteca NIST21), (E) experimental para composto $t_{R}=10,00$ minutos, (F) 1-triacontanol (similaridade 85\%, biblioteca NIST05s).
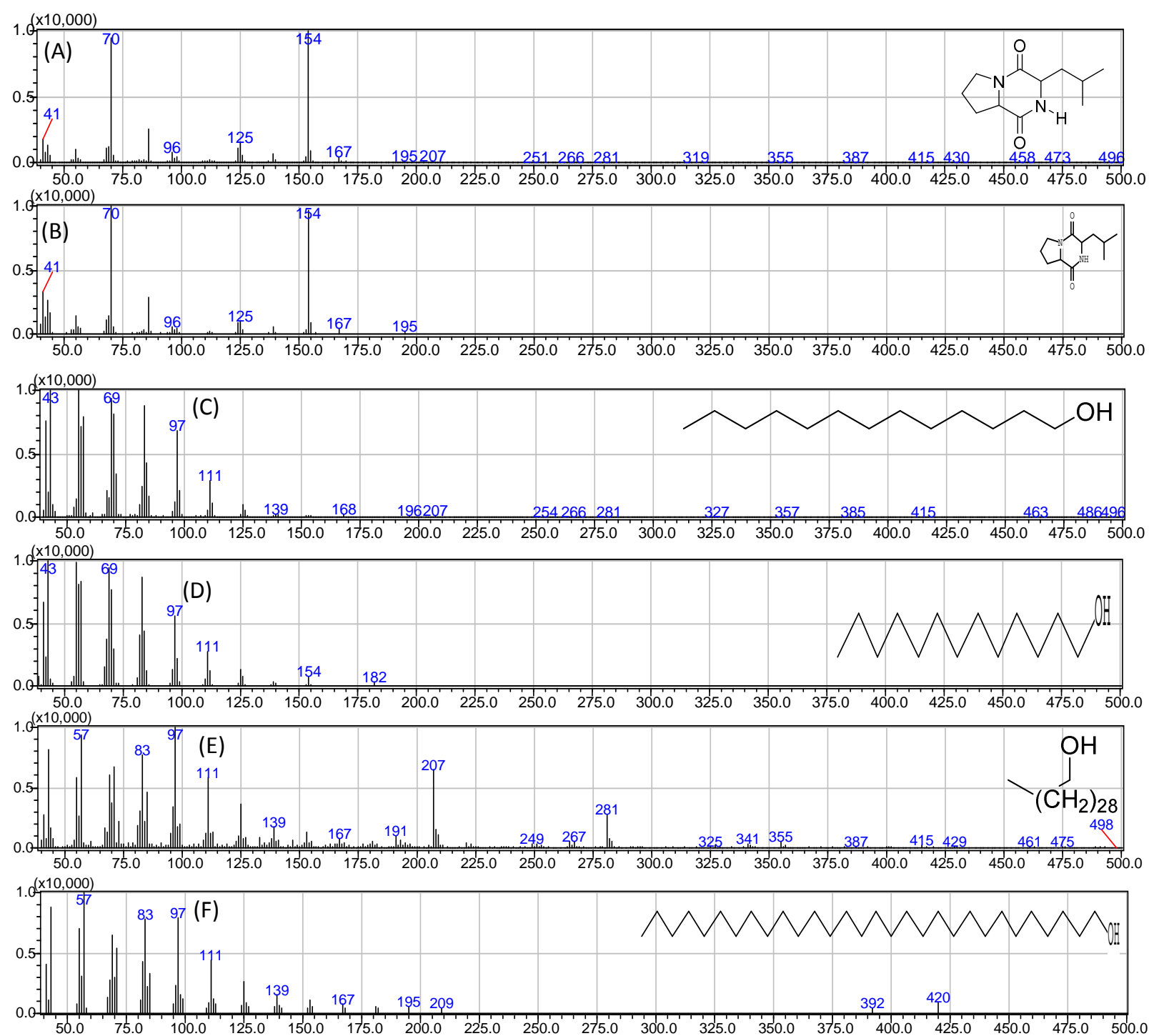

*Nota: As estruturas contidas nos espectros de massas fornecidos pelas bibliotecas não são de boa qualidade gráfica. Os programas disponíveis para a edição das imagens do texto desta dissertação não permitiram retirar a estrutura original dos espectros de massas fornecidos pelas bibliotecas e substituir por uma estrutura de melhor qualidade gráfica. Sendo assim, este tipo de edição foi possível ser realizada inserindo estruturas confeccionadas, segundo os nomes fornecidos pelas bibliotecas, nos espectros de massas obtidos experimentalmente, e este é o padrão de apresentação dos espectros de massas neste texto. 
De um modo geral, pôde-se concluir a partir da observação dos cromatogramas, que a quantidade dos metabólitos presentes nos caldos enzimáticos na ausência dos esteroides foi praticamente desprezível em relação à intensidade dos picos dos padrões observado na análise dos mesmos (Figura 31). Desse modo, a presença destes metabólitos não causou interferência significativa tanto na análise dos cromatogramas das reações, quanto no isolamento dos compostos por cromatografia em coluna.

A Figura 34 apresenta os cromatogramas obtidos das análises por CG-EM dos extratos com acetato de etila provenientes dos micélios dos fungos utilizados neste estudo, na ausência dos esteroides após 14 dias de agitação, tempo limite definido para a ocorrência das reações de biotransformação.

Figura 34. Cromatogramas obtidos dos extratos dos meios com massa micelial na ausência dos esteroides após 14 dias de agitação.

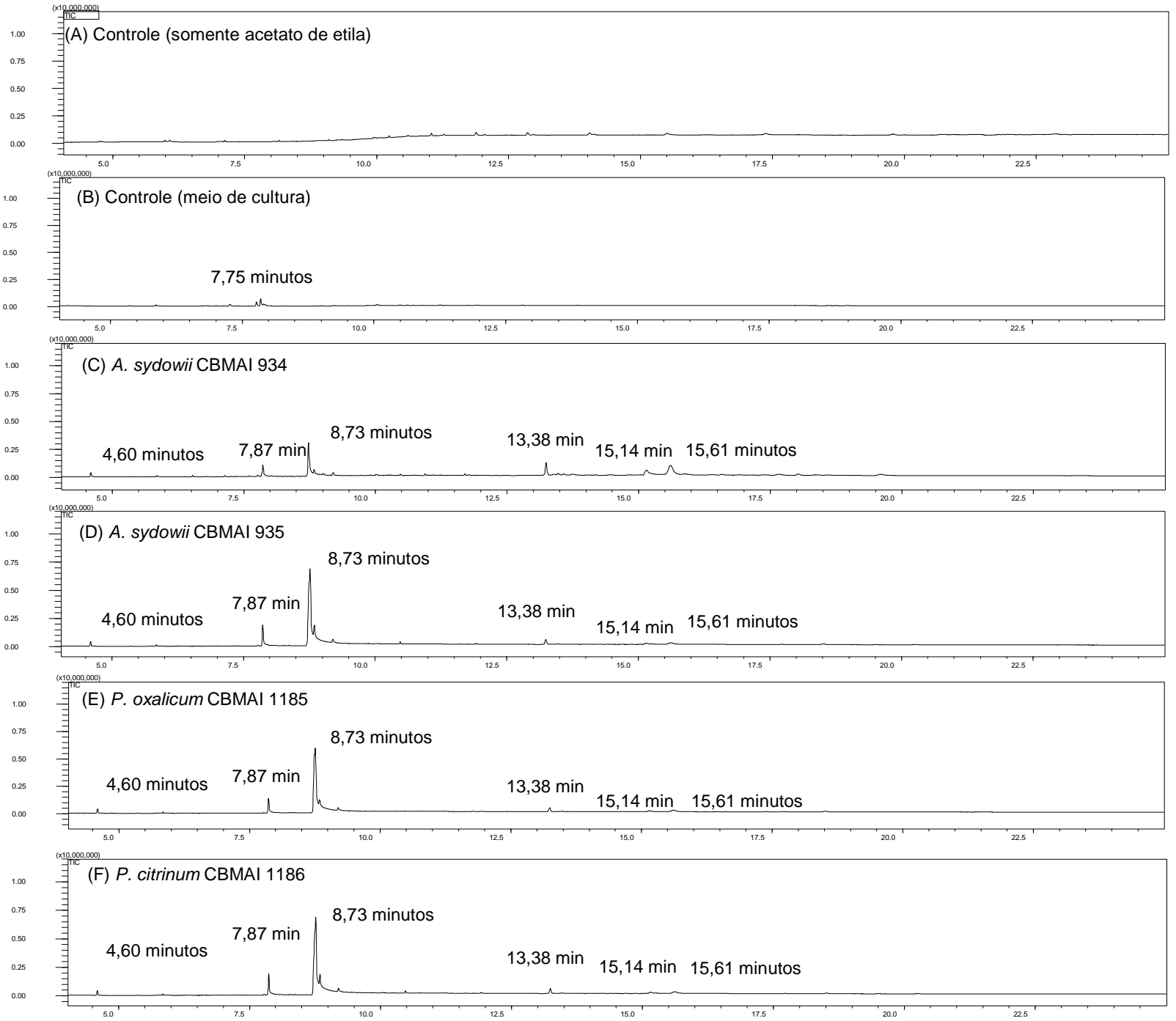


Como pôde ser observado nos cromatogramas da Figura 34 os extratos dos micélios em acetato de etila apresentara, praticamente os mesmos sinais, exceto o sinal em 7,75 minutos do extrato do meio de cultura que correspondeu ao pirrol[1,2-a]pirazina-1,4-diona,hexa-hidro-3(2-metilpropil), como já abordado no monitoramento dos meios reacionais utilizando os caldos enzimáticos dos fungos na ausência dos esteroides. Alguns dos sinais observados mostraram quantidades de metabólitos que foram significativas na faixa de intensidade a ser considerada para análise dos picos das substâncias envolvidas nos processos enzimáticos (1,2 x10 7 TIC). Outros apresentaram intensindades muito pequenas em alguns cromatogramas. Discorreremos um pouco sobre os sinais observados nos cromatogramas dos extratos dos micélios dos fungos:

a) $t_{R}=4,60$ minutos que forneceu um espectro de massas com $95 \%$ de similaridade ao espectro de massas do 1-trideceno de acordo com a biblioteca NIST21 (Figuras 35A e 36B), este sinal teve de pequena intensidade em todos os cromatogramas;

b) $t_{R}=7,87$ minutos que forneceu um espectro de massas com $92 \%$ de similaridade ao espectro de massas do ácido 1-pentadecanoico de acordo com a biblioteca WILEY8 (Figuras $35 \mathrm{C}$ e $35 \mathrm{D})$;

c) $t_{R}=8,73$ minutos que forneceu um espectro de massas com $92 \%$ de similaridade ao espectro de massas do ácido 9,12 (Z,Z) octadecadienoico de acordo com a biblioteca NIST05 (Figuras 35E e 35F).

Estes dois sinais ( $\operatorname{tr}=7,87 \mathrm{~min}$ e 8,73 $\mathrm{min}$ ) apresentaram intensidades consideráveis e representam ácidos graxos que comumente são encontrados na membrana plasmática de fungos ${ }^{66}$.

Os próximos picos foram observados com pequena intensidade nos cormatogramas, porém o cromatograma obtido do extrato fúngico do A. sydowii CBMAI 934 estes sinais foram observados com uma intensidade maior em relação aos demais:

d) $t_{R}=13,24$ minutos que forneceu um espectro de massas com $63 \%$ de similaridade ao espectro de massas do antiaergosta-1,5,7,9,22-penataeno de acordo com a biblioteca NIST05 (Figuras 35G e 35H);

e) $t_{R}=15,14$ minutos que forneceu um espectro de massas com $63 \%$ de similaridade ao espectro de massas do 5,9(11)androstatrieno,3-hidroxi-17-oxo de acordo com a biblioteca NIST05 (Figuras 35I e 35J);

f) $t_{R}=15,61$ minutos que forneceu um espectro de massas com $86 \%$ de similaridade ao espectro de massas do ergosterol de acordo com a biblioteca NIST05 (Figuras 35K e 35L).

Destes três compostos relacionados aos sinais dos cromatogramas, somente o Ergosterol possui referência de ser encontrado na membrana plasmática de fungos ${ }^{66}$. 
Figura 35. Espectros de massas $(70 \mathrm{eV})$ : (A) experimental para composto $t_{\mathrm{R}}=436 ., 60$ minutos (fungo $A$. sydowii CBMAI 934), (B) 1-trideceno (similaridade 95\%, biblioteca NIST21), (C) experimental composto $t_{\mathrm{R}}=$ 7,87 minutos (fungo A. sydowii CBMAI 934), (D) ácido 1-pentadecanoico (similaridade 92\%, biblioteca WILEY 8), (E) experimental para composto $t_{\mathrm{R}}=8,73$ minutos (fungo A. sydowii CBMAI 934), (F) ácido 9,12 (Z,Z) octadienoico (similaridade 85\%, biblioteca NIST05s). (G) experimental para composto $\mathrm{t}_{\mathrm{R}}=13,24$ minutos (fungo A. sydowii CBMAI 934), (H) antiaergosta-1,5,7,9,22-pentaeno (similaridade 63\%, biblioteca NIST05), (I) experimental composto $t_{\mathrm{R}}=15,14$ minutos (fungo A. sydowii CBMAI 934), (J) 5,9(11)androstatrieno,3-hidroxi17-oxo (similaridade 63\%, biblioteca NIST 05), (K) experiemntal para composto $t_{\mathrm{R}}=15,61$ minutos (fungo $A$. sydowii CBMAI 934), (L) ergosterol (similaridade 86\%, biblioteca NIST05).
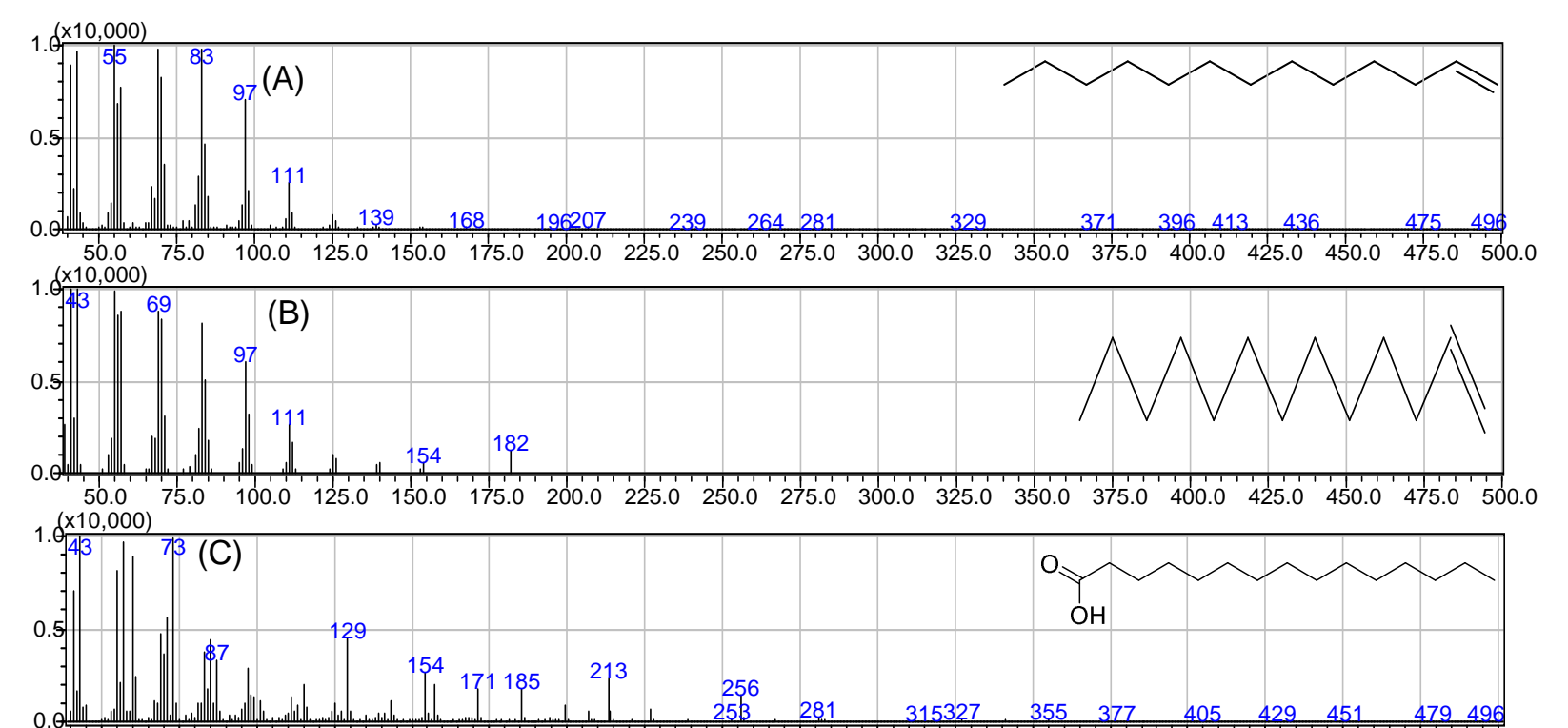
\begin{tabular}{lllllllllllllllllllllll}
\hline$\times 15,000$ & 75.0 & 100.0 & 125.0 & 150.0 & 175.0 & 200.0 & 225.0 & 250.0 & 275.0 & 300.0 & 325.0 & 350.0 & 375.0 & 400.0 & 425.0 & 450.0 & 475.0 & 500.0
\end{tabular}
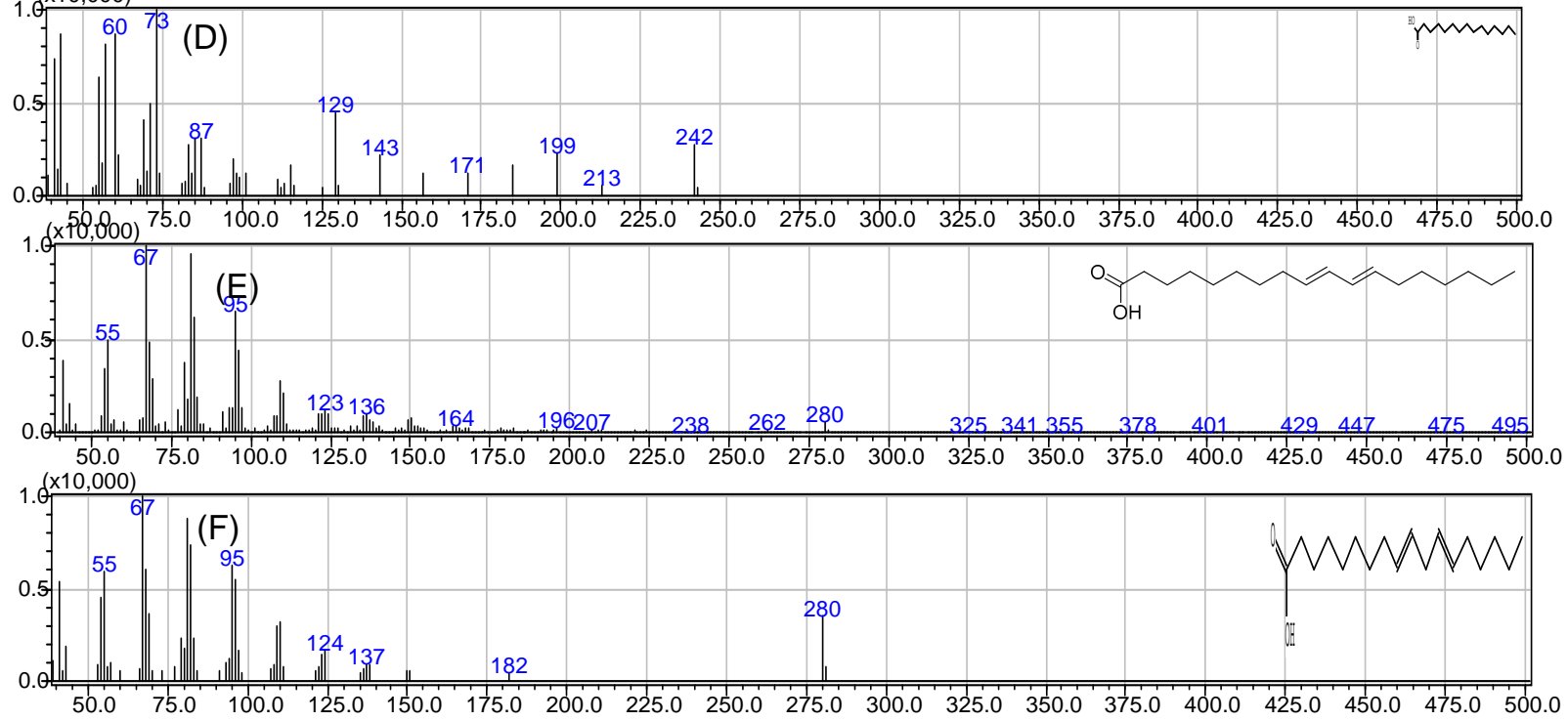

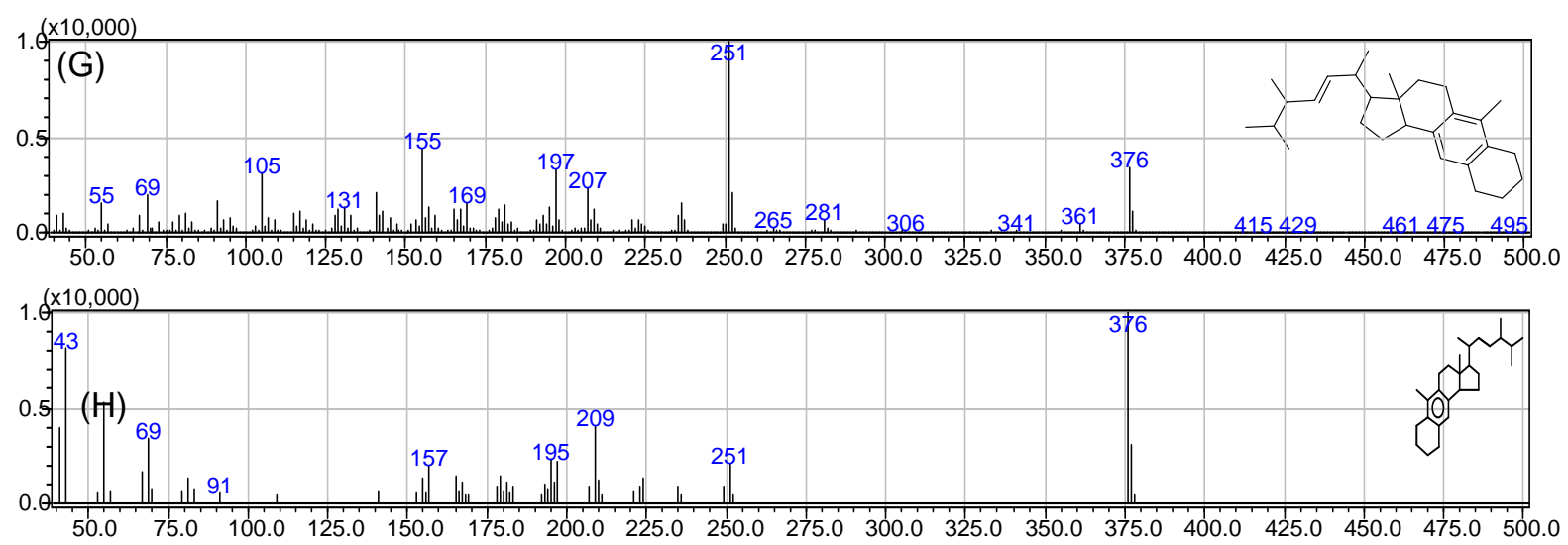
$1 .(\times 10,000)$
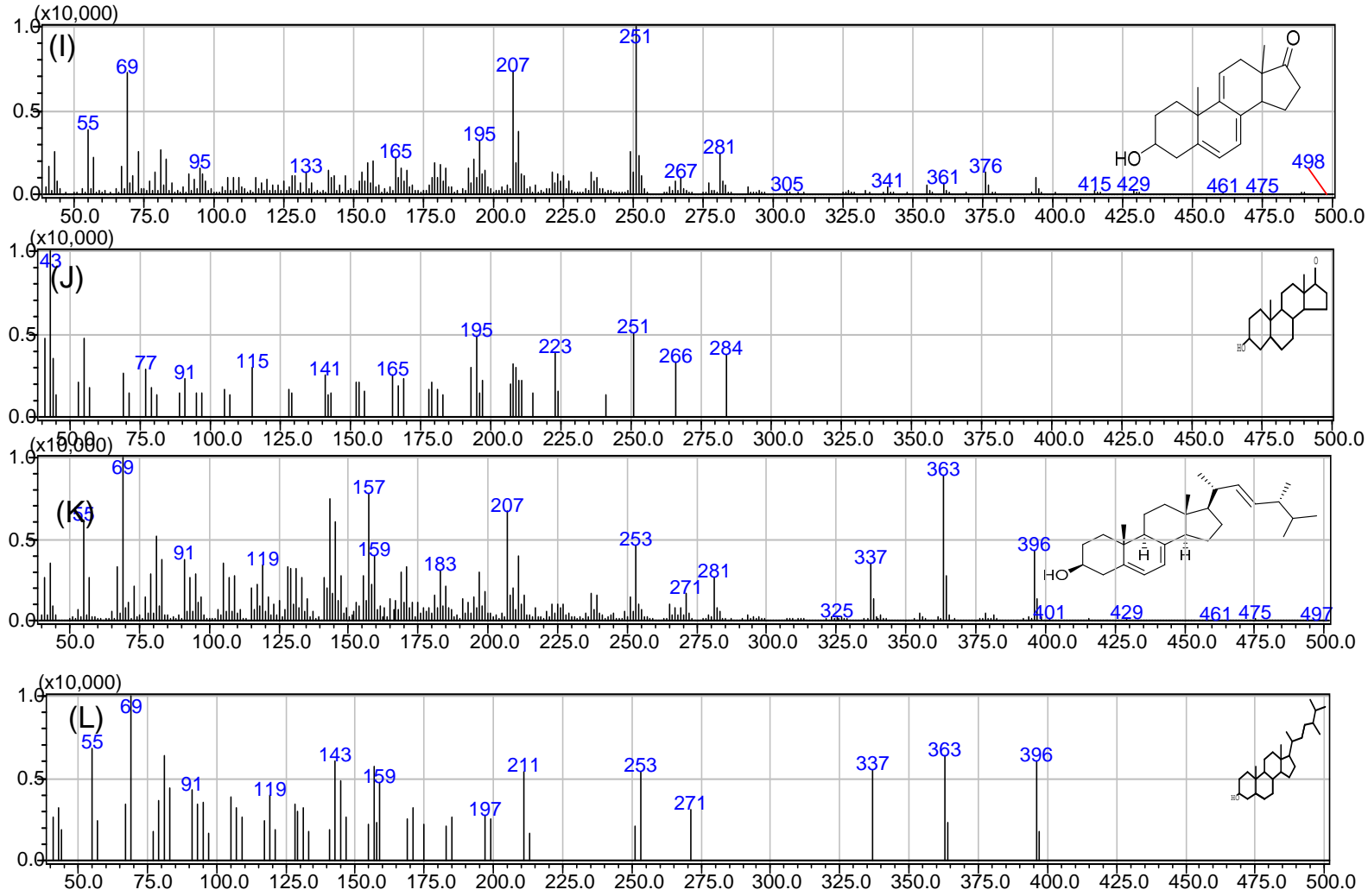

\section{D.5 REAÇÕES DE BIOTRANSFORMAÇÃO DA PROGESTERONA}

O objetivo de se realizar reações com os micélios e com o caldo enzimático foi verificar os diferentes perfis para executar tais biotransformações. Esses perfis podem ser em função da retirada de interferentes no processo de filtração do meio de cultivo, ou mesmo a avaliação da atividade das enzimas envolvidas nas biotransformações dos esteroides, na ausência dos micélios.

Uma vez conhecido o processo de biotransformação destes compostos, especialmente pela oxidação de carbonos não ativados eletronicamente, pode-se traçar processos de biotransformação de outros tipos de esteroides das respectivas classes, prever os possíveis 
metabólitos obtidos e verificar quais carbonos das estruturas destas moléculas podem sofrer oxidação.

\section{D.5.1. REAÇÕES COM OS CALDOS ENZIMÁTICOS - TRIAGEM}

Após 7 dias foram feitas análises por CG-EM dos extratos provenientes das triagens das reações utilizando os caldos enzimáticos dos fungos empregados neste trabalho. Foi feito também um controle abiótico que consistiu em um frasco Erlenmeyer contendo o substrato disperso no meio de cultura estéril na ausência dos microrganismos (Figura 36).

Figura 36. Cromatogramas obtidos daa análisea dos extratos em acetato de etila provenientes das triagens das reações de biotransformação da progesterona com os caldos enzimáticos dos fungos empregados neste trabalho após 7 dias de reação.

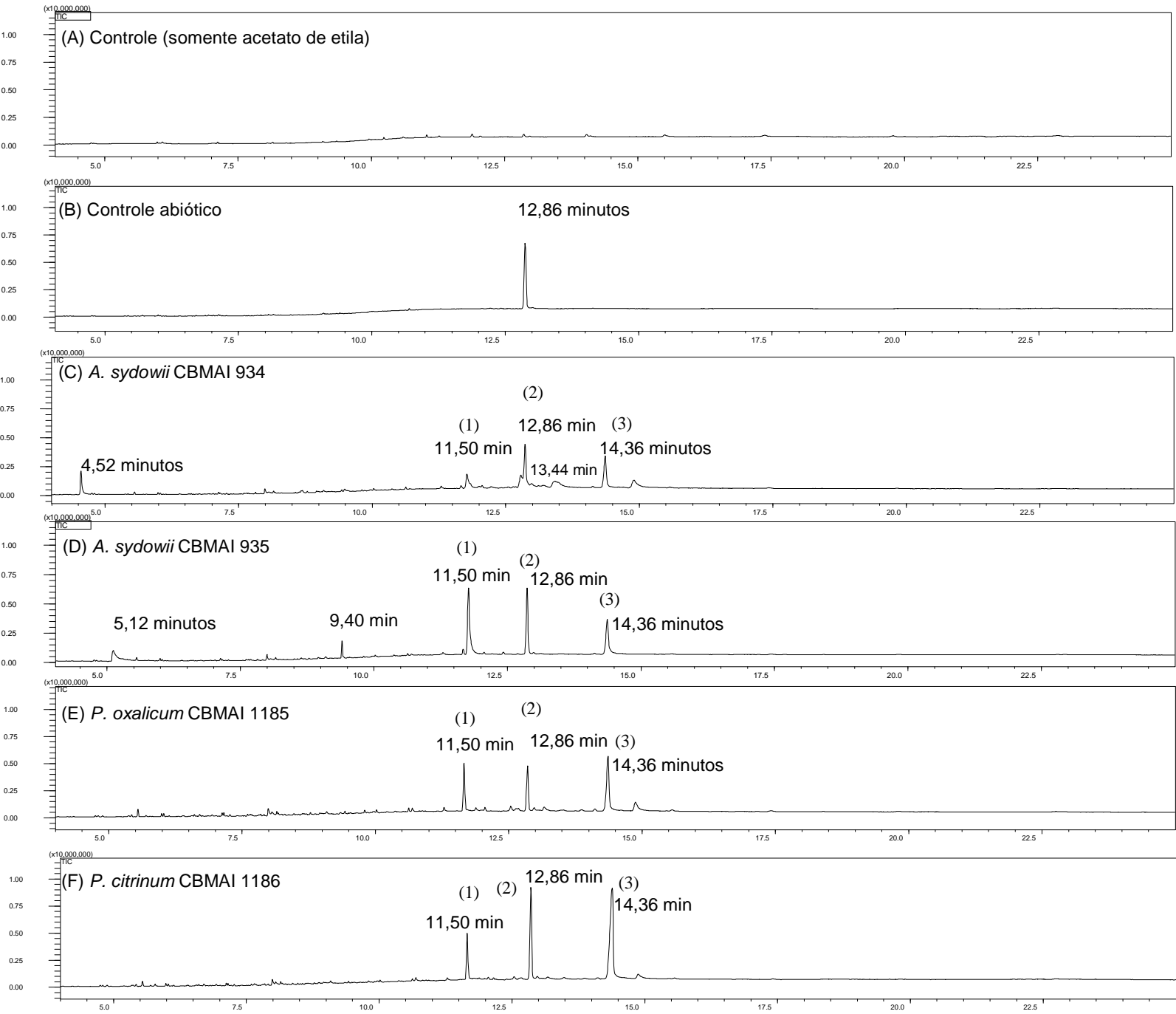


Comparando os sinais dos cromatogramas percebeu-se que os cromatogramas dos caldos enzimáticos dos fungos $A$. sydowii CBMAI 935, $P$. oxalicum CBMAI 1185 e $P$. citrinum CBMAI 1186 (Figuras 36D, 36E e 36F) apresentaram basicamente 3 sinais com os seguintes tempos de retenção: $(1)=11,50$ minutos, $(2)=12,86$ minutos e $(3)=14,36$ minutos. Comparando com o cromatograma do padrão autêntico do substrato, pôde-se concluir que o sinal (2) correspondeu à progesterona. Pelas análises dos espectros de massas fornecidos para os sinais (1) e (3) dos cromatogramas, comparados com os espectros das bibliotecas (Figuras 38B e 38D) sugeriu-se que o sinal (1) corresponderia à testosterona (Figura 37A) e o sinal (3) corresponderia à testololactona (Figura 37C).

Figura 37. Espectros de massas $(70 \mathrm{eV})$ : (A) experimental para composto $t_{\mathrm{R}}=11,50$ minutos (fungo $A$. sydowii CBMAI 935), (B) testosterona (similaridade 85\% biblioteca WILEY 8, (C) experimental composto $t_{\mathrm{R}}=$ 14,36 minutos (fungo A. sydowii CBMAI 935), (D) testololactona (similaridade 83\%, biblioteca NIST107).
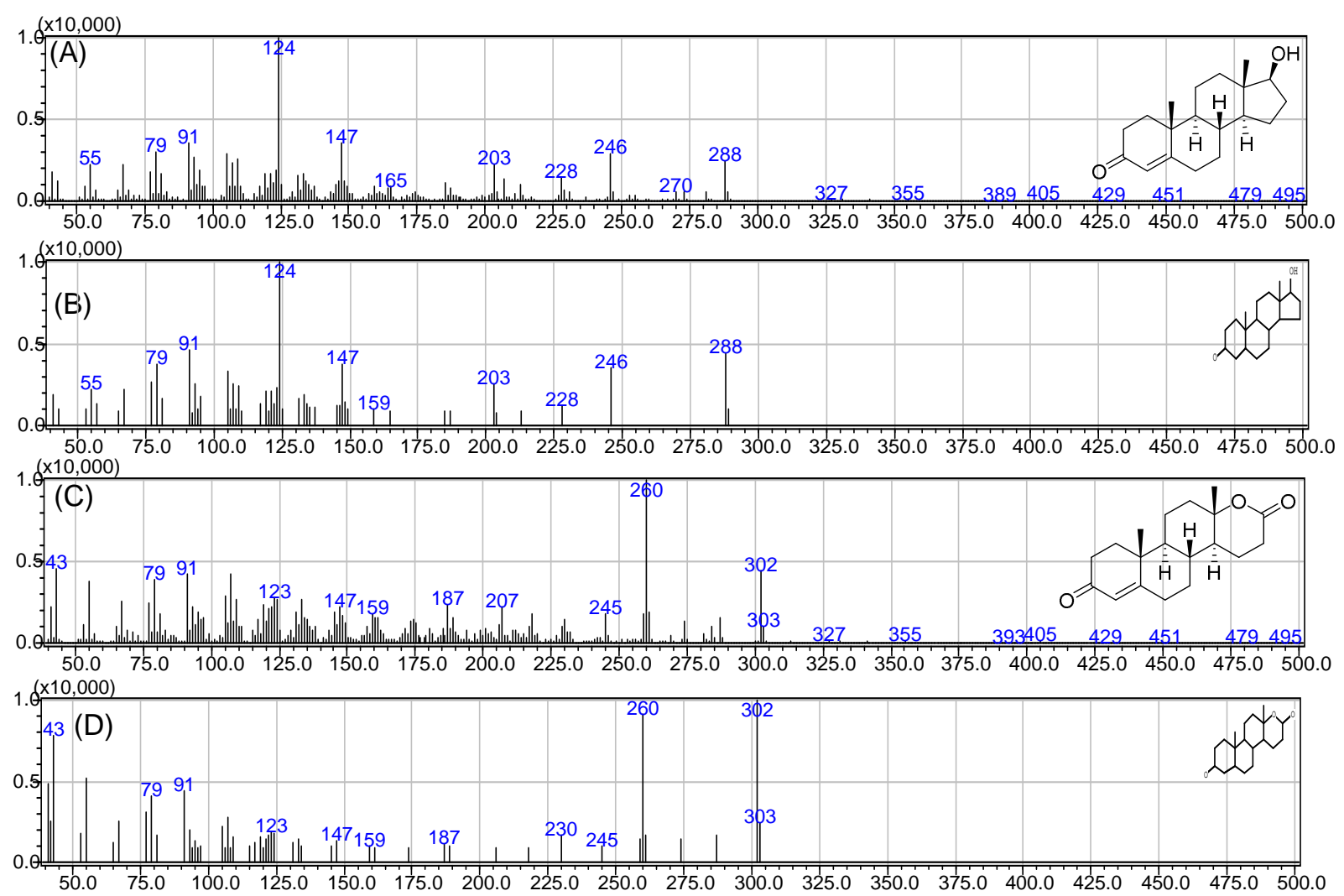

Como pôde ser observado nos espectros de massas experimentais, foram bem característicos os picos relativos aos íons moleculares: $m / z, 288$ (Figura 37A) que correspondeu a massa molar da testosterona $(288,43 \mathrm{~g} / \mathrm{mol}) ; \mathrm{m} / z 302$ (Figura 37B) que correspondeu à massa molar da testololactona $(302,41 \mathrm{~g} / \mathrm{mol})$. Como foram espectros relativos aos esteroides que não foram observados nos extratos dos caldos enzimáticos na ausência dos esteroides, concluímos 
que os sinais (1) e (3) corresponderiam aos produtos de biotranformação da progesterona no caldo enzimáticos frente à triagem realizada.

No cromatograma do extrato do caldo enzimático do fungo A. sydowii CBMAI 934 da Figura 36C foram observados 3 sinais diferentes dos demais cromatogramas com os seguintes tempos de retenção:

a) $\operatorname{tr}=4,50$ minutos que forneceu um espectro de massas de $95 \%$ de similaridade ao espectro de massas do 4-nitrobenzaldeído, segundo a biblioteca WILLEY 8. Este composto não foi observado no branco, no controle abiótico e nem nos extratos dos caldos enzimáticos na ausência da progestorona. O que nos leva a supor que seja um contaminante na coluna do equipamento.

b) $\operatorname{tr}=13,44$ minutos que forneceu um espectro de massas de $65 \%$ de similaridade ao espectro de massas do 11 $\alpha$-hidroxiprogesterona, segundo a biblioteca NIST21. (Figuras 38A e 38B).

Figura 38. Espectros de massas $\left(70 \mathrm{eV}\right.$ ): (A) experimental para composto $\mathrm{t}_{\mathrm{R}}=13,44$ minutos (fungo $A$. sydowii CBMAI 934), (B) 11 $\alpha$-hidroxiprogesterona (similaridade 65\%, biblioteca NIST21). (x10,000)
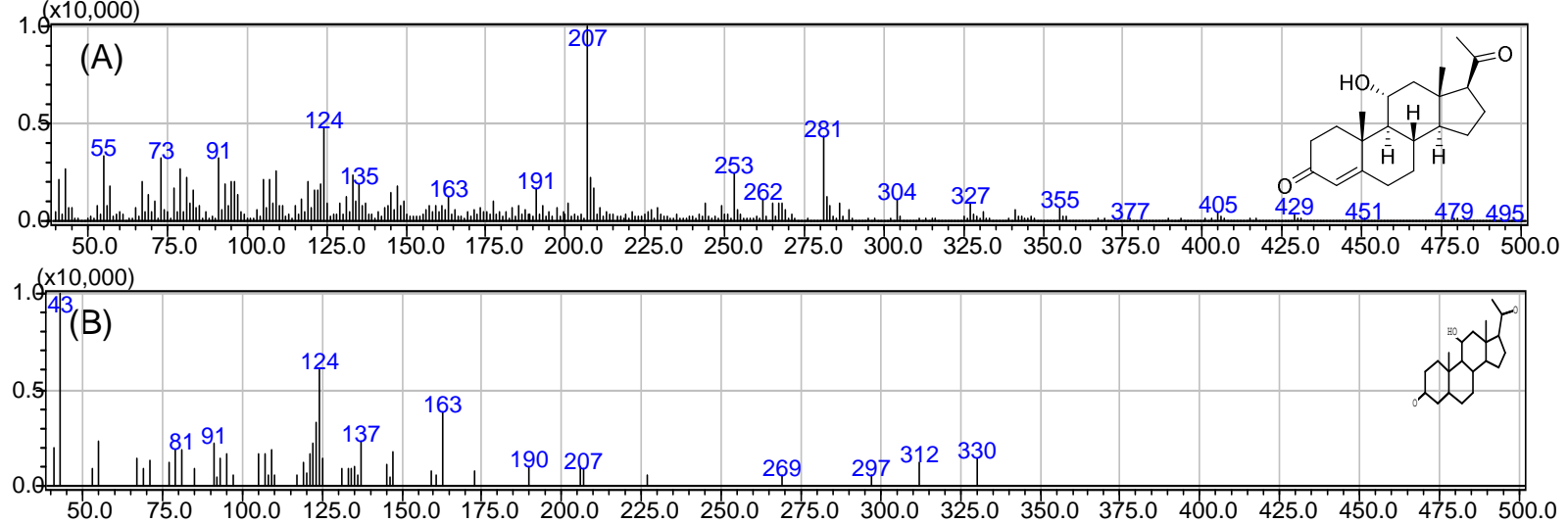

Como a estrutura sugerida pela biblioteca é de um esteroide que não foi observado nos cromatogramas dos extratos dos caldos enzimáticos sem a presença do substrato, concluiu-se que o sinal com o $t_{R}=13,44$ minutos poderia ser referente a um produto de biotransformação da progesterona efetuado pelas enzimas presentes no caldo enzimático do fungo A. sydowii CBMAI 934 após 7 dias de reação.

No cromatograma da Figura 36D, além dos sinais relativos aos produtos de biotransformação, observados em todas as triagens, foram obtidos os sinais com $t_{R}=5,12$ minutos cujo espectro de massas apresentou $65 \%$ de similaridade ao espectro de massas da 4piran-4-ona,5-hidroxi-2(hidroximetil) fornecido pela biblioteca NIST21, e outro sinal de $t_{R}=$ 
9,40 minutos cujo espectro de massas teve $65 \%$ de similaridade ao espectro de massas do tributilacetilcitrato fornecido pela biblioteca NIST05. Estes compostos não foram observados tanto nos cromatogramas dos caldos enzimáticos na ausência dos esteroides e suas estruturas não correspondem aos possíveis produtos de biotransformação da progesterona, de acordo com o banco de dados obtidos na biblioteca, indicando que sejam possíveis contaminantes externos.

As reações de triagem com o caldo enzimático foram também efetuadas por mais 7 dias totalizando 14 dias de reação. Após este período as reações foram finalizadas e feitas análises cromatográficas dos extratos dos meios reacionais por CG-EM (Figura 39).

Figura 39. Cromatogramas obtidos das análises dos extratos em acetato de etila provenientes das triagens das reações de biotransformação da progesterona com os caldos enzimáticos dos fungos empregados neste trabalho após 14 dias de reação.

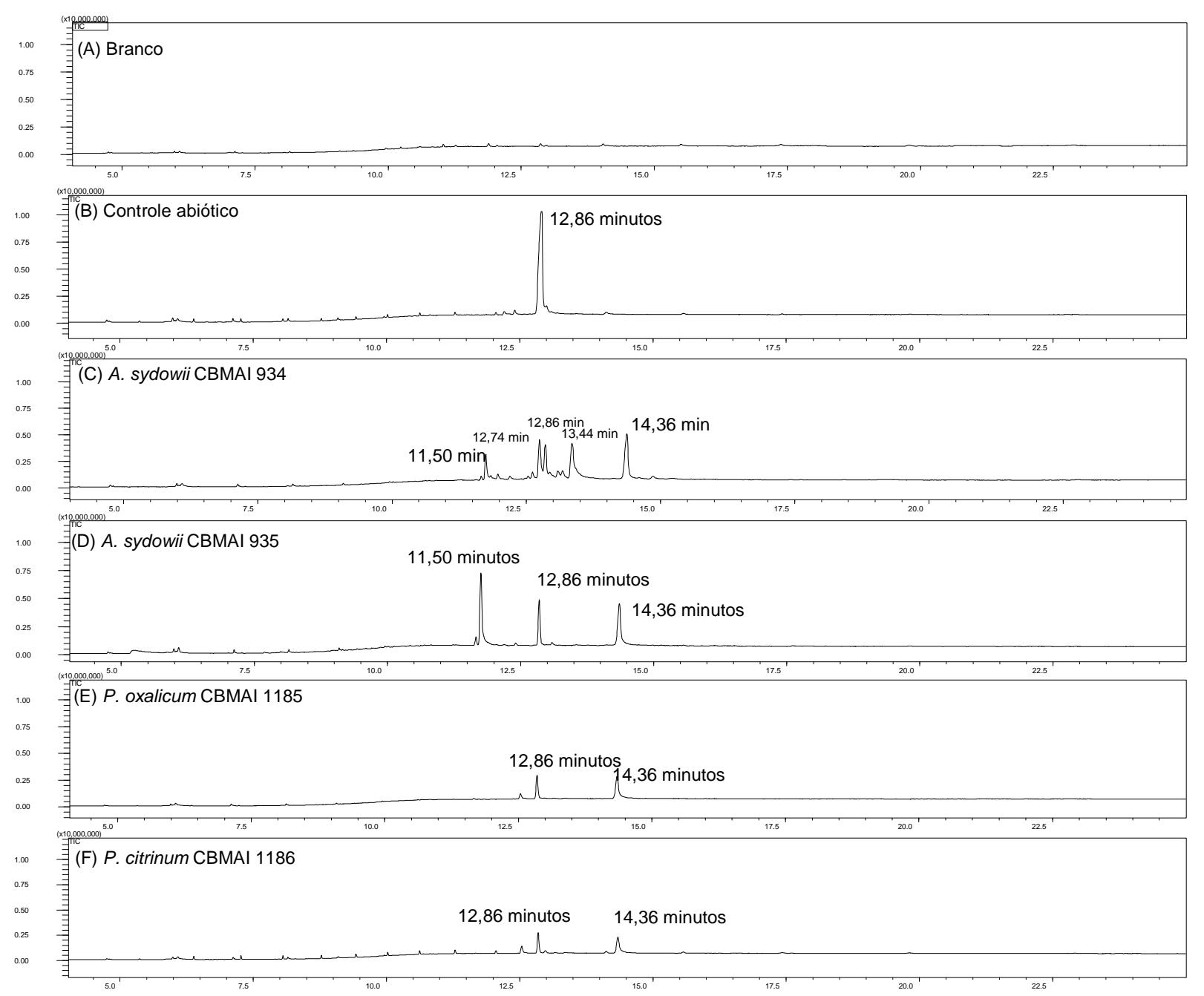


Como pôde ser observado pelos cromatorgramas (Figura 39) dos caldos utilizados pelos fungos, todos apresentaram um sinal com $t_{R}=14,36$ minutos que poderia corresponder à testololactona. Os cromatogramas das Figuras 39C e 39D apresentaram um sinal com $t_{R}=11,50$ minutos que poderia corresponder à testosterona. Os cromatogramas das Figuras 39E e 39F não apresentaram este pico, o que sugeriu que o possível composto poderia ser convertido ao produto com sinal de $t_{R}=14,36$ minutos Além disso, nos cromatogramas das Figuras 39E e $39 \mathrm{~F}$ foi observado um pequeno sinal de $t_{R}=12,53$ minutos que forneceu um espectro de massas de $59 \%$ de similaridade ao espectro de massas do 10-hidroxi-1,3,4,7,7-pentametil-2oxabiciclo(4,4,0)deca-3,5-dieno segundo a biblioteca NIST107. Esse composto não foi encontrado no extrato do caldo enzimático deste fungo na ausência da progesterona. Logo este composto poderia ser um contaminante.

O cromatograma da Figura 39C apresentou dois picos diferentes das demais análises: um com $t_{R}=12,74$ minutos que forneceu um espectro de massas de $77 \%$ de similaridade ao espectro de massas da 6 $\beta$-hidroxiprogesterona segundo a biblioteca NIST05 (Figura 40A e 40B) e outro de $t_{R}=13,44$ minutos que, assim como no cromatograma da Figura 36C poderia corresponder à $11 \alpha$-hidroxiprogesterona.

Figura 40. Espectros de massas $(70 \mathrm{eV})$ : (A) experimental para composto $\mathrm{t}_{\mathrm{R}}=12,74$ minutos (fungo $A$. sydowii CBMAI 934), (B) padrão 6 $\beta$-hidroxiprogesterona (similaridade 77\% biblioteca NIST05).
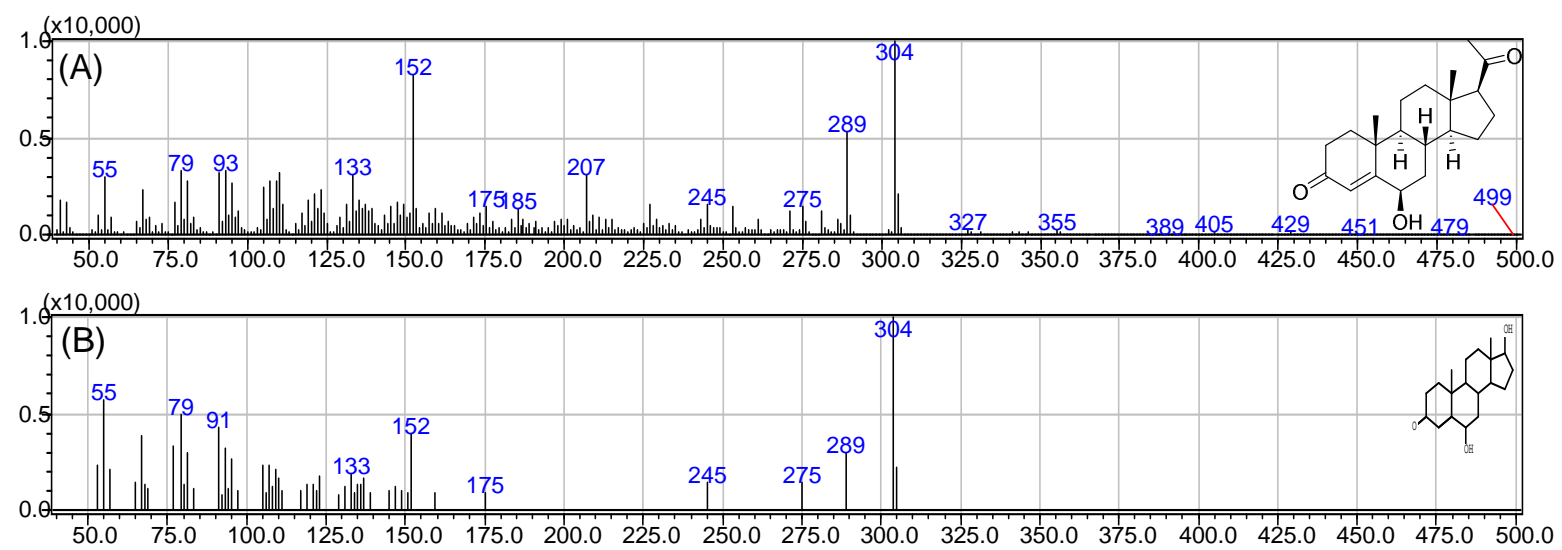

Finalmente em todos os cromatogramas (Figuras 39C-39F) dos extratos fúngicos ainda foi observado que o o substrato não foi completamente consumido. 


\section{D.5.2 REAÇÕES COM OS MICÉLIOS - TRIAGEM}

Após 7 dias de reação foram realizadas análises por CG-EM dos extratos provenientes das triagens das reações utilizando os micélios dos fungos empregados. Foi feito também um controle abiótico que consistiu em um frasco Erlenmeyer contendo a progesterona disperso no meio de cultura estéril na ausência dos microrganismos (Figura 41).

Figura 41. Cromatogramas obtidos das análises dos extratos em acetato de etila provenientes das triagens das reações de biotransformação da progesterona com os micélios dos fungos empregados neste trabalho após 7 dias de reação.
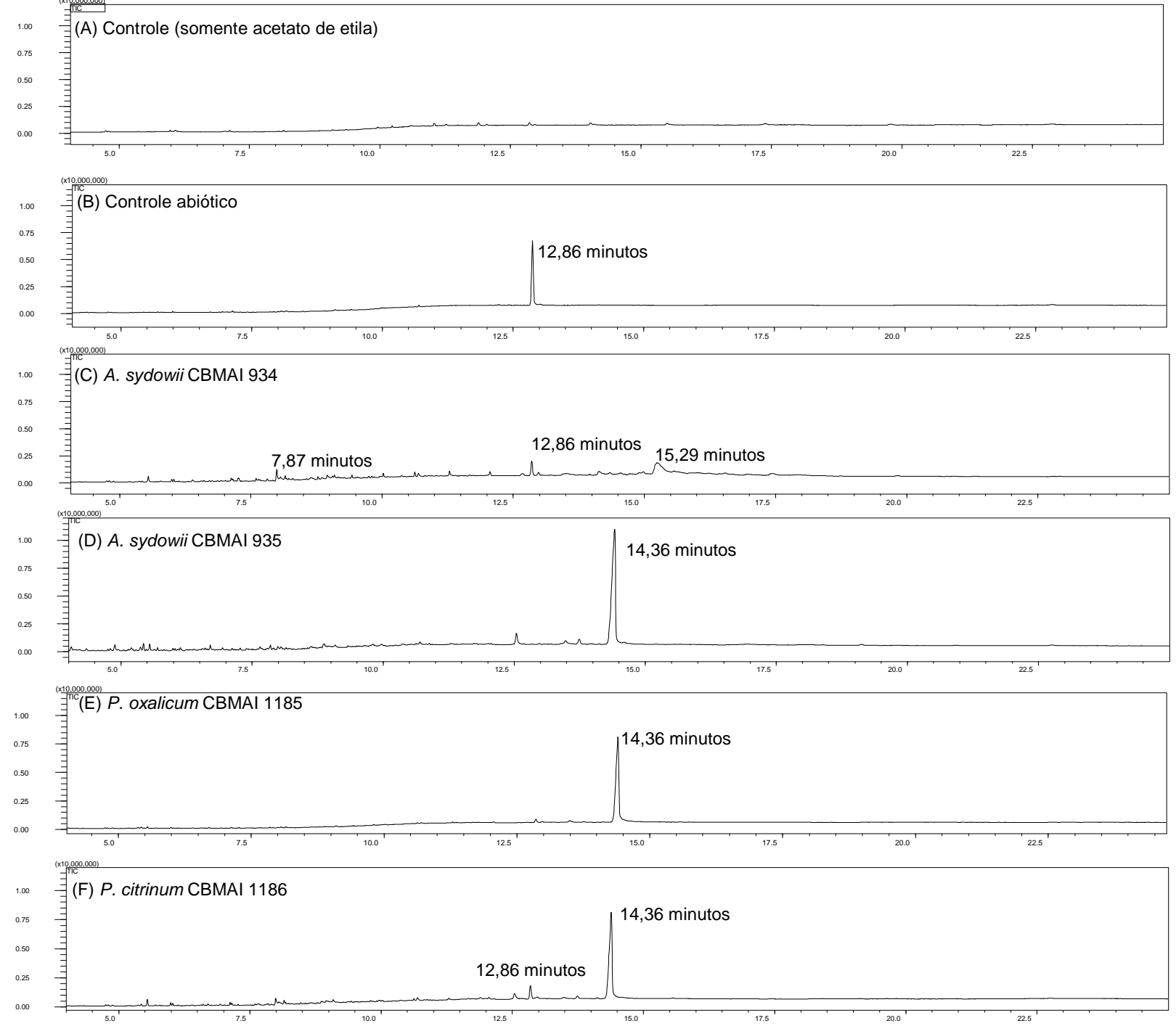

Como pode ser observado nos cromatogramas, após 7 dias de reação, todos os micélios, exceto o do fungo A. sydowii CBMAI 934 converteram praticamente toda a progesterona em 
um produto com $t_{R}=14,46$ minutos o qual pode ter sido a testololactona, conforme já abordado nas discussões referente à triagem das reações com o caldo enzimático. Foi observado que o cromatograma da Figura 41D apresentou este pico com maior intensidade, o que sugeriu que o fungo A. sydowii CBMAI 935 promoveu a formação deste produto com maior rendimento.

O cromatograma da Figura 41C obtido com o fungo A. sydowii CBMAI 934 não apresentou o produto com $t_{R}=14,36$ minutos como observado pelos demais. Foram observados dois picos: um de $t_{R}=7,87$ minutos que forneceu um espectro de massas de $91 \%$ de similaridade ao espectro de massas do ácido 1-pentadecanoico, segundo a biblioteca WILEY 8 e outro de $t_{R}=15,29$ minutos que forneceu um espectro de massas de $66 \%$ de similaridade ao espectro de massas do 6 $\beta$-hidroximetanodienona, segundo a biblioteca NIST05 (Figura 42).

Figura 42. Espectros de massas $(70 \mathrm{eV})$ : (A) experimental para composto $\mathrm{t}_{\mathrm{R}}=15,29$ minutos (fungo $A$. sydowii CBMAI 934), (B) 63-hidroximetanodienona (similaridade 66\% biblioteca NIST05).
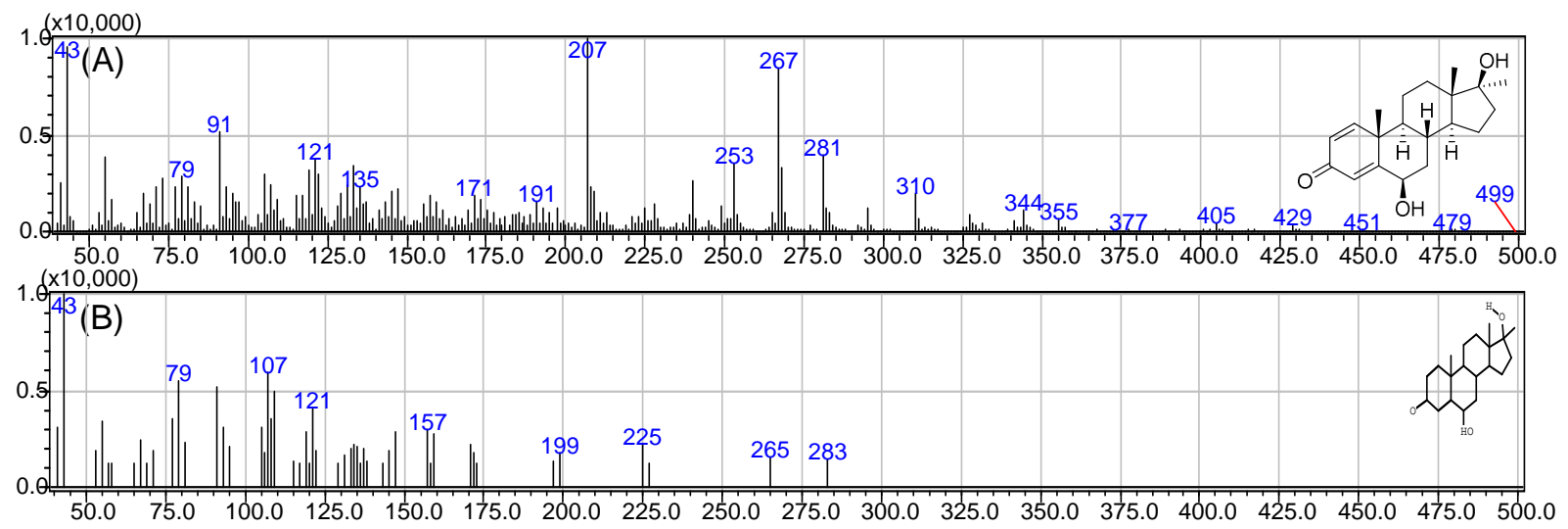

$\mathrm{O}$ pico com $t_{\mathrm{R}}=15,29$ minutos forneceu o espectro de massas semelhante a $6 \beta$ Hidroximetanodienona. Como este composto é um esteroide que não apareceu na análise cromatográfica do meio reacional deste fungo na ausência do substrato, pode-se sugerir que esta substância é um produto de biotransformação da progesterona efetuada pelo fungo $A$. sydowii CBMAI 934.

As reações de triagem com os micélios também foram realizadas por mais 7 dias totalizando 14 dias de reação. Após este período as reações foram finalizadas e realizadas as análises cromatográficas dos extratos dos meios reacionais (Figura 43). 
Figura 43. Cromatogramas obtidos das análises dos extratos em acetato de etila provenientes das triagens das reações de biotransformação da progesterona com os micélios dos fungos empregados neste trabalho após 14 dias de reação.
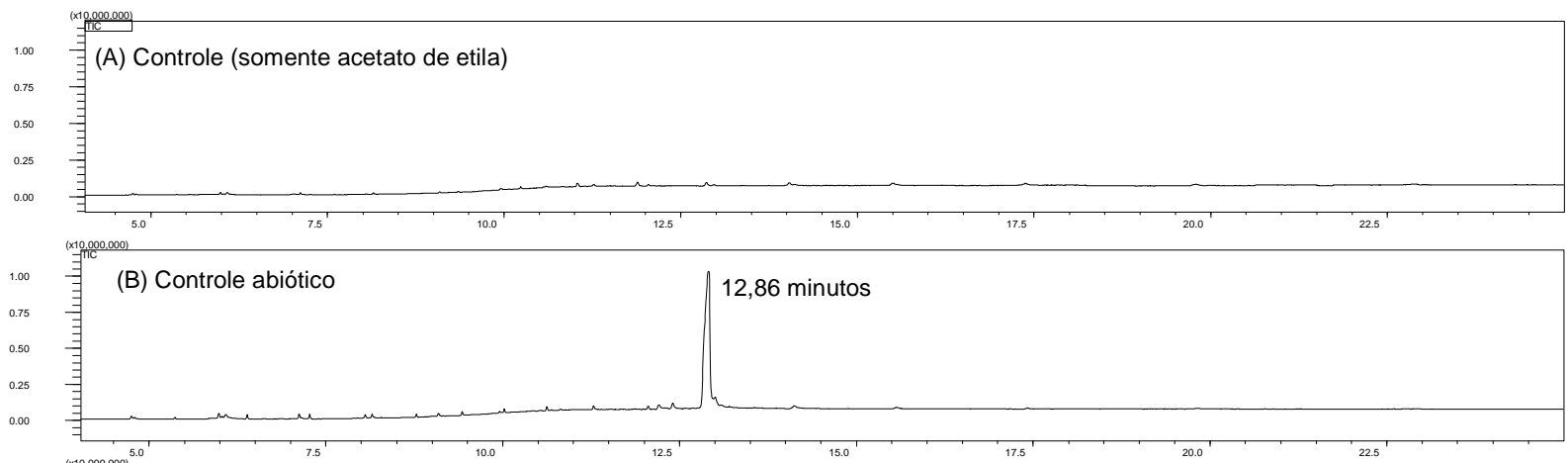

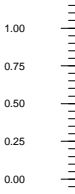

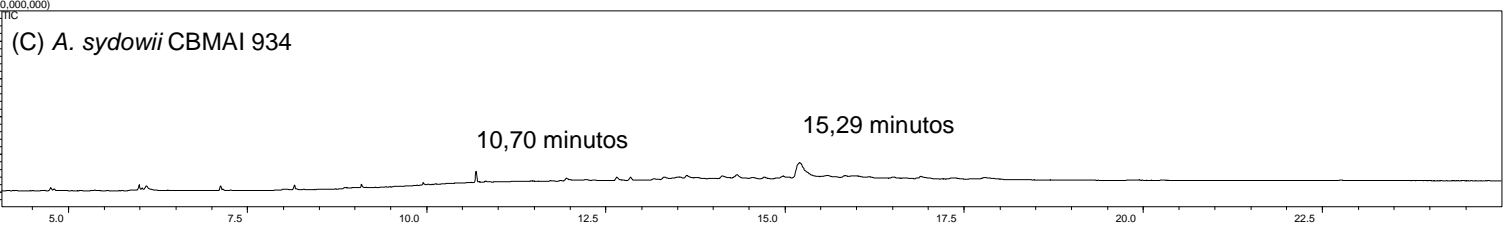

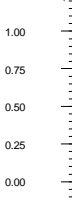
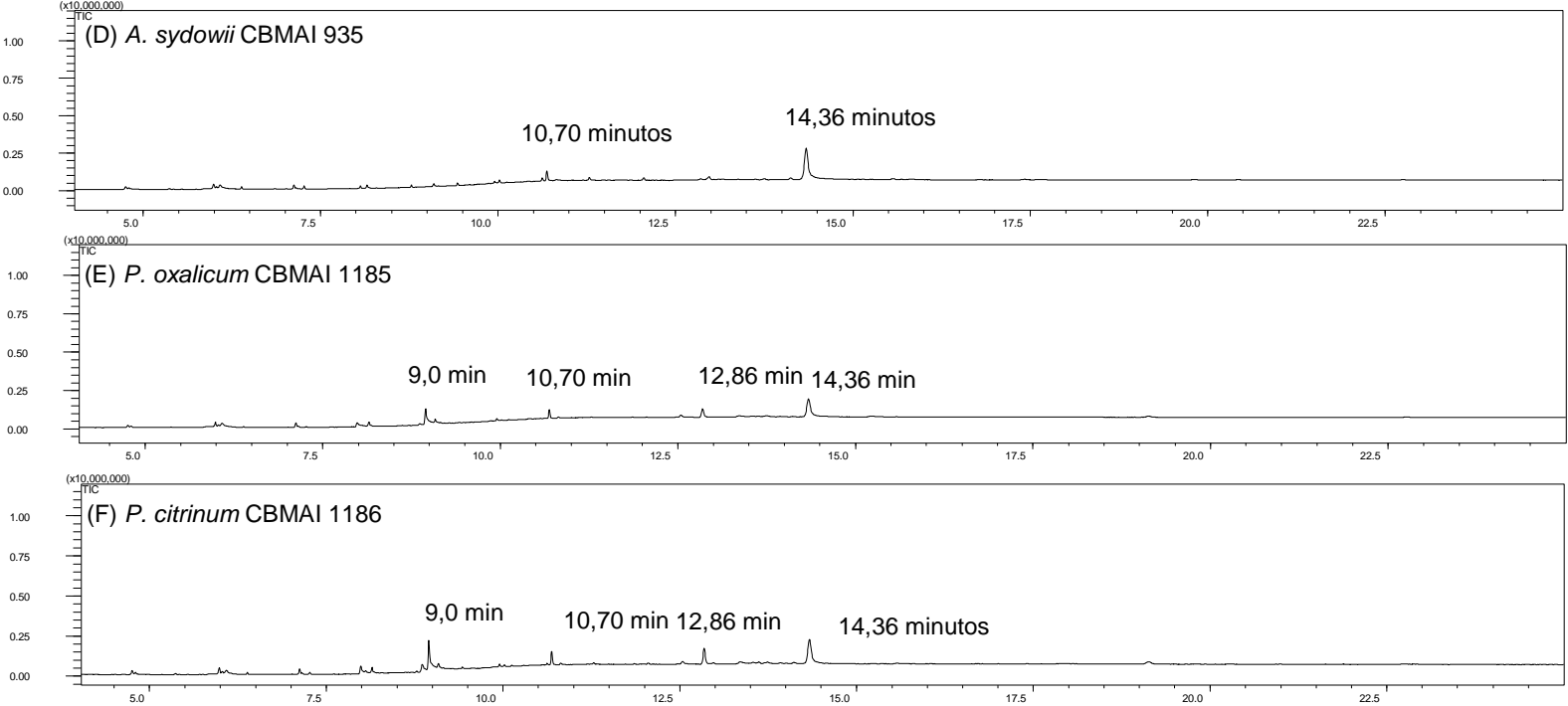

Em todos os cromatogramas da Figura 43 o o sinal com $t_{R}=14,36$ minutos foi observado com uma menor intensidade em relação aos sinais deste mesmo tempo de retenção nas reações de triagem com o caldo enzimático e com o micélio após 7 dias de reação. Pôde-se inferir que possivelmente o composto relativo a este sinal estaria sendo biotransformado em outros produtos. Em todas as reações foi observado um sinal com $t_{R}=10,70$ minutos Os espectros de massas fornecidos para este sinal sugeriram que este composto seria o bis(2-etilhexil)ftalato, um possível contaminante. Nas reações com os fungos $P$. oxalicum CBMAI 1185 e $P$. citrinum CBMAI 1186 foi observado um sinal com $t_{R}=9,00$ minutos que forneceu um espectro de massas com $91 \%$ de similaridade ao espectro de massas do ácido 1-octadecanoico, segundo a biblioteca NIST05 (Figura 44). 
Figura 44. Espectros de massas $(70 \mathrm{eV})$ : (A) experimental para composto $t_{R}=9,0$ minutos (fungo P.citrinum CBMAI 1186), (B) ácido 1-octadecanoico (similaridade 91\% biblioteca NIST05).

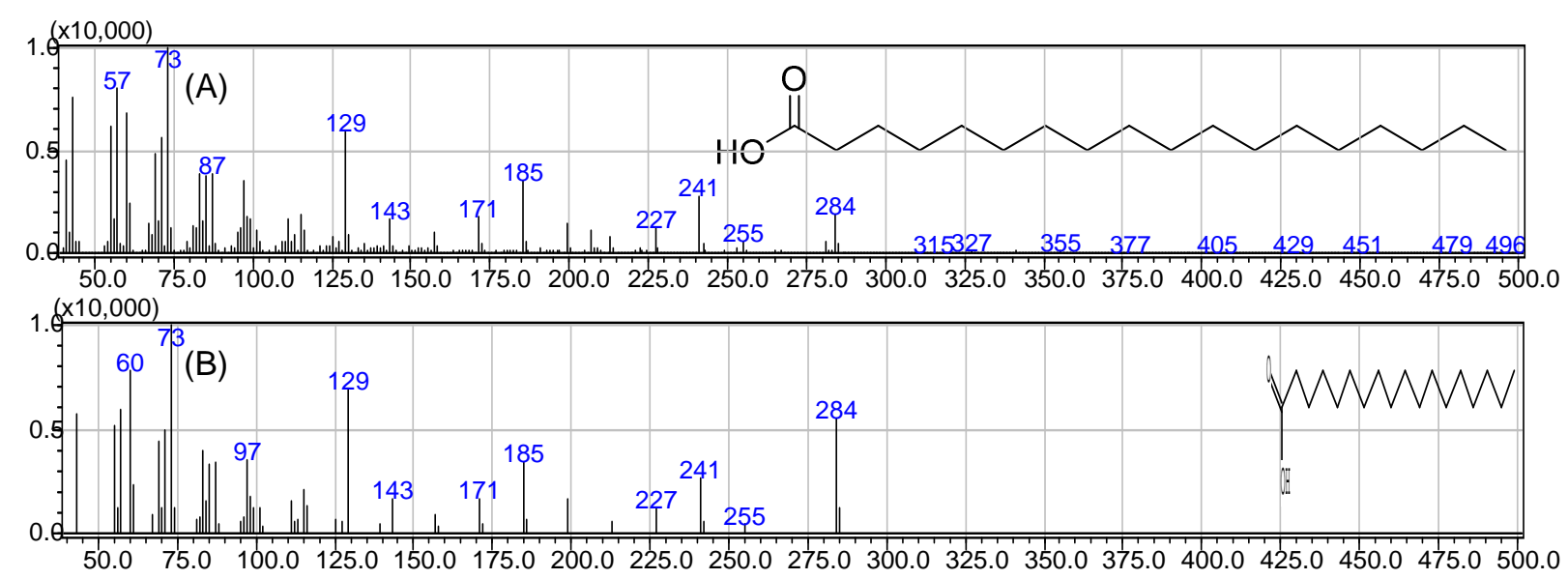

O ácido 1-octadecanoico assim como o ácido 1-pentadecanoico é um ácido graxo. Possivelmente esteja presente na parede celular dos fungos $P$. oxalicum CBMAI 1185 e $P$. citrinum CBMAI 1186, embora este composto não foi detectado no monitoramento do meio reacional destes fungos na ausência da progesterona. Os estroides cortisol (Figura 45) e testosterona estão envolvidos na hidrólise de lipídeos ${ }^{67}$, tendo como produtos álcoois de cadeia longa e ácidos graxos. Não são encontradas referências relativas à biossíntese de ácidos graxos ou ao metabolismo de lipídeos através da progesterona. Porém na literatura é descrito que a testosterona é um intermediário da biotransformação da progesterona, produzindo testololactona ${ }^{68}$. Apesar de nos cromatogramas das Figuras 43C-43F não foram observados sinais relativos à testosterona, mais adiante será discutido com maiores detalhes sobre esta biotransformação.

Figura 45. Estrutura molecular do cortisol.

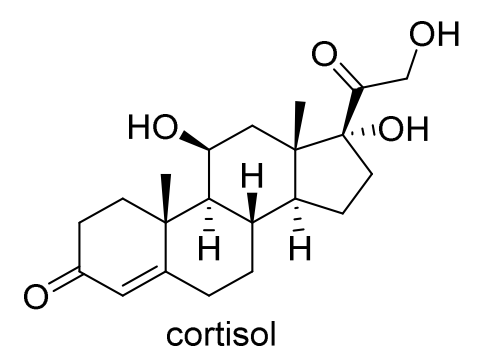

No cromatograma da Figura 44C foi observado o sinal $t_{R}=15,29$ minutos que pode ser a $6 \beta$-hidroximetanodieona. Este esteroide foi observado também na triagem com este fungo após 7 dias de reação. 
Após as triagens realizadas tanto com os caldos enzimáticos quanto com os micélios, comparando os sinais que foram obtidos nas reações, bem como as intensidades, decidiu-se fazer quintuplicatas das reações com o objetivo de obter os metabólitos em quantidades suficientes para isolá-los e caracterizá-los por técnicas espectroscópicas (Tabela 7).

Tabela 7. Meios reacionais selecionados utilizando caldos enzimáticos e micélios provenientes de fungos de ambiente marinho dos gêneros Aspergillus e Penicilium para isolamento e caracterização dos produtos de biotransformação da progesterona.

\begin{tabular}{|c|c|c|c|}
\hline Fungo & Meio reacional & $\begin{array}{c}\text { Tempo de } \\
\text { reação (dias) }\end{array}$ & Objetivo \\
\hline A. sydowii CBMAI 934 & Caldo Enzimático & 14 & $\begin{array}{c}\text { Obtenção dos compostos } 6 \beta \text { - } \\
\text { hidroxiprogesterona }\left(t_{R}=12,74 \text { minutos }\right) \mathrm{e} \\
\left.11 \alpha \text {-hidroxiprogesterona } t_{R}=13,44 \text { minutos }\right)\end{array}$ \\
\hline A. sydowii CBMAI 934 & Micélio & 14 & $\begin{array}{c}\text { Obtenção do composto } 6 \beta \text { - } \\
\text { hidroximetanodienona }\left(t_{R}=15,29 \text { minutos }\right)\end{array}$ \\
\hline A. sydowii CBMAI 935 & Caldo Enzimático & 7 & $\begin{array}{l}\text { Obtenção do composto } \\
\text { testosterona }\left(t_{R}=11,50 \text { minutos }\right)\end{array}$ \\
\hline A. sydowii CBMAI 935 & Micélio & 7 & $\begin{array}{l}\text { Obtenção do composto } \\
\text { testololactona }\left(t_{R}=14,36 \text { minutos }\right)\end{array}$ \\
\hline
\end{tabular}

Mediante às escolhas feitas a partir das triagens pôde ser observado que as linhagens dos fungos do gênero Aspergillus utilizados neste ensaio apresentaram um melhor perfil de biotransformação em relação aos fungos do gênero Penicilium. Foi observado também que a linhagem do fungo A. sydowii CBMAI 934 promoveu principalmente reações de hidroxilação da progesterona e produziu uma variedade maior de metabólitos, enquanto que a linhagem do fungo A. sydowii CBMAI 935, assim como as linhagens do gênero Penicilium que promoveram uma modificação de grupo funcional. Ou seja, o grupo acetila ligada ao carbono C-17 do anel $\mathrm{D}$ do núcleo esteroidal da progesterona foi substituída por uma hidroxila, formando a testosterona. E além disso, esse grupo acetila desapareceu da estrutura da progesterona e o anel D do seu núcleo esteroidal passou de 5 a 6 membros, se transformando em um anel de lactônico, formando a testololactona. Sobre os mecanismos envolvidos na biotransformação da progesterona, os produtos e intermediários, será discutido com maiores detalhes mais adiante. 


\section{D.5.3 BIOTRANSFORMAÇÕES EM QUINTUPLICATAS}

Com o objetivo de isolar os produtos de biotransformação da progesterona as reações foram realizadas em quintuplicatas para a obtenção de maior quantidade de metabólitos.

\section{D.5.3.1 Reação de biotransformação da progesterona com o caldo enzimático do fungo $A$. sydowii CBMAI 934}

Após 14 dias foi finalizada a reação de biotransformação da progesterona pelo caldo enzimático do fungo A. sydowii CBMAI 934. Foi obtida uma massa de extrato seco de $357 \mathrm{mg}$ que foi dissolvido em acetato de etila. Desta solução foi tomada uma alíquota de $0,3 \mathrm{~mL}$, diluída 5 vezes e então feita uma análise por CG-EM com o intuito de verificar quais metabólitos foram produzidos na reação (Figura 46).

Figura 46. Cromatograma obtido por CG-EM do extrato em acetato de etila obtido da biotransformação da progesterona pelo caldo enzimático proveniente do fungo A. sydowii CBMAI 934.

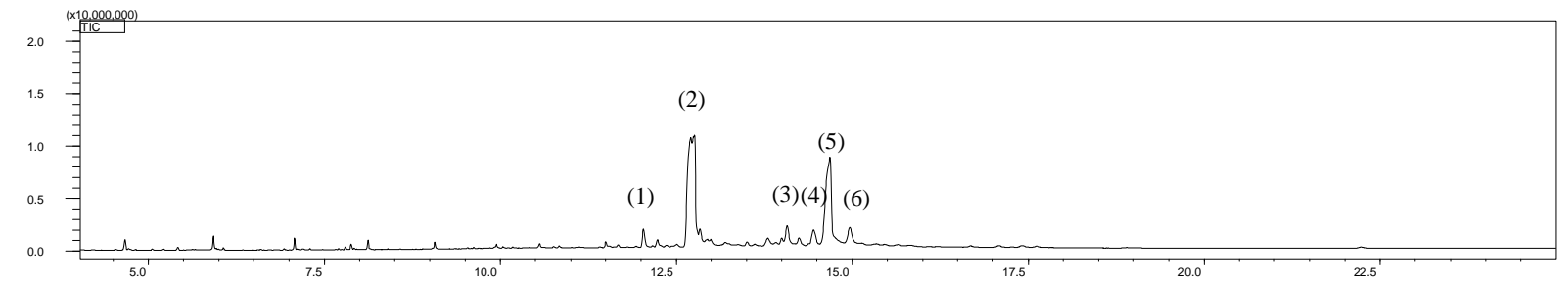

De acordo com a Figura 46 foram observados alguns sinais no cromatograma. Dentre estes sinais, foram observados possíveis metabólitos de biotransformação da progesterona, que estão destacados na Tabela 8. 
Tabela 8. Possíveis produtos de biotransformação da progesterona após reações em quintuplicatas com o caldo enzimático proveninente do fungo A. sydowii CBMAI 934.

\begin{tabular}{|c|c|c|c|c|}
\hline Sinal & $\mathrm{t}_{\mathrm{R}}($ minutos $)$ & Possível composto & Similaridade $(\%)$ & Biblioteca de dados \\
\hline (1) & 12,04 & & 72 & NIST21 \\
\hline (2) & 12,86 & & 91 & NIST21 \\
\hline (3) & 14,09 & & 77 & NIST107 \\
\hline (4) & 14,45 & & 74 & NIST05 \\
\hline (5) & 14,68 & & 81 & NIST107 \\
\hline (6) & 14,97 & $\mathrm{H}$ & 70 & NIST05 \\
\hline
\end{tabular}

A Tabela 8 apresentou mais de um sinal no cromatograma para um mesmo composto (no caso a progesterona) e um tempo de retenção diferente do observado na triagem para outro composto (no caso a testololactona). Além disso, o sinal de número 5 ( $\mathrm{t}_{\mathrm{R}}=14,68$ minutos Figura 46), apresentou um composto que não foi observado na triagem do caldo enzimático deste fungo na reação com a progesterona que foi a 15 $\beta$-hidroxiprogesterona (Figuras 47A e 47B). Conforme a Tabela 8, a similaridade entre os espectros de massas experimental e fornecido pela biblioteca não foi muito alta. O Espectrômetro de Massas acoplado à técnica de Cromatografia a gás utilizada é um equipamento de baixa resolução. Sendo assim, uma certeza 
maior da confirmação da obtenção da ocorrência do composto se dá quando a similaridade entre o espectro de massas experimental e o fornecido pela biblioteca de dados for superior a $90 \%$.

Figura 47. Espectros de massas $(70 \mathrm{eV})$ : (A) experimental para composto $t_{R}=14,68$ minutos (B) $15 \beta$ hidroxiprogesterona (similaridade $81 \%$ biblioteca NIST05).
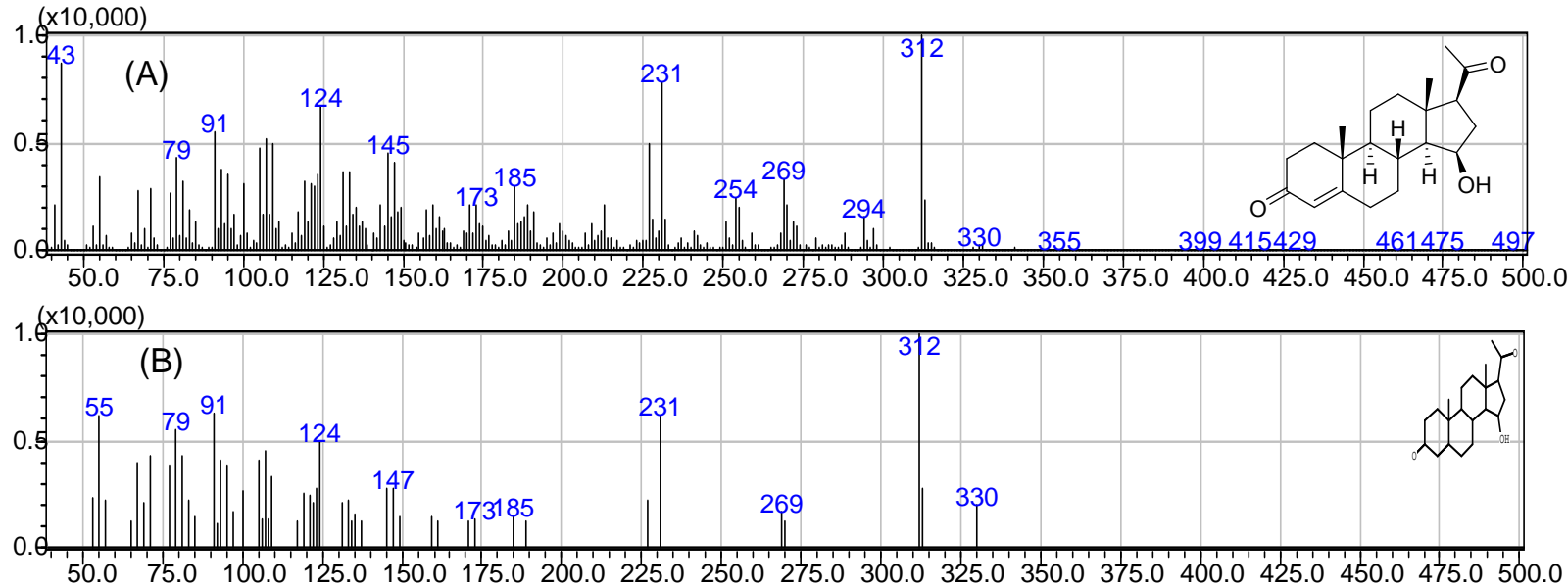

\section{D.5.3.2 Purificação e isolamento dos produtos de biotransformação da progesterona com o caldo enzimático do fungo $A$. sydowii CBMAI 934}

Foi feito inicialmente um estudo do gradiente de eluição por CCD para determinação das proporções de n-hexano e acetato de etila a serem utilizadas como fase móvel na cromatografia em coluna para a separação dos compostos obtidos frente a biotransformação com caldo enzimático do fungo A. sydowii CBMAI 934 no extrato obtido pela análise cromatográfica. Foi observado que a separação dos compostos foi mais adequada na proporção 3:7 de acetato de etila e n-hexano. A separação cromatográfica iniciou com essa proporção e finalizou com eluição com acetato de etila puro, sendo obtido um total de 100 frações (Tabela 9).

Tabela 9. Frações obtidas na separação cromatográfica do extrato obtido após a biotransformação da Progesterona pelo caldo enzimático do fungo A. sydowii CBMAI 935 após 14 dias de reação.

\begin{tabular}{cc}
\hline Grupos de frações & Gradiente (acetato de etila:n-hexano) \\
\hline $1-20$ & $3: 7$ \\
$21-30$ & $4: 6$ \\
$31-40$ & $5: 5$ \\
$41-50$ & $6: 4$ \\
$51-70$ & $7: 3$ \\
$71-78$ & $8: 2$ \\
$79-89$ & $9: 1$ \\
$90-100$ & acetato de etila $(100 \%)$ \\
\hline
\end{tabular}


O processo de purificação foi monitorado por CCD a fim de determinar os grupos de substâncias semelhantes presentes nas frações. Uma vez determinados esses grupos foram tomadas alíquotas de cada fração do mesmo grupo e reunidas essas alíquotas em um único frasco, diluídas e por fim analisadas por CG-EM a fim de se verificar se o grupo de frações determinado apresentava, um único produto, confirmando assim o isolamento do metabólito. As frações em que foram possíveis obter produtos majoritários isolados foram: 37-44, 67-68 e 69-73 (Figura 48).

Figura 48. Análise das frações obtidas por CG-EM após separação por cromatografia em coluna dos metabólitos majoritários presentes no extrato da biotransformação da progesterona com caldo enzimático do fungo A sydowii CBMAI 934.
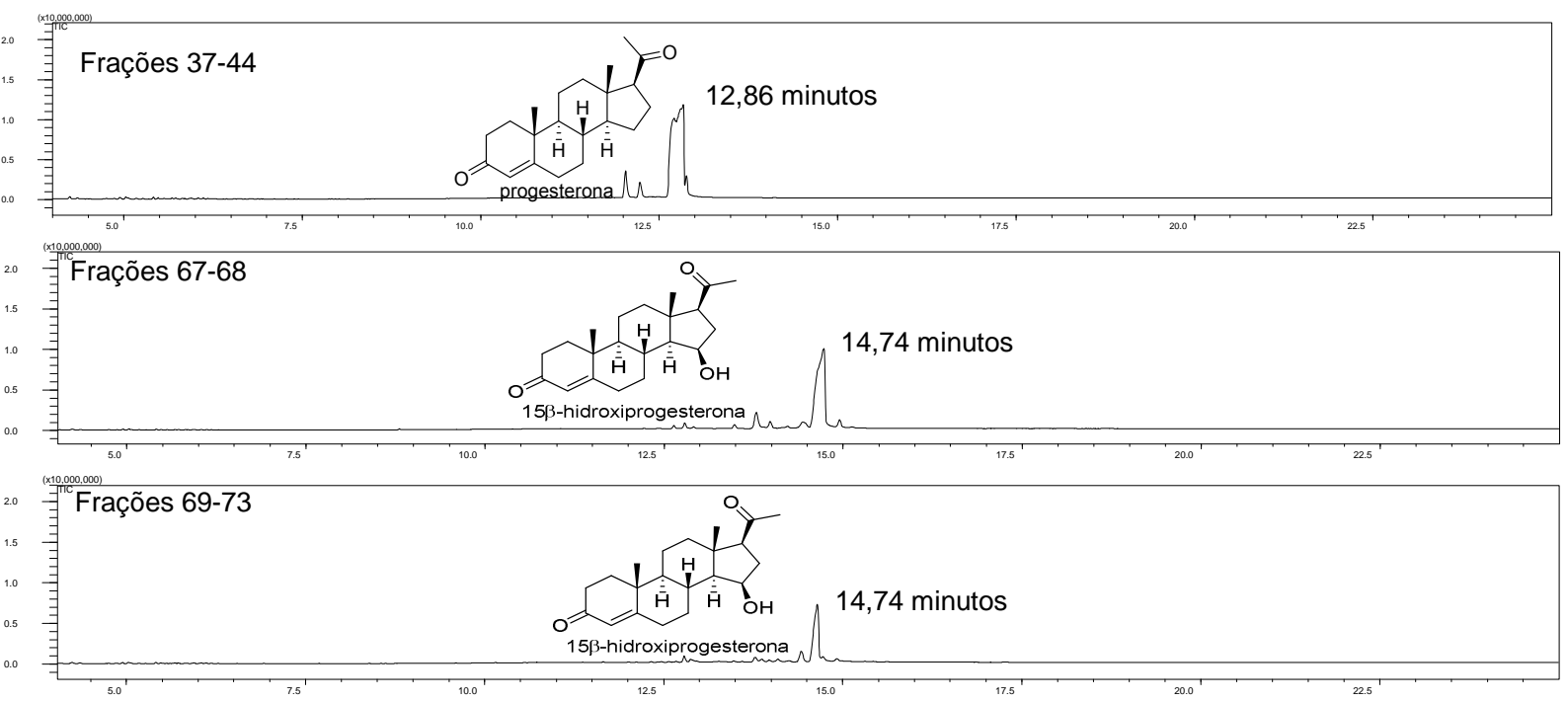

Por comparação com o padrão, as frações 37-44 corresponderam à progesterona remanescente da reação. Pelas análises dos cromatogramas das frações 67-68 e 69-73 apresentaram um sinal com $t_{R}=14,74$ minutos. Em ambos os cromatogramas, este sinal forneceu um espectro de massas com $82 \%$ de similaridade para a $15 \beta$-hidroxiprogesterona segundo a biblioteca NIST05 (Figura 49). Notou-se que em ambos os espectros experimentais foi praticamente desprezível a intensidade do sinal de $\mathrm{m} / \mathrm{z} 330$ (Figuras 50A e 50B) que corresponderia a massa molar da $15 \beta$-hidroxiprogesterona $(330,47 \mathrm{~g} / \mathrm{mol})$. Além disso, devido a similaridade entre o espectro de massas fornecido pela biblioteca e o obtido experimentalmente não foi possível concluir no momento que de fato este foi o composto isolado através do processo cromatográfico. 
Figura 49. Espectros de massas $(70 \mathrm{eV})$ : $(\mathrm{A})$ experimental para composto $t_{\mathrm{R}}=14,74$ minutos (frações 67 68), (B) experimental para composto $t_{R}=14,74$ minutos (frações 69-73), (C) 15 $\beta$-hidroxiprogesterona (similaridade $82 \%$ biblioteca NIST05).
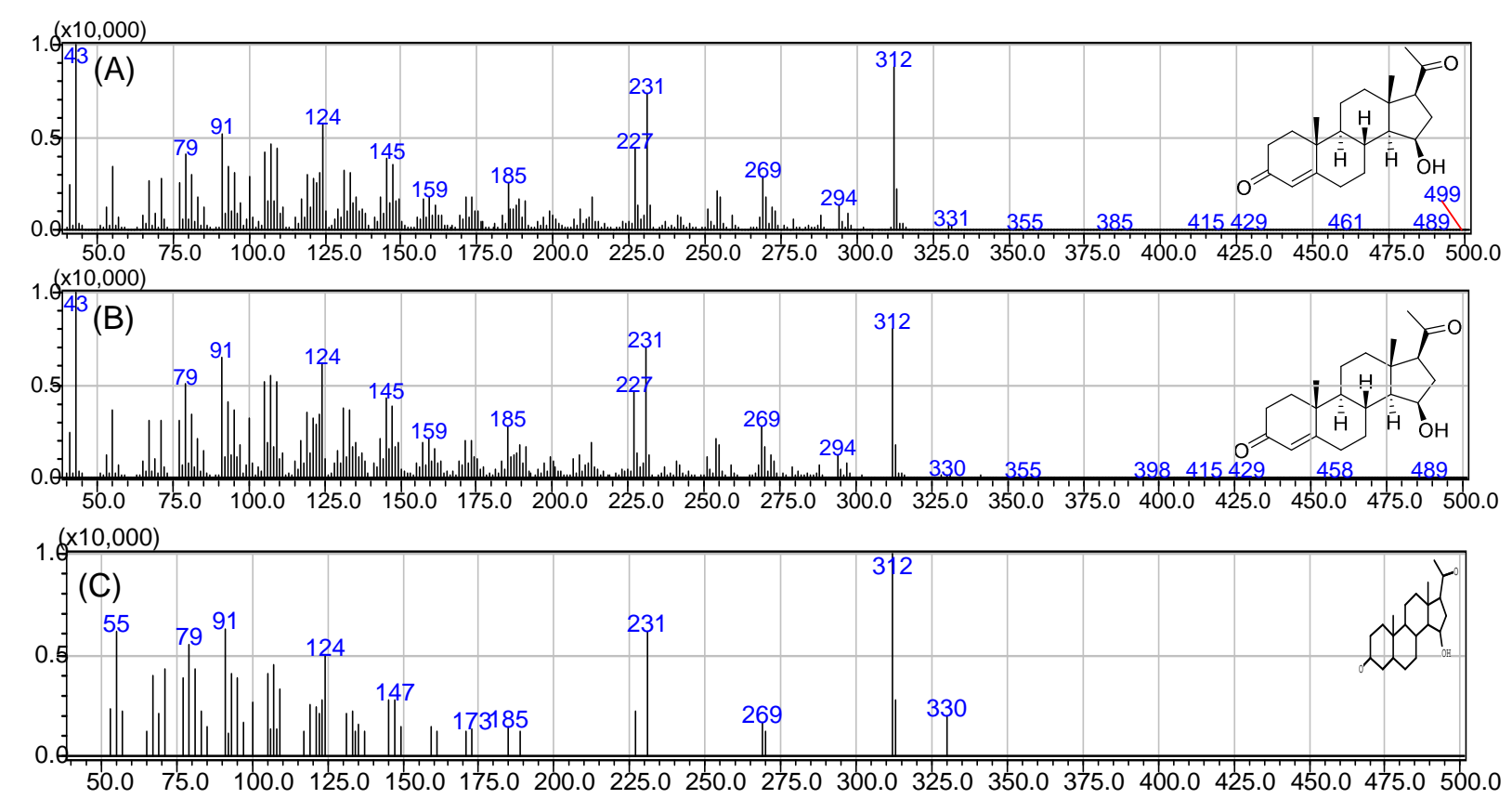

Como pôde ser observado, o processo cromatográfico permitiu a separação dos dois compostos majoritários do extrato: a progestesterona (substrato) e o produto, mesmo com impurezas em quantidades reduzidas. As frações 67-73 foram reunidas, o solvente foi evaporado em rotaevaporador e obtida uma massa de $37 \mathrm{mg}$ de composto. A princípio, o composto majoritário poderia ser a $15 \beta$-hidroxiprogesterona e considerando que a cada frasco das quintuplicatas foi adicionado $50 \mathrm{mg}$ de progesterona, o rendimento em massa obtido foi de 14,0\%. Vale considerar que durante a extração e purificação ocorrem perdas de material. O composto obtido foi caracterizado pelas técnicas espectroscópicas cuja discussão será feita mais adiante. 


\section{D.5.3.3 Reação de biotransformação da progesterona com a massa micelial do fungo $A$. sydowii CBMAI 934}

Após 14 dias foi finalizada a reação de biotransformação da progesterona pela massa micelial do fungo A. sydowii CBMAI 934. Após a extração dos compostos foram medidas a massa micelial úmida e a masssa micelial seca após secagem da massa micelial úmida em estufa por 48 horas a $32^{\circ} \mathrm{C}$. Os valores obtidos estão apresentados na Tabela 10.

Tabela 10. Valores de massa micelial úmida e seca do fungo A. sydowii CBMAI 934 após 14 dias da reação de biotransformação da progesterona.

\begin{tabular}{cccc}
\hline Massa úmida inicial $(\mathrm{g})$ & Massa úmida final $(\mathrm{g})$ & Massa seca $(\mathrm{g})$ & Perda de umidade $(\%)$ \\
\hline 15 & 14 & 4 & 71 \\
\hline
\end{tabular}

Como a Tabela 10 apresentou ao final do processo houve uma perda de massa micelial de 1,0 g. Essa perda foi em função dos processos de extração e filtração, bem como parte ter sido transferida para o extrato. Também, observou-se que $71 \%$ da umidade da massa micelial úmida foi perdida após secagem em estufa. A quantidade de umidade fornece ideia da capacidade catalítica do sistema enzimático do fungo uma vez que muitas das enzimas envolvidas são intracelulares e uma célula eucariótica é majoriamente constituída de água.

Foi obtida uma massa de extrato seco de $595 \mathrm{mg}$. O extrato seco da reação foi dissolvido em acetato de etila. Desta solução foi tomada uma alíquota de $0,3 \mathrm{~mL}$, diluída 5 vezes e então feita uma análise por CG-EM com o intuito de verificar quais metabólitos foram produzidos na reação (Figura 50).

Figura 50. Cromatograma obtido por CG-EM do extrato em acetato de etila obtido da biotransformação da progesterona pela massa micelial do fungo A. sydowii CBMAI 934.

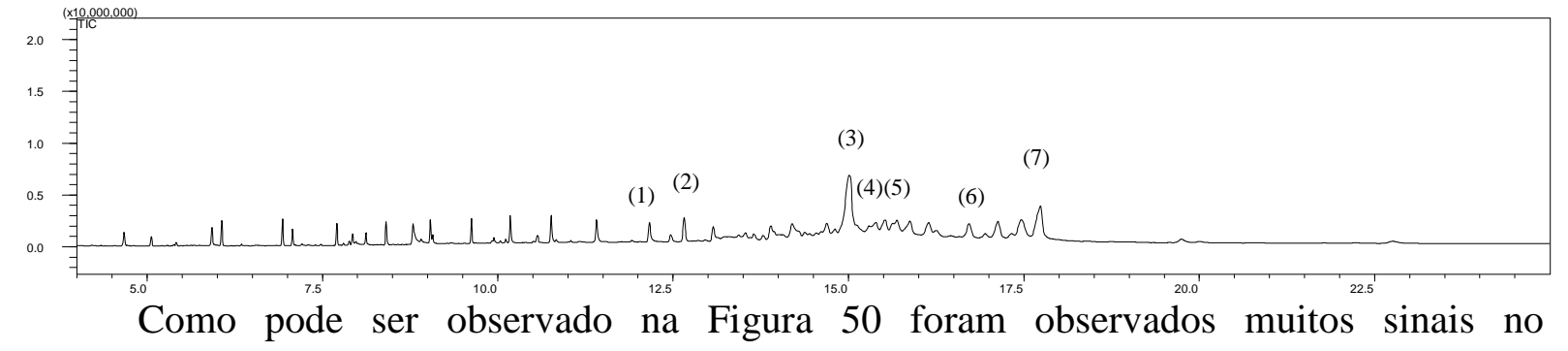

cromatograma. Alguns podem ser contaminantes do solvente ou metabólitos do próprio fungo. Outros foram relacionados aos esteroides: tanto o substrato, quanto possíveis produtos e estes picos foram considerados e destacados na análise do cromatograma, como pode ser verificado na Tabela 11. 
Tabela 11. Possíveis produtos de biotransformação da progesterona após reações em quintuplicatas com a massa micelial proveninente do fungo A. sydowii CBMAI 934.

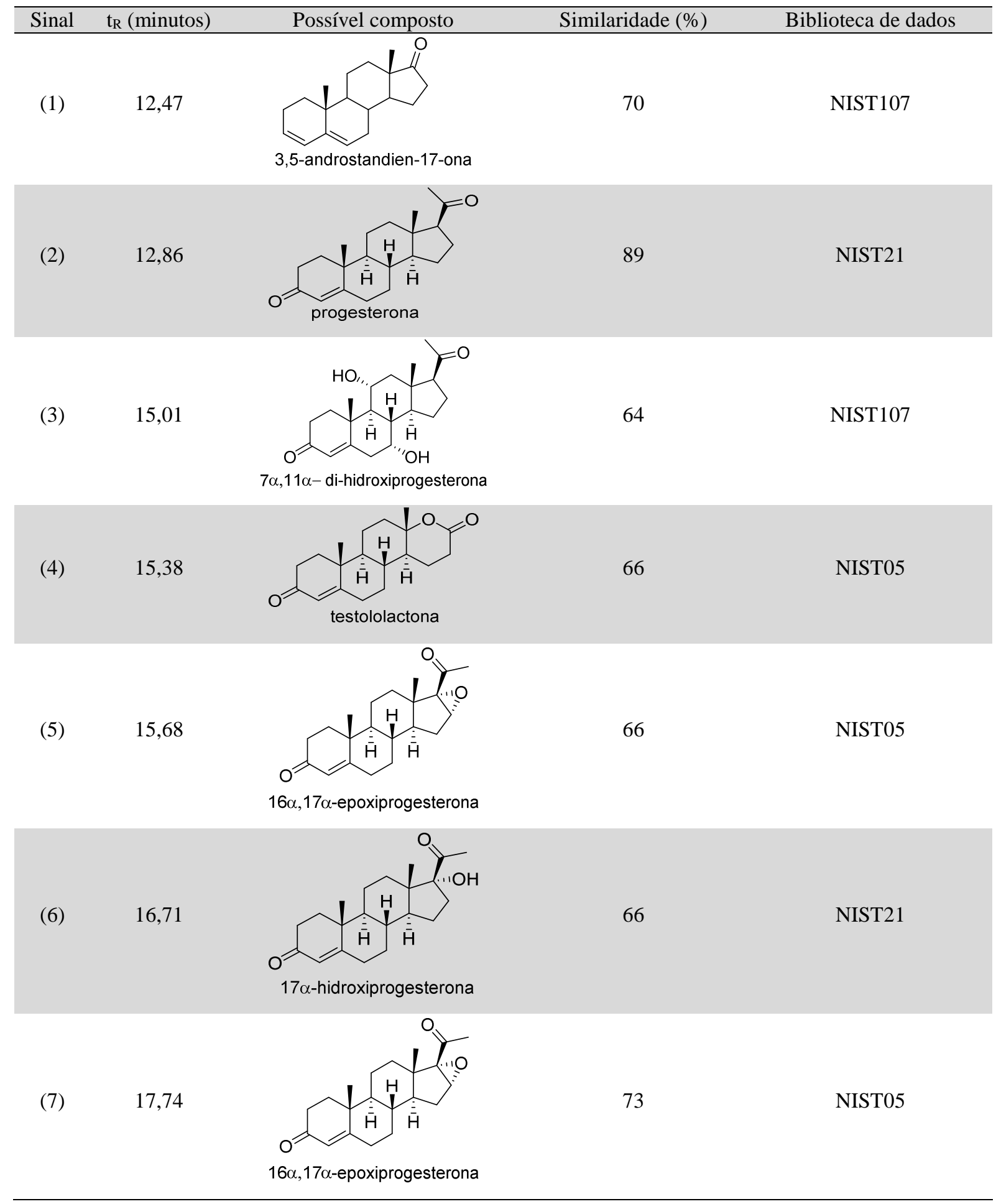

Muitos produtos de biotransformação utilizando a massa micelial do fungo A. sydowii CBMAI 934 foram observados, o que indicou a alta versatilidade e baixa especificidade deste fungo em promover a biotransformação da progesterona. Sendo assim, buscou-se como objetivo principal na etapa posterior, isolar os produtos majoritários referentes aos sinais de 
número $3\left(\mathrm{t}_{\mathrm{R}}=15,01\right.$ minutos) que forneceu um espectro de massas com $66 \%$ de similaridade com o espectro da 7 $\alpha, 11 \alpha$-di-hidroxiprogesterona segundo a biblioteca NIST07 (Figuras 51A e 51B) e o de número $7\left(\mathrm{t}_{\mathrm{R}}=17,74\right.$ minutos) que forneceu um espectro de massas com $73 \%$ de similaridade com o espectro da $16 \alpha, 17 \alpha$-epoxiprogesterona segundo a biblioteca NIST05 (Figuras 51C e 51D).

Figura 51. Espectros de massas (70 eV): (A) experimental para composto $t_{R}=14,68$ minutos, (B) $7 \alpha, 11 \alpha$ di-hidroxiprogesterona (similaridade: $64 \%$, biblioteca NIST07). (C) experimental para o composto com $\mathrm{t}_{\mathrm{R}}=17,74$ minutos (fração 69-73), (D) 16 $\alpha, 17 \alpha$-epoxiprogesterona (similaridade 73\% biblioteca NIST07).
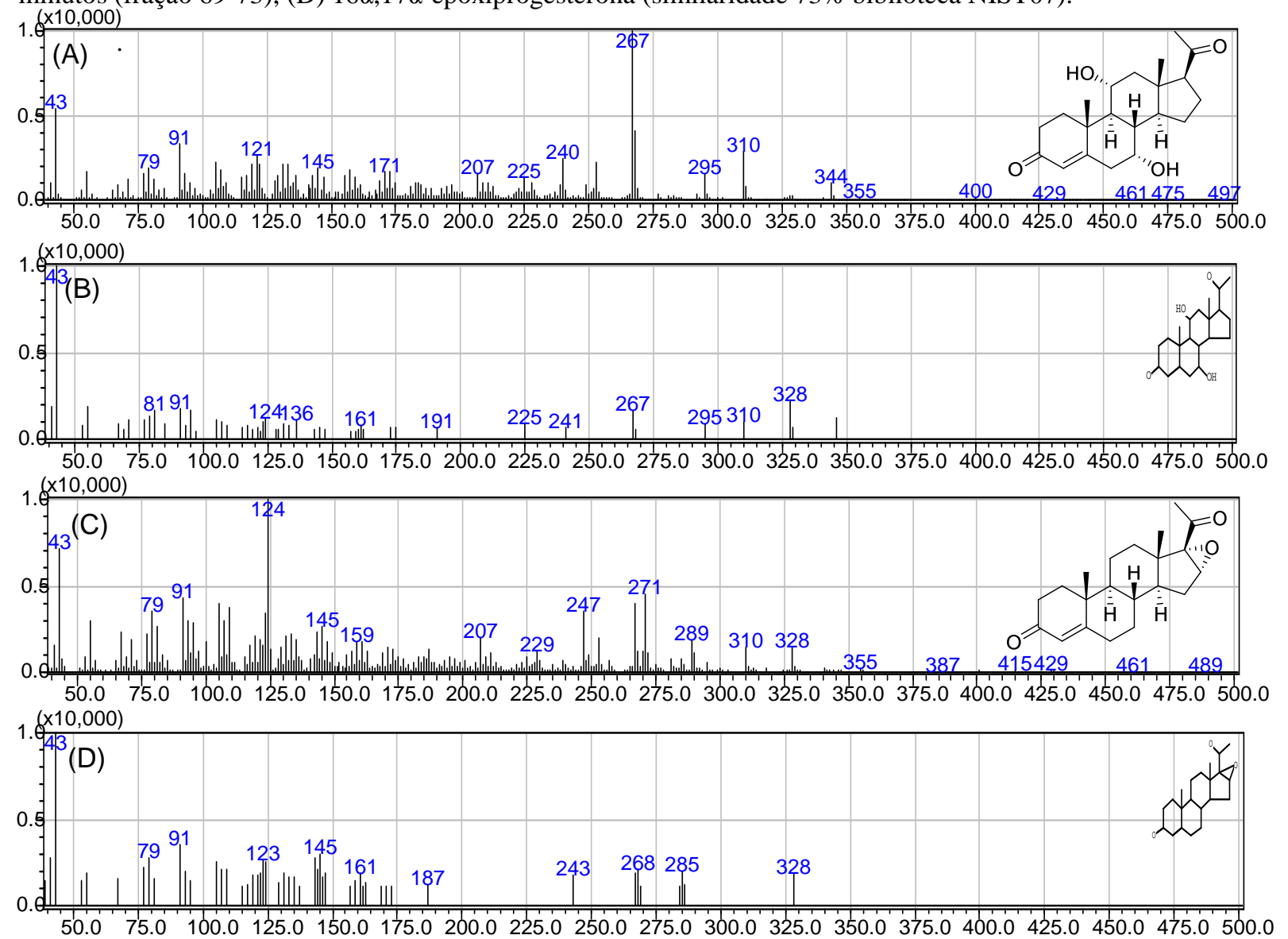

\section{D.5.3.4 Purificação e isolamento dos produtos da biotransformação da progesterona com a massa micelial do fungo $A$. sydowii CBMAI 934}

Foi feito inicialmente um estudo do gradiente de eluição por CCD para determinação das proporções de n-hexano e acetato de etila a serem utilizadas como fase móvel na cromatografia em coluna para a separação dos compostos obtidos frente a biotransformação com a massa micelial do fungo A. sydowii CBMAI 934. Foi observado que a separação dos compostos foi mais adequada na proporção 1:9 de acetato de etila e n-hexano. A separação 
cromatográfica iniciou-se com essa proporção e finalizou com eluição com metanol, uma vez que no cromatograma do extrato foi observado um pico com $t_{R}=17,74$ minutos, sugerindo ser um composto de alta polaridade. Do processo cromatográfico foram obtidas 183 frações (Tabela 12).

Tabela 12. Frações obtidas na separação cromatográfica do extrato obtido da progesterona frente a biotransformação com a massa micelial do fungo A. sydowii CBMAI 935.

\begin{tabular}{cc}
\hline Grupos de frações & Gradiente (acetato de etila:n-hexano) \\
\hline $1-14$ & $1: 9$ \\
$15-21$ & $2: 8$ \\
$22-28$ & $3: 7$ \\
$29-49$ & $4: 6$ \\
$50-58$ & $5: 5$ \\
$59-78$ & $6: 4$ \\
$79-96$ & $7: 3$ \\
$97-105$ & $8: 2$ \\
$106-115$ & $9: 1$ \\
$116-158$ & acetato de etila (100\%) \\
$159-183$ & metanol (100\%) \\
\hline
\end{tabular}

O processo de purificação foi monitorado por CCD com o intuito de determinar os grupos de substâncias semelhantes presentes nas frações. Uma vez determinados esses grupos foram tomadas alíquotas de cada fração do mesmo grupo e reunidas em um único frasco, diluídas e analisadas por CG-EM com o objetivo de se verificar se o grupo de frações determinado apresentava, um único produto, confirmando assim o isolamento do metabólito. As frações em que foram possíveis obter produtos majoritários foram: 33-34 e 86-121 (Figura 52). 
Figura 52. Análise das frações obtidas por CG-EM após separação por cromatografia em coluna dos metabólitos majoritários presentes no extrato obtido da biotransformação da progesterona com a massa micelial do fungo A.sydowii CBMAI 934.

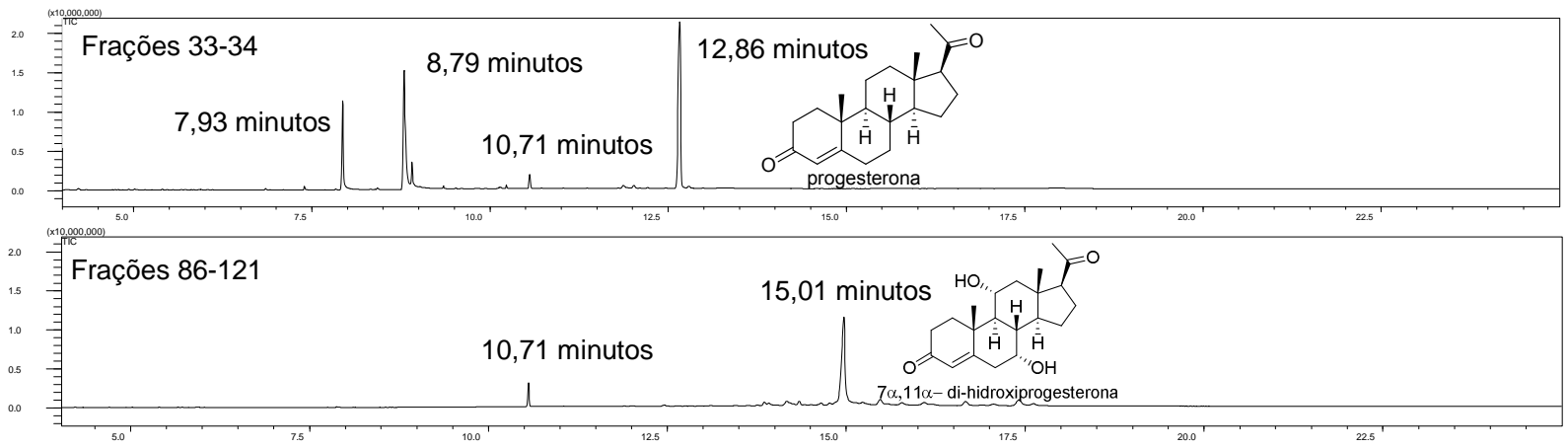

Por comparação com o padrão, no cromatograma das frações 33-34 o sinal de maior intensidade com $t_{R}=12,86$ minutos correspondeu à progesterona remanescente da reação. Nesta fração outros três sinais foram observados: $t_{R}=7,93$ minutos que correspondeu ao ácido 1hexadecanoico, $\mathrm{t}_{\mathrm{R}}=8,79$ minutos que correspondeu ao éster 9,12 octadecadienoato de metila $t_{R}=10,71$ minutos que corresponde ao bis(2-etilhexil)ftalato, que também estava presente no cromatograma das frações 86-121, sendo um possível contaminante.

A partir do cromatograma obtido da análise do extrato das quintuplicatas desta reação (Figura 50), eram esperados dois produtos de biotransformação. No entanto, apenas um produto majoritário foi isolado, presente nas frações 86-121 e que correspondeu ao sinal de $t_{R}=15,01$ minutos que forneceu um espectro de massas com $70 \%$ de similaridade com o espectro de massas da $7 \alpha, 11 \alpha$ di-hidroxiprogesterona segundo a biblioteca NIST107 (Figuras 53A e 53B). Notou-se que no espectro experimental não se observou o pico de $\mathrm{m} / \mathrm{z}, 346$ (Figura 53A) que corresponde a massa molar da $7 \alpha, 11 \alpha$-di-hidroxiprogesterona $(346,47 \mathrm{~g} / \mathrm{mol})$. Além disso, devido a baixa similaridade entre o espectro de massas da biblioteca e o fornecido experimentalmente não foi possível concluir no momento que de fato este foi o composto isolado através do processo cromatográfico. 
Figura 53. Espectros de massas $(70 \mathrm{eV})$ : $(\mathrm{A})$ experimental para composto $t_{R}=15,01$ minutos (frações 86-121), (B) $7 \alpha, 11 \alpha$ di-hidroxiprogesterona (similaridade 70\%, biblioteca NIST107).
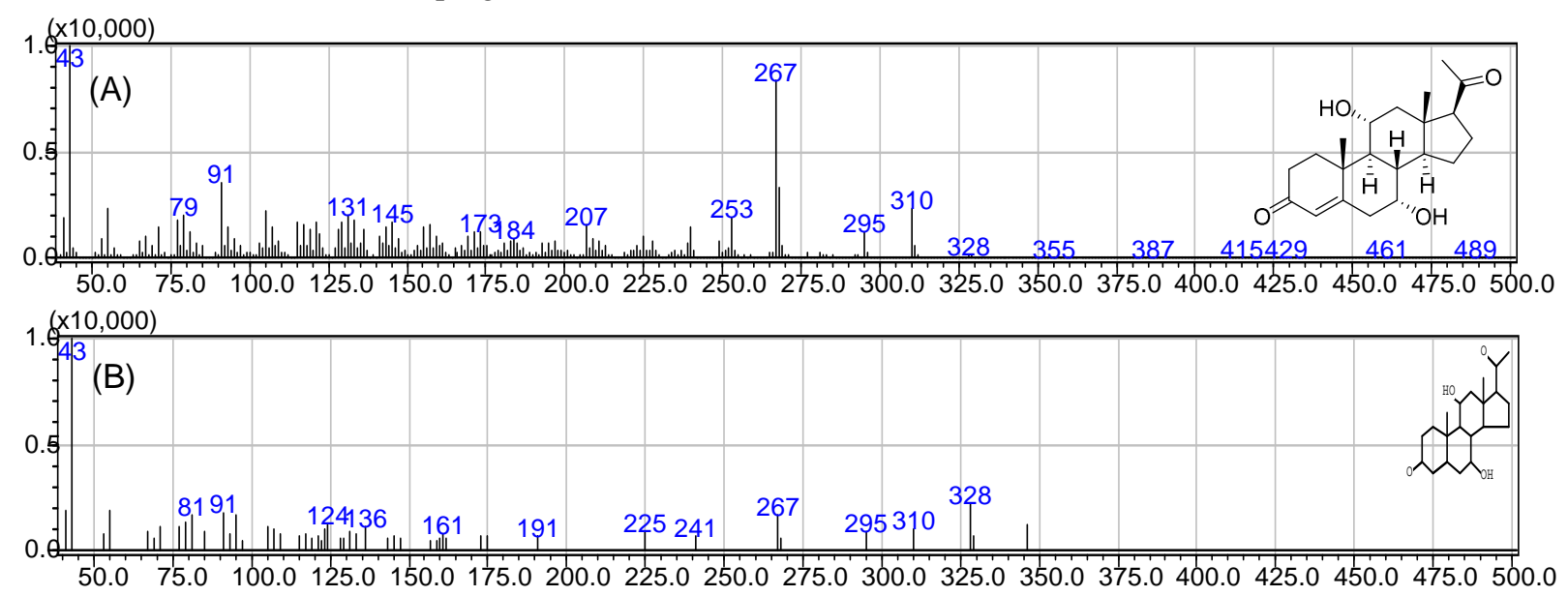

As frações 86-121 foram reunidas, o solvente foi evaporado em um rotaevaporador e obtida uma massa de 153,2 mg de composto. Esperando que o composto isolado das frações 86-121 fosse a $7 \alpha, 11 \alpha$ di-hidroxiprogesterona e considerando que a cada frasco Erlenmeyer das quintuplicatas foi adicionado $50 \mathrm{mg}$ de progesterona, o rendimento em massa obtido foi de 56 \%. Vale considerar que durante a extração e purificação ocorreram perdas de material. O composto obtido foi caracterizado pelas técnicas espectroscópicas cuja discussão será feita mais adiante.

\section{D.5.3.5 Reação de biotransformação da progesterona com o caldo enzimático do fungo $A$. sydowii CBMAI 935}

Após 7 dias foi finalizada a reação de biotransformação da progesterona pelo caldo enzimático do fungo A. sydowii CBMAI 935. Foi obtida uma massa de extrato seco de 296,9 mg. O extrato seco da reação foi dissolvido em acetato de etila e uma alíquota de $0,3 \mathrm{~mL}$ desta solução foi tomada e diluída 5 vezes e então feita uma análise por CG-EM com o intuito de verificar quais metabólitos foram produzidos na reação (Figura 54).

Figura 54. Cromatograma obtido por CG-EM do extrato em acetato de etila da biotransformação da progesterona pelo caldo enzimático proveniente do fungo A. sydowii CBMAI 935.

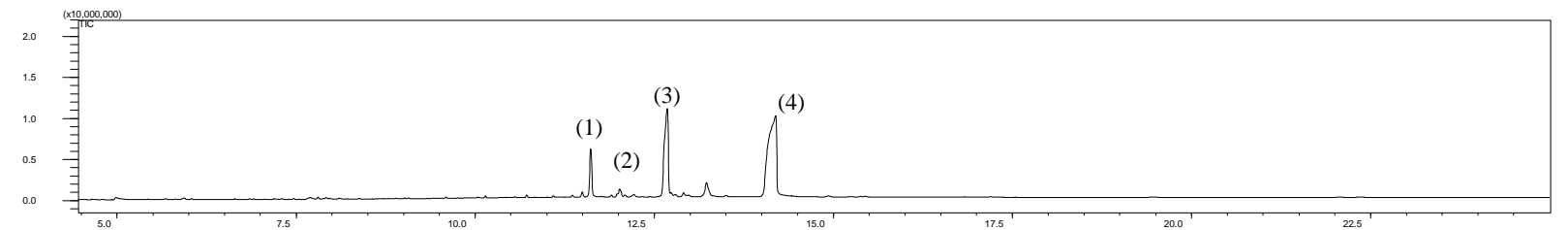


Como pode ser observado na Figura 54 foram obtidos alguns sinais no cromatograma. Dentre estes sinais foram observados possíveis metabólitos de biotransformação da progesterona, que estão destacados na Tabela 13.

Tabela 13. Possíveis produtos de biotransformação da progesterona após reações em quintuplicatas com o caldo enzimático do fungo A. sydowii CBMAI 935.

\begin{tabular}{|c|c|c|c|c|}
\hline Sinal & $t_{R}$ (minutos) & Possível composto & Similaridade (\%) & Biblioteca de dados \\
\hline (1) & 11,50 & & 91 & NIST21 \\
\hline (2) & 12,00 & & 67 & NIST21 \\
\hline (3) & 12,86 & & 93 & NIST21 \\
\hline (4) & 14,36 & & 83 & NIST107 \\
\hline
\end{tabular}

Como a Figura 54 e a Tabela 13 apresentaram, a biotransformação da progesterona utilizando o caldo enzimático da linhagem do fungo A. sydowii CBMAI 935 foi menos versátil e mais específica em relação à biotransformação deste substrato executado pelo caldo enzimático e pela massa micelial da linhagem do fungo A. sydowii CBMAI 934. Observou-se também mais de um sinal no cromatograma para um mesmo composto (no caso a progesterona). Vale considerar que o Espectrômetro de Massas acoplado à técnica de Cromatografia a Gás utilizada é um equipamento de baixa resolução.

Os sinais observados no cromatograma da triagem com o caldo enzimático do fungo $A$. sydowii CBMAI 935 (Figura 36D) com os $\mathrm{t}_{\mathrm{R}}=11,50$ minutos e $\mathrm{t}_{\mathrm{R}}=14,36$ minutos também foram observados no cromatograma do extrato das reações em quintuplicata, indicando que elas tiveram o mesmo comportamento da triagem, sendo que os respectivos picos corresponderam a testosterona e a testololactona. 


\section{D.5.3.6 Purificação e isolamento dos produtos de biotransformação da progesterona com o caldo enzimático do fungo A. sydowii CBMAI 935}

Foi feito inicialmente um estudo do gradiente de eluição por CCD para a determinação das proporções de n-hexano e acetato de etila a serem utilizadas como fase móvel na cromatografia em coluna para a separação dos compostos obtidos frente à biotransformação com o caldo enzimático do fungo A. sydowii CBMAI 935. Foi observado que a separação dos compostos foi mais adequada na proporção 3:7 de acetato de etila e n-hexano. A separação cromatográfica iniciou com essa proporção e finalizou com a proporção 9:1 de acetato de etila e n-hexano. Do processo cromatográfico foram obtidas 65 frações (Tabela 14).

Tabela 14. Frações obtidas na separação cromatográfica do extrato obtido da progesterona frente a biotransformação com o caldo enzimático do fungo A. sydowii CBMAI 935.

\begin{tabular}{cc}
\hline Grupos de frações & Gradiente (acetato de etila:n-hexano) \\
\hline $1-8$ & $3: 7$ \\
$9-18$ & $4: 6$ \\
$19-29$ & $5: 5$ \\
$30-39$ & $6: 4$ \\
$40-49$ & $7: 3$ \\
$50-61$ & $8: 2$ \\
$61-65$ & $9: 1$ \\
\hline
\end{tabular}

O processo de purificação foi monitorado por CCD a fim de determinar os grupos de substâncias semelhantes presentes nas frações. Uma vez determinados esses grupos foram tomadas alíquotas de cada fração do mesmo grupo e reunidas em um único frasco, diluídas e analisadas por CG-EM a fim de se verificar se o grupo de frações apresentava um único produto, confirmando assim, o isolamento do metabólito. As frações em que foram possíveis obter produtos majoritários foram: 19-27, 29-35 e 47-59 (Figura 55). 
Figura 55. Análise das frações obtidas por CG-EM após separação por cromatografia em coluna dos metabólitos majoritários presentes no extrato da biotransformação da progesterona com o caldo enzimático do fungo A.sydowii CBMAI 935.

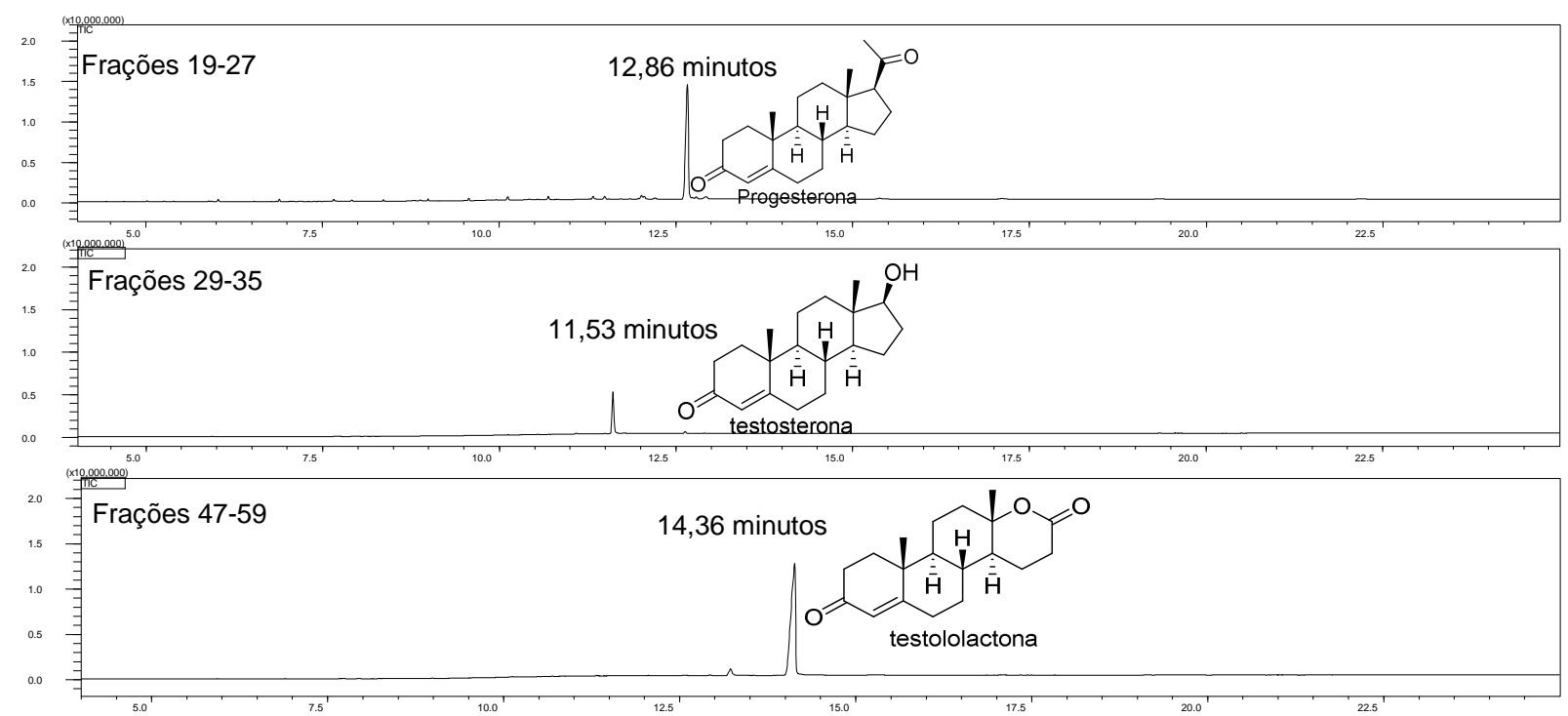

Por comparação com o padrão, as frações 19-27 corresponderam à progesterona remanescente da reação. Pelas análises dos cromatogramas das frações 29-35 foi observado um sinal com $t_{R}=11,53$ minutos que forneceu um espectro de massas com $93 \%$ de similaridade para a testosterona segundo a biblioteca NIST21 (Figura 56). No espectro experimental foi observado o pico de $\mathrm{m} / \mathrm{z} 288$ (Figura 56A) que correspondeu a massa molar da testosterona $(288,43 \mathrm{~g} / \mathrm{mol})$. Este dado concomitante à alta similaridade entre o espectro de massas experimental e o fornecido pela biblioteca sugeriu-se que foi a testosterona o composto isolado através do processo cromatográfico com confirmação a ser feita pelas caracterizações espectroscópicas.

Figura 56. Espectros de massas $(70 \mathrm{eV})$ : $(\mathrm{A})$ experimental para composto $t_{R}=11,53$ minutos (frações 29-35), (B) testosterona (similaridade 93\%, biblioteca NIST21).

As frações 29-35 foram reunidas, o solvente foi evaporado e obtida uma massa de 55 mg de composto. Possivelmente o composto isolado das frações 29-35 seria a testosterona e considerando que em cada frasco Erlenmeyer das quintuplicatas foi adicionado $50 \mathrm{mg}$ de progesterona, o rendimento em massa obtido foi de $24 \%$. Vale considerar que durante a extração e purificação ocorreram perdas de material. O composto obtido foi caracterizado pelas técnicas espectroscópicas cuja discussão será feita mais adiante neste texto.

Pelas análises dos cromatogramas das frações 47-59 foi observado um sinal com $t_{\mathrm{R}}=$ 14,36 minutos que forneceu um espectro de massas com $82 \%$ de similaridade para a testololactona segundo a biblioteca NIST107 (Figura 57). No espectro experimental foi observado o pico de $\mathrm{m} / \mathrm{z} 302$ (Figura 57A) que correspondeu a massa molar da testololactona $(302,41 \mathrm{~g} / \mathrm{mol})$ com considerável intensidade. Este é um dado que forneceu boas evidências que de fato este composto isolado pelo processo cromatográfico seria a testololactona.

Figura 57. Espectros de massas $(70 \mathrm{eV})$ : (A) experimental para composto $t_{R}=14,36$ minutos (frações 47-59), (B) testololactona (similaridade 82\%, biblioteca NIST107).

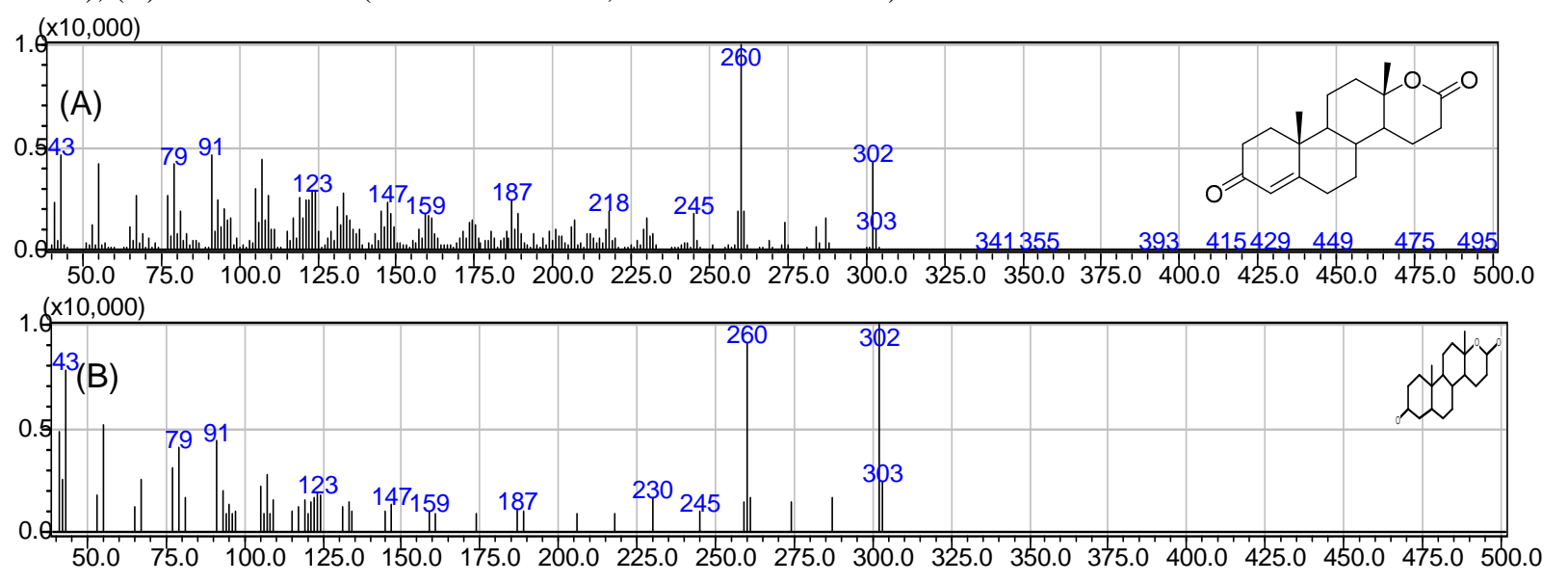

As frações 47-59 foram reunidas, o solvente foi evaporado e obtida uma massa de 86,4 mg de composto. Esperando que o composto majoritário das frações 47-59 seria a testosterona e considerando que em cada frasco Erlenmeyer das quintuplicatas foi adicionado $50 \mathrm{mg}$ de progesterona, o rendimento em massa obtido foi de $36 \%$. Vale considerar que durante a extração e purificação ocorreram perdas de material. 


\section{D.5.3.7 Reação de biotransformação da progesterona com o micélio do fungo A. sydowii CBMAI 935}

Embora o produto esperado desta reação fosse a testololactona que também foi obtida na reação com o caldo enzimático do fungo A. sydowii CBMAI 935, esta biotransformação foi efetuada por ser altamente específica e, através da triagem efetuada com o micélio do referido fungo (Figura 42D), promover total conversão da progesterona à testololactona.

Após 7 dias foi finalizada a reação de biotransformação da progesterona pela massa micelial do fungo A. sydowii CBMAI 935. Após a extração dos compostos, foram medidas a massa micelial úmida e a masssa micelial seca após secagem em estufa por 48 horas a $32^{\circ} \mathrm{C}$. Os valores obtidos estão apresentados na Tabela 15.

Tabela 15. Valores de massa micelial úmida e seca do fungo A. sydowii CBMAI 934 após 14 dias da reação de biotransformação da progesterona.

\begin{tabular}{cccc}
\hline Massa úmida inicial $(\mathrm{g})$ & Massa úmida final $(\mathrm{g})$ & Massa seca $(\mathrm{g})$ & Perda de umidade $(\%)$ \\
\hline 15 & 13 & 4 & 70 \\
\hline
\end{tabular}

Como a Tabela 15 apresentou ao final do processo houve uma perda de massa micelial de $2 \mathrm{~g}$. Essa perda foi em função dos processos de extração e filtração, bem como parte ter sido transferida para o extrato. Também, observou-se que $70 \%$ da umidade da massa micelial úmida foi perdida após secagem em estufa. A quantidade de umidade fornece uma capacidade catalítica do sistema enzimático do fungo uma vez que muitas das enzimas envolvidas são intracelulares e uma célula eucariótica fúngica é composta majoriamente por água.

Foi obtida uma massa de extrato seco de 495,4 mg. O extrato seco da reação foi dissolvido em acetato de etila e dessa solução uma alíquota de $0,3 \mathrm{~mL}$ foi tomada, diluída 5 vezes e então feita uma análise por CG-EM com o intuito de verificar quais metabólitos foram produzidos na reação (Figura 58).

Figura 58. Cromatograma obtido por CG-EM do extrato em acetato de etila da biotransformação da progesterona pela massa micelial do fungo A. sydowii CBMAI 935.

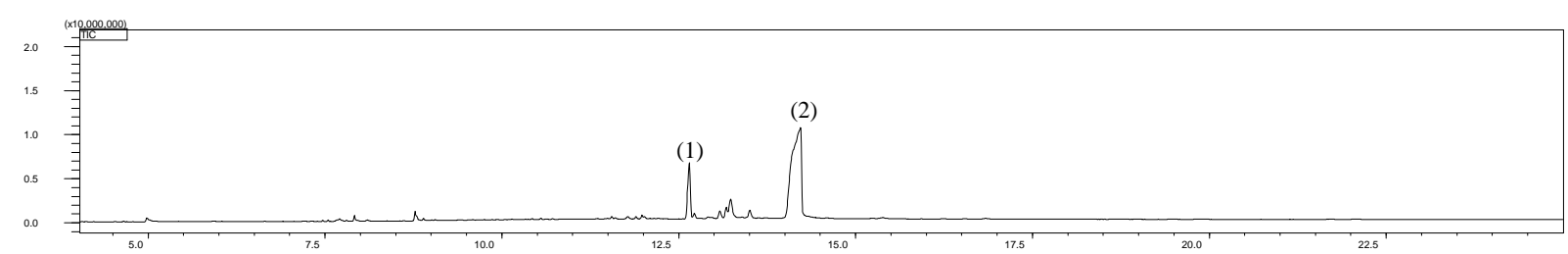


Diferente do esperado da biotransformação da progesterona com a massa micelial, o cromatograma da Figura 59 mostrou que a conversão da progesterona, não foi completa. Além disso, foram observados alguns outros sinais no cromatograma da Figura 58. Dentre estes sinais, foram observados possíveis metabólitos de biotransformação da progesterona, que estão destacados na Tabela 16.

Tabela 16. Possíveis produtos de biotransformação da progesterona após reações em quintuplicatas com a massa micelial do fungo A. sydowii CBMAI 935.

\begin{tabular}{|c|c|c|c|c|}
\hline Sinal & $t_{R}$ (minutos) & Possível composto & Similaridade $(\%)$ & Biblioteca de dados \\
\hline (1) & 12,86 & & 93 & NIST21 \\
\hline (2) & 14,36 & & 82 & NIST107 \\
\hline
\end{tabular}

Como a Figura 58 e a Tabela 16 apresentaram, a biotransformação da progesterona utilizando o micélio da linhagem do fungo A. sydowii CBMAI 935, apesar de não ocorrer a conversão total do substrato em testololactona, a alta especificidade da reação foi mantida, uma vez que um produto majoritário de biotransformação foi observado.

\section{D.5.3.8 Purificação e isolamento de biotransformação da progesterona com a massa micelial do fungo A. sydowii CBMAI 935}

Foi feito inicialmente um estudo do gradiente de eluição por CCD para a determinação das proporções de n-hexano e acetato de etila a serem utilizadas como fase móvel na cromatografia em coluna para a separação dos compostos obtidos frente a biotransformação com a massa micelial do fungo A. sydowii CBMAI 935. Foi observado que a separação dos compostos foi mais adequada na proporção 3:7 de acetato de etila e n-hexano. A separação cromatográfica iniciou-se com essa proporção e finalizou com a proporção 9:1 de acetato de etila e n-hexano. Do processo cromatográfico foram obtidas 70 frações (Tabela 17). 
Tabela 17. Frações obtidas na separação cromatográfica do extrato da biotransformação da progesterona com a massa micelial do fungo A. sydowii CBMAI 935.

\begin{tabular}{cc}
\hline Grupos de frações & Gradiente (acetato de etila : n-hexano) \\
\hline $1-12$ & $3: 7$ \\
$13-24$ & $4: 6$ \\
$25-33$ & $5: 5$ \\
$35-42$ & $6: 4$ \\
$43-48$ & $7: 3$ \\
$49-60$ & $8: 2$ \\
$61-70$ & $9: 1$ \\
\hline
\end{tabular}

O processo de purificação foi monitorado por CCD a fim de determinar os grupos de substâncias semelhantes presentes nas frações. Uma vez determinados esses grupos foram tomadas alíquotas de cada fração e reunidas em um único frasco, diluídas e por fim analisadas por CG-EM a fim de se verificar se o grupo de frações determinado apresentava, um único produto, confirmando assim o isolamento do metabólito. As frações em que foram possíveis obter produtos majoritários foram: 20-28 e 50-63 (Figura 59).

Figura 59. Análise das frações obtidas por CG-EM após separação por cromatografia em coluna dos metabólitos majoritários presentes no extrato obtido da biotransformação da progesterona com a massa micelial do fungo A. sydowii CBMAI 935.

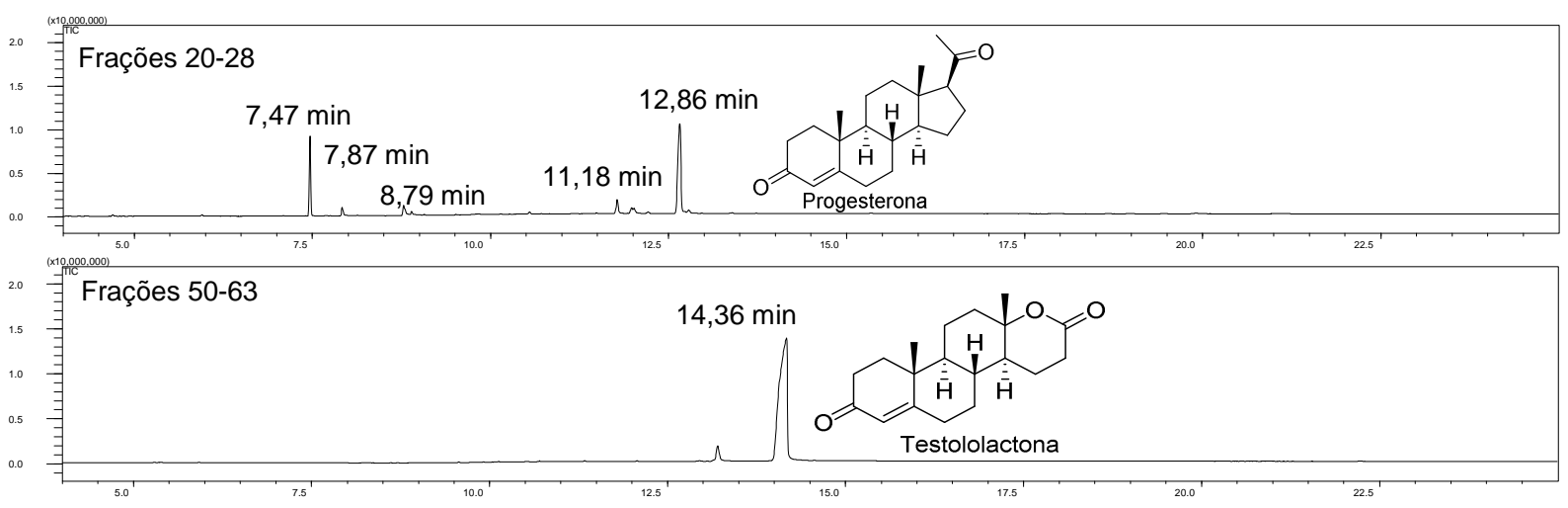

Por comparação com o padrão autêntico da progesterona o sinal com $t_{R}=12,86$ minutos do cromatograma das frações 20-28 correspondeu à progesterona. Os outros sinais observados se referiram a contaminantes, ésteres, álcoois de cadeia longa é ácidos graxos possivelmente produzidos pela massa micelial do fungo.

Por comparação com o cromatograma da testololactona isolada na reação com o caldo enzimático do fungo A. sydowii CBMAI 935, o sinal de $t_{\mathrm{R}}=14,36$ minutos do cromatograma das frações 50-63 correspondeu à testololactona. 
As frações 50-63 foram reunidas, o solvente foi evaporado e obtida uma massa de 209 $\mathrm{mg}$ de composto. Esperando que o composto majoritário das frações 50-63 seja a testololactona e considerando que a cada frasco Erlenmeyer das quintuplicatas foi adicionado $50 \mathrm{mg}$ de progesterona, o rendimento em massa obtido desta biotransformação foi de $87 \%$. Vale considerar que durante a extração e purificação ocorreram perdas de material. Todo o produto obtido foi reunido à testololactona obtida da reação com o caldo enzimático do fungo A. sydowii CBMAI 935 e realizadas as caracterizações espectroscópicas. 


\section{D.5.4 CARACTERIZAÇÃo POR TÉCNICAS ESPECTROSCÓPICAS DOS COMPOSTOS ISOLADOS}

Para se ter uma maior dimensão da estrutura dos compostos obtidos por este trabalho, foram feitas caracterizações destas substâncias por Espectroscopia no Infravermelho (IV) para identificação dos grupos funcionais, medida de rotação ótica (Polarimetria) para verficar se houve mudança das propriedades ópticas dos compostos, Espectroscopia de Ressonância Magnética Nuclear (RMN) para elucidação estrutural e quando necessário, foram realizadas caracterizações por Espectrometria de Massas de Alta Resolução (EMAR) como técnica complementar à elucidação estrutrual.

Foram executados experimentos de RMN utilizando técnicas unidimensionais $\left({ }^{13} \mathrm{C} \mathrm{e}\right.$ ${ }^{1} \mathrm{H}$ ) e bidimensionais (COSY, HSQC e HMBC) pelo fato de que as moléculas deste trabalho apresentarem prótons enantiotópicos e diastereotópicos, sendo que cada núcleo das moléculas em questão serem magneticamente diferentes por estarem em ambientes químicos diferentes. Além disso, os dados da literatura evidenciaram que os espectros de $\mathrm{RMN}$ de ${ }^{1} \mathrm{H}$ tanto do substrato, quanto dos produtos apresentam sobreposição de sinais, o que de fato foi observado nos espectros obtidos neste estudo. Os espectros obtidos dos experimentos bidimensionais evidenciam as conectividades dos átomos de $\mathrm{C}$ e $\mathrm{H}$, permitindo diferenciar os átomos das moléculas deste trabalho.

Os experimentos foram feitos tanto no substrato (progesterona), quanto nos produtos obtidos das reações. Ao longo do texto será discutido separadamente as respectivas caracterizações de cada produto de forma comparativa com a progesterona, evidenciando as alterações ocorridas que determinaram as caracterizações dos compostos obtidos.

Para a determinação da rotação óptica, todos os compostos foram dissolvidos em clorofórmio grau espectroscópico. As determinações foram feitas à temperatura de $23^{\circ} \mathrm{C} \mathrm{em}$ equipamento com lâmpada de sódio com comprimento de onda $\lambda=589 \mathrm{~nm}$.

Para a caracterização no IV as amostras foram misturadas em $\mathrm{KBr}$ previamente seco feitas pastilhas de 1,0 cm de diâmetro e em seguida determinadas as bandas características dos grupos funcionais.

Para a caracterização por RMN todos os compostos foram solubilizados em deuteroclorofórmio $\left(\mathrm{CDCl}_{3}\right)$ e foi utilizado como referência o tetrametil-silano (TMS) para os valores de deslocamentos químicos. 
Para a caracterização por EMAR as amostras foram dissolvidas em acetonitrila grau espetroscópico com $0,1 \%$ de ácido fórmico na concentração de $2 \mu \mathrm{g} / \mathrm{mL}$ por inserção direta e com ionização por eletrospray.

Como base de comparação com os produtos obtidos serão apresentados a seguir os dados espectroscópicos obtidos experimentalmente para a progesterona juntamente com os dados descritos na literatura ${ }^{69}$.

A Tabela 18 apresenta os valores de rotação óptica para a progesterona obtidos experimentalmente e de referência.

Tabela 18. Valores de rotação óptica para a progesterona.

\begin{tabular}{cccccc}
\hline \multicolumn{2}{c}{ Valores descritos na literatura ${ }^{69}$} & \multicolumn{3}{c}{ Valores experimentais } \\
\hline $\begin{array}{c}\text { Concentração } \\
(\mathrm{g} / 100 \mathrm{~mL})^{\mathrm{a}}\end{array}$ & Temperatura $\left({ }^{\circ} \mathrm{C}\right)$ & {$\left[\alpha_{D}\right]_{589}^{21}(\mathrm{deg})$} & $\begin{array}{c}\text { Concentração } \\
(\mathrm{g} / 100 \mathrm{~mL})^{\mathrm{a}}\end{array}$ & Temperatura $\left({ }^{\circ} \mathrm{C}\right)$ & {$\left[\alpha_{D}\right]_{589}^{23}(\mathrm{deg})$} \\
\hline 0,5 & 21 & 227,6 & 0,5 & 23 & 150,7 \\
\hline a: $\mathrm{CHCl}_{3}$ & & &
\end{tabular}

Como mostrado na Tabela 18 observou-se que há uma diferença da rotação óptica entre o valor experimental e o da literatura, apesar que o sentido da rotação permaneceu o mesmo. Possivelmente esta diferença se deve à temperatura em que o experimento foi executado.

A Tabela 19 apresenta os valores das bandas experimentais $\left(v_{\text {máx }}\right)$ obtidas na Espectroscopia no IV $\left(\mathrm{em}^{-1}\right)$ atribuídas para a progesterona segundo Mohamed et al. $(2014)^{70}$, que apresentou de maneira mais detalhada as atribuições das bandas relativas as ligações dos grupos funcionais e segundo Silverstein et al. (2006) ${ }^{71}$, que apresentou de maneira geral as faixas em que as bandas vibracionais podem ocorrer no espectro de IV. Muitas dessas bandas, como as relacionadas para as ligações $\mathrm{C}-\mathrm{H}, \mathrm{C}=\mathrm{C}$ e $\mathrm{C}=\mathrm{O}$ de cetonas, foram encontradas também nos produtos de biotransformação com os valores muito semelhantes com os valores de $v_{\text {máx }}\left(\mathrm{cm}^{-1}\right)$. Logo, essas referências foram utilizadas para atribuição das bandas apresentadas nos espectros de IV dos produtos, bem como utilizando referências que apresentassem atribuições detalhadas para a progesterona. $\mathrm{O}$ espectro deste composto será apresentado ao longo do texto para evidenciar as diferenças entre os espectros do substrato e dos metabólitos, mostrando as respectivas alterações. Como pôde-se perceber os dados experimentais e os descritos na literatura são bastante concordantes entre si. 
Tabela 19. Valores das bandas vibracionais obtidas por IV para a progesterona.

\begin{tabular}{|c|c|c|}
\hline \multirow{2}{*}{ Ligação/tipo de vibração } & \multicolumn{2}{|c|}{ Valores de $v_{\text {máx }}\left(\mathrm{cm}^{-1}\right)$} \\
\hline & literatura & experimental \\
\hline Deformação axial $\mathrm{H}-\mathrm{C}=$ & acima de $3000^{71}$ & \multirow{2}{*}{3026} \\
\hline Deformação axial C-H ( $\mathrm{CH}_{2}$ cíclico $)$ & $3100-2990^{71}$ & \\
\hline Deformação axial C-H ( $\mathrm{CH}_{2}$ cíclico $)$ & $3100-2990^{71}$ & 2970 \\
\hline Estiramento assimétrico $\mathrm{C}-\mathrm{H}$ & $2939,95^{70}$ & 2939 \\
\hline Estiramento assimétrico C-H & $2854,13^{70}$ & \multirow{2}{*}{2850} \\
\hline Deformação axial de C-H (carbono terciário) & $2890^{71}$ & \\
\hline Estiramento $\mathrm{C}=\mathrm{O}$ de cetona $(\mathrm{C}-20)$ & $1698,28^{70}$ & 1699 \\
\hline Estiramento $\mathrm{C}=\mathrm{O}$ de cetona $(\mathrm{C}-3)$ & $1632,34^{70}$ & \multirow{2}{*}{1664} \\
\hline Deformação axial $\mathrm{C}=\mathrm{O}$ de cetona $\alpha, \beta$ insaturada $(\mathrm{C}-3)$ & $1685-1666^{71}$ & \\
\hline Estiramento $\mathrm{C}=\mathrm{C}(\mathrm{C}-4$ e $\mathrm{C}-5)$ & $1617,02^{70}$ & 1614 \\
\hline Deformação angular - $\mathrm{CH}_{2}$ (anel de ciclohexano) & $1442^{71}$ & 1437 \\
\hline Deformação angular simétrica $\mathrm{C}-\mathrm{H}\left(\mathrm{CH}_{3}\right)$ & $1375^{71}$ & 1385 \\
\hline Deformação angular simétrica fora do plano $\left(\mathrm{CH}_{2}\right.$ cíclico $)$ & $1350^{71}$ & 1356 \\
\hline Deformação axial e angular de $\mathrm{C}-(\mathrm{C}=\mathrm{O})-\mathrm{C}$ & $1300-1100^{71}$ & 1279 \\
\hline Deformação axial e angular de $\mathrm{C}-(\mathrm{C}=\mathrm{O})-\mathrm{C}$ & $1300-1100^{71}$ & 1226 \\
\hline Deformação axial e angular de $\mathrm{C}-(\mathrm{C}=\mathrm{O})-\mathrm{C}$ & $1300-1100^{71}$ & 1203 \\
\hline Deformação axial e angular de $\mathrm{C}-(\mathrm{C}=\mathrm{O})-\mathrm{C}$ & $1300-1100^{71}$ & 1161 \\
\hline
\end{tabular}

Como base de comparação com os produtos obtidos a Tabela 20 apresenta os valores de deslocamentos químicos obtidos da progesterona a partir dos experimentos de $\mathrm{RMN}$ de ${ }^{13} \mathrm{C}$ (100 MHz), ${ }^{1} \mathrm{H}(400 \mathrm{MHz})$ e HSQC (125 MHz e $\left.500 \mathrm{MHz}\right)$ em comparação com os dados descritos na literatura ${ }^{72,73}$. A Figura 60 apresenta as estruturas químicas para a progesterona na forma planar e tridimensional. Ao longo do texto serão mostrados os espectros de RMN da progesterona de forma comparativa aos espectros dos produtos obtidos nas reações de biotransformação. Nos anexos serão apresentados os espectros tanto da progesterona quanto dos produtos isolados. Como pode ser observado na Tabela 20 os dados são bastante concordantes entre os resultados experimentais e os descritos na literatura ${ }^{72,73}$. 
Figura 60. Estruturas químicas para a progesterona: (A) planar, (B) tridimensional.

(A)

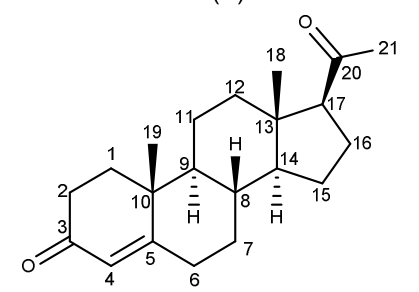

(B)

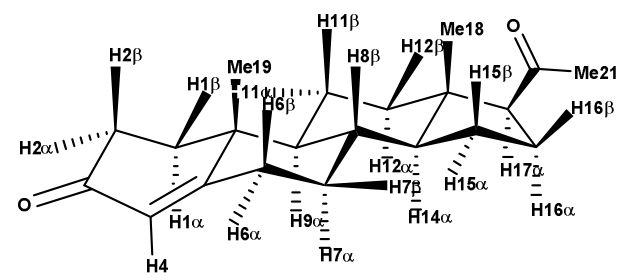

Tabela 20. Valores de deslocamentos químicos (ppm) de $\mathrm{RMN}\left({ }^{13} \mathrm{C} \mathrm{e}{ }^{1} \mathrm{H}\right)$ para a progesterona.

\begin{tabular}{|c|c|c|c|c|c|}
\hline${ }^{13} \mathrm{C}$ & $\delta^{13}{ }_{C}\left(\text { literatura }^{72}\right)^{\mathrm{a}}$ & $\delta^{13} \mathrm{C}(\text { experimental })^{\mathrm{a}}$ & ${ }^{1} \mathrm{H}$ & $\delta_{\mathrm{H}}^{1}\left(\text { literatura }^{73}\right)^{\mathrm{b}}$ & $\delta^{1}{ }_{\mathrm{H}}(\text { experimental })^{\mathrm{c}}$ \\
\hline \multirow{2}{*}{1} & \multirow{2}{*}{35,9} & \multirow{2}{*}{35,6} & $1 \alpha$ & 1,72 & 1,71 \\
\hline & & & $1 \beta$ & 2,05 & 2,03 \\
\hline \multirow{2}{*}{2} & \multirow{2}{*}{34,3} & \multirow{2}{*}{34,0} & $2 \alpha$ & 2,34 & 2,33 \\
\hline & & & $2 \beta$ & 2,44 & 2,45 \\
\hline 3 & 199,8 & 199,4 & - & - & - \\
\hline 4 & 124,3 & 123,9 & 4 & 5,73 & 5,76 \\
\hline 5 & 171,3 & 170,9 & - & - & - \\
\hline \multirow{2}{*}{6} & \multirow{2}{*}{32,2} & \multirow{2}{*}{32,8} & $6 \alpha$ & 2,28 & 2,32 \\
\hline & & & $6 \beta$ & 2,41 & 2,40 \\
\hline \multirow{2}{*}{7} & \multirow{2}{*}{33,1} & \multirow{2}{*}{32,0} & $7 \alpha$ & 1,07 & 1,08 \\
\hline & & & $7 \beta$ & 1,87 & 1,85 \\
\hline 8 & 36,1 & 35,6 & $8 \beta$ & 1,57 & 1,55 \\
\hline 9 & 54,0 & 53,7 & $9 \alpha$ & 0,99 & 0,99 \\
\hline 10 & 39,0 & 38,7 & - & - & - \\
\hline \multirow{2}{*}{11} & \multirow{2}{*}{21,4} & \multirow{2}{*}{21,0} & $11 \alpha$ & 1,65 & 1,63 \\
\hline & & & $11 \beta$ & 1,46 & 1,44 \\
\hline \multirow{2}{*}{12} & \multirow{2}{*}{38,9} & \multirow{2}{*}{38,6} & $12 \alpha$ & 1,46 & 1,48 \\
\hline & & & $12 \beta$ & 2,08 & 2,07 \\
\hline 13 & 44,3 & 43,9 & - & - & - \\
\hline 14 & 56,4 & 56,0 & $14 \alpha$ & 1,18 & 1,14 \\
\hline \multirow{2}{*}{15} & \multirow{2}{*}{24,7} & \multirow{2}{*}{24,4} & $15 \alpha$ & 1,72 & 1,71 \\
\hline & & & $15 \beta$ & 1,27 & 1,28 \\
\hline \multirow{2}{*}{16} & \multirow{2}{*}{23,2} & \multirow{2}{*}{22,9} & $16 \alpha$ & 1,68 & 1,68 \\
\hline & & & $16 \beta$ & 2,19 & 2,18 \\
\hline 17 & 63,8 & 63,5 & $17 \alpha$ & 2,55 & 2,52 \\
\hline 18 & 13,7 & 13,3 & 18 & 0,67 & 0,68 \\
\hline 19 & 17,7 & 17,4 & 19 & 1,20 & 1,19 \\
\hline 20 & 209,7 & 209,3 & - & - & - \\
\hline 21 & 31,9 & 31,5 & 21 & 2,13 & 2,13 \\
\hline
\end{tabular}

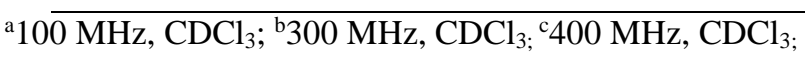




\section{D.5.4.1 Caracterização do produto 7,15-di-hidroxiprogesterona isolado da reação com o caldo enzimático do fungo A. sydowi CBMAI 934 (14 dias, $\left.3^{\circ} \mathrm{C}, 130 \mathrm{rpm}\right)$}

Conforme abordado na seção D.5.3.2 as análises por CG-EM do produto isolado dessa reação (Figuras 48 e 49) sugeriram que este composto fosse a $15 \beta$-hidroxiprogesterona. Entretanto, as análises do espectro de $\mathrm{RMN}$ de ${ }^{13} \mathrm{C}$ do composto isolado mostraram dois sinais de carbono carbinólico (Figura 61B) $\operatorname{com} \delta=71,5$ e $\delta=74,0$, evidenciando que tal composto na verdade seria um di-hidroxilado. Comparando com o espectro de $\mathrm{RMN}$ de ${ }^{13} \mathrm{C}$ pôde-se constatar que não foram observados nas suas regiões características de deslocamento químico os sinais relativos aos carbonos C-7 e C-15 (Figura 61A), sugerindo que a hidroxilação da progesterona ocorreu nestes carbonos. 

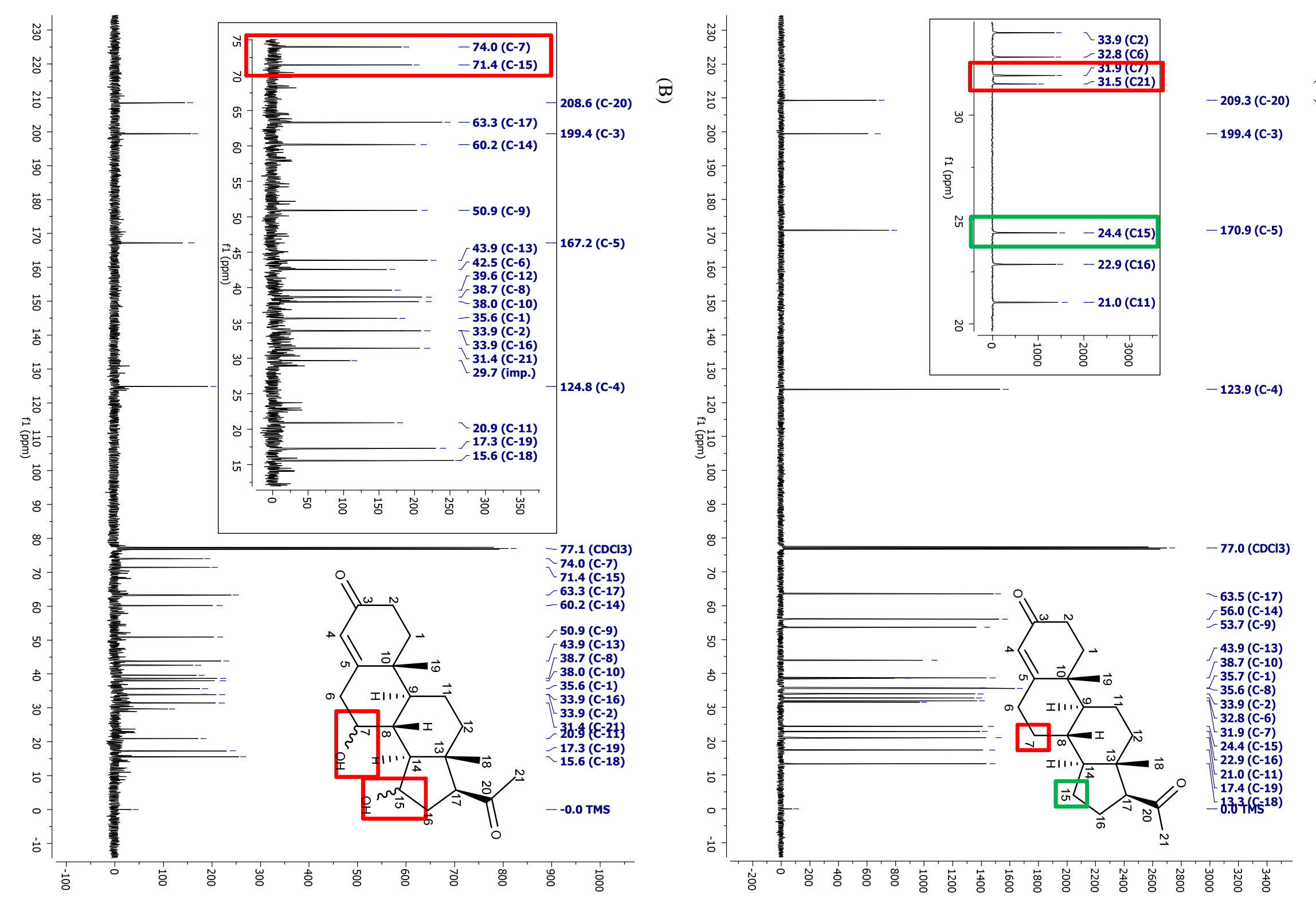
Nas bases de dados de compostos orgânicos na internet (REAXYS, Scifinder, ChemSpider, PubChem, CheMBL, NIAID, Chembank, ChemlDplus, ToxNet, BindingDB, Drugbank, KEGG Drug) foram feitas buscas de referências de dados espectroscópicos dos quatro possíveis estereoisômeros di-hidroxilados nos carbonos C-7 e C-15 (Figuras 62 e 63). Foram encontradas referências para dois estereoisômeros: $7 \beta, 15 \beta$-di-hidroxiprogesterona ${ }^{74,75} \mathrm{e}$ $7 \alpha, 15 \beta$-di-hidroxiprogesterona ${ }^{74,76}$ e além disso, não se obteve muitos dados de deslocamentos químicos para esses composotos na literatura ${ }^{74,75,76}$. A Tabela 21 apresenta os dados de deslocamento químico de ${ }^{13} \mathrm{C}$ e ${ }^{1} \mathrm{H}$ descritos na literatura para o estereoisômeros referenciados, comparativo com os dados experimentais obtidos dos espectros de RMN de ${ }^{13} \mathrm{C},{ }^{1} \mathrm{He}$ e HSQC do composto isolado.

Figura 62. Estruturas químicas dos possíveis estereoisômeros di-hidroxilados nos carbonos C-7 e C-15:

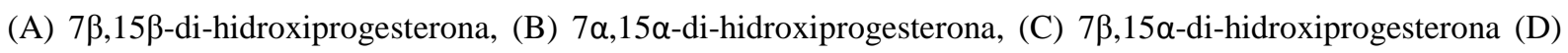
$7 \alpha, 15 \beta$-di-hidroxiprogesterona.

(A)

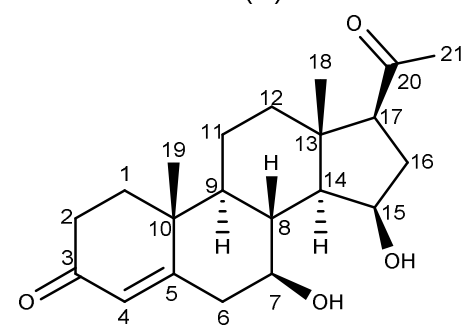

$7 \beta, 15 \beta$-di-hidroxiprogesterona

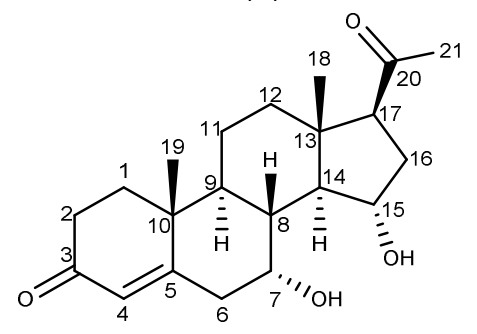

$7 \alpha, 15 \alpha$-di-hidroxiprogesterona

(C)

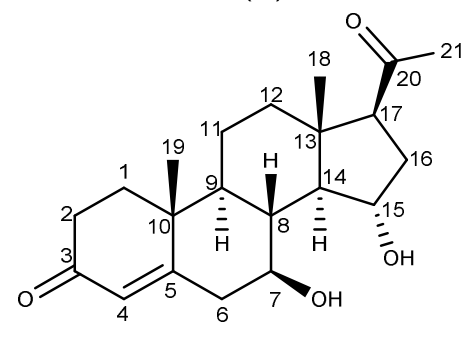

$7 \beta, 15 \alpha$-di-hidroxiprogesterona

(D)

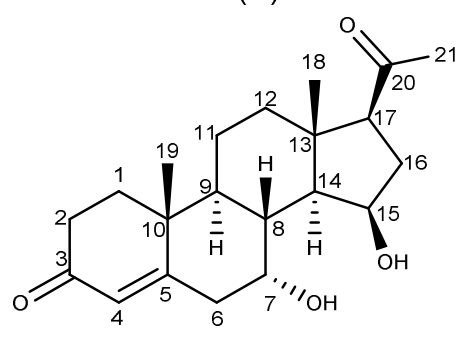

$7 \alpha, 15 \beta$-di-hidroxiprogesterona

Figura 63. Estruturas químicas tridimensionais de dois possíveis estereoisômeros nos carbonos C-7 e C15: (A) 7 $\beta, 15 \beta$-di-hidroxiprogesterona, (B) $7 \alpha, 15 \beta$-di-hidroxiprogesterona.
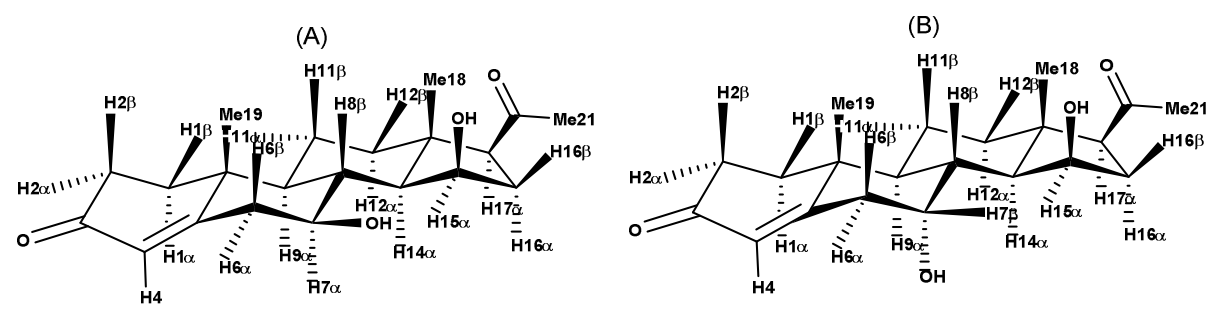
Tabela 21. Valores de deslocamentos químicos (ppm) de $\mathrm{RMN}\left({ }^{13} \mathrm{C}\right.$ e $\left.{ }^{1} \mathrm{H}\right)$ para os estereoisômeros $7 \beta, 15 \beta$-di-hidroxiprogesterona, $7 \alpha, 15 \beta$-di-hidroxiprogesterona.

\begin{tabular}{|c|c|c|c|c|c|c|c|}
\hline \multirow[b]{2}{*}{${ }^{13} \mathrm{C}$} & \multicolumn{2}{|c|}{$\delta^{13} \mathrm{C}$ (literatura) } & \multirow{2}{*}{$\begin{array}{c}\delta^{13} \mathrm{C} \\
(\text { experimental })^{\mathrm{c}}\end{array}$} & \multirow[b]{2}{*}{${ }^{1} \mathrm{H}$} & \multicolumn{2}{|c|}{$\delta_{\mathrm{H}}^{1}($ literatura) } & \multirow{2}{*}{$\begin{array}{c}\delta_{\mathrm{H}}^{1} \\
(\text { experimental })^{\mathrm{e}}\end{array}$} \\
\hline & $\begin{array}{c}\text { Isômero } \\
\left(7 \beta, 15 \beta^{74}\right)^{\mathrm{a}}\end{array}$ & $\begin{array}{c}\text { Isômero } \\
\left(7 \alpha, 15 \beta^{76}\right)^{\mathrm{b}}\end{array}$ & & & $\begin{array}{c}\text { Isômero } \\
\left(7 \beta, 15 \beta^{75}\right)^{\mathrm{d}}\end{array}$ & $\begin{array}{c}\text { Isômero } \\
\left(7 \alpha, 15 \beta^{76}\right)^{\mathrm{b}}\end{array}$ & \\
\hline \multirow{2}{*}{1} & \multirow{2}{*}{35,7} & \multirow{2}{*}{35,5} & \multirow{2}{*}{35,6} & $1 \alpha$ & 1,68 & NR & 1,71 \\
\hline & & & & $1 \beta$ & 2,07 & NR & 2,09 \\
\hline \multirow{2}{*}{2} & \multirow{2}{*}{34,0} & \multirow{2}{*}{33,9} & \multirow{2}{*}{33.9} & $2 \alpha$ & 2,35 & NR & 2,38 \\
\hline & & & & $2 \beta$ & 2,42 & NR & 2,45 \\
\hline 3 & 199,4 & 198,7 & 199,4 & - & - & NR & - \\
\hline 4 & 124,9 & 127,0 & 124,8 & 4 & 5,79 & NR & 5,75 \\
\hline 5 & 167,1 & 167,1 & 167,2 & - & - & - & - \\
\hline \multirow{2}{*}{6} & \multirow{2}{*}{42,6} & \multirow{2}{*}{41,2} & \multirow{2}{*}{42,6} & $6 \alpha$ & 2,55 & NR & 2,56 \\
\hline & & & & $6 \beta$ & 2,55 & NR & 2.56 \\
\hline \multirow{2}{*}{7} & \multirow{2}{*}{71,5} & \multirow{2}{*}{67,6} & \multirow{2}{*}{74,0} & $7 \alpha$ & 3,65 & - & \multirow{2}{*}{3,62} \\
\hline & & & & $7 \beta$ & - & 4,41 & \\
\hline 8 & 38,6 & 45,5 & 38,7 & $8 \beta$ & 2,04 & NR & 2,01 \\
\hline 9 & 50,9 & 45,5 & 50,9 & $9 \alpha$ & 1,06 & NR & 1,06 \\
\hline 10 & 38,0 & 38,6 & 38,0 & - & - & - & - \\
\hline \multirow{2}{*}{11} & \multirow{2}{*}{20,9} & \multirow{2}{*}{20,8} & \multirow{2}{*}{20,9} & $11 \alpha$ & 1,71 & NR & 1,71 \\
\hline & & & & $11 \beta$ & 1,50 & NR & 1,51 \\
\hline \multirow{2}{*}{12} & \multirow{2}{*}{39,6} & \multirow{2}{*}{39,8} & 396 & $12 \alpha$ & 1,40 & NR & 1,40 \\
\hline & & & & $12 \beta$ & 2,07 & NR & 2,07 \\
\hline 13 & 43,9 & 43,6 & 43,9 & - & - & - & - \\
\hline 14 & 60,2 & 54,8 & 60,2 & $14 \alpha$ & 1,19 & 1,14 & 1,16 \\
\hline 15 & 74.1 & 702 & 715 & $15 \alpha$ & 4,48 & - & 4.46 \\
\hline & & & & $15 \beta$ & - & 4,44 & \\
\hline 16 & 330 & 367 & 320 & $16 \alpha$ & 2,30 & NR & 2,30 \\
\hline 10 & & & , , & $16 \beta$ & 2,30 & NR & 2,26 \\
\hline 17 & 63,3 & 63,7 & 63,3 & $17 \alpha$ & 2,45 & NR & 2,43 \\
\hline 18 & 15,6 & 15,8 & 15,6 & 18 & 0,97 & 0,27 & 0,96 \\
\hline 19 & 17,3 & 16,9 & 17,3 & 19 & 1,26 & NR & 1,25 \\
\hline 20 & 208,5 & 208,0 & 208,6 & - & - & - & - \\
\hline 21 & 31,4 & 35,9 & 31,4 & 21 & 2,16 & NR & 2,16 \\
\hline
\end{tabular}

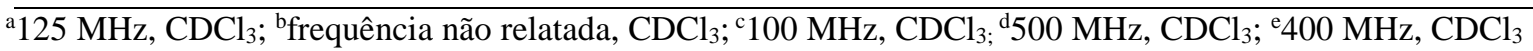
NR: Não Relatado

Comparando os dados experimentais com os dados descritos na literatura, pôde ser observado que os dados obtidos experimentalmente são mais próximos do isômero de configuração $7 \beta, 15 \beta$, pois, os valores de $\delta$ experimentais dos núcleos de ${ }^{1} \mathrm{H}$ relativos aos 
hidrogênios H-7 e H-15 são mais concordantes com o valores descritos na literatura para o composto de configuração $7 \beta, 15 \beta^{75}$. Para o composto isolado, há uma diferença observada entre os valores de $\delta$ experimentais dos núcleos de ${ }^{13} \mathrm{C}$ relativos aos carbonos C-7 e C-15 e os valores de $\delta$ descritos na literatura relativos a esses carbonos nos dois estereoisômeros: o de configuração $7 \beta, 15 \beta^{74}$ e o de configuração $7 \alpha, 15 \beta^{76}$ (Tabela 21). Considerando a abundância dos núcleos que geram sinais no experimento de $\mathrm{RMN}$, os núcleos de ${ }^{1} \mathrm{H}$ são mais abundantes que os núcleos de ${ }^{13} \mathrm{C}$. Sendo assim, seria preferível utilizar os valores de deslocamento químico de ${ }^{1} \mathrm{H}$ para indicar qual a configuração dos hidrogênios H-7 e H-15 do composto di-hidroxilado, que no caso, seria 7 $\beta, 15 \beta$. Entretando, como será apresentado ao longo dessa seção, não foi possível determinar com exatidão a configuração destes hidrogênios.

Destaca-se que na Tabela 21 para o isômero $7 \beta, 15 \beta$ apenas os carbonos C-7 e C-15 apresentaram diferenças de aproximadamente $2 \mathrm{ppm}$ entre os valores experimentais e os descritos na literatura. Todos os sinais relativos aos demais carbonos foram semelhantes.

No espectro de HSQC ampliado da progesterona (Figura 64A) foi observado que o sinal relativo ao carbono C-7 $(\delta=32,0)$ está correlacionado a dois sinais: $\delta=1,09$ e $\delta=1,85$ correspondendo aos hidrogênios H-7 $\alpha$ e H-7 $\beta$, respectivamente. Já o sinal relativo ao carbono C-15 $(\delta=24,4)$ está correlacionado aos sinais de $\delta=1,24$ e $\delta=1,77$ correspondendo aos hidrogênios H-15 $\alpha$ e H-15 $\beta$ respectivamente. Comparando com o espectro de HSQC ampliado do composto isolado (Figura 64B) não foram observadas correlações nas regiões de 32,0 ppm e 24,0 ppm, evidenciando que os carbonos C-7 e C-15 sofreram hidroxilações. Os sinais em $\delta$ $=71,5$ e $\delta=74,0$ correlacionaram cada um a um único sinal respectivamente: $\delta=3,59$ e $\delta=$ 4,48 típicos de hidrogênios ligados à carbonos carbinólicos secundários (Figura 65B). Correlações na região de 70,0 a 75,0 ppm não foram observadas no espectro de HSQC da progesterona (Figura 65A). 
Figura 64. Espectros de RMN de HSQC (125 MHz E $500 \mathrm{MHz}, \mathrm{CDCl}_{3}$ ) ampliados: (A) progesterona; (B) produto di-hidroxilado isolado da reação com o caldo enzimático do fungo A.sydowii CBMAI 934.

(A)

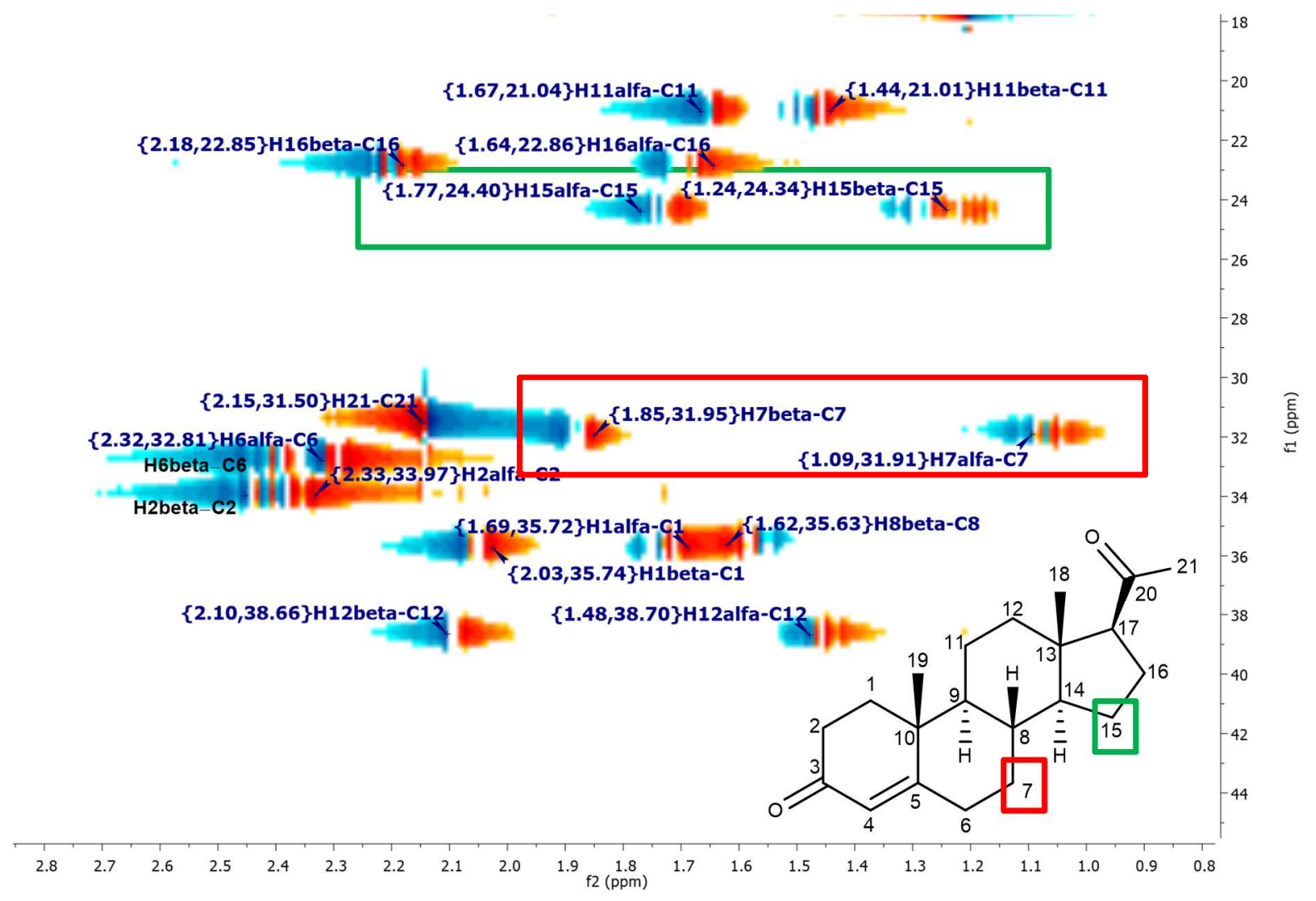

(B)

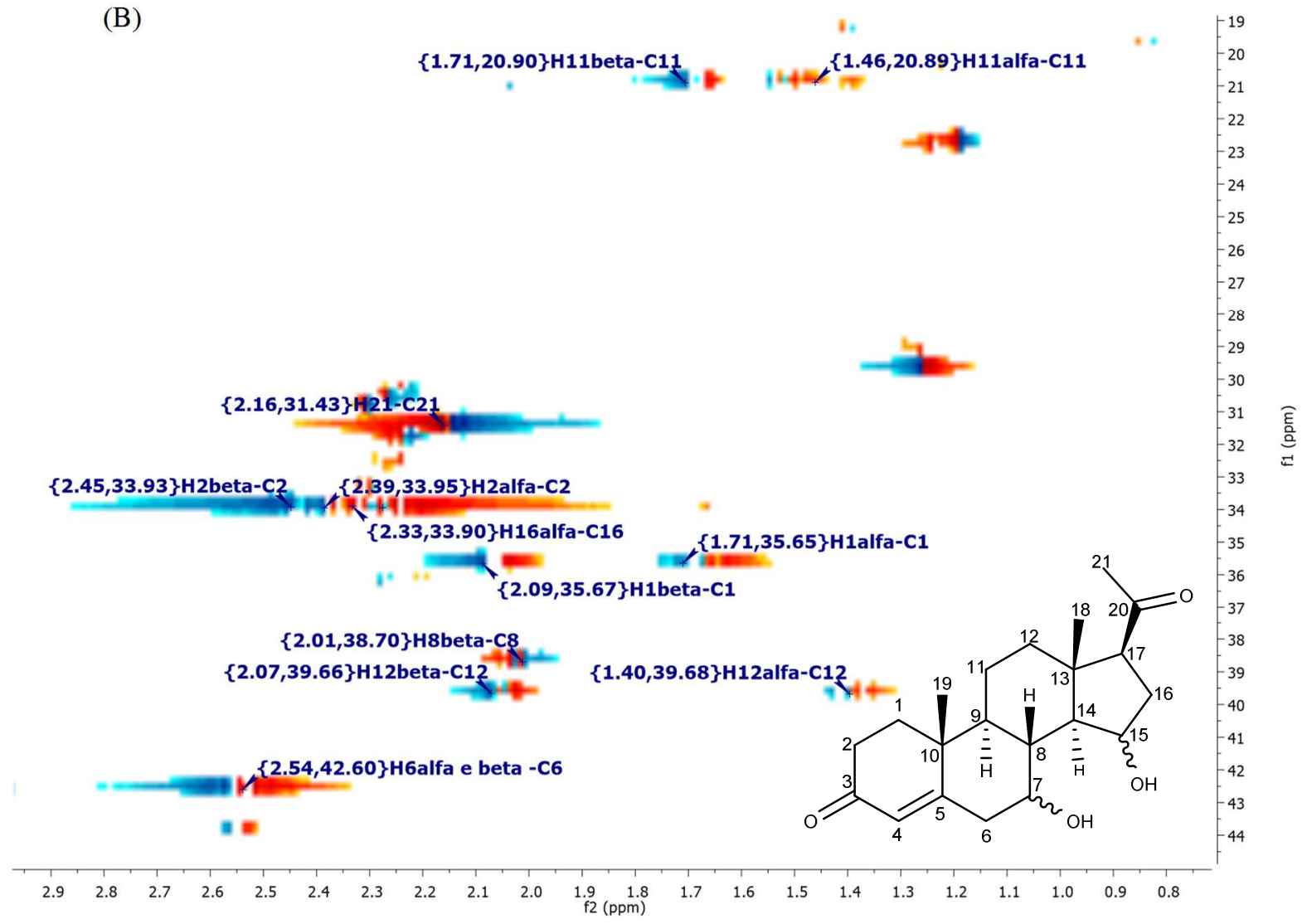


Figura 65. Espectros de RMN de HSQC (125 MHz e $500 \mathrm{MHz}, \mathrm{CDCl}_{3}$ ) completos: (A) progesterona; (B) produto di-hidroxilado isolado da reação com o caldo enzimático do fungo A sydowii CBMAI 934.

(A)

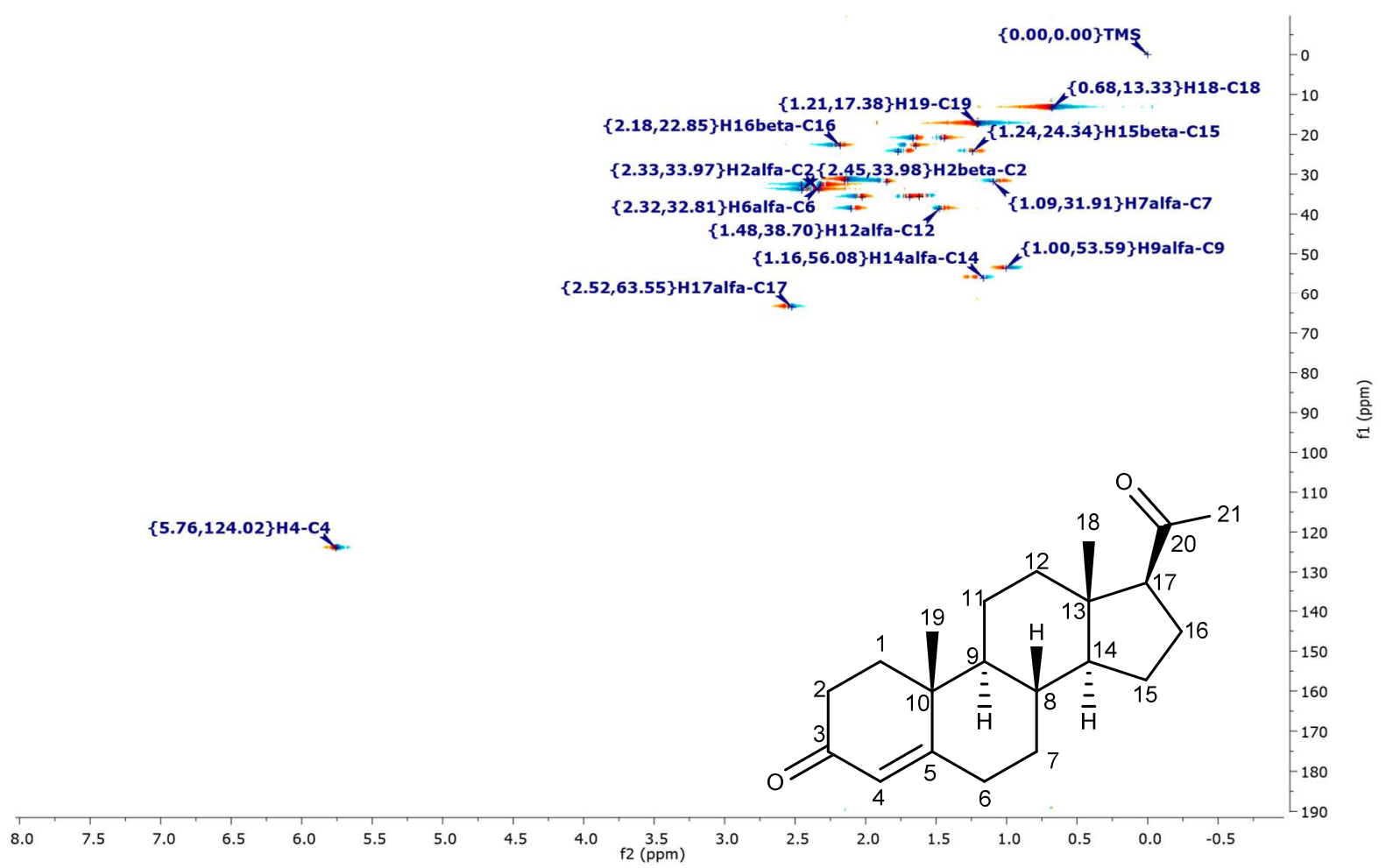

(B)

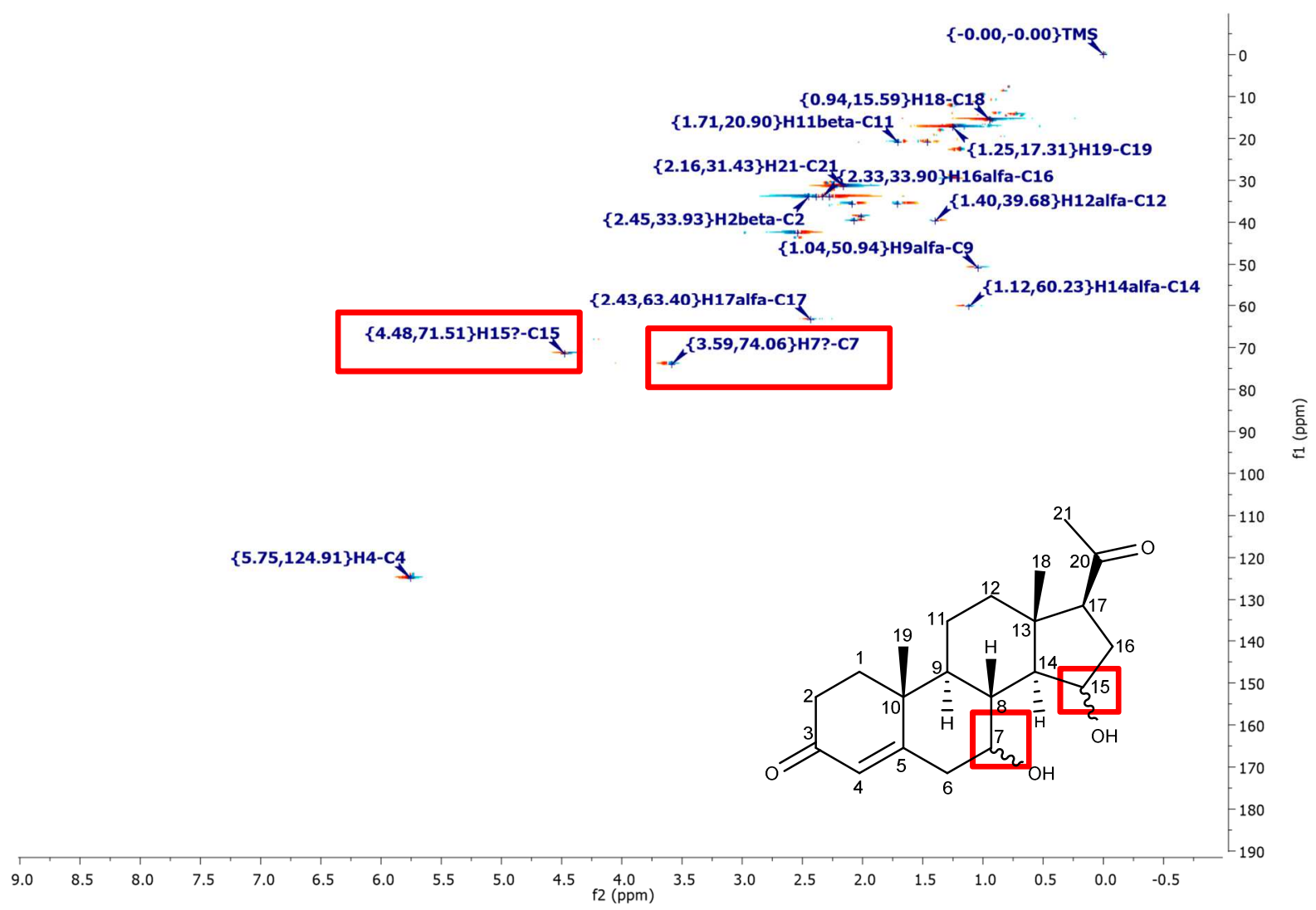


Como verificado houve uma diferença observada entre os valores de $\delta$ experimentais dos núcleos de ${ }^{13} \mathrm{C}$ relativos aos carbonos C-7 e C-15 e os valores de $\delta$ descritos na literatura relativos a esses carbonos nos dois estereoisômeros: o de configuração $7 \beta, 15 \beta^{74}$ e o de configuração $7 \alpha, 15 \beta^{76}$.

Através das análises do espectro de HMBC do composto di-hidroxilado isolado foi observado que o sinal em $\delta=3,62$ apresentou correlações com os sinais atribuídos aos carbonos C-8 $(\delta=38,7)$, C-14 $(\delta=60,3)$ (Figura 67). Como mostrado no espectro de HSQC (Figuras 64B e 65B) este sinal está correlacionado com o sinal de $\delta=74,0$ que por sua vez no espectro de HMBC (Figura 67) está correlacionado aos sinais dos hidrogênios H-9 $\alpha(\delta=1,04), H-14 \alpha(\delta=$

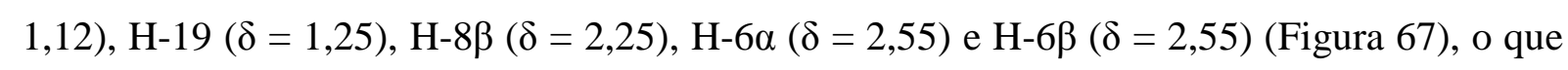
levou a sugerir que este sinal se refere ao carbono C-7. A partir destes dados ficou evidente a não conformidade com os dados fornecidos pela literatura, tanto para o de configuração $7 \beta, 15 \beta^{74}$ quanto para o de configuração $7 \alpha, 15 \beta^{76}$ (Tabela 21) .

Para o outro sinal de carbono carbinólico $(\delta=71,5)$ foi observado que no espectro de HMBC este sinal se correlacionou aos sinais dos hidrogênios H-14 $\alpha(\delta=1,12), \mathrm{H}-16 \alpha(\delta=2,3)$ e H-16 $(\delta=2,31)$ (Figura 67). Além disso, no espectro de HSQC do composto isolado, (Figuras 65B e 66B) o sinal de $\delta=71,5$ foi correlacionado ao sinal de $\delta=4,48$ que por sua vez se correlacionou aos sinais dos carbonos C-13 $(\delta=43,9)$ e C-17 $(\delta=63,9)$ no espectro de HMBC (Figura 67). Estas correlações observadas sugeriram que este sinal foi relativo ao carbono C-15. Sendo assim, seu valor de $\delta$ não foi concordante com o valor descrito na literatura para o isômero de configuração $7 \beta, 15 \beta^{74}$, mas foi plausível com o valor descrito para o isômero de configuração $7 \alpha, 15 \beta^{76}$ (Tabela 21). As correlações encontradas no espectro de HMBC envolvendo os carbonos C-7, C-15 e os hidrogênios ligados a eles estão representadas na Figura 66. 
Figura 66. Algumas correlações $J_{\mathrm{HC}}$ observadas nos espectros de HMBC do produto di-hidroxilado isolado da reação com o caldo enzimático do fungo $A$. sydowii CBMAI 934 (A) $J_{\mathrm{H} 7-\mathrm{C}}(\mathrm{B}) J_{\mathrm{H}-\mathrm{C} 7}$, (C) $J_{\mathrm{H}-\mathrm{C} 15}$, (D) $J_{\mathrm{H} 15-}$ C.

(A)

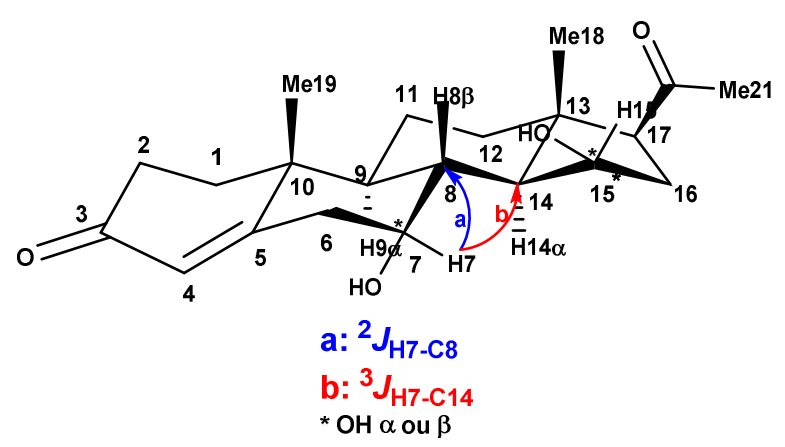

(B)

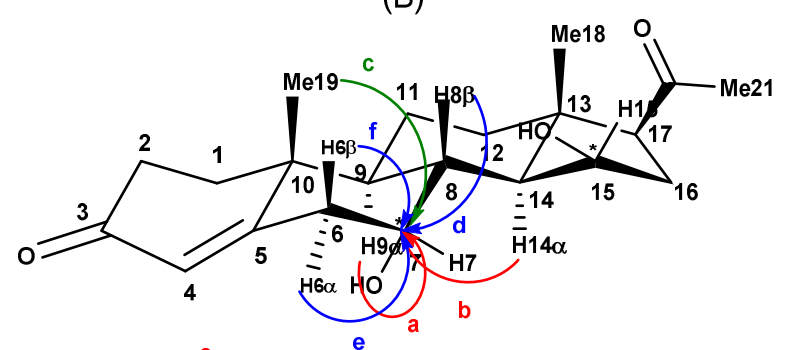

a: ${ }^{3} J_{\mathrm{H} 9 \alpha-\mathrm{C} 7}$

b: ${ }^{3} J_{\mathrm{H} 14 \alpha-\mathrm{C} 7}$

d: ${ }^{2} J_{\mathrm{H} 8 \beta-\mathrm{C} 7}$

c: ${ }^{4} J_{\mathrm{H} 19-\mathrm{C} 7}$

e: ${ }^{2} J_{\mathrm{H} 6 \alpha-\mathrm{C} 7}$

f: ${ }^{2} J_{\mathrm{H} 6 \beta-\mathrm{C} 7}$
(C)

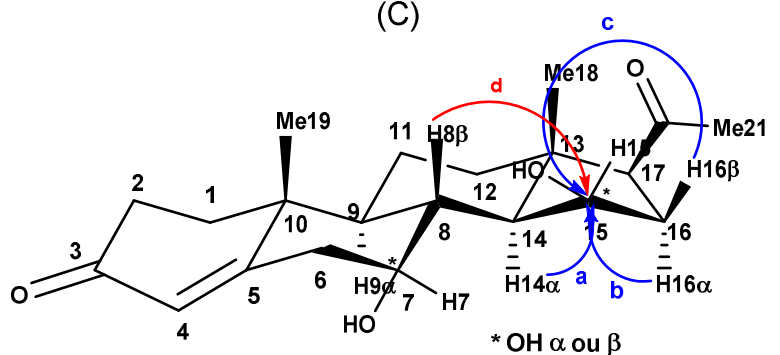

$\begin{array}{ll}\text { a: }{ }^{2} J_{\mathrm{H} 14 \alpha-\mathrm{C} 15} & \text { c: }{ }^{2} J_{\mathrm{H} 16 \beta-\mathrm{C} 15} \\ \text { b: }{ }^{2} J_{\mathrm{H} 16 \alpha-\mathrm{C} 15} & \text { d: }{ }^{3} J_{\mathrm{H} 8 \beta-\mathrm{C} 15}\end{array}$

(D)

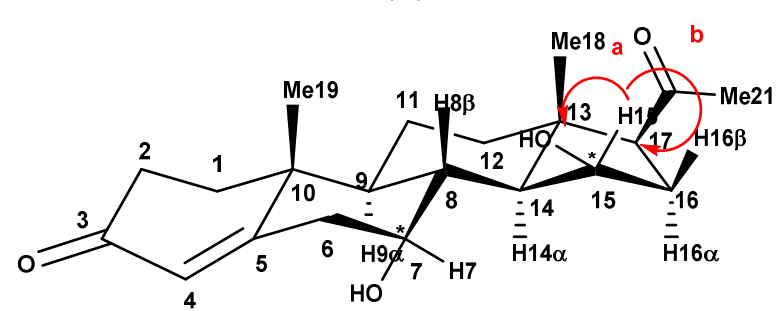

a: ${ }^{3} J_{\mathrm{H} 15-\mathrm{C} 13}$

b: ${ }^{3} J_{\mathrm{H} 15-\mathrm{C} 17}$

* $\mathrm{OH} \alpha$ ou $\beta$

* $\mathrm{OH} \alpha$ ou $\beta$ 
Figura 67. Ampliação do espectro de RMN de $\mathrm{HMBC}\left(125 \mathrm{MHz}\right.$ e $\left.500 \mathrm{MHz}, \mathrm{CDCl}_{3}\right)$ do produto dihidroxilado isolado da reação com o caldo enzimático do fungo A.sydowii CBMAI 934.

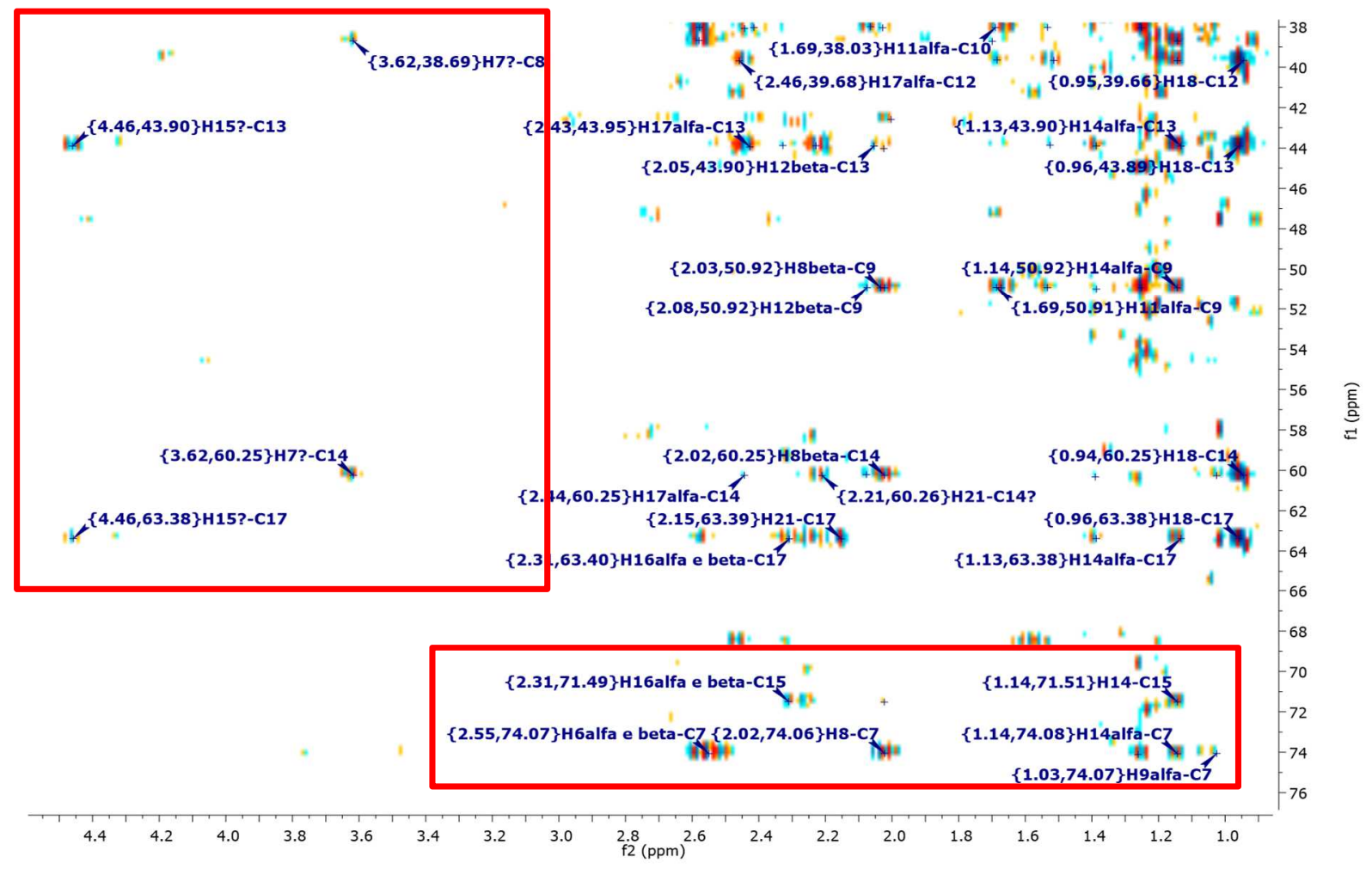

Através das análises do espectro de COSY do produto di-hidroxilado isolado da reação com o caldo enzimático do fungo A. sydowii CBMAI 934, como mostra a Figura 69, foram observadas correlações do hidrogênio carbinólico $\delta=3,59$ (neste espectro aparece com $\delta=$

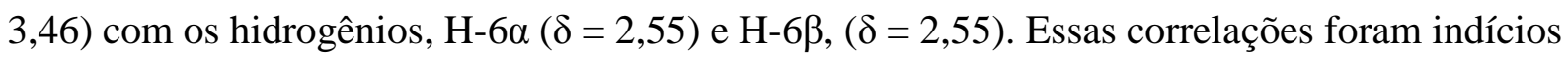
de que a hidroxilação ocorreu no carbono C-7 da progesterona. Para o hidrogênio carbinólico $\delta$ $=4,48$ (neste espectro aparece $\operatorname{com} \delta=4,35$ ) foram observadas correlações intensas nas regiões de $\delta=1,05$, indicando ser uma correlação com o hidrogênio $H-14 \alpha(\delta=1,16)$. Outro sinal intenso foi observado na região de $\delta=2,24$ indicando ser correlações com os hidrogênios H-21 $(\delta=2,16), \mathrm{H}-16 \alpha(\delta=2,32)$ e H-16 $\beta,(\delta=2,32)$. Esses sinais evidenciaram que o carbono C15 da progesterona também foi hidroxilado. Contudo, os dados das análises do espectro de COSY não permitem concluir quais são orientações, $\alpha$ ou $\beta$, das hidroxilas do produto obtido. As possíveis correlações encontradas no espectro de COSY do produto di-hidroxilado estão representadas na Figura 68. 
Figura 68. Algumas correlações $J_{\mathrm{HH}}$ observadas nos espectros de COSY do produto di-hidroxilado

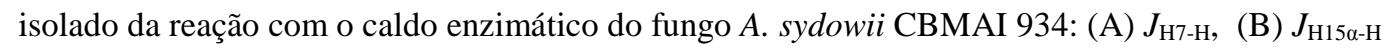

(A)

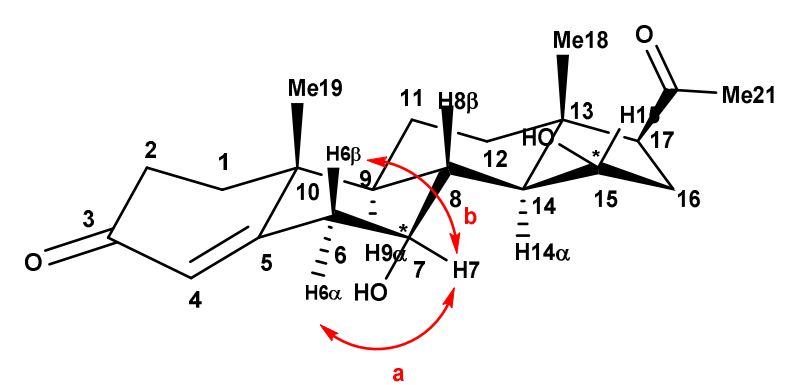

a: ${ }^{3} J_{\mathrm{H} 7-\mathrm{H} 6 \alpha}$

b: ${ }^{3} J_{\mathrm{H} 7-\mathrm{H} 6 \beta}$
(B)

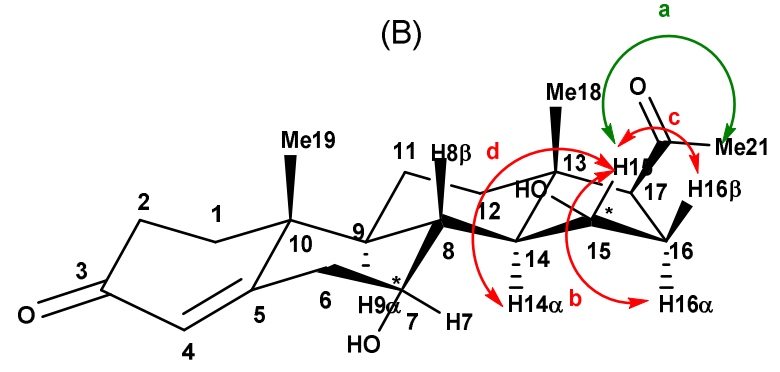

$$
\begin{array}{ll}
\text { a: }{ }^{6} J_{\mathrm{C} 15-\mathrm{H} 21} & \text { c: }{ }^{3} J_{\mathrm{H} 15-\mathrm{H} 16 \beta} \\
\text { b: }{ }^{3} J_{\mathrm{H} 15-\mathrm{H} 16 \alpha} & \text { d: }{ }^{3} J_{\mathrm{H} 15-\mathrm{H} 14 \alpha}
\end{array}
$$

* OH $\alpha$ ou $\beta$

Figura 69. Ampliação do espectro de $\mathrm{RMN}$ de $\operatorname{COSY}\left(400 \mathrm{MHz}, \mathrm{CDCl}_{3}\right)$ do produto di-hidroxilado isolado da reação com o caldo enzimático do fungo A .sydowii CBMAI 934.

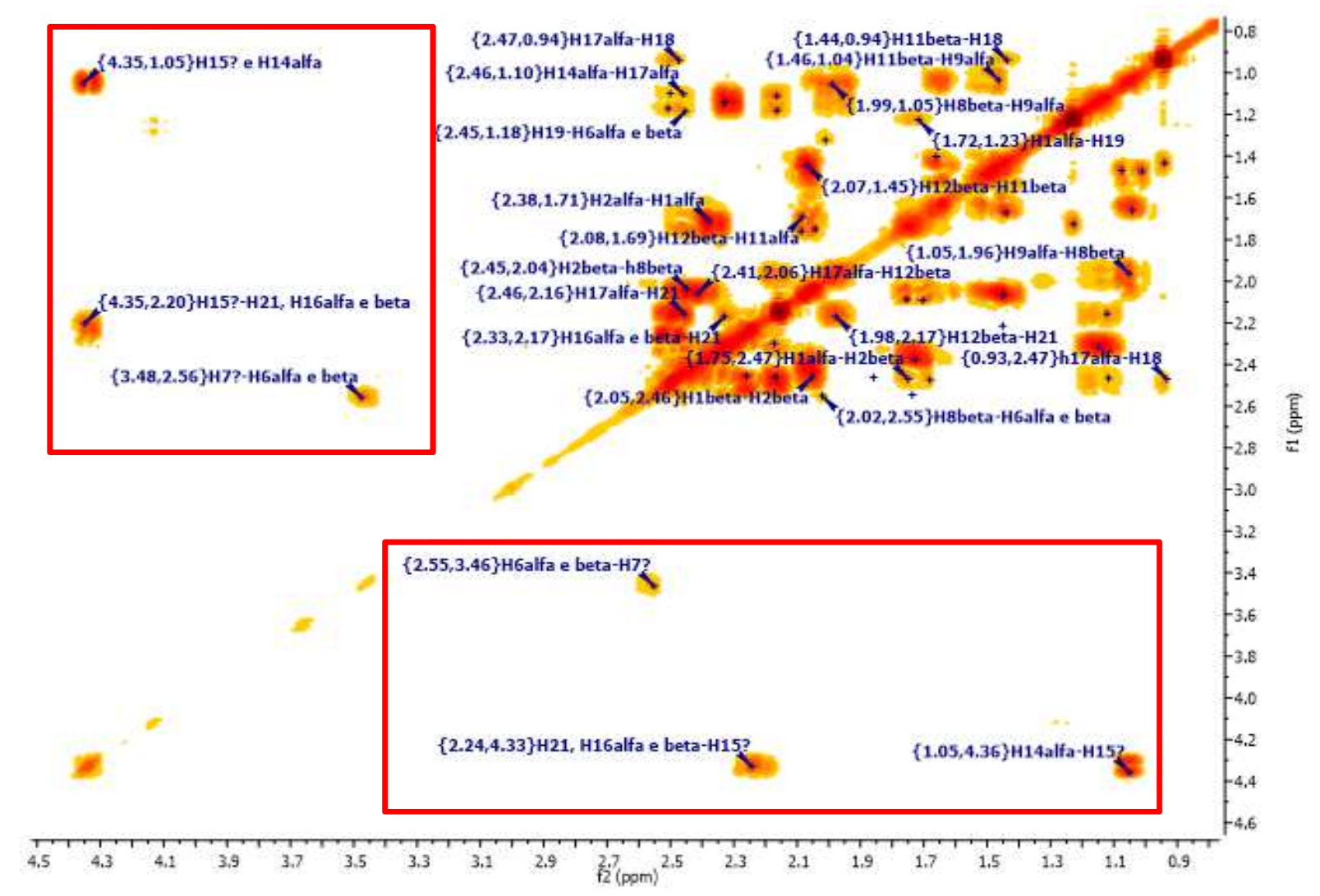

Kirk, et al. (1990) ${ }^{75}$ apresentaram dados de deslocamentos químicos de ${ }^{1} \mathrm{H}$ para 166 esteroides e perceberam que ao analisar os espectros de $\mathrm{RMN}$ de ${ }^{1} \mathrm{H}$ que a grande maioria dos sinais de prótons do esqueleto esteroidal tinham essencialmente o mesmo perfil de multiplicidade e esta diminuía com a presença de substituintes geminais, vicinais ou instaurações. Dessas observações concluíram que o perfil do multipleto dos hidrogênios do 
núcleo esteroidal poderia servir como um modelo para identificar a orientação espacial $\alpha$ ou $\beta$ dos hidrogênios dos esteroides. A Figura 70 apresenta os modelos de multiplicidades para os hidrogênios ligados aos carbonos C-7 e C-15 de acordo com a literatura ${ }^{75}$.

Figura 70. Modelos para reconhecimento de sinais de ${ }^{1} \mathrm{H}$ em espectros de RMN de esteroides ${ }^{75}$ : (A) H7, (B) H-15.

(A)<smiles>C1=CC1</smiles>

(a)

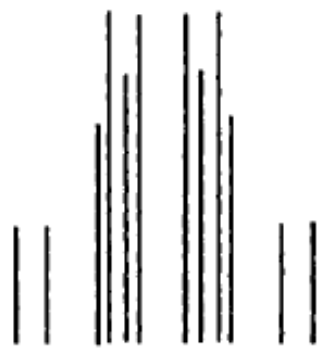

(b)

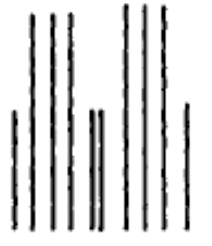

$\mathrm{H}-7 \beta$

$H-7 \alpha$

(B)

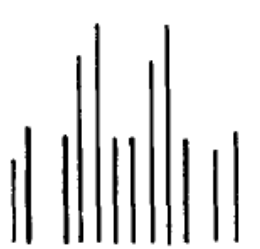

(c)

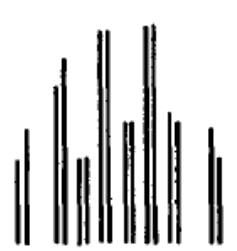

(d)

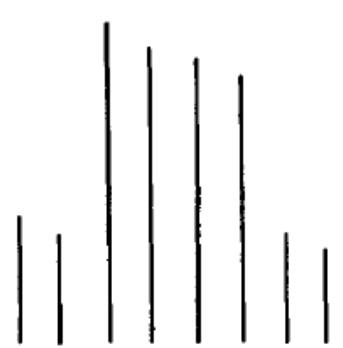

(c)

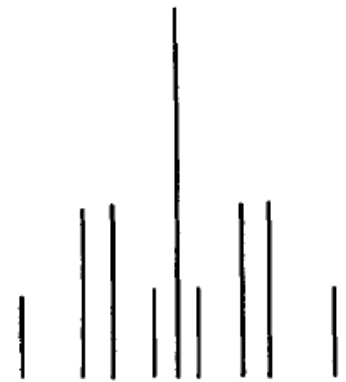

(d)

$\mathrm{H}-15 \alpha$

$\mathrm{H}-15 \beta$

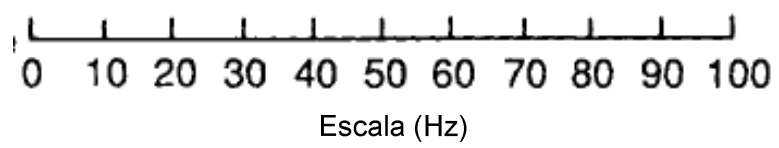

a e b: variações comuns resultantes de leves diferenças nas constantes de acoplamento

c: modelos observados normalmente em esteroides do tipo $17 \beta$-substituídos

d: modelos observados normalmente em esteroides de C-17 cetônico

Fonte: Adaptação de Kirk, D.N., et al. A survey of the high-field ${ }^{1} \mathrm{H}$ NMR spectra of the steroid hormones, their hydroxylated derivates and related compounds. Journal of the Chemical Society, Perkin Transactions. 2, 1990, n.9, p.1570 e 1571.

Comparando as multipletos dos hidrogênios $\mathrm{H}-7$, tanto da progesterona quanto do produto di-hidroxilado isolado, com o modelo de reconhecimento de sinais da literatura, como mostra a Figura 71 foi observado que o multipleto do hidrogênio H-7 do produto di-hidroxilado isolado possui uma semelhança maior com o $\mathrm{H}-7 \alpha$ da progesterona. Esses dois multipletos, 
tanto da progesterona, quanto do produto di-hidroxilado possuem semelhanças com o perfil do modelo descrito na literatura para o hidrogênio H-7 $\alpha$. Contudo, observou-se também que a multiplicidade do H-7 do produto isolado foi menor em relação ao sinal do hidrogênio H-7 $\beta$ da progesterona e isso pode estar relacionado justamente à presença de hidroxila geminal a esse hidrogênio na estrutura do produto. Sendo assim, este hidrogênio pode ser de orientação $\beta$.

Figura 71. Sinais de multipletos de hidrogênios H-7 obtidos de espectros de RMN de ${ }^{1} \mathrm{H}(400 \mathrm{MHz}$, $\mathrm{CDCl}_{3}$ ): (A) progesterona (B) produto di-hidroxilado isolado da reação com o caldo enzimático do fungo $A$. sydowii CBMAI 934.
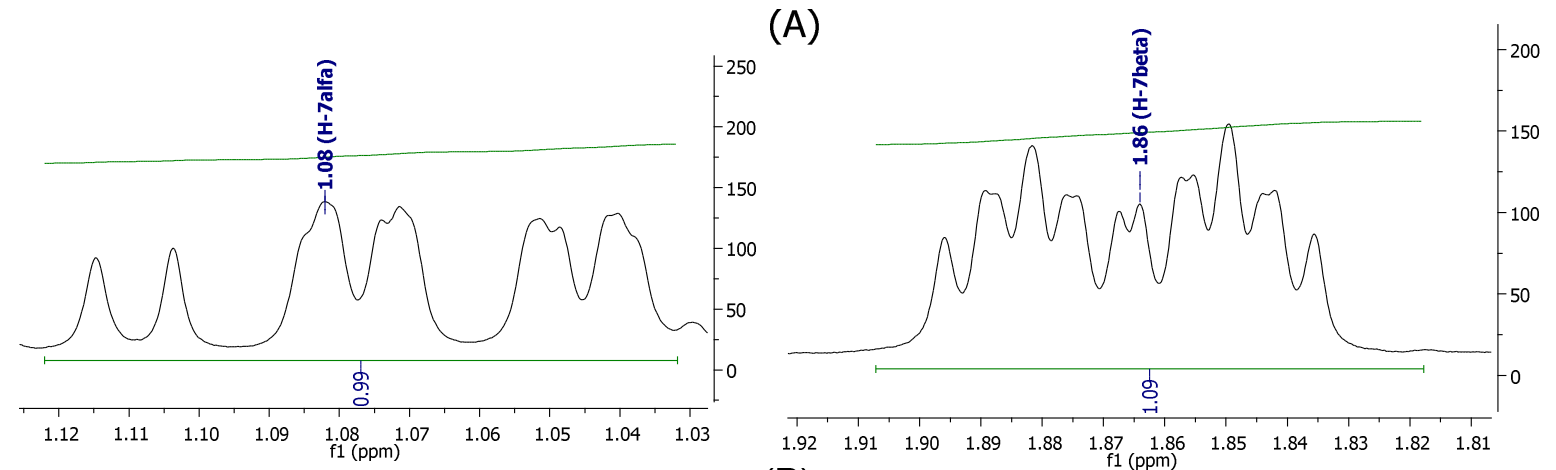

(B)

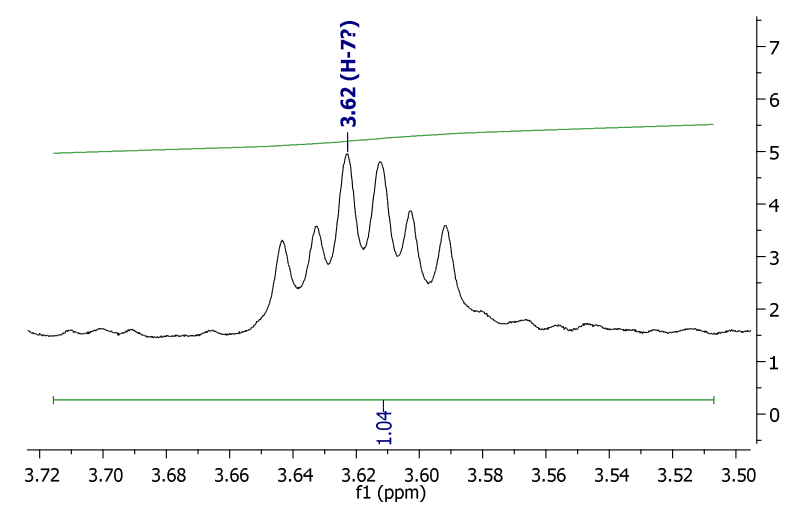

Na Tabela 22 estão descritas as constantes de acoplamento encontradas para os hidrogênios H-7 $\alpha$ e H-7 $\beta$ da progesterona, bem como os hidrogênios envolvidos nos acoplamentos. A Figura 72 representa as possíveis correlações encontradas para os hidrogênios H-7 $\alpha$ e H-7 $\beta$ da progesterona. 
Tabela 22. Constantes de acoplamento $(J)$ obtidas experimentalmente para os hidrogênios H-7 $\alpha$ e H-7 $\beta$ da progesterona.

\begin{tabular}{ccc}
\hline & H-7 $\alpha$ & \\
$J(\mathrm{~Hz})$ & Tipo de acoplamento & Hidrogênios envolvidos \\
\hline 4,41 & Vicinal axial-equatorial & H-7 $\alpha-\mathrm{H}-6 \alpha$ \\
12,7 & Vicinal axial-axial & H-7 $\alpha-\mathrm{H}-6 \beta$ e H-7 $\alpha-\mathrm{H}-8 \beta$ \\
13,5 & Geminal axial-equatorial & H-7 $\alpha-\mathrm{H}-7 \beta$ \\
\hline$J(\mathrm{~Hz})$ & $\mathrm{H}-7 \beta$ & $\mathrm{Hidrogennios} \mathrm{envolvidos}$ \\
\hline 2,95 & Tipo de acoplamento & $\mathrm{H}-7 \beta-\mathrm{H}-6 \alpha$ \\
3,22 & Vicinal equatorial-equatorial & $\mathrm{H}-7 \beta-\mathrm{H}-6 \alpha$ \\
5,13 & Vicinal equatorial-equatorial & $\mathrm{H}-7 \beta-\mathrm{H}-6 \beta$ e H-7 $\beta-\mathrm{H}-8 \beta$ \\
12,9 & Vicinal equatorial-axial & $\mathrm{H}-7 \beta-\mathrm{H}-7 \alpha$ \\
\hline
\end{tabular}

Figura 72. Algumas possíveis correlações $J_{\mathrm{HH}}$ da progesterona obtidas a partir das constantes de acoplamentos calculdas dos sinais dos hidrogênios H-7: (A) $J_{\mathrm{H} 7 \alpha-\mathrm{H}}$, (B) $J_{\mathrm{H} 7 \mathrm{\beta}-\mathrm{H}}$

(A)

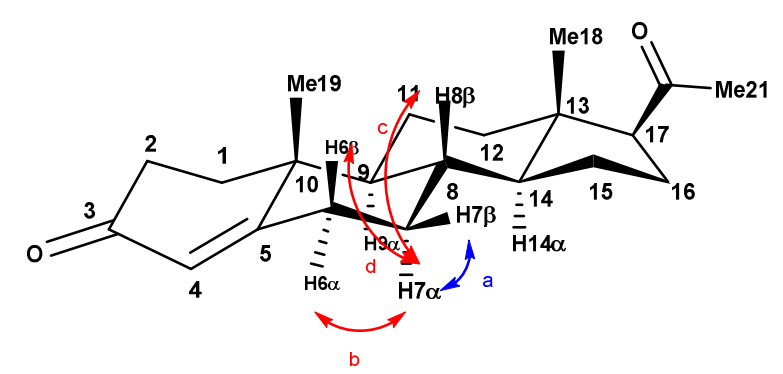

$\begin{array}{ll}\text { a: }{ }^{2} J_{H 7 \alpha-H 7 \beta} & \text { c: }{ }^{3} J_{H 7 \alpha-H 8 \beta} \\ \text { b: }{ }^{3} J_{H 7 \alpha-H 6 \alpha} & \text { d: }{ }^{3} J_{H 7 \alpha-H 6 \beta}\end{array}$
(B)

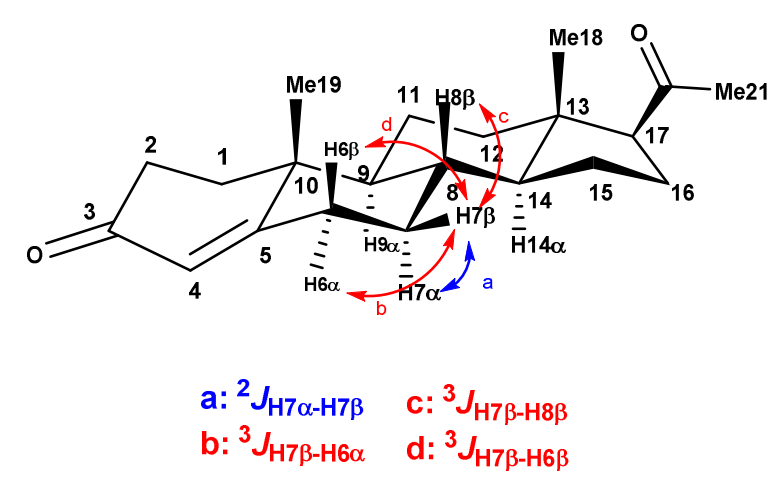

Já a Tabela 23 apresenta os valores das constantes de acoplamento encontradas para o hidrogênio H-7 do produto isolado, bem como os hidrogênios envolvidos nos acoplamentos.

Tabela 23. Constantes de acoplamento $(J)$ obtidas experimentalmente para o hidrogênio H-7 do produto di-hidroxilado isolado da reação com o caldo enzimático do fungo A. sydowii CBMAI 934.

\begin{tabular}{ccc}
$J(\mathrm{~Hz})$ & Tipo de acoplamento & Possíveis hidrogênios envolvidos \\
\hline 5,11 & Vicinal equatorial-equatorial & H-7 $\beta-\mathrm{H}-6 \alpha$ \\
10,9 & Vicinal equatorial-axial & H-7 $\beta-\mathrm{H}-6 \beta$ e H-7 $\beta-\mathrm{H}-8 \beta$ \\
11,1 & Vicinal equatorial-axial & H-7 $\beta-\mathrm{H}-6 \beta$ e H-7 $\beta-\mathrm{H}-8 \beta$ \\
\hline
\end{tabular}

Entendeu-se que as constantes $J=10,9 \mathrm{~Hz}$ e $J=11,1 \mathrm{~Hz}$ por serem muito próximas representam o mesmo acoplamento. A partir das comparações do perfil de multiplicidade do 
sinal do H-7 do metabólito di-hidroxilado com o sinal do hidrogênio H-7 $\beta$ da progesterona, com o modelo de multiplicidade descrito na literatura ${ }^{75}$ e por fim, se baseando nas constantes de acoplamento obtidas, sugeriu-se que a orientação do hidrogênio H-7 do produto dihidroxilado foi $\beta$. Consequentemente, sugeriu-se que a orientação da hidroxila ligada ao carbono C-7 foi $\alpha$. No entanto, vale lembrar que o valor de delosccamento químico para o H-7 do composto di-hidroxilado é concordante com o valor descrito na literatura para o composto de configuração $7 \beta, 15 \beta$. Ou seja, a sugestão não é concordante com a comparação do valor de deslocamento químico obtido na literatura com o experimetal. Considerando que a orientação do hidrogênio H-7 do produto hidroxilado foi $\beta$, a Figura 73 representa as possíveis correlações encontradas para o hidrogênio H-7 do composto di-hidroxilado isolado.

Figura 73. Algumas possíveis correlações $J_{\mathrm{HH}}$ do produto di-hidroxilado obtidas a partir das constantes de acoplamentos calculdas dos sinais dos hidrogênios H-7: (A) $J_{\mathrm{H} 7 \alpha-\mathrm{H}}$, (B) $J_{\mathrm{H} 7 \mathrm{\beta}-\mathrm{H}}$

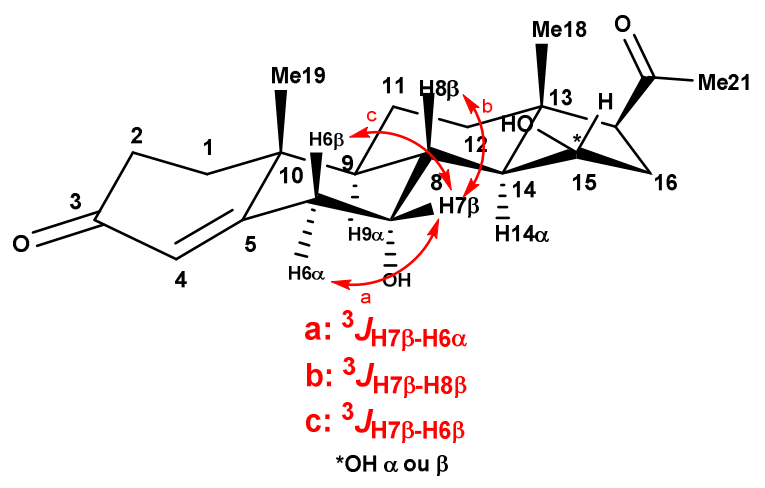

Comparando as multipletos dos hidrogênios H-15, tanto da progesterona quanto do produto isolado, com o modelo de reconhecimento de sinais da literatura ${ }^{75}$ como mostra a Figura 74, foi observado que o multipleto do hidrogênio H-15 não possui semelhança com algum perfil de multipleto dos hidrogênios H-15 da progesterona. Porém, o multipleto do hidrogênio H-15 do composto di-hidroxilado foi semelhante ao modelo de multiplicidade para o hidrogênio H-15ß de esteroides com carbono C-17 cetônico, como mostra a Figura 71. Todavia, tanto a progesterona, quanto composto di-hidroxilado são de carbono C-17 $\beta$ substituído. Sendo assim, com esses dados obtidos não foi possível determinar a configuração da hidroxila ligada ao carbono C-15 e consequentemente a estereoquímica relativa desta molécula. 
Figura 74. Sinais de multipletos de hidrogênios H-15 obtidos de espectros de RMN de ${ }^{1} \mathrm{H}(400 \mathrm{MHz}$, $\mathrm{CDCl}_{3}$ ): (A) progesterona (B) produto di-hidroxilado isolado da reação com o caldo enzimático do fungo A.sydowii CBMAI 934.

(A)
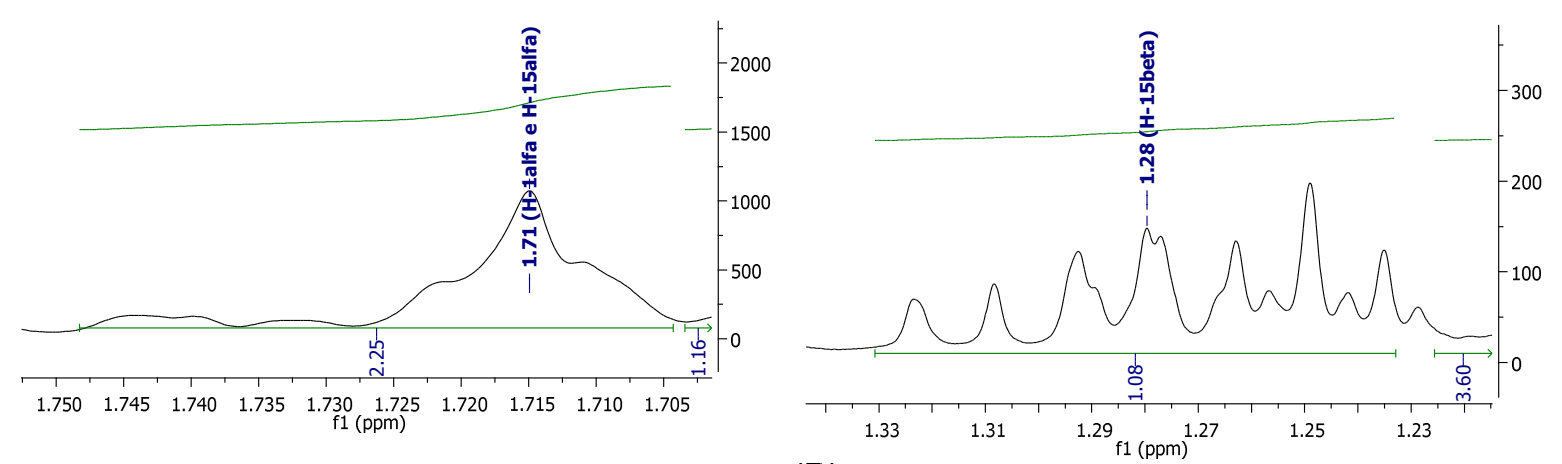

(B)

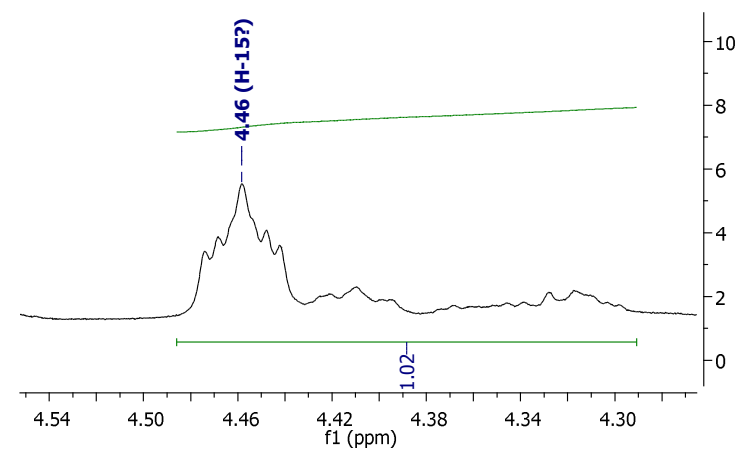

Foram feitos estudos teóricos de simulação de espectros de RMN pelo Prof. Dr. Isac George Rosset do Departamento de Engenharias e Exatas da Universidade Federal do Paraná Setor Palotina, dos quatro possíveis isômeros hidroxilados do composto isolado nos carbonos C-7 e C-15 solvatados em $\mathrm{CDCl}_{3}$ utilizando o Gaussian03 como software de execução dos cálculos e Gabedit 2.4.8 como software de interface gráfica. O Nível de teoria utilizado foi DFT/B3LYP/6-31G(d,p)// DFT/B3LYP/6-31G(d,p). O método de solvatação utilizado foi o IEFPCM (em inglês: Integral Equation Formalism Polarizable Continum Model.) A Tabela 24 apresenta os dados de deslocamentos químicos de ${ }^{13} \mathrm{C}$ e ${ }^{1} \mathrm{H}$ obtidos com o estudo teórico comparativo com os obtidos experimentalmente. 
Tabela 24. Valores de deslocamentos químicos (ppm) de $\mathrm{RMN}\left({ }^{13} \mathrm{C}\right.$ e $\left.{ }^{1} \mathrm{H}\right)$ teóricos comparativos com os dados experimentais para os isômeros do produto di-hidroxilado isolado da reação com o caldo enzimático do fungo A. sydowii CBMAI 934.

\begin{tabular}{|c|c|c|c|c|c|c|c|c|c|c|c|}
\hline \multirow{3}{*}{${ }^{13} \mathrm{C}$} & \multicolumn{4}{|c|}{$\delta^{13} \mathrm{C}$ (teórico) } & \multirow{3}{*}{$\begin{array}{c}\delta^{13} \mathrm{C} \\
(\exp .)^{\mathrm{b}}\end{array}$} & \multirow{3}{*}{${ }^{1} \mathrm{H}$} & \multicolumn{4}{|c|}{$\delta^{1}{ }_{\mathrm{H}}($ teórico) } & \multirow{3}{*}{$\begin{array}{c}\delta^{1}{ }_{\mathrm{H}} \\
(\exp .)^{\mathrm{c}}\end{array}$} \\
\hline & \multicolumn{4}{|c|}{ Isômeros $^{\mathrm{a}}$} & & & & Isôn & $\operatorname{eros}^{\mathrm{a}}$ & & \\
\hline & $7 \beta, 15 \beta$ & $7 \alpha, 15 \alpha$ & $7 \beta, 15 \alpha$ & $7 \alpha, 15 \beta$ & & & $7 \beta, 15 \beta$ & $7 \alpha, 15 \alpha$ & $7 \beta, 15 \alpha$ & $7 \alpha, 15 \beta$ & \\
\hline \multirow{2}{*}{1} & \multirow{2}{*}{37,7} & \multirow{2}{*}{37,6} & \multirow{2}{*}{37,7} & \multirow{2}{*}{37,5} & \multirow{2}{*}{35,6} & $1 \alpha$ & 1,76 & 1,87 & 1,76 & 1,89 & 1,71 \\
\hline & & & & & & $1 \beta$ & 2,04 & 2,08 & 2,06 & 2,04 & 2,09 \\
\hline \multirow{2}{*}{2} & \multirow{2}{*}{34,3} & \multirow{2}{*}{34,3} & \multirow{2}{*}{34,3} & \multirow{2}{*}{34,4} & \multirow{2}{*}{33.9} & $2 \alpha$ & 2,16 & 2,08 & 2,14 & 2,18 & 2,38 \\
\hline & & & & & & $2 \beta$ & 2,58 & 2,53 & 2,59 & 2,58 & 2,45 \\
\hline 3 & 190,9 & 190,2 & 190,8 & 190,3 & 199,4 & - & - & - & - & - & - \\
\hline 4 & 121,5 & 122,0 & 121,6 & 122,7 & 124,8 & 4 & 5,86 & 5,91 & 5,87 & 5,89 & 5,75 \\
\hline 5 & 164,3 & 167,2 & 164,0 & 166,5 & 167,2 & - & - & - & - & - & - \\
\hline \multirow{2}{*}{6} & \multirow{2}{*}{44,4} & \multirow{2}{*}{41,2} & \multirow{2}{*}{44,3} & \multirow{2}{*}{44,5} & \multirow{2}{*}{42,6} & $6 \alpha$ & 2,42 & 2,53 & 2,30 & 2,30 & 2,56 \\
\hline & & & & & & $6 \beta$ & 2,85 & 2,80 & 2,84 & 2,91 & 2.56 \\
\hline \multirow{2}{*}{7} & \multirow{2}{*}{75,2} & 69,6 & 74,1 & 706 & 74.0 & $7 \alpha$ & 3,93 & - & 3,96 & & 362 \\
\hline & & & & & & $7 \beta$ & - & 4,21 & - & 4,22 & \\
\hline 8 & 39,6 & 41,6 & 42,6 & 38,2 & 38,7 & $8 \beta$ & 2,42 & 1,87 & 2,14 & 2,30 & 2,01 \\
\hline 9 & 53,9 & 49,9 & 52,9 & 48,7 & 50,9 & $9 \alpha$ & 1,20 & 1,87 & 1,21 & 2,04 & 1,06 \\
\hline 10 & 42,3 & 42,6 & 42,3 & 43,1 & 38,0 & - & - & - & - & - & - \\
\hline 11 & 230 & 220 & 226 & 230 & 200 & $11 \alpha$ & 1,67 & 1,71 & 1,65 & 1,64 & 1,71 \\
\hline & & & & & & $11 \beta$ & 1,76 & 1,63 & 1,65 & 1,71 & 1,51 \\
\hline & & & & & & $12 \alpha$ & 1,29 & 1,51 & 1,36 & 1,32 & 1,40 \\
\hline & & & & & & $12 \beta$ & 2,04 & 2,08 & 2,14 & 2,04 & 2,07 \\
\hline 13 & 50,1 & 45,7 & 50,6 & 49,8 & 43,9 & - & - & - & - & -- & - \\
\hline 14 & 61,6 & 58,6 & 63,2 & 55,7 & 60,2 & $14 \alpha$ & 1,09 & 1,87 & 1,36 & 1,64 & 1,16 \\
\hline 15 & 725 & 743 & 726 & 727 & 715 & $15 \alpha$ & 4,60 & - & - & 4,76 & 146 \\
\hline & & & 12,0 & $12, I$ & 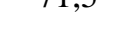 & $15 \beta$ & - & 4,69 & 4,56 & - & 4,40 \\
\hline 16 & 364 & 277 & 34 & 370 & 320 & $16 \alpha$ & 2,42 & 2,08 & 1,99 & 2,58 & 2,30 \\
\hline & & & & & & $16 \beta$ & 2,42 & 2,71 & 2,78 & 2,30 & 2,26 \\
\hline 17 & 63,7 & 61,9 & 61,3 & 63,5 & 63,3 & $17 \alpha$ & 2,16 & 2,71 & 2,51 & 2,30 & 2,43 \\
\hline 18 & 15,4 & 14,8 & 14,7 & 15,3 & 15,6 & 18 & 1,32 & 0,93 & 0,99 & 1,27 & 0,96 \\
\hline 19 & 18,2 & 18,1 & 18,2 & 17,8 & 17,3 & 19 & 1,46 & 1,36 & 1,46 & 1,43 & 1,25 \\
\hline 20 & 206,9 & 205,8 & 206,9 & 206,5 & 208,6 & - & - & - & - & - & - \\
\hline 21 & 30,7 & 30,3 & 30,7 & 30,7 & 31,4 & 21 & 2,34 & 2,35 & 2,30 & 2,35 & 2,16 \\
\hline $\mathrm{R}^{2}$ & 0,9971 & 0,9948 & 0,9963 & 0,9953 & 1,0000 & $\mathrm{R}^{2}$ & 0,9723 & 0,9385 & 0,9721 & 0,9348 & 1,0000 \\
\hline
\end{tabular}

${ }^{\mathrm{a}} \mathrm{CDCl}_{3},{ }^{\mathrm{b}} 100 \mathrm{MHz}, \mathrm{CDCl}_{3},{ }^{\mathrm{c}} 400 \mathrm{MHz}, \mathrm{CDCl}_{3}$ 
Segundo Rosset, a comparação entre os dados do estudo teórico e os obtidos experimentalmente não são conclusivos para se determinar extamente a configuração do composto di-hidroxilado, sendo $70 \%$ a probabilidade de ser o isômero de configuração $7 \beta, 15 \beta$ inicalmente proposto pelas análises de RMN com os resultados preliminares que possui discordância entre os valores de deslocamento químico descritos na literatura ${ }^{74}$ e experimental para os carbonos C-7 e C-15, mas há concordância entre os valores de deslocamento químico da literatura e experimentais para os hidrogênios H-7 $\beta$ e H-15ß. Porém, é maior que $70 \%$ a probabilidade de ser o isômero de configuração $7 \alpha, 15 \beta$, segundo mensagem enviada pelo referido pesquisador por correio eletrônico, transcrita abaixo:

\begin{abstract}
"De acordo com os cálculos, o isômero que foi proposto na posição $15 \beta$, foi o único que deu uma diferença de $1 \mathrm{ppm}$ do valor calculado para o valor experimental, o que pode estar dentro do erro. Para os outros 3 possíveis estereoisômeros, os valores de C-15 dão mais que $1 \mathrm{ppm}$ de diferença entre o calculado e o experimental. Porém, esse $70 \%$ de certeza não se deve apenas à diferença entre o os valores calculados e os experimentais obtidos, mas também ao valor experimental da literatura.

Aqueles valores estatísticos foram baseados nos dados experimentais obtidos. Entretanto, baseando nos dados experimentais da literatura, o isômero proposto pela literatura não está correto, pois os cálculos mostram que o isômero correto seria o $7 \alpha, 15 \beta$ ! Mas, não sei se cabe discutir isso.
\end{abstract}

Apesar do poder e da acurácia computacional de métodos quânticos terem evoluídos, particularmente confio mais nos valores experimentais.

Então, concluindo, comparando os valores calculados com os valores experimentais obtidos, os cálculos mostraram que a probabilidade de ser o isômero $7 \beta, 15 \beta$ é de $70 \%$.

Porém, comparando os valores calculados com os valores da literatura, os cálculos mostraram que a probabilidade de ser o isômero $7 \alpha, 15 \beta$ é maior que $70 \% ! ! ! "$

(ROSSET, I. G - Mensagem enviada por correio eletrônico em 03/03/2016).

Considerando que o composto isolado da reação de biotransformação da progesterona com o caldo enzimático do fungo A. sydowii CBMAI 934 seja o isômero de configuração $7 \alpha, 15 \beta$ os dados do estudo teórico são concordantes com as comparações entre perfis de multiplicidade do hidrogênio $\mathrm{H}-7 \beta$ da progesterona, do modelo descrito na literatura ${ }^{75}$ e do composto di-hidroxilado. Para confirmação dessa configuração, é necessário ser feito experimentos de de RMN bidimensional de NOESY ou caracterizar o cristal do composto por difração de Raios-X. Foram feitas tentativas de executar esses experimentos, porém não foram bem-sucedidas.

Foram feitos experimentos no IV com o composto isolado. As bandas encontradas estão descritas na Tabela 25 atribuídas segundo Mohamed et al. $(2014)^{71}$, Silverstein et al., $(2006)^{71}$ 
e Pavia et al. (2015) $)^{77}$. A Figura 75 apresenta de forma comparativa o espectro de IV obtido experimentalmente para a progesterona e para o produto di-hidroxilado. ${ }^{69,70}$

Tabela 25. Valores das bandas vibracionais obtidas por IV para o produto di-hidroxilado isolado da reação com o caldo enzimático do fungo $A$.sydowii CBMAI 934.

\begin{tabular}{|c|c|c|}
\hline \multirow{2}{*}{ Ligação/tipo de vibração } & \multicolumn{2}{|c|}{ Valores de $v_{\text {máx }}\left(\mathrm{cm}^{-1}\right)$} \\
\hline & literatura & experimental \\
\hline Deformação axial O-H & $3550-3200^{71}$ & \multirow{2}{*}{3371} \\
\hline Deformação axial $\mathrm{H}-\mathrm{C}=$ & acima de 300071 & \\
\hline Estiramento assimétrico $\mathrm{C}-\mathrm{H}$ & $2939,95^{70}$ & 2931 \\
\hline Estiramento assimétrico $\mathrm{C}-\mathrm{H}$ & $2854,13^{70}$ & \multirow{2}{*}{2852} \\
\hline Deformação axial de C-H (carbono terciário) & $2890^{71}$ & \\
\hline Estiramento $\mathrm{C}=\mathrm{O}$ de cetona $(\mathrm{C}-20)$ & $1698,28^{70}$ & 1699 \\
\hline Estiramento $\mathrm{C}=\mathrm{O}$ de cetona $(\mathrm{C}-3)$ & $1632,34^{70}$ & \multirow{2}{*}{1672} \\
\hline Deformação axial $\mathrm{C}=\mathrm{O}$ de cetona $\alpha, \beta$ insaturada $(\mathrm{C}-3)$ & $1685-1666^{71}$ & \\
\hline Estiramento $\mathrm{C}=\mathrm{C}(\mathrm{C}-4$ e $\mathrm{C}-5)$ & $1617,02^{70}$ & 1616 \\
\hline Deformação angular - $\mathrm{CH}_{2}$ (anel de ciclo-hexano) & $1452^{71}$ & 1454 \\
\hline Deformação angular simétrica fora do plano $\left(\mathrm{CH}_{2}\right.$ cíclico $)$ & $1350^{7170}$ & 1360 \\
\hline Dobramento C-O-H & $1440-1220^{77}$ & \multirow{2}{*}{1275} \\
\hline Deformação axial e angular de $\mathrm{C}-(\mathrm{C}=\mathrm{O})-\mathrm{C}$ & $1300-1100^{71}$ & \\
\hline Estiramento C-O & $1260-1110^{77}$ & \multirow{2}{*}{1230} \\
\hline Deformação axial e angular de $\mathrm{C}-(\mathrm{C}=\mathrm{O})-\mathrm{C}$ & $1300-1100^{71}$ & \\
\hline Estiramento C-O & $1260-1110^{77}$ & \multirow{2}{*}{1171} \\
\hline Deformação axial e angular de $\mathrm{C}-(\mathrm{C}=\mathrm{O})-\mathrm{C}$ & $1300-1100^{71}$ & \\
\hline Deformação axial C-O de álcoois secundários & $1085-1050^{71}$ & 1078 \\
\hline
\end{tabular}


Figura 75. Espectros de IV: (A) progesterona (B) produto di-hidroxilado isolado da reação com o caldo enzimático do fungo A. sydowii CBMAI 934.

(A)

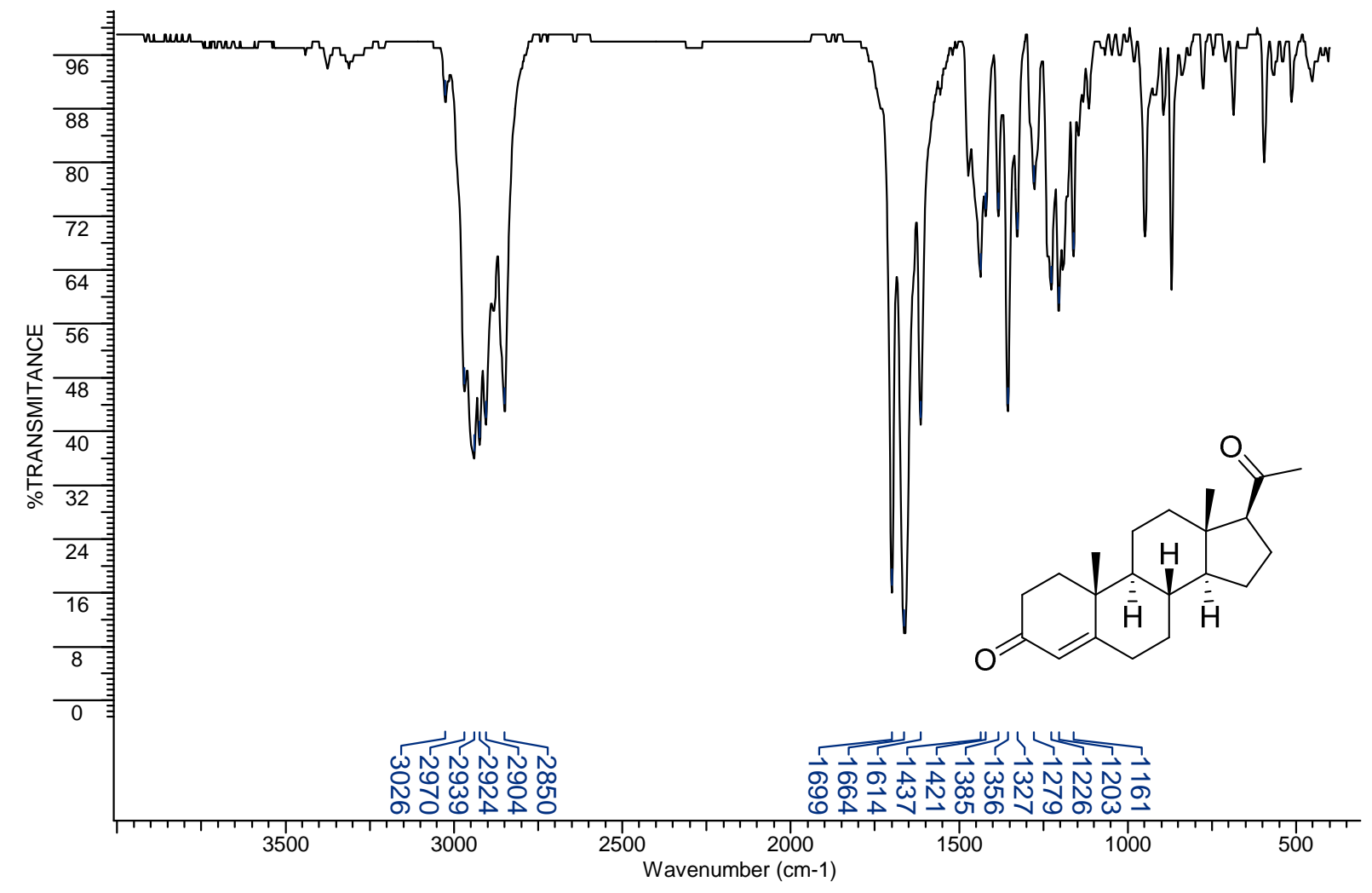

(B)

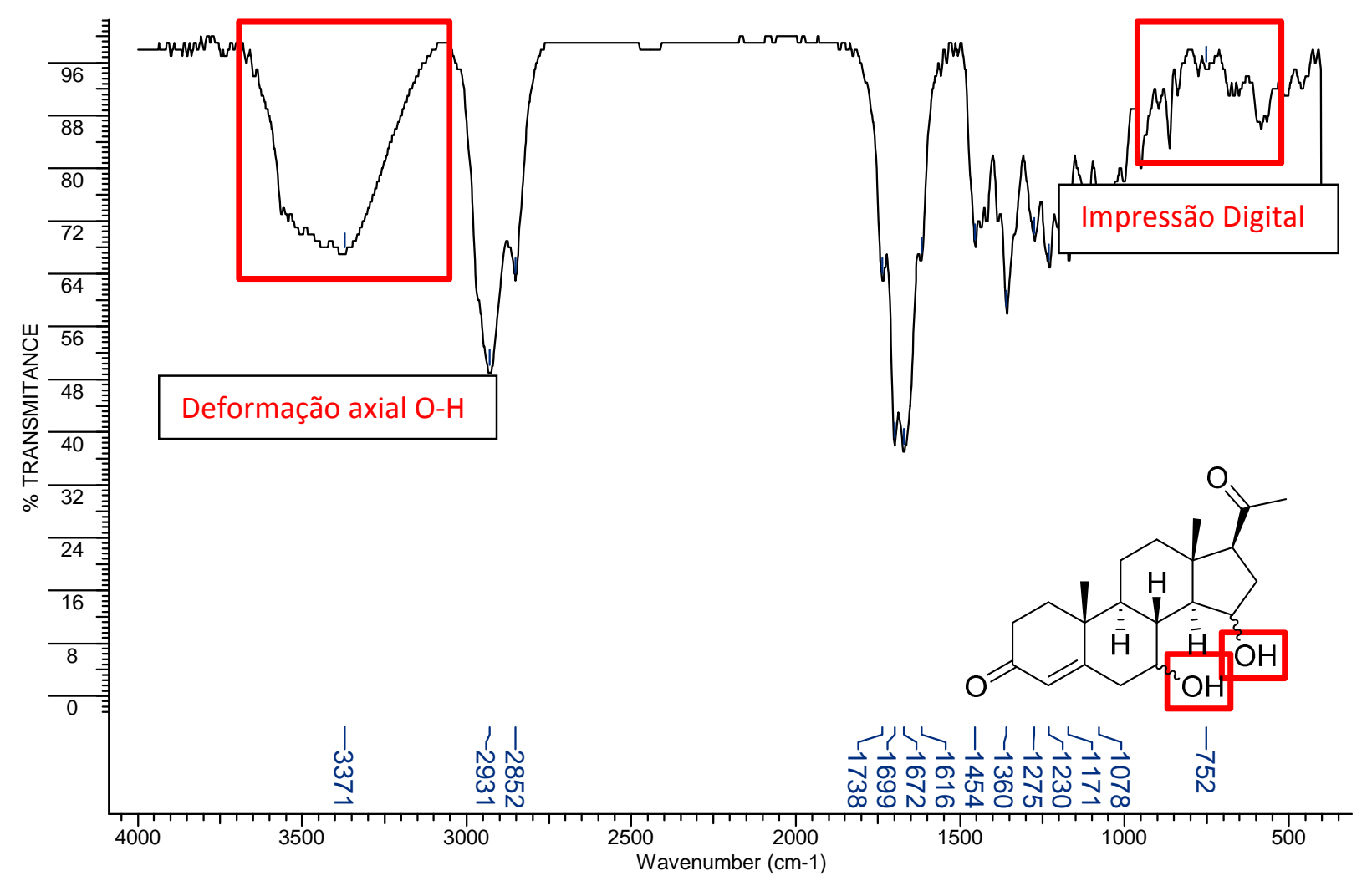


Como pôde ser observado pela Figura 75 a principal diferença entre os dois espectros é a presença de uma banda larga em $3371 \mathrm{~cm}^{-1}$ referente a deformação axial da ligação O-H indicando a presença de hidroxila no composto. Para os isômeros di-hidroxilados descritos na literatura foi encontrado apenas um espectro de IV fornecido por Asai, et al. (1958) ${ }^{78}$ que afirmaram ser da $7 \alpha, 15 \beta$-di-hidroxiprogesterona. Porém, não há dados de RMN nesta referência ${ }^{78}$.

Devido os dados de RMN evidenciarem a presença de duas hidroxilas no metabólito de biotransformação foi feito um experimento de EMAR. A Figura 76 apresenta o espectro de massas obtido experimentalmente para o metabólito isolado da reação do caldo enzimático do fungo A. sydowii CBMAI 934.

Figura 76. Espectro de massas de alta resolução modo positivo $\left(\mathrm{H}^{+}\right)$do produto di-hidroxilado isolado da reação com o caldo enzimático do fungo A.sydowii CBMAI 934.

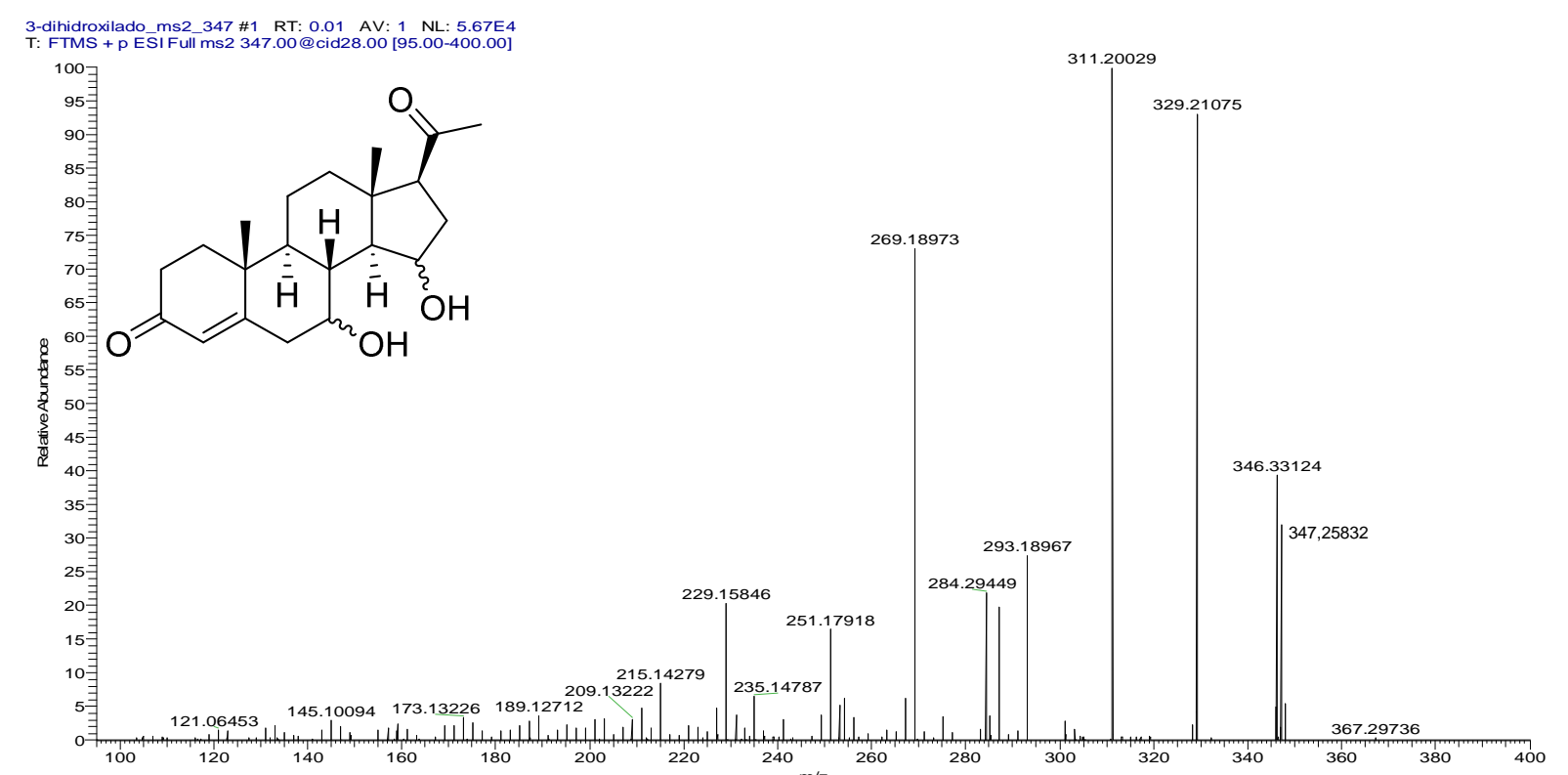

Como o espectro de massas da Figura 76 apresentou, foram observados dois picos de $m / z$ 347,25832 e $m / z$ 346,33124. Este pico se referiu ao íon molecular de um produto dihidroxilado (massa molar $=346,47 \mathrm{~g} / \mathrm{mol}$ ) e aquele ao íon molecular deste mesmo composto, porém protonado, uma vez que o composto foi dissolvido em acetonitrila acidificada com $0,1 \%$ de ácido fórmico para execução da análise. Esse dado mostra que de fato foi obtido um composto di-hidroxilado da biotransformação da progesterona pelo caldo enzimático do fungo A.sydowii CBMAI 934. Sendo assim, o rendimento em massa da reação foi de $13 \%$.

A Tabela 26 apresenta os resultados das medidas de rotação óptica para o composto dihidroxilado isolado, comparativo os valores descritos na literatura para os isômeros de configuração $7 \beta, 15 \beta^{79}$ e $7 \alpha, 15 \beta^{80}$. 
Tabela 26. Valores de rotação óptica para os isômeros di-hidroxilados de configuração $7 \beta, 15 \beta, 7 \alpha, 15 \beta$ e obtido experimentalmente do produto di-hidroxilado isolado da reação com o caldo enzimático do fungo A.sydowii CBMAI 934.

\begin{tabular}{cccc}
\hline Isômero & Concentração $(\mathrm{g} / 100 \mathrm{~mL})^{\mathrm{a}}$ & Temperatura $\left({ }^{\circ} \mathrm{C}\right)$ & {$\left[\alpha_{D}\right]_{589}(\mathrm{deg})$} \\
\hline $7 \beta, 15 \beta^{79}$ & 0,7 & 25 & 136 \\
$7 \alpha, 15 \beta^{80}$ & 0,9 & 18 & 122 \\
Produto isolado & 0,65 & 23 & 84,43 \\
\hline
\end{tabular}

${ }^{\mathrm{a}} \mathrm{CHCl}_{3}$

Como a Tabela 26 apresentou, há uma diferença da rotação óptica entre o valor experimental e os da literatura ${ }^{79,80}$, apesar que o sentido da rotação permaneceu o mesmo. Possivelmente esta diferença se deve à temperatura em que o experimento foi executado, bem como às diferenças de concentração. $\mathrm{O}$ experimento foi realizado sugerindo que se tratasse do isômero $7 \beta, 15 \beta$.

Tendo enfim a certeza de que o produto obtido foi um di-hidroxilado e a partir dos dados fornecidos pelas caracterizações espectroscópicas, sugeriu-se que o composto isolado obtido na reação de biotransformação da progesterona pelo caldo enzimático do fungo A.sydowii CBMAI 934 foi a $7 \alpha, 15 \beta$-di-hidroxiprogesterona. Na seção de anexos são apresentados os espectros de RMN deste composto.

Para a produção do isômero $7 \alpha, 15 \beta$ sem a obtenção de outros produtos a partir da biotransformação da progesterona foi encontrada uma única referência. Tsuda et al. $(1958)^{80}$ utilizando o fungo Syncephalastrum sp. promoveram a biotransformação da progesterona por 6 horas a $30^{\circ} \mathrm{C}, 120 \mathrm{rpm}, \mathrm{pH} \mathrm{4,0} \mathrm{4,2} \mathrm{obtendo} \mathrm{o} \mathrm{o} \mathrm{referido} \mathrm{composto} \mathrm{hidroxilado} \mathrm{com}$ rendimento de 5\% como mostra o Esquema 16.

Esquema 16. Biotransformação da progesterona utilizando o fungo Syncephalastrum sp.

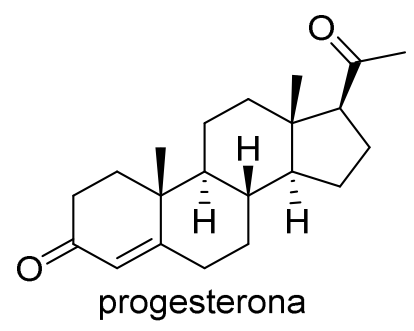

$\underset{6 \text { horas, } 30^{\circ} \mathrm{C}, 120 \mathrm{rpm},}{\stackrel{\text { Syncephalastrum } \mathrm{sp} .}{\longrightarrow}}$ $\mathrm{pH} \mathrm{4,0} \mathrm{4,2}$

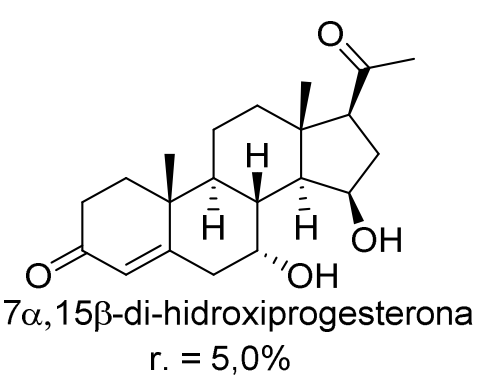

r. $=5,0 \%$

Janeczko et al. (2012) ${ }^{74}$ promoveram a biotransformação da progesterona utilizando o fungo Didymosphaeria igniaria $\mathrm{KCH} 6670$ e obtiveram uma grande variedade de produtos hidroxilados, dentre eles os dois isômeros di-hidroxilados de configuração $7 \beta, 15 \beta$ e $7 \alpha, 15 \beta$, 
sendo este obtido com maior rendimento (41\%) como mostra o Esquema 17. As condições de reação não foram relatadas.

Esquema 17. Biotransformação da progesterona utilizando o fungo Didymosphaeria igniaria $\mathrm{KCH}$ $6670^{74}$.

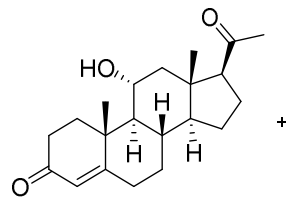

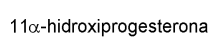

$r .=20 \%$

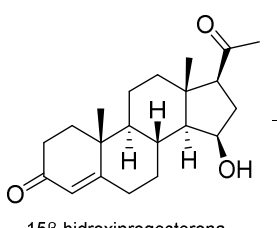

15ß-hidroxiprogesterona
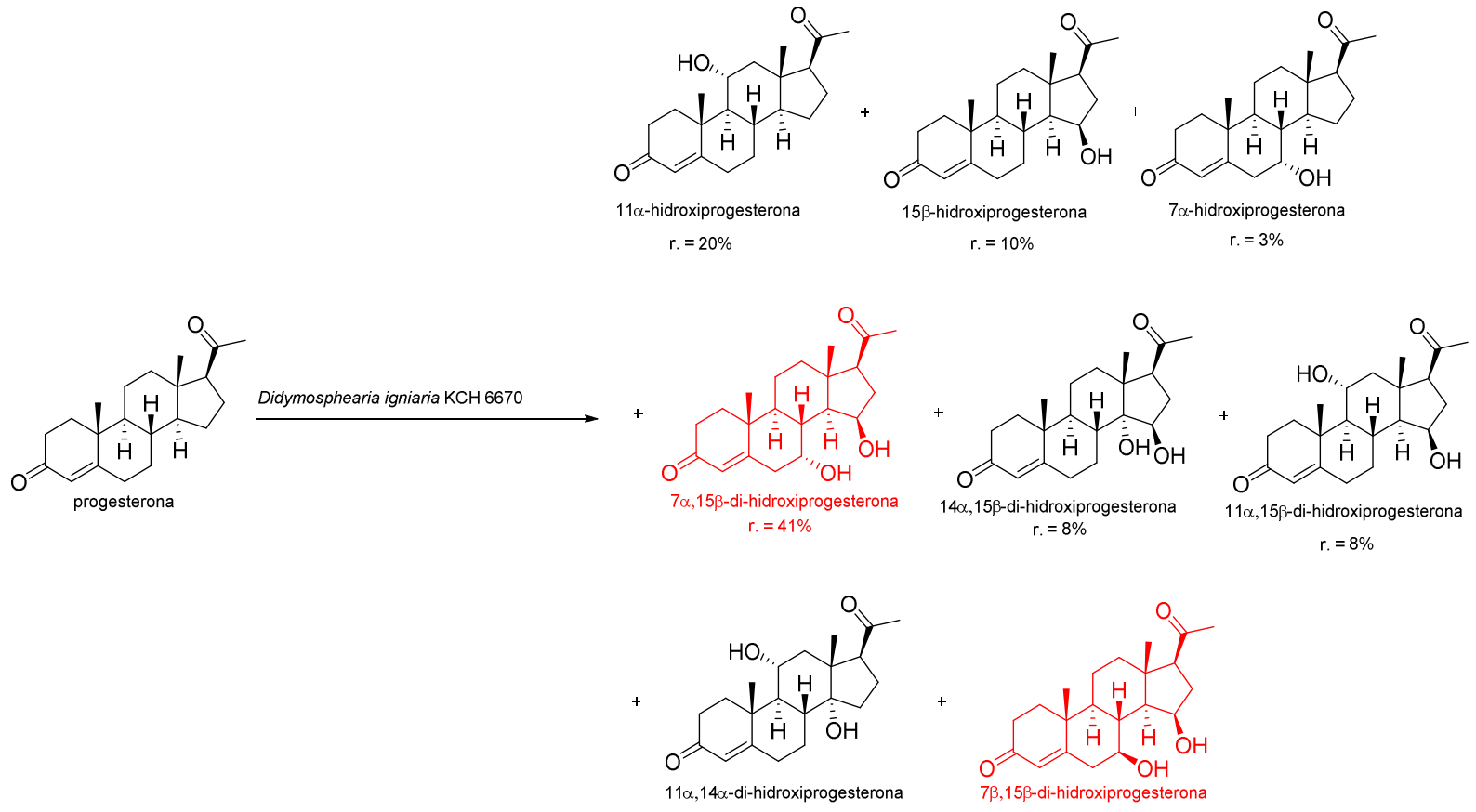

$r .=21 \%$

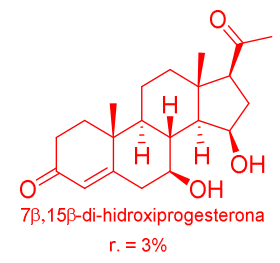




\section{D.5.4.2 Caracterização da $15 \beta$-hidroxiprogesterona isolada da reação com a massa micelial do fungo $A$. sydowii CBMAI 934 (14 dias, $32^{\circ} \mathrm{C}, 130 \mathrm{rpm}$ )}

Conforme abordado na seção D.5.3.4 as análises por CG-EM do produto isolado dessa reação (Figuras 52 e 53) sugeriram que este composto fosse a $7 \alpha, 11 \alpha$-di-hidroxiprogesterona. Entretanto, as análises do espectro de $\mathrm{RMN}$ de ${ }^{13} \mathrm{C}$ do composto isolado evidenciaram apenas um sinal de carbono carbinólico (Figura 78B) $\operatorname{com} \delta=70,2$ evidenciando que tal composto na verdade seria um produto mono-hidroxilado. Comparando com o espectro de $\mathrm{RMN}$ de ${ }^{13} \mathrm{C}$ da progesterona, pôde-se constatar que não foram observados nas suas regiões características de deslocamento químico o sinal relativo ao carbono C-15 (Figura 78A), sugerindo que a hidroxilação na progesterona ocorreu neste carbono.

A Tabela 27 apresenta os dados de deslocamentos químicos obtidos através dos espectros de RMN de ${ }^{13} \mathrm{C}(125 \mathrm{MHz}),{ }^{1} \mathrm{H}(500 \mathrm{MHz})$ feito para o produto isolado da reação com a massa micelial do fungo A. sydowi CBMAI 934, comparativo com os dados dos estereoisômeros mono-hidroxilados 15-hidroxiprogesteronas descritos na literatura ${ }^{74,75,81}$. A Figura 76 apresenta as estrutruas químicas planares e tridimensionais dos isômeros em questão.

Figura 77. Estruturas químicas planas e tridimensionais: (A) 15ß-hidroxiprogesterona, (B) $15 \alpha$ hidroxiprogesterona.
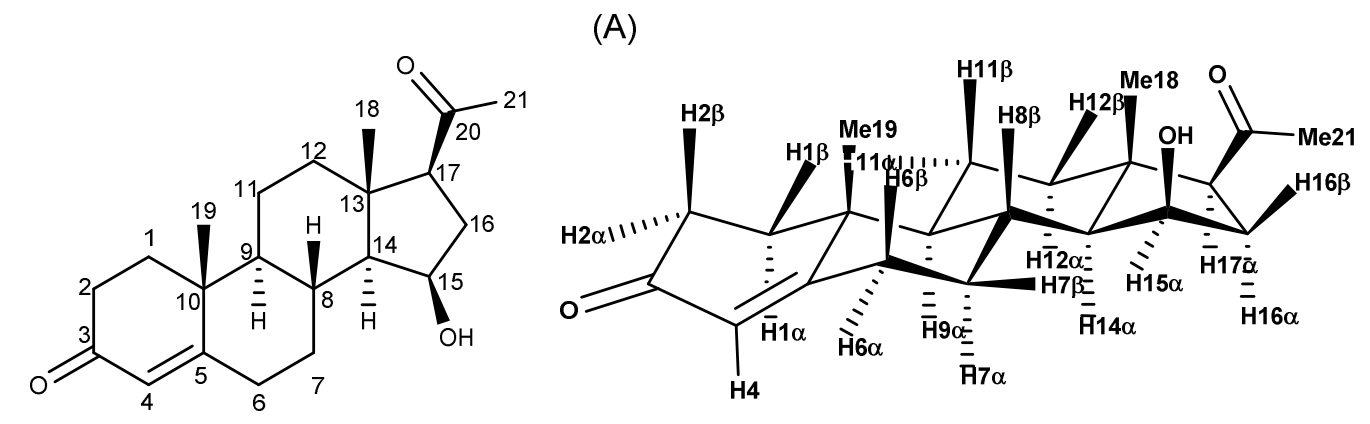

$15 \beta$-hidroxiprogesterona

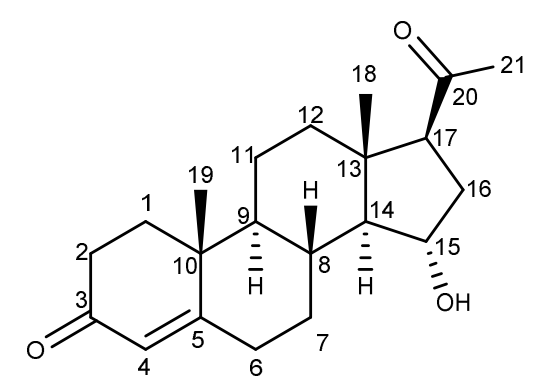

(B)

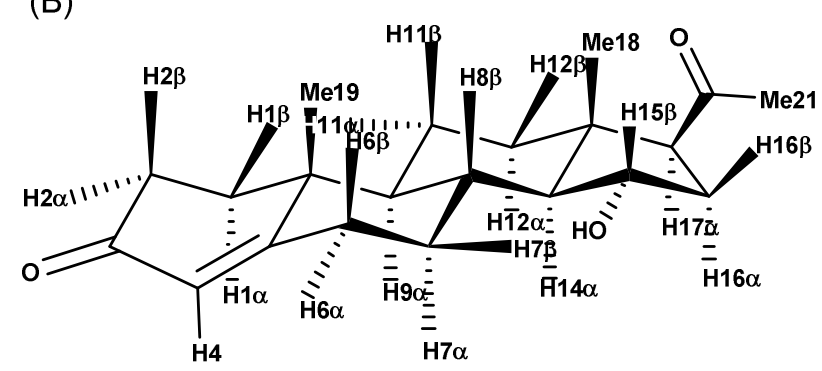

$15 \alpha$-hidroxiprogesterona 
Tabela 27. Valores de deslocamentos químicos (ppm) de RMN $\left({ }^{13} \mathrm{C}\right.$ e $\left.{ }^{1} \mathrm{H}\right)$ para os estereoisômeros $15 \alpha$ hidroxiprogesterona e 15ß-hidroxiprogesterona.

\begin{tabular}{|c|c|c|c|c|c|c|c|}
\hline \multirow[b]{2}{*}{${ }^{13} \mathrm{C}$} & \multicolumn{2}{|c|}{$\delta^{13} \mathrm{C}$ (literatura) } & \multirow{2}{*}{$\begin{array}{c}\delta^{13} \mathrm{C} \\
(\text { experimental })^{\mathrm{a}}\end{array}$} & \multirow[b]{2}{*}{${ }^{1} \mathrm{H}$} & \multicolumn{2}{|c|}{$\delta_{\mathrm{H}}^{1}$ (literatura) } & \multirow{2}{*}{$\begin{array}{c}\delta^{1}{ }_{\mathrm{H}} \\
(\text { experimental })^{\mathrm{b}}\end{array}$} \\
\hline & $\begin{array}{l}\text { Isômero } \\
\left(15 \alpha^{81}\right)^{\mathrm{a}}\end{array}$ & $\begin{array}{l}\text { Isômero } \\
\left(15 \beta^{74}\right)^{\mathrm{a}}\end{array}$ & & & $\begin{array}{l}\text { Isômero } \\
\left(15 \alpha^{81}\right)^{b}\end{array}$ & $\begin{array}{l}\text { Isômero } \\
\left(15 \beta^{75}\right)^{\mathrm{b}}\end{array}$ & \\
\hline \multirow{2}{*}{1} & \multirow{2}{*}{35,7} & \multirow{2}{*}{36,2} & \multirow{2}{*}{35,8} & $1 \alpha$ & 1,73 & 1,72 & 1,75 \\
\hline & & & & $1 \beta$ & 2,04 & 2,05 & 2,07 \\
\hline \multirow{2}{*}{2} & \multirow{2}{*}{33,9} & \multirow{2}{*}{35,7} & \multirow{2}{*}{33,9} & $2 \alpha$ & 2,31 & 2,32 & 2,33 \\
\hline & & & & $2 \beta$ & 2,43 & 2,45 & 2,45 \\
\hline 3 & 199,3 & 199,7 & 199,4 & - & - & - & - \\
\hline 4 & 123,9 & 123,9 & 123,9 & 4 & 5,74 & 5,74 & 5,76 \\
\hline 5 & 170.5 & 171,2 & 170,9 & - & - & - & - \\
\hline \multirow{2}{*}{6} & \multirow{2}{*}{32,7} & \multirow{2}{*}{32,7} & \multirow{2}{*}{32,8} & $6 \alpha$ & 2,35 & 2,32 & 2,39 \\
\hline & & & & $6 \beta$ & 2,41 & 2,48 & 2,49 \\
\hline \multirow{2}{*}{7} & \multirow{2}{*}{32,0} & \multirow{2}{*}{31,1} & \multirow{2}{*}{31,0} & $7 \alpha$ & 1,26 & 1,15 & 1,15 \\
\hline & & & & $7 \beta$ & 2,18 & 2,15 & 2,19 \\
\hline 8 & 35,2 & 31,7 & 31,6 & $8 \beta$ & 1,78 & 1,97 & 1,96 \\
\hline 9 & 53,7 & 54,0 & 53,7 & $9 \alpha$ & 1,03 & 1,05 & 1,04 \\
\hline 10 & 38,6 & 38,7 & 38,7 & - & - & - & - \\
\hline \multirow{2}{*}{11} & \multirow{2}{*}{20,8} & \multirow{2}{*}{21,0} & \multirow{2}{*}{20,9} & $11 \alpha$ & 1,65 & 1,66 & 1,67 \\
\hline & & & & $11 \beta$ & 1,45 & 1,47 & 1,51 \\
\hline \multirow{2}{*}{12} & \multirow{2}{*}{38,9} & \multirow{2}{*}{40,1} & \multirow{2}{*}{40,2} & $12 \alpha$ & 1,54 & 1,47 & 1,45 \\
\hline & & & & $12 \beta$ & 2,02 & 2,07 & 2,07 \\
\hline 13 & 44,6 & 43,6 & 43,9 & - & - & - & - \\
\hline 14 & 62,8 & 60,3 & 60,4 & $14 \alpha$ & 1,20 & 1,07 & 1,05 \\
\hline 15 & 73.4 & 702 & 702 & $15 \alpha$ & - & 4,33 & 433 \\
\hline & 15,4 & 10,2 & 10,2 & $15 \beta$ & 4,11 & - & 4,33 \\
\hline 16 & 354 & 339 & 362 & $16 \alpha$ & 1,56 & 2,24 & 2,26 \\
\hline 10 & $3 J, 4$ & נJ, & 30,2 & $16 \beta$ & 2,78 & 2,24 & 2,26 \\
\hline 17 & 60,9 & 63,7 & 63,5 & $17 \alpha$ & 2,81 & 2,49 & 2,49 \\
\hline 18 & 14,6 & 15,9 & 15,9 & 18 & 0,70 & 0,94 & 0,94 \\
\hline 19 & 17,9 & 17,3 & 17,9 & 19 & 1,20 & 1,22 & 1,22 \\
\hline 20 & 208,2 & 208,3 & 209,3 & - & - & - & - \\
\hline 21 & 31,5 & 31,1 & 31,4 & 21 & 2,13 & 2,15 & 2,15 \\
\hline
\end{tabular}

${ }^{\mathrm{a}} 125 \mathrm{MHz}, \mathrm{CDCl}_{3} ;{ }^{\mathrm{b}} 500 \mathrm{MHz}, \mathrm{CDCl}_{3}$ 

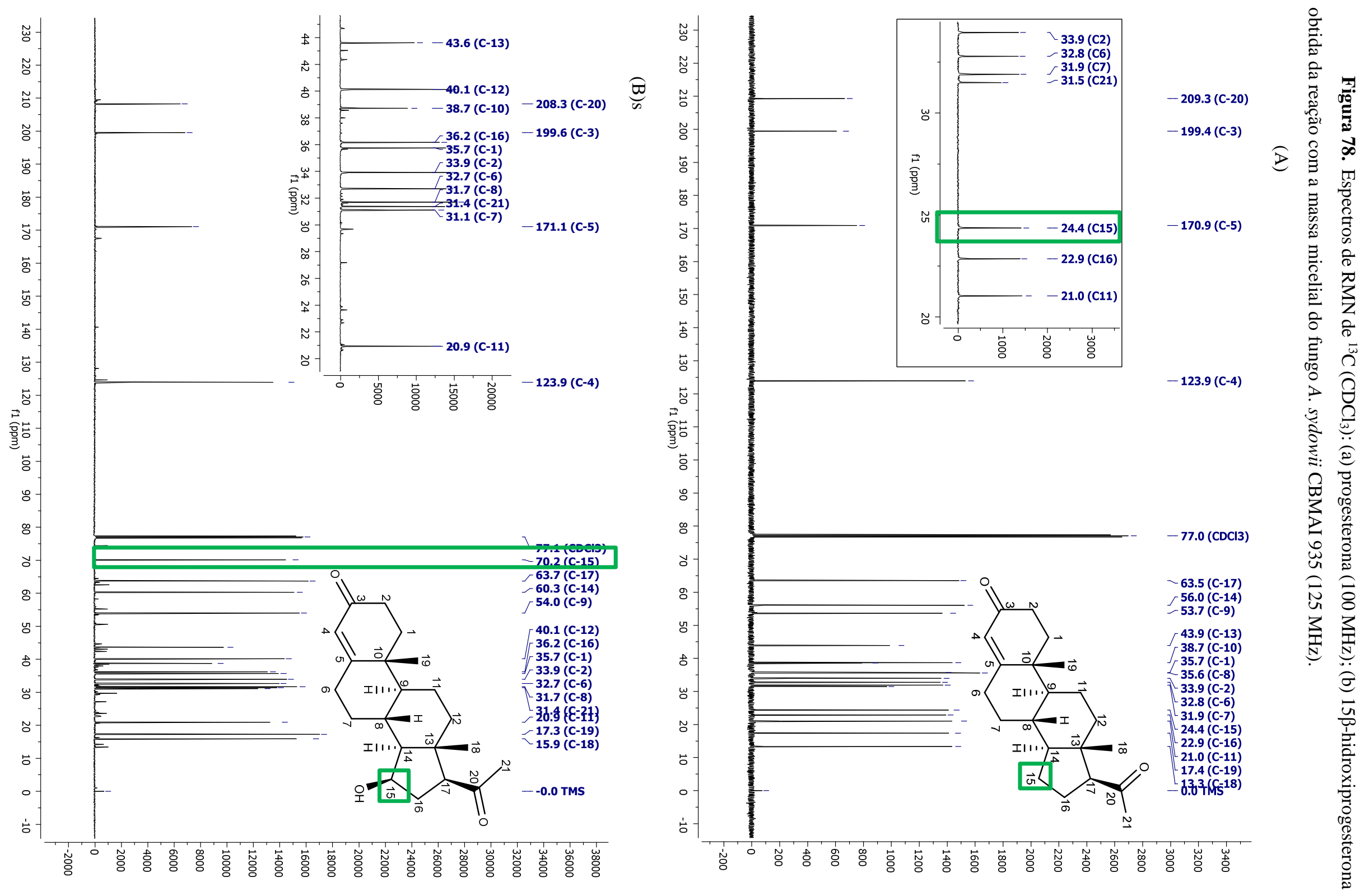
Os dados de deslocamentos químicos obtidos foram bastante concordantes com os dados de referência da literatura para o isômero 15 $\beta$-hidroxiprogesterona, especialmente para o carbono C-15 e o hidrogênio H-15a. Esses resultados forneceram fortes evidências que nesta reação a progesterona foi biotransformada, produzindo este composto, como foi confirmado nos dados de RMN que se seguem. Sendo assim, assumiu-se que o isômero $15 \beta$ foi o composto produzido na reação de biotransformação com a massa micelial do fungo A. sydowii CBMAI 934.

No espectro de HSQC ampliado da progesterona (Figura 79A) foram observadas duas correlações com o sinal $\delta=24,4$ : uma com $\delta=1,77$ e outra com $\delta=1,24$ que corresponderam

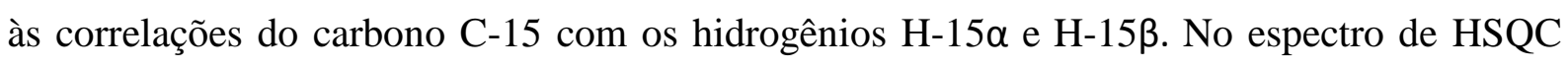
ampliado da 15ß-hidroxiprogesterona (Figura 79B) não foram observadas correlações com esses valores de deslocamentos químicos.

No espectro de HSQC completo da 15 $\beta$-hidroxiprogesterona (Figura 80B) foi observada uma correlação entre os sinais de $\delta=70,3$ e $\delta=4,30$ que corresponderam respectivamente ao carbono C-15 e ao hidrogênio H-15 $\alpha$. No espectro de HSQC completo da progesterona (Figura 80A) não foram observadas correlações com esses valores. 
Figura 79. Espectros de RMN de $\mathrm{HSQC}\left(\mathrm{CDCl}_{3}\right)$ ampliados: (A) progesterona (125 $\mathrm{MHz}$ e $\left.500 \mathrm{MHz}\right)$; (B) 15ß-hidroxiprogesterona (100 MHz e $400 \mathrm{MHz}$ ).

(A)

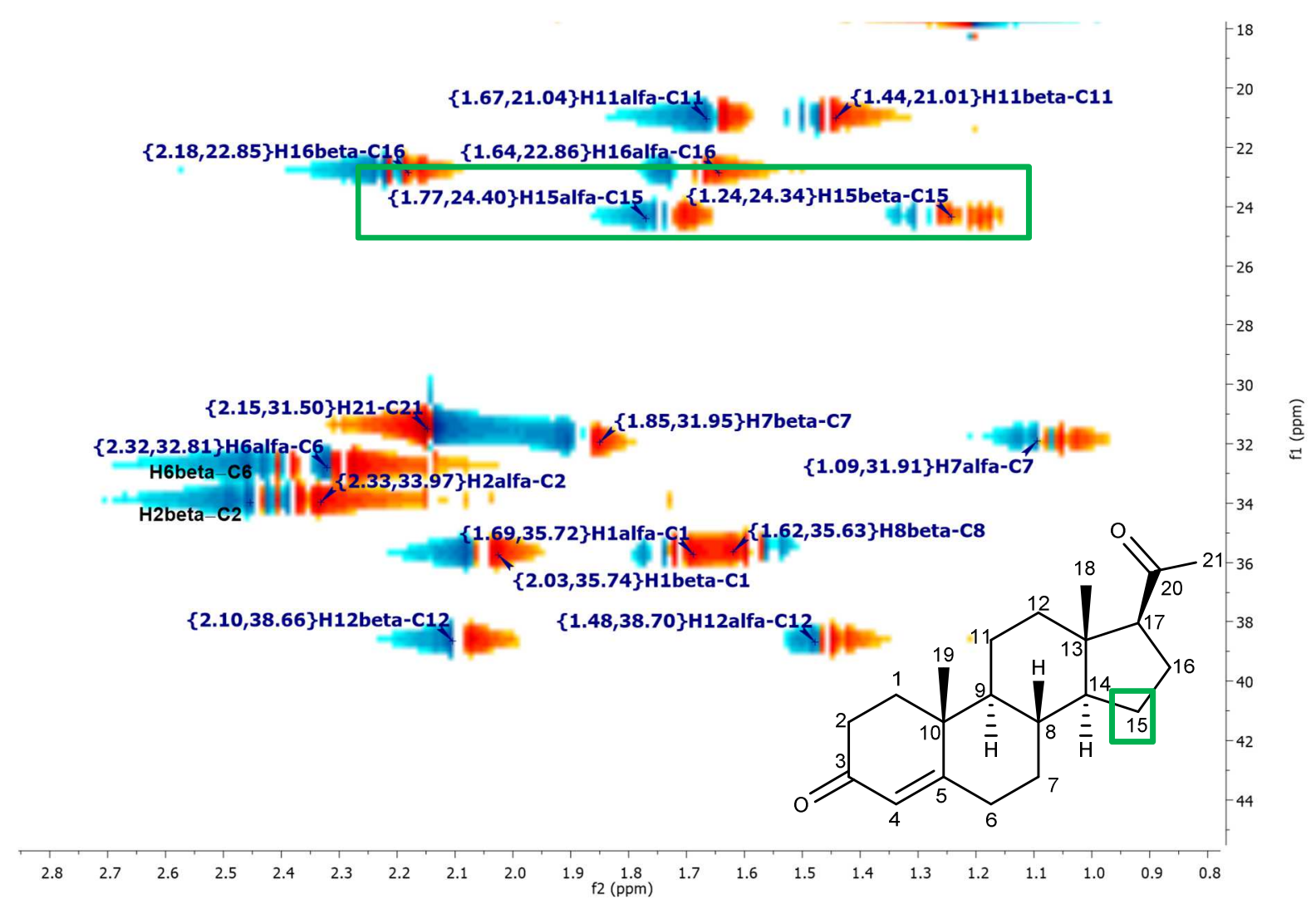

(B)
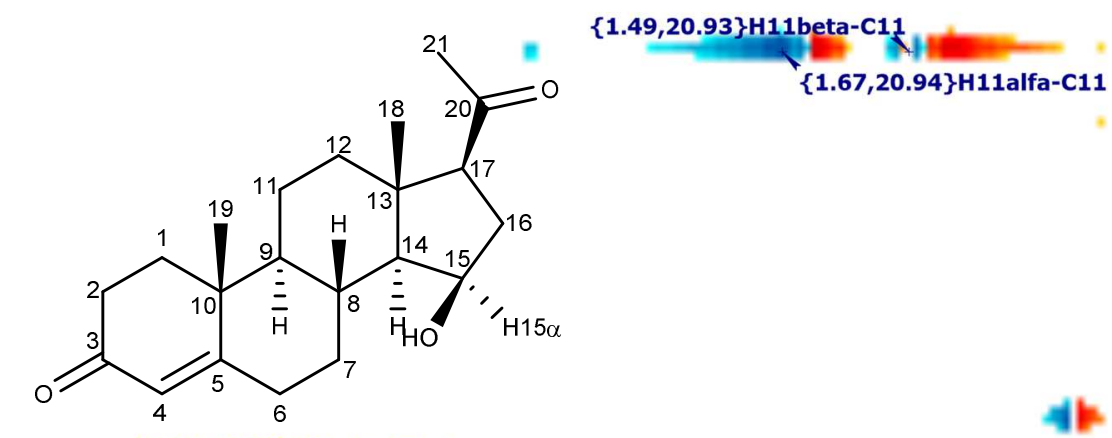

$\{2.19,30.98\}$ H 7 beta-C

$\{1.91,31.62\} \mathrm{H} 21-\mathrm{C} 21$

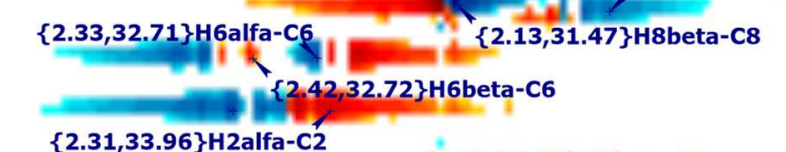

$\{1.16,31.18\}$ H7alfa-c7

$\{2.31,33.96\}$ H2alfa-C2

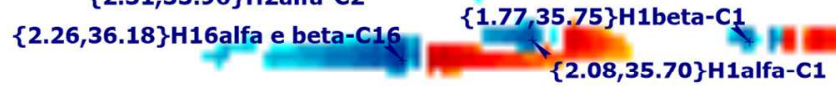

$\{2.08,40.16\}$ H12beta-C12

$\{1.47,40.16\}$ H12alfa-C12

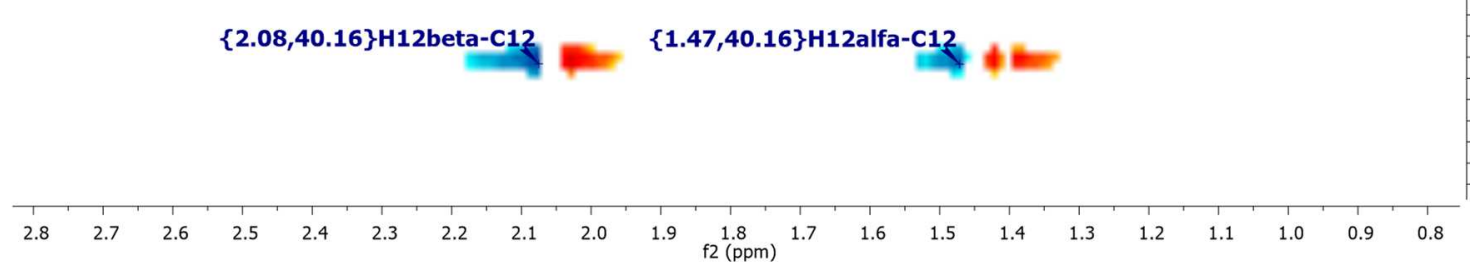


Figura 80. Espectros de RMN de HSQC $\left(\mathrm{CDCl}_{3}\right)$ completos: (A) progesterona (125 $\mathrm{MHz}$ e $\left.500 \mathrm{MHz}\right)$; (B) $15 \beta$-hidroxiprogesterona (100 MHz e $400 \mathrm{MHz}$ ).

(A)

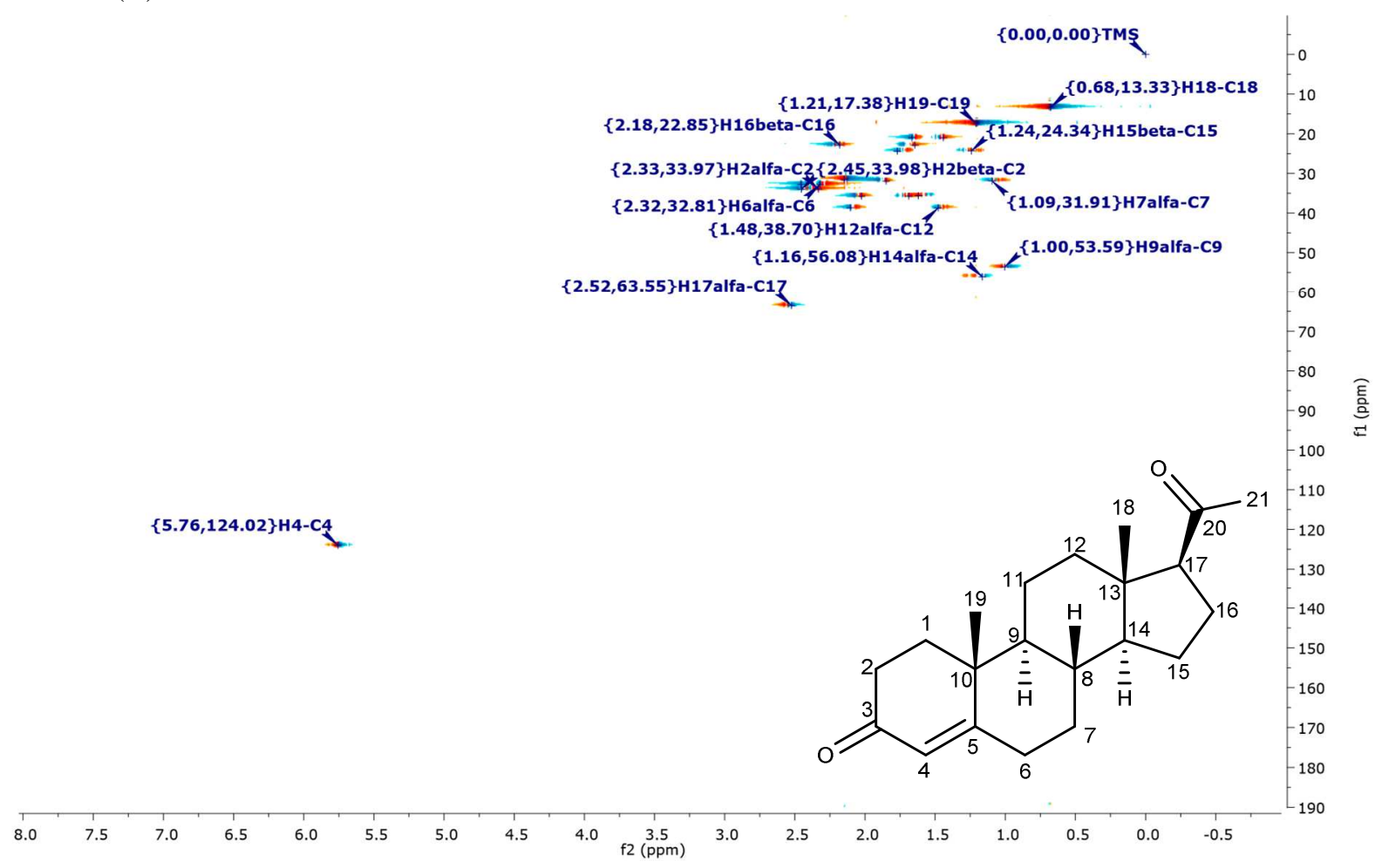

(B)

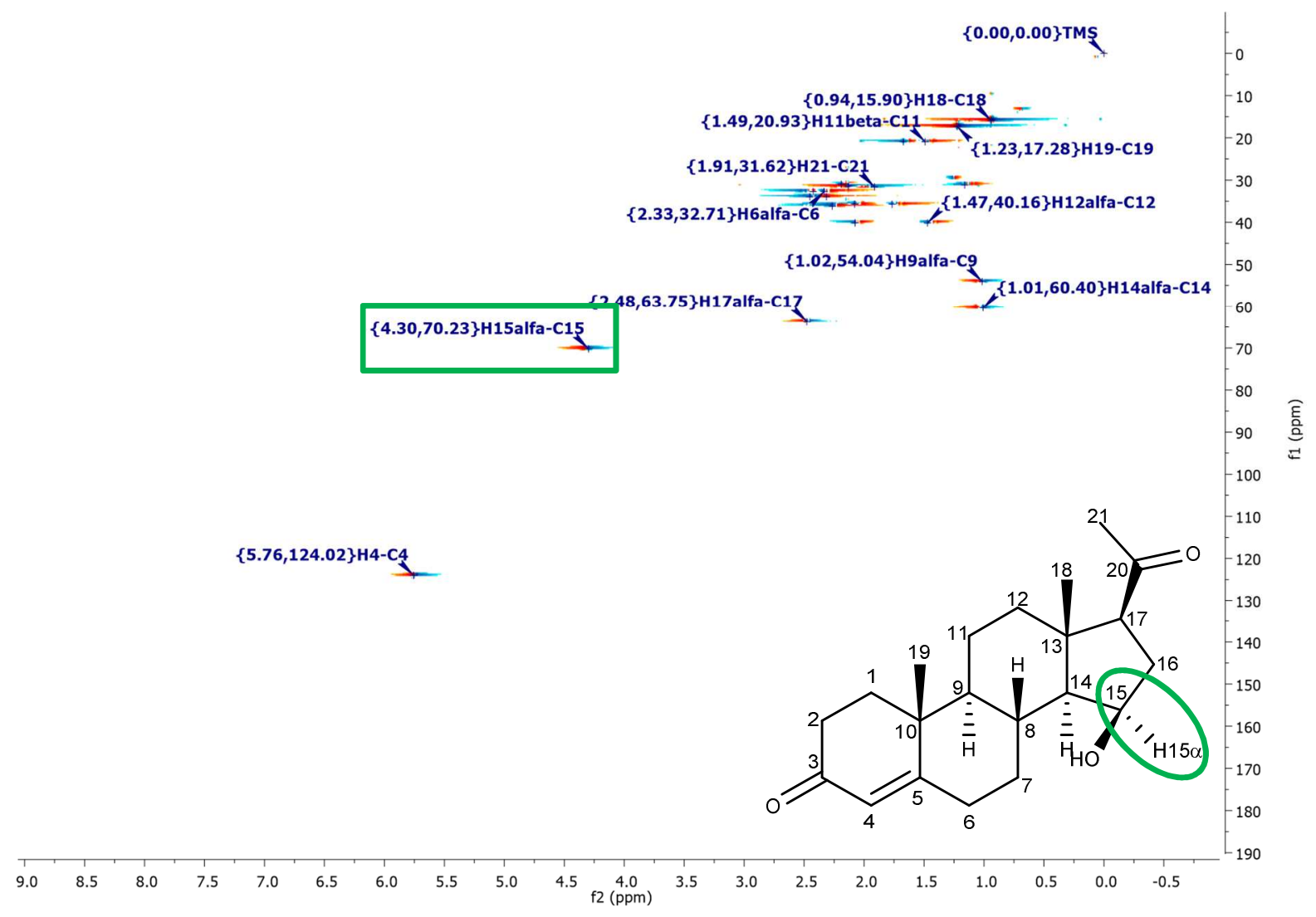


Através da análise do espectro de HMBC da 15ß-hidroxiprogesterona (Figura 82), foi observado que o sinal de carbono carbinólico $\delta=70,2$ se correlacionou aos sinais de $\delta=2,25$, que corresponderam aos hidrogênios H-16 $\alpha$ e H-16 $\beta$, e $\delta=1,05$ que correspondeu ao sinal do hidrogênio H-14 $\alpha$. Essas correlações reforçaram que o esse sinal de carbono carbinólico foi relativo ao carbono C-15. Já o sinal de hidrogênio carbinólico $\delta=4,33$ foi observado correlações com sinais $\delta=63,8$ (relativo ao carbono C-17), $\delta=60,4$ (relativo ao carbono C14 ), $\delta=43,6$ (relativo ao carbono C-13) e $\delta=36,2$ (relativo ao carbono C-16). Esses sinais no espectro de HMBC evidenciaram a hidroxilação no carbono C-15, com hidroxila na orientação $\beta$, uma vez que o sinal de hidrogênio carbinólico foi concordante com o valor para o hidrogênio H-15 $\alpha$.

Foram observadas duas diferenças dos valores de deslocamentos químicos para os carbonos C-2 e C-16, comparativo com a literatura ${ }^{74}$. Contudo, pelas observações no espectro de HMBC, foi verificada uma correlação bem nítida do sinal $\delta=33,9$ com o sinal de $\delta=5,75$ que foi relativo ao hidrogênio H-4. Na literatura ${ }^{74}$, esse sinal de carbono foi relativo ao carbono C-16. Entretanto, devido à longa distância, não seria possível haver uma correlação entre esses núcleos de ${ }^{1} \mathrm{He} \mathrm{e}^{13} \mathrm{C}$. Sendo assim, concluiu-se que o sinal de $\delta=33,9$ é relativo ao carbono C2 , sendo perfeitamente possível ocorrer uma correlação deste carbono com o hidrogênio $\mathrm{H}-4$ por estarem bem próximos. Consequentemente, o outro sinal $\delta=36,2$ foi relativo ao carbono C-16. Outras correlações reforçaram essa conclusão: as correlações do sinal $\delta=33,9$ com $\delta=$ 1,76 (relativo ao hidrogênio $\mathrm{H}-1 \alpha$ ), $\delta=1,76$ (relativo ao hidrogênio $\mathrm{H}-2 \beta$ ) e a do sinal $\delta=36,2$ com $\delta=1,76$ relativo ao hidrogênio $\mathrm{H}-17 \alpha$.

As principais correlações descritas para os carbonos C-2, C-15 e C-16 e do hidrogênio H-15 $\alpha$ estão representadas na Figura 81, sendo que as Figuras 80B a 80D evidenciam apenas o anel D do núcleo esteroidal, onde de fato ocorreu a biotransformação da progesterona. 
Figura 81. Algumas correlações $J_{\mathrm{HC}}$ observadas nos espectros de HMBC da 15ß-hidroxiprogesterona: (A) $J_{\mathrm{H}-\mathrm{C} 2},(\mathrm{~B}) J_{\mathrm{H}-\mathrm{C} 15},(\mathrm{C}) J_{\mathrm{H}-\mathrm{C} 16},(\mathrm{D}) J_{\mathrm{H} 15 \alpha-\mathrm{C}}$

(A)

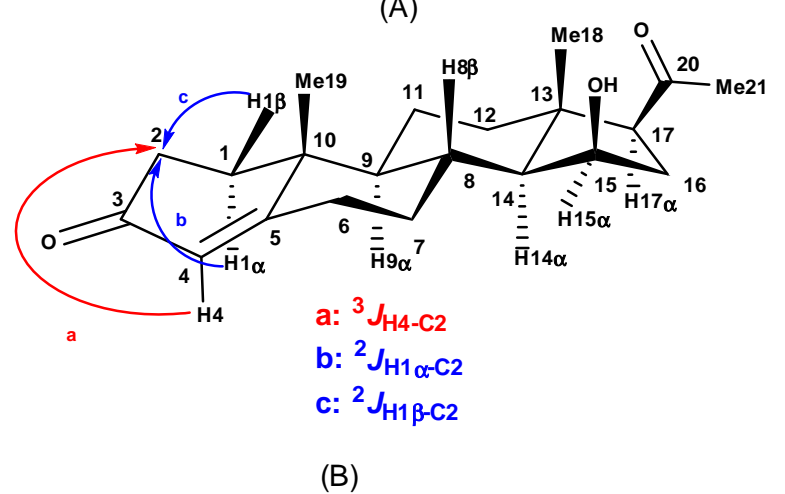

a: ${ }^{2} J_{\mathrm{H} 14 \alpha-\mathrm{C} 15}$

b: ${ }^{2} J_{\mathrm{H} 16 \beta-\mathrm{C} 15}$

c: ${ }^{2} J_{\mathrm{H} 16 \alpha-\mathrm{C} 15}$
(C)

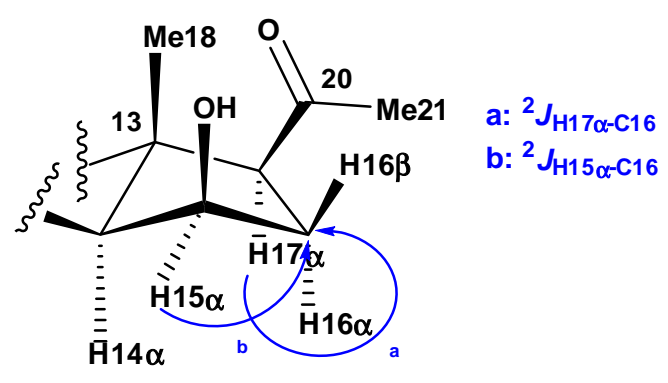

(D)

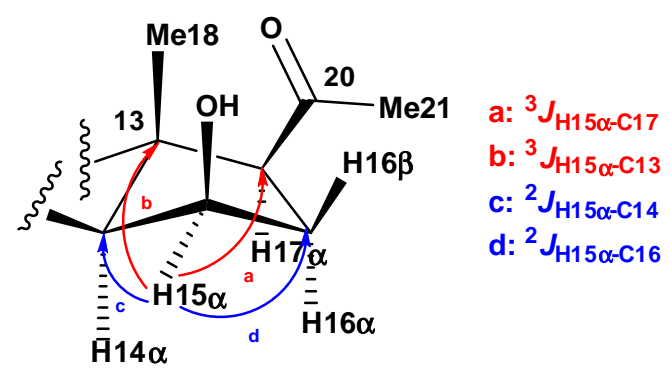

Figura 82. Espectros de RMN de HMBC ampliado (100 $\mathrm{MHz}$ e $\left.400 \mathrm{MHz} \mathrm{CDCl}_{3}\right)$ da $15 \beta$ hidroxiprogesterona.

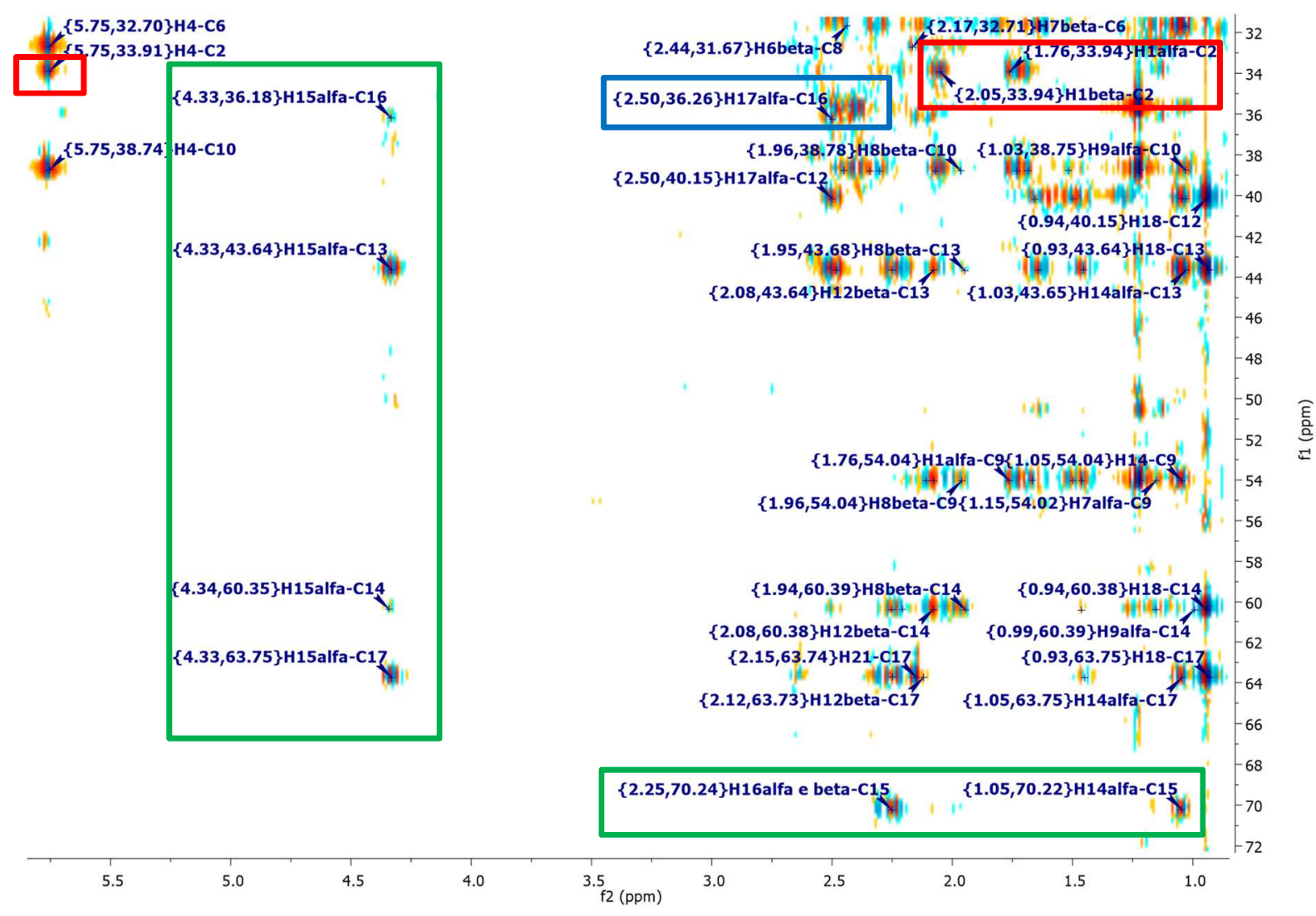


Através da análise do espectro de COSY da $15 \beta$-hidroxiprogesterona como mostra a Figura 84, foram observadas correlações do hidrogênio $\mathrm{H}-15 \alpha(\delta=4,30)$ com os hidrogênios H-14 $\alpha(\delta=0,98), \mathrm{H}-7 \beta(\delta=2,17), \mathrm{H}-16 \alpha$ e H-16 $(\delta=2,21 \mathrm{ppm})$ mostrando que a hidroxilação ocorreu no carbono C-15. Interessante notar as correlações ${ }^{3} J_{\mathrm{H} 15 \alpha-\mathrm{H} 14 \alpha} \mathrm{e}^{4} J_{\mathrm{H} 15 \alpha-\mathrm{H} 7 \beta}$ que mostraram fortes evidências da orientação $\beta$ da hidroxila. As correlações envolvendo o hidrogênio H-15a observadas no espectro de COSY estão representadas na Figura 83 destacandoo anel $\mathrm{D}$ do esqueleto esteroidal da $15 \beta$-hidroxiprogesterona.

Figura 83. Algumas correlações $J_{\mathrm{HH}}$ observadas nos espectros de COSY da $15 \beta$-hidroxiprogesterona envolvendo o hidrogênio H-15a.

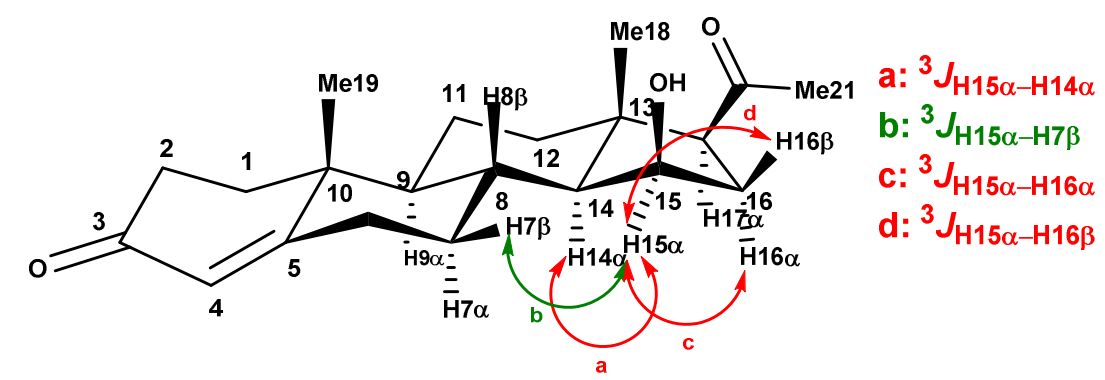

Figura 84. Espectros de RMN de COSY ampliado (400 MHz, $\mathrm{CDCl}_{3}$ ) da 15 $\beta$-hidroxiprogesterona.

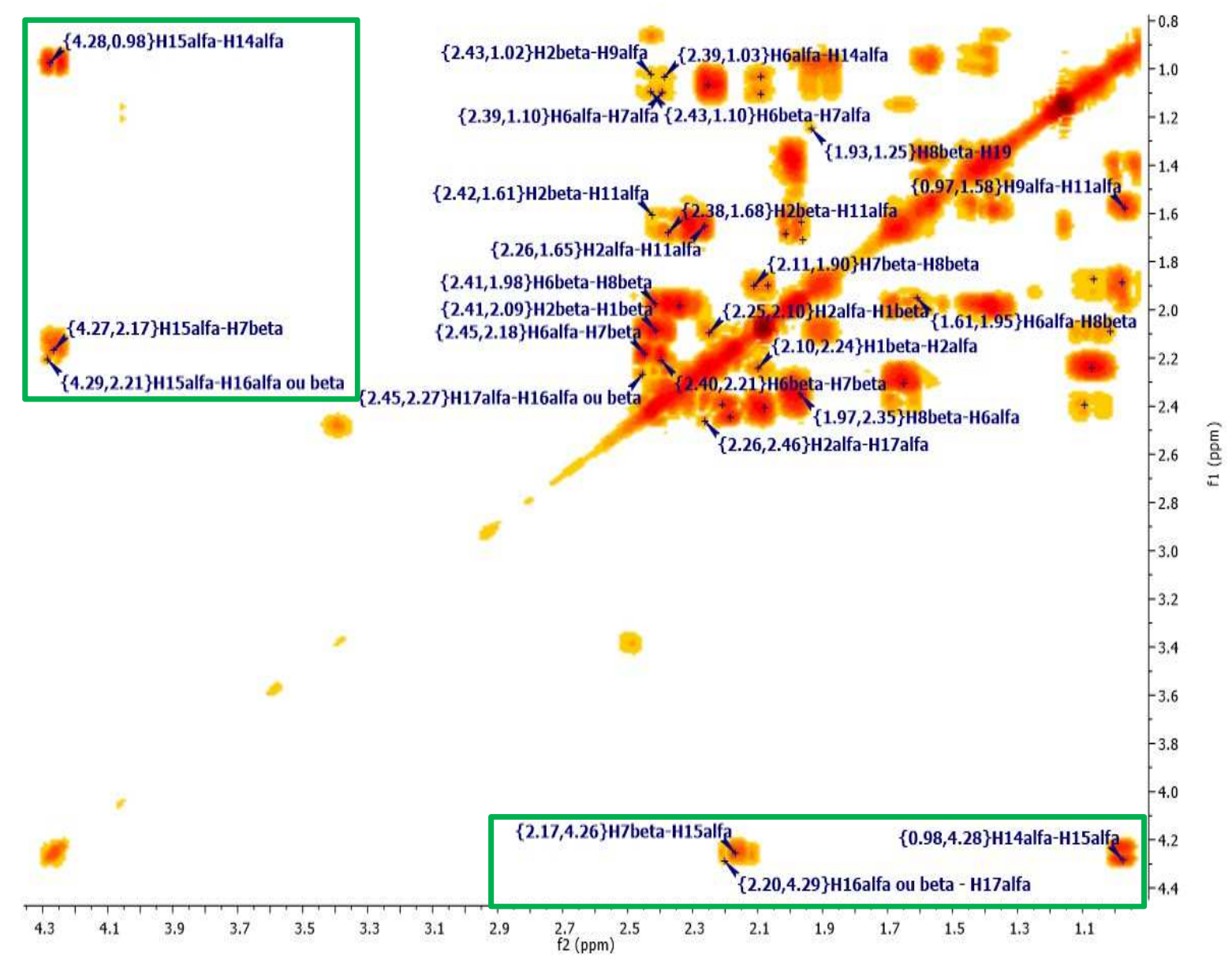


Comparando o sinal do multipleto relativo ao hidrogênio $\mathrm{H}-15 \alpha$ da $15 \beta$ hidroxiprogesterona com os multipletos dos hidrogênios H-15 da progesterona nos espectros de RMN, tanto do substrato quanto do metabólito (Figura 85), não foi possível encontrar semelhanças entre esses sinais envolvidos. Comparando com o modelo de multiplicidade de sinais de hidrogênios do núcleo esteroidal (Figura 70) foi observado que o sinal de multipleto

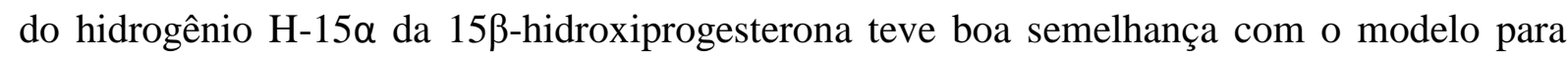
hidrogênio H-15 $\alpha$ para esteroides $17 \beta$-substituídos. Isso reforçou a conclusão da orientação $\beta$ da hidroxila da $15 \beta$-hidroxiprogesterona.

Figura 85. Sinais de multipletos de hidrogênios H-15 obtidos de espectros de RMN de ${ }^{1} \mathrm{H}(400 \mathrm{MHz}$, $\mathrm{CDCl}_{3}$ ): (A) progesterona (B) $\mathrm{H}-15 \alpha$ da $15 \beta$-hidroxiprogesterona.

$(\mathrm{A})$
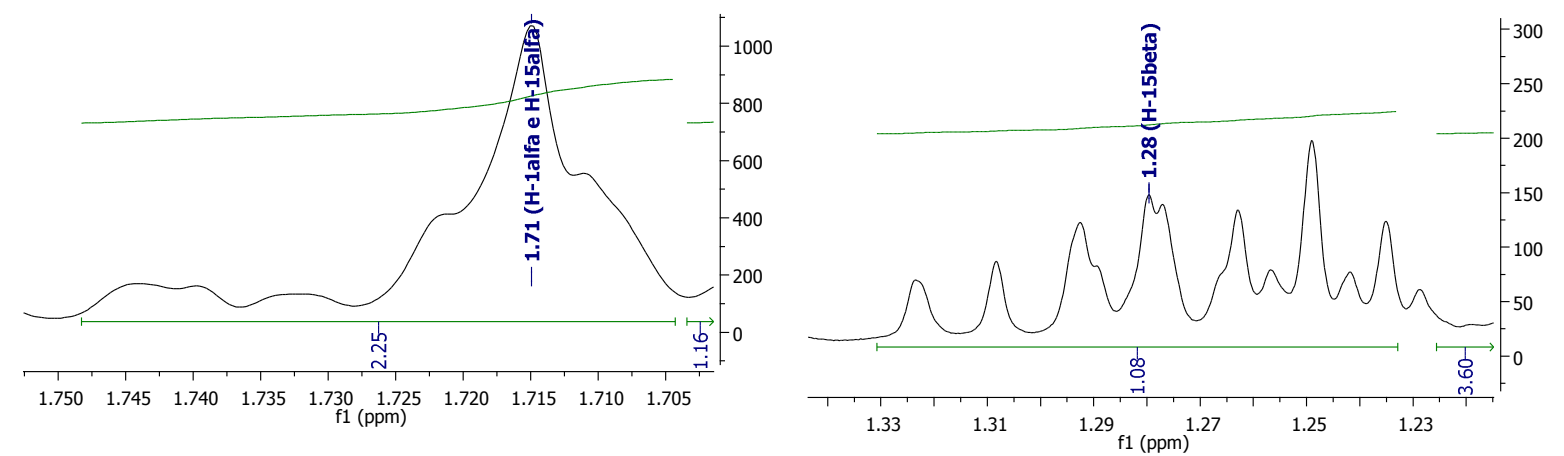

(B)

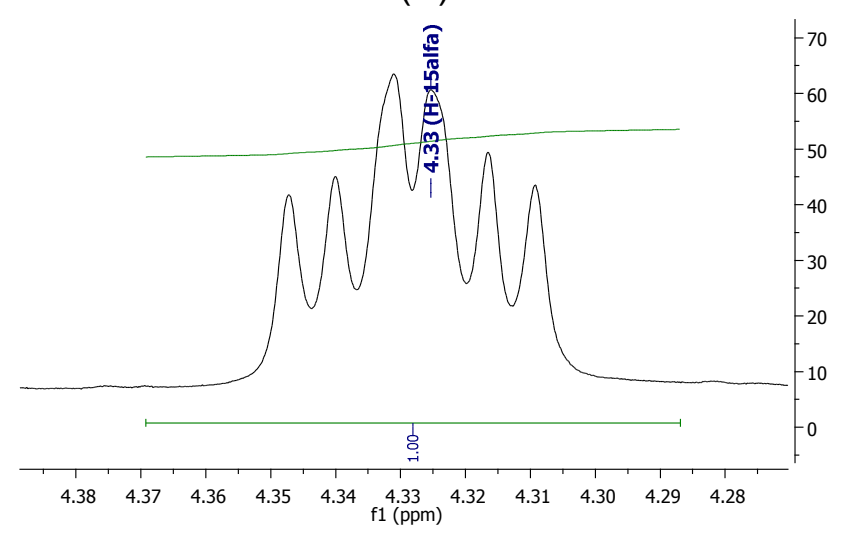

Já a Tabela 28 apresenta os valores das constantes de acoplamento encontradas para o hidrogênio H-15 $\alpha$ do produto isolado, bem como os hidrogênios envolvidos nos acoplamentos. 
Tabela 28. Constantes de acoplamento $(J)$ obtidas experimentalmente para o hidrogênio H-15a da $15 \beta$ hidroxiprogesterona.

\begin{tabular}{|c|c|c|}
\hline$J(\mathrm{~Hz})$ & Tipo de acoplamento & Possíveis hidrogênios envolvidos \\
\hline 3,0 & Vicinal cis & 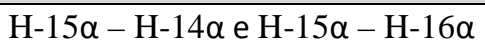 \\
\hline 6,0 & Vicinal trans & $H-15 \alpha-H-16 \beta$ \\
\hline 6,2 & Vicinal trans & $H-15 \alpha-H-16 \beta$ \\
\hline
\end{tabular}

Entendeu-se que as constantes $J=6,0 \mathrm{~Hz}$ e $J=6,2 \mathrm{~Hz}$ por serem muito próximas representam o mesmo acoplamento. As constantes de acoplamento calculadas confirmaram algumas interações encontrados no espectro de COSY envolvendo o hidrogênio H-15a (Figura 83) da 15 $\beta$-hidroxiprogesterona isolada da reação da progesterona com o micélio do fungo $A$. sydowii CBMAI 934. A seção de anexos apresenta os espectros de RMN sem ampliação obtidos experimentalmente para a $15 \beta$-hidroxiprogesterona.

Foram feitos estudos teóricos pelo Prof $^{\circ}$ Dr. Isac G. Rosset para a $15 \beta$ hidroxiprogesterona usando os mesmos parâmetros para o estudo teórico do produto dihidroxilado isolado da reação da progesterona com o caldo enzimático do fungo A. sydowii CBMAI 934 com o objetivo de reforçar a configuração do metabólito $15 \beta$-hidroxiprogesterona.

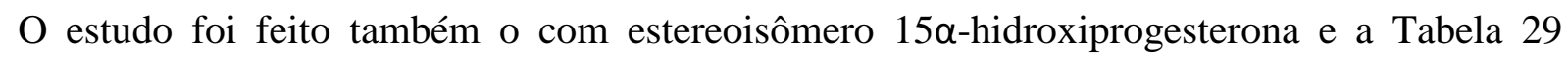
apresenta os valores de deslocamentos químicos obtidos para os dois isômeros, comparativo com os valores experimentais obtidos. 
Tabela 29. Valores de deslocamentos químicos (ppm) de $\mathrm{RMN}\left({ }^{13} \mathrm{C} \mathrm{e}{ }^{1} \mathrm{H}\right)$ teóricos e experimentais para os isômeros 15-hidroxiprogesterona.

\begin{tabular}{|c|c|c|c|c|c|c|c|}
\hline \multirow[b]{2}{*}{${ }^{13} \mathrm{C}$} & \multicolumn{2}{|c|}{$\delta^{13} \mathrm{C}$ (teórico) } & \multirow{2}{*}{$\begin{array}{c}\delta^{13} \mathrm{C} \\
(\text { experimental })^{\mathrm{b}}\end{array}$} & \multirow[b]{2}{*}{${ }^{1} \mathrm{H}$} & \multicolumn{2}{|c|}{$\delta^{1}{ }_{\mathrm{H}}($ teórico $)$} & \multirow{2}{*}{$\begin{array}{c}\delta^{1}{ }_{\mathrm{H}} \\
(\text { experimental) }\end{array}$} \\
\hline & $\begin{array}{c}\text { Isômero } \\
(15 \alpha)^{\mathrm{a}}\end{array}$ & $\begin{array}{c}\text { Isômero } \\
\qquad(15 \beta)^{\mathrm{a}}\end{array}$ & & & $\begin{array}{l}\text { Isômero } \\
(15 \alpha)^{\mathrm{a}}\end{array}$ & $\begin{array}{c}\text { Isômero } \\
(15 \beta)^{\mathrm{a}}\end{array}$ & \\
\hline \multirow{2}{*}{1} & \multirow{2}{*}{37,7} & \multirow{2}{*}{37,7} & \multirow{2}{*}{35,8} & $1 \alpha$ & 1,79 & 1,82 & 1,75 \\
\hline & & & & $1 \beta$ & 2,06 & 2,06 & 2,07 \\
\hline \multirow{2}{*}{2} & \multirow{2}{*}{34,4} & \multirow{2}{*}{34,4} & \multirow{2}{*}{33,9} & $2 \alpha$ & 2,15 & 2,14 & 2,33 \\
\hline & & & & $2 \beta$ & 2,78 & 2,59 & 2,45 \\
\hline 3 & 190,7 & 190,8 & 199,4 & - & - & - & - \\
\hline 4 & 120,7 & 120,7 & 123,9 & 4 & 5,85 & 5,86 & 5,76 \\
\hline 5 & 167.6 & 167,5 & 170,9 & - & - & - & - \\
\hline \multirow{2}{*}{6} & \multirow{2}{*}{34,6} & \multirow{2}{*}{34,9} & \multirow{2}{*}{32,8} & $6 \alpha$ & 2,32 & 2,32 & 2,39 \\
\hline & & & & $6 \beta$ & 2,78 & 2,80 & 2,49 \\
\hline \multirow{2}{*}{7} & \multirow{2}{*}{33,5} & \multirow{2}{*}{33,5} & \multirow{2}{*}{31,0} & $7 \alpha$ & 1,54 & 1,43 & 1,15 \\
\hline & & & & $7 \beta$ & 1,79 & 1,90 & 2,19 \\
\hline 8 & 36,3 & 33,6 & 31,6 & $8 \beta$ & 2,15 & 2,32 & 1,96 \\
\hline 9 & 55,9 & 56,1 & 53,7 & $9 \alpha$ & 1,24 & 1,21 & 1,04 \\
\hline 10 & 43,0 & 38,7 & 38,7 & - & - & - & - \\
\hline \multirow{2}{*}{11} & \multirow{2}{*}{22,7} & \multirow{2}{*}{22,8} & \multirow{2}{*}{20,9} & $11 \alpha$ & 1,61 & 1,64 & 1,67 \\
\hline & & & & $11 \beta$ & 1,79 & 1,73 & 1,51 \\
\hline \multirow{2}{*}{12} & \multirow{2}{*}{38,8} & \multirow{2}{*}{39,8} & ? & $12 \alpha$ & 1,24 & 1,30 & 1,45 \\
\hline & & & & $12 \beta$ & 2,41 & 2,06 & 2,07 \\
\hline 13 & 47,1 & 49,7 & 43,9 & - & - & - & - \\
\hline 14 & 64,1 & 60,6 & 60,4 & $14 \alpha$ & 1,24 & 0,99 & 1,05 \\
\hline 15 & 736 & 724 & 2 & $15 \alpha$ & - & 4,59 & 132 \\
\hline 10 & r & $12, T$ & 70,2 & $15 \beta$ & 4,50 & - & נס, ד \\
\hline & & & & $16 \alpha$ & 2,15 & 2,53 & 2,26 \\
\hline & & & & $16 \beta$ & 2,57 & 2,32 & 2,26 \\
\hline 17 & 61,7 & 63,5 & 63,5 & $17 \alpha$ & 2,57 & 2,20 & 2,49 \\
\hline 18 & 13,5 & 15,3 & 15,9 & 18 & 1,11 & 1,29 & 0,94 \\
\hline 19 & 18,2 & 18,1 & 17,9 & 19 & 1,41 & 1,44 & 1,22 \\
\hline 20 & 204,5 & 206,5 & 209,3 & - & - & - & - \\
\hline 21 & 28,5 & 30,6 & 31,4 & 21 & 2,20 & 2,35 & 2,15 \\
\hline $\mathrm{R}^{2}$ & 0,9980 & 0,9985 & 1,0000 & $\mathrm{R}^{2}$ & 0,9654 & 0,9670 & 1,0000 \\
\hline
\end{tabular}

${ }^{\mathrm{a}} \mathrm{CDCl}_{3},{ }^{\mathrm{b}} 100 \mathrm{MHz}, \mathrm{CDCl}_{3},{ }^{\mathrm{c}} 400 \mathrm{MHz}, \mathrm{CDCl}_{3}$

Como o estudo teórico evidenciou, especialmente pelos valores de $\mathrm{R}^{2}$, os dados teóricos obtidos forneceram indícios que o produto de biotransformação é o isômero $15 \beta$. Rosset a partir 
de suas considerações realizadas por cálculos teóricos também concordou que fosse esse o isômero obtido, conforme transcrição abaixo de mensagem eletrônica enviada:

"A molécula mono-hidroxilada apresentou uma exatidão de mais de $98 \%$ de chance de ser a molécula em questão. Acho que não há problemas em relação a ela."

(Rosset, I. G. - Mensagem enviada por correio eletrônico em 03/03/2016).

Foram feitos experimentos de IV com o composto isolado. As bandas encontradas estão descritas na Tabela 30 atribuídas segundo Mohamed et al. $(2014)^{70}$, Silverstein et al., $(2006)^{71}$ e Pavia et al.(2015) ${ }^{77}$ A Figura 86 apresenta de forma comparativa o espectro de IV obtido experimentalmente para a progesterona e para o produto mono-hidroxilado.

Tabela 30. Valores das bandas vibracionais obtidas por IV para o produto $15 \beta$-hidroxiprogesterona isolado da reação com o micéilo do fungo A. sydowii CBMAI 934.

\begin{tabular}{|c|c|c|}
\hline \multirow{2}{*}{ Ligação/tipo de vibração } & \multicolumn{2}{|c|}{ Valores de $v_{\text {máx }}\left(\mathrm{cm}^{-1}\right)$} \\
\hline & literatura & experimental \\
\hline Deformação axial O-H & $3550-3200^{71}$ & \multirow{2}{*}{3394} \\
\hline Deformação axial $\mathrm{H}-\mathrm{C}=$ & acima de 300071 & \\
\hline Estiramento assimétrico $\mathrm{C}-\mathrm{H}$ & $2939,95^{70}$ & 2930 \\
\hline Estiramento assimétrico C-H & $2854,13^{70}$ & \multirow{2}{*}{2850} \\
\hline Deformação axial de C-H (carbono terciário) & $2890^{71}$ & \\
\hline Estiramento $\mathrm{C}=\mathrm{O}$ de cetona $(\mathrm{C}-20)$ & $1698,28^{70}$ & 1701 \\
\hline Estiramento $\mathrm{C}=\mathrm{O}$ de cetona $(\mathrm{C}-3)$ & $1632,34^{70}$ & \multirow{2}{*}{1678} \\
\hline Deformação axial $\mathrm{C}=\mathrm{O}$ de cetona $\alpha, \beta$-insaturada $(\mathrm{C}-3)$ & $1685-1666^{71}$ & \\
\hline Estiramento $\mathrm{C}=\mathrm{C}(\mathrm{C}-4$ e $\mathrm{C}-5)$ & $1617,02^{70}$ & 1616 \\
\hline Deformação angular - $\mathrm{CH}_{2}$ (anel de ciclo-hexano) & $1452^{71}$ & 1454 \\
\hline Deformação angular simétrica fora do plano $\left(\mathrm{CH}_{2}\right.$ cíclico $)$ & $1350^{71}$ & 1360 \\
\hline Dobramento C-O-H & $1440-1220^{77}$ & \multirow{2}{*}{1269} \\
\hline Deformação axial e angular de $\mathrm{C}-(\mathrm{C}=\mathrm{O})-\mathrm{C}$ & $1300-1100^{71}$ & \\
\hline Estiramento C-O & $1260-1110^{77}$ & \multirow{2}{*}{1240} \\
\hline Deformação axial e angular de $\mathrm{C}-(\mathrm{C}=\mathrm{O})-\mathrm{C}$ & $1300-1100^{71}$ & \\
\hline Estiramento C-O & $1260-1110^{77}$ & \multirow{2}{*}{1169} \\
\hline Deformação axial e angular de $\mathrm{C}-(\mathrm{C}=\mathrm{O})-\mathrm{C}$ & $1300-1100^{71}$ & \\
\hline Deformação axial C-O de álcoois secundários & $1085-1050^{71}$ & 1078 \\
\hline
\end{tabular}


Figura 86. Espectros de IV: (A) progesterona (B) 15ß-hidroxiprogesterona.

(A)

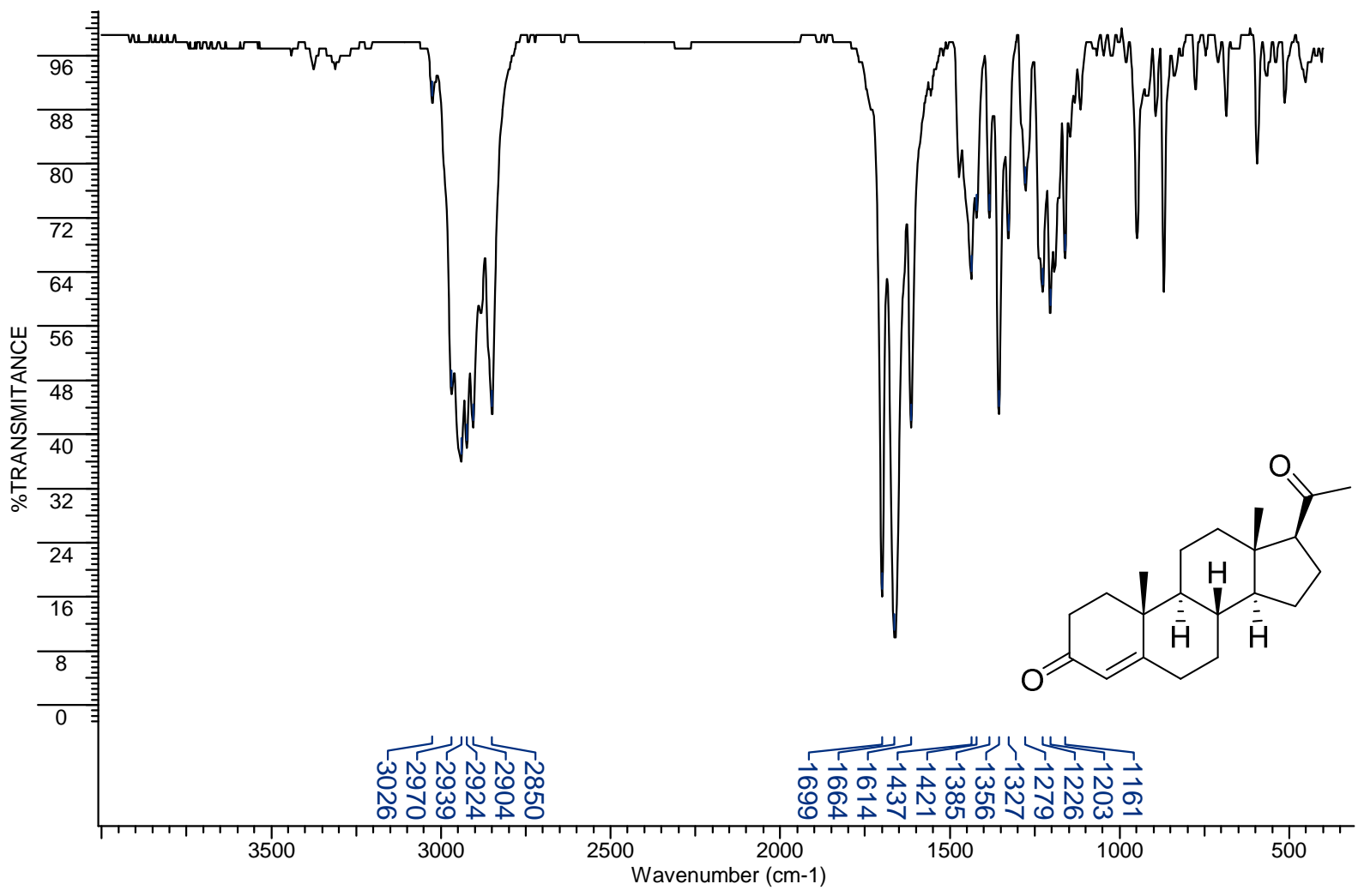

(B)

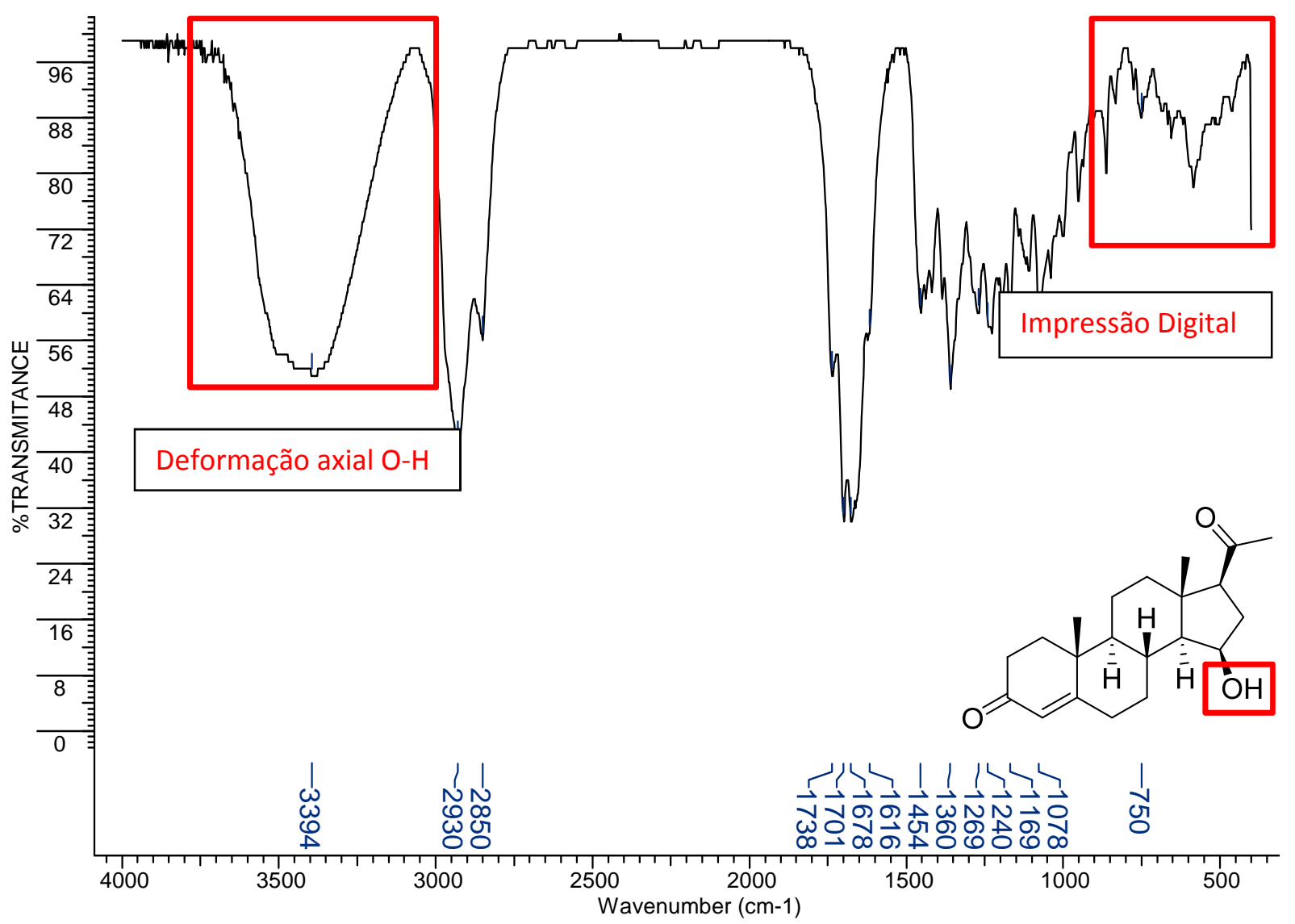


Como observado na Figura 86 a principal diferença entre os dois espectros foi a presença de uma banda larga em $3394 \mathrm{~cm}^{-1}$ referente à deformação axial e ligação O-H que indicou a presença de grupo hidroxila no composto. Comparando as atribuições, bem como o espectro do composto em questão com os dados de IV do produto isolado da reação com o caldo enzimático do fungo A. sydowii CBMAI 934 (Tabela 25 e Figura 75), observou-se que as atribuições foram as mesmas e os espectros foram muito semelhantes. A diferença entre os espectros se dá na região denominada "impressão digital" (entre $450 \mathrm{~cm}^{-1}$ a $1000 \mathrm{~cm}^{-1}$ ) que por vezes é crucial na identificação de compostos orgânicos, uma vez que por mais semelhantes que sejam os espectros entre compostos orgânicos contendo os mesmos grupos funcionais, os espectros não serão exatamente iguais.

Devido os dados de RMN evidenciarem a presença de uma hidroxila no metabólito de biotransformação foi feito um experimento de EMAR pelo fato de ter sido um espectro de massas de baixa resolução por CG-EM do composto isolado da reação com o micélio do fungo A. sydowii CBMAI 934 indicando um composto di-hidroxilado (seção D.5.3.4). A Figura 87 apresenta o espectro de massas de alta resolução obtido experimentalmente para o metabólito 15 $\beta$-hidroxiprogesterona isolado da reação com o micélio do fungo A. sydowii CBMAI 934.

Figura 87. Espectro de massas de alta resolução modo positivo $\left(\mathrm{H}^{+}\right)$da $15 \beta$-hidroxiprogesterona isolada da reação da progesterona com a massa micelial do fungo A. sydowii CBMAI 934.

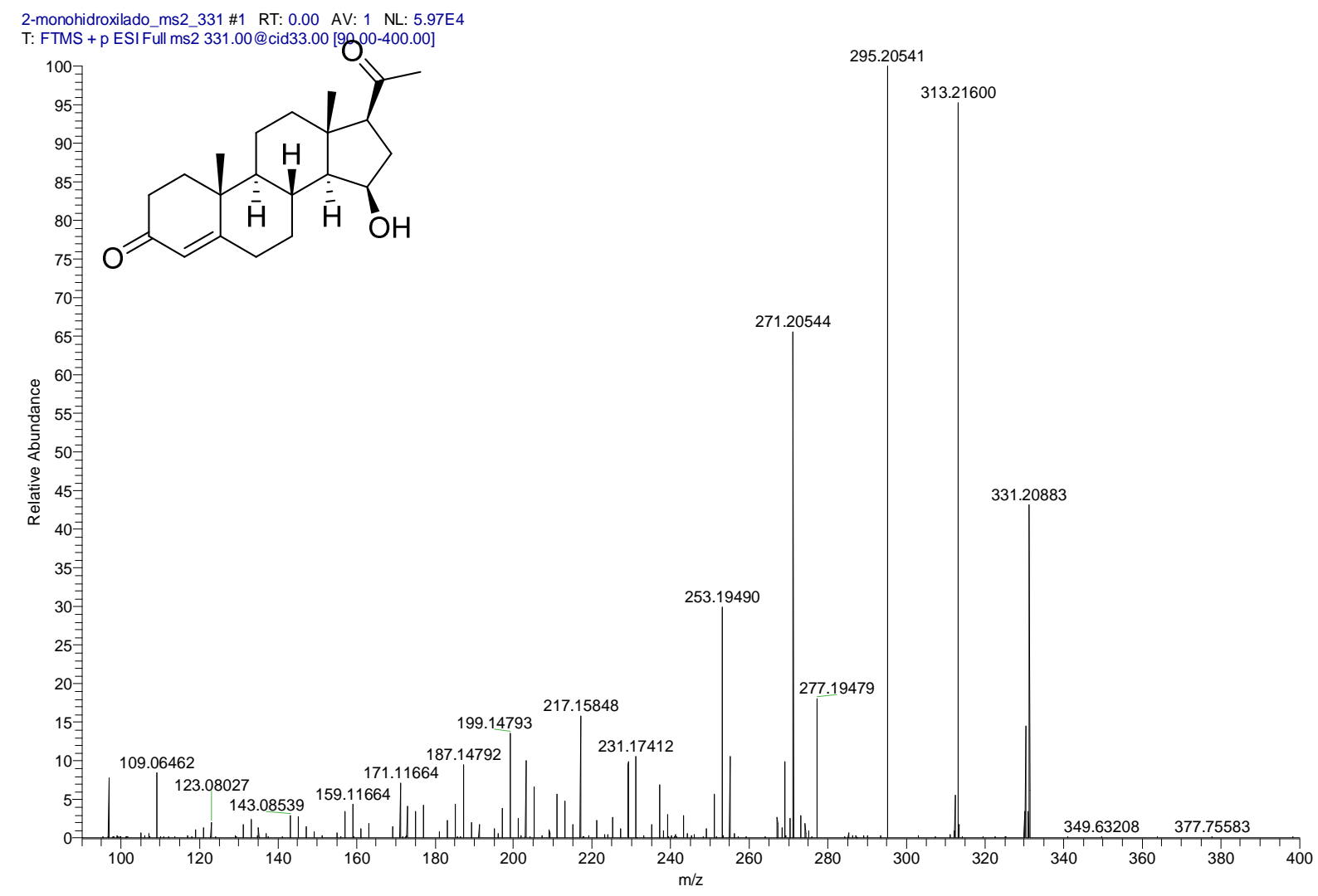


Como o espectro de massas da Figura 86 apresentou, foi observado o pico de $\mathrm{m} / \mathrm{z}$ 331,20883 . Este pico se referiu ao íon molecular do produto $15 \beta$-hidroxiprogesterona (massa molar $=330,47 \mathrm{~g} / \mathrm{mol}$ ), porém protonado, uma vez que o composto foi dissolvido em acetonitrila acidificada com $0,1 \%$ de ácido fórmico para execução da análise.

Como mostrou o Esquema 17, Janeczko et al. (2012) ${ }^{74}$ obtiveram este composto e outros produtos hidroxilados a partir da biotransformação da progesterona pelo fungo Didymosphaeria igniaria KCH 6670. Foi obtido o espectro de massas da 15ßhidroxiprogesterona por CG-EM e foi indicado como íon molecular $m / z 331$, o que foi concordante com a massa molecular e com os dados de EMAR obtido neste estudo para o referido composto. Esses dados mostraram que foi obtido o produto $15 \beta$-hidroxiprogesterona da biotransformação da progesterona pelo caldo enzimático do fungo A. sydowii CBMAI 934. Sendo assim, o rendimento em massa da reação foi de $58 \%$.

A Tabela 31 apresenta os resultados das medidas de rotação óptica para o composto dihidroxilado isolado, comparativo os valores descritos na literatura para a $15 \beta$ hidroxiprogesterona ${ }^{82}$.

Tabela 31. Valores de rotação óptica para a $15 \beta$-hidroxiprogesterona.

\begin{tabular}{cccccc}
\hline \multicolumn{2}{c}{ Valores descritos na literatura ${ }^{82}$} & \multicolumn{3}{c}{ Valores experimentais } \\
\hline $\begin{array}{c}\text { Concentração } \\
(\mathrm{g} / 100 \mathrm{~mL})^{\mathrm{a}}\end{array}$ & Temperatura $\left({ }^{\circ} \mathrm{C}\right)$ & {$\left[\alpha_{D}\right]_{589}^{20}(\mathrm{deg})$} & $\begin{array}{c}\text { Concentração } \\
(\mathrm{g} / 100 \mathrm{~mL})^{\mathrm{a}}\end{array}$ & $\begin{array}{c}\text { Temperatura }\left({ }^{\circ} \mathrm{C}\right) \\
{\left[\alpha_{D}\right]_{589}^{23}(\mathrm{deg})}\end{array}$ \\
\hline 1,03 & 20 & 149 & 0,8 & 23 & 70,6 \\
\hline${ }^{\mathrm{a}} \mathrm{CHCl}_{3}$ & & &
\end{tabular}

Como a Tabela 31 apresentou, há uma diferença da rotação óptica entre o valor experimental e o da literatura ${ }^{82}$, apesar que o sentido da rotação permaneceu o mesmo. Possivelmente esta diferença se deve à temperatura em que o experimento foi executado, bem como às diferenças de concentração.

Para a obtenção da 15ß-hidroxiprogesterona a partir da biotransformação da progesterona utilizando microganismos, na literatura encontram-se algumas referências. A biotransformação da progesterona pelo fungo D. igniaria $\mathrm{KCH} 6670$ por Janeczko et al. $(2012)^{74}$ forneceu vários produtos de hidroxilação já foi citada neste texto (Esquema 17). Dentre os produtos descritos foi obtida a $15 \beta$-hidroxiprogesterona com rendimento em massa de $10 \%$.

McAleer et al. $(1958)^{83}$ promoveram a biotransoformação da progesterona utilizando a bactéria Bacillus megaterium em alta agitação (408 rpm) e com injeção de ar por 24 horas a $28^{\circ} \mathrm{C}$ sendo $38,4 \%$ do substrato convertido em $15 \beta$-hidroxiprogesterona, como mostra o Esquema 18. 
Esquema 18. Biotransformação da progesterona utilizando a bactéria B. megaterium com injeção de $\operatorname{ar}^{83}$.<smiles>CC(=O)[C@H]1CC[C@H]2[C@@H]3CCC4=CC(=O)CC[C@]4(C)[C@H]3CC[C@]12C</smiles>

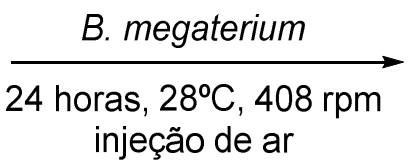

c: $38,4 \%$<smiles>CC(=O)[C@H]1C[C@@H](O)[C@H]2[C@@H]3CCC4=CC(=O)CC[C@]4(C)[C@H]3CC[C@]12C</smiles>

$15 \beta$-hidroxiprogesterona

Outra biotransformação da progesterona obtendo $15 \beta$-hidroxiprogesterona foi descrita por Herzog et al. (1959) ${ }^{84}$ também utilizando a bactéria B. megaterium por 48 horas a $28^{\circ} \mathrm{C}$ sendo $9 \%$ o rendimento obtido (Esquema 19).

Esquema 19. Biotransformação da progesterona utilizando a bactéria B. megaterium sem injeção de ar ${ }^{84}$.

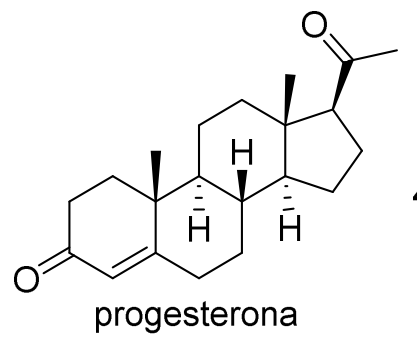

\section{B. megaterium}

48 horas, $28^{\circ} \mathrm{C}, 220 \mathrm{rpm}$

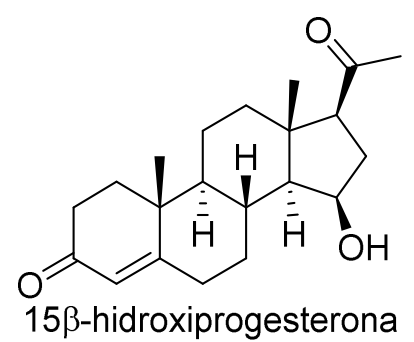

r. $=9,0 \%$ 


\section{D.5.4.3 Caracterização da testosterona obtida da reação com o caldo enzimático do fungo} A. sydowii CBMAI 935 (7 dias, $\left.32^{\circ} \mathrm{C}, 130 \mathrm{rpm}\right)$

Conforme abordado na seção D.5.3.6 as análises por CG-EM do composto isolado dessa reação (Figuras 56 e 57) evidenciaram que a testosterona foi obtida da biotransformação da progesterona pelo caldo enzimático do fungo A. sydowii CBMAI 935. O espectro de massas obtido por CG-EM do metabólito isolado teve alta similaridade com o espectro fornecido pela biblioteca (93\%, biblioteca NIST21 - Figura 56). As análises por RMN confirmaram que o composto isolado foi a testosterona, conforme será apresentado ao longo dessa seção.

A Figura 88 apresenta as estruturas planar e tridimensional da testosterona e a Tabela 32 apresenta os dados de deslocamentos químicos obtidos através dos espectros de RMN de ${ }^{13} \mathrm{C}(100 \mathrm{MHz}),{ }^{1} \mathrm{H}(400 \mathrm{MHz})$ obtidos experimentalmente para a testosterona e comparados com os dados descritos na literatura ${ }^{85,75}$. 
Figura 88. Estruturas químicas para a testosterona: (A) planar, (B) tridimensional.

(A)

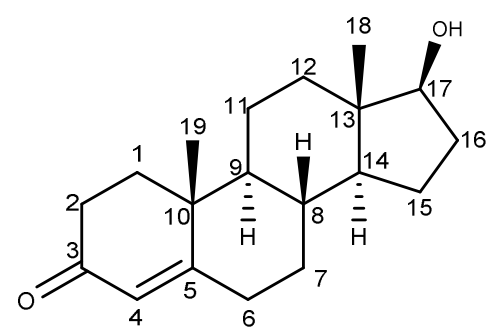

(B)

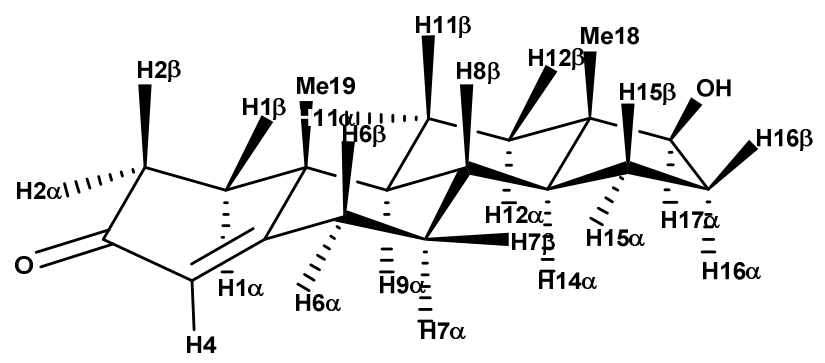

Tabela 32. Valores de deslocamentos químicos (ppm) de $\operatorname{RMN}\left({ }^{13} \mathrm{C} \mathrm{e}{ }^{1} \mathrm{H}\right)$ para a testosterona.

\begin{tabular}{|c|c|c|c|c|c|}
\hline${ }^{13} \mathrm{C}$ & $\delta^{13}{ }_{C}\left(\text { literatura }{ }^{85}\right)^{\mathrm{a}}$ & $\delta^{13}{ }_{C}(\text { experimental })^{\mathrm{a}}$ & ${ }^{1} \mathrm{H}$ & $\delta^{1}{ }_{H}\left(\text { literatura }^{75}\right)^{\mathrm{b}}$ & $\delta^{1}{ }_{\mathrm{H}}(\text { experimental })^{\mathrm{c}}$ \\
\hline \multirow{2}{*}{1} & \multirow{2}{*}{36,1} & \multirow{2}{*}{35,8} & $1 \alpha$ & 1,70 & 1,73 \\
\hline & & & $1 \beta$ & 2,03 & 2,08 \\
\hline \multirow{2}{*}{2} & \multirow{2}{*}{34,1} & \multirow{2}{*}{34,0} & $2 \alpha$ & 2,35 & 2,36 \\
\hline & & & $2 \beta$ & 2,42 & 2,46 \\
\hline 3 & 198,0 & 199,6 & - & - & - \\
\hline 4 & 124,2 & 123,9 & 4 & 5,73 & 5,76 \\
\hline 5 & 170,4 & 171,6 & - & - & - \\
\hline \multirow{2}{*}{6} & \multirow{2}{*}{32,8} & \multirow{2}{*}{32,8} & $6 \alpha$ & 2,29 & 2,29 \\
\hline & & & $6 \beta$ & 2,42 & 2,39 \\
\hline \multirow{2}{*}{7} & \multirow{2}{*}{32,2} & \multirow{2}{*}{31,6} & $7 \alpha$ & 1,00 & 1,05 \\
\hline & & & $7 \beta$ & 1,85 & 1,86 \\
\hline 8 & 36,1 & 35,6 & $8 \beta$ & 1,57 & 1,59 \\
\hline 9 & 54,6 & 53,9 & $9 \alpha$ & 0,93 & 0,92 \\
\hline 10 & 39,0 & 38,7 & - & - & - \\
\hline \multirow{2}{*}{11} & \multirow{2}{*}{21,2} & \multirow{2}{*}{20,7} & $11 \alpha$ & 1,60 & 1,62 \\
\hline & & & $11 \beta$ & 1,43 & 1,44 \\
\hline \multirow{2}{*}{12} & \multirow{2}{*}{37,1} & \multirow{2}{*}{36,5} & $12 \alpha$ & 1,10 & 1,12 \\
\hline & & & $12 \beta$ & 1,86 & 1,86 \\
\hline 13 & 43,2 & 42,8 & - & - & - \\
\hline 14 & 51,1 & 50,5 & $14 \alpha$ & 0,98 & 0,98 \\
\hline \multirow{2}{*}{15} & \multirow{2}{*}{23,8} & \multirow{2}{*}{23,4} & $15 \alpha$ & 1,62 & 1,69 \\
\hline & & & $15 \beta$ & 1,31 & 1,32 \\
\hline \multirow{2}{*}{16} & \multirow{2}{*}{30,7} & \multirow{2}{*}{30,5} & $16 \alpha$ & 2,09 & 2,10 \\
\hline & & & $16 \beta$ & 1,48 & 1,51 \\
\hline 17 & 81,3 & 81,6 & $17 \alpha$ & 3,65 & 3,65 \\
\hline 18 & 11,3 & 11,1 & 18 & 0,80 & 0,79 \\
\hline 19 & 17,3 & 17,4 & 19 & 1,19 & 1,20 \\
\hline
\end{tabular}

${ }^{\mathrm{a}} 100 \mathrm{MHz}, \mathrm{CDCl}_{3} ;{ }^{\mathrm{b}} 500 \mathrm{MHz}, \mathrm{CDCl}_{3} ;{ }^{\mathrm{c}} 400 \mathrm{MHz}, \mathrm{CDCl}_{3}$ 
Como a Tabela 32 apresentou os dados de deslocamentos químicos obtidos foram bastante concordantes com os dados de referência da literatura ${ }^{85,75}$, fornecendo uma forte evidência que nesta reação a progesterona foi biotransformada, produzindo a testosterona.

Comparando os espectros de $\mathrm{RMN}$ de ${ }^{13} \mathrm{C}$ da progesterona e da testosterona, como mostra a Figura 89, não foram observados no espectro da testosterona os sinais típicos de carbonilas e metilas do grupo acetila $(\delta=209,3$ e 31,5 na progesterona relativos respectivamente aos carbonos C-20 e C-21). Além disso, não foi observado algum sinal entre 60 - 70 ppm relativo ao carbono C-17 ( $\delta=63,5$ na progesterona). Foi observado no espectro da progesterona um sinal em $\delta=81,6$ típico de carbono carbinólico, que de fato correspondeu ao carbono C-17 da testosterona. 

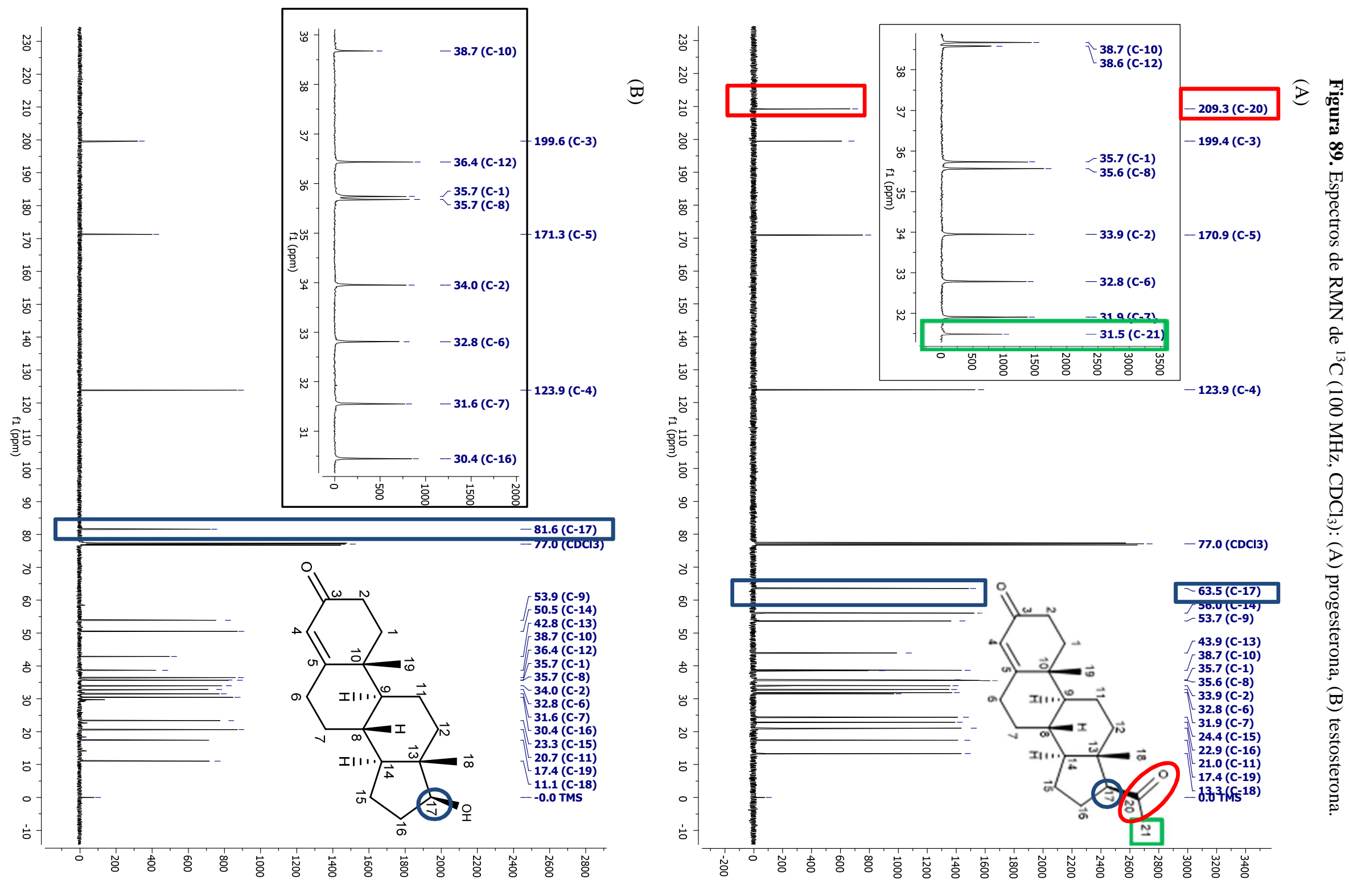
Comparando entre si os espectros de RMN de HSQC da progesterona e da testosterona (Figuras 90 e 91) foi observado no espectro ampliado da progesterona uma correlação entre os sinais $\delta=2,15$ e $\delta=31,5$ referentes respectivamente aos hidrogênios $\mathrm{H}-21$ e ao carbono C-21 da metila do grupo acetila da progesterona (Figura 90A). No espectro ampliado da testosterona (Figura 90B), nessa mesma região, não foi observada alguma correlação com esses valores. No espectro completo da progesterona (Figura 91A) foi bem nítida a correlação entre os sinais do hidrogênio H-17 $\alpha$ e o carbono $\mathrm{C}-17$ ( $\delta=2,52$ e $\delta=63,6$ respectivamente). No espectro completo da testosterona (Figura 91B) não foi observada alguma correlação nessa região. Entretanto, o sinal relativo ao carbono carbinólico $\delta=81,6$ (C-17) se correlacionou ao sinal $\delta$ = 3,66 típico de hidrogênio ligado a carbono carbinólico $\mathrm{sp}^{3}$, indicando ser o hidrogênio $\mathrm{H}-17 \alpha$. Esses dados obtidos dos espectros de $\mathrm{RMN}$ de ${ }^{13} \mathrm{C}$ e HSQC reforçaram que o grupo acetila ligado ao carbono C-17 foi substituído por um grupo hidroxila, evidenciando a biotransformação da progesterona em testosterona. 
Figura 90. Espectros de RMN de HSQC $\left(\mathrm{CDCl}_{3}\right)$ ampliados: (A) progesterona (125 MHz e $\left.500 \mathrm{MHz}\right)$; (B) testosterona (100 MHz e $400 \mathrm{MHz}$ ).

(A)

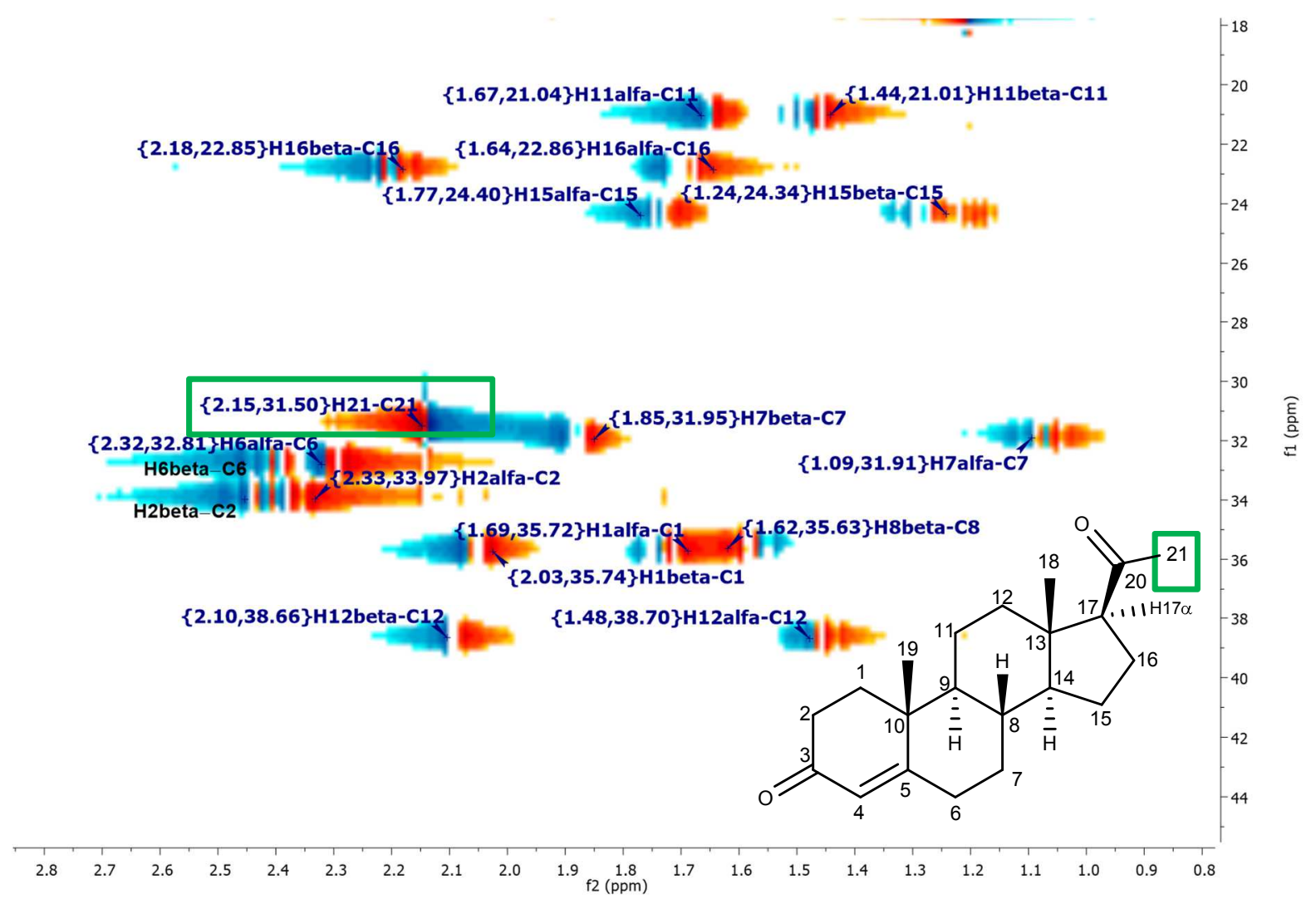

(B)

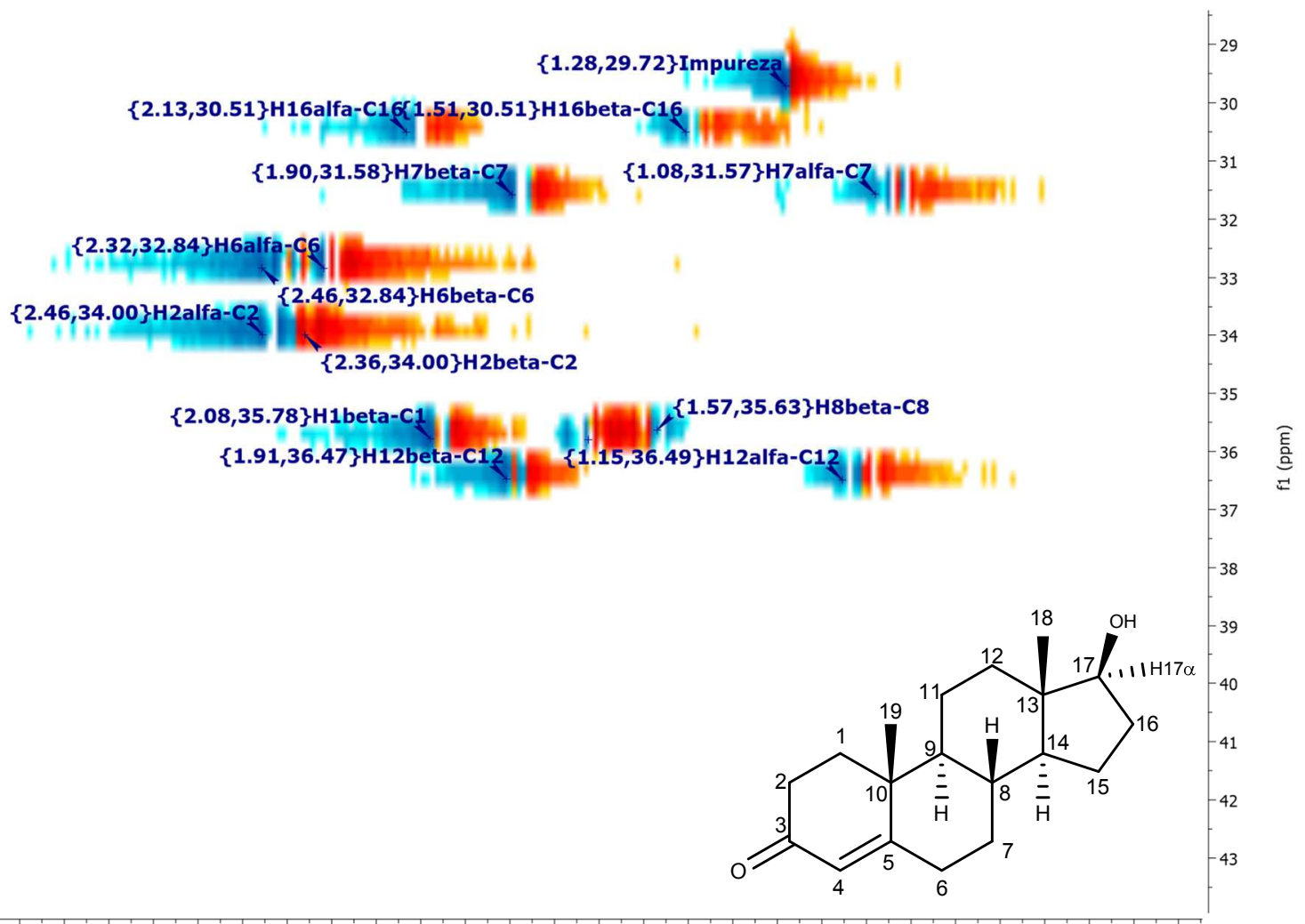

$\begin{array}{lllllllllllllllllllllllllllll}3.2 & 3.1 & 3.0 & 2.9 & 2.8 & 2.7 & 2.6 & 2.5 & 2.4 & 2.3 & 2.2 & 2.1 & 2.0 & 1.9 & 1.8 & 1.7 & 1.6 & 1.5 & 1.4 & 1.3 & 1.2 & 1.1 & 1.0 & 0.9 & 0.8 & 0.7 & 0.6 & 0.5 & 0.4\end{array}$ 
Figura 91. Espectros de RMN de HSQC $\left(\mathrm{CDCl}_{3}\right)$ completos: (A) progesterona (125 MHz e $\left.500 \mathrm{MHz}\right)$; (B) testosterona (100 MHz e $400 \mathrm{MHz}$ ).

(A)

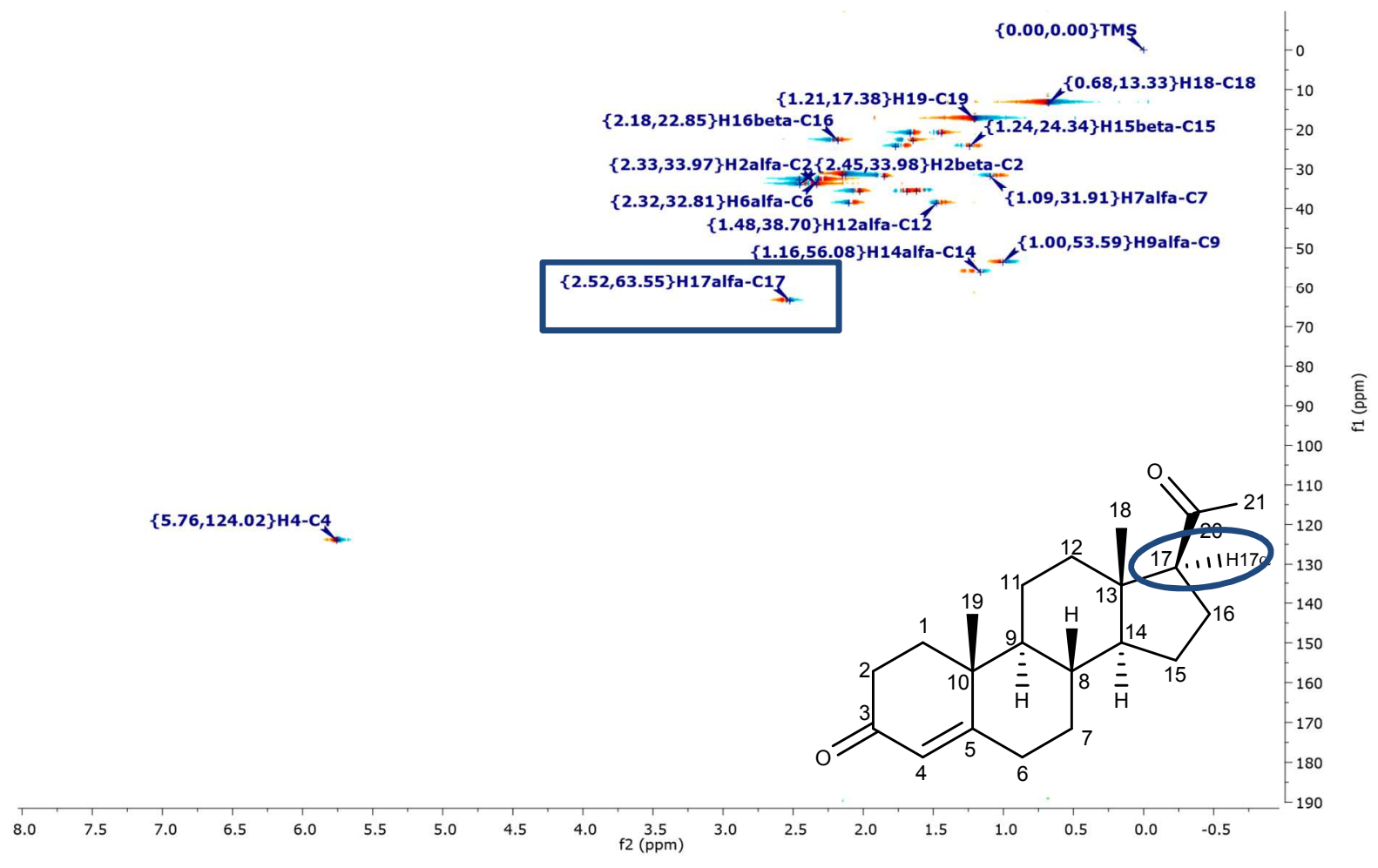

(B)

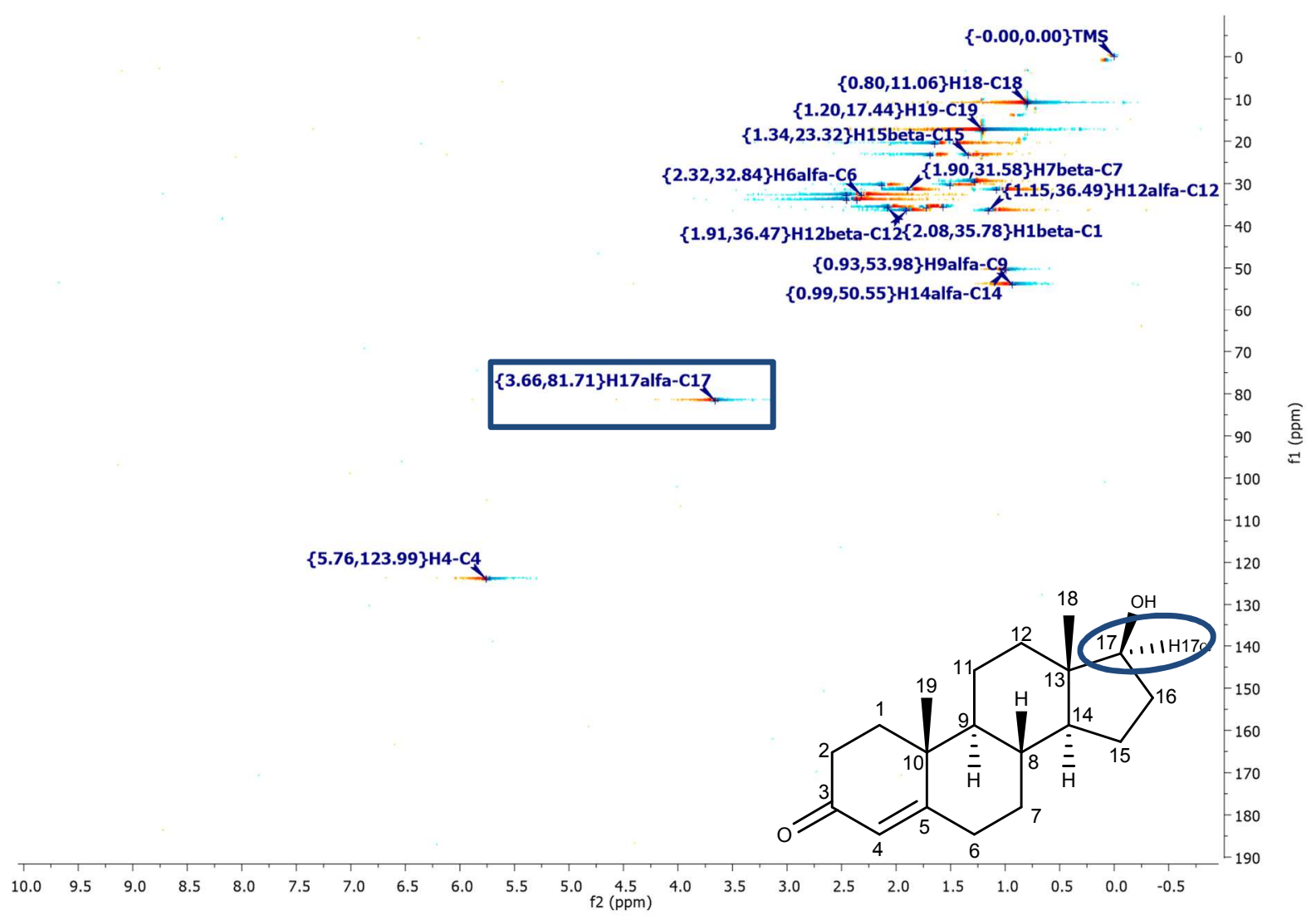


Através das análises do espectro de HMBC da testosterona (Figura 93) em relação o sinal de carbono carbinólico C-17 $(\delta=81,7)$ foram observadas as seguintes correlações: duas ${ }^{2} J_{\mathrm{HC}}$ com os sinais $\delta=2,11$ (hidrogênio $\mathrm{H}-16 \alpha$ ) e $\delta=1,48$ (hidrogênio H-16ß); cinco ${ }^{3} J_{\mathrm{HC}}$ com os sinais $\delta=1,66$ (hidrogênio $\mathrm{H}-15 \alpha$ ), $\delta=1,33$ (hidrogênio $\mathrm{H}-15 \beta$ ), $\delta=1,12$ (hidrogênio H$12 \alpha$ ), $\delta=0,97$ (hidrogênio $\mathrm{H}-14 \alpha$ ) e $\delta=0,80$ (hidrogênio $\mathrm{H}-18$ ). As correlações relativas ao carbono C-17 estão representadas na Figura 92A, que mostra o anel D do núcleo esteroidal da testosterona.

Além disso, em relação ao sinal de hidrogênio carbinólico $\mathrm{H}-17 \alpha(\delta=3,68)$ foram observadas no espectro de HMBC da testosterona (Figura 93) as seguintes correlações com os sinais: $\delta=11,1$ (carbono C-18), $\delta=30,5$ (carbono C-16), $\delta=36,5$ (carbono C-12) e $\delta=36,5$ (carbono C-13). As correlações relativas ao hidrogênio H-17 $\alpha$ estão representadas na Figura 91B, que mostra o anel D do núcleo esteroidal da testosterona.

As correlações relativas ao carbono C-17 e ao hidrogênio H-17 $\alpha$ encontradas no espectro de $\mathrm{HMBC}$ com os átomos de carbono e hidrogênios vizinhos evidenciaram que o carbono C-17 foi o sítio em que ocorreu a biotransformação da progesterona pelo caldo enzimático do fungo A. sydowii CBMAI 935, ocorrendo a substituição ddo grupo acetila por um grupo hidroxila no carbono $\mathrm{C}-17$. 
Figura 92. Algumas correlações $J_{\mathrm{HC}}$ observadas nos espectros de $\mathrm{HMBC}(100 \mathrm{MHz}$ e $400 \mathrm{MHz}) \mathrm{da}$ testosterona: (A) $J_{\mathrm{H}-\mathrm{C} 17},(\mathrm{~B}) J_{\mathrm{H} 17 \alpha-\mathrm{C}}$.

(A)

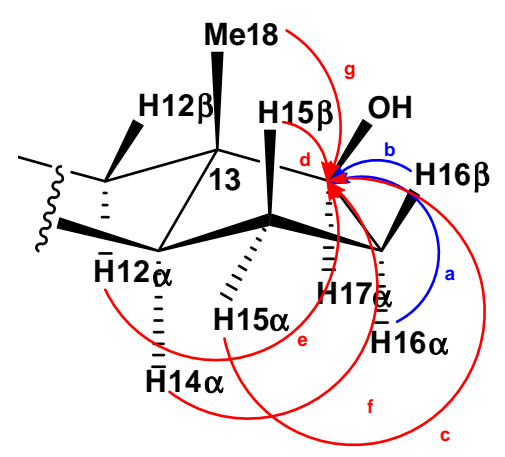

a: ${ }^{2} J_{\mathrm{H} 16 \alpha-\mathrm{C} 17}$

b: ${ }^{2} J_{\mathrm{H} 16 \beta-\mathrm{C} 17}$

c: ${ }^{3} J_{\mathrm{H} 15 \alpha-\mathrm{C} 17}$

d: ${ }^{3} J_{\mathrm{H} 15 \beta-\mathrm{C} 17}$

e: ${ }^{3} J_{\mathrm{H} 12 \alpha-\mathrm{C} 17}$

f: ${ }^{3} J_{\mathrm{H} 14 \alpha-\mathrm{C} 17}$

g: ${ }^{3} J_{\mathrm{H} 18-\mathrm{C} 17}$
(B)

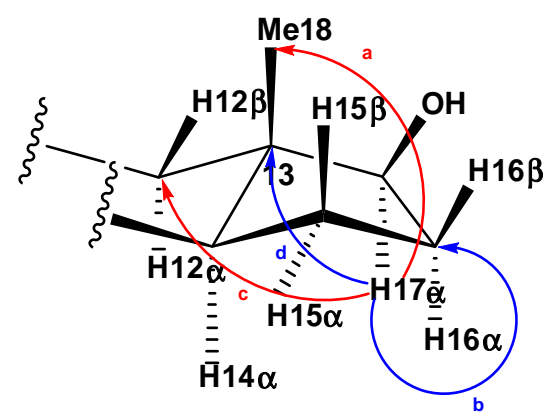

a: ${ }^{2} J_{\mathrm{H} 177_{\alpha}-\mathrm{C} 18}$

b: ${ }^{3} J_{\mathrm{H} 17 \alpha-\mathrm{C} 16}$

c: ${ }^{2} J_{\mathrm{H} 17 \alpha-\mathrm{C} 12}$

d: ${ }^{3} J_{\mathrm{H} 17 \alpha-\mathrm{C} 13}$

Figura 93. Espectros de RMN de HMBC ampliado (100 MHz e $400 \mathrm{MHz} \mathrm{CDCl}_{3}$ ) da testosterona.
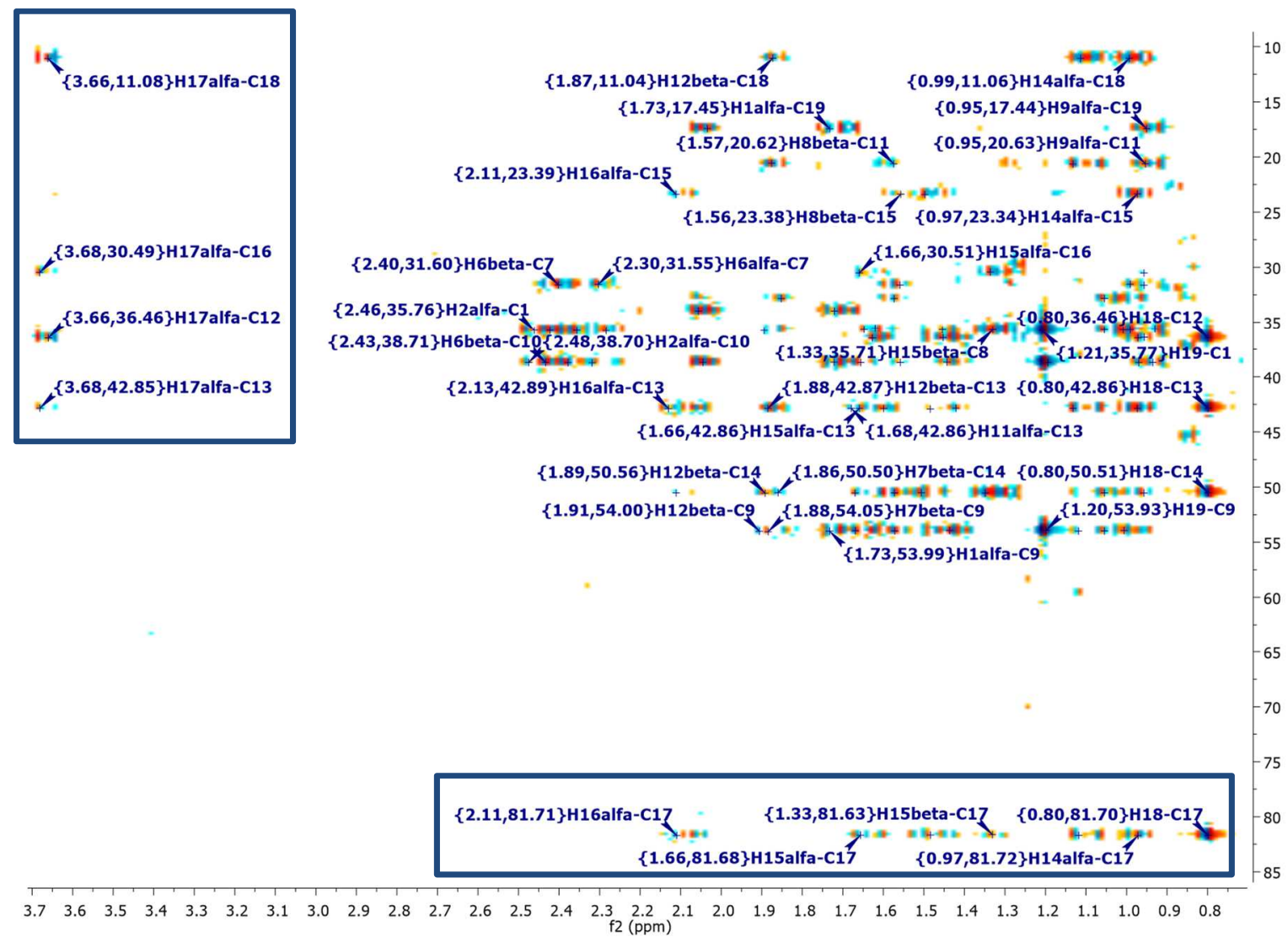

Através das análises do espectro de COSY da testosterona, comparada com o espectro da progesterona, como mostra a Figura 95, foram observadas as seguintes correlações relativas ao sinal de hidrogênio $\mathrm{H}-17 \alpha$ da testosterona $(\delta=3,66)$ : duas ${ }^{3} J_{\mathrm{HH}}$ com os sinais $\delta=2,15$ (hidrogênio $\mathrm{H}-16 \alpha$ ) e $\delta=1,46$ (hidrogênio H-16ß). Estas correlações foram encontradas no espectro de COSY da progesterona para o hidrogênio H-17 $\alpha$. 
Foram observadas quatro correlações a longa distância ${ }^{4} J_{\mathrm{HH}}$ relativas ao sinal de hidrogênio H-17 $\alpha$ da testosterona $(\delta=3,66)$ sendo elas com os sinais: $\delta=0,79$ (hidrogênios

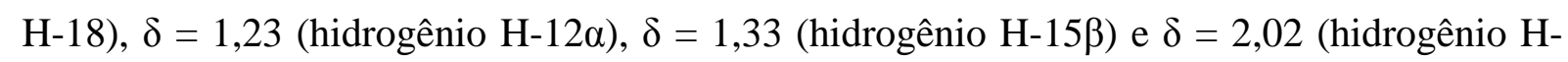

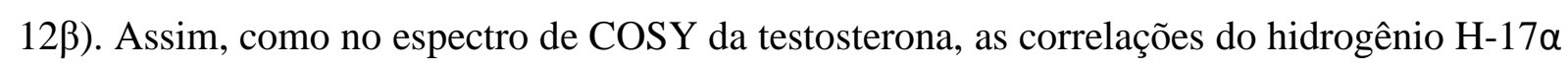

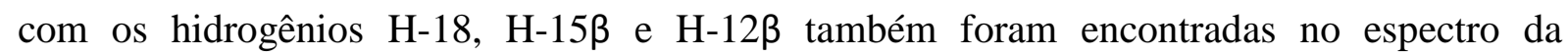
progesterona (Figura 95A). Vale destacar as correlações com o hidrogênio H-18 encontrado em ambos os espectros. Esse tipo de correlação é denominado "acoplamento W" (Figuras 94C e D) e é comum ser encontrado entre os hidrogênios H-18 e H-17 $\alpha$ mesmo que eles possuam configurações opostas. Ou seja, a metila 18 ligada ao carbono C-13 na posição $\beta$ e o hidrogênio H-17 ligado ao carbono C-17 na posição $\alpha^{77}$.

Correlações do sinal do hidrogênio H-17 $\alpha$ com os hidrogênios H-15a e especialmente com o hidrogênio H-21 não foram encontradas no espectro da testosterona. A não visualização desta última correlação no espectro de COSY da testosterona evidenciou que de fato o grupo acetila ligada ao carbono C-17 da progesterona foi substituída por um grupo hidroxila, mostrando assim a biotransformação da progesterona pelo caldo enzimático do fungo $A$. sydowii CBMAI 935, produzindo testosterona. As correleções encontradas nos espectros de COSY, tanto da progesterona, quanto da testosterona envolvendo o hidrogênio H-17 $\alpha$ estão representadas na Figura 94. 
Figura 94. Algumas correlações $J_{\mathrm{HH}}$ observadas nos espectros de COSY envolvendo o hidrogênio H-17 $\alpha$ no anel D do núcleo dos esteroides: (A) progesterona, (B) testosterona isolda da reação com o caldo enzimático do fungo A. sydowii CBMAI 935, (C) “acoplamento W" entre H-18 e H-17 a na progesterona, (D) “acoplamento W" entre H-18 e H-14 $\alpha$ na testosterona.

(A)

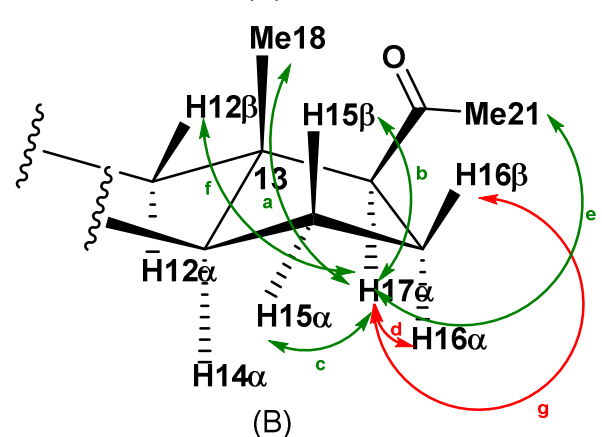

(B)

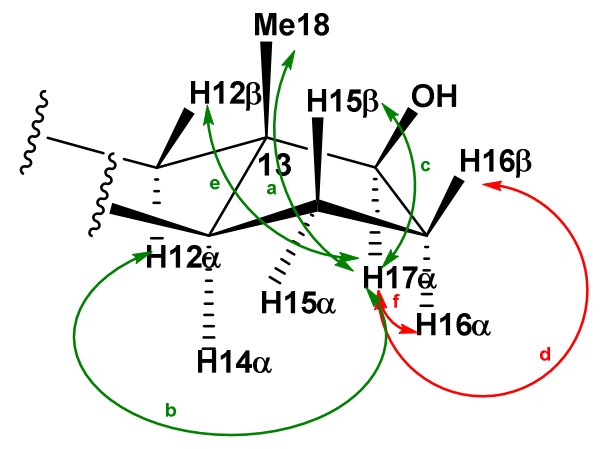

a: ${ }^{4} J_{\mathrm{H} 17 \alpha-\mathrm{H} 18}$

b: ${ }^{4} J_{\mathrm{H} 17 \alpha-\mathrm{H} 15 \beta}$

c: ${ }^{3} J_{\mathrm{H} 17 \alpha-\mathrm{H} 15 \alpha}$

d: ${ }^{3} J_{\mathrm{H} 17 \alpha-\mathrm{H} 16 \alpha}$

e: ${ }^{4} J_{\mathrm{H} 17 \alpha-\mathrm{H} 21}$

f: ${ }^{4} J_{\mathrm{H} 17 \alpha-\mathrm{H} 12 \beta}$

g: ${ }^{3} J_{\mathrm{H} 17 \alpha-\mathrm{H} 16 \beta}$

a: ${ }^{4} J_{\mathrm{H} 17 \alpha-\mathrm{H} 18}$

b: ${ }^{4} J_{\mathrm{H} 17 \alpha-\mathrm{H} 12 \alpha}$

c: ${ }^{3} J_{\mathrm{H} 17 \alpha-\mathrm{H} 15 \beta}$

d: ${ }^{3} J_{\mathrm{H} 17 \alpha-\mathrm{H} 16 \beta}$

e: ${ }^{4} J_{\mathrm{H} 17 \alpha-\mathrm{H} 12 \beta}$

f: ${ }^{3} J_{\mathrm{H} 17 \alpha-\mathrm{H} 16 \alpha}$
(C)

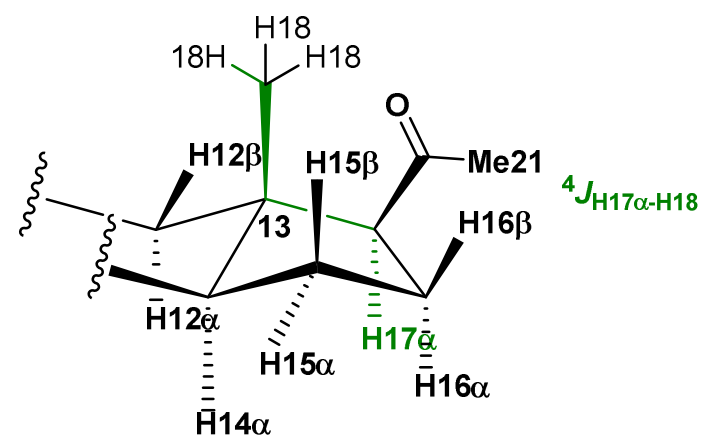

(D)

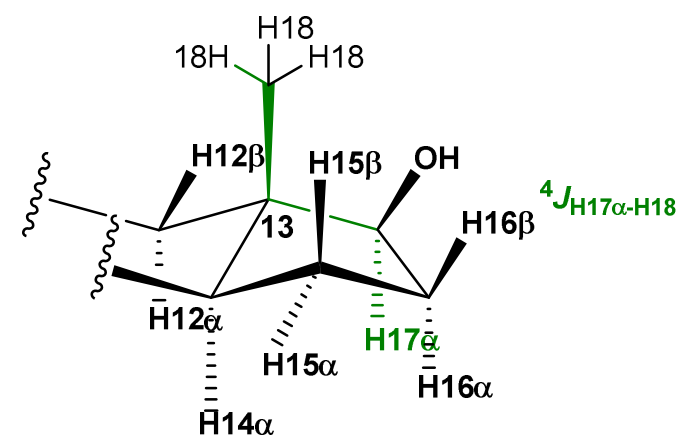


Figura 95. Espectros de RMN de COSY ampliados: (A) progesterona (500 $\mathrm{MHz}, \mathrm{CDCl}_{3}$ ), (B) testosterona isolada da reação com o caldo enzimático do fungo A. sydowii CBMAI 935 (400 MHz, CDCl ${ }_{3}$ ).

(A)

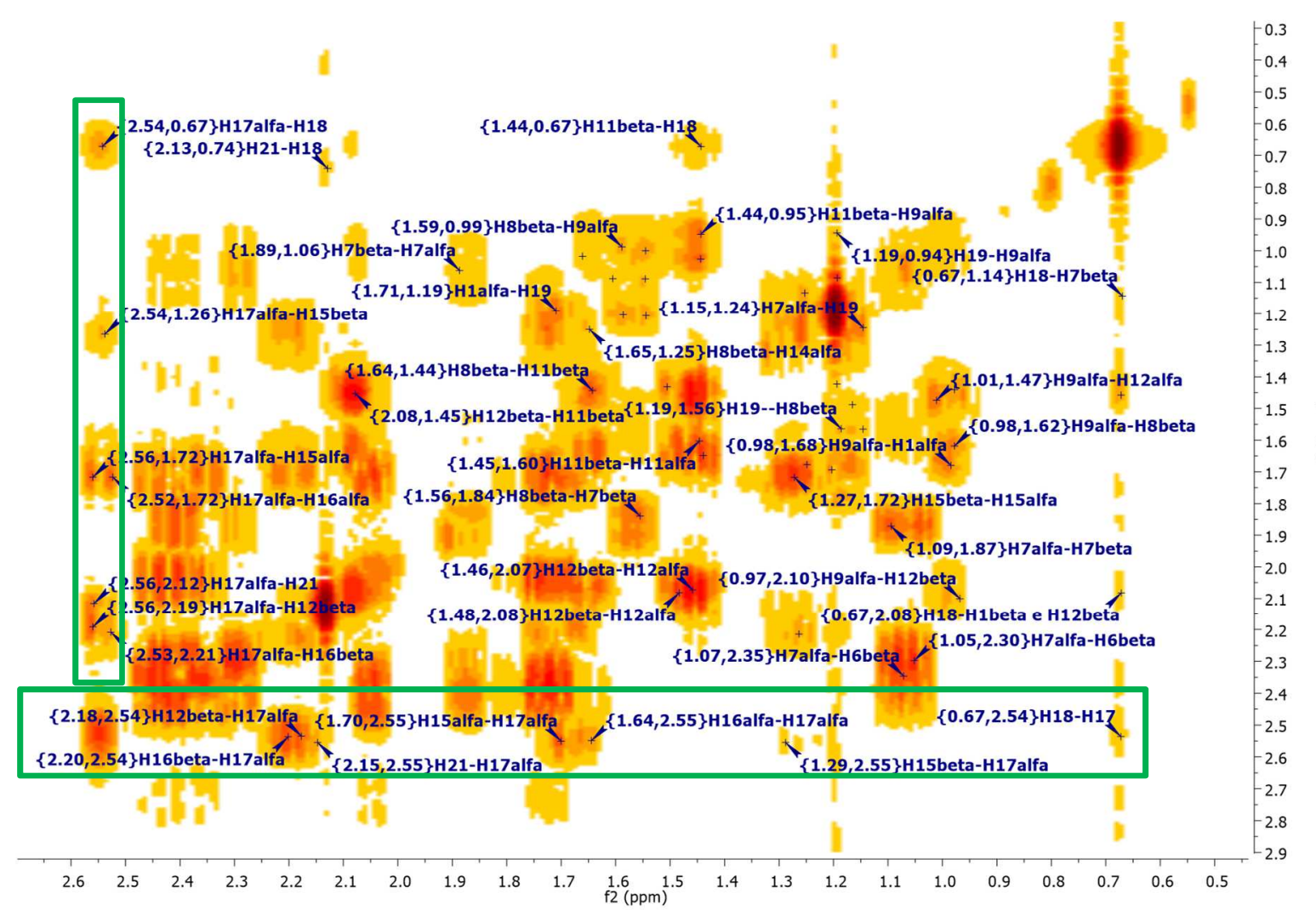

(B)

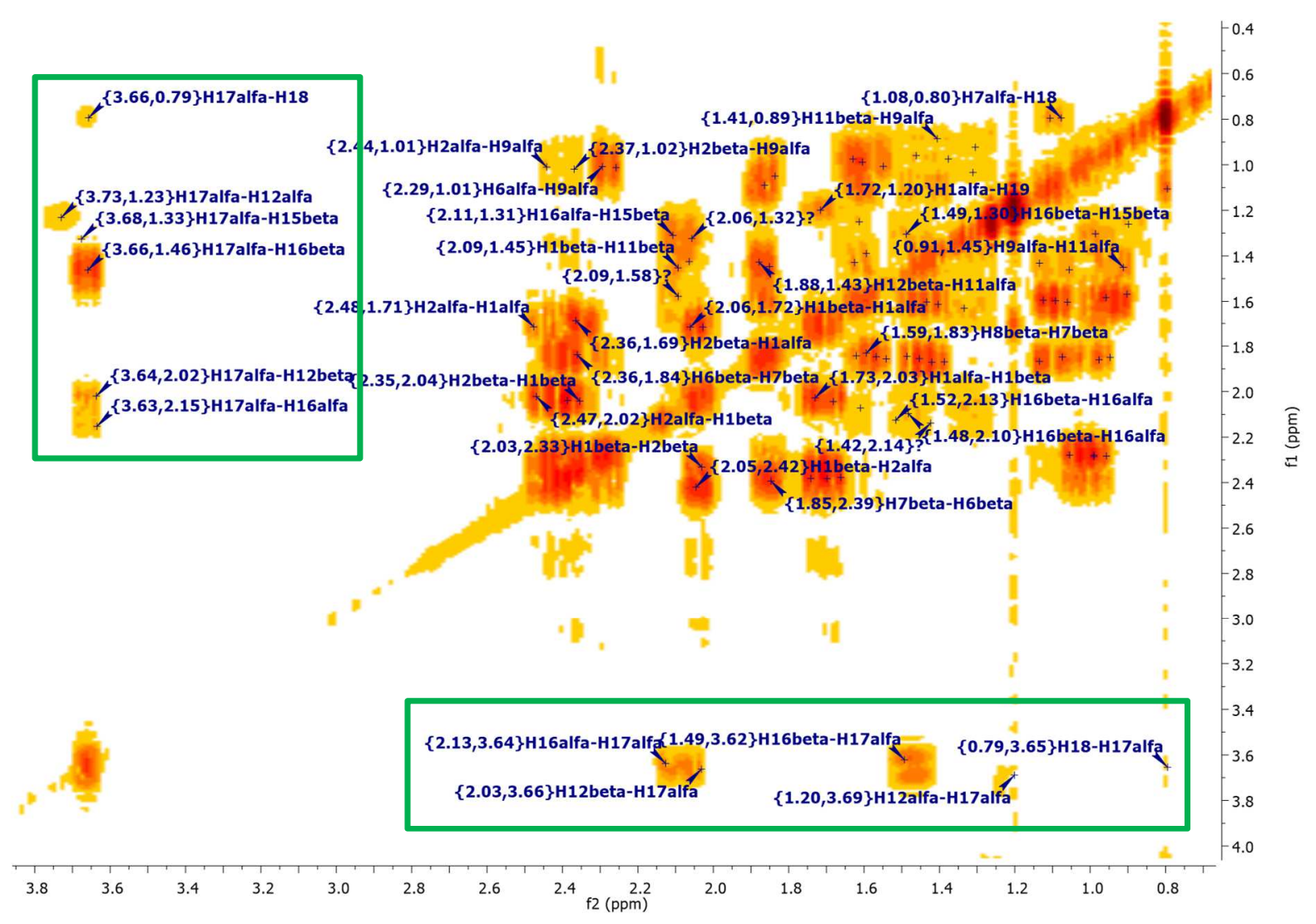


Através das análises dos espectros de $\mathrm{RMN}$ de ${ }^{1} \mathrm{H}$ da progesterona e da testosterona (Figura 95) pôde-se observar que no espectro da progesterona (Figura 96A) foram observados três singletos referentes às três metilas presentes na molécula: $\delta=0,67$ (hidrogênios H-18), $\delta=$ 1,19 (hidrogênios H-19) e $\delta=2,13$ (hidrogênios H-21). Comparando com o espectro de RMN de ${ }^{1} \mathrm{H}$ da testosterona (Figura 96B) foram observados dois singletos referentes aos hidrogênios H-18 $(\delta=0,79)$ e aos hidrogênios H-19 $(\delta=1,20)$. Isso mostrou que o carbono C-17 de fato foi o sítio de biotransformação da progesterona pelo caldo enzimático do fungo A. sydowii CBMAI 935, ocorrendo a substituição do grupo acetila ligada ao carbono C-17 por um grupo hidroxila, produzindo testosterona.

Foram calculadas as constantes de acoplamento dos sinais referentes ao hidrogênio H$17 \alpha$ da progesterona $(\delta=2,54)$ e da testosterona $(\delta=3,65)$. Foi encontrado para a progesterona uma constante de $J=8,5 \mathrm{~Hz}$ e para a testosterona uma constante de $J=9,2 \mathrm{~Hz}$. Como são constantes semelhantes elas se referem ao mesmo tipo de acoplamento vicinal $\operatorname{trans}{ }^{3} \boldsymbol{J}_{\mathrm{H} 17 \alpha-\mathrm{H} 16 \beta}$. Além disso, como os valores foram próximos, eles indicam que não houve inversão de configuração do hidrogênio H-17, se mantendo na posição $\alpha$.

Foi observado que os sinais de multipletos dos hidrogênios $\mathrm{H}-17 \alpha$, tanto da progesterona quanto da testosterona é um tripleto e comparando ambos os multipletos com o perfil de multiplicidade para o hidrogênio H-17 $\alpha$ proposto por Kirk, et al. (1990) ${ }^{75}$, como mostra a Figura 97, observou-se que o perfil foi mantido, indicando que este hidrogênio se manteve na configuração $\alpha$, que é a orientação deste átomo de hidrogênio ligado ao carbono C-17 tanto na progesterona, quanto na testosterona. 

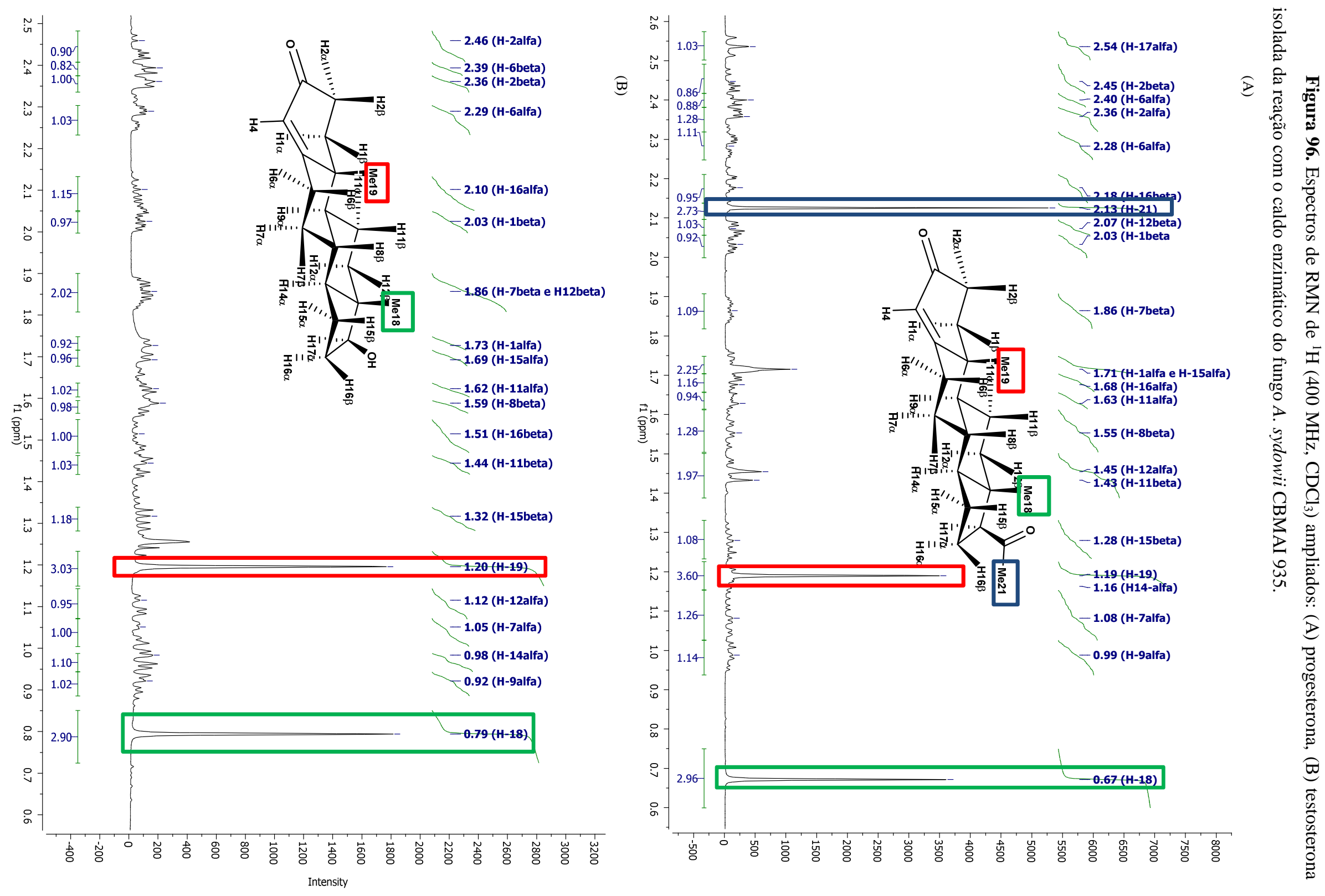
Figura 97. Comparação dos perfis de multiplicidade para o hidrogênio H-17 $\alpha$ do núcleo esteroidal: (A) modelo proposto por Kirk, et al. $(1990)^{75}$, (B) multipleto para a progesterona, (C) multipleto para a testosterona isolada da reação com o caldo enzimático do fungo A. sydowii CBMAI 935.

(A)

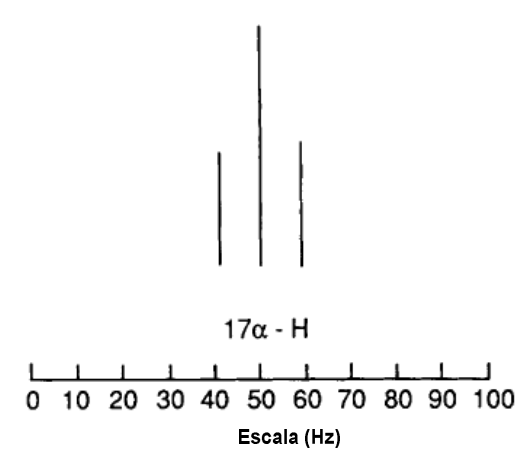

(B)

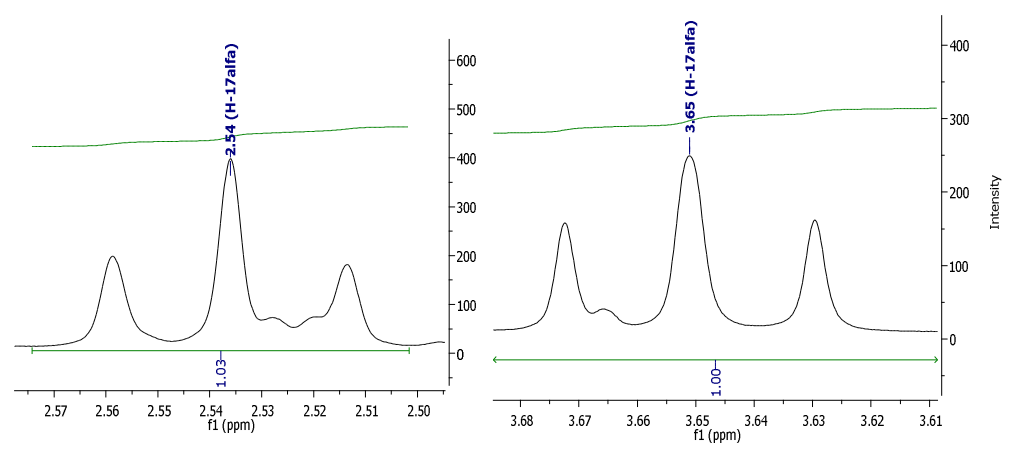

Foram feitos experimentos de IV com o composto isolado. As bandas encontradas estão descritas na Tabela 33 e foram atribuídas segundo Mohamed et al. (2014) ${ }^{70}$, Silverstein et al., $(2006)^{71}$ e Pavia et al.(2015) ${ }^{77}$. A Figura 98 apresenta de forma comparativa o espectro de IV obtido experimentalmente para a progesterona e para a testosterona. 
Tabela 33. Valores das bandas vibracionais obtidas por Espectroscopia no IV para a testosterona isolada da reação com o caldo enzimático do fungo A. sydowii CBMAI 935.

\begin{tabular}{|c|c|c|}
\hline \multirow{2}{*}{ Ligação/tipo de vibração } & \multicolumn{2}{|c|}{ Valores de $v_{\operatorname{máx}}\left(\mathrm{cm}^{-1}\right)$} \\
\hline & literatura & experimental \\
\hline Deformação axial O-H & $3550-3200^{71}$ & 3522 \\
\hline Deformação axial O-H & $3550-3200^{71}$ & \multirow{2}{*}{3373} \\
\hline Deformação axial H-C= & acima de 300071 & \\
\hline Deformação axial C-H ( $\mathrm{CH}_{2}$ cíclico $)$ & $3100-2990^{71}$ & 2964 \\
\hline Estiramento assimétrico C-H & $2939,95^{70}$ & 2931 \\
\hline Estiramento assimétrico $\mathrm{C}-\mathrm{H}$ & $2854,13^{70}$ & \multirow{2}{*}{2852} \\
\hline Deformação axial de C-H (carbono terciário) & $2890^{71}$ & \\
\hline Estiramento $\mathrm{C}=\mathrm{O}$ de cetona $(\mathrm{C}-3)$ & $1632,34^{70}$ & \multirow{2}{*}{1672 e 1664} \\
\hline Deformação axial $\mathrm{C}=\mathrm{O}$ de cetona $\alpha, \beta$-insaturada $(\mathrm{C}-3)$ & $1685-1666^{71}$ & \\
\hline Estiramento $\mathrm{C}=\mathrm{C}(\mathrm{C}-4$ e $\mathrm{C}-5)$ & $1617,02^{70}$ & 1612 \\
\hline Deformação angular - $\mathrm{CH}_{2}$ (anel de ciclo-hexano) & $1442^{71}$ & 1444 \\
\hline Deformação angular simétrica fora do plano $\left(\mathrm{CH}_{2}\right.$ cíclico $)$ & $1350^{71}$ & 1356 \\
\hline Dobramento C-O-H & $1440-1220^{77}$ & \multirow{2}{*}{1269} \\
\hline Deformação axial e angular de $\mathrm{C}-(\mathrm{C}=\mathrm{O})-\mathrm{C}$ & $1300-1100^{71}$ & \\
\hline Estiramento C-O & $1260-1110^{77}$ & \multirow{2}{*}{1226} \\
\hline Deformação axial e angular de $\mathrm{C}-(\mathrm{C}=\mathrm{O})-\mathrm{C}$ & $1300-1100^{71}$ & \\
\hline Estiramento $\mathrm{C}-\mathrm{O}$ & $1260-1110^{77}$ & \multirow{2}{*}{1184} \\
\hline Deformação axial e angular de $\mathrm{C}-(\mathrm{C}=\mathrm{O})-\mathrm{C}$ & $1300-1100^{71}$ & \\
\hline Estiramento C-O & $1260-1110^{77}$ & \multirow{2}{*}{1134} \\
\hline Deformação axial e angular de $\mathrm{C}-(\mathrm{C}=\mathrm{O})-\mathrm{C}$ & $1300-1100^{71}$ & \\
\hline Estiramento C-O & $1260-1110^{77}$ & \multirow{2}{*}{1116} \\
\hline Deformação axial e angular de $\mathrm{C}-(\mathrm{C}=\mathrm{O})-\mathrm{C}$ & $1300-1100^{71}$ & \\
\hline Deformação axial C-O de álcoois secundários & $1085-1050^{71}$ & 1057 \\
\hline
\end{tabular}


Figura 98. Espectros de IV: (A) progesterona (B) testosterona isolada da reação com o caldo enzimático do fungo A. sydowii CBMAI 935.

(A)

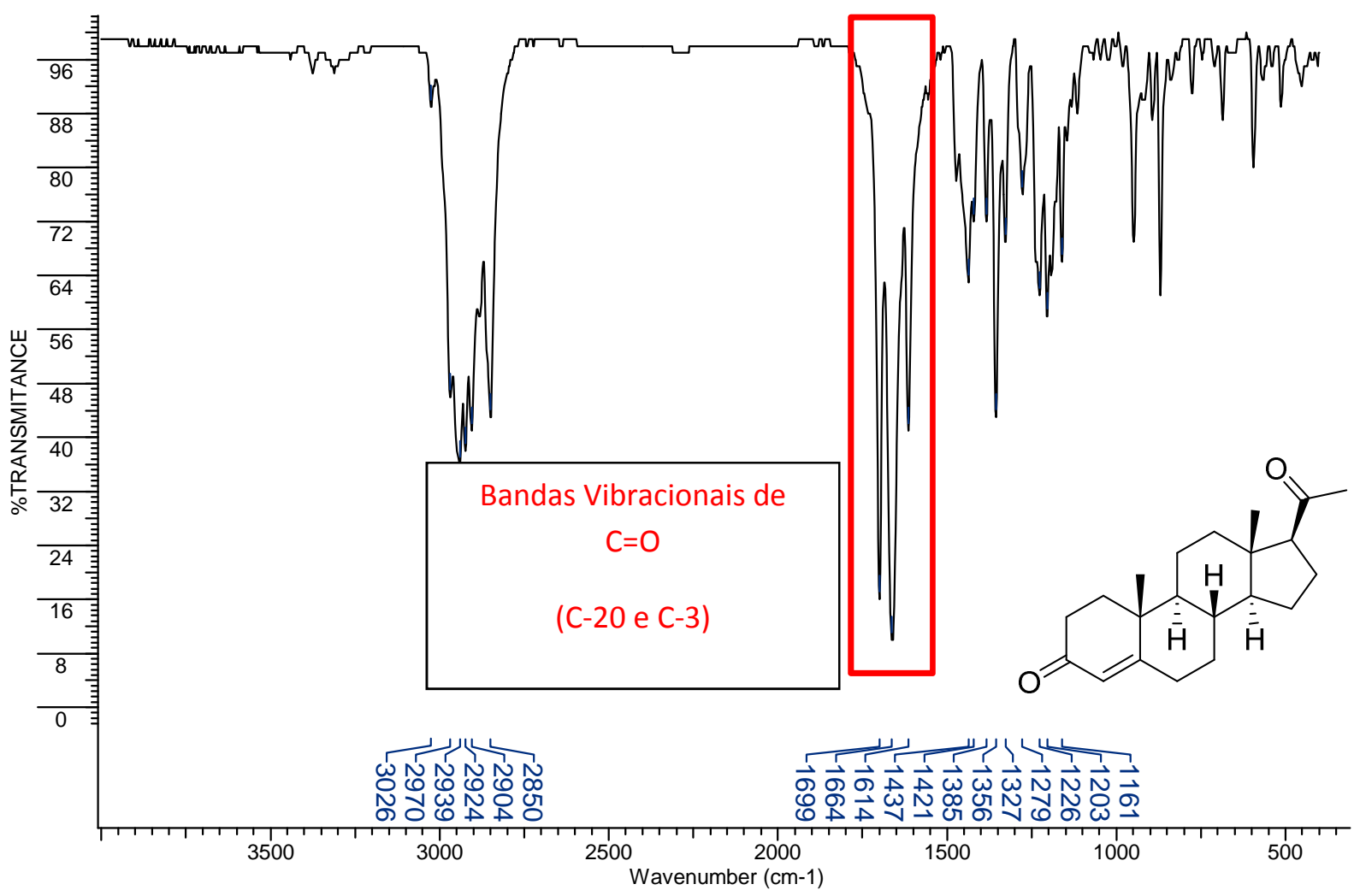

(B)

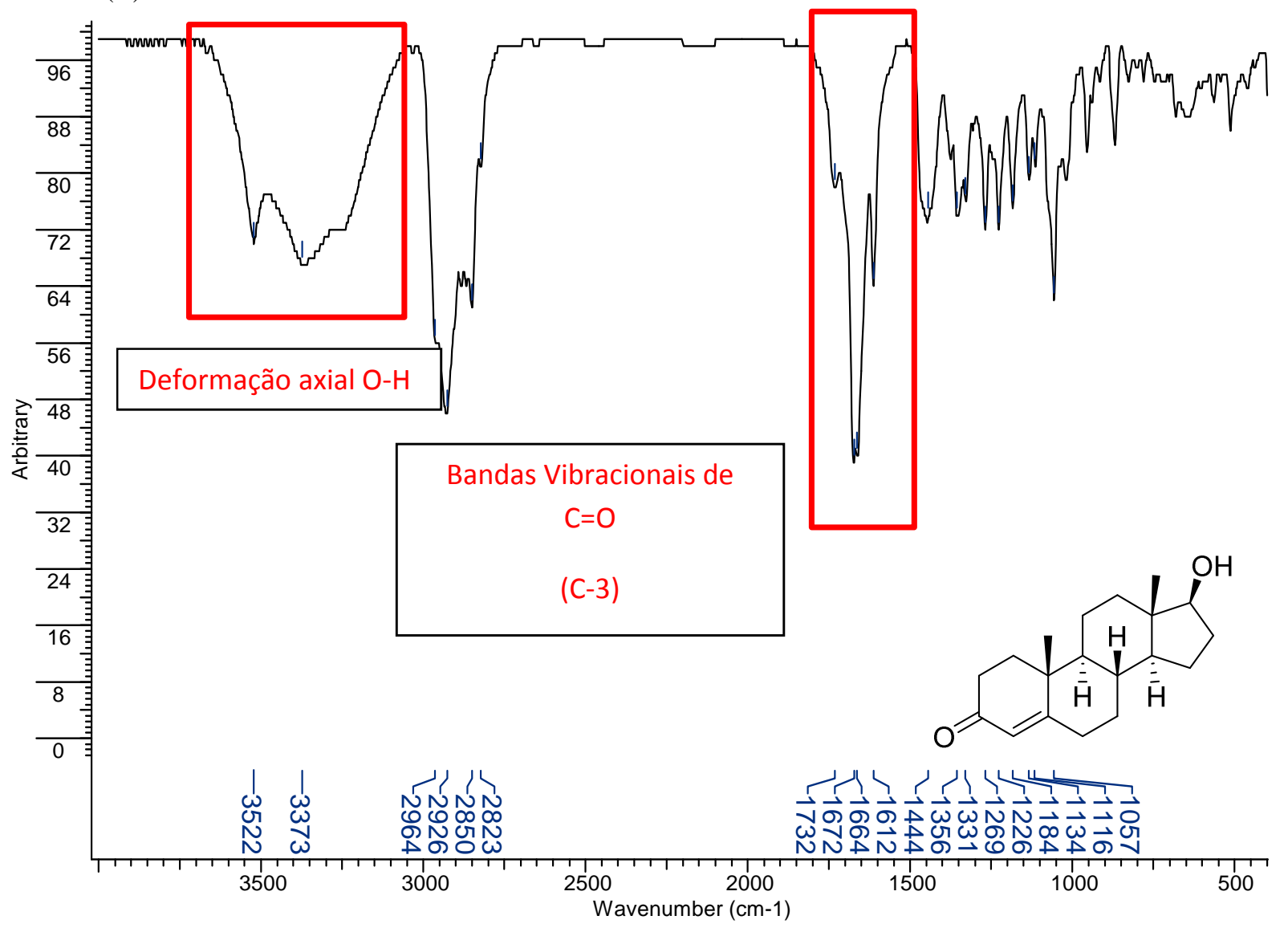


Como pode-se observar pela Figura 98 as principais diferenças entre os dois espectros foram: a presença de uma banda larga com $3522 \mathrm{~cm}^{-1}$ e $3373 \mathrm{~cm}^{-1}$ no espectro da testosterona referentes a deformação axial da ligação $\mathrm{O}-\mathrm{H}$ que indicou a presença de grupo hidroxila na testosterona; o deslocamento das bandas vibracionais relativas à ligação dupla $\mathrm{C}=\mathrm{O}$ em relação ao espectro da progesterona, bem como uma modificação da intensidades dessas bandas indicando, como nas caracterizações por RMN mostraram, a ausência do carbono cetônico C20 devido à substituição do grupo acetila por um grupo hidroxila em função da biotransformação da progesterona pelo caldo enzimático do fungo A. sydowii CBMAI 935. Quan et al. (2011) ${ }^{86}$, apesar de não terem feito as atribuições específicas das bandas, obtiveram um espectro de IV para a testosterona muito semelhante ao obtido por este estudo como mostra a Figura 99.

Figura 99. Espectro de IV para a testosterona ${ }^{86}$.

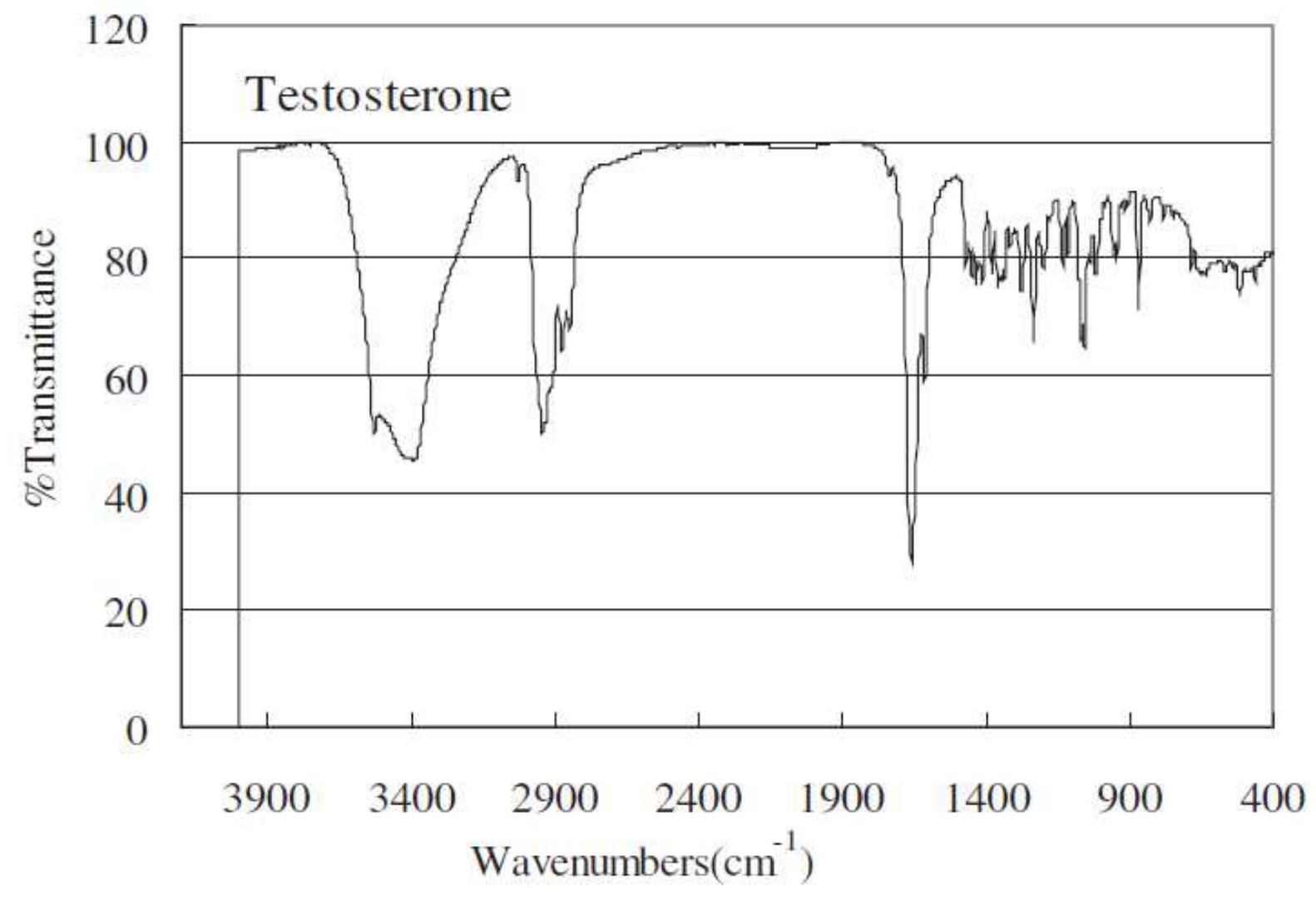

Fonte: Extraído de QUAN, C., et al. Development of anaboic-androgenic steroids purity certified reference materials for anti-doping. Steroids, 2011, v.76, p. 1531

O espectro de massas obtido da testosterona apresentou uma similaridade superior a 90\% com o espectro fornecido pela biblioteca NIST21(Figura 57) comprovando que se trata do mesmo composto. 
A Tabela 34 apresenta os resultados das medidas de rotação óptica para a testosterona comparativo os valores descritos na literatura ${ }^{87}$.

Tabela 34. Valores de rotação óptica para a testosterona isolada da reação com o caldo enzimático do fungo A. sydowii CBMAI 935.

\begin{tabular}{|c|c|c|c|c|c|}
\hline \multicolumn{3}{|c|}{ Valores descritos na literatura ${ }^{87}$} & \multicolumn{3}{|c|}{ Valores experimentais } \\
\hline $\begin{array}{r}\text { Concentração } \\
(\mathrm{g} / 100 \mathrm{~mL})^{\mathrm{a}}\end{array}$ & $\begin{array}{c}\text { Temperatura } \\
\left({ }^{\circ} \mathrm{C}\right)\end{array}$ & {$\left[\alpha_{D}\right]_{589}^{24}(\mathrm{deg})$} & $\begin{array}{c}\text { Concentração } \\
(\mathrm{g} / 100 \mathrm{~mL})^{\mathrm{a}}\end{array}$ & $\begin{array}{c}\text { Temperatura } \\
\left({ }^{\circ} \mathrm{C}\right)\end{array}$ & {$\left[\alpha_{D}\right]_{589}^{23}(\mathrm{deg})$} \\
\hline 0,4 & 24 & 104 & 0,42 & 23 & 83,9 \\
\hline
\end{tabular}

Como a Tabela 34 apresentou, há uma diferença da rotação óptica entre o valor experimental e o da literatura, apesar que o sentido da rotação permaneceu o mesmo. Possivelmente esta diferença se deve à temperatura em que o experimento foi executado, bem como às diferenças de concentrações.

A literatura apresenta alguns exemplos de biotransformação da progesterona utilizando microrganismos sendo um dos metabólitos produzidos foi a testosterona. Yang, et al. $(2014)^{68}$ promoveram a biotransformação da progesterona pelo fungo Penicilium simplicissimum WY134-2. A testosterona foi obtida como um intermediário após duas horas de reação pois o produto final da reação foi a testololactona com $96 \%$ de rendimento isolado após 24 horas de reação (Esquema 20).

Esquema 20. Biotransformação da progesterona pelo fungo P.simplicissimum ${ }^{68}$.
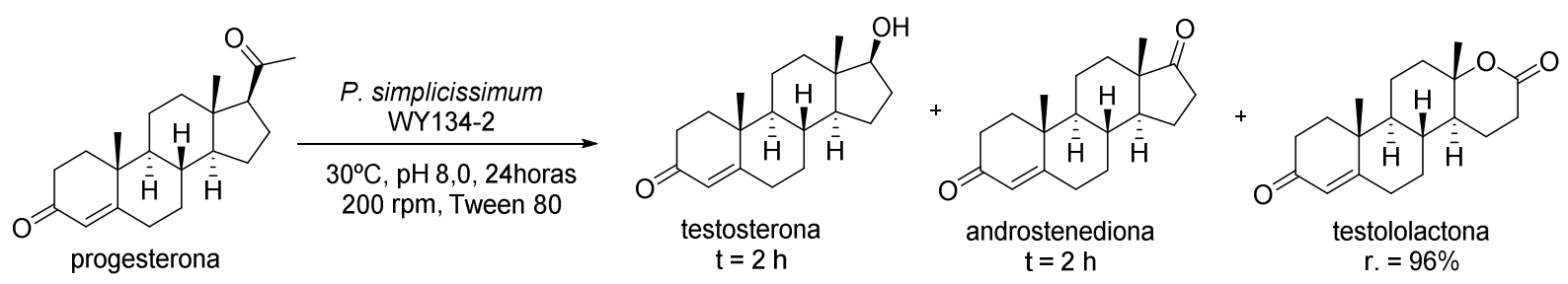

Yildirim, Uzuner e Gulcuoglu (2011) $)^{88}$ promoveram a biotransformação da progesterona pelo fungo Aspergillus tamarii MRC 72400. A testosterona foi observada como um intermediário após 8 horas de reação, pois o produto final da reação foi a testololactona com $86 \%$ de rendimento isolado após 24 horas de reação (Esquema 21). 
Esquema 21. Biotransformação da progesterona pelo fungo A. tamarii ${ }^{88}$.
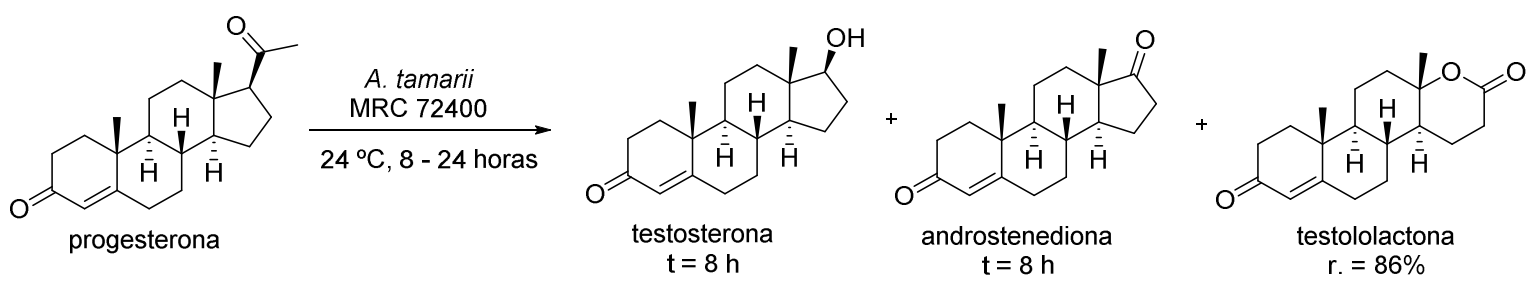

Dutta e Samanta (1997) ${ }^{89}$ também promoveram a biotransformação da progesterona utilizando esporos imobilizados do fungo o Aspergillus ochraceus TS em alginato de cálcio. Dentre os vários produtos, a testosterona foi observada por análise do extrato do meio reacional por CLAE comparativa com a análise do padrão autêntico. Os rendimentos da reação não foram informados (Esquema 22).

Esquema 22. Biotransformação da progesterona por esporos do fungo A. ochraceus ${ }^{89}$.
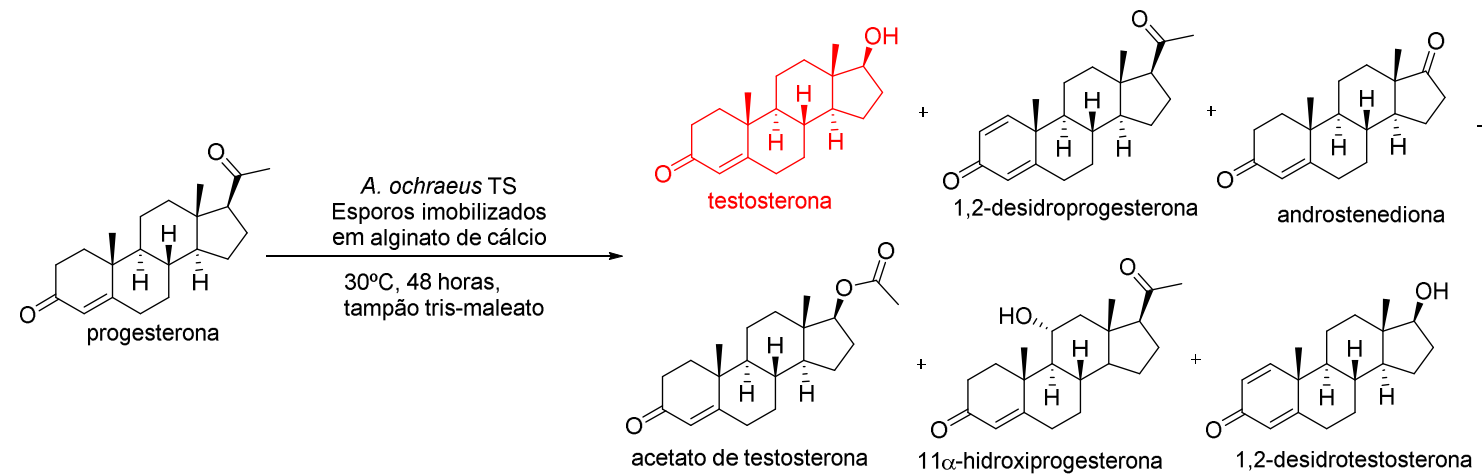


\section{D.5.4.4 Caracterização da testololactona obtida das reações com o caldo enzimático e com a massa micelial do fungo A. sydowii CBMAI 935 ( 7 dias, $32^{\circ} \mathrm{C}, 130 \mathrm{rpm}$ )}

Conforme abordado na seção D.5.3.6 as análises por CG-EM do produto isolado da reação de biotransformação da progesterona com o caldo enzimático do fungo A. sydowii CBMAI 935 (Figuras 55 e 57) evidenciaram que a testololactona foi o produto obtido e isolado desta reação. Este produto também foi obtido da biotransformação da progesterona pelo micélio do mesmo fungo conforme abordado na seção D.5.3.7. O espectro de massas obtido por CGEM do metabólito isolado da reação com o caldo enzimático teve similaridade menor que $90 \%$ para a testololactona (82\%, biblioteca NIST107 - Figura 57). Contudo, as análises por RMN não deixaram dúvidas que o composto isolado foi a testololactona, conforme será apresentado ao longo dessa seção.

A Figura 100 apresenta as estruturas planar e tridimensional da testololactona. A Tabela 35 apresenta os dados de deslocamentos químicos obtidos através dos espectros de RMN de ${ }^{13} \mathrm{C}(125 \mathrm{MHz}),{ }^{1} \mathrm{H}(500 \mathrm{MHz})$ obtidos experimentalmente para a testololactona comparados com os dados descritos na literatura. Os dados de deslocamentos químicos obtidos foram bastante concordantes com os dados de referências da literatura ${ }^{90,73}$ dando uma forte evidência que nesta reação a progesterona foi biotransformada produzindo a testololactona. 
Figura 100. Estruturas químicas para a testololactona: (A) planar, (B) tridimensional.

\section{(A)}

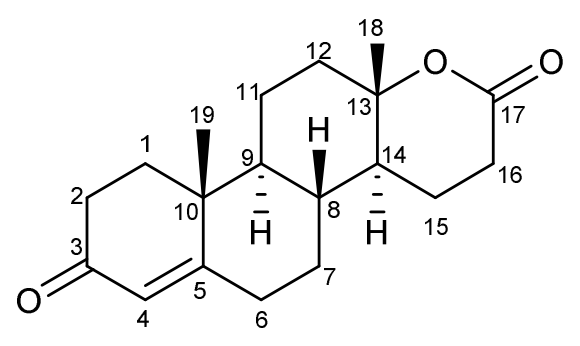

(B)

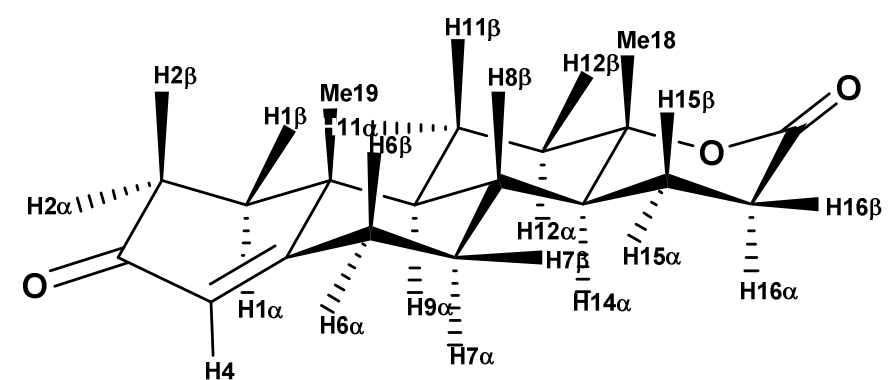

Tabela 35. Valores de deslocamentos químicos (ppm) de $\mathrm{RMN}\left({ }^{13} \mathrm{C} \mathrm{e}{ }^{1} \mathrm{H}\right)$ para a testololactona.

\begin{tabular}{|c|c|c|c|c|c|}
\hline${ }^{13} \mathrm{C}$ & $\delta^{13} \mathrm{C}\left(\text { literatura }{ }^{90}\right)^{\mathrm{a}}$ & $\delta^{13} \mathrm{C}(\text { experimental })^{\mathrm{b}}$ & ${ }^{1} \mathrm{H}$ & $\delta^{1}{ }_{\mathrm{H}}\left(\text { literatura }^{73}\right)^{\mathrm{c}}$ & $\delta_{\mathrm{H}}^{1}(\text { experimental })^{\mathrm{c}}$ \\
\hline \multirow{2}{*}{1} & \multirow{2}{*}{35,5} & \multirow{2}{*}{35,5} & $1 \alpha$ & 1,74 & 1,76 \\
\hline & & & $1 \beta$ & 2,07 & 2,04 \\
\hline \multirow{2}{*}{2} & \multirow{2}{*}{33,8} & \multirow{2}{*}{33,8} & $2 \alpha$ & 2,35 & 2,36 \\
\hline & & & $2 \beta$ & 2,43 & 2,43 \\
\hline 3 & 199,0 & 199,0 & - & - & - \\
\hline 4 & 124,1 & 124,1 & 4 & 5,76 & 5,77 \\
\hline 5 & 169,2 & 169,2 & - & - & - \\
\hline \multirow{2}{*}{6} & \multirow{2}{*}{32,3} & \multirow{2}{*}{32,3} & $6 \alpha$ & 2,34 & 2,36 \\
\hline & & & $6 \beta$ & 2,40 & 2,43 \\
\hline \multirow{2}{*}{7} & \multirow{2}{*}{30,4} & \multirow{2}{*}{30,4} & $7 \alpha$ & 1,11 & 1,10 \\
\hline & & & $7 \beta$ & 2,05 & 2,04 \\
\hline 8 & 38,0 & 38,0 & $8 \beta$ & 1,41 & 1,43 \\
\hline 9 & 52,5 & 52,5 & $9 \alpha$ & 1,17 & 1,17 \\
\hline 10 & 38,5 & 38,5 & - & - & - \\
\hline \multirow{2}{*}{11} & \multirow{2}{*}{21,8} & \multirow{2}{*}{21,8} & $11 \alpha$ & 1,82 & 1,82 \\
\hline & & & $11 \beta$ & 1,34 & 1,33 \\
\hline \multirow{2}{*}{12} & \multirow{2}{*}{38,0} & \multirow{2}{*}{39,0} & $12 \alpha$ & 1,68 & 1,70 \\
\hline & & & $12 \beta$ & 2,01 & 2,04 \\
\hline 13 & 82,7 & 82,7 & - & - & - \\
\hline 14 & 45,7 & 45,7 & $14 \alpha$ & 1,44 & 1,43 \\
\hline \multirow{2}{*}{15} & \multirow{2}{*}{19,9} & \multirow{2}{*}{19,9} & $15 \alpha$ & 2,01 & 2,04 \\
\hline & & & $15 \beta$ & 1,57 & 1,57 \\
\hline \multirow{2}{*}{16} & \multirow{2}{*}{28,5} & \multirow{2}{*}{28,5} & $16 \alpha$ & 2,59 & 2,59 \\
\hline & & & $16 \beta$ & 2,70 & 2,70 \\
\hline 17 & 171,1 & 171,1 & - & - & - \\
\hline 18 & 20,1 & 20,1 & 18 & 1,36 & 1,36 \\
\hline 19 & 17,4 & 17,4 & 19 & 1,18 & 1,17 \\
\hline
\end{tabular}

${ }^{\mathrm{a}} 100 \mathrm{MHz}, \mathrm{CDCl}_{3} ;{ }^{\mathrm{b}} 125 \mathrm{MHz}, \mathrm{CDCl}_{3} ;{ }^{\mathrm{c}} 500 \mathrm{MHz}, \mathrm{CDCl}_{3}$ 
Comparando os espectros de $\mathrm{RMN}$ de ${ }^{13} \mathrm{C}$ da progesterona e da testololactona, como mostra a Figura 101, não foram observados no espectro da testololactona os sinais típicos da carbonila e da metila do grupo acetila $(\delta=209,3$ e 31,5 na progesterona relativos respectivamente aos carbonos C-20 e C-21). Além disso, não foi observado sinal entre 60 - 70 ppm relativo ao carbono $\mathrm{C}-17$ ( $\delta=63,5$ na progesterona). Foi observado no espectro da testololactona um sinal em $\delta=171,1$ típico de carbono carbonílico de éster ou lactona atribuído ao carbono C-17 da testololcatona. Outra mudança interessante observada pela comparação entre os espectros de $\mathrm{RMN}$ de ${ }^{13} \mathrm{C}$ dos dois compostos foi o sinal em $\delta=82,7$ encontrado no espectro da testololactona e atribuído ao carbono C-13. Este carbono, no espectro de RMN de ${ }^{13} \mathrm{C}$ da progesterona, possui valor de deloscamento químico de $\delta=43,9$. Esses dados indicaram a lactonização do anel D do núcleo esteroidal da progesterona devido a sua biotransformação pelo caldo enzimático do fungo A. sydowii CBMAI 935 produzindo a testololactona. 
Figura 101. Espectros de $\mathrm{RMN}$ de ${ }^{13} \mathrm{C}$ : (A) progesterona (100 MHz, $\mathrm{CDCl}_{3}$ ), (B) testololactona (100 $\left.\mathrm{MHz}, \mathrm{CDCl}_{3}\right)$.

(A)

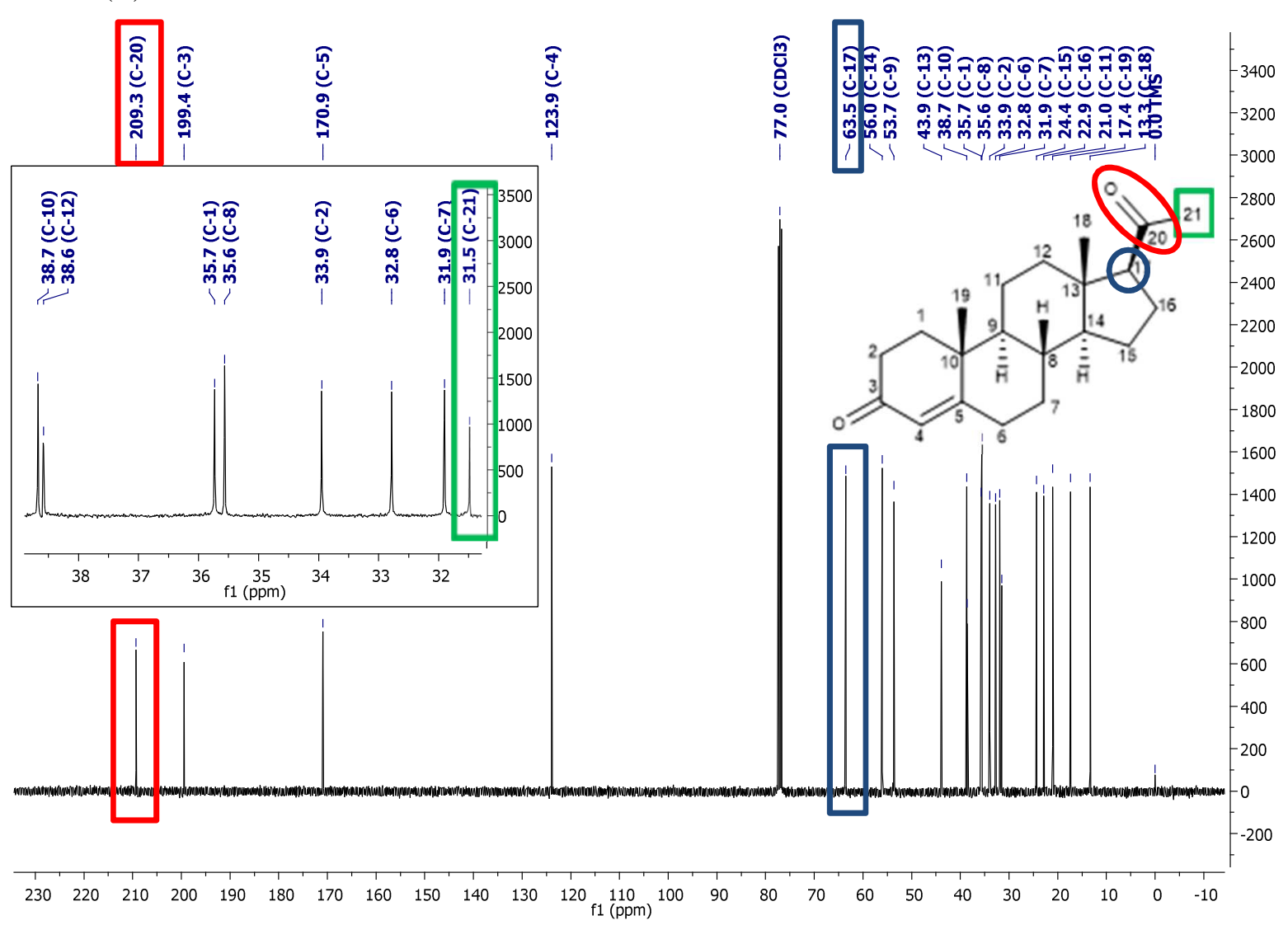

(B)

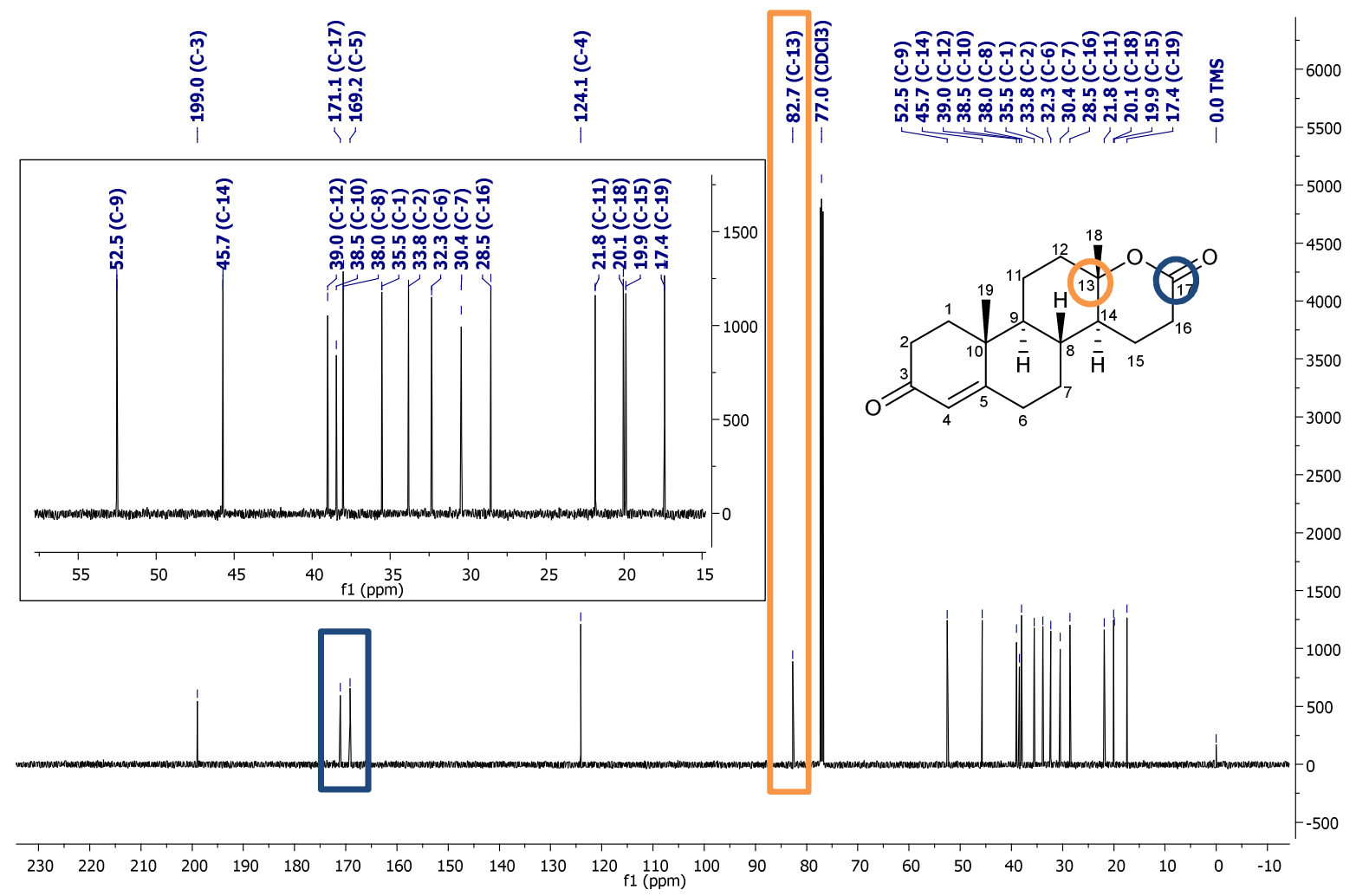


Comparando entre si os espectros de RMN de HSQC da progesterona e da testololactona (Figuras 102 e 103) foi observado no espectro ampliado da progesterona uma correlação entre os sinais $\delta=2,15$ e $\delta=31,5$ referentes respectivamente aos hidrogênios $\mathrm{H}-21$ e ao carbono C21 da metila do grupo acetila da progesterona (Figura 102A). No espectro ampliado da testololactona (Figura 102B) nessa mesma região não foi observada correlação com esses valores. No espectro completo da progesterona (Figura 103A) foi bem nítida a correlação entre os sinais do hidrogênio $\mathrm{H}-17 \alpha$ e o carbono C-17 ( $\delta=2,52$ e $\delta=63,6$ respectivamente). No espectro da testololactona (Figura 103B) não foram observados sinais nessas regiões. Esses dados obtidos dos espectros de RMN de ${ }^{13} \mathrm{C}$ e HSQC reforçaram a lactonização do anel D do grupo esteroidal devido à biotransformação da progesterona em testololactona. 
Figura 102. Espectros de RMN de $\mathrm{HSQC}\left(\mathrm{CDCl}_{3}\right)$ ampliados: (A) progesterona (125 $\mathrm{MHz}$ e $\left.500 \mathrm{MHz}\right)$; (B) testololactona (100 MHz e $400 \mathrm{MHz}$ ).

(A)

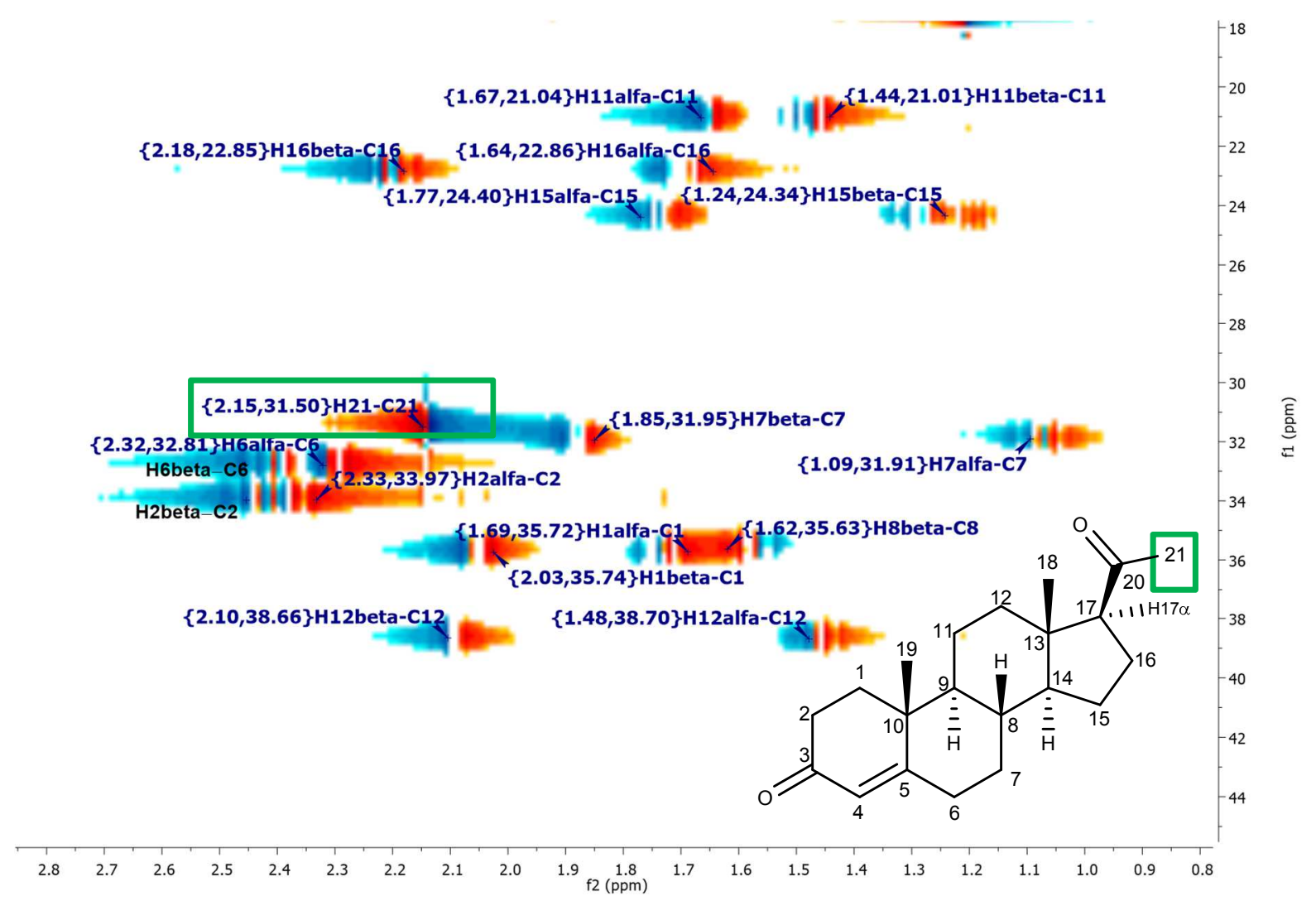

(B)

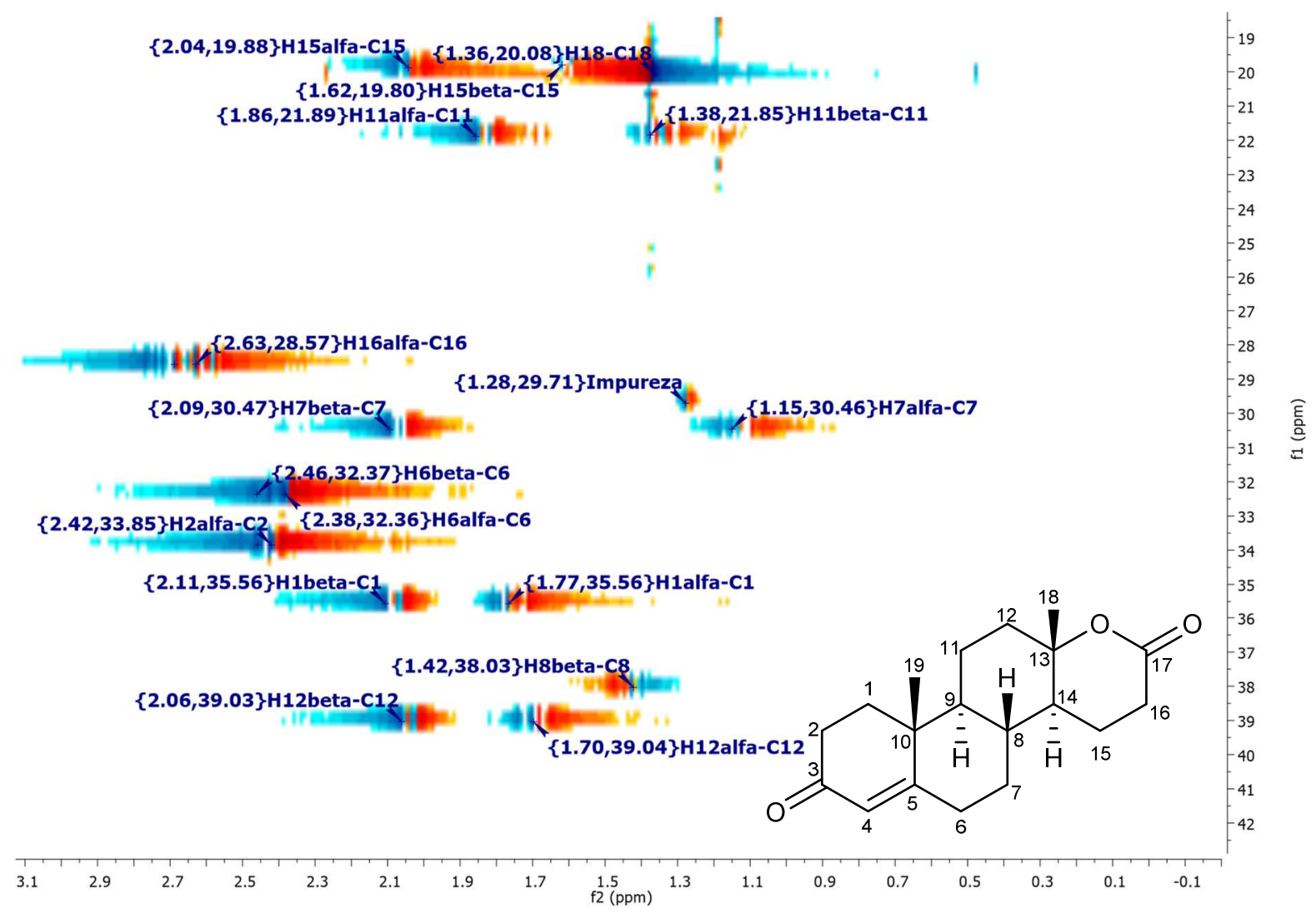


Figura 103. Espectros de RMN de HSQC $\left(\mathrm{CDCl}_{3}\right)$ completos: (A) progesterona (125 MHz e $\left.500 \mathrm{MHz}\right)$; (B) testololactona (100 MHz e $400 \mathrm{MHz}$ ).

(A)

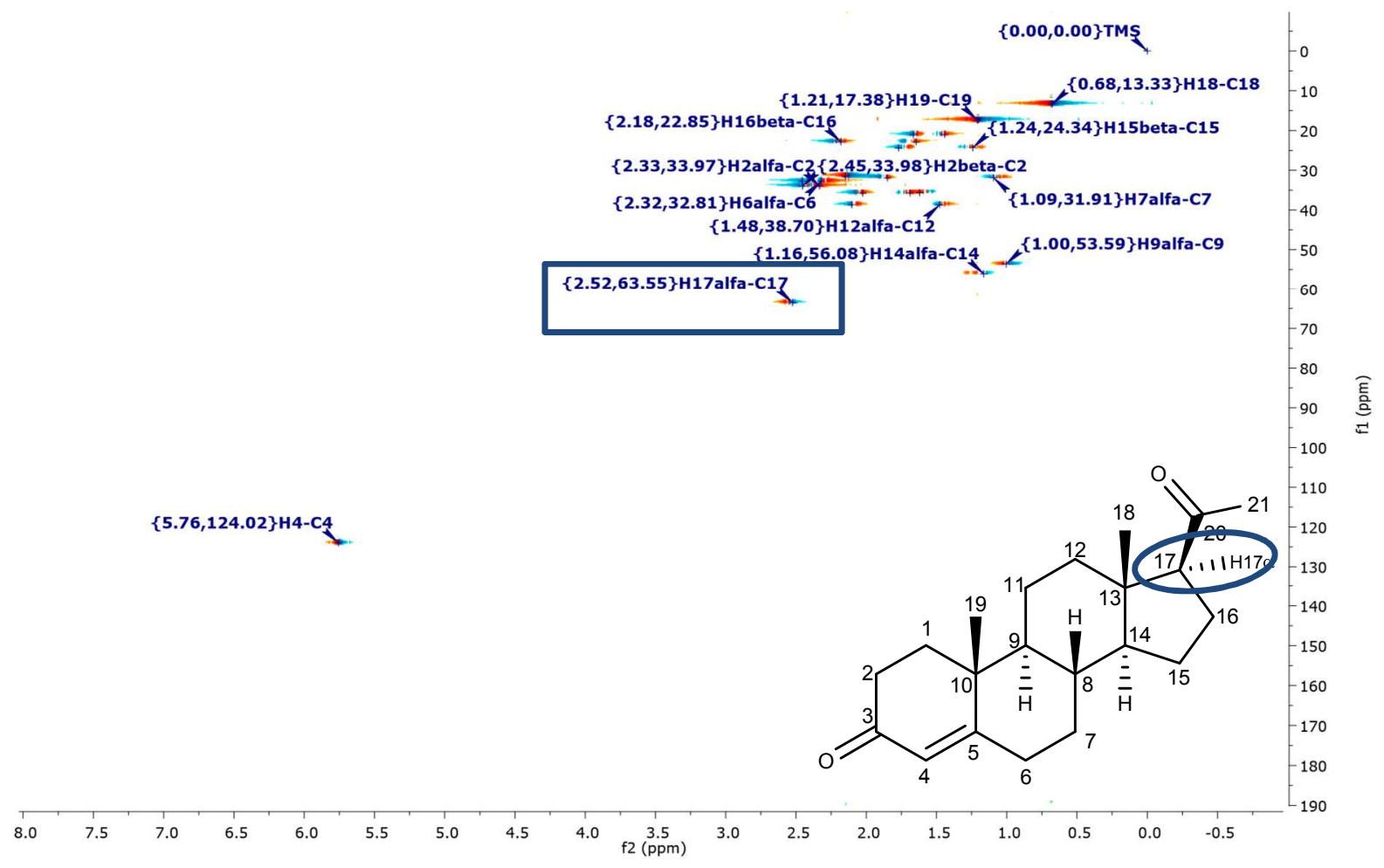

(B)

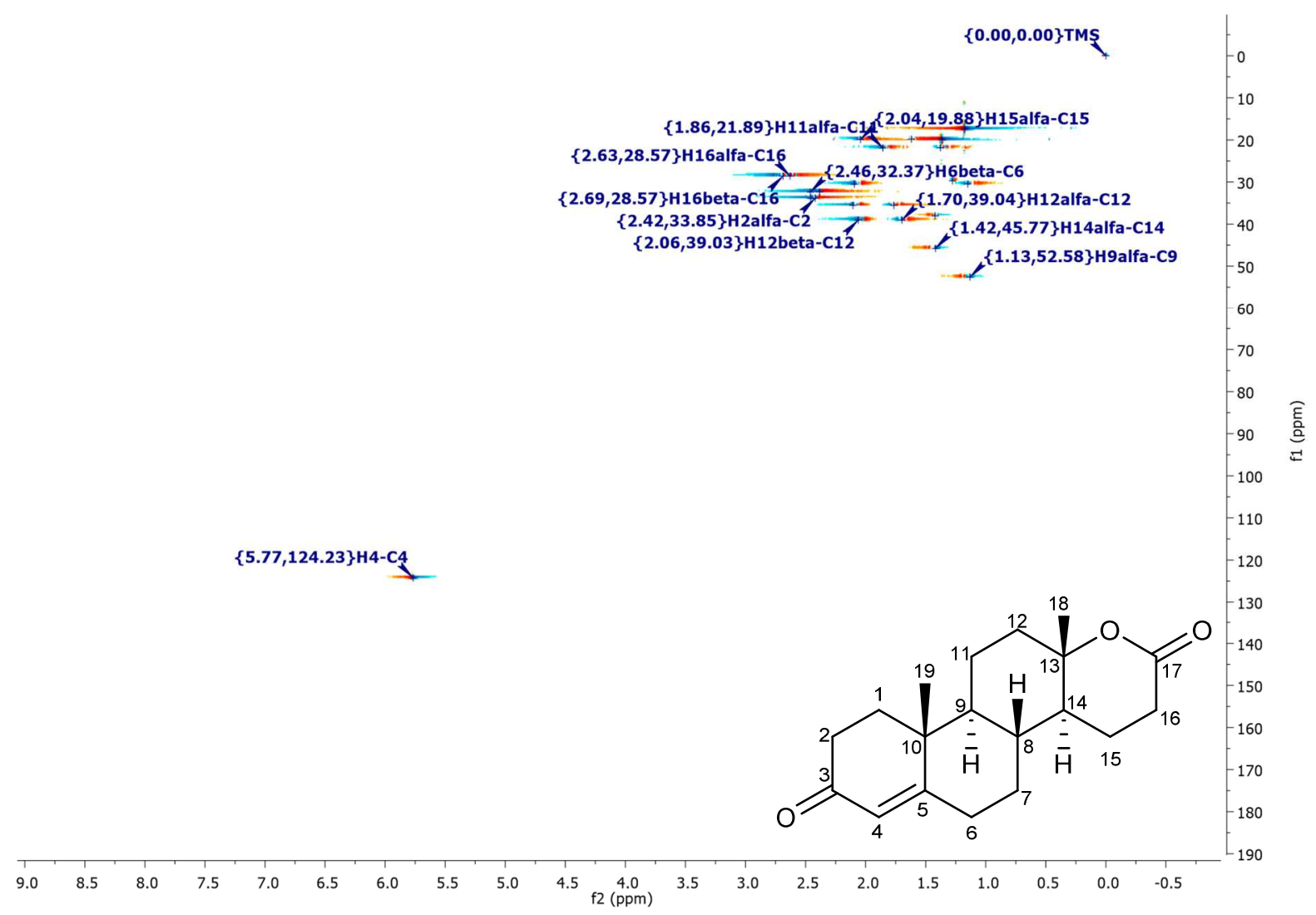


Através da análise do espectro de HMBC da testololactona, comparativa com o espectro de HMBC da progesterona (Figura 105), observou-se que no espectro da progesterona (Figura 105A) foram encontradas correlações do sinal do C-13 $(\delta=43,9)$ com os sinais $\delta=0,69$ (hidrogênios $\mathrm{H}-18$ ), $\delta=1,14$ (hidrogênio $\mathrm{H}-14 \alpha$ ) $\delta=1,20$ (hidrogênio $\mathrm{H}-15 \beta$ ), $\delta=1,48$ (hidrogênio $\mathrm{H}-12 \alpha$ ), $\delta=1,66$ (hidrogênio $\mathrm{H}-16 \alpha$ ), $\delta=1,71$ (hidrogênio $\mathrm{H}-15 \alpha$ ), $\delta=2,09$

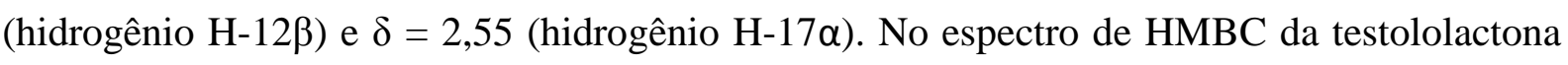
(Figura 105B), das correlações para o sinal do carbono C-13 $(\delta=82,8)$ todas foram encontradas com os hidrogênios vizinhos ao carbono C-13 no anel D do núcleo esteroidal, exceto com os hidrogênios H-16 $\alpha(\delta=2,59)$ e H-16 $(\delta=2,70)$ e, obviamente, nenhuma correlação com algum sinal que seria referente ao hidrogênio $\mathrm{H}-17 \alpha(\delta=2,55$ na progesterona). O fato de não haver no anel D do núcleo esteroidal da testololactona interações entre o carbono C-13 e os hidrogênios ligados ao carbono C-16 foi um indício do aumento da distância entre esses núcleos devido à presença de um heteroátomo (no caso o oxigênio) entre os carbonos C-13 e C-17. Isso evidencia que o anel D passou de cinco para seis membros (anel lactônico), ocorrendo a biotransformação da progesterona em testololactona pelo caldo enzimático do fungo $A$. sydowii CBMAI 935.

Foi observado no espectro de HMBC da progesterona o sinal referente ao carbono C-17 $(\delta=63,6)$ que se correlacionou com os seguintes sinais: $\delta=0,69$ (hidrogênios $H-18$ ), $\delta=1,16$ (hidrogênio $\mathrm{H}-14 \alpha$ ), $\delta=1,20$ (hidrogênio $\mathrm{H}-15 \beta$ ), $\delta=1,46$ (hidrogênio $\mathrm{H}-12 \alpha$ ), $\delta=1,67$ (hidrogênio $\mathrm{H}-16 \alpha$ ), $\delta=1,71$ (hidrogênio $\mathrm{H}-15 \alpha$ ) 2,14 (hidrogênios $\mathrm{H}-21$ ) e $\delta=2,18$ (hidrogênio H-16ß). No espectro de HMBC da testololactona as correlações para o sinal do carbono C-17, $(\delta=171,1)$ foram encontradas com os hidrogênios ligados aos carbonos C-15 e C-16 e nenhuma interação a longa distância com os hidrogênios ligados aos carbonos C-12, C14 e C-18. Além disso, não foram observados, obviamente, sinais que indiquem correlação com com os hidrogênios H-21 ( $\delta=2,55$ na progesterona). Essas correlações não encontradas indicaram uma maior distância do carbono C-17 com os carbonos C-12, C-14 e C-18 da testololactona, o que reforçou a evidência da lactonização do anel D do núcleo esteroidal devido a biotransformação da progesterona. As correlações encontradas tanto na progesterona, quanto na testololactona estão representadas na Figura 104 evidenciando o anel D do núcleo esteroidal de ambos os compostos. 
Figura 104. Correlações $J_{\mathrm{HC}}$ observadas nos espectros de HMBC no anel D do núcleo esteroidal: (A) $J_{\mathrm{H}-}$ C13 na progesterona (B) $J_{\mathrm{H}-\mathrm{C} 13}$ na testololactona, (C) $J_{\mathrm{H}-\mathrm{C} 17}$ na progesterona, (D) $J_{\mathrm{H}^{-} \mathrm{C} 17}$ na testololactona.
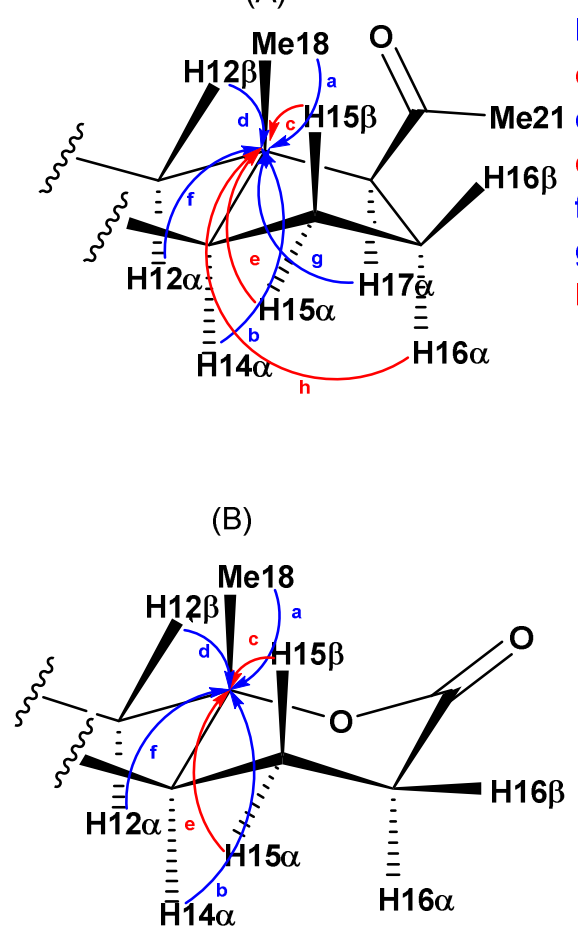

(A)

(B)

a: ${ }^{2} J_{\mathrm{H} 18-\mathrm{C} 13}$

b: ${ }^{2} J_{\mathrm{H} 14 \alpha-\mathrm{C} 13}$

c: ${ }^{3} J_{\mathrm{H} 15 \beta-C 13}$

d: ${ }^{2} J_{\mathrm{H} 12 \beta-\mathrm{C} 13}$

e: ${ }^{3} J_{\mathrm{H} 15 \alpha-C 13}$

f: ${ }^{2} J_{\mathrm{H} 12 \alpha-\mathrm{C} 13}$

g: ${ }^{2} J_{\mathrm{H} 17 \alpha-\mathrm{C} 13}$

h: ${ }^{3} \mathrm{~J}_{\mathrm{H} 16 \alpha-\mathrm{C} 13}$

मे140 $\overline{\mathrm{H}} 16 \alpha$

a: ${ }^{2} J_{\mathrm{H} 18-\mathrm{C} 13}$

b: ${ }^{2} J_{\mathrm{H} 14 \mathrm{\alpha}-\mathrm{C} 13}$

c: ${ }^{3} \mathrm{~J}_{\mathrm{H} 15 \beta-\mathrm{C} 13}$

d: ${ }^{2} J_{\mathrm{H} 12 \beta-\mathrm{C} 13}$

e: ${ }^{3} J_{\mathrm{H} 15 \alpha-\mathrm{C} 13}$

f: ${ }^{2} J_{\mathrm{H} 12 \alpha-\mathrm{C} 13}$
(C)

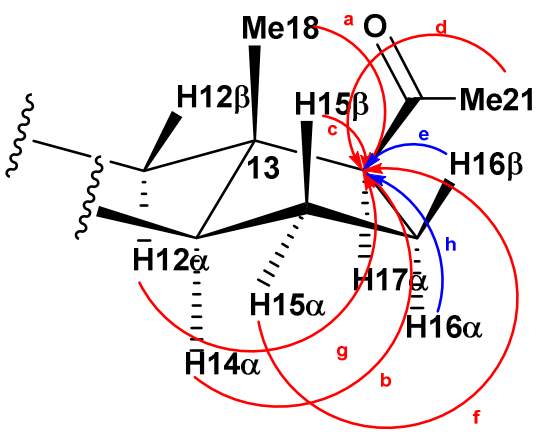

a: ${ }^{3} J_{\mathrm{H} 18-\mathrm{C} 17}$

b: ${ }^{3} J_{\mathrm{H} 14 \alpha-\mathrm{C} 17}$

c: ${ }^{3} J_{\mathrm{H} 15 \beta-\mathrm{C} 17}$

d: ${ }^{3} J_{\mathrm{H} 21-\mathrm{C} 17}$

e: ${ }^{2} J_{\mathrm{H} 16 \beta-C 17}$

f: ${ }^{3} J_{\mathrm{H} 15 \alpha-\mathrm{C} 17}$

g: ${ }^{3} J_{\mathrm{H} 12 \alpha-\mathrm{C} 17}$

h: ${ }^{2} J_{\mathrm{H} 16 \alpha-\mathrm{C} 17}$

(D)

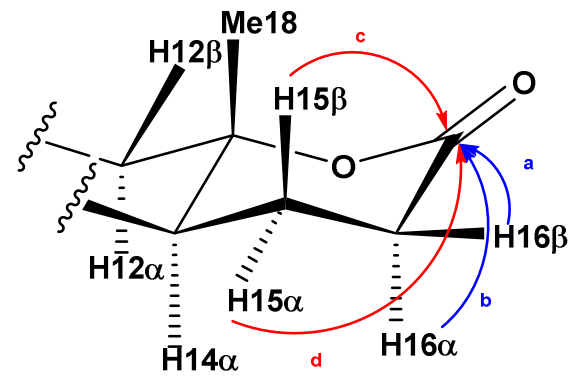

a: ${ }^{2} J_{\mathrm{H} 16 \beta-\mathrm{C} 17}$

b: ${ }^{2} J_{\mathrm{H} 16 \alpha-\mathrm{C} 17}$

c: ${ }^{3} J_{\mathrm{H} 15 \beta-\mathrm{C} 17}$

d: ${ }^{3} J_{\mathrm{H} 15 \alpha-\mathrm{C} 17}$ 
Figura 105. Espectros de RMN de HMBC (100 MHz e $400 \mathrm{MHz}$ ) ampliados: (A) progesterona; (B) testololactona.

(A)

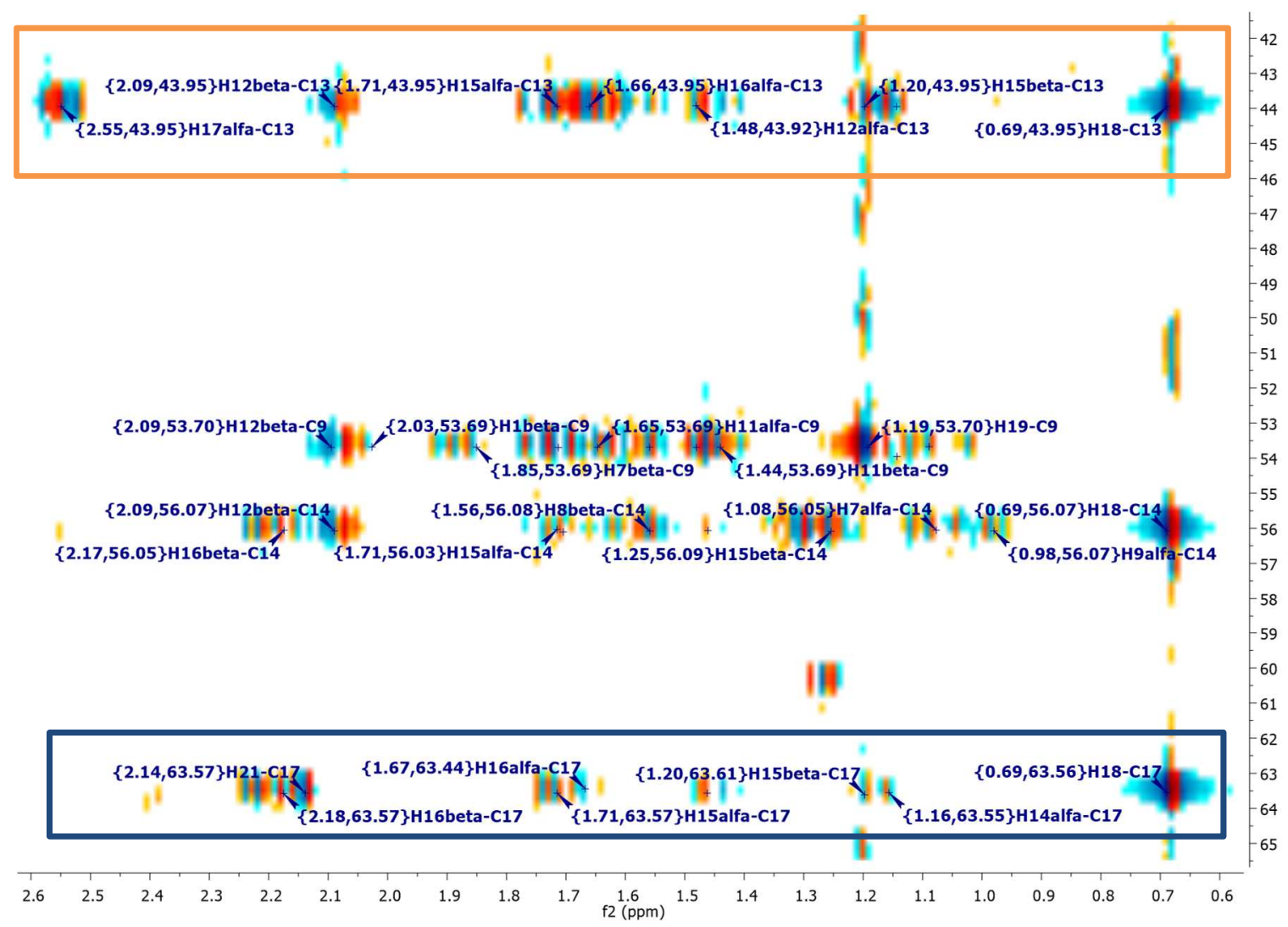

(B)

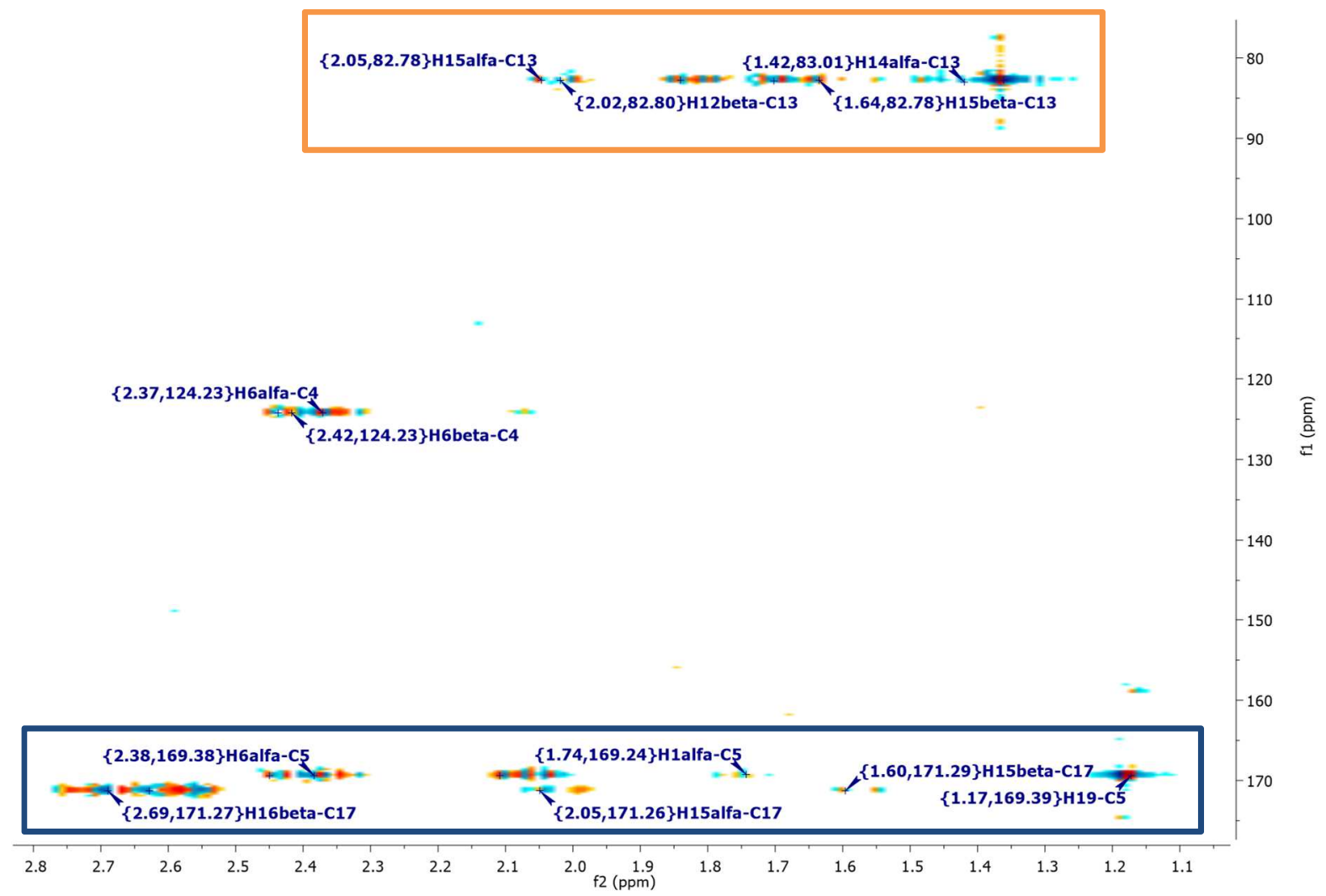


Através das análises do espectro de COSY da testololactona, comparada com o espectro de COSY da progesterona (a Figura 107) mostrando apenas as assinalações relativas aos hidrogênios envolvidos no anel D, não foram encontradas correlações envolvendo os sinais que seriam relativos aos hidrogênios $\mathrm{H}-17 \alpha(\delta=2,54$ na progesterona) e $\mathrm{H}-21$ ( $\delta=2,13$ na progesterona) com os hidrogênios vizinhos no anel D do núcleo esteroidal da testololactona. Essa evidência indicou a lactonização do anel D da progesterona. Como os espectros de COSY ampliados e a Figura 106 mostraram, tanto na progesterona quanto na testololactona, foram encontradas todas as correlações envolvendo os hidrogênios do anel D no núcleo esteroidal. A preservação dessas interações entre os hidrogênios do anel D e, pelo fato de não terem sido observadas no espectro de COSY da testololactona correlações que envolvessem os sinais relativos aos hidrogênios $\mathrm{H}-17 \alpha$ e H-21, evidenciam a biotransformação da progesterona em testololactona pelo caldo enzimático do fungo A. sydowii CBMAI 935.

Figura 106. Algumas correlações $J_{\mathrm{HH}}$ observadas nos espectros de COSY envolvendo o hidrogênio H$17 \alpha$ no anel D do núcleo dos esteroides: (A) progesterona, (B) testololactona.
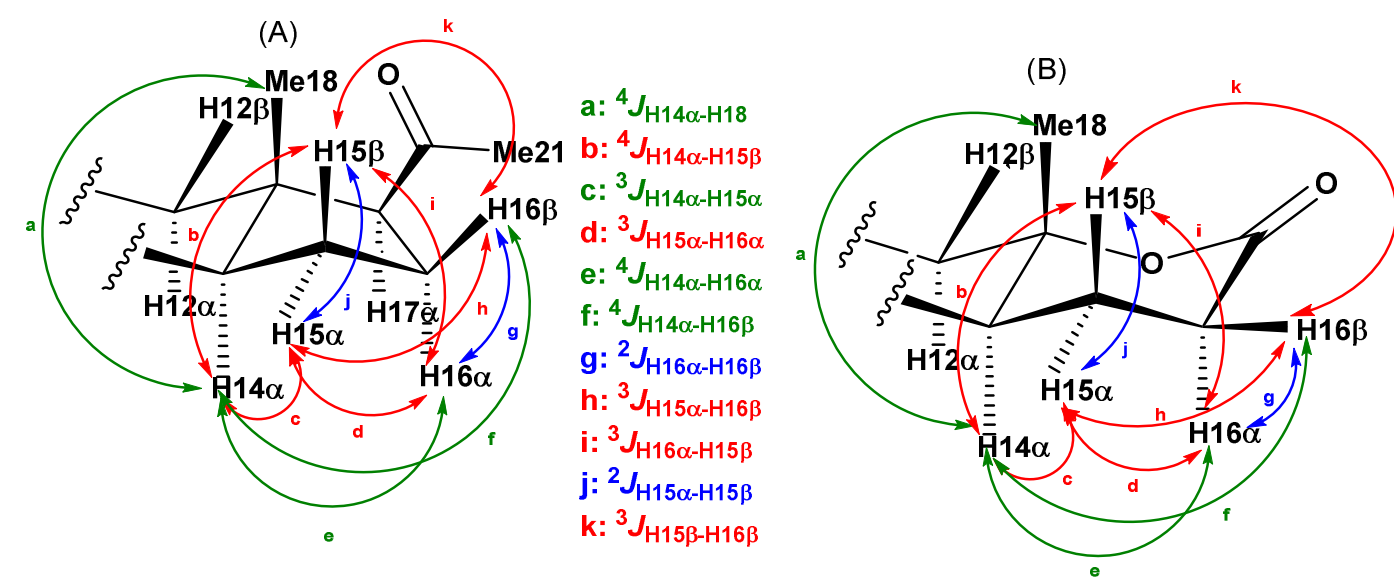

a: ${ }^{4} J_{\mathrm{H} 14 \alpha-\mathrm{H} 18}$ b: ${ }^{4} J_{\mathrm{H} 14 \alpha-\mathrm{H} 15 \beta}$ c: ${ }^{3} J_{\mathrm{H} 14 \alpha-\mathrm{H} 15 \alpha}$ d: ${ }^{3} J_{\mathrm{H} 15 \alpha-\mathrm{H} 16 \alpha}$ e: ${ }^{4} J_{H 14 \alpha-H 16 \alpha}$ f: ${ }^{4} J_{\mathrm{H} 14 \alpha-\mathrm{H} 16 \beta}$ g: ${ }^{2} J_{\mathrm{H} 16 \alpha-\mathrm{H} 16 \beta}$ h: ${ }^{3} J_{H 15 \alpha-H 16 \beta}$ i: ${ }^{3} J_{\mathrm{H} 16 \alpha-\mathrm{H} 15 \beta}$ j: ${ }^{2} J_{\mathrm{H} 15 \alpha-\mathrm{H} 15 \beta}$ k: ${ }^{3} J_{H 15 \beta-H 16 \beta}$ 
Figura 107. Espectros de RMN de COSY ampliados: (A) progesterona (500 $\mathrm{MHz}, \mathrm{CDCl}_{3}$ ), (B) testololactona.

(A)

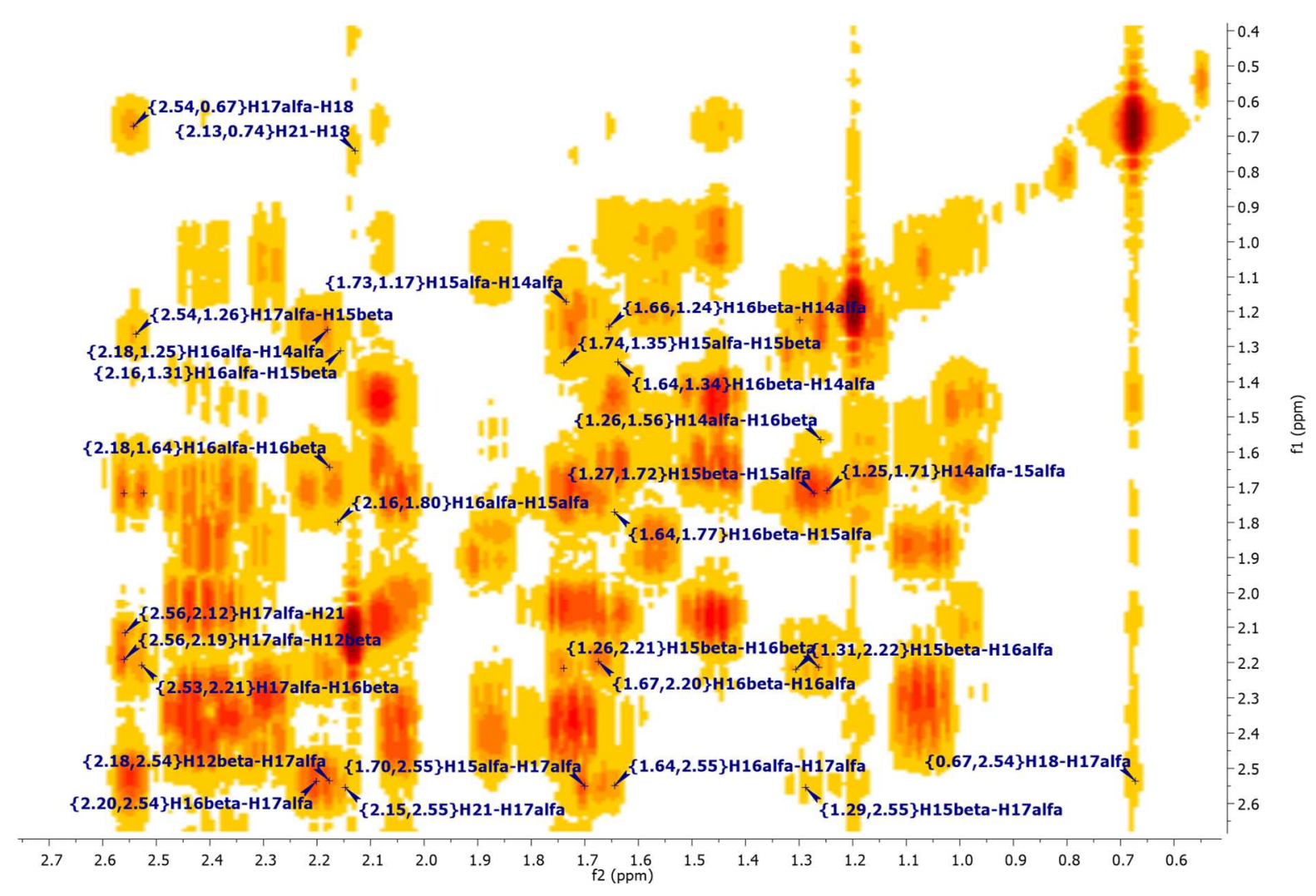

(B)

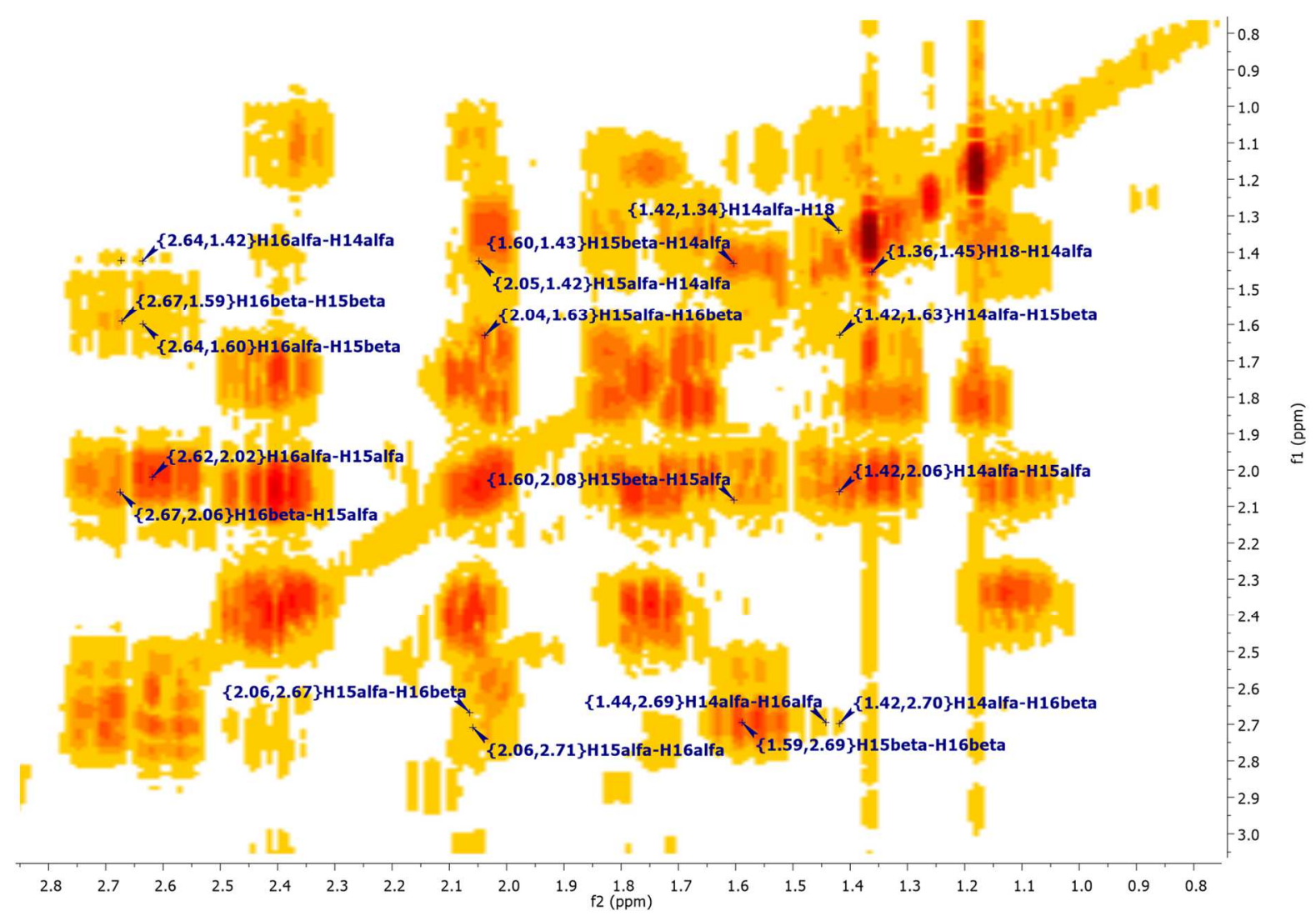


Através das análises dos espectros de $\mathrm{RMN}$ de ${ }^{1} \mathrm{H}$ da progesterona e da testololactona (Figura 108), pôde-se observar que no espectro da progesterona (Figura 108A) três sinais de alta intensidade referentes às metilas presentes na molécula: $\delta=0,67$ (hidrogênios $\mathrm{H}-18$ ), $\delta=$ 1,19 (hidrogênios H-19) e $\delta=2,13$ (hidrogênios H-21). Comparando com o espectro de RMN de ${ }^{1} \mathrm{H}$ da testololactona (Figura 108B) foram observados dois sinais de singletos referentes aos hidrogênios H-18 $(\delta=0,79)$ e aos hidrogênios H-19 $(\delta=1,20)$. Isso mostrou que o carbono C17 de fato foi o sítio de biotransformação da progesterona pelo caldo enzimático e pela massa micelial do fungo A. sydowii CBMAI 935, ocorrendo a lactonização do anel D do núcleo esteroidal, modificado assim o carbono C-17 para um carbono carbonílico de éster cíclico. 

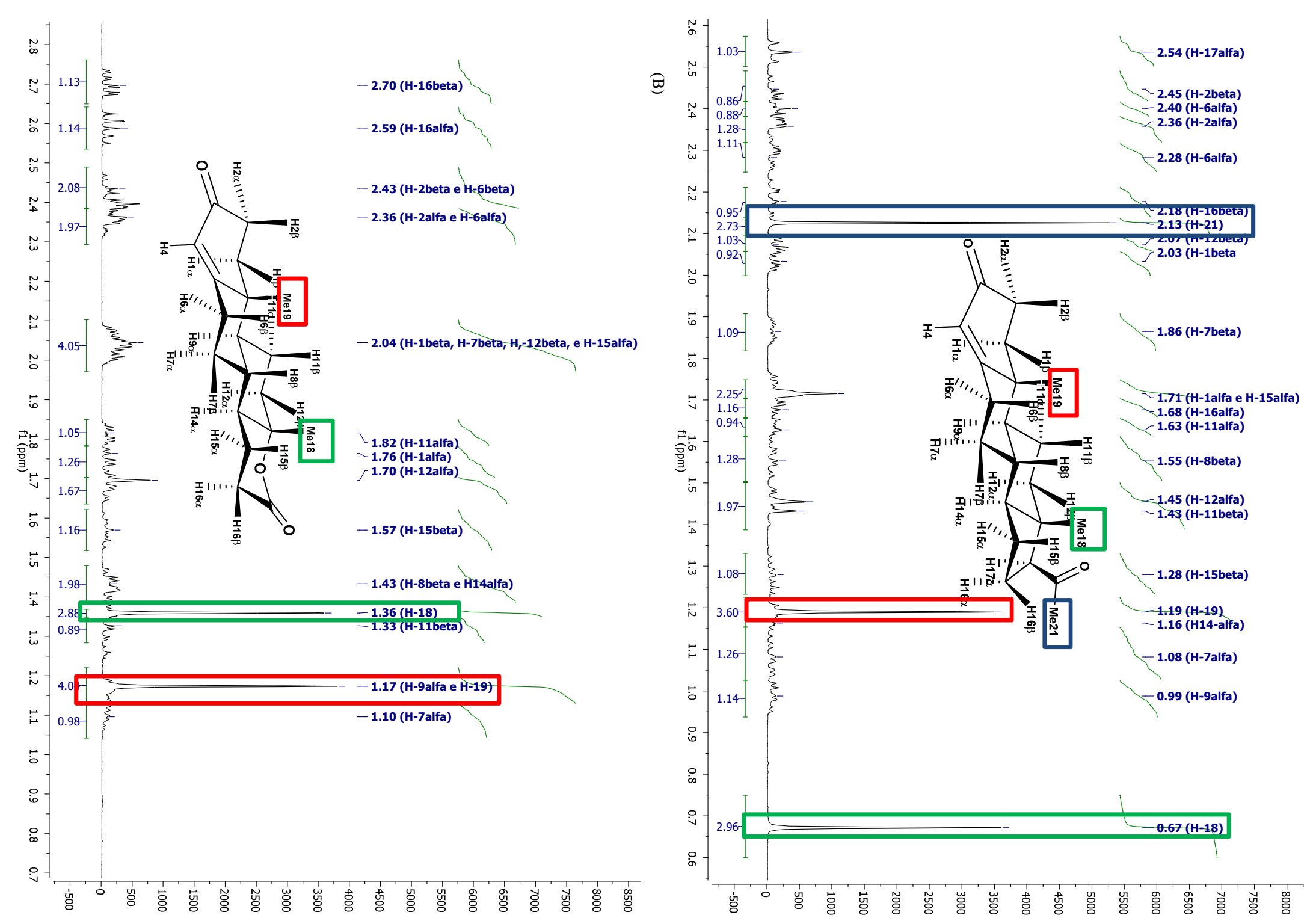
Foi observado no espectro de $\mathrm{RMN}$ de ${ }^{1} \mathrm{H}$ da testololactona que os sinais relativos aos hidrogênios H-16 $\alpha(\delta=2,59)$ e H-16 $\beta(\delta=2,70)$ apresentaram multipletos bem definidos. A Figura 109 apresenta os perfis de multiplicidade propostos por Kirk, et al. (1990) ${ }^{75}$ para estes hidrogênios e a Figura 110 mostra os multipletos destes sinais tanto para a progesterona quanto para a testololactona. Comparando os multipletos obtidos experimentalmente de ambos os esteroides com os perfis dos modelos, pôde ser observado que houve semelhança entre os multipletos experimentais e os propostos pelo modelo. Interessante observar que os multipletos experimentais da testololactona apresentaram uma semelhança maior com os perfis dos modelos propostos para esteroides do tipo C-17 cetônico, apesar de na testololactona o carbono C-17 é do tipo carbonílico de éster cíclico.

Figura 109. Modelos de perfis de multiplicidade propostos por Kirk, et al. $(1990)^{75}$ para reconhecimento de sinais de ${ }^{1} \mathrm{H}$ em espectros de RMN: (A) H-14 $\alpha$, (B) H-15 e (C) H-16.

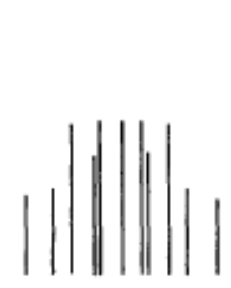

(a)

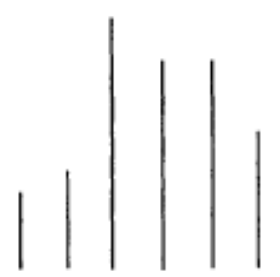

(b)

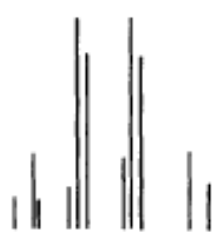

(a)

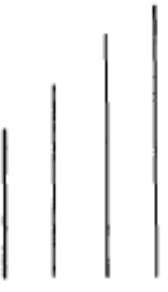

(b)

$$
\begin{aligned}
& \text { H-16 } \alpha \\
& \begin{array}{ccccccccccc}
\frac{1}{4} & 1 & 1 & 1 & 1 & 1 & 1 & 1 & 1 & 1 \\
0 & 10 & 20 & 30 & 40 & 50 & 60 & 70 & 80 & 90 & 100 \\
& \text { Escala }(\mathrm{Hz})
\end{array}
\end{aligned}
$$$$
\mathrm{H}-16 \beta
$$

a: modelos observados normalmente em esteroides do tipo $17 \beta$-substituídos b: modelos observados normalmente em esteroides de C-17 cetônico

Fonte: Adaptação de Kirk, D.N., et al. A survey of the high-field ${ }^{1} \mathrm{H}$ NMR spectra of the steroid hormones, their hydroxylated derivates and related compounds. Journal of the Chemical Society, Perkin Transactions 2, 1990, n.9, p.1570 e 1571 . 
Figura 110. Multipletos obtidos do espectro de RMN de ${ }^{1} \mathrm{H}$ dos hidrogênios H-16 $\alpha$ e H-16ß: (A) progesterona (400 MHz, $\mathrm{CDCl}_{3}$ ), (B) testololactona (500 MHz, $\mathrm{CDCl} 3$ ).

(A)

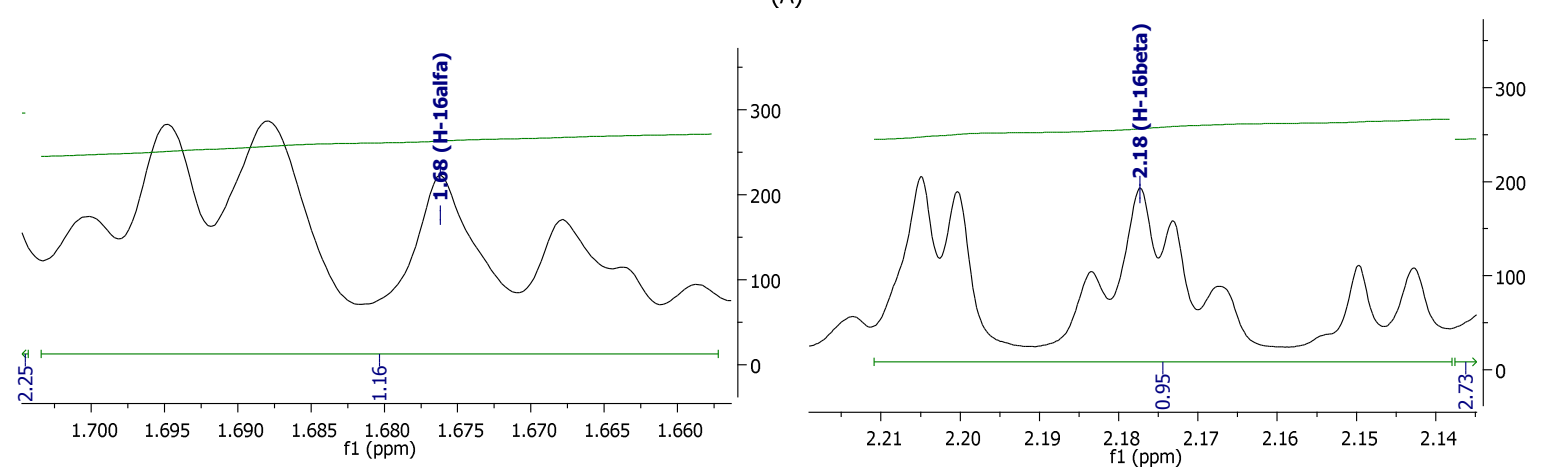

(B)

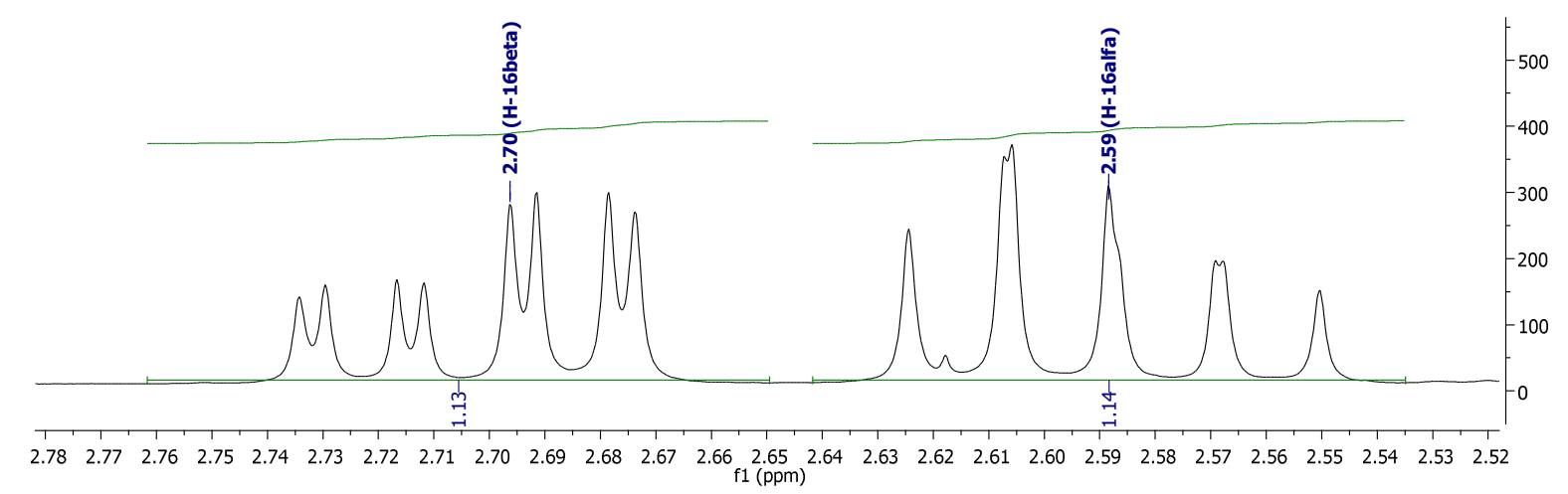

As Tabelas 36 e 37 apresentam os valores das constantes de acoplamento encontradas a partir dos sinais de hidrogênios H-16 $\alpha$ e H-16ß tanto da progesterona quanto da testololactona de maneira comparatativa.

Tabela 36. Constantes de acoplamento $(J)$ encontradas experimentalmente para o hidrogênio H-16 $\alpha$ da progesterona e da testololactona.

\begin{tabular}{ccc}
\hline$J(\mathrm{~Hz})$ & $\begin{array}{c}\text { progesterona } \\
\text { Tipo de acoplamento }\end{array}$ & Hidrogênios envolvidos \\
\hline 2,2 & Vicinal trans & $\mathrm{H}-16 \alpha-\mathrm{H}-15 \beta$ \\
3,7 & Vicinal cis & $\mathrm{H}-16 \alpha-\mathrm{H}-15 \alpha$ \\
11,0 & Geminal & $\mathrm{H}-16 \alpha-\mathrm{H}-16 \beta$ \\
\hline$(\mathrm{Hz})$ & testololactona & Hidrogênios envolvidos \\
\hline 8,5 & Tipo de acoplamento & $\mathrm{H}-16 \alpha-\mathrm{H}-15 \beta$ \\
9,3 & Vicinal axial-axial $($ trans $)$ & $\mathrm{H}-16 \alpha-\mathrm{H}-15 \beta$ \\
19,4 & Vicinal axial-axial (trans) & $\mathrm{H}-16 \alpha-\mathrm{H}-16 \beta$ \\
\hline
\end{tabular}


Tabela 37. Constantes de acoplamento $(J)$ encontradas experimentalmente para o hidrogênio H-16 $\beta$ da progesterona e da testololactona.

\begin{tabular}{ccc}
\hline$(\mathrm{Hz})$ & $\begin{array}{c}\text { progesterona } \\
\text { Tipo de acoplamento }\end{array}$ & Hidrogênios envolvidos \\
\hline 2,2 & Vicinal trans & $\mathrm{H}-16 \beta-\mathrm{H}-15 \alpha$ \\
8,5 & Vicinal cis & $\mathrm{H}-16 \beta-\mathrm{H}-15 \beta$ \\
13,8 & Geminal & $\mathrm{H}-16 \alpha-\mathrm{H}-16 \beta$ \\
\hline$J(\mathrm{~Hz})$ & testololactona & Hidrogênios envolvidos \\
\hline 2,4 & Tipo de acoplamento & $\mathrm{H}-16 \beta-\mathrm{H}-15 \beta$ \\
8,9 & Vicinal equatorial-axial $($ cis $)$ & $\mathrm{H}-16 \beta-\mathrm{H}-15 \alpha$ \\
18,9 & Vicinal equatorial-equatorial $($ trans $)$ & $\mathrm{H}-16 \alpha-\mathrm{H}-16 \beta$ \\
\hline
\end{tabular}

Como pôde ser observado na Tabela 36 foi possível observar no multipleto do hidrogênio H-16 $\alpha$ da testololactona o acoplamento geminal ${ }^{2} J_{\mathrm{H} 16 \alpha-\mathrm{H} 16 \beta}$, e, essa correlação foi sido observada no espectro de COSY da testololactona (Figuras 106B e 107B) e no multipleto do hidrogênio H-16ß da testololactona (Figura 110B e Tabela 37). Entretanto, comparando as interações vicinais cis e trans entre si obtidas de cada sinal de multipleto entre os hidrogênios H-16 da progesterona e da testololactona, percebeu-se as diferenças entre os valores das constantes de acoplamento para as mesmas interações. Sugeriu-se que essas mudanças ocorreram primeiramente pela perda do hidrogênio $H-17 \alpha$ da progesterona devido a sua biotransformação, e também, por uma uma mudança da orientação espacial dos hidrogênios H15 e H-16 como consequência da lactonização do anel D do núcleo esteroidal. Na progesterona, os hidrogênios H-15 e H-16 possuem uma configuração "semi-axial" no anel D de cinco membros na conformação envelope, se os carbonos C-13, C-15, C-16 e C-17 estiverem no mesmo plano perpendicular à folha de papel. Na testololactona, o anel $\mathrm{D}$ de seis membros assumindo uma conformação cadeira, os hidrogênios passam assumir definitivamente as orientações axial e equatorial (Figura 111). Desse modo, as distâncias entre esses hidrogênios H-15 e H-16 foram ateradas e, consequentemente, mudanças nos valores das constantes de acoplamento foram observadas. 
Figura 111. Orientações espaciais dos hidrogênios H-15 e H-16 no anel D do núcleo esteroidal: (A) progestesrona. (B) testololactona.

(A)

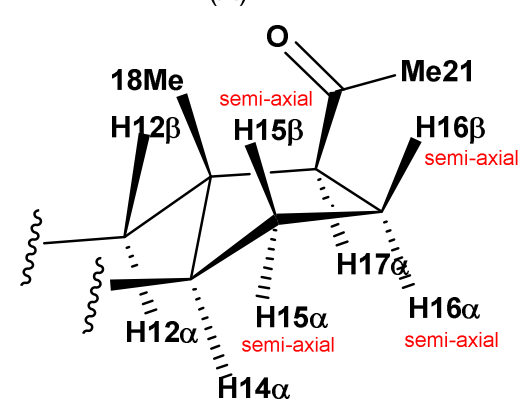

(B)

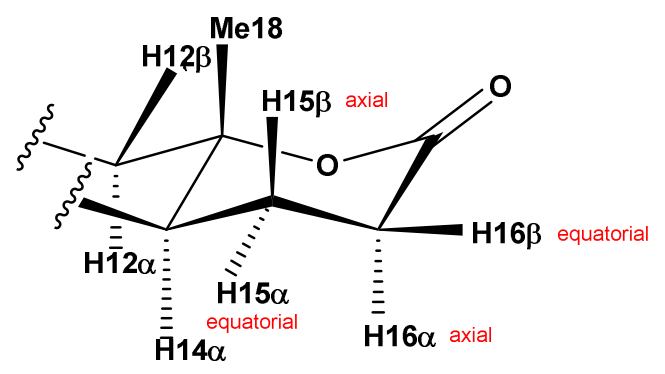

Foram feitos experimentos de IV com o composto isolado. As bandas encontradas estão descritas na Tabela 38 e atribuídas segundo Mohamed et al. (2014) ${ }^{70}$, Silverstein et al., (2006) ${ }^{71}$, Pavia et al.(2015) ${ }^{77}$, Bartmańska, Dmochowska-Gladysz e Huszcza (2005) ${ }^{91}$. A Figura 112 apresenta de forma comparativa o espectro de IV obtido experimentalmente para a progesterona e para a testololactona. 
Tabela 38. Valores das bandas vibracionais obtidas por Espectroscopia no IV para a testololactona isolada da reação com o caldo enzimático do fungo A. sydowii CBMAI 935.

\begin{tabular}{|c|c|c|}
\hline \multirow{2}{*}{ Ligação/tipo de vibração } & \multicolumn{2}{|c|}{ Valores de $v_{\text {máx }}\left(\mathrm{cm}^{-1}\right)$} \\
\hline & literatura & experimental \\
\hline Deformação axial O-H (presença de umidade) & $3550-3200^{71}$ & \multirow{2}{*}{3419} \\
\hline Deformação axial H-C= & acima de 300071 & \\
\hline Deformação axial $\mathrm{H}-\mathrm{C}=$ & acima de $3000{ }^{71}$ & 3030 \\
\hline Deformação axial C-H ( $\mathrm{CH}_{2}$ cíclico $)$ & $3100-2990^{71}$ & 2960 \\
\hline Estiramento assimétrico $\mathrm{C}-\mathrm{H}$ & $2939,95^{70}$ & 2955 \\
\hline Estiramento assimétrico $\mathrm{C}-\mathrm{H}$ & $2854,13^{70}$ & \multirow{2}{*}{2891} \\
\hline Deformação axial de C-H (carbono terciário) & $2890^{71}$ & \\
\hline Estiramento asimétrico C-H & $2854,13^{70}$ & \multirow{2}{*}{2860} \\
\hline Deformação axial de C-H (carbono terciário) & $2890^{71}$ & \\
\hline Deformação axial $\mathrm{C}=\mathrm{O}$ de lactona $(\mathrm{C}-17)$ & $1717^{91}$ & 1718 \\
\hline Estiramento $\mathrm{C}=\mathrm{O}$ de cetona $(\mathrm{C}-3)$ & $1632,34^{70}$ & \multirow{2}{*}{1668} \\
\hline Deformação axial $\mathrm{C}=\mathrm{O}$ de cetona $\alpha, \beta$-insaturada $(\mathrm{C}-3)$ & $1685-1666^{71}$ & \\
\hline Estiramento $\mathrm{C}=\mathrm{C}(\mathrm{C}-4$ e $\mathrm{C}-5)$ & $1617,02^{70}$ & 1616 \\
\hline Deformação angular $-\mathrm{CH}_{2}$ (anel de ciclo-hexano) & $1442^{71}$ & 1452 e 1437 \\
\hline Deformação angular simétrica fora do plano $\left(\mathrm{CH}_{2}\right.$ cíclico $)$ & $1350^{71}$ & 1387 e 1333 \\
\hline $\begin{array}{c}\text { Deformação axial C-O assimétrica acoplada de } \mathrm{C}-(\mathrm{C}=\mathrm{O})-\mathrm{O} \text { e } \\
\text { O-C-C de ésteres }\end{array}$ & $1300-1000^{71}$ & \multirow[t]{2}{*}{1294 e 1275} \\
\hline Deformação axial e angular de $\mathrm{C}-(\mathrm{C}=\mathrm{O})-\mathrm{C}$ & $1300-1100^{71}$ & \\
\hline $\begin{array}{l}\text { Deformação axial C-O assimétrica acoplada de } \mathrm{C}-(\mathrm{C}=\mathrm{O})-\mathrm{O} \text { e } \\
\qquad \mathrm{O}-\mathrm{C}-\mathrm{C} \text { de ésteres }\end{array}$ & $1300-1000^{71}$ & \multirow{4}{*}{$\begin{array}{c}1232 \text { e } 1211,1167 \\
1132 \text { e } 1095\end{array}$} \\
\hline Deformação axial C-O acoplada de $\mathrm{C}-(\mathrm{C}=\mathrm{O})-\mathrm{O}$ de lactonas & $1250-1111^{71}$ & \\
\hline Deformação axial e angular de $\mathrm{C}-(\mathrm{C}=\mathrm{O})-\mathrm{C}$ & $1300-1100^{71}$ & \\
\hline Estiramento C-O & $1260-1110^{77}$ & \\
\hline $\begin{array}{l}\text { Deformação axial C-O assimétrica acoplada de } \mathrm{C}-(\mathrm{C}=\mathrm{O})-\mathrm{O} \text { e } \\
\qquad \mathrm{O}-\mathrm{C}-\mathrm{C} \text { de ésteres }\end{array}$ & $1300-1000^{71}$ & 1061 e 1012 \\
\hline
\end{tabular}


Figura 112. Espectros de IV: (A) progestesterona (B) testololactona.

(A)

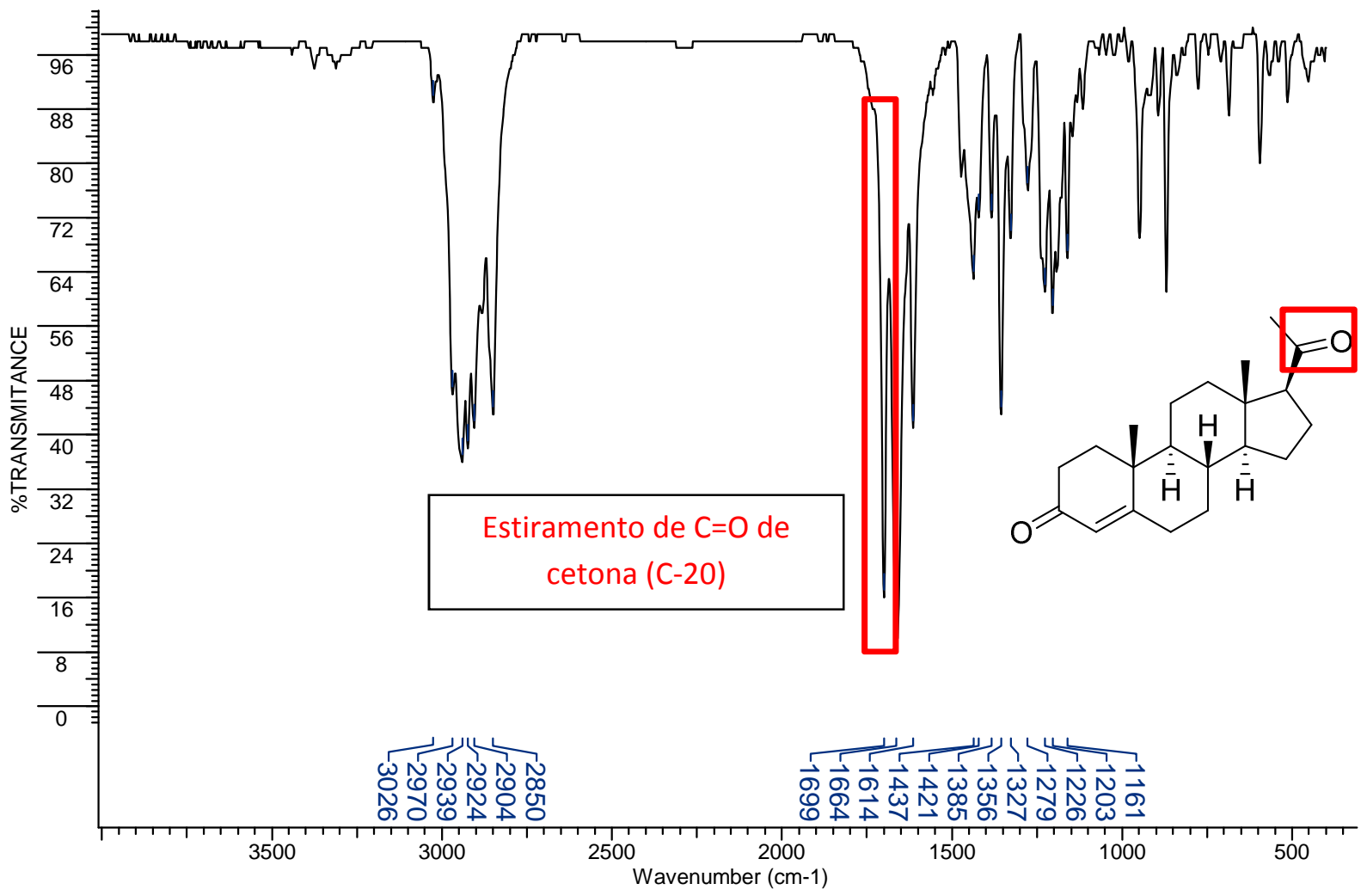

(B)

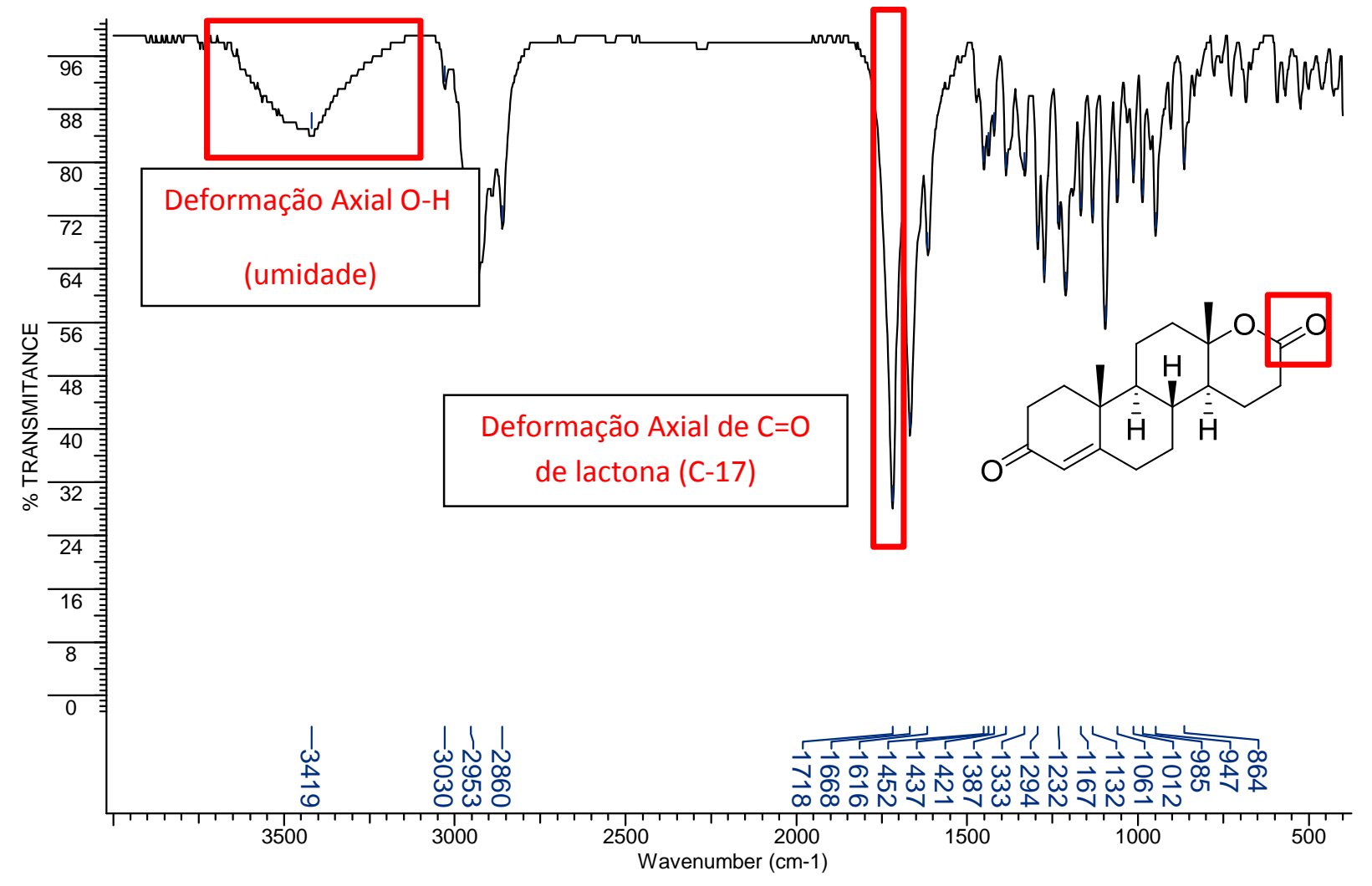


Como pôde-se observar pela Figura 112 no espectro de IV da progesterona um deslocamento da banda de $1699 \mathrm{~cm}^{-1}$ referente ao estiramento $\mathrm{C}=\mathrm{O}$ de carbonila de cetona no carbono C-20. No espectro da testololactona, uma banda de $1718 \mathrm{~cm}^{-1}$ foi observada indicando ser a absorção por deformação axial $\mathrm{C}=\mathrm{O}$ da carbonila de éster do carbono $\mathrm{C}-17$ segundo descrito na literatura ${ }^{91}$. Esse deslocamento de banda vibracional foi a principal evidência observada no espectro de IV da testololactona indicando a biotransformação da progesterona pelo caldo enzimático do fungo A. sydowii CBMAI 935.

Entretanto, no espectro da testololactona foi observada uma banda larga em $3419 \mathrm{~cm}^{-1}$. A literatura indica que este sinal é devido a deformação axial de uma ligação O-H ${ }^{71}$. Sugeriuse que essa banda ocorreu devido à presença de umidade no composto.

Devido o fato do espectro de massas obtido por CG-EM do metabólito isolado da reação com o caldo enzimático teve uma similaridade inferior que $90 \%$ para a testololactona $(82 \%$, biblioteca NIST107 - Figura 58), foi feito um experimento de EMAR da testololactona oriunda das reações com o caldo enzimático e com a massa micelial do fungo A. sydowii CBMAI 935 para reforçar a confirmação da obtenção da testololactona. A Figura 113 apresenta o espectro de massas de alta resolução obtido experimentalmente a testololactona.

Figura 113. Espectro de massas de alta resolução modo positivo $\left(\mathrm{H}^{+}\right)$da testololactona isolada da reação com o caldo enzimático do fungo A.sydowii CBMAI 935.

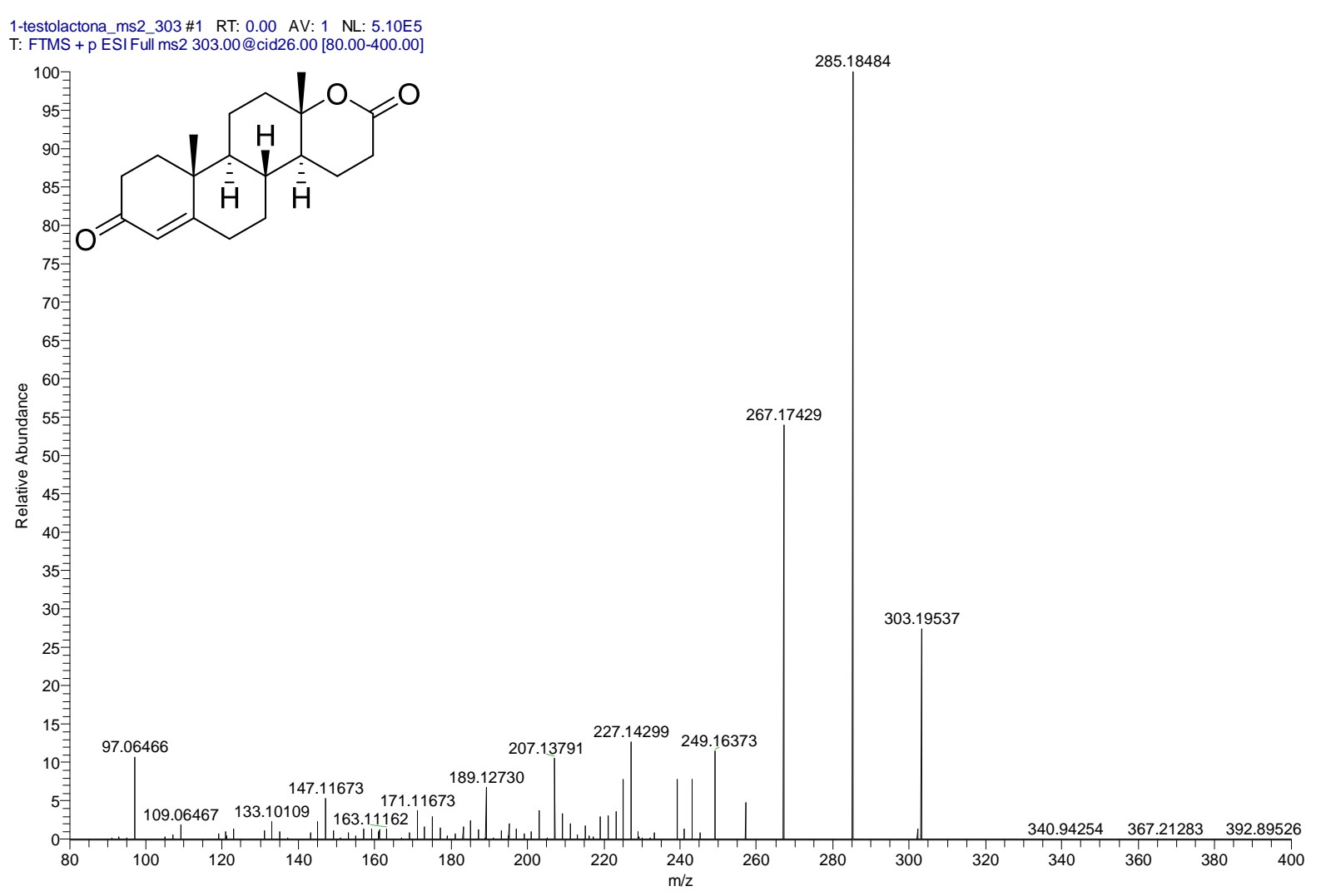


Como o espectro de massas da Figura 113 apresentou, foi observado o pico de $\mathrm{m} / \mathrm{z}$ 303,19537 que se referiu ao íon molecular protonado da testololactona (massa molar $=302,41$ $\mathrm{g} / \mathrm{mol}$ ) reforçando que a testololactona foi composto isolado das reações da progesterona com o caldo enzimático e a massa micelial do fungo A.sydowii CBMAI 935.

A Tabela 39 apresenta os resultados das medidas de rotação óptica para o composto dihidroxilado isolado, comparativo os valores descritos na literatura ${ }^{88}$ para a testololactona.

Tabela 39. Valores de rotação óptica para a testololactona.

\begin{tabular}{cccccc}
\hline \multicolumn{3}{c}{ Valores descritos na literatura ${ }^{88}$} & \multicolumn{3}{c}{ Valores experimentais } \\
\hline $\begin{array}{c}\text { Concentração } \\
(\mathrm{g} / 100 \mathrm{~mL})^{\mathrm{a}}\end{array}$ & $\begin{array}{c}\text { Temperatura } \\
\left({ }^{\circ} \mathrm{C}\right)\end{array}$ & {$\left[\alpha_{D}\right]_{589}^{20}(\mathrm{deg})$} & $\begin{array}{c}\text { Concentração } \\
(\mathrm{g} / 100 \mathrm{~mL})^{\mathrm{a}}\end{array}$ & $\begin{array}{c}\text { Temperatura } \\
\left({ }^{\circ} \mathrm{C}\right)\end{array}$ & {$\left[\alpha_{D}\right]_{589}^{23}(\mathrm{deg})$} \\
\hline 0,1 & 20 & 44 & 0,1 & 23 & -5 \\
\hline${ }^{\mathrm{a}} \mathrm{CHCl}_{3}$ & & & &
\end{tabular}

A literatura ${ }^{88}$ indicou que a testololactona promove o desvio da luz polarizada no sentido positivo. No entanto, o resultado obtido foi desvio negativo. A Figura 56 na seção D.5.3.6 e a Figura 59 na seção D.5.3.8 apresentaram cromatogramas obtidos por CG-EM da reunião das frações continham a testololactona purificada por CC dos extratos das reações de biotransformação da progesterona com o caldo enzimático e com a massa micelial do fungo A.sydowii CBMAI 935. Nesses cromatogramas foi observado um pequeno pico com $t_{R}=13,23$ minutos. Para esse sinal, em ambos produtos isolados das reações, foi obtido um espectro de massas com $69 \%$ de similaridade com o espectro de massas do octacosa-hidro-2H-di-ciclodeca[c,J][1] oxa-ciclo-tetradecino fornecido pela biblioteca NIST107 (Figura 114).

Figura 114. Espectros de massas $(70 \mathrm{eV})$ : (A) experimental para composto $t_{R}=13,23 \mathrm{~min}$. (B) octacosahidro-2H-di-ciclo-deca[c,J][1] oxa-ciclo-tetradecino (similaridade: 69\%, biblioteca NIST07).

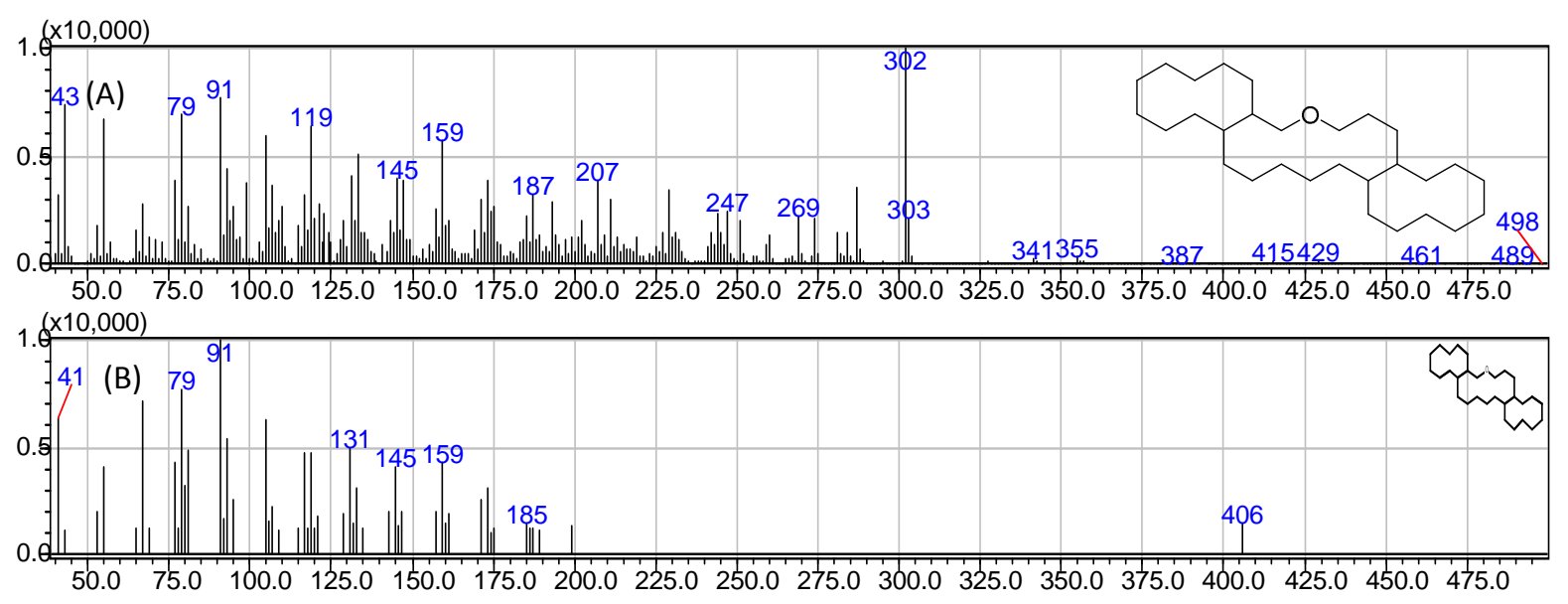


Este composto possivelmente é um contaminante e por estar presente em pequena quantidade junto com a testololactona isolada possivelmente seja o responsável pelo desvio negativo da luz polarizada na determinação da rotação óptica.

Já foi apresentado na seção D.5.4.3 alguns exemplos descritos na literatura ${ }^{68,88}$ da biotransoformação da progesterona em testololactona como metabólito, sendo a testosterona um dos compostos observados (Esquemas 20 e 21). Um exemplo interessante descrito por Bartmańska, Dmochowska-Gladysz e Huszcza $(2005)^{91}$ foi a obtenção da testololactona a partir da biotransformação da progesterona utilizando o fungo Penicilium notatum KCH 904 por 48 horas, não sendo observados compostos intermediários (Esquema 23).

Esquema 23. Biotransformação da progesterona pelo fungo P.notatum $\mathrm{KCH} 904^{91}$.
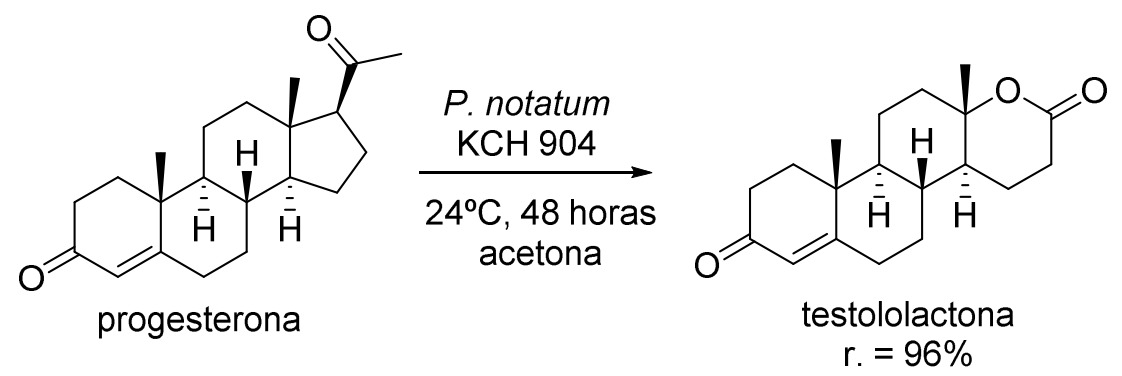

Liu et al. (2006) $)^{92}$ estudaram a biotransformação da progesterona utiliznado o fungo Penicilium citreo-viride A.C.C.C. 0402 por 120 horas tendo observado além da testololactona, a androstenediona como metabólitos (Esquema 24).

Esquema 24. Biotransformação da progesterona pelo fungo P. citreo-viride A.C.C.C. $0402^{92}$.

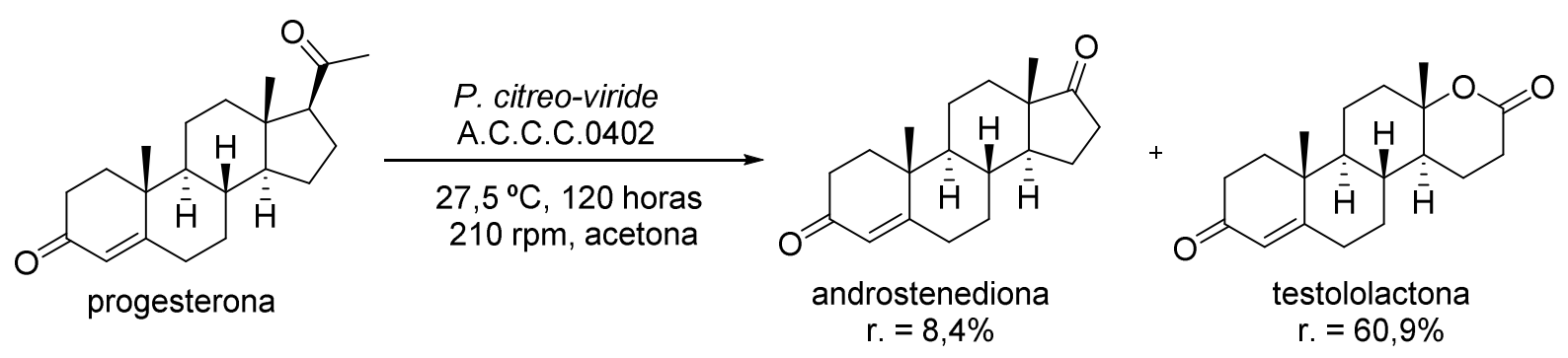


A partir dos resultados das caracterizações espectroscópicas dos produtos obtidos das biotransformações da progesterona utilizando fungos de ambiente marinho a seguir será descrito de forma sucinta as reações efetuadas.

Na biotransformação em quintuplicatas da progesterona com a linhagem do fungo $A$. sydowii CBMAI 934, utilizando o caldo enzimático foi possível isolar um metabólito dihidroxilado nos carbonos C-7 e C-15 que sugerimos que seja o 7 $\alpha, 15 \beta$-di-hidroxiprogesterona, conforme evidenciaram os resultados obtidos por meio das caracterizações espectroscópicas. $\mathrm{O}$ rendimento em massa desta reação foi de $13 \%$ (Esquema 25).

Esquema 25. Biotransformação da progesterona pelo caldo enzimático do fungo A. sydowii CBMAI 934.
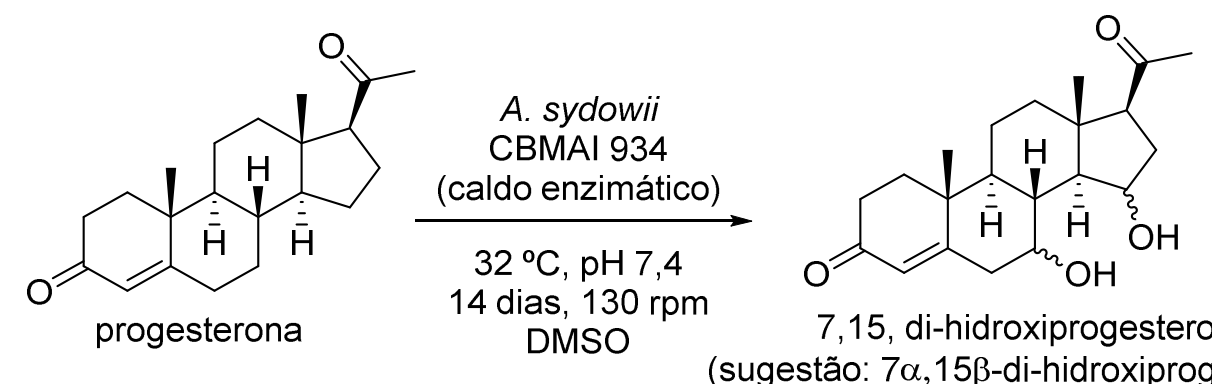

(sugestão: $7 \alpha, 15 \beta$-di-hidroxiprogesterona)

$r .=13 \%$

Utilizando a massa micelial da linhagem fungo A. sydowii CBMAI 934 foi possível isolar o metabólito $15 \beta$-hidroxiprogesterona, conforme evidenciaram os resultados obtidos por meio das caracterizações espectroscópicas. O rendimento em massa desta reação foi de $58 \%$ (Esquema 26).

Esquema 26. Biotransformação da progesterona pela masssa micelial do fungo A. sydowii CBMAI 934.

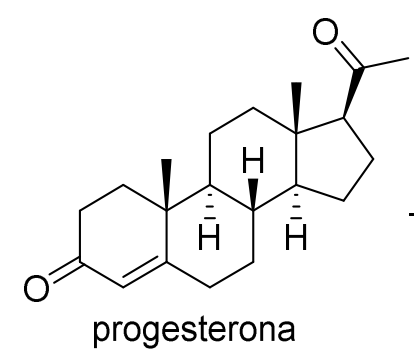

progesterona

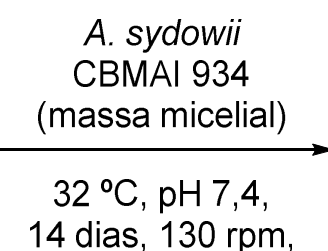

DMSO

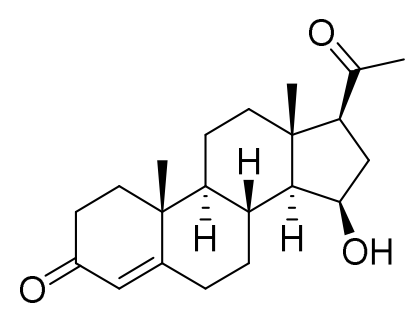

$15 \beta$-hidroxiprogesterona r. $=58 \%$

Nas biotransformações em quintuplicatas da progesterona com a linhagem do fungo $A$. sydowii CBMAI 935, utilizando o caldo enzimático foi possível isolar os metabólitos testosterona e testololactona, conforme evidenciaram os resultados obtidos por meio das caracterizações espectroscópicas. O rendimento em massa para a obtenção da testosterona foi de $24 \%$. Para a obtenção da testololactona, o rendimento em massa foi de 36\% (Esquema 27). 
Esquema 27. Biotransformação da progesterona pelo caldo enzimático do fungo A. sydowii CBMAI 935.
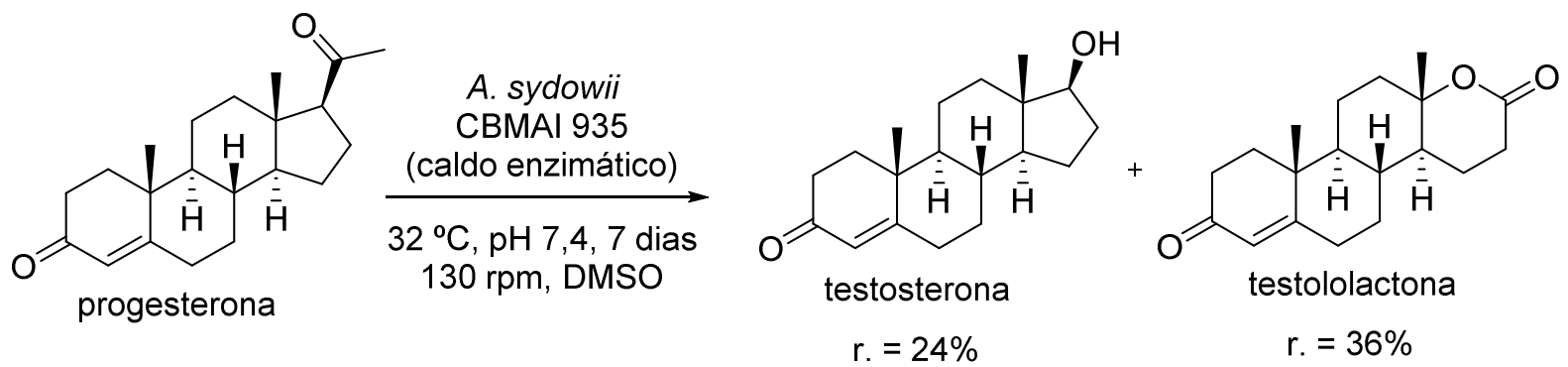

Utilizando a massa micelial da linhagem do fungo A. sydowii CBMAI 935 foi possível isolar o metabólito testololactona. O rendimento em massa desta reação foi de $87 \%$. (Esquema 28).

Esquema 28. Biotransformação da progesterona pela massa micelial do fungo A. sydowii CBMAI 935.

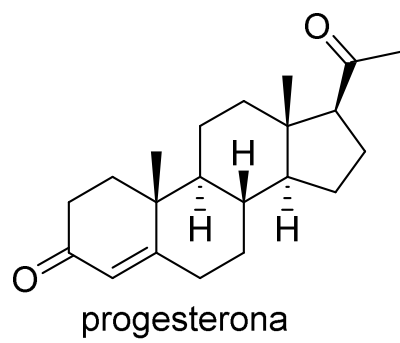
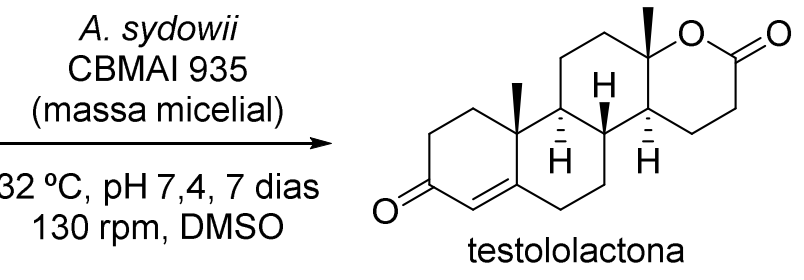

r. $=87 \%$ 


\section{D.5.5 MECANISMOS ENZIMÁTICOS DE BIOTRASNFORMAÇÃO DA PROGESTERONA PARA OBTENÇÃO DOS COMPOSTOS DESCRITOS}

Mediante os compostos obtidos e descritos neste trabalho é interessante buscar entender os mecanismos e as reações envolvidas descritas na literatura que possam elucidar a biotransformação da progesterona por fungos de ambiente marinho.

Nas caracterizações espectroscópicas (Seção D.5.4) dos metabólitos obtidos neste estudo, a maioria das fontes de onde os exemplos de biotransformação da progesterona relatados não se preocupou em elucidar os mecanismos enzimáticos envolvidos na biotransformação da progesterona que levam aos produtos descritos neste trabalho. A preocupação das fontes, de modo geral, foi apenas em relatar as condições de reação, os produtos obtidos e suas quantidades, bem como as caracterizações ${ }^{68,74,80,82,83,84,88,91,92}$.

\section{D.5.5.1 Obtenção da testosterona e testololactona}

Como já mencionado, Yang et al. $(2014)^{68}$ promoveram a biotransformação da progesterona utilizando cepas do fungo Penicilium simplicissimum WY134-2 isolado de amostras de solo coletadas da província de Sichuan na China. A biotransformação foi efetuada por 24 horas obtendo como produto final a testololactona que em condições muito ácidas $(\mathrm{pH}$ = 1 2) se mantém em equilíbrio com o ácido testólico. Durante a biotransformação da progesterona, foram observados os intermediários testosterona e androstenediona como mostra a rota proposta de biotransformação (Esquema 29).

Esquema 29. Rota de biotransformação da progesterona por cepas de P. simplicissimum WY134- ${ }^{68}$.
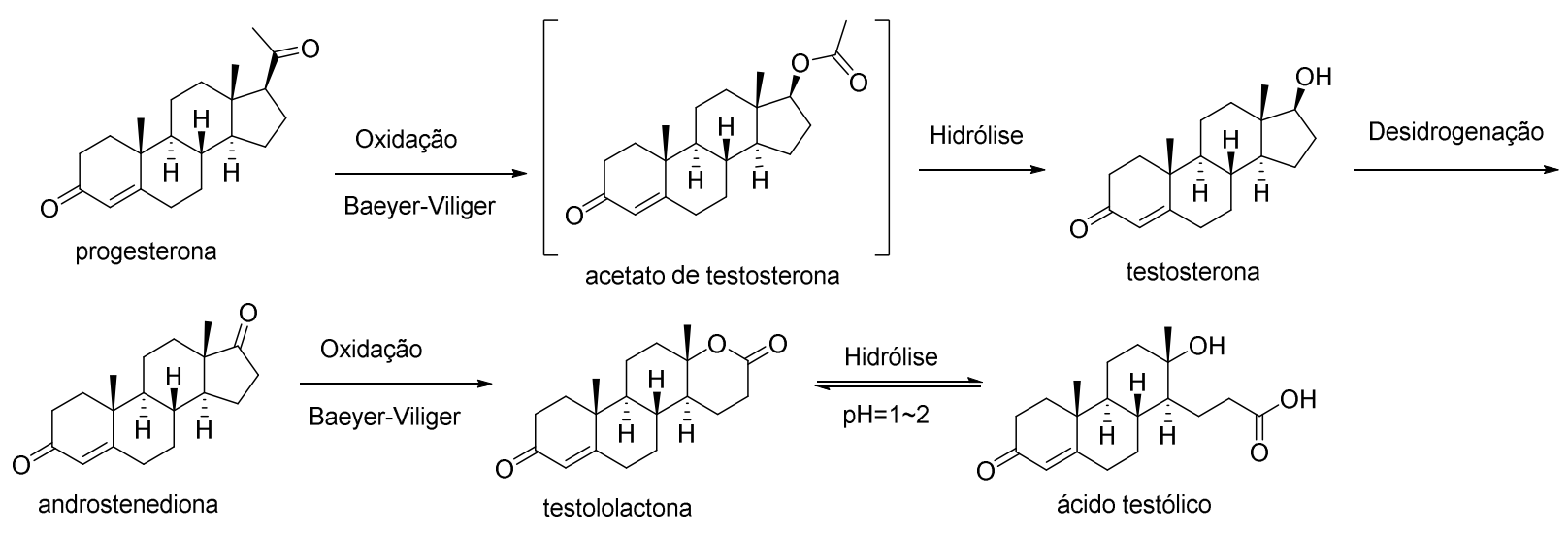

Condições iniciais: $\mathrm{pH} 8,0,30^{\circ} \mathrm{C}, 200 \mathrm{rpm}$, Meio de cultura: glicose 3\%, $\mathrm{NaNO}_{3}(0,3 \%), \mathrm{MgSO}_{4} .7 \mathrm{H}_{2} \mathrm{O}(0,05 \%)$, $\mathrm{KCl}(0,05 \%), \mathrm{FeSO}_{4} \cdot 4 \mathrm{H}_{2} \mathrm{O}(0,002 \%), \mathrm{K}_{2} \mathrm{HPO}_{4} \cdot 3 \mathrm{H}_{2} \mathrm{O}(0,2 \%), \mathrm{KH}_{2} \mathrm{PO}_{4}(0,1 \%)$. 
$\mathrm{O}$ anel D da progesterona foi oxidado por uma enzima Baeyer-Villiger monoxigenase formando o acetato de testosterona, que por sua vez foi hidrolisado à testosterona. Este esteroide sofre oxidação por desidrogenação formando a androstenediona que foi oxidada por uma Baeyer-Villiger monoxigenase fornecendo a testololactona que por fim, em condições muito ácidas, se mantém em equilíbro com o ácido testólico.

Neste estudo, não foram observados o acetato de testosterona e a androstenediona como intermediários na biotransformação da progesterona utilizando o caldo enzimático e a massa micelial do fungo A. sydowii CBMAI 935. Sendo assim, pode-se inferir que as oxidações de Baeyer-Villiger foram as etapas rápidas da biotransformação da progesterona e catalisadas por enzimas do tipo Baeyer-Villiger monoxigenases produzidas pelo fungo A. sydowii CBMAI 935.

O ácido testólico não foi observado como produto final, indicando que as condições finais da biotransformação da progesterona não foram severamente ácidas que levaria a hidrólise da testololactona.

Outros autores descreveram que as etapas da biotransformação da progesterona mostradas no Esquema 24 podem ser catalisadas por enzimas. Na etapa de oxidação de BaeyerVilliger da progesterona a acetato de testosterona, Morii et. al. (1999) ${ }^{93}$ descreveram que a enzima Cetoesteroide Monoxigenase EC1.14.13.54 expressa pela bactéria Rhodoccoccus rhodochrous foi a enzima responsável por esta etapa utilizando como cofator NADPH. Francheschini et al. (2012) ${ }^{94}$, a partir do cristal desta enzima, determinaram por difração de Raios-X sua estrutura (Figura 115). 
Figura 115. Estrutura Cristalina da enzima Cetoesteroide Monoxigenase EC1.14.13.5494.

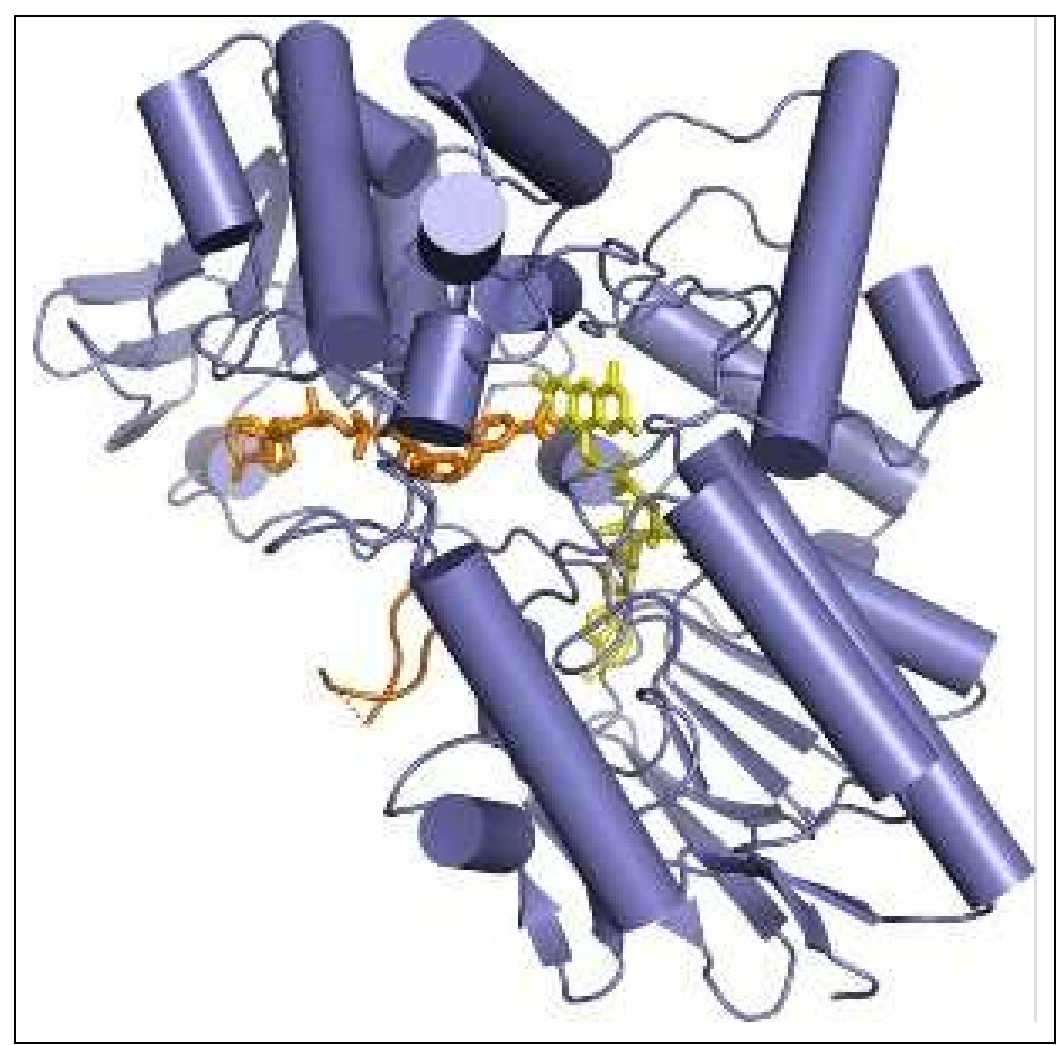

Fonte: Extraído de FRANCESCHINI, S. et al. Exploring the Structural Basis of Substrate Preferences in BaeyerVilliger Monooxygenase insight from steroid monooxygenase. Journal of Biological Chemistry, 2010, v.287, n.27, p.22629.

Um mecanismo geral de oxidação enzimática de Baeyer-Villiger foi descrito por Sheng, Ballou e Massey (2001) ${ }^{95}$ utilizando como substrato a ciclo-hexanona, a flavina e o NADPH como cofatores (Esquema 30). 

substrato $^{95}$

Esquema 30. Mecanismo enzimático de oxidação de Baeyer-Villiger utilizando ciclo-hexanona como

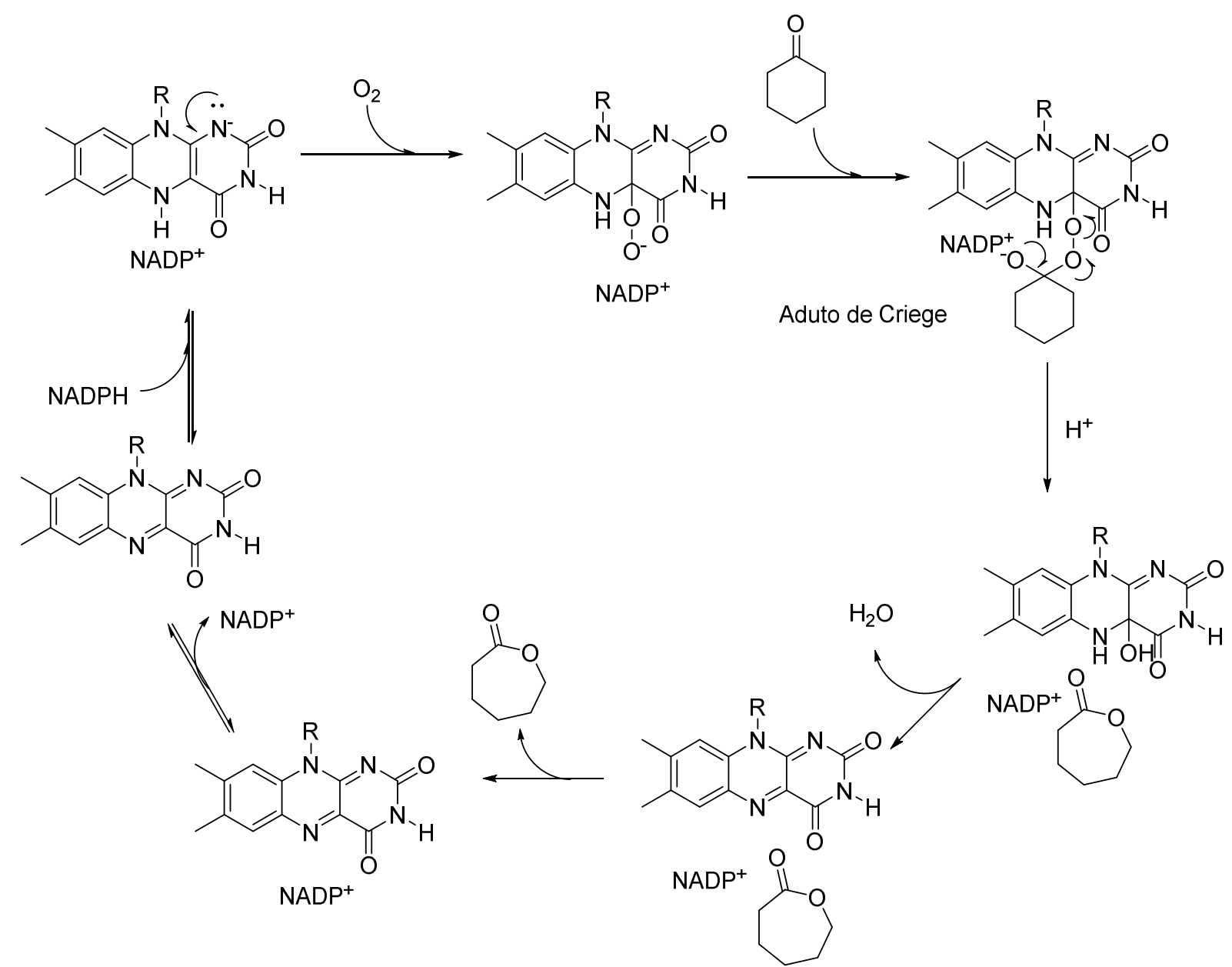

Fonte: Adaptação de SHENG, D., BALlOU D.P., MASSEY, V. Mechanistic Studies of Cyclohexanone Monooxygenase: Chemical Properties of Intermediates Involved in Catalysis. Biochemistry, 2001, v. 40, n.37, p. 11166.

Conforme Sheng, Ballou e Massey (2001) $)^{95}$ descreveram, a enzima reage com o NADPH e a flavina formando um complexo de Michaelis (Enzima-flavina-NADP ${ }^{+}$). Este por sua vez reage rapidamente com o oxigênio na forma presumida de um ânion flavinoperóxido. O substrato se liga ao peróxido formando um aduto de Criege. Em seguida, ocorre a lactonização da ciclo-hexanona em meio ácido formando a $\epsilon$-caprolactona e o aduto é defeito. O complexo de Michaelis sofre uma desidratação e posteriormente a lactona formada se desprende do complexo. O cofator $\mathrm{NADP}^{+}$se desliga do complexo se tornando um aceptor de hidrogênio formando o NADPH, finalizando o ciclo catalítico.

$\mathrm{Na}$ etapa de hidrólise do acetato de testosterona, não se tem conhecimento se esta etapa é intermediada por uma enzima hidrolase ou se é típica de uma hidrólise espontânea de ésteres formando ácido carboxílico. Cheeseman et al. (2004) ${ }^{96}$ apresentaram, como mostra o Esquema 
31, um mecanismo enzimático geral de hidrólise de éstesres por esterases utilizando resíduos de aminoácidos de ácido aspártico (Asp), histidina, (His), serina (Ser), triptofano (Trp), metionina (Met) ou treoina (Thr).

Esquema 31. Mecanismo enzimático de hidrólise de éster catalisada por esterase ${ }^{96}$.

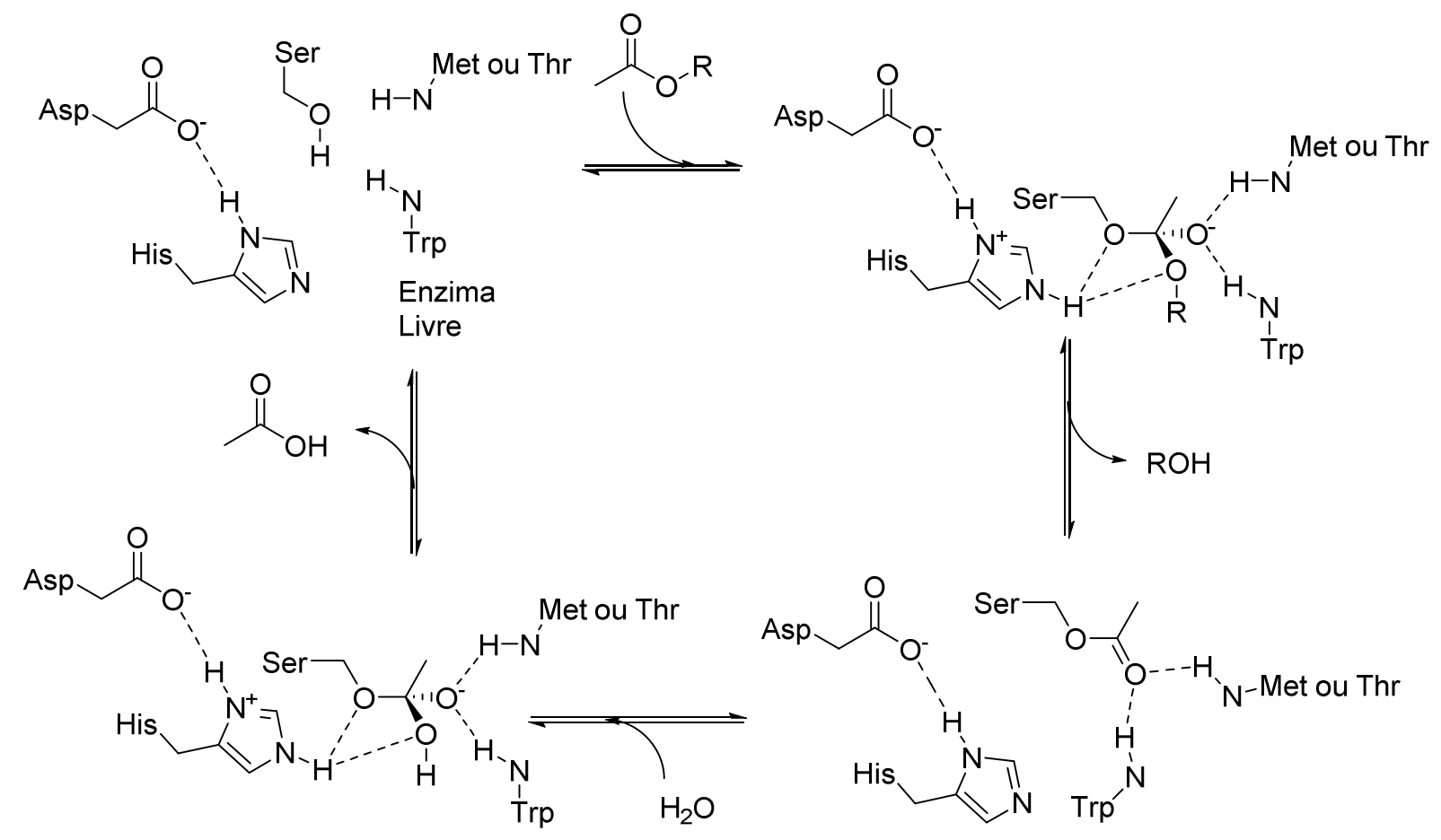

Fonte: Adaptação de CHEESEMAN, J.D. et al. Structure of na aryl esterase from Pseudomonas fluorescens. Acta Crystallographica Section D Biological Crystallography. 2004., v.60, ed.7, p.1238. Reprodução sob permissão da União Internacional de Cristalografia (em inglês: IUCr - International Union of Crystalography).

Conforme o mecanismo apresentado por Cheeseman et al. (2004) ${ }^{96}$ o éster forma um complexo com os resíduos de aminoácido do sítio ativo. Deste complexo, o álcool proveniente do éster é liberado do complexo, (no caso de aplicação deste mecanismo, o álcool é a testosterona), sendo que o hidrogênio da hidroxila do álcool é proveniente da serina e o complexo é defeito e dois complexos passam a ser observados: um complexo formado pelos resíduos de ácido aspártico e histidina e outro constituído pela acetila do éster e os resíduos de serina, triptofano, metionina ou treonina. Uma molécula de água se liga aos dois resíduos de serina e histidina e um novo complexo é formado. Assim, o ácido carboxílico (ácido acético) é liberado do complexo e os resíduos voltam à suas conformações na enzima livre. 
A testosterona é o principal hormônio sexual encontrado em mamíferos machos, segregado pelos testículos e o principal hormônio responsável pelo desenvolvimento dos caracteres masculinos.

Para a etapa de oxidação por desidrogenação da testosterona levando a androstenediona, Inano e Tamaoki (1986) ${ }^{97}$ observaram que a enzima testosterona 17 $\beta$-desidrogenase EC.1.1.1.64 encontrada nos testículos de humanos é a responsável em catalisar essa reação utilizando como cofatores $\mathrm{NAD}^{+}$e $\mathrm{NADP}^{+}$. Gangloff et al. (2003) ${ }^{98}$ por difração de Raios-X determinaram a estrutura cristalina desta enzima quando complexada com a testosterona (Figura 116).

Figura 116. Estrutura cristalina da testosterona 17ß-desidrogenase EC.1.1.1.649

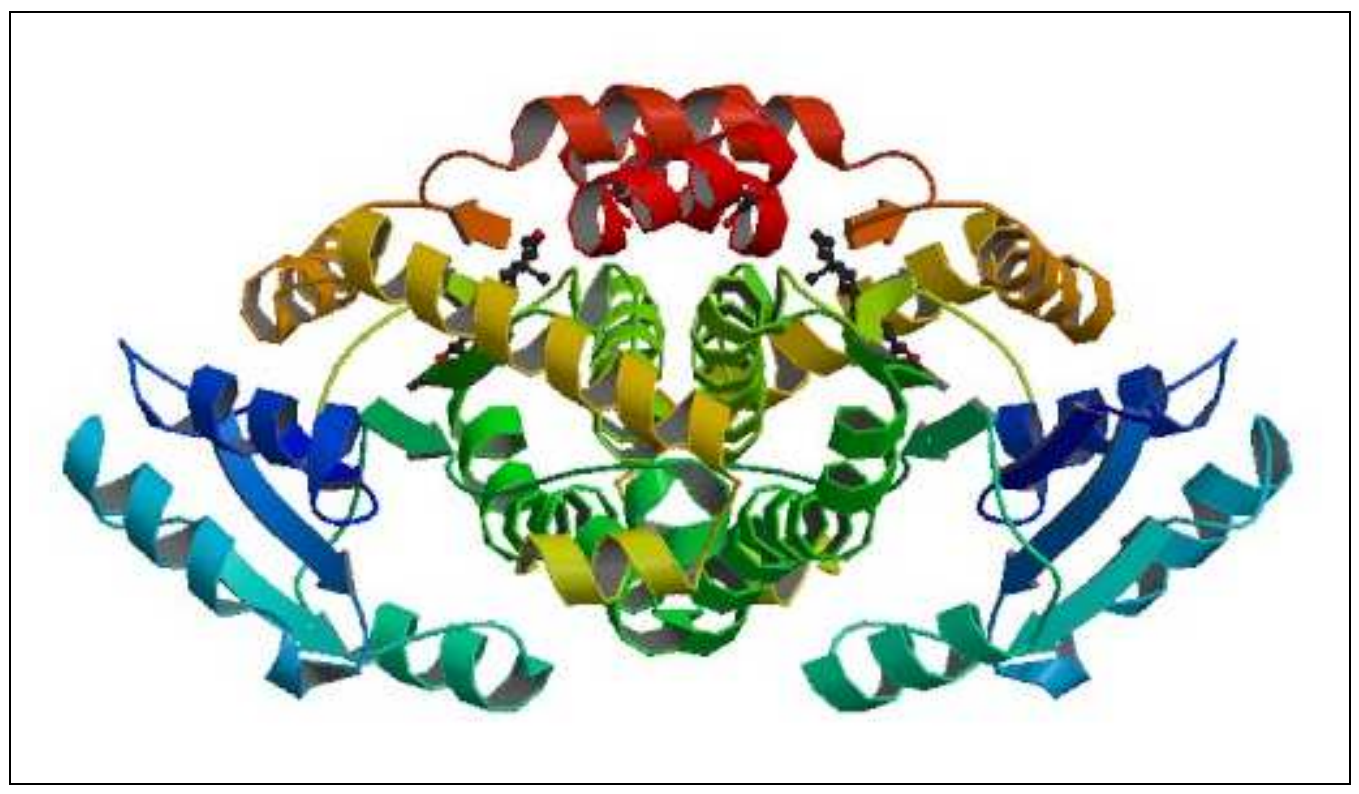

Fonte: Extraído do Protein Data Bank sob PDB ID 1JTV. Descrito e depositado por GANGLOFF, A. et al. Pseudosymetry of C19 steroids, alternative dinding orientations, and multispecificity in human estrogenic 17 $\beta-$ hdroxysteroid dehydrogenase. The FASEB Journal., v.17, n.2, 2003, p.274-276.

Não foram encontrados mecanismos enzimáticos que relatem a desidrogenação da testosterona pela enzima testosterona 17 $\beta$-desidrogenase EC.1.1.1.64. No entanto existem dois mecanismos enzimáticos interessantes relatados na literatura sobre oxidação de álcoois secundários às cetonas como mostra o Esquema 3299,100: 
Esquema 32. Mecanismos de desidrogenação de álcoois desidrogenase: (A) Mecanismo por perda de próton de anel pirrólico de histidina ${ }^{99}$, (B) mecanismo por sistema de zinco penta-coordenado ${ }^{100}$.

(A)

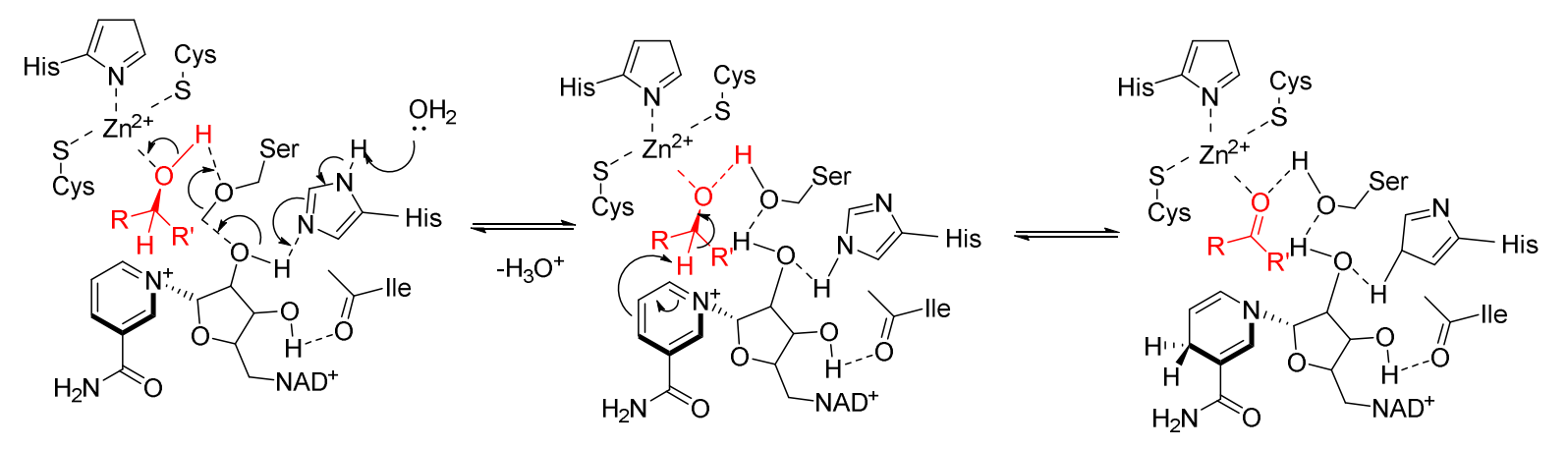

(B)
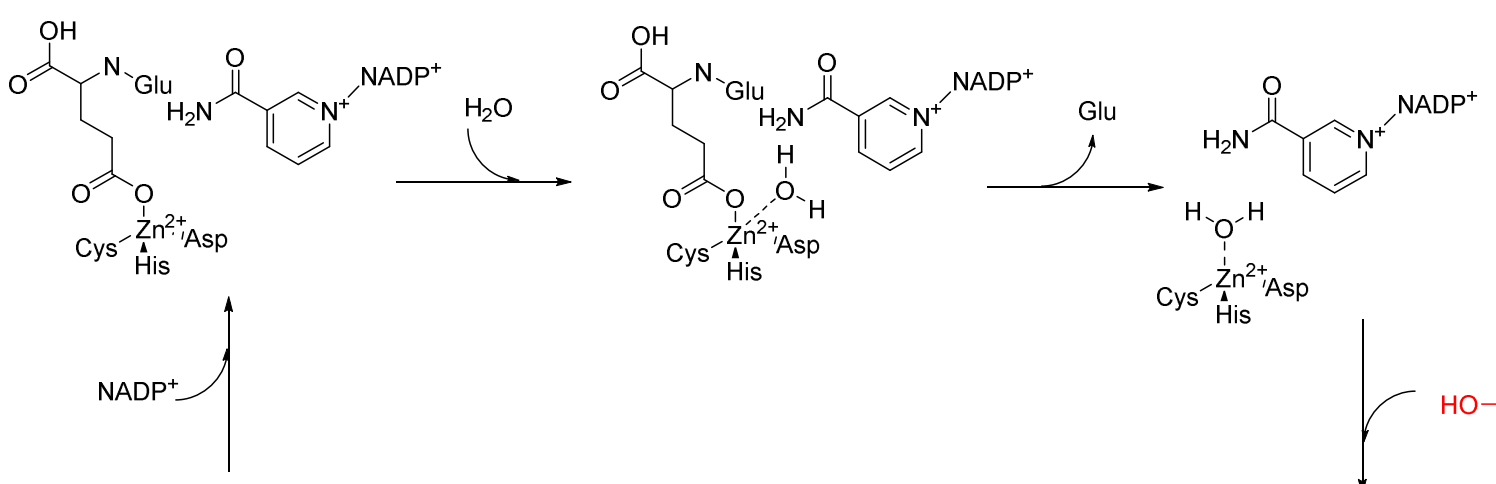

Cys $^{-} \underset{\text { His }}{Z}{ }_{\text {His }}^{2+}{ }^{2+}$ Asp

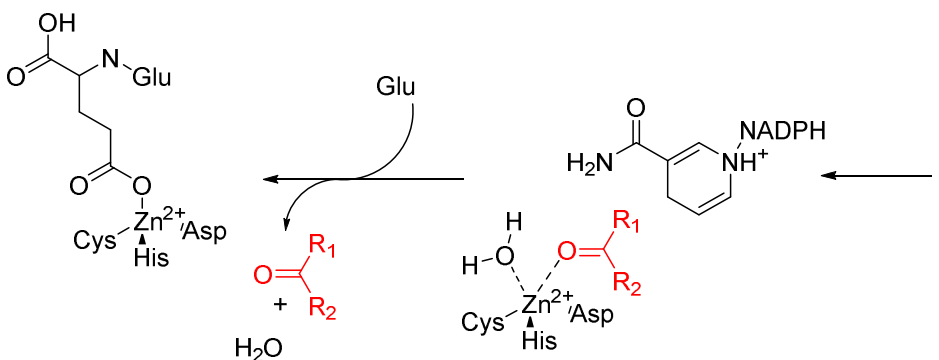

Cys= $\operatorname{Zn}_{\text {His }}^{2+}$ Asp $^{R_{2}}$

$\mathrm{H}_{2} \mathrm{O}$

Fontes: (A) Adaptação de EKLUND, H. et al. Binding of substrate in a ternary complex of horse liver alcohol dehydrogenase. Journal of Biological Chemistry, 1982, v. 257, n.23, p. 14357.

(B) Adaptação de KLEIFELD, O. et al. Active site eletronic structure and dynamics during metalloenzyme catalysis. Nature Structural \& Molecular Biology, 2003, v.10, ed.2, p. 102.

No mecanismo do Esquema 32A descrito por Eklund et al. (1982) ${ }^{99}$ o álcool participa de um complexo de Zinco tetra-coordenado com dois resíduos de cisteína (Cys) e um de histidina (His). Uma molécula de água abstrai um próton do anel pirrólico do resíduo de histidina ligado ao cofator $\mathrm{NAD}^{+}$, ocorrendo a liberação de um cátion hidrônio, enfraquecendo as ligações $\mathrm{O}-\mathrm{H}$ da hidroxila e $\mathrm{O}-\mathrm{Zn}^{2+}$ do complexo. Um par de elétrons se desloca formando uma ligação $\mathrm{C}=\mathrm{O}$ e um dos hidrogênios carbinólicos é abstraído pelo anel piridínico do cofator $\mathrm{NAD}^{+}$, deixando então a cetona formada parcialmente ligada ao resíduo de cisteína e ao $\mathrm{Zn}^{2+}$, possibilitando assim a sua posterior liberação. 
Já o mecanismo do Esquema 32B descrito por Kleifeld et al. (2003) ${ }^{100}$ começa com complexo de Zinco tetra-coordenado com resíduos de histidina, cisteína, ácido aspártico e ácido glutâmico (Glu) e o cofator é o $\mathrm{NADP}^{+}$. Uma molécula de água participa como ligante do complexo, passando a ser um complexo penta-coordenado. O resíduo de ácido glutâmico deixa de ser ligante do complexo e é substituído pelo álcool. O anel piridínico do cofator abstrai o próton carbinólico do álcool e o par de elétrons da ligação $\mathrm{O}-\mathrm{Zn}^{2+}$ se desloca, formando uma ligação $\mathrm{C}=\mathrm{O}$. Assim, a cetona e uma molécula de água são liberadas do complexo e o resíduo de Ácido Glutâmico volta a ser um ligante do $\mathrm{Zn}^{2+}$, regenerando o complexo.

Por fim, a última etapa da reação é a oxidação de Baeyer-Villiger da androstenediona, formando a testololactona. Itagaki, E. (1986) ${ }^{101}$, observou que a enzima Androst-4-ene-3,17diona monoxygenase EC 1.14.99.12 de Cylindrocarpon radicicola foi capaz de catalisar a oxidação da androstenediona à testololactona utilizando como cofatores o NADPH e Flavina. A estrutura desta enzima é desconhecida, porém o mecanismo de reação pode ser considerado o descrito no Esquema 30.

A testololactona pode suprimir a síntese de estrógenos por inibição de enizmas aromatases $^{102}$. Tal função indica que ela pode ser usada no tratamento de câncer de mama ${ }^{103}$, hiperplasia prostática e câncer de próstata ${ }^{104}$. Pode ser usada como agente terapêutico no tratamento de desordens causadas pelo desbalanceamento entre as ações de estrógenos e andrógenos, como ginecomastia ${ }^{105}$ e puberdade precoce ${ }^{106}$.

Para comprovação de parte da rota de biotransformação da progesterona foi adicionado ao caldo enzimático do fungo A. sydowii CBMAI $93510 \mathrm{mg}$ de testosterona e o meio foi condicionado a $32^{\circ} \mathrm{C}, 130 \mathrm{rpm}$ por 2 dias. Seguindo os procedimentos de monitoramento do meio reacional, a cada 24 horas foi feita uma análise por CG-EM do extrato das alíquotas tomadas como mostra a Figura 117. 
Figura 117. Análises cromatográficas da conversão da testosterona em testololactona pelo caldo enzimático do fungo A. sydowii CBMAI 935.

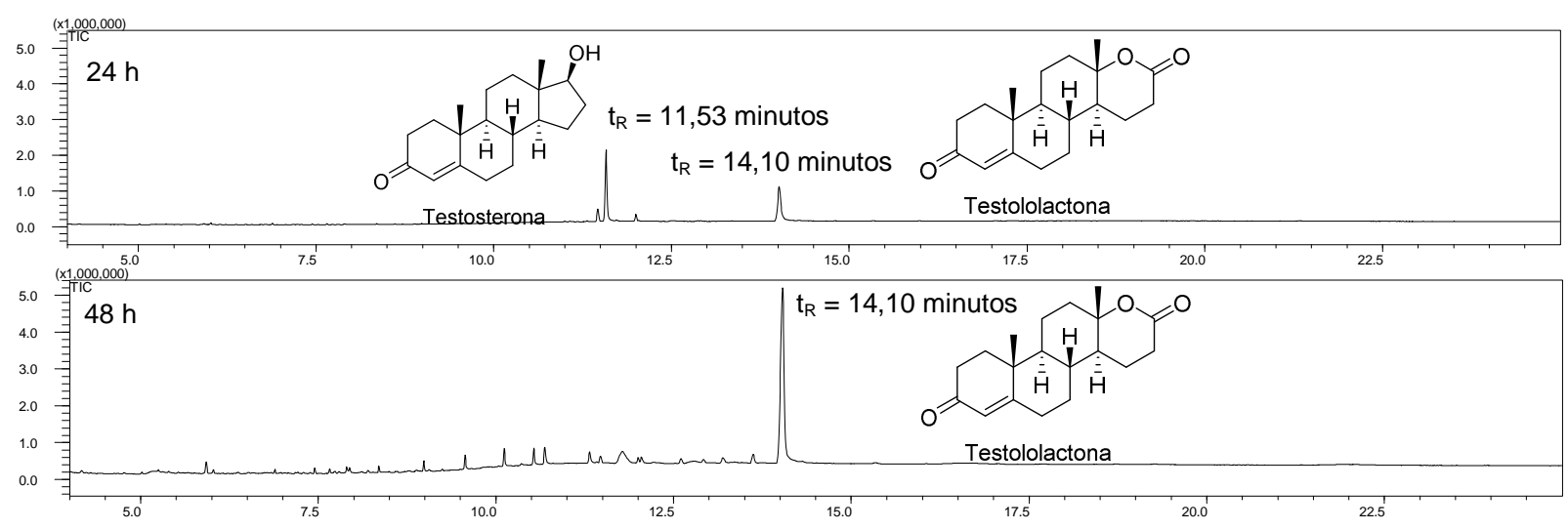

Como os cromatogramas da Figura 116 mostraram em 48 horas toda a progesterona foi bioconvertida à testololactona. A pequena diferença de tempo de retenção para a testosterona ocorreu em função do uso de uma nova coluna DB-5 ms que foi substituída no decorrer do trabalho. Contudo, os espectros de massas da testololactona foram idênticos aos espectros de massas do pico referente à testololactona isolada da reação como caldo enzimático do fungo $A$. sydowii CBMAI 935 (Seção D.5.3.6 - Figuras 55 e 57).

\section{D.5.5.2 Obtenção dos compostos 15 $\beta$-hidroxiprogesterona e da 7,15 di- hidroxiprogesterona}

As reações a seguir apresentam as enzimas envolvidas na hidroxilação da progesterona no carbono C-15 obtendo a 15 $\beta$-hidroxiprogesterona. Para o composto di-hidroxilado nos carbonos C-7 e C-15 obtido neste estudo (7,15-di-hidroxiprogesterona) não foram encontradas referências que descrevem alguma enzima que promova a hidroxilação da progesterona nos carbonos C-7 e C-15 simultaneamente. Também não foram encontradas referências na literatura a algum composto di-hidroxilado nos carbonos C-7 e C-15 que tenha sido obtido a partir da hidroxilação enzimática da $7 \beta$-hidroxiprogesterona ou da $15 \beta$-hidroxiprogesterona. Contudo, sugeriu-se que o mecanismo enzimático de hidroxilação de carbonos não ativados eletronicamente de esteroides é o que foi descrito na seção A.2.3 deste trabalho por Urlacher et al. $(2003)^{24}$ e representado na Figura 6 de acordo com Ener et al. (2010) ${ }^{25}$. Este mecanismo apresenta de modo geral a hidroxilação enzimática de compostos orgânicos por monoxigenases do citocromo P-450 e sugeriu-se que sejam estas enzimas que participaram das reações de hidroxilação da progesterona pelo caldo enzimático e pelo micéilo do fungo A. sydowii CBMAI 934. 
Jacobsen et al. (2006) ${ }^{107}$ observaram a hidroxilação da progesterona nos carbonos C-2 e C-15 utilizando uma monoxigenase do citocromo P-450 denominada CYP6A1 proveniente de Musca domestica (Esquema 33). Não foram encontradas referências na literatura a respeito da estrutura cristalina desta enzima.

Esquema 33. Obtenção da $2 \beta$-hidroxiprogesterona e $15 \beta$-hidroxiprogesterona utilizando a enzima CYP6A1

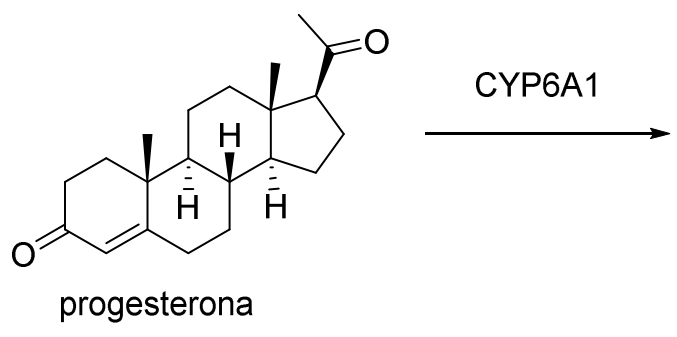

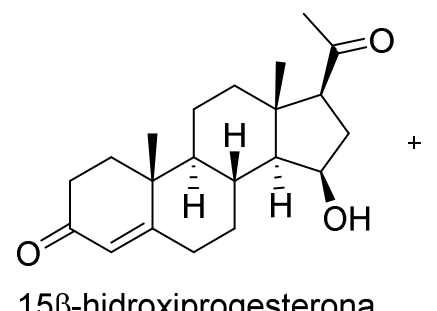

15ß-hidroxiprogesterona<smiles>CC(=O)[C@H]1CC[C@H]2[C@@H]3CCC4=CC(=O)[C@@H](O)C[C@]4(C)[C@H]3CC[C@]12C</smiles>

23-hidroxiprogesterona

Fonte: Adaptação de JACOBSEN et al. Structure and stereochemistry of products of hydroxylation of human steroid hormones by a housefly cytochrome P450 (CYP6A1). Magnetic Resonance in Chemistry, 2006, v. 44, n. 4, p. 470 .

Berg, Gustafsson e Ingelman-Sundberg (1979) $)^{108}$ verificaram uma enzima monoxigenase do citoromo P-450 proveninente de Bacillus megaterium denominada esteroide 15 $\beta$-monoxigenase EC 1.14.15.8 que na presença de megarredoxina reduzida promoveu a hidroxilação da progesterona no carbono C-15 (Esquema 34). A megarredoxina reduzida é uma proteína ferrossulfúrica do tipo flavoproteína que participa como uma enzima auxiliar na hidroxilação da progesterona produzindo $15 \beta$-hidroxiprogesterona ${ }^{108}$.

Esquema 34. Obtenção da 15 $\beta$-hidroxiprogesterona utilizando a enzima esteroide $15 \beta$-monoxigenase EC 1.14.15.8 na presença de megarredoxina reduzida.

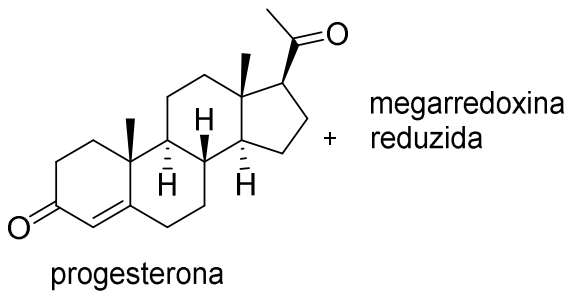

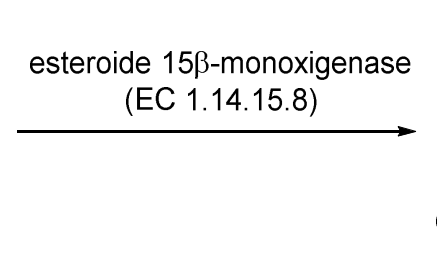

15ß-hidroxiprogesterona

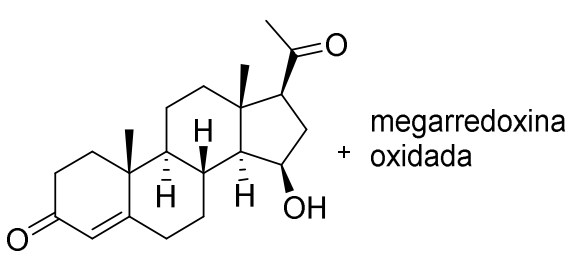

Para a megarredoxina reduzida não foram encontradas referências na literatura com relação a sua estrutura cristalina e, para a esteroide $15 \beta$-monoxigenase EC 1.14.15.8 não foram encontradas referências na literatura relacionadas a determinação experimental da estrutura desta enzima. Entretanto, por estudos teóricos combinados a dados experimentais de outras enzimas do citocromo P-450, cujas estruturas já foram determinadas, um modelo homólogo 
com a progesterona ancorada ao sítio ativo foi proposto por Lisurek et al.(2008) ${ }^{109}$, e então, determinaram a estrutura terciária desta enzima conforme mostra a Figura 118.

Figura 118. Estrutura terciária da enzima esteroide 15ß-monoxigenase EC 1.14.15.8 determinada computacionalmente $^{109}:$ (A) estrutura geral (B) progesterona ancorada ao sítio ativo da enzima

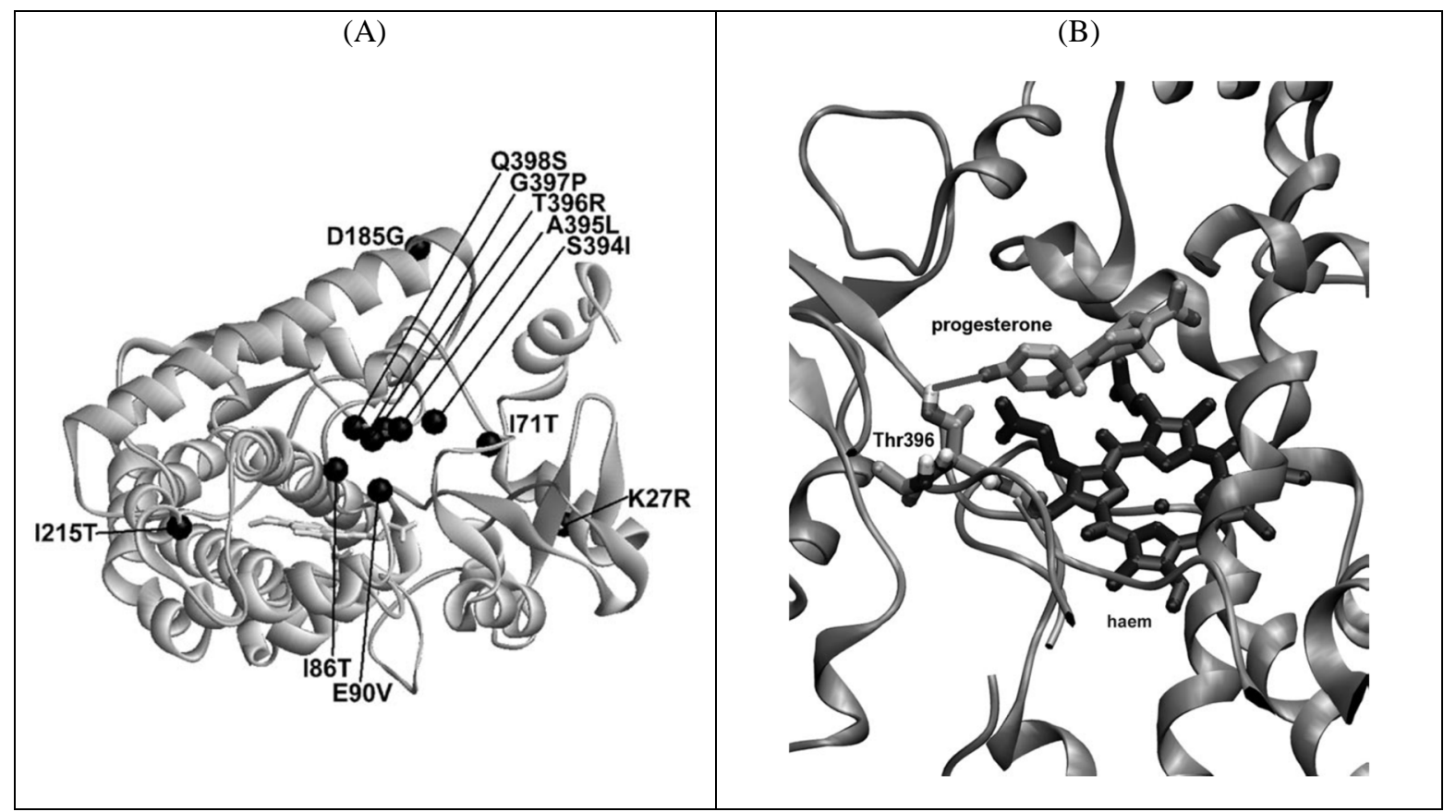

Fonte: Extraído de LISUREK, M. et al. Theoretical and Experimental Evaluation of a CYP106A2 Low Homology Model and Production of Mutants with Changed Activity and Selectivity of Hydroxylation. ChemBioChem., 2009, v.9, n.9, p. 1441 e 1443.

Como mostra a Figura 118B a progesterona, no sítio ativo, permanece ligada ao resíduo de treonina 396 próximo ao grupo HEME, que é o grupo prostético comum às enzimas do citocromo P-450 e responsável pelas oxidações catalíticas dos substratos.

Embora a $15 \beta$-hidroxiprogesterona seja descrita na literatura ${ }^{74,75,82}$ e tenham poucas descrições de sua obtenção por biocatálise ${ }^{83,84}$, pesquisando em bases de dados na internet como ChemSpider, PubChem, CheMBL, NIAID, Chembank, ChemlDplus, ToxNet, BindingDB, Drugbank, KEGG Drug, não foram encontradas referências relacionadas às propriedades biológicas deste composto. Isso pode ser devido à dificuldade de se obter este composto, mesmo por processos enzimáticos. 


\section{D.6 BIOTRANSFORMAÇÃO DO 17 $\alpha$-ETINILESTRADIOL}

O monitoramento dos meios reacionais (caldo enzimático e micélios) na ausência dos esteroides descrito na biotransformação da progesterona também foi feito visando a biotransformação do 17 1 -etinilestradiol. Logo, as discussões já feitas quanto a esse monitoramento são válidas para os estudos prévios da biotransformação desse composto.

Utilizando o 17 $\alpha$-etinilestradiol como substrato, a fim de verificar o perfil de biotransformação deste esteroide, foi feita uma triagem de reações utilizando tanto as massas miceliais, quanto os caldos enzimáticos das linhagens dos fungos A. sydowii CBMAI 935, $P$. oxalicum CBMAI 1185 e P. citrinum CBMAI 1186. O caldo enzimático e a massa micelial do fungo A. sydowii CBMAI 934 não foi utilizada nesta triagem para o $17 \alpha$-etinilestradiol.

Definiu-se excluir esta linhagem na triagem de biotransformação do $17 \alpha$-etinilestradiol porque nas triagens de biotransformação da progesterona (Seções D.5.1 e D.5.2) foi observado que nas reações empregando a massa micelial e o caldo enzimático da linhagem do fungo $A$. sydowii CBMAI 934 houve maior variedade de produtos de biotransformação em relação ao emprego da massa micelial e do caldo enzimático das linhages dos fungos A. sydowii CBMAI 935, P. oxalicum CBMAI 1185 e P. citrinum CBMAI 1186.

Além disso, nas biotransformações em quintuplicata da progesterona empregando o caldo enzimático e a massa micelial da linhagem do fungo A. sydowii CBMAI 934, (Seções D.5.3.1 e D.5.3.3) muitos produtos de biotransformação também foram observados (Figuras 47 e 51, Tabelas 8 e 11). Contudo, nos processos de purificação e isolamento dos produtos de biotransformação da progesterona utilizando o caldo enzimático e a massa micelial da linhagem do fungo A. sydowii CBMAI 934 (Seções D.5.3.2 e D.5.3.4), apenas dois produtos foram isolados: 7,15-di-hidroxiprogesterona, proveniente da reação com o caldo enzimático e $15 \beta$ hidroxiprogesterona, proveniente da reação com a massa micelial.

Sendo assim, na triagem de biotransformação do 17 $\alpha$-etinilestradiol, buscou-se empregar fungos que possivelmente promovessem uma biotransformação mais direcionada, ou seja, que não biotransformasse o substrato em muitos produtos, facilitando assim o processo de purificação por CC, evitando a obtenção de número muito grande de frações cromatográficas e o isolamento de uma quantidade pequena de produtos frente a grande variedade que poderia ser observada. Uma biotransformação mais direcionada foi observada justamente empregando as linhagens dos fungos A. sydowii CBMAI 935, P. oxalicum CBMAI 1185 e P. citrinum CBMAI 1186 nas triagens da biotransformação da progesterona, sendo apenas dois produtos observados: testosterona e testololactona e que foram obtidos e isolados das reações em 
quintuplicata da progesterona utilizando a linhagem do fungo A. sydowii CBMAI 935 (Seções D.5.3.5 - D.5.3.8)

\section{D.6.1 MONITORAMENTO DOS MEIOS REACIONAIS (CALDO ENZIMÁTICO E MASSA MICELIAL) NA PRESENÇA DO 17 $\alpha$-ETINILESTRADIOL}

Após 7 dias foram feitas análises de CG-EM dos extratos provenientes das triagens das reações utilizando os caldos enzimáticos (Figura 119) e da massa micelial (Figura 121) dos fungos empregados neste trabalho, exceto A. sydowii CBMAI 934, na presença do substrato. Foi feito também um controle abiótico que consistiu em um frasco Erlenmeyer contendo o substrato disperso no meio de cultura estéril na ausência dos microrganismos.

Figura 119. Cromatogramas obtidos da análise dos extratos em acetato de etila provenientes das triagens das reações de biotransformação do $17 \alpha$-etinilestradiol com os caldos enzimáticos dos fungos empregados neste trabalho após 7 dias de reação.
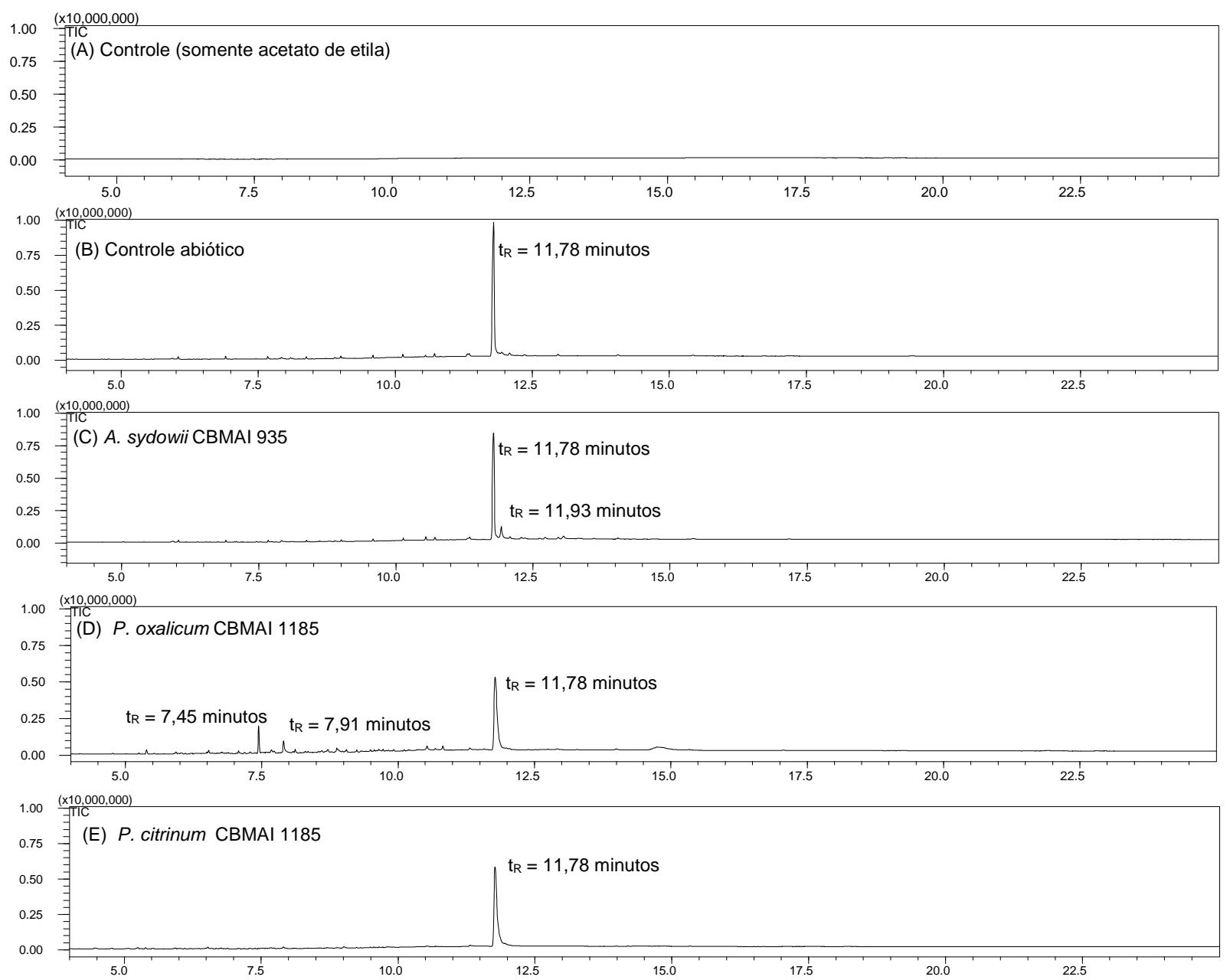
Em todos os cromatogramas o pico de $t_{R}=11,78$ minutos se refere ao substrato $17 \alpha$ etinilestradiol. O tempo de retenção está diferente do sinal observado no padrão $\left(t_{R}=11,96\right.$ minutos - Figura 31C) devido a utilização de uma nova coluna DB-5 ms que foi substituída no decorrer do trabalho. Os picos diferentes encontrados foram:

a) $t_{R}=11,93$ minutos no cromatograma do caldo enzimático do fungo A. sydowii CBMAI 935 (Figura 119C) que se referiu ao 9(1H)fenantrona,23,4,4a-tetra-hidro-1 $\alpha, 4 a . \beta-$ dimetil, pois, o espectro de massas experimental deste sinal apresentou $56 \%$ de similaridade com o espectro deste composto segundo a biblioteca WILEY8 (Figuras 120A e 120B).

b) $t_{R}=7,45$ minutos no cromatograma do caldo enzimático do fungo $P$. oxalicum CBMAI 1185 (Figura 119D) que refere se ao bis(2-etil-hexil)ftalato, pois, o espectro de massas experimental deste sinal apresentou $96 \%$ de similaridade com o espectro deste composto segundo a biblioteca NIST05 (Figura 120C e 120D). Tanto este sinal quanto o de $t_{R}=11,93$ minutos no cromatograma da Figura 119C foram relativos a compostos que não são metabólitos de biotransformação ou produtos naturais dos próprios fungos. Sugere-se então que sejam contaminantes externos;

c) $t_{R}=7,91$ minutos no cromatograma do caldo enzimático do fungo $P$. oxalicum CBMAI 1185 que se referiu ao ácido pentadecanoico, pois o espectro de massas deste sinal apresentou $90 \%$ de similaridade com este composto segundo a biblioteca NIST21 (Figuras $120 \mathrm{E}$ e 120F). Este é um ácido graxo encontrado no monitoramento das massas miceliais fúngicas na ausência dos esteroides (Seção D.4 Figuras 34, 35C e 35D), o que nos sugeriu que é um metabólito produzido pelo próprio fungo. 
Figura 120. Espectros de massas: $(70 \mathrm{eV})$ : (A) experimental para o composto de $t_{\mathrm{R}}=11,93$ minutos (fungo A. sydowii CBMAI 935), (B) 9(1H)fenantrona,23,4,4a-tetra-hidro-1 $\alpha, 4 a$. $\beta$-dimetil (similaridade 56\%, biblioteca WILEY 8), (C) experimental para o composto de $t_{R}=7,45$ minutos (fungo P. oxalicum CBMAI 1185), (D) bis(2-etil-hexil)ftalato (similaridade 96\%, biblioteca NIST05), (E) experimental para o composto de $\mathrm{t}_{\mathrm{R}}=7,45$ minutos (fungo P. oxalicum CBMAI 1185), (F) ácido pentadecanoico (similaridade 90\%, biblioteca NIST21).
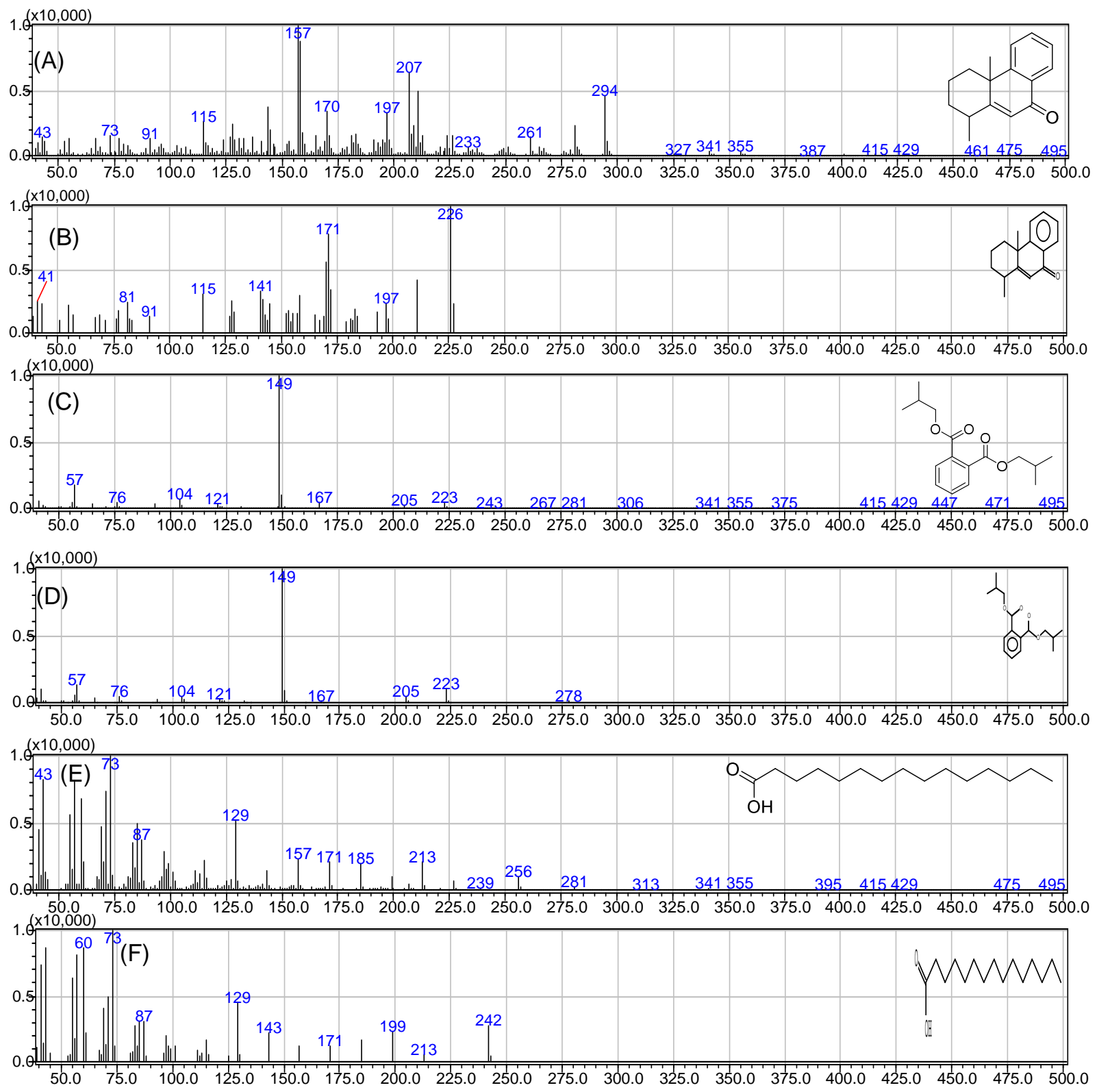
Figura 121. Cromatogramas obtidos da análise dos extratos em acetato de etila provenientes das triagens das reações de biotransformação do $17 \alpha$-etinilestradiol com a massa micelial dos fungos empregados neste trabalho após 7 dias de reação.
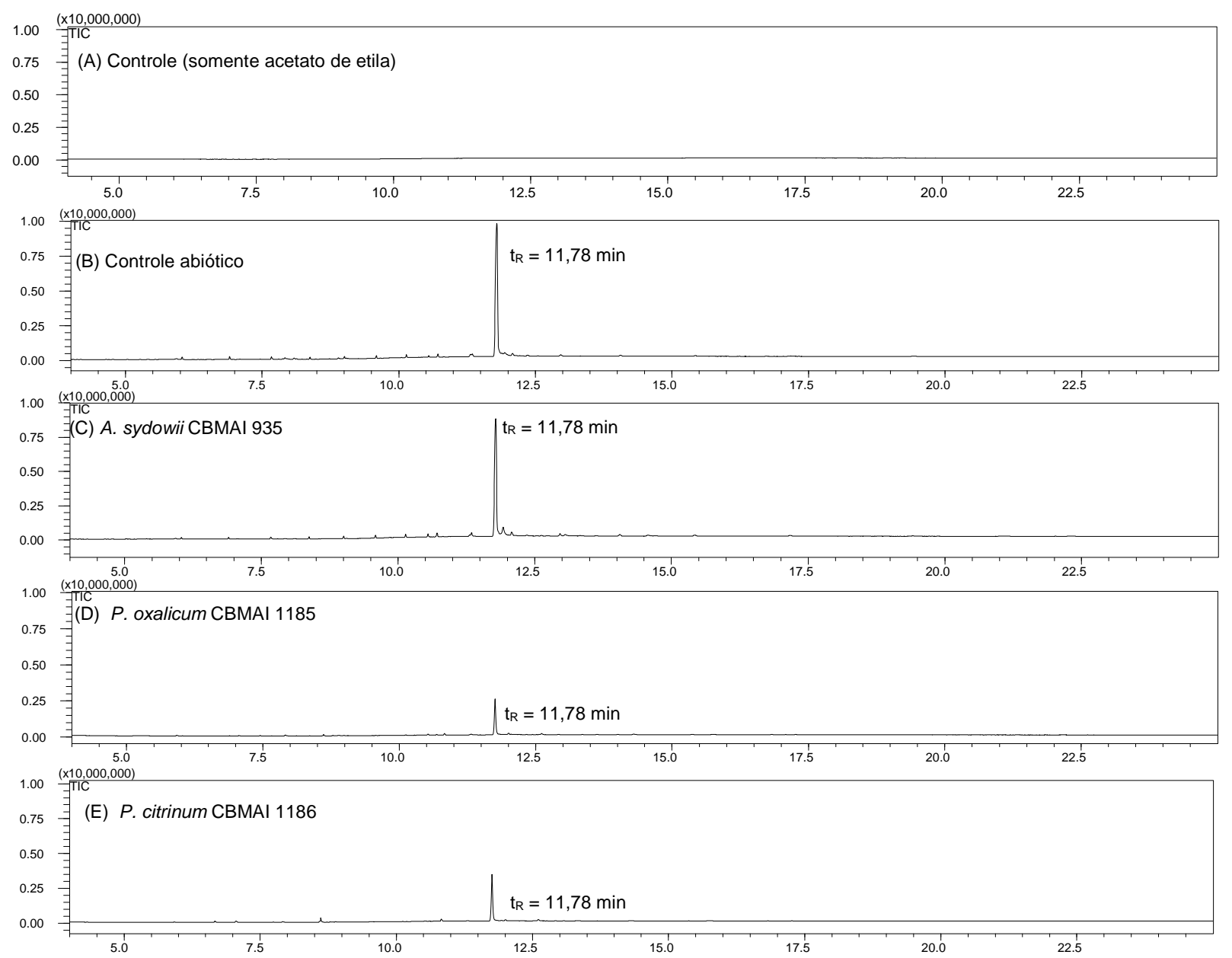

Todos os cromatogramas da Figura 121 apresentaram o pico referente ao substrato $17 \alpha-$ Etinilestradiol $\left(\mathrm{t}_{\mathrm{R}}=11,78 \mathrm{~min}\right.$.) e nenhum sinal diferente que indique algum produto de biotransformação.

Como os resultados mostraram, não ocorreu a biotransformação do $17 \alpha$-Etinilestradiol nos meios reacionais dentro das condições estabelecidas $\left(32^{\circ} \mathrm{C}, 130 \mathrm{rpm}, \mathrm{pH} \mathrm{7,4,} 7\right.$ dias de reação) em quantidades apreciáveis. Comparando com os resultados da triagem de biotransformação da progesterona com os fungos em questão na triagem do $17 \alpha$-Etinilestradiol, observou-se que estes fungos promoveram reações de oxidação, de Baeyer-Villiger e hidrólise no carbono C-17 da progesterona. Na estrutura do $17 \alpha$-etinilestradiol e, como o próprio nome do composto sugere, ao carbono C-17 está ligado um grupo etinil na posição $\alpha$. Entende-se que este grupo promove um impedimento estéreo impossibilitando que o sítio ativo da(s) enzima(s) promova as reações de biotransformação neste ponto da molécula. 
Contudo, existem referências na literatura que mostram a biotransformação do $17 \alpha$ etinilestradiol por enzimas do citocromo P-450. Guenguerich (1988) $)^{110}$ observou a hidroxilação deste esteroide no carbono C-2 do núcleo fenólico (anel A) obtendo o 2-Hidroxi,17 $\alpha$ etinilestradiol (2-OH EE) em $\mathrm{pH} 7,4$, temperatura de $37^{\circ} \mathrm{C}$, tampão fosfato, NADPH como cofator utilizando a enzima P-450 $0_{\mathrm{NF}}$ encontrada em microssomos de células humanas. O processo ocorreu por 10 minutos e teve um rendimento de $90 \%$ (Esquema 35).

Esquema 35. Biotransformação do $17 \alpha$-Etinilestradiol utilizando a enzima P-450 $0_{\mathrm{NF}}$ e NADPH.

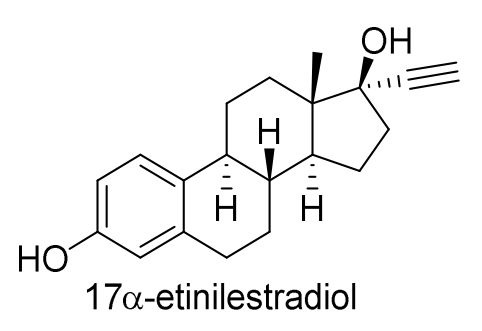

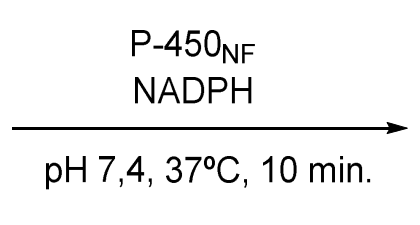

$\mathrm{pH} 7,4,37^{\circ} \mathrm{C}, 10 \mathrm{~min}$<smiles>C#C[C@]1(O)CC[C@H]2[C@H]3CCc4cc(O)c(O)cc4[C@H]3CC[C@]21C</smiles>

2-hidroxi, $17 \alpha$-etinilestradiol $r=90 \%$

Em 1990, Guengerich publicou uma proposota que mostra o metabolismo completo deste esteroide em humanos ${ }^{111}$ (Esquema 36). Nota-se que o 17 1 -etinilestradiol também é uma espécie de prófarmaco da estrona, que também é um contraceptivo e um produto de reação de oxidação do substrato no carbono C-17. 
Esquema 36. Rotas envolvidas no metabolismo do $17 \alpha$-etinilestradiol em humanos. As rotas mais proeminentes são indicadas com setas cheias ${ }^{111}$.

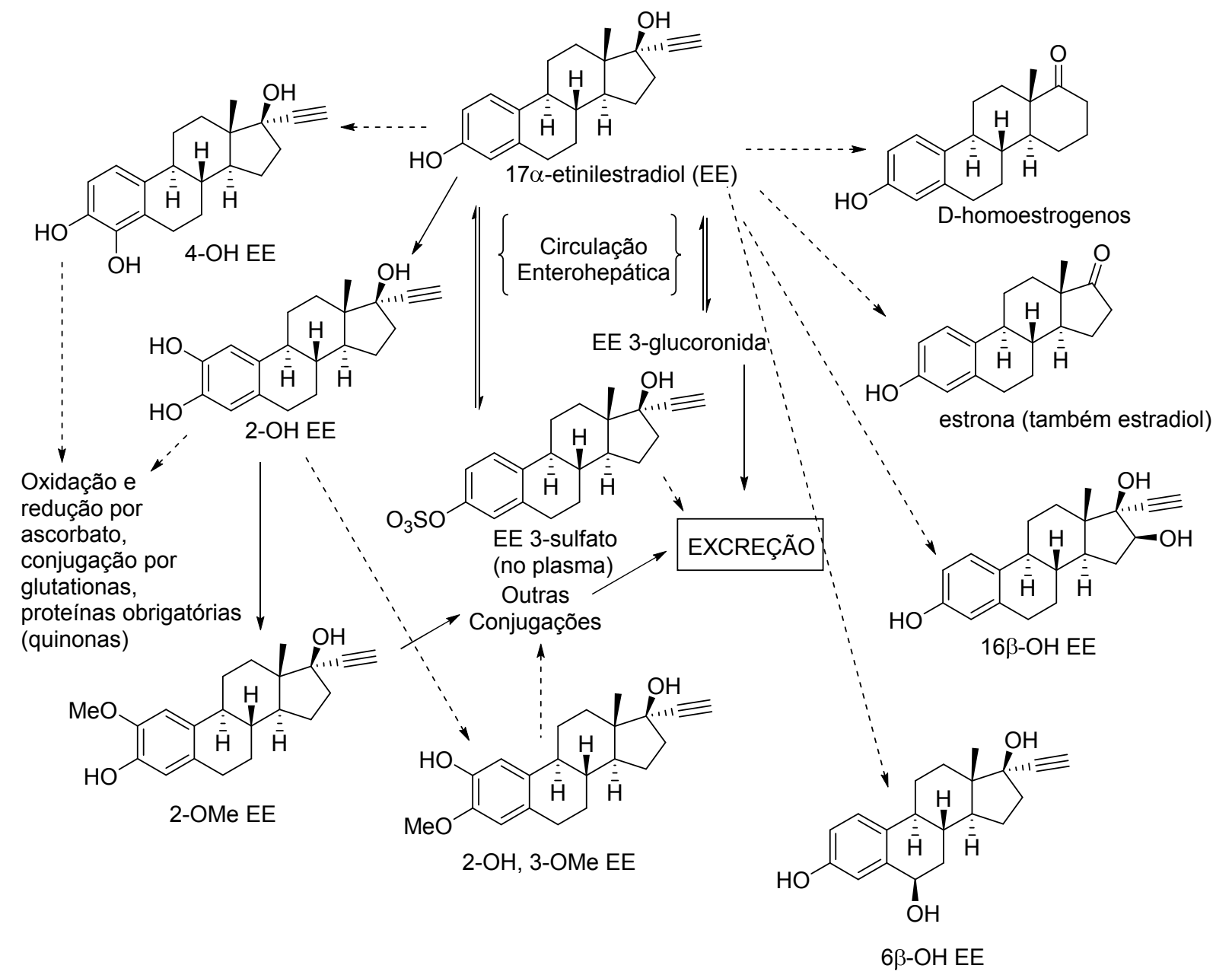

Fonte: Extraído de GUENGERICH, F.P. Metabolism of 17 $\alpha$-Ethynylestradiol in humans. Life Sciences, 1990, v.47, n.22, p. 1982.

Os dados da literatura mostram que as biotransformações do $17 \alpha$-etinilestradiol são principalmente reações de hidroxilação e os carbonos que sofreram esse tipo de oxidação não tinham algum impedimento estéreo. Reações do tipo Baeyer-Villiger são descritas na literatura $^{110}$, porém produtos deste tipo de oxidação não foram observados nas triagens. Sendo assim entendeu-se que o sistema enzimático desses fungos, nas condições experimentais deste estudo pode efetuar reações de oxidação, Baeyer-Villiger no carbono C-17 de esteroides, desde que este carbono esteja desimpedido estericamente. 


\section{E. CONCLUSÕES}

Nas biotransformações da progesterona, tanto com os caldos enzimáticos quanto com as massas miceliais das linhagens dos fungos A. sydowii CBMAI 935, P. oxalicum CBMAI 1185 e P. citrinum CBMAI 1186 foram obtidos metabólitos de oxidação de Baeyer Villiger: testosterona e testololactona. Estes dois produtos foram observados concomitantemente nas biotransformações utilizando o caldo enzimático. Nas biotransformações utilizando a massa micelial somente a testololactona foi observada. Esses resultados sugerem que as enzimas que promoveram as biotransformações que levam a obtenção desses metabólitos são do tipo BaeyerVilliger monoxigenases dependentes de cofatores como $\mathrm{NADP}^{+}$e flavinas.

Tanto com o caldo enzimático, quanto com a massa micelial da linhagem do fungo $A$. sydowii CBMAI 934 foram observados produtos de hidroxilação na biotransformação da progesterona. Na reação com o caldo enzimático foi isolado a 7,15-di-hidroxiprogesterona, não sendo possível determinar as configurações dos grupos hidroxilas e, na reação com a massa micelial, foi isolado a $15 \beta$-hidroxiprogesterona. Esses resultados sugerem que as enzimas que promovem as biotransformações que levam a esses produtos são do tipo hidroxilases pertencentes a monoxigenases do citocromo P450. Essas enzimas não são obrigatoriamente dependetes de cofatores não ligados às enzimas, uma vez que esta possui um grupo prostético do tipo HEME que é o sítio ativo da enzima.

Nas condições estabelecidas através da triagem para biotransformação do $17 \alpha$ etinilestradiol utilizando tanto as massas miceliais, quanto os caldos enzimáticos, das linhagens dos fungos A. sydowii CBMAI 935, P. oxalicum CBMAI 1185 e P. citrinum CBMAI 1186, não foram observados produtos de biotransformação. Sugeriu-se que o sistema enzimático presente nesses fungos promoveram reações de oxidação Baeyer-Villiger no carbono C-17 de esteroides desde que este carbono esteja estericamente desimpedido, o que não ocorre devido ao grupo etinil ligado na posição $\alpha$ ao carbono C-17 do $17 \alpha$-etinilestradiol.

Considerando que os meios reacionais utilizados neste estudo mimetizaram o ambiente marinho, as linhagens de fungos utilizadas que promoveram as biotransformações da progesterona são típicas desse ambiente que, por sua vez, é o receptáculo final do descarte de resíduos farmacêuticos produzidos pelo ser humano, este trabalho fornece uma ideia das reações de biotransformação de tais fármacos no ambiente marinho. Levando em conta as atividades biológicas conhecidas e suspeitas dos compostos isolados neste estudo, indaga-se 
sobre os impactos ambientais e aos problemas na saúde humana que podem ocorrer no meio ambiente, uma vez que algumas referências deste trabalho sugerem uma relação destes problemas com o aumento do consumo e do descarte indevido destes compostos. 


\section{F. PERSPECTIVAS}

A partir da metodologia e dos resultados obtidos deste trabalho, outras linhas de trabalho podem ser trilhadas no que tange a biotransformação de fármacos esteroidais, podendo listar algumas:

- biotransformação do $17 \alpha$-etinilestradiol utilizando a linhagem do fungo A. sydowii CBMAI 934, para verificar se assim como na biotransformação da progesterona, são observados produtos de hidroxilação;

- biotransformação de fármacos esteroidais utilizando enzimas isoladas ou imobilizadas do tipo Baeyer-Villiger monoxigenases e hidroxilases, variando as condições de reação;

- biotransformação dos fármacos deste estudo com fungos de outros gêneros encontrados no ambiente marinho como Bostriophaera, Eutypella, Xylaria, Rhizopus.

- identificação de compostos esteroidais em amostras ambientais in natura e adicionar essas amostras a meios reacionais semelhantes aos empregados neste trabalho, simulando o ambiente marinho a fim de estudar de forma mais objetiva o processo de biotransformação destes compostos no ambiente marinho;

- estudo, otimização e desenvolvimento em escala piloto, seguindo os princípios da Química Verde, para produção dos metabólitos obtidos neste estudo a partir da biotransformação da progesterona visando a aplicação e desenvolvimento de processos industriais para obtenção destes esteroides de acordo com as demandas da indústria farmacêutica. Vale lembrar que as condições estabelecidas neste estudo na biotransformação da progesterona não são severas o que atende as demandas da indústria farmacêutica na economia de energia. 


\section{G. REFERÊNCIAS}

1. BUCHHOLZ, K.B.; POULSEN, P.B. Introduction. In: STRAATHOF, A. J. J.; ADLERCREUTZ, P. (Ed.). Applied biocatalysis. Amsterdam: Harwood Academic, 2000. $443 \mathrm{p}$.

2. LENARDÃO, E.J.; FREITAG, R.A.; DABDOUB, M.J; BATISTA, A.C.F. 'Green Chemistry' - Os 12 princípios da química verde e sua inserção nas atividades de ensino e pesquisa. Química Nova, v. 26, n. 1, p. 123-129, 2003.

3. VERT, M.; DOI, Y.; HELLWICH, K.; HESS, M.; HODGE P.; KUBISA, P.; RINAUDO, M. SCHOUÉ, F. Terminology for biorelated polymers and applications (IUPAC

Recommendations 2012). Pure and Applied Chemistry, v. 84, n. 2, p. 377-410, 2012.

4. SATO, S. Produção de esteroides. In: LIMA, U.A.; AQUARONE, E.; BORZANI, W.; SCHIMIDELL, W. Biotecnologia industrial: processos fermentativos e enzimáticos. São Paulo: Edgard Blücher, 2001. v. 3, p. 179-197.

5. TALAFOUS, J.; SAYRE, L. M.; MIEYAL, J. J.; KLOPMAN, G. Meta 2 a dictionary model of mammalian xenobiotic metabolism. Journal of Chemical Information and Computer Sciences, v. 34, n. 6, p. 1326-1333, 1994.

6. BORGES, K. B. Análise estereosseletiva da tioridazina e seus principais metabólitos: um estudo cinético de biotransformação empregando fungos. 2006. 155f. Dissertação (Mestrado em Toxicologia) - Faculdade de Ciências Farmacêuticas de Ribeirão Preto, Universidade de São Paulo, Ribeirão Preto, 2006.

7. BORGES, K. B. Análise estereosseletiva de fármacos com aplicação em estudos de biotransformação empregando fungos. 2010. 65f. Tese (Doutorado em Ciências Toxicologia) - Faculdade de Ciências Farmacêuticas de Ribeirão Preto, Universidade de São Paulo, Ribeirão Preto, 2010.

8. HULT, K.; BERGLUND, P. Enzyme promiscuity: mechanism and applications. Trends in Biotechnology, v. 25, n. 5, p. 231-238, 2007.

9. LIESSE, A.; SEELBACH, K; WANDREY, C. Industrial biotransformations. Weinheim: Wiley-VCH, 2006. 556 p.

10. SATO, S. Produção de antibióticos. In: LIMA, U.A.; AQUARONE, E.; BORZANI, W.; SCHIMIDELL, W. Biotecnologia industrial: processos fermentativos e enzimáticos. São Paulo: Edgard Blücher, 2001. v. 3, p. 101-124. 
11. OTTEN, S.; ROSAZZA, J.P. Microbial transformations of natural antitumor agents: coversion of Lapachol to Dehydro- $\alpha$-Lapachone by Curvularia lunata. Applied and Environmental Microbiology, v. 38, n. 2, p.311-313, 1979.

12. BARREIRO, E. J.; SILVA, J. F. M.; FRAGA, C. A. M. Noções básicas de metabolismo de fármacos. Química Nova, v. 19, n. 6, p. 641-650, 1996.

13. GRUNWALD, P. Biocatalysis-biochemical fundamental and applications. London: Imperial College, 2009. 1035 p.

14. NELSON, D.L.; COX, M.M. Lehninger: principios de bioquímica. Tradução de Fabiana Horn. $5^{\text {a }}$ ed. Porto Alegre, Artmed, 2011. 1274p.

15. BLANK, L. M.; BUEHLER, K.; BUHLER, B.; EBERT, B. E. Redox biocatalysis and metabolism: molecular mechanisms and metabolic network analysis. Antioxidants \& Redox Signaling, v. 13, n. 3, p. 349-394, 2010.

16. MARTINS, M. P. Resolução cinética de haloidrinas racêmicas com a lipase B de Candida antarctica e biotransformação de produtos naturais por micro-organismos. 2012. 170f. Tese (Doutorado em Ciências - Fisico-Química) - Instituto de Química de São Carlos, Universidade de São Paulo, São Carlos, 2012).

17. BOLLINGER JR, J.; M.; BRODERICK, J. B. Frontiers in enzymatic C-H-bond activation. Current Opinion in Chemical Biology, v. 13, n. 1, p. 51-57, 2009.

18. BURTON, S. G. Oxidizing enzymes as biocatalysts. Trends in Biotechnology, v. 21, n. 12, p. 543-549, 2003.

19. KAMERBEEK, N. M.; JANSSEN, D. B.; VAN BERKEL, W. J. H.; FRAAIJE, M. W. Baeyer-Villiger monooxygenases, an emerging family of flavin-dependent biocatalysts. Advanced Synthesis \& Catalysis, v. 345, n. 6-7, p. 667-678, 2003.

20. ARCHELAS, A.; FURSTOSS, R. Synthesis of enantiopure epoxides through biocatalytic approaches. Anual Review of Microbiology, v. 51, n .1, p. 491-525, 1997.

21. ULLRICH, R.; HOFRICHTER, M. Enzymatic hydroxylation of aromatic compounds. Cellular and Molecular Life Sciences, v. 64, n. 3, p. 271-293, 2007.

22. BURTON, S. G. Laccases and phenol oxidases in organic synthesis - a review. Current Organic Chemistry, v. 7, n. 13, p. 1317-1331, 2003. 
23. VAN DEN HEUVEL, R. H. H.; FRAAIJE, M. W.; MATTEVI, A.; LAANE, C.; VAN BERKEL, W. J. H. Vanillyl-alcohol oxidase, a tasteful biocatalyst. Journal of Molecular Catalysis B. Enzymatic, v. 11, n. 4-6, p. 185-188, 2001.

24. URLACHER, V. B.; LUTZ-WAHL, S.; SCHMID, R. D. Microbial P450 enzymes in biotechnology. Applied Microbiology and Biotechnology, v. 64, n. 3, p. 317-325, 2004.

25. ENER, M. E.; LEE, Y.; WINKLER, J. R.; GRAY; H. B.; CHERUZEL, L. Photooxidation of cytochrome P450-BM3. Procedings of the National Academy of Sciences of the United States of America, v. 107, n. 44, p. 18783-18786, 2010.

26. OMURA, T.; SATO, R. The carbon monoxide-binding pigment of liver microsomes I. evidence for its hemoprotein nature. Journal of Biological Chemistry, v. 239, n. 7, p. 2370 2378, 1964.

27. KOYMANS, L.; DONNÉ-OP DEN KELDER, G. M.; TE KOPPELE, J. M.; VERMEULEN, N. P. E. Cytochromes P450: their active-site structure and mechanism of oxidation. Drug Metabolism Reviews., v. 25, n. 3, p. 325-387, 1993.

28. MARZZOCO, A; TORRES, B. B. Bioquímica básica. $2^{\mathrm{a}}$ Ed. Rio de Janeiro: Guanabara Koogan, 1999, 360 p.

29. GOEPTAR, A. R.; SCHEERENS, H.; VERMEULEN, N. P. E. Oxygen and xenobiotic eeductase activities of cytochrome P450. Critical Reviews in Toxicology, v. 25, n. 1, p. 2565, 1995.

30. HOGSON, E; LEVI, P.E. Introduction to biochemical toxicology. $2^{\text {a }}$ Ed. Connecticut: Appleton and Lange, 1994, 588 p.

31. GARCIA, A. K. Avaliação da atividade lipolítica de fungos filamentosos da costa brasileira. 2011. 56f. Dissertação (Mestrado em Biotecnologia) - Instituto Butantan, Instituto de Pesquisas Tecnológicas, Universidade de São Paulo, São Paulo, 2011.

32. XIE, L; WANG, G.; ZHANG, H.; OUYANG, Y; SUN, W.; LI, X. Microbial biotransformation of water-insoluble Herbimycin A to 11-Hydroxy-(11-demethoxy)herbimycin C by Eupenicillium sp. SD017. Journal of Molecular Catalysis B. Enzymatic, v. 62, n. 1, p. 75-79, 2010.

33. KENNEDY, J.; MARCHESI, J. R.; DOBSON, A. D. Marine metagenomics: strategies for the discovery of novel enzymes with biotechnological applications from marine environments. Microbial Cell Factories, v. 7, n. 27 p. 1-8, 2008. 
34. WHITMAN, W. B.; COLEMAN, D. C.; WIEBE, W. J. Prokaryotes: the unseen majority. Procedings of the National Academy of Sciences of the United States of America, v. 95, n. 12, p. 6578-6583, 1998.

35. LOQUE, C. P. Fungos associados à macroalgas do litoral do Paraná e Península Antártica. 2009. 77f. Dissertação (Mestrado em Ecologia - Ciências Biológicas) - Instituto de Ciências Exatas e Biológicas, Universidade Federal de Ouro Preto, Ouro Preto, 2009

36. MARTINS, M. P.; MOUAD, A. M.; BOSCHINI, L.; SELEGHIM, M. H. R; PORTO, A.L.M. Marine fungi Aspergillus sydowii and Trichoderma sp. Catalyze the hydrolysis of Benzyl-glycidyl-ether. Marine Biotechnology, v. 13, n. 2, p. 314-320, 2010).

37. SILVA, N. A. Biodegradação dos pesticidas clorpirifós, metil paration e profenofós por fungos de origem marinha. 2013. 161f. Dissertação (Mestrado em Ciências - Química Orgânica e Biológica) - Instituto de Química de São Carlos, Universidade de São Paulo, São Carlos, 2013.

38. SILVA, N.A.; BIROLLI, W. G.; SELEGHIM, M. H. R.; PORTO, A. L. M. Biodegradation of the organophosphate pesticide Profenofos by marine fungi. In: PATIL, Y. B.; RAO, P. Applied bioremediation: active and passive approaches. Rijeka: InTech, 2013. p. 147-178.

39. ALVARENGA, N.; BIROLLI, W. G.; SELEGHIM, M. H. R.; PORTO, A. L. M. Biodegradation of Methyl-parathion by whole cells of marine-derived fungi Aspergillus sydowii and Penicillium decaturense. Chemosphere, v. 117, p. 47-52, 2014.

40. MARTINS, M. P.; OUAZZANI, J.; ARLICE, G.; JELLER, A. H.; DE LIMA, J.P.F.; SELEGHIM, M.H.R.; OLIVEIRA, A.L.L.; DEBONSI, H.M.; VENÂNCIO, T. YOKOYA, N.S.; FUJII, M.T.; PORTO, A.L.M. Biohydroxylation of (-)-Ambrox®, (-)-Sclareol, and (+)Sclareolide by Whole Cells of Brazilian Marine-Derived Fungi. Marine Biotechnology, v. 17, n. 2, p. 211-218, 2015.

41. HILL, R.A.; KIRK, D.N.; MAKIN, H.L.J.; MURPHY, G.M. Dictionary of steroids chemical data, structures and bibliographies. London: Chapman \& Hall, 1991. v. 1.

42. RYAN, K. J. Biochemistry of aromatase: significance to female reproductive physiology. Cancer Research, v. 42, n. 8s, p. 3342s-3344s, 1982.

43. TORRES, N. H. Monitoração de resíduos dos hormônios 17 $\alpha$-Etinilestradiol, 17 $\beta$ estradiol e estriol em águas de abastecimento urbano da cidade de Piracicaba, SP. 2009. 83f. Dissertação (Mestrado em Ciências - Química na Agricultura e no Ambiente) - Centro de Energia Nuclear na Agricultura, Universidade de São Paulo, Piracicaba, 2009. 
44. PHILLIPS, A.; HAHN, D. W.; KLIMEK, S.; MCGUIRE, J. L. A comparison of the potencies and activities of progestogens used in contraceptives. Contraception, v. 36, n. 2, p. 181-192, 1987.

45. NOBEL PRIZE. Stockholm: The Royal Swedish Acabemy of Sciences, 2015. Apresenta os laureados em 1950 pelo Prêmio Nobel em Medicina. Disponível em:

http://www.nobelprize.org/nobel_prizes/medicine/laureates/1950/. Acesso em: 01 set. 2015

46. ŽNIDARŠIČ-PLAZL, P.; PLAZL, I. Development of a continuous steroid biotransformation process and product extraction within microchannel system. Catalysis Today, v. 157, n. 1-4, p. 315-320, 2010.

47. SONOMOTO, K.; HOQ, M. M.; TANAKA, A.; FUKUI, S. 11ß-Hydroxylation of cortexolone (Reichstein Compound $\mathrm{S}$ ) to hydrocortisone by Curvularia lunata entrapped in Photo-Cross-Linked Resin Gels. Applied and Environmental Microbiology, v. 45, n. 2, p. 436-443, 1983.

48. FRIED, J.; PERLMAN, D. 16a-hydroxylation steroids. US n. 2855343, 7 out. 1958.

49. MANOSROI, J.; ABE, M.; MANOSROI, A. Biotransformation of steroidal drugs using microorganisms screened from various sites in Chiang Mai, Thailand. Bioresource

Technology, v. 69, n. 1, p. 67-73, 1999.

50. SEBEK, O.K.; SPERO, G.B. 6-methyl-1-dehydro analogues of cortisone, hydrocortisone and 21-esters thereof. US n. 2897218, 28 jul. 1959.

51. NOBILE, A.; CHARNEY, W.; PERLMAN, P.L.; HERZOG, H.L.; PAYNE, C.C.; TULLY, M.E., JEVNIK, M.A. HERSHBERG, E.B. Microbiological transformation of steroids. I. $\Delta$ 1,4-diene-3-ketosteroids. Journal of the American Chemical Society, v. 15, n. 77, p. 4184-4184, 1955.

52. STOELWINDER, J.; VAN ZOEST, W.J.; VAN LEUSEN, A.M. Chemistry of N,Pacetals: Applications to the synthesis of 20-ketosteroids. The Journal of Organic Chemistry, v. 57, n. 8, p. 2249-2252, 1992.

53. INSTITUTO BRASILEIRO DE GEOGRAFIA E ESTATÍSTICA (IBGE). Síntese de indicadores sociais, 2006. Rio de Janeiro: Instituto Brasileiro de Geografia e Estatística, 2006, 317 p.

54. RADKE, M.; ULRICH, H.; WURM, C.; KUNKEL, U. Dynamics and attenuation of acidic pharmaceuticals along a river stretch. Environmental Science \& Technology, v. 44, n. 8, p. 2968-2974, 2010. 
55. ESCHER, B. I.; PRONK, W.; SUTER, M. J.-F.; MAURER, M. Monitoring the removal efficiency of pharmaceuticals and hormones in different treatment processes of sourceseparated urine with bioassays. Environmental Science \& Technology, v. 40, n, 16, p. 5095-5101, 2006.

56. MACLEOD, S. L.; WONG, C. S. Loadings, trends, comparisons, and fate of achiral and chiral pharmaceuticals in wastewaters from urban tertiary and rural aerated lagoon treatments.

Water Research, v. 44, n. 2, p. 533-544, 2010.

57. FERREIRA, M.G.M, Remoção da atividade estrogênica de $17 \beta$-Estradiol e $17 \alpha$ Etinilestradiol pelos processos de ozonização e $\mathbf{O}_{3} / \mathbf{H}_{2} \mathbf{O}_{2}$. 2008. 192f. Tese (Doutorado em Ciências - Engenharia Química) - Coordenação dos Programas de Pós-gradualçao de Engenharia da Universidade Federal do Rio de Janeiro. Rio de Janeiro, 2008

58. HARRISON, P. T. C.; HOLMES, P.; HUMFREY, C. D. N. Reproductive health in humans and wildlife: are adverse trends associated with environmental chemical exposure? Science of The Total Environment, v. 205, n. 2-3, p. 97-106, 1997.

59. SNYDER, S. A.; WESTERHOFF, P.; YOON, Y.; SEDLAK, D. L. Pharmaceuticals, personal care products, and endocrine disruptors in water: Implications for the water industry. Environmental Engineering Science, v. 20, n. 5, p. 449-469, 2003.

60. FERREIRA, I. M.; MEIRA, E. B.; ROSSET, I. G.; PORTO, A. L. M. Chemoselective biohydrogenation of $\alpha, \beta$ - and $\alpha, \beta, \gamma, \delta$-unsaturated ketones by the marine-derived fungus Penicillium citrinum CBMAI 1186 in a biphasic system Journal of Molecular Catalysis B. Enzymatic, v. 115, p. 59-65, 2015.

61. OLIVEIRA, J. R. DE; SELEGHIM, M. H. R.; PORTO, A. L. M. Biotransformation of methylphenylacetonitriles by brazilian marine fungal strain Aspergillus sydowii CBMAI 934: eco-friendly reactions Marine Biotechnology, v. 16, n. 2, p. 156-160, 2014.

62. BIROLLI, W. G.; FERREIRA, I.M.; ALVARENGA, N.; SANTOS, D.A.; DE MATOS, I.L.; COMASSETO, J.V.; PORTO, A.L.M. Biocatalysis and biotransformation in Brazil: An overview. Biotechnology Advances, v. 33, n. 5, p. 481-510, 2015.

63. FERREIRA, I.M.; ROCHA, L.C.; YOSHIOKA, S.A.; NITSCHKE, M., JELLER, A.H., PIZZUTI, SELEGHIM, M.H.R., PORTO, A.L.M. Chemoselective reduction of chalcones by whole hyphae of marine fungus Penicillium citrinum CBMAI 1186, free and immobilized on biopolymers. Biocatalysis and Agricultural Biotechnology, v. 3, n. 4, p. 358-364, 2014.

64. ROCHA, L.C.; LUIZ, R.F., ROSSET, I.G., RAMINELLI, C. SELEGHIM, M.H.R., SETTE, L.D. PORTO, A.L.M Bioconversion of iodoacetophenones by marine fungi. Marine biotechnology, v. 14, n. 4, p.396-401, 2012. 
65. GOMES, P.C.F.L.; BARNES, B. B.; SANTOS-NETO, Á. J.; LANÇAS, F. M.; SNOW, N. H. Determination of steroids, caffeine and methylparaben in water using solid phase microextraction-comprehensive two dimensional gas chromatography-time of flight mass spectrometry. Journal of Chromatography A, v. 1299, p. 126-130, 2013.

66. HANSON, J.R. The chemistry fungi. Cambridge: RSC, 2008. 221 p.

67. LORENZETI, F. M.; LIMA, W.P.; ZANUTO, R.; CARNEVALI JÚNIOR, L.C.; CHAVES, D.F.S.; LANCHA JÚNIOR, A.H. O exercício físico modulando alterações hormonais em vias metabólicas dos tecidos musculoesquelético, hepático e hipotalâmico relacionado ao metabolismo energético e consumo alimentar. Revista Brasileira de Fisiologia do Exercício, v. 10, n. 3, p. 172-177, 2011.

68. YANG, B.; WANG, Y.; CHEN, X.; FENG, J.; WU, Q.; ZHU, D.; MA, Y. Biotransformations of steroids to Testololactone by a multifunctional strain Penicillium simplicissimum WY134-2. Tetrahedron, v. 70, n.1, p. 41-46, 2014.

69. HU, S.; GENAIN, G.; AZERAD, R. Microbial transformation of steroids: Contribution to 14a-hydroxylations. Steroids, v. 60, n.4, p. 337-352, 1995.

70. MOHAMED, S. S.; EL-REFAI, A.-M. H.; HASHEM, A.-G. M.; ALI, H. A. Approaches to improve the solubility and availability of Progesterone biotransformation by Mucor racemosus. Biocatalysis and Biotransformation v. 32, n. 3, p. 141-150, 2014.

71. SILVERSTEIN, R.M.; WEBSTER, F.X.; KIEMLE, D.J. Identificação espectrométrica de compostos orgânicos. Tradução de Ricardo Bicca de Alencastro. 6. Ed. Rio de Janeiro: LTC, 2006. 490p.

72. KOLET, S. P.; HALDAR, S.; NILOFERJAHAN, S.; THULASIRAM, H. V. Mucor hiemalis mediated $14 \alpha$-hydroxylation on steroids: In vivo and in vitro investigations of $14 \alpha-$ hydroxylase activity. Steroids, v. 85, p. 6-12, 2014.

73. KIRK, D. N.; TOMS, H. C. $\omega 1$-Decoupled ${ }^{1} \mathrm{H}$ homonuclear shift-correlated nuclear magnetic resonance spectroscopy (COSYDEC) applied to steroids. Steroids, v. 56, n. 4, p.195-200, 1991.

74. JANECZKO, T.; ŚWIZDOR, A.; DMOCHOWSKA-GŁADYSZ, J.; BIAŁOŃSKA, A.; CIUNIK, Z.; KOSTRZEWA-SUSŁOW, E. Novel metabolites of dehydroepiandrosterone and progesterone obtained in Didymosphearia igniaria KCH 6670 culture. Journal of Molecular Catalysis B. Enzymatic, v. 82, p. 24-31, 2012.

75. KIRK, D. N.; TOMS, H.C.; DOUGLAS, C.; WHITE, K.A.; SMITH, K.E.; LATIF, S.; HUBBARD, R.W.P. A survey of the high-field ${ }^{1} \mathrm{H}$ NMR spectra of the steroid hormones, 
their hydroxylated derivatives, and related compounds. Journal of the Chemical Society, Perkin Transactions 2, n. 9, p. 1567-1594, 1990.

76. HUNTER, A. C.; RYMERM, S.; DEDI, C.; DODD, H.T.; NWOZDOR, Q.C. Transformation of structurally diverse steroidal analogues by the fungus Corynespora cassiicola CBS 161.60 results in generation of $8 \beta$-monohydroxylated metabolites with evidence in favour of $8 \beta$-hydroxylation through inverted binding in the $9 \alpha$-hydroxylase.

Biochimica et Biophysica Ata (BBA) - Molecular and Cell Biology of Lipids, v. 1811, n. 12, p.1054-1061, 2011.

77. PAVIA, D.L.; LAMPMAN, G.M.; KRIZ, G.S.; VYVYAN, J.R. Introdução à espectroscopia. Tradução de Pedro Barros. 4. Ed. São Paulo: Cengage Learning, 2015. 700 p.

78. ASAI, T.; AIDA, K.; OHKI, E.; TANAKA, T.; HATTORI, M. Hydroxylation of Progesterone by Syncephalastrum sp. Nippon Nōgeikagaku Kaishi, v. 32, n. 9, p. 723-728, 1958.

79. TSUDA, K.; ASAI, T.; SATO, Y.; TANAKA, T.; MATSUHISA, T.; HASEGAWA, H.; Mikrobiologische hydroxylierung der steroide. X. Uber 7 $\beta$, 15 $\beta$-Dihydroxypregn-4-en-3, 20dion. Chemical \& Pharmaceutical Bulletin, v. 8, n. 7, p. 626-628, 1960.

80. TSUDA, K.; ASAI, T.; OHKI, E.; TANAKA, A.; HATTORI, M. Microbiological Hydroxylation of steroids. IV. 7 $\alpha, 15 \beta$-Dihydroxylation of Progesterone by Syncephalastrum sp. (2). Chemical \& Pharmaceutical Bulletin, v. 6, n, 4, p. 387-391, 1958.

81. BRYAN, M. B.; SCOTT, A. P.; C̆ERNÝ, I.; YOUNG, B. A.; LI, W. $15 \alpha-$ Hydroxyprogesterone in male sea lampreys, Petromyzon marinus L. Steroids, v. 69, n. 7, p.473-481, 2004.

82. TSUDA, K.; ASAI, T.; SATO, Y.; TANAKA, T.; HASEGAWA, H. Untersuchungen auf dem Gebiet der mikrobiologischen Umsetzung. XI. Hydroxylierung von Progesteron in der $7 \alpha-, 7 \beta-, 14 \alpha-, 15 \alpha$ - oder 15 $\beta$-Stellung durch Helminthosporium sativum. Chemical \& Pharmaceutical Bulletin, v. 9, n. 9, p. 735-739, 1961.

83. MCALEER, W. J.; JACOB, T. A.; TURNBULL, L. B.; SCHOENEWALDT, E. F.; STOUDT, T. H. Hydroxylation of Progesterone by Bacillus cereus and Bacillus megaterium. Archives of Biochemistry and Biophysics, v. 73, n. 1, p. 127-130, 1958.

84. HERZOG, H.; GENTLES, M. J.; CHARNEY, W.; SUTTER, D.; TOWNLEY, E. YOUDIS, M.; KABASAKALIAN, P.; HERSHBERG, E. Notes. Microbiological transformation of steroids. VII. 15 $\beta$-Hydroxylation The Journal of Organic Chemistry, v. 24, n. 5, p. 691-695, 1959. 
85. AL-AWADI, S., AFZAL, M.; OOMMEN, S. Studies on Bacillus stearothermophilus. Part III. Transformation of Testosterone. Applied Microbiology and Biotechnology, v. 62., n.1, p. $48-52,2003$.

86. QUAN, C.; SU, F.; WANG, H.; LI, H. Development of anabolic-androgenic steroids purity certified reference materials for anti-doping. Steroids, v. 76, n. 14, p. 1527-1534, 2011.

87. JOUBERT, C.; BENEY, C.; MARSURA, A.; LUU-DUC, C. Synthesis of labelled [13C6]Testosterone and [13C5]19-nortestosterone. Journal of Labelled Compouds and Radiopharmaceuticals, v. 36, n. 8, p. 745-754, 1995.

88. YILDIRIM, K.; UZUNER, A.; GULCUOGLU, E. Y. Baeyer-Villiger oxidation of some steroids by Aspergillus tamarii MRC 72400. Collection of Chechoslovak Chemical Communications, v. 76, n. 6, p. 743-754, 2011.

89. DUTTA, T. K.; SAMANTA, T. B. Novel catalytic activity of immobilized spores under reduced water activity. Bioorganic \& Medicinal Chemistry Letters, v. 7, n. 5, p. 629-632, 1997.

90. HUANG, L.; LI, J.; XU, G.; ZHANG, X.; YIN, Y.; LIU, H. Biotransformation of dehydroepiandrosterone (DHEA) with Penicillium griseopurpureum Smith and Penicillium glabrum (Wehmer) Westling. Steroids, v. 75, n. 13-14, p.1039-1046, 2010.

91. BARTMAŃSKA, A.; DMOCHOWSKA-GŁADYSZ, J.; HUSZCZA, E. Steroids' transformations in Penicillium notatum culture. Steroids, v. 70, n. 3, p. 193-198, 2005.

92. LIU, H.; LI, H.; SHAN, L.; WU, J. Synthesis of steroidal lactone by Penicillium citreoviride. Steroids, v. 71, n. 3, p. 931-934, 2006.

93. MORII, S.; SAWAMOTO, S.; YAMAUCHI, Y. MIYAMOTO, M. IWAMI, M. ITAGAKI, E. Steroid monooxygenase of Rhodococcus rhodochrous: sequencing of the genomic DNA, and hyperexpression, purification, and characterization of the recombinant enzyme. Journal of Biochemistry, v. 126, n. 3, p. 624-631, 1999.

94. FRANCESCHINI, S.; VAN BEEK, H.L.; PENNETTA, A.; MARTINOLI, C.; FRAAIJE, M.W.; MARREVI, A. Exploring the structural basis of substrate preferences in BaeyerVilliger monooxygenases insight from steroid monooxygenase. Journal of Biological Chemistry, v. 287, n. 27, p. 22626-22634, 2012.

95. SHENG, D.; BALLOU, D. P.; MASSEY, V. Mechanistic Studies of Cyclohexanone Monooxygenase: Chemical Properties of Intermediates Involved in Catalysis $\dagger$.

Biochemistry, v. 40, n. 37, p. 1156-11167, 2001. 
96. CHEESEMAN, J. D.; TOCILJ, A.; PARK, S.; SCHRAG, J. D.; KAZLAUSKAS, R. J. Structure of an aryl esterase from Pseudomonas fluorescens. Acta Crystallographica Section D Biological Crystallography, v. 60, n. 7, p. 1237-1243, 2004.

97. INANO, H.; TAMAOKI, B.; Testicular 17 $\beta$-hydroxysteroid dehydrogenase: Molecular properties and reaction mechanism. Steroids, v. 48, n. 1-2, p. 1-26, 1986.

98. GANGLOFF, A.; SHI, R.; NAHOUM, V.; LIN, S.; Pseudo-symmetry of C19 steroids, alternative binding orientations, and multispecificity in human estrogenic $17 \beta$-hydroxysteroid dehydrogenase. The FASEB Journal, v. 17, n. 2, p. 274-276, 2003.

99. EKLUND, H.; PLAPP, B. V.; SAMAMA, J. P.; BRÄNDÉN, C. I. Binding of substrate in a ternary complex of horse liver alcohol dehydrogenase. Journal of Biological Chemistry, $v$. 257, n. 23, p.14349-14358, 1982.

100. KLEIFELD, O.; FRENKEL, A.; MARTIN, J. M. L.; SAGI, I. Active site electronic structure and dynamics during metalloenzyme catalysis. Natural Structural \& Molecular Biology, v. 10, n.2, p. 98-103, 2003.

101. ITAGAKI, E. Studies on steroid monooxygenase from Cylindrocarpon radicicola ATCC 11011. Oxygenative lactonization of Androstenedione to Testololactone. Journal of Biochemistry, v. 99, n. 3, p. 825-832, 1986.

102. COCCONI, G. First generation aromatase inhibitors - Aminoglutethimide and Testololactone. Breast Cancer Research and Treatment, v. 30, n. 1, p. 57-80, 1994.

103. BUDNICK, R. M.; DAO, T. L. Inhibition of estrogen synthesis in human breast tumors by testololactone and bromoandrostenedione. Steroids, v. 35, n. 5, p. 533-541, 1980.

104. LI, S.; PARISH, E. J. Design and action of steroidal aromatase inhibitors. Journal of the American Oil Chemists' Society. v. 73, n. 11, p. 1435-1451, 1996.

105. BRAUNSTEIN, G. D. Aromatase and gynecomastia. Endocrine-Related Cancer, v. 6, n. 2, p. 315-324, 1999.

106. FEUILLAN, P.; MERKE, D.; LESCHEK, E. W.; CUTLER, G. B. Use of aromatase inhibitors in precocious puberty. Endocrine-Related Cancer, v. 6, n. 2, p. 303-306, 1999. 
107. JACOBSEN, N. E.; KÖVÉR, K. E.; MURATALIEV, M. B.; FEYEREISEN, R.;

WALKER, F. A. Structure and stereochemistry of products of hydroxylation of human steroid hormones by a housefly cytochrome P450 (CYP6A1). Magnetic Resonance in Chemistry, v. 44, n. 4, p.467-474, 2006.

108. BERG, A.; INGELMAN-SUNDBERG, M.; GUSTAFSSON, J. A. Purification and characterization of cytochrome P-450meg. Journal of Biological Chemistry, v. 254, n. 12, p. 5264-5271, 1979.

109. LISUREK, M.; SIMGEN, B.; ANTES, I.; BERNHARDT, R. Theoretical and experimental evaluation of a CYP106A2 low homology model and production of mutants with changed activity and selectivity of hydroxylation. ChemBioChem, v. 9, n. 9, p. 14391449, 2008.

110. GUENGERICH, P.F. Oxidation of $17 \alpha$-Ethynylestradiol by human liver cytochrome P450. Molecular Pharmacology, v. 33, n. 5, p. 500-508, 1988.

111. GUENGERICH, P.F. Metabolism of $17 \alpha$-Ethynylestradiol in humans. Life Sciences, v. 47, n. 22, p. 1981-1988, 1990. 


\section{ANEXOS}

Espectro de RMN HMBC (100 MHz e $\left.400 \mathrm{MHz}, \mathrm{CDCl}_{3}\right)$ da progesterona.

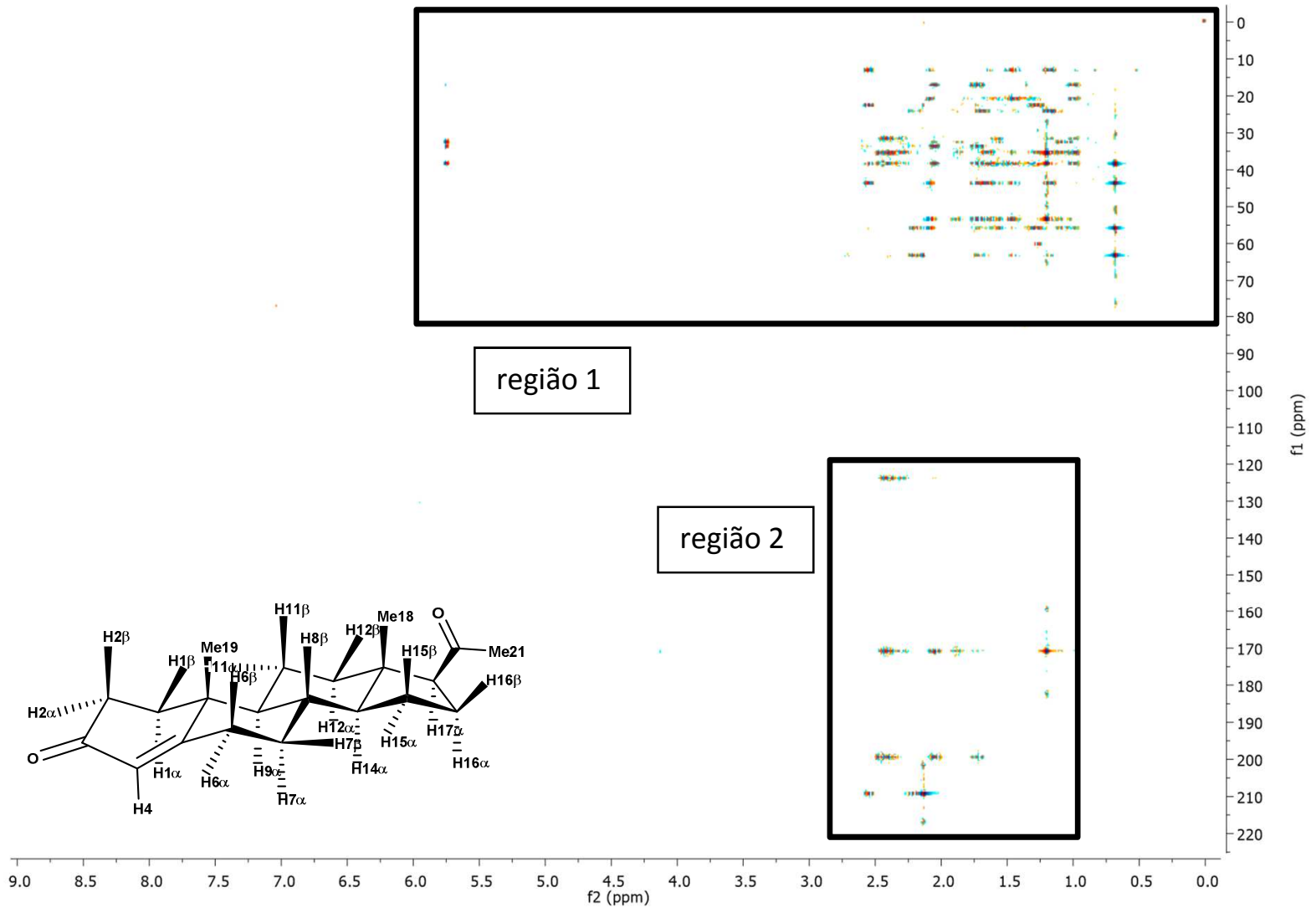

Espectro de RMN HMBC (100 MHz e $400 \mathrm{MHz}, \mathrm{CDCl}_{3}$ ) da progesterona (região 1).

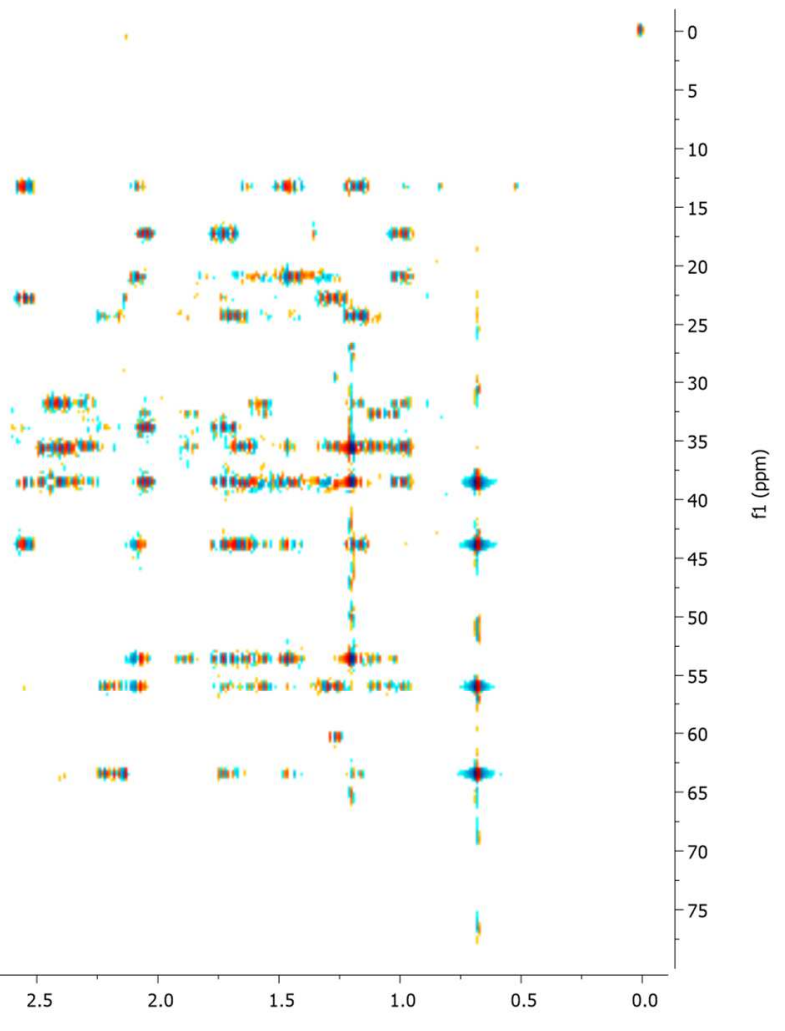


Espectro de RMN HMBC (100 MHz e $400 \mathrm{MHz}, \mathrm{CDCl}_{3}$ ) da progesterona (região 2).

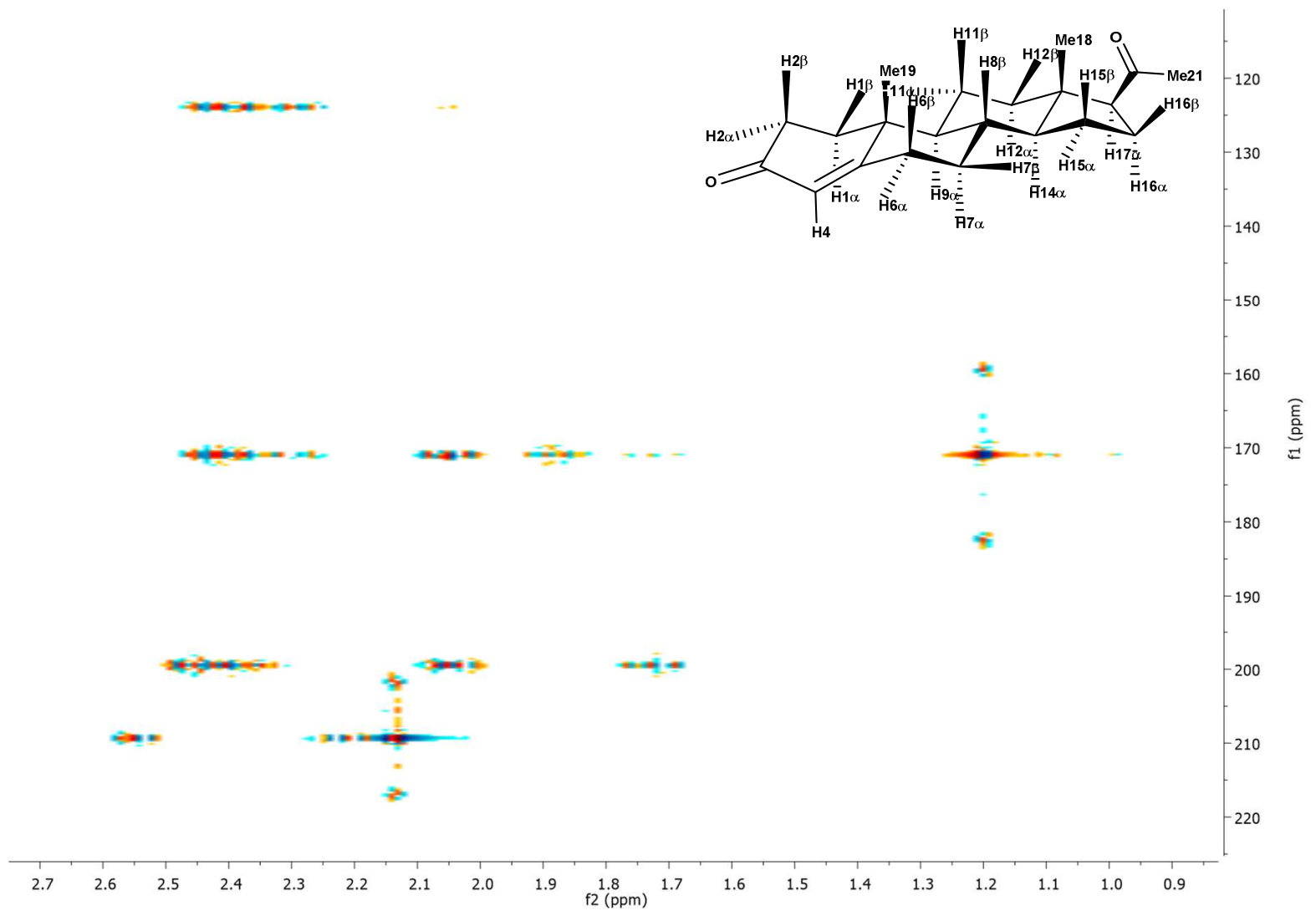

Espectro de RMN COSY (400 MHz, $\left.\mathrm{CDCl}_{3}\right)$ da progesterona.

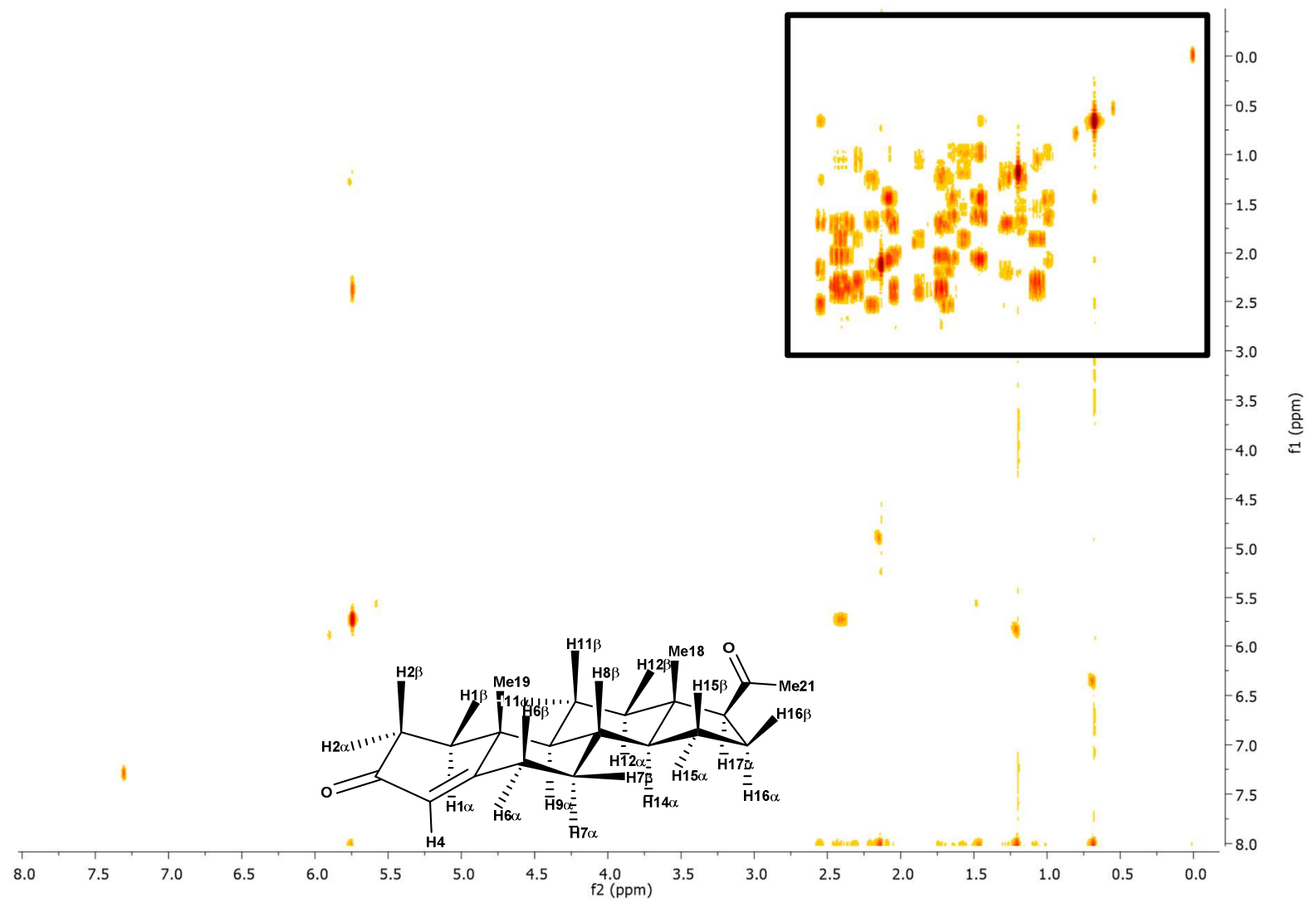


Espectro de RMN COSY (400 MHz, $\mathrm{CDCl}_{3}$ ) da progesterona (ampliação).
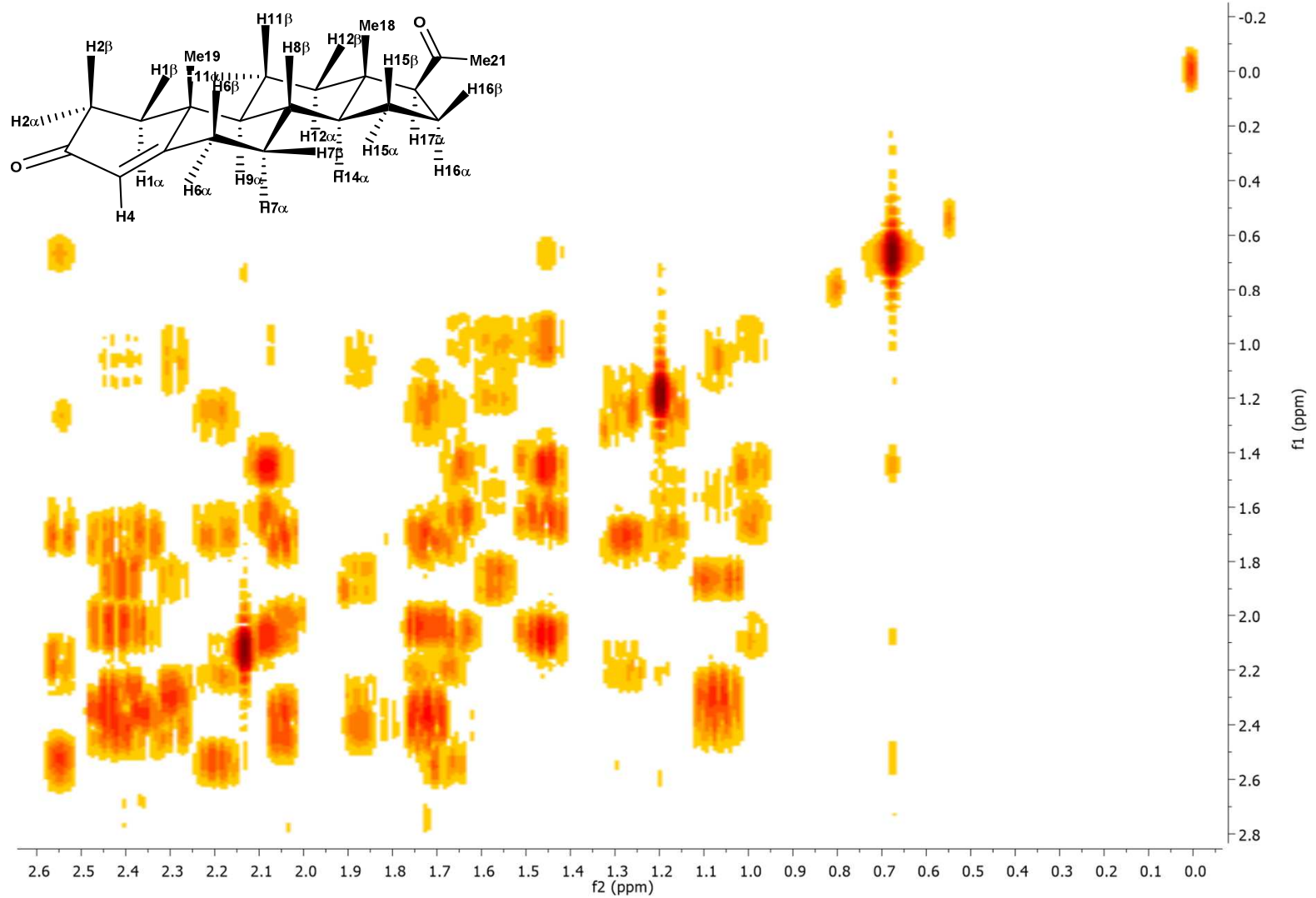

Espectro de $\mathrm{RMN}{ }^{1} \mathrm{H}\left(400 \mathrm{MHz}, \mathrm{CDCl}_{3}\right)$ da progesterona.
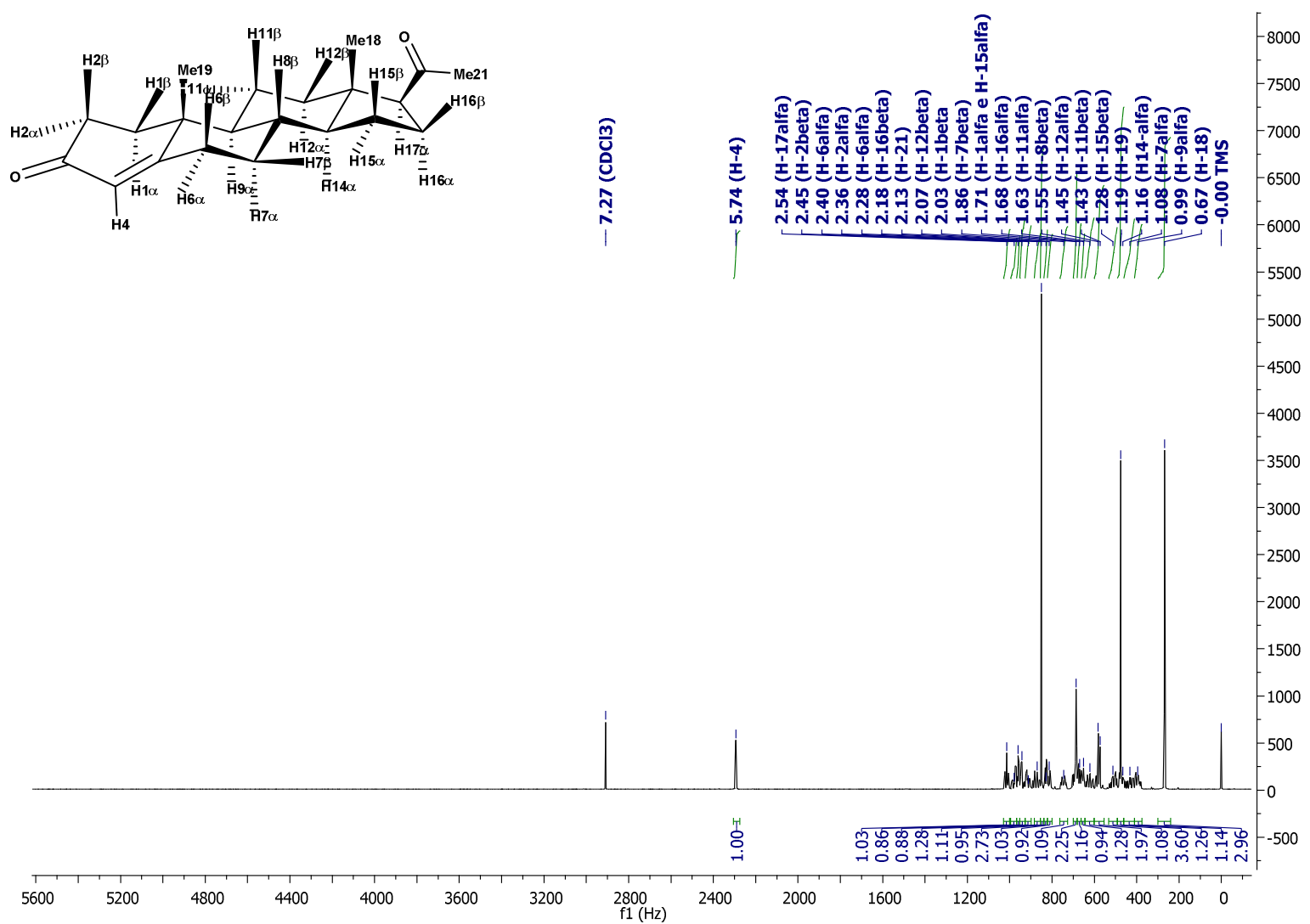
Espectro de $\mathrm{RMN}{ }^{1} \mathrm{H}\left(400 \mathrm{MHz}, \mathrm{CDCl}_{3}\right.$ ) da progesterona (ampliação 0,93 - 1,22 ppm).

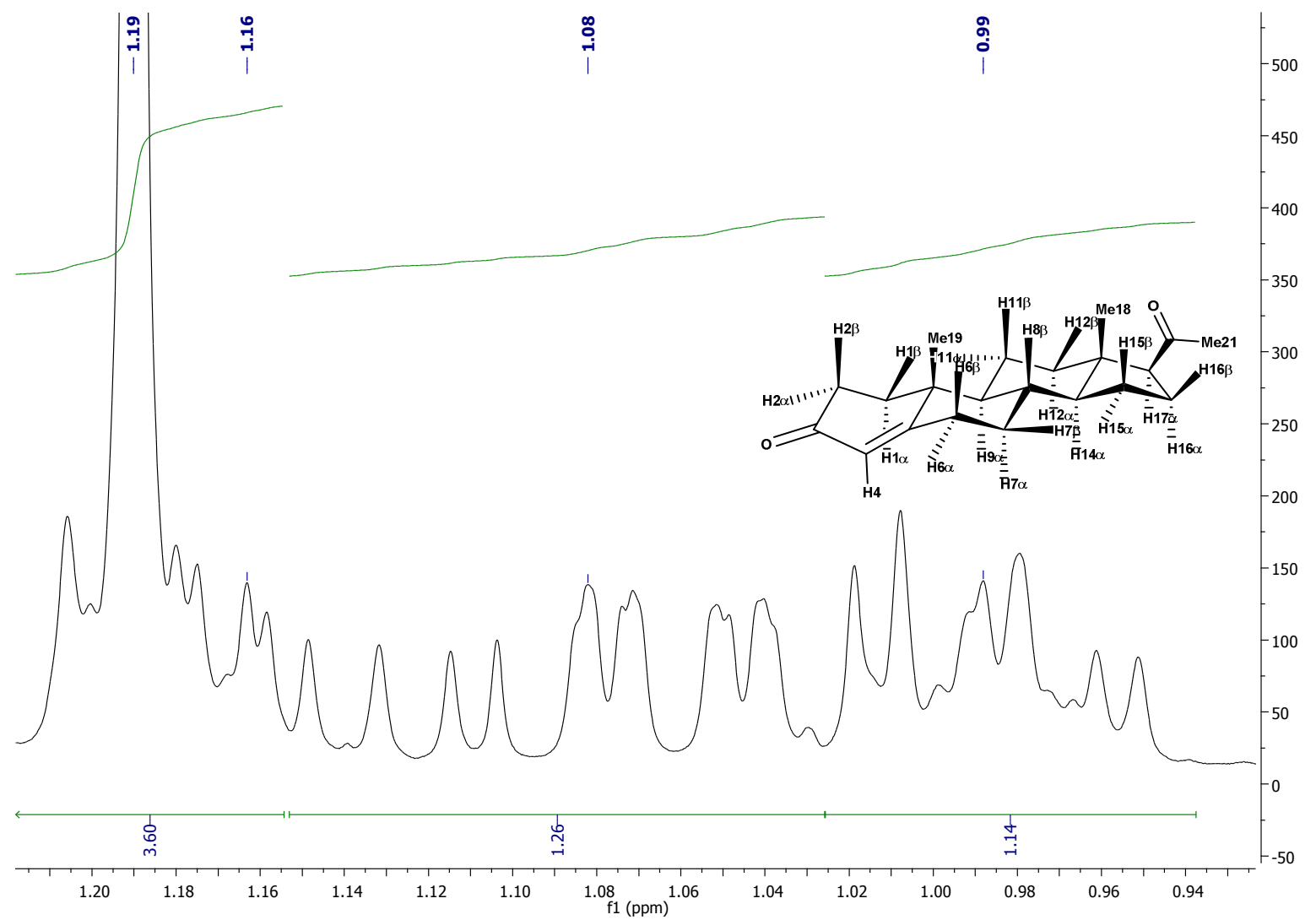

Espectro de $\mathrm{RMN}{ }^{1} \mathrm{H}\left(400 \mathrm{MHz}, \mathrm{CDCl}_{3}\right)$ da progesterona (ampliação 1,13 - 2,13 ppm).

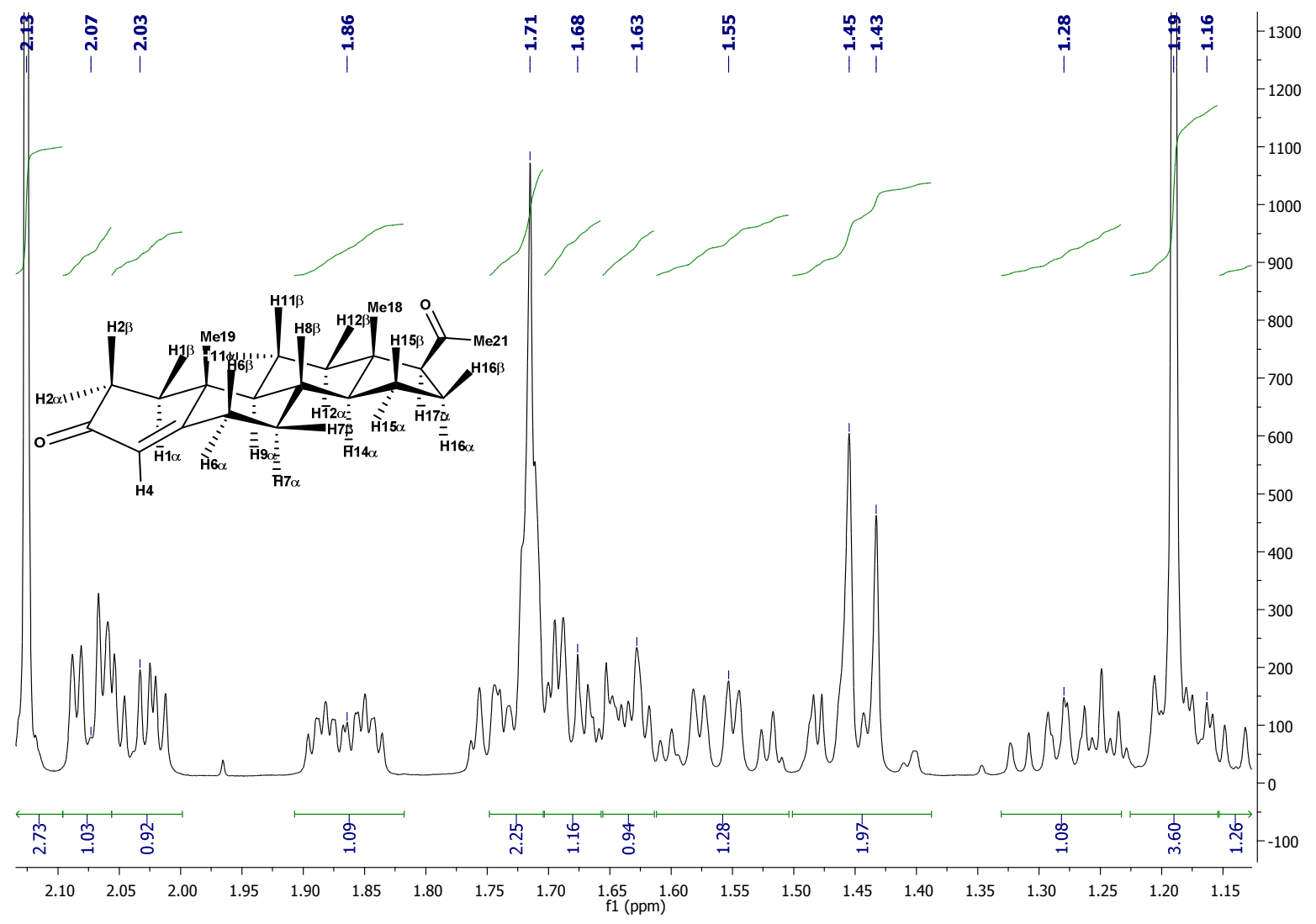


Espectro de $\mathrm{RMN}{ }^{1} \mathrm{H}\left(400 \mathrm{MHz}, \mathrm{CDCl}_{3}\right.$ ) da progesterona (ampliação 2,14 - 2,60 ppm).

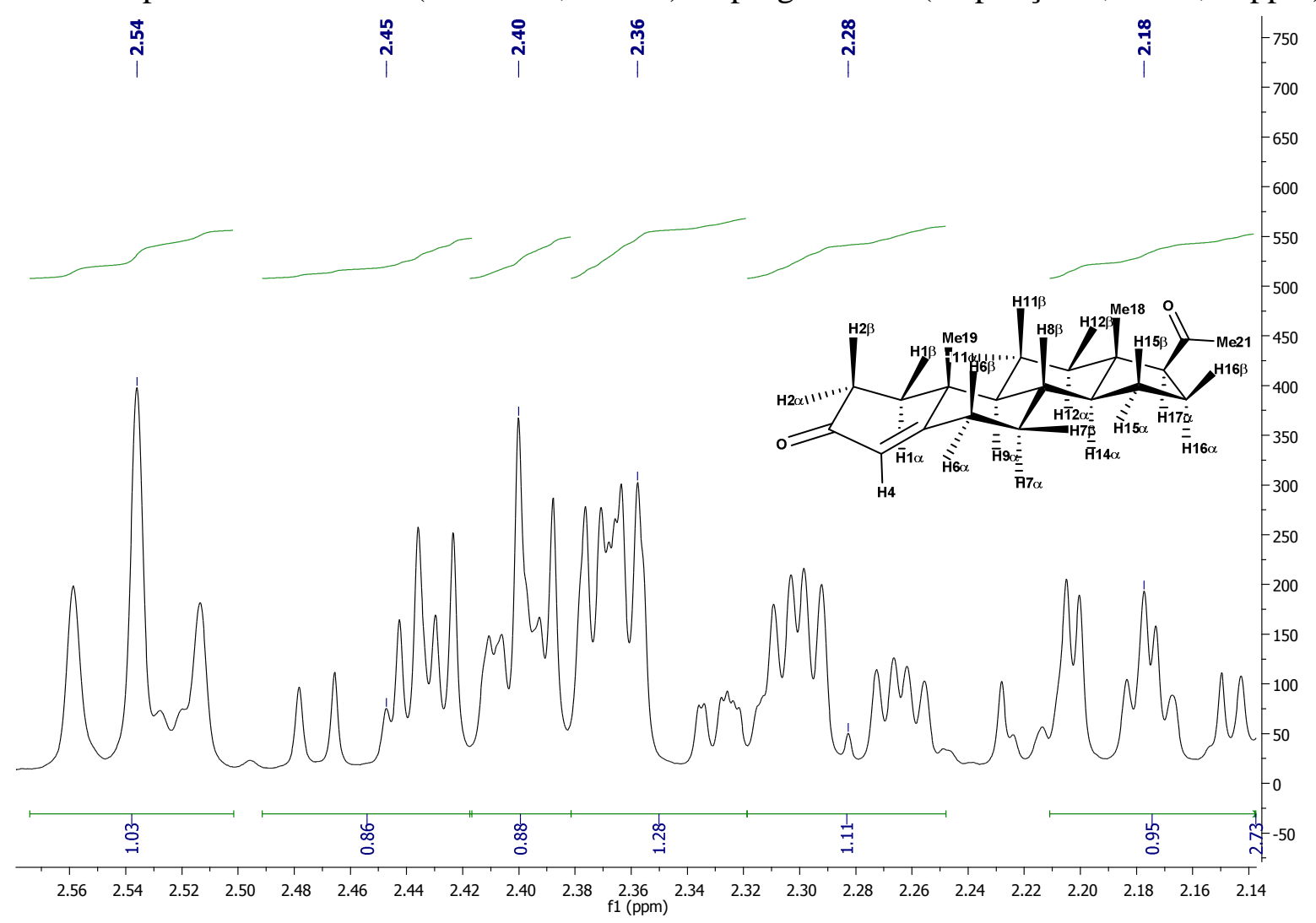

Constantes de acoplamento encontradas no sinal de multipleto do hidrogênio $\mathrm{H}-7 \alpha$ da progesterona a partir do seu espectro de $\mathrm{RMN}^{1} \mathrm{H}\left(400 \mathrm{MHz}, \mathrm{CDCl}_{3}\right)$.

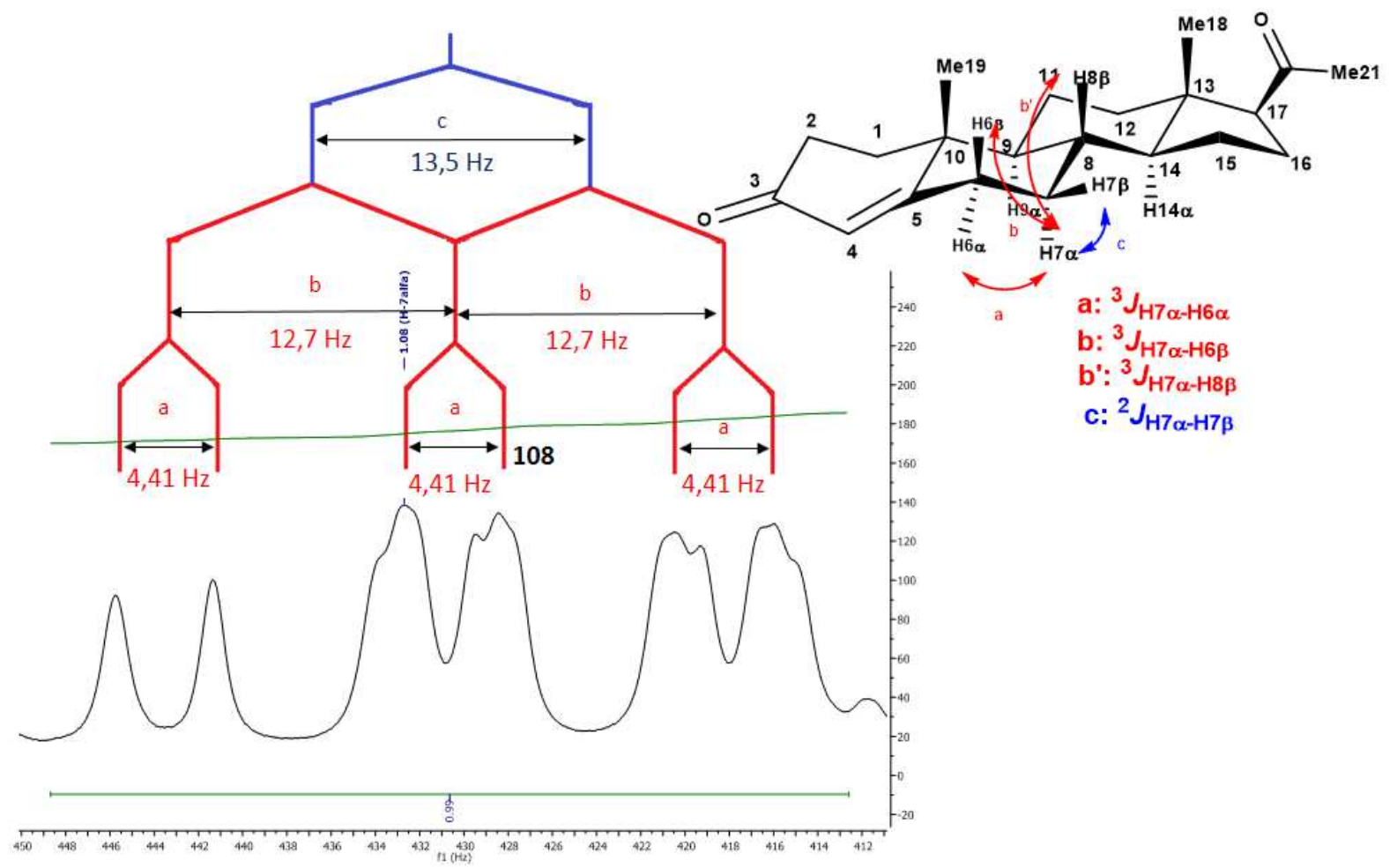


Constantes de acoplamento encontradas no sinal de multipleto do hidrogênio $\mathrm{H}-7 \beta$ da progesterona a partir do seu espectro de $\mathrm{RMN}^{1} \mathrm{H}\left(400 \mathrm{MHz}, \mathrm{CDCl}_{3}\right)$.

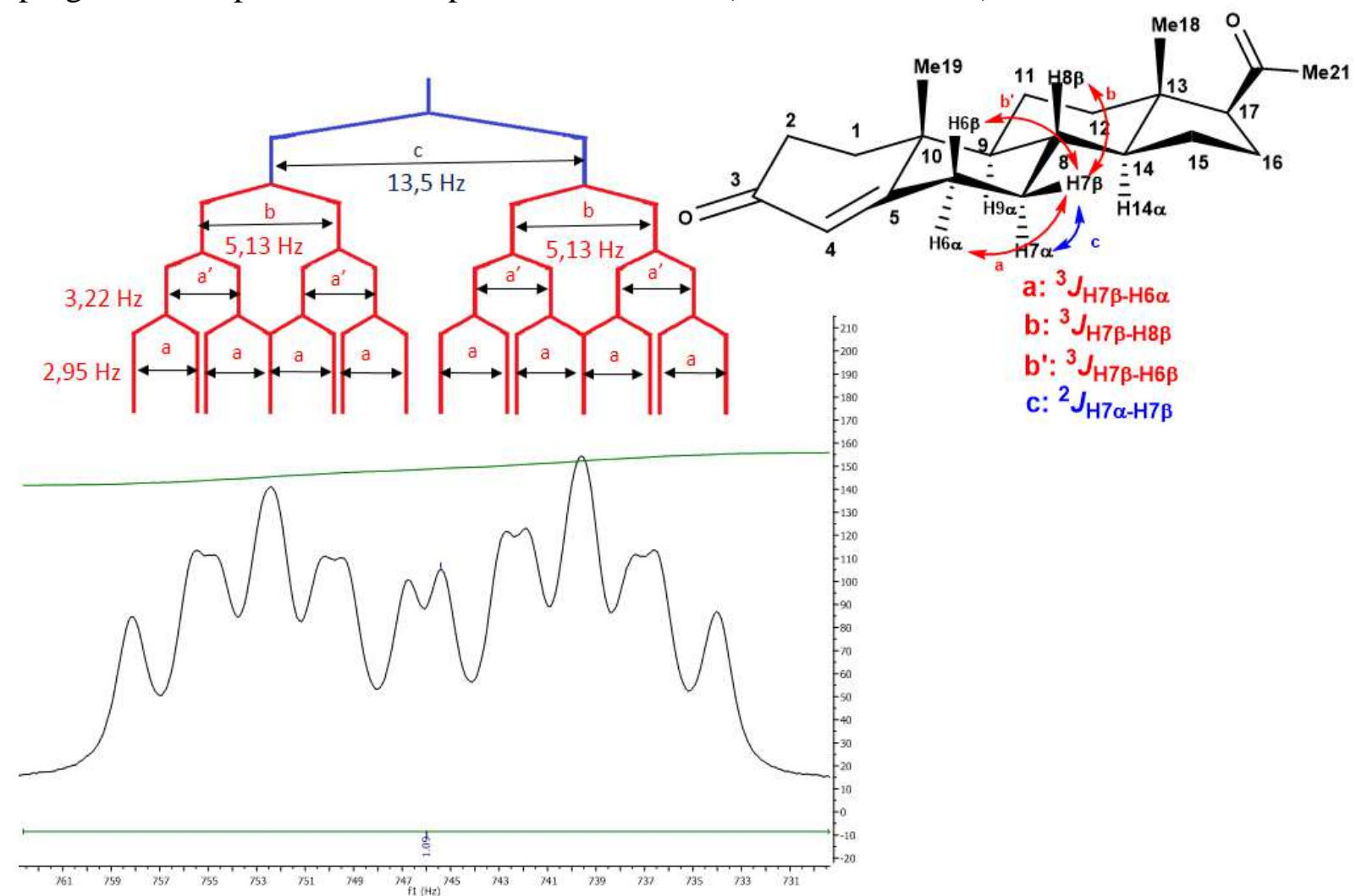

Constantes de acoplamento encontradas no sinal de multipleto do hidrogênio H-17 $\alpha$ da progesterona a partir do seu espectro de $\mathrm{RMN}{ }^{1} \mathrm{H}\left(400 \mathrm{MHz}, \mathrm{CDCl}_{3}\right)$.
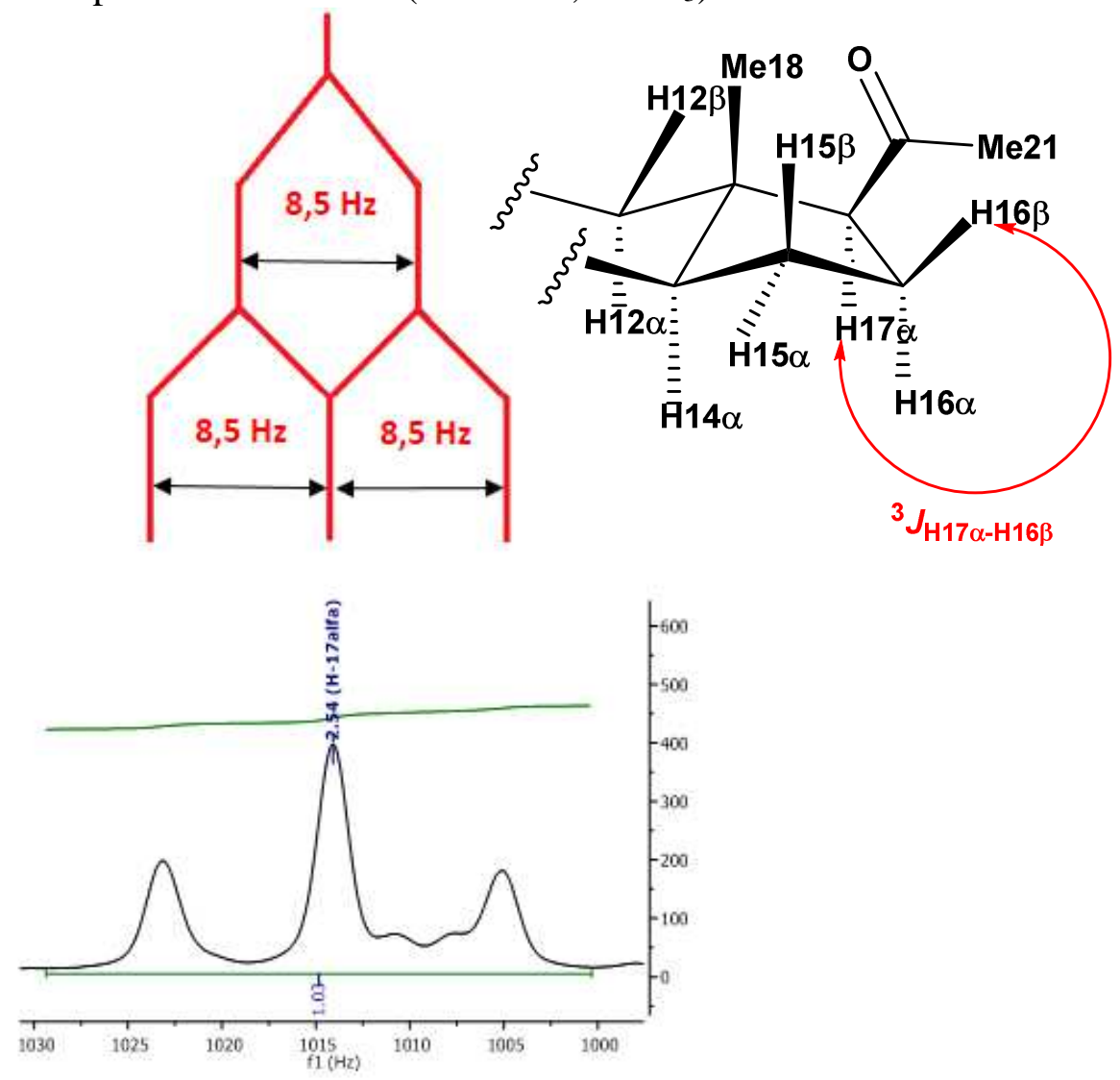
Constantes de acoplamento encontradas no sinal de multipleto do hidrogênio H-16 $\alpha$ da progesterona a partir do seu espectro de $\mathrm{RMN}^{1} \mathrm{H}\left(400 \mathrm{MHz}, \mathrm{CDCl}_{3}\right)$.
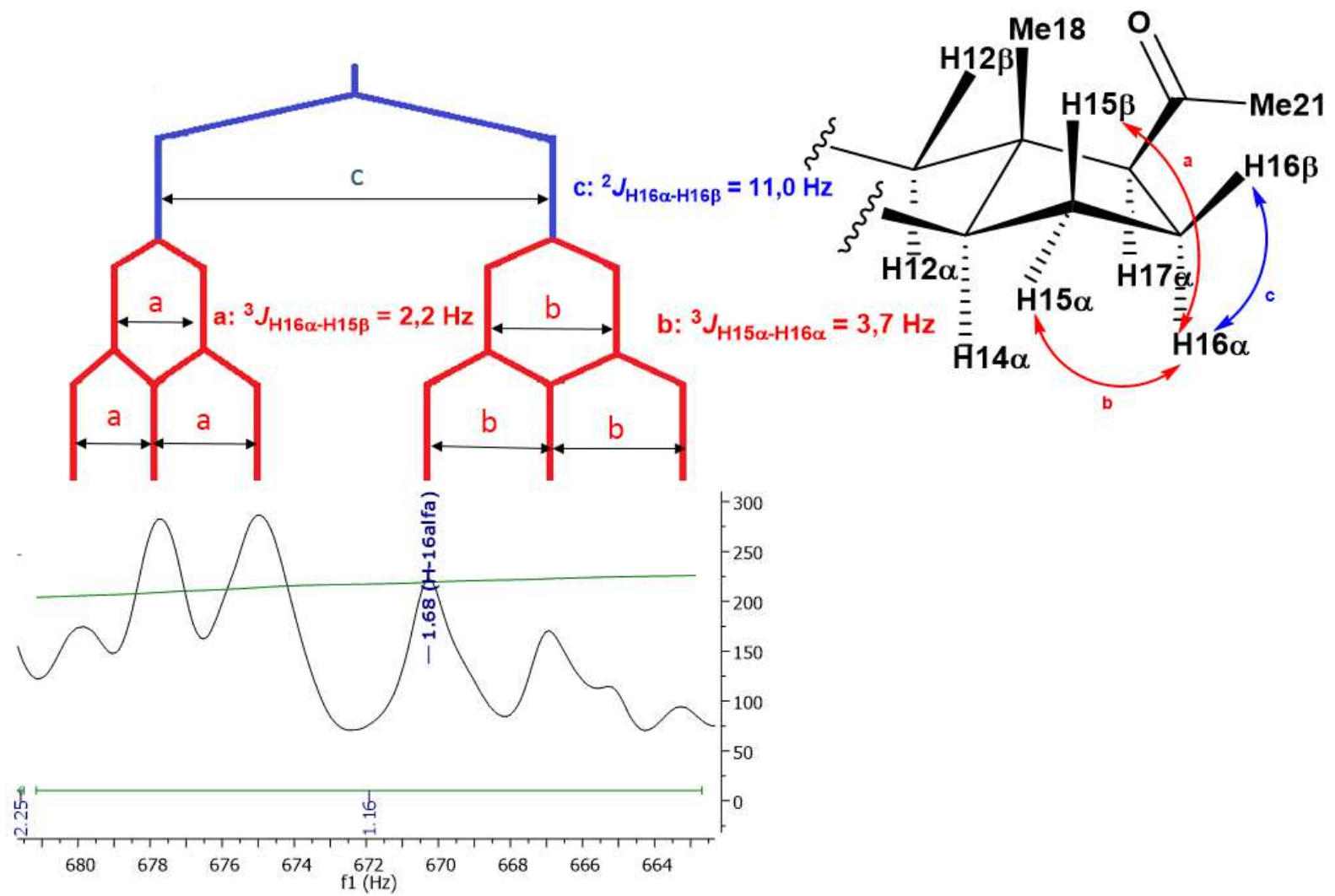

Constantes de acoplamento encontradas no sinal de multipleto do hidrogênio H-16ß da progesterona a partir do seu espectro de $\mathrm{RMN}{ }^{1} \mathrm{H}\left(400 \mathrm{MHz}, \mathrm{CDCl}_{3}\right)$.

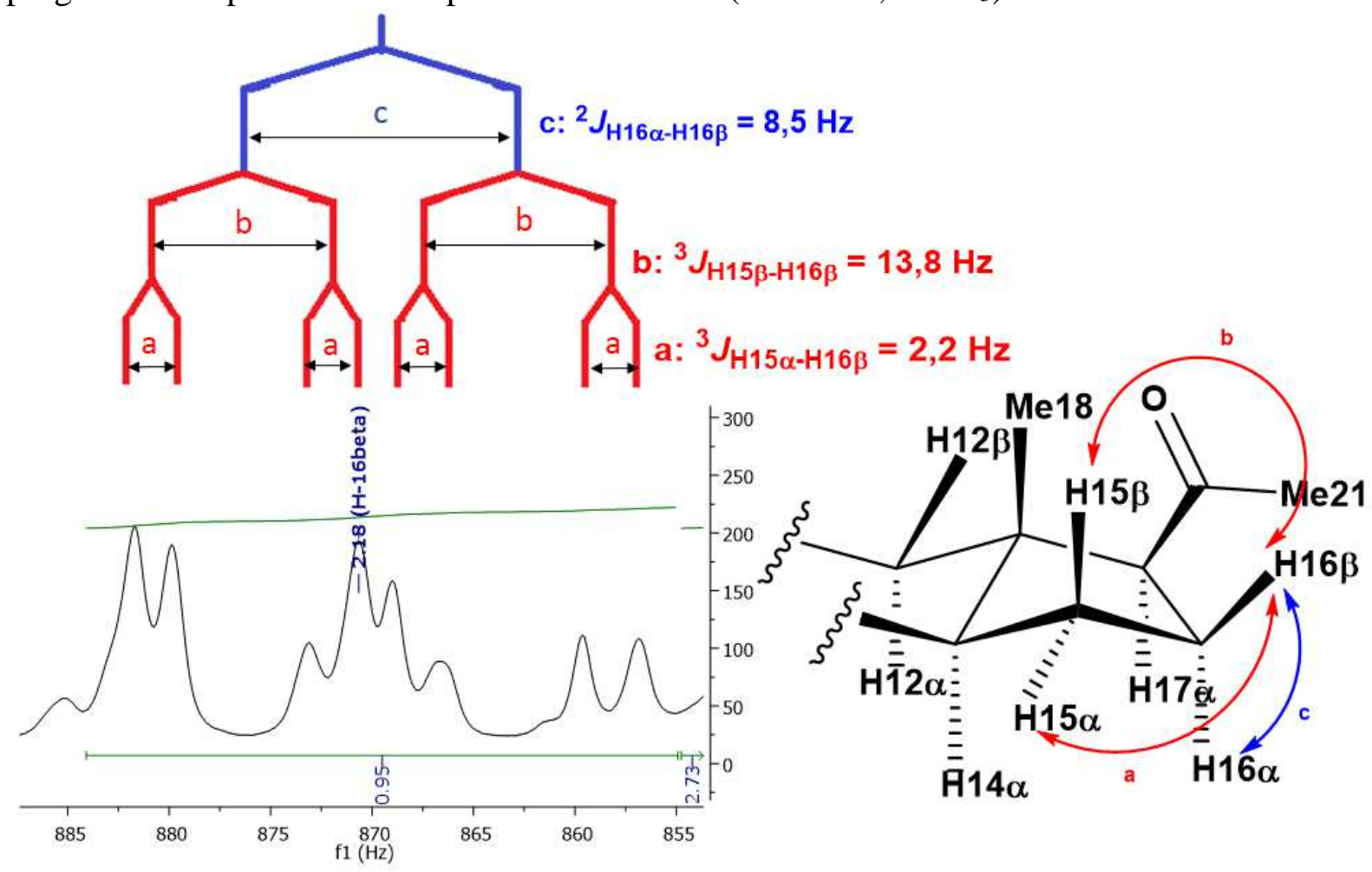


Espectro de RMN HMBC (125 MHz e $500 \mathrm{MHz}, \mathrm{CDCl}_{3}$ ) 7,15-di-hidroxiprogesterona
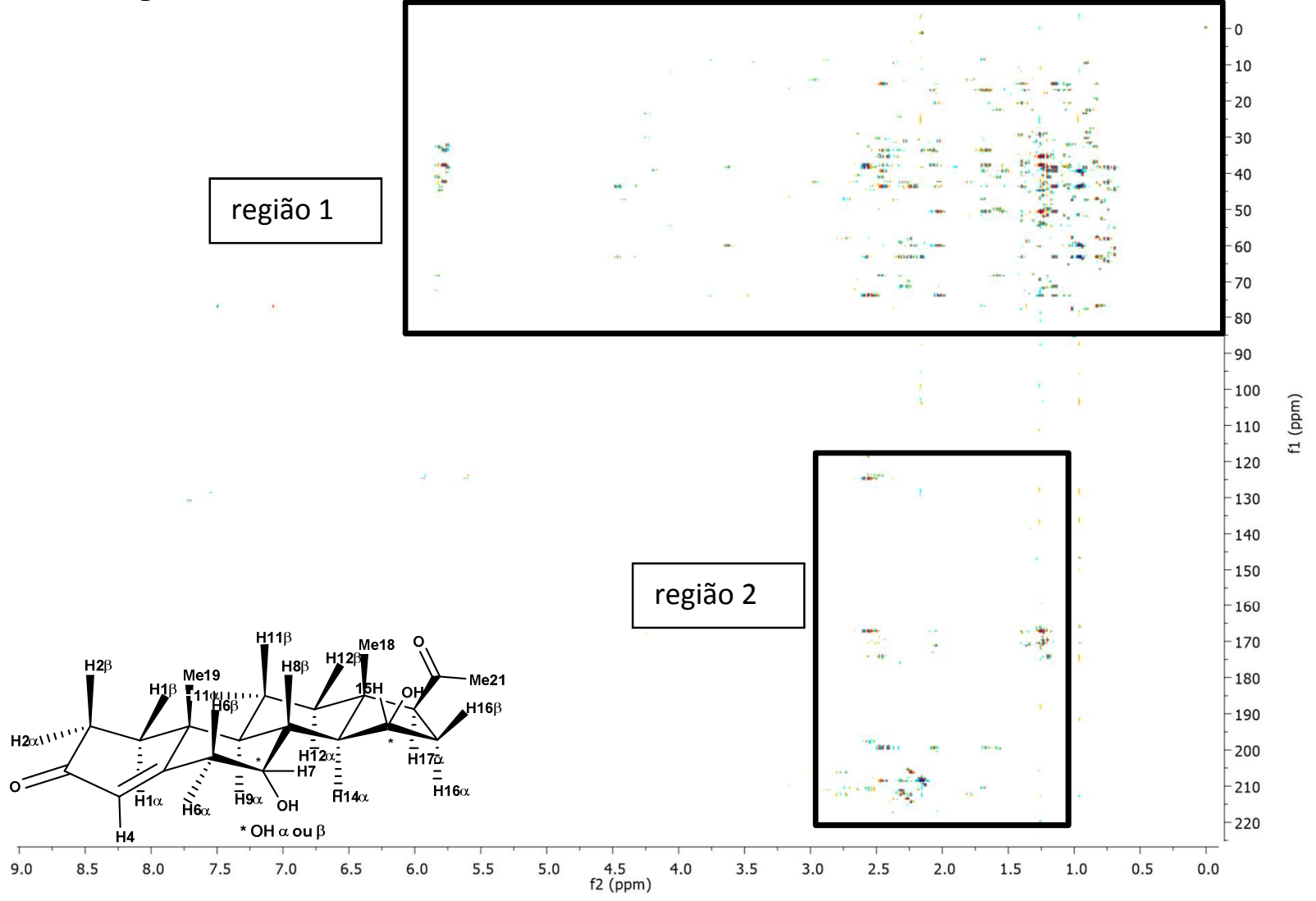

Espectro de RMN HMBC (125 MHz e $500 \mathrm{MHz}, \mathrm{CDCl}_{3}$ ) 7,15-di-hidroxiprogesterona (região 1).
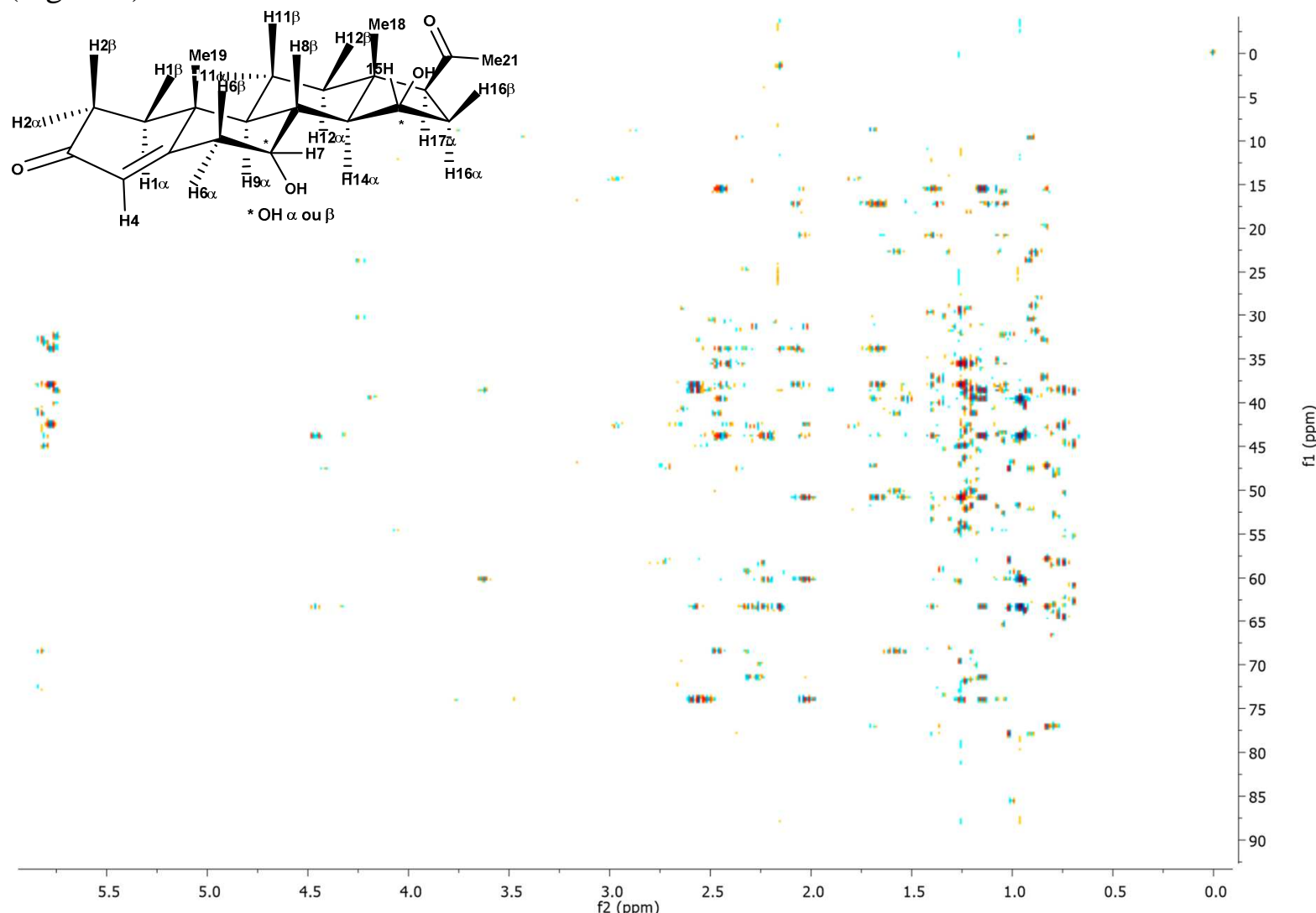

(região 2).

Espectro de RMN HMBC (125 MHz e $500 \mathrm{MHz}, \mathrm{CDCl}_{3}$ ) 7,15-di-hidroxiprogesterona

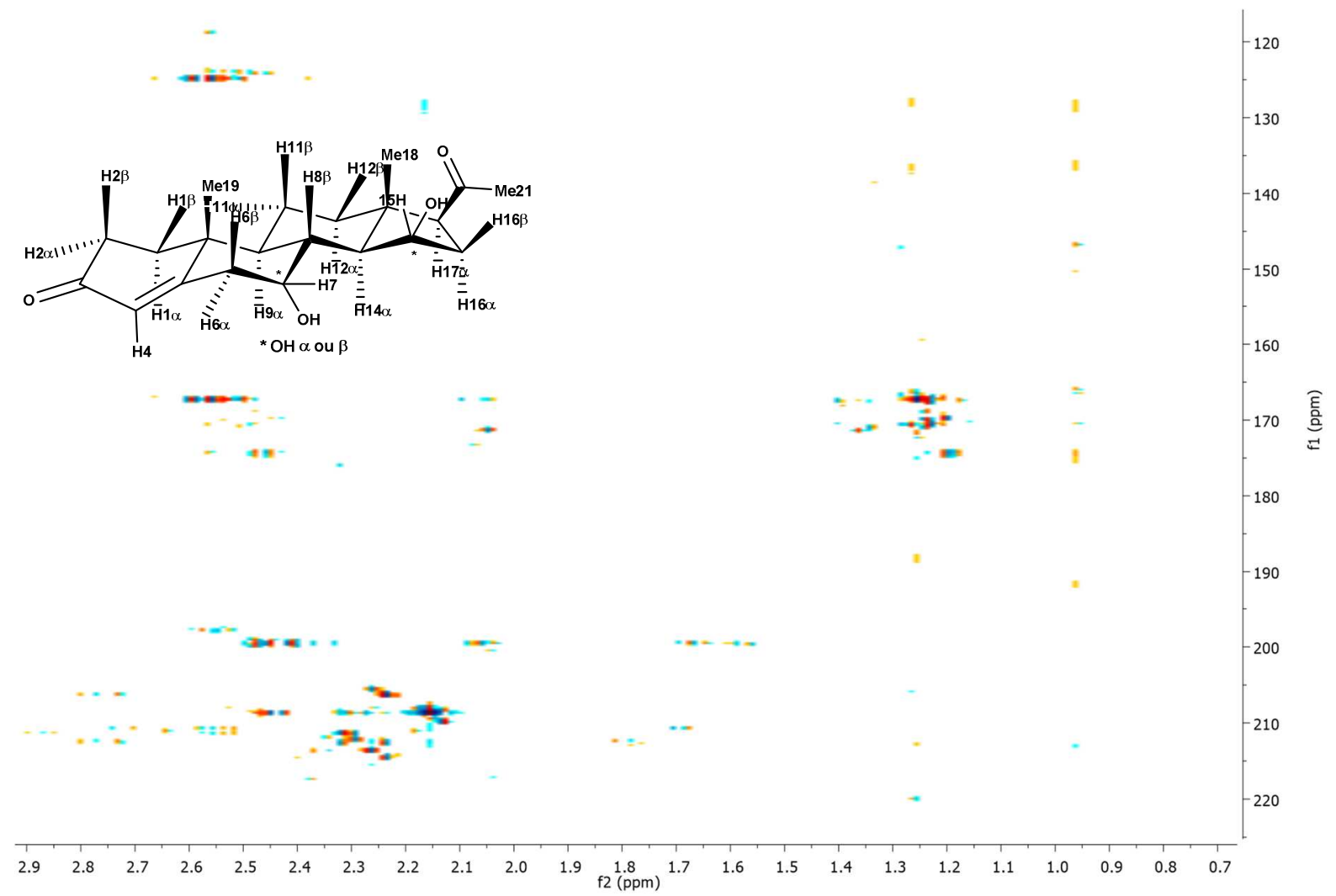

Espectro de RMN COSY (400 MHz, $\left.\mathrm{CDCl}_{3}\right)$ 7,15-di-hidroxiprogesterona.

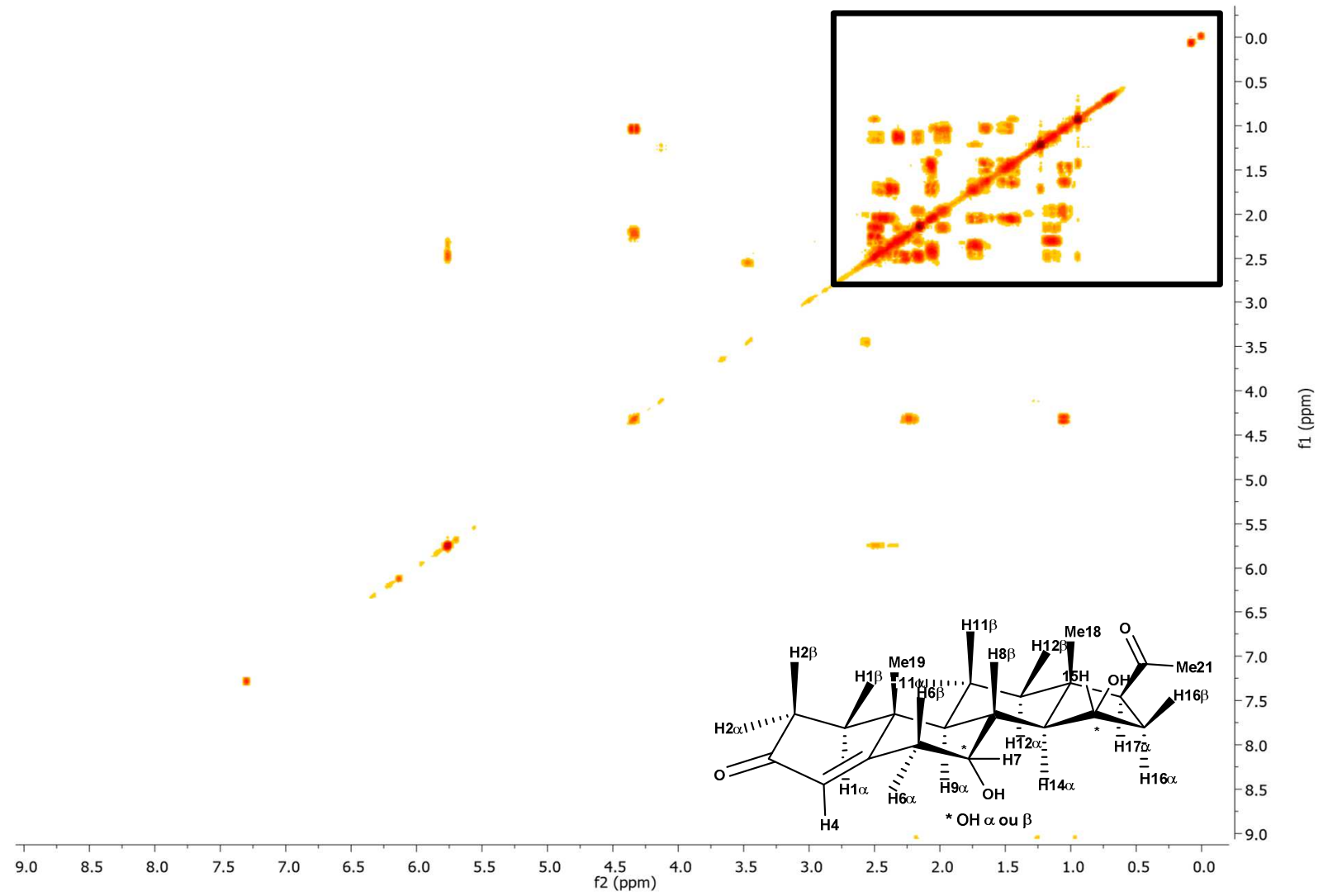



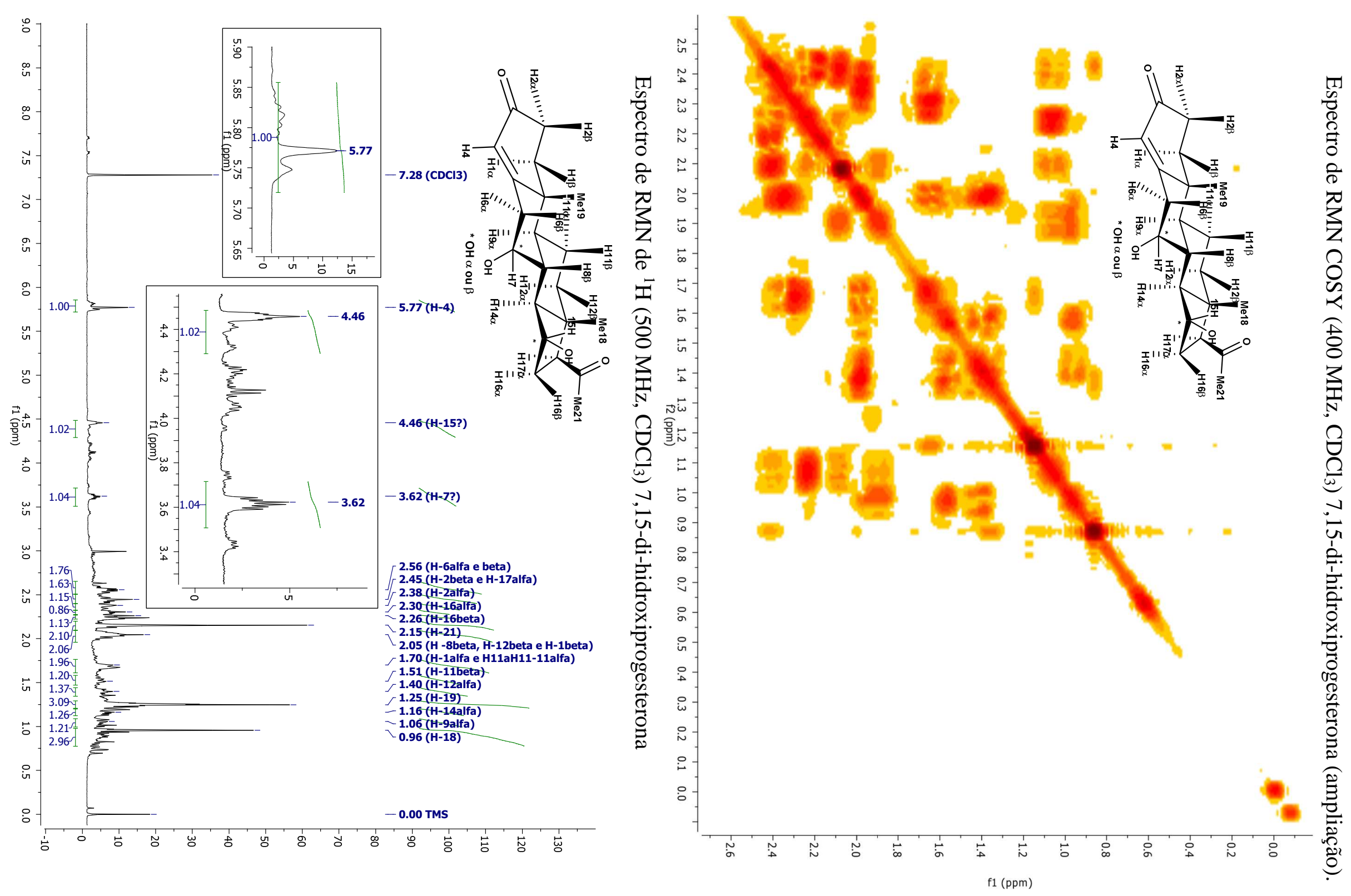
Espectro de RMN de ${ }^{1} \mathrm{H}\left(500 \mathrm{MHz}, \mathrm{CDCl}_{3}\right)$ 7,15-di-hidroxiprogesterona (ampliação $0,65-1,80 \mathrm{ppm})$.

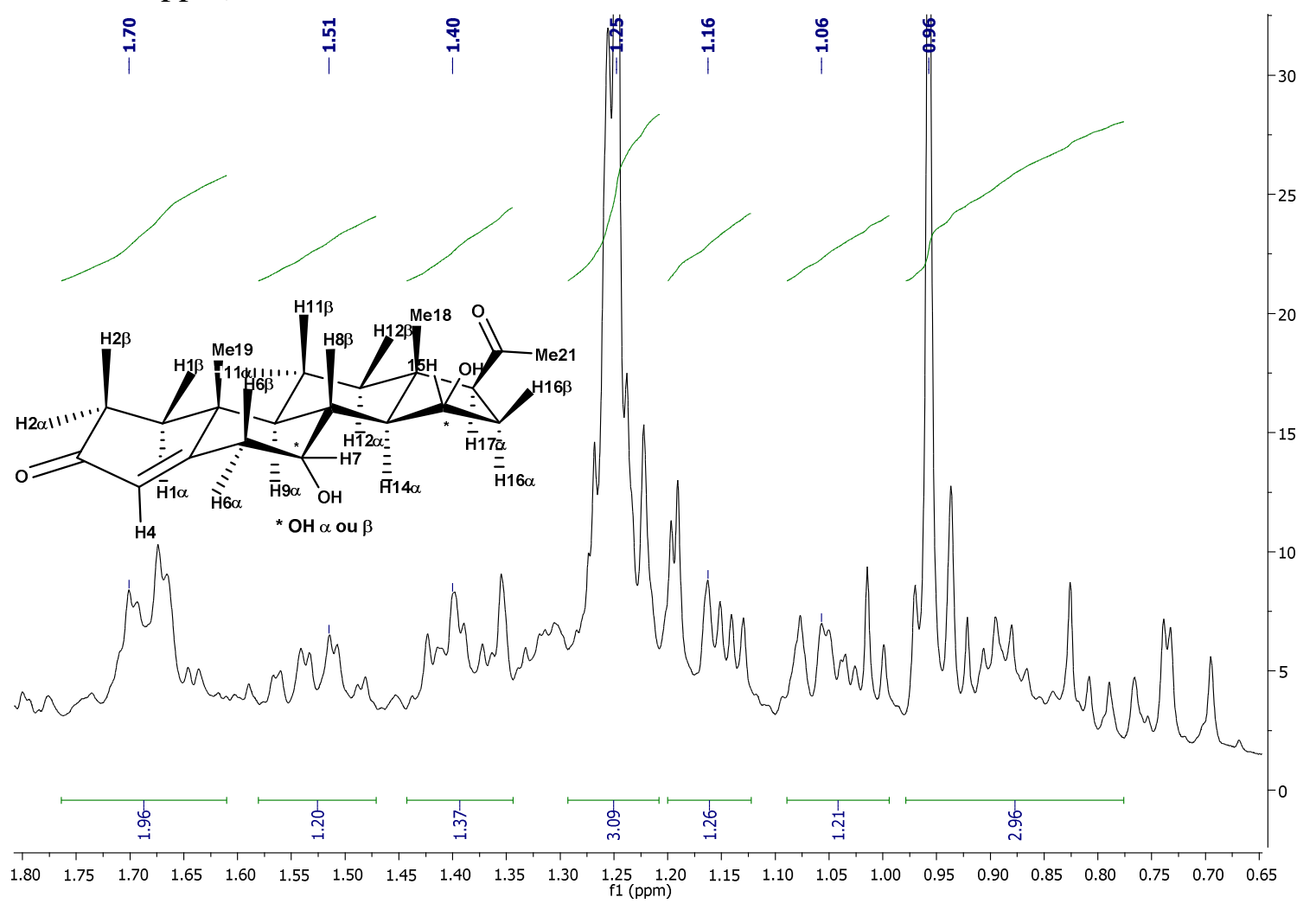

Espectro de $\mathrm{RMN}$ de ${ }^{1} \mathrm{H}\left(500 \mathrm{MHz}, \mathrm{CDCl}_{3}\right)$ 7,15-di-hidroxiprogesterona (ampliação $1,88-2,72 \mathrm{ppm})$.

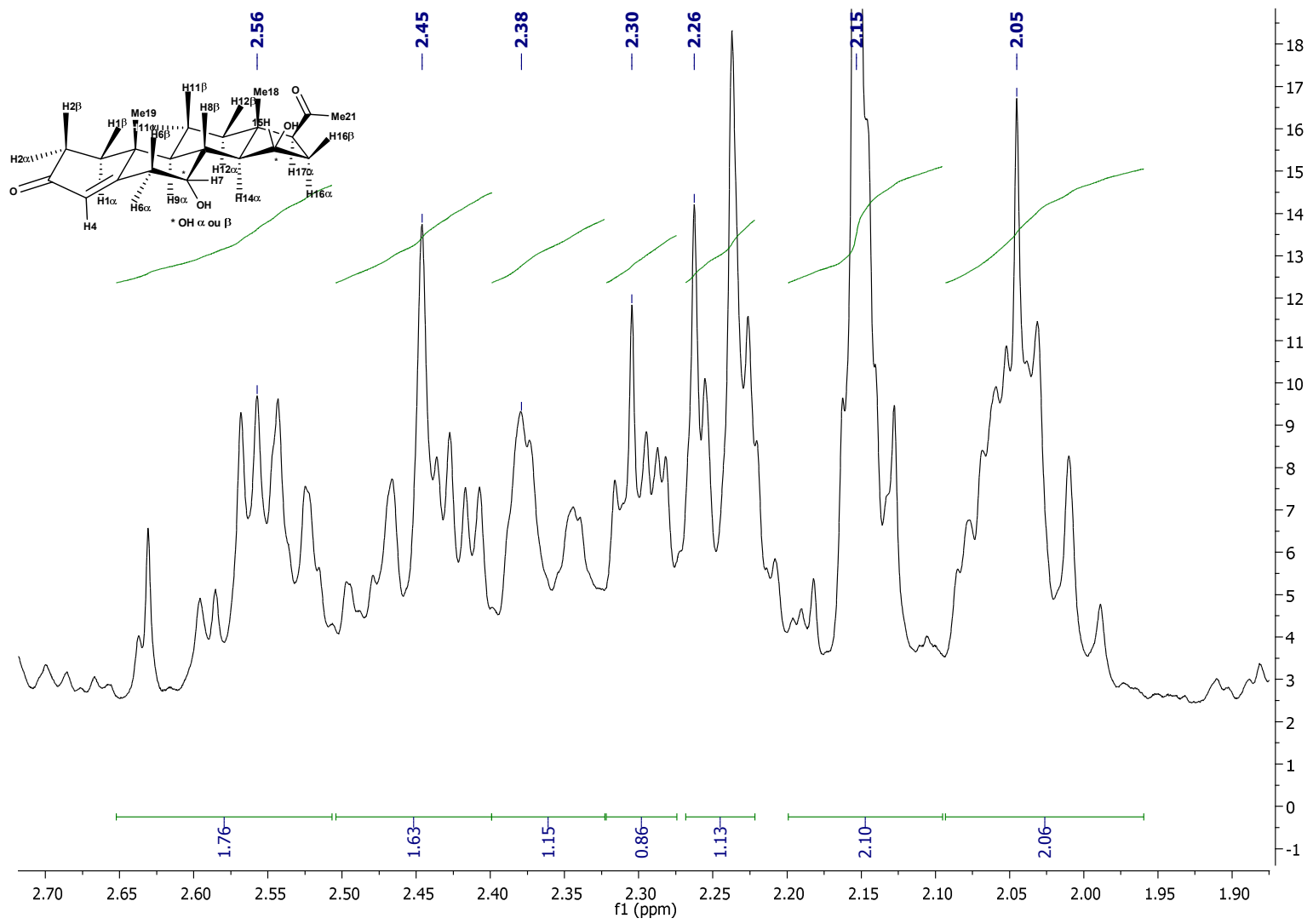


Constantes de acoplamento encontradas no sinal de multipleto do hidrogênio H-7 da 7,15-di-hidroxiprogesterona a partir do seu espectro de $\mathrm{RMN}{ }^{1} \mathrm{H}\left(500 \mathrm{MHz}, \mathrm{CDCl}_{3}\right)$.

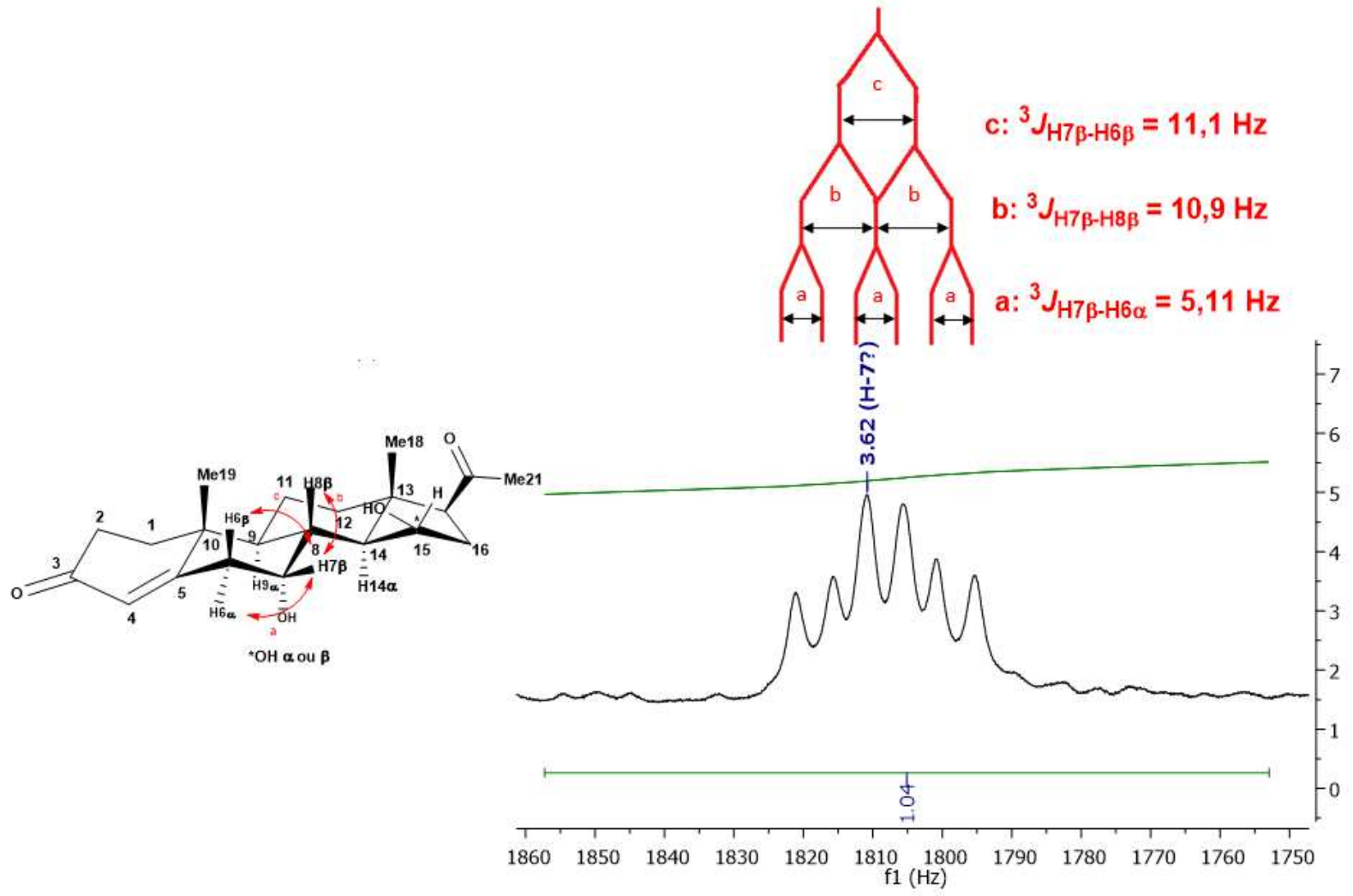

Espectro de EMAR - Modo positivo $\left({ }^{+} \mathrm{H}\right)$ - Full Scan da 7,15-di-hidroxiprogesterona.

3-dihidroxilado_ms1 \#1 RT: 0.01 AV: 1 NL: $1.58 E 7$

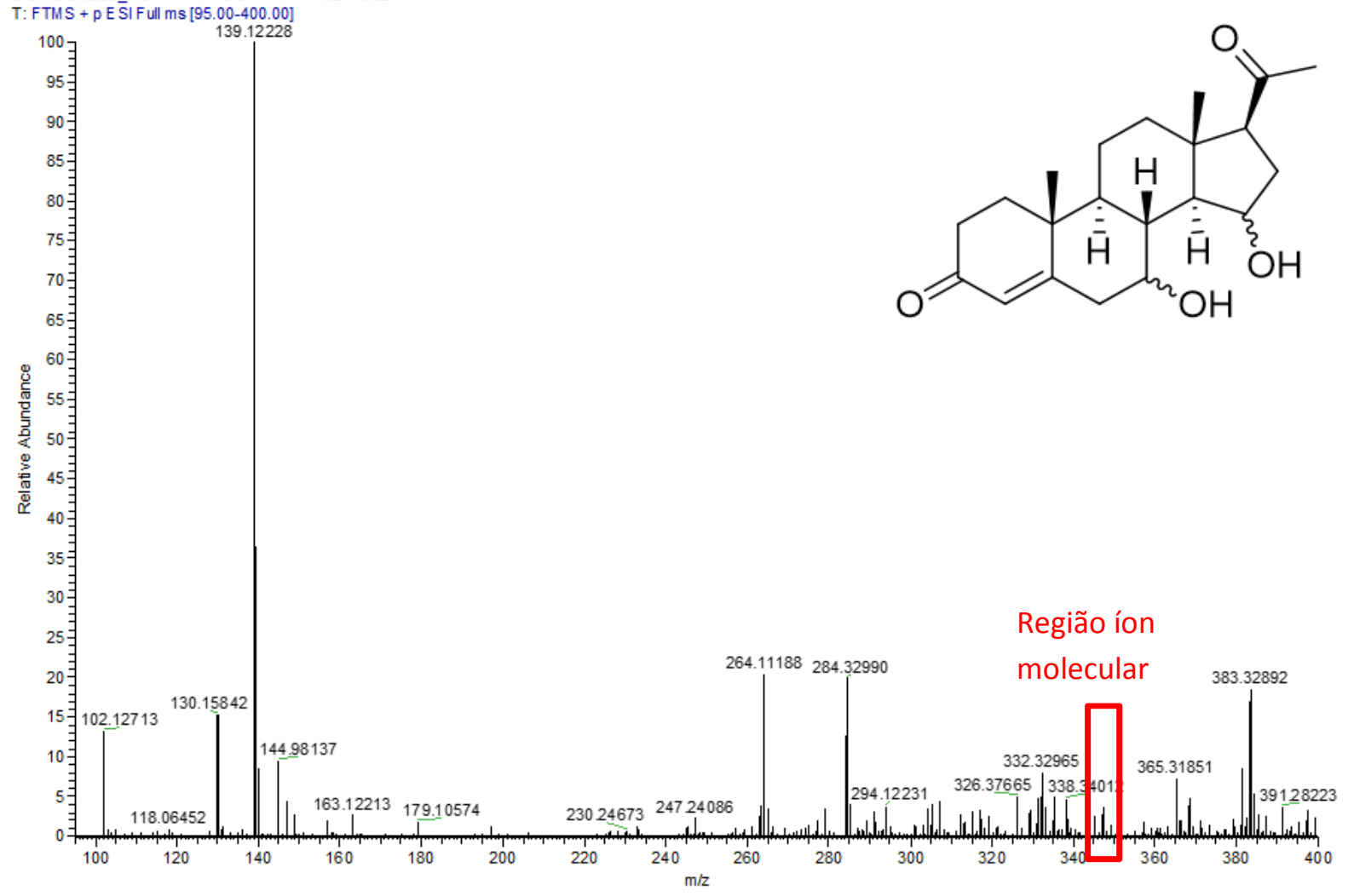


Espectro de EMAR - Modo positivo $\left({ }^{+} \mathrm{H}\right)$ - Full Scan da 7,15-di-hidroxiprogesterona. Ampliação da região do íon molecular e pico teórico do íon molecular.

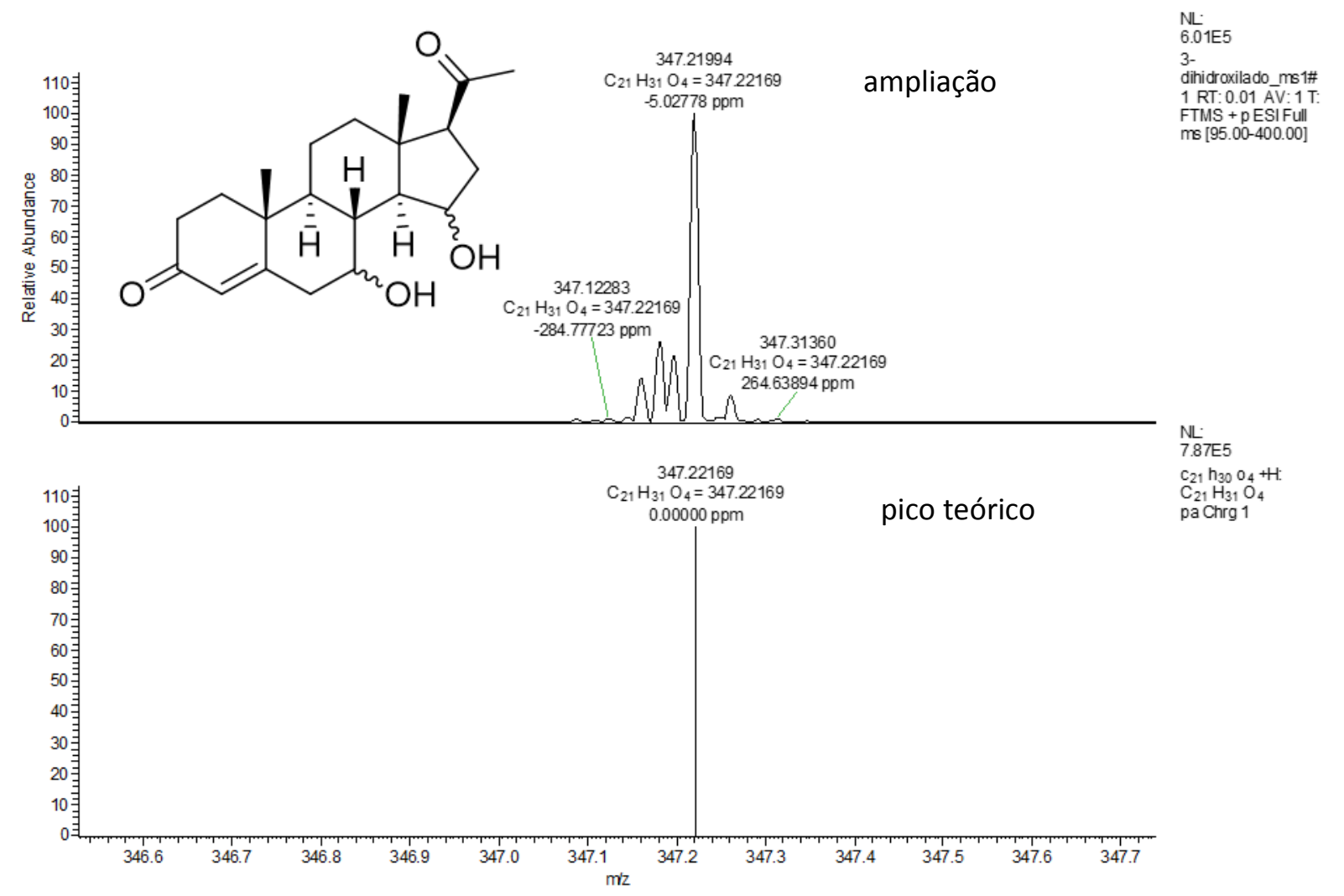

Espectro de RMN HMBC (100 MHz e $400 \mathrm{MHz}, \mathrm{CDCl}_{3}$ ) 15ß-hidroxiprogesterona.
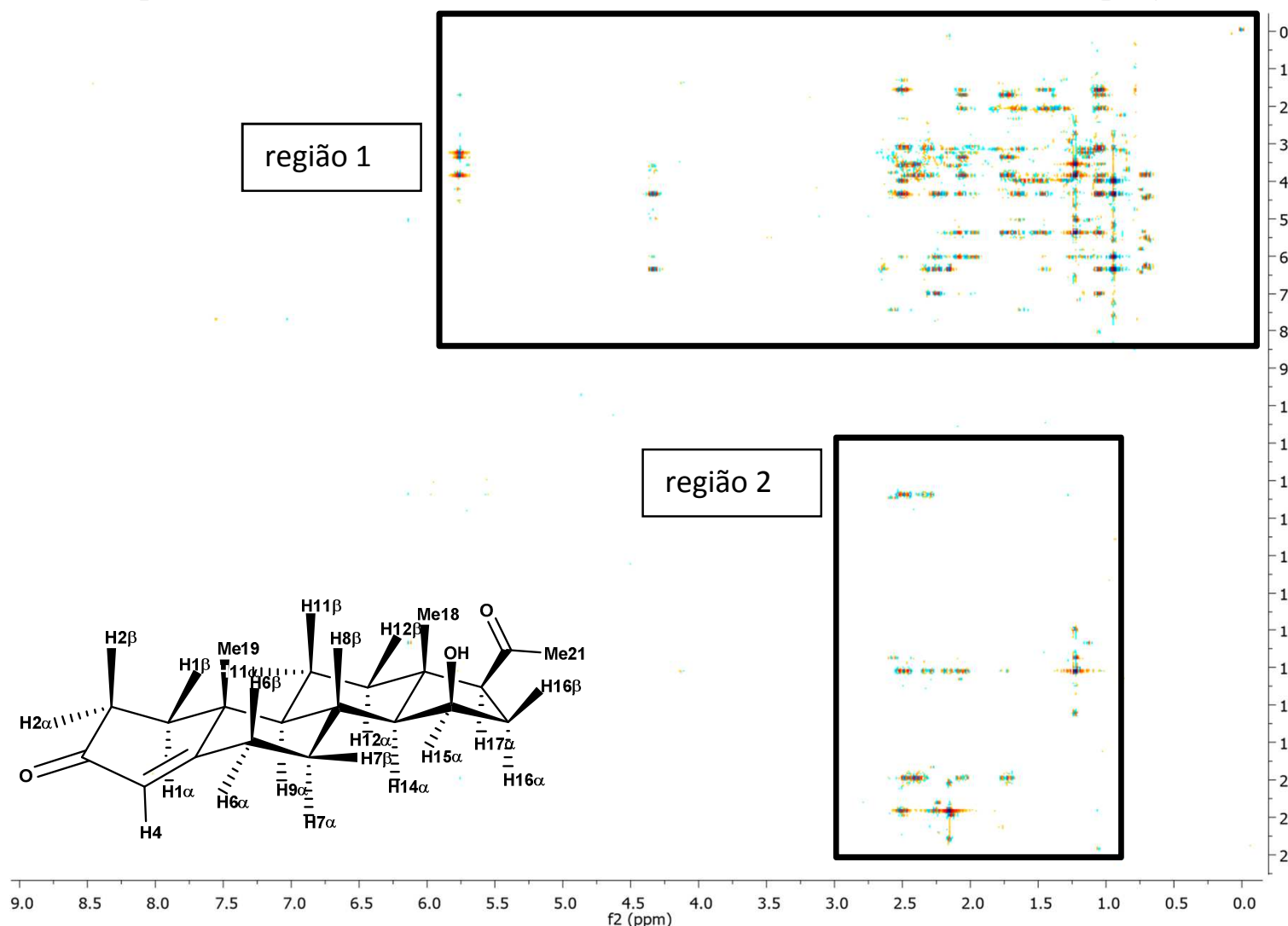

(região 1).

Espectro de RMN HMBC (100 MHz e $\left.400 \mathrm{MHz}, \mathrm{CDCl}_{3}\right)$ 15ß-hidroxiprogesterona

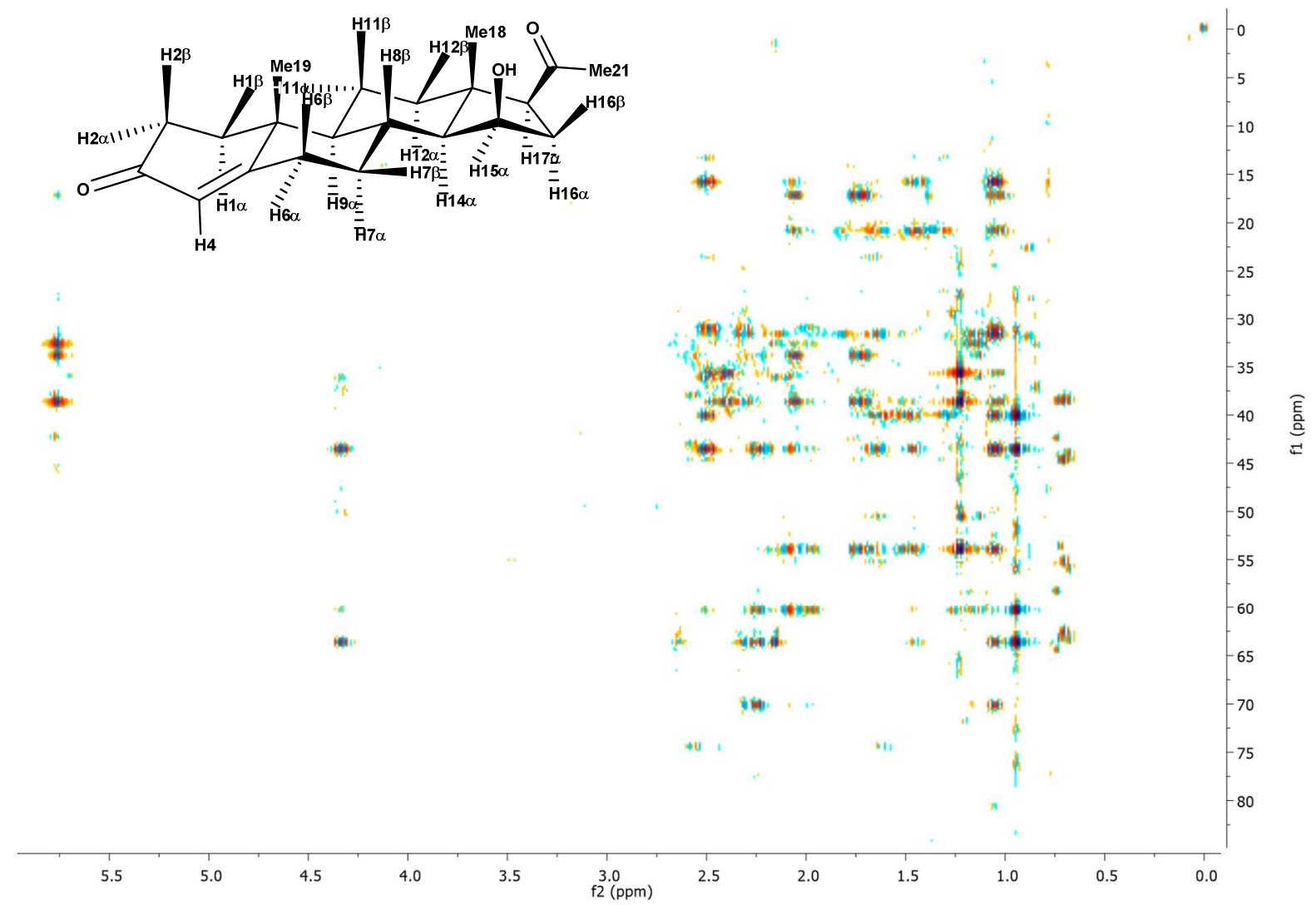

Espectro de RMN HMBC (100 MHz e $400 \mathrm{MHz}, \mathrm{CDCl}_{3}$ ) 15ß-hidroxiprogesterona (região 2).

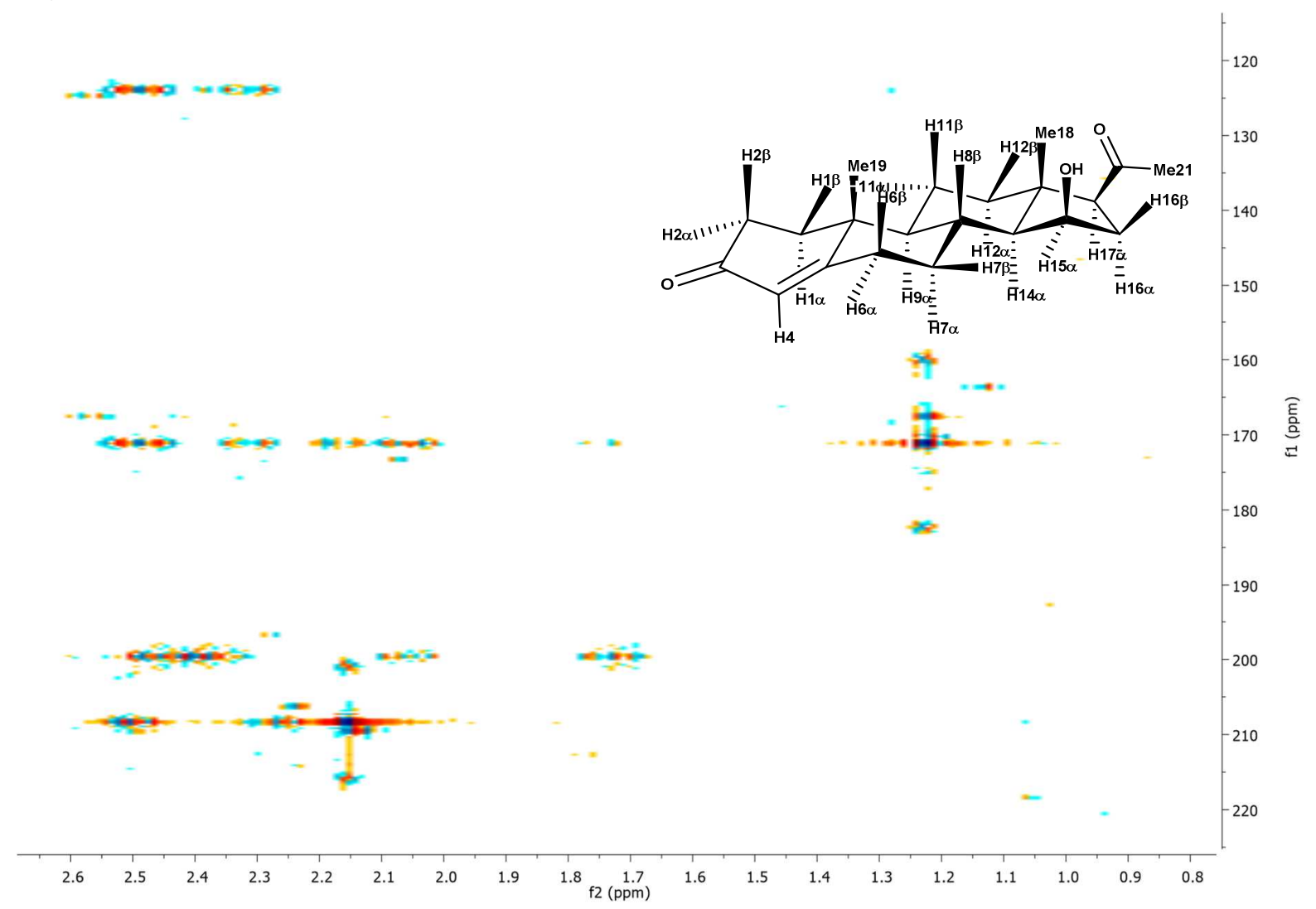


Espectro de RMN de COSY (400 MHz, $\mathrm{CDCl}_{3}$ ) 15ß-hidroxiprogesterona.
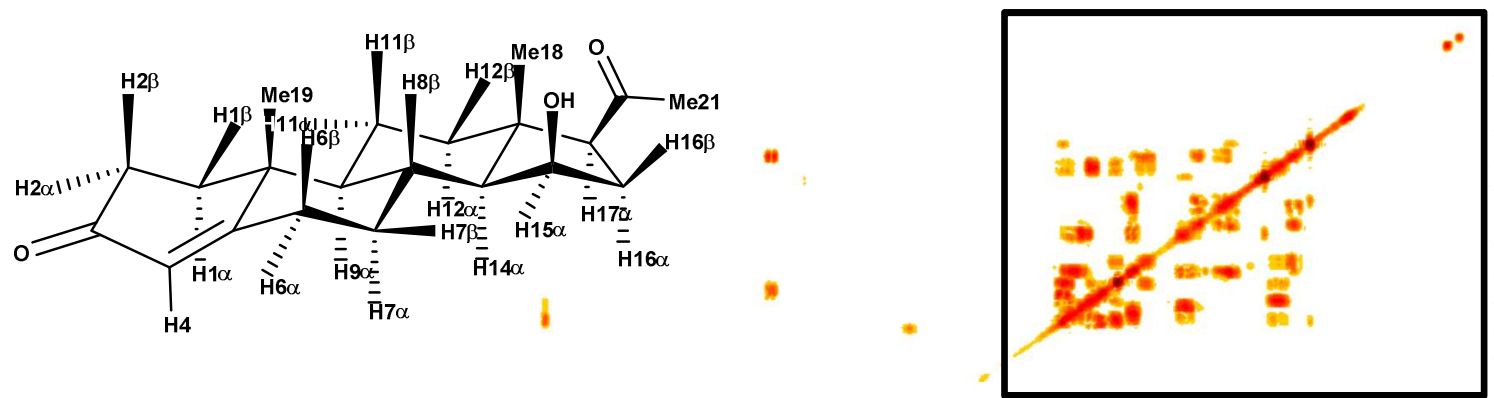

$-0.0$

$-0.5$

$-1.0$

1.5

$-2.0$ 2.5

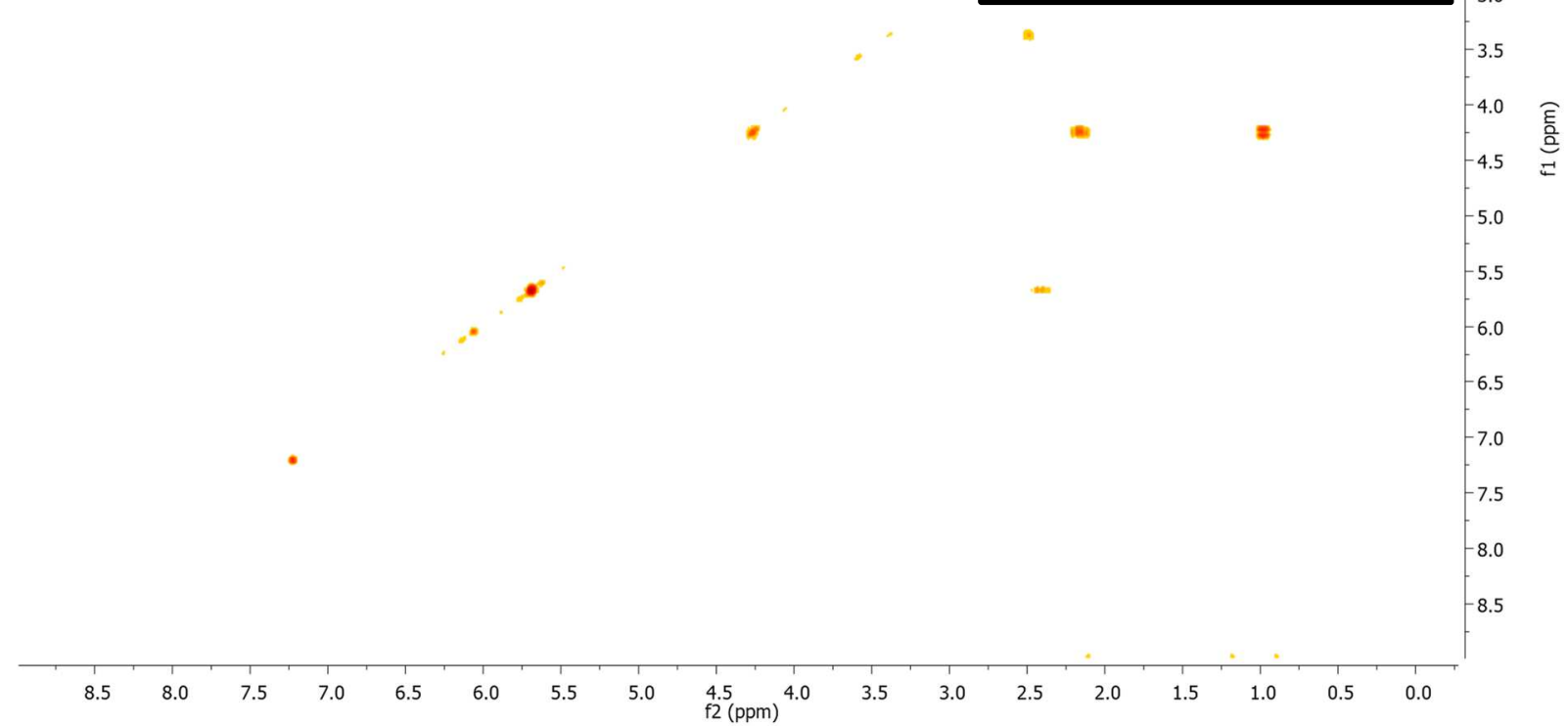

Espectro de RMN de COSY (400 MHz, $\mathrm{CDCl}_{3}$ ) 15ß-hidroxiprogesterona (ampliação).
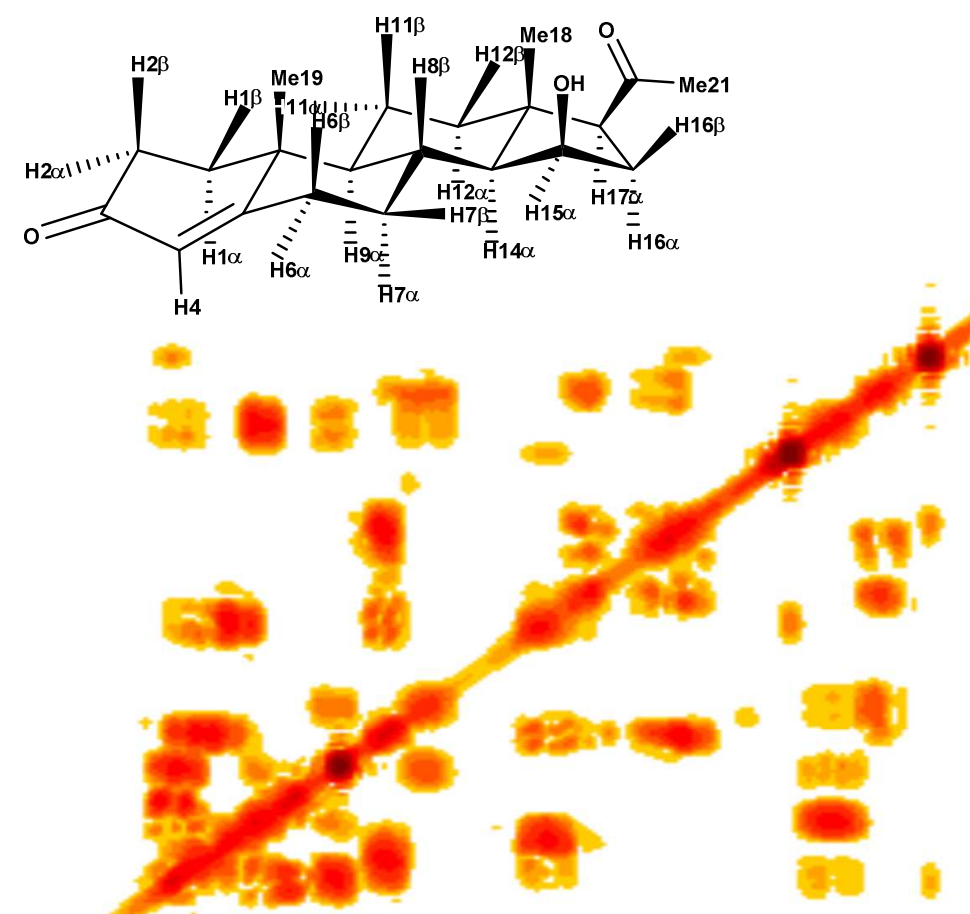

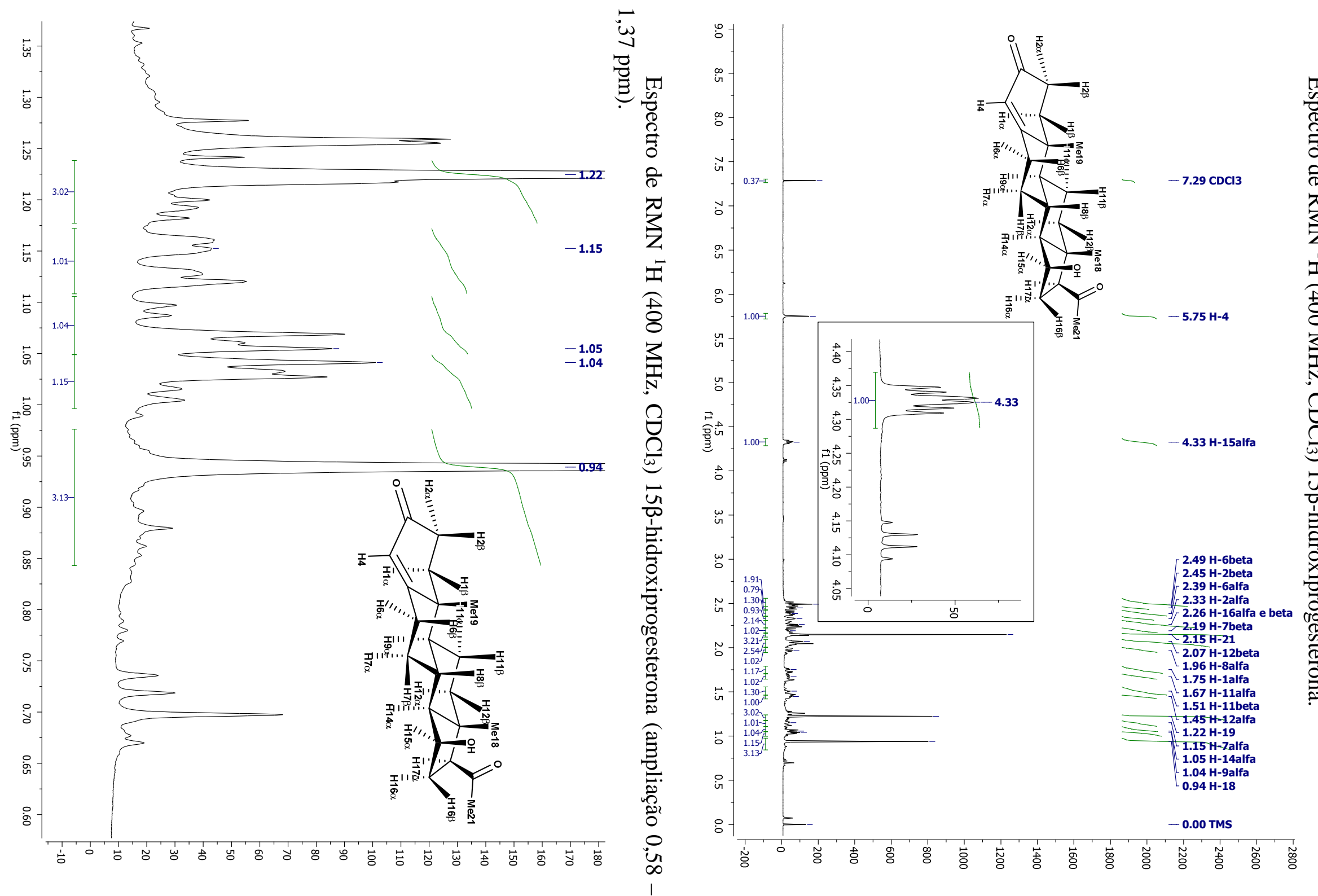

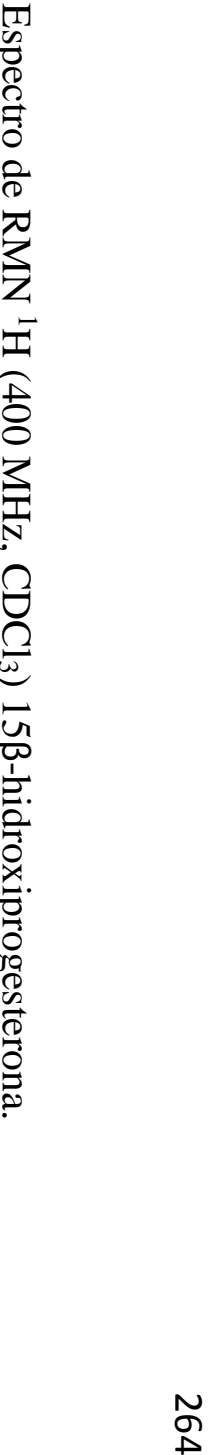



$1,80 \mathrm{ppm})$.

Espectro de RMN ${ }^{1} \mathrm{H}\left(400 \mathrm{MHz}, \mathrm{CDCl}_{3}\right.$ ) 15ß-hidroxiprogesterona (ampliação 1,33 -

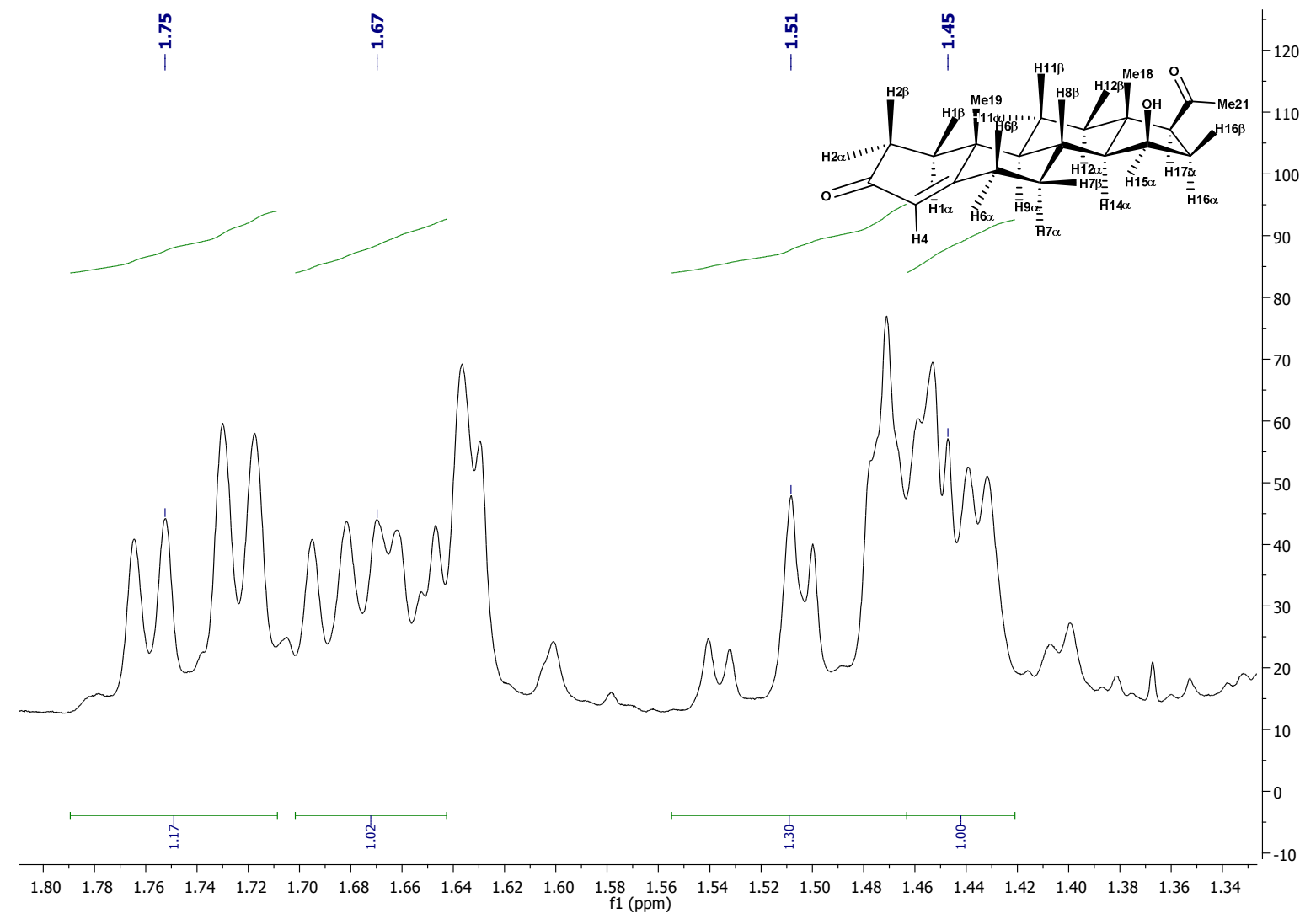

Espectro de $\mathrm{RMN}{ }^{1} \mathrm{H}\left(400 \mathrm{MHz}, \mathrm{CDCl}_{3}\right)$ 15ß-hidroxiprogesterona (ampliação 1,80 2,66 ppm).

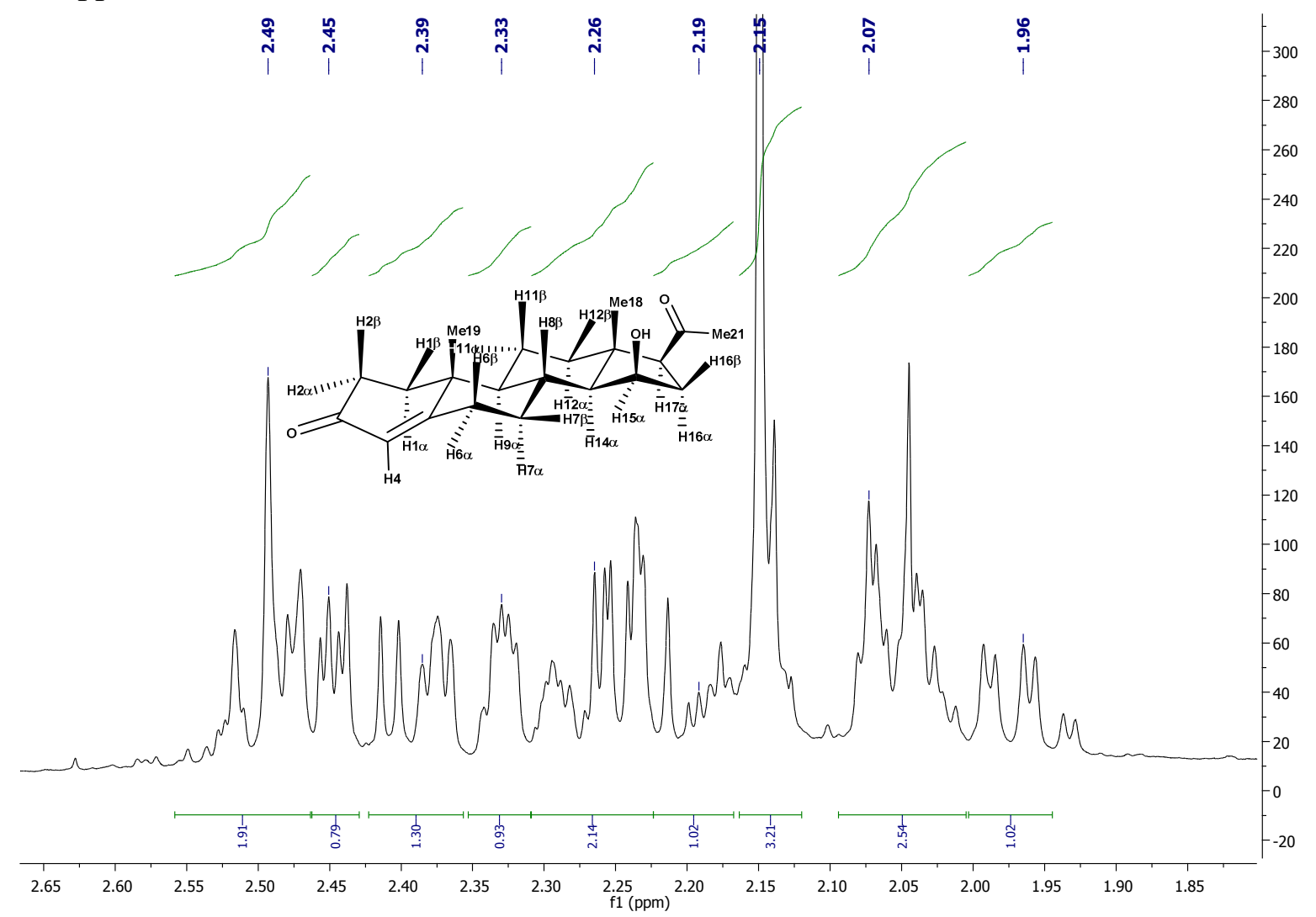


Constantes de acoplamento encontradas no sinal de multipleto do hidrogênio H-15 $\alpha$ da $15 \beta$-hidroxiprogesterona a partir do seu espectro de $\mathrm{RMN}{ }^{1} \mathrm{H}\left(500 \mathrm{MHz}, \mathrm{CDCl}_{3}\right)$.

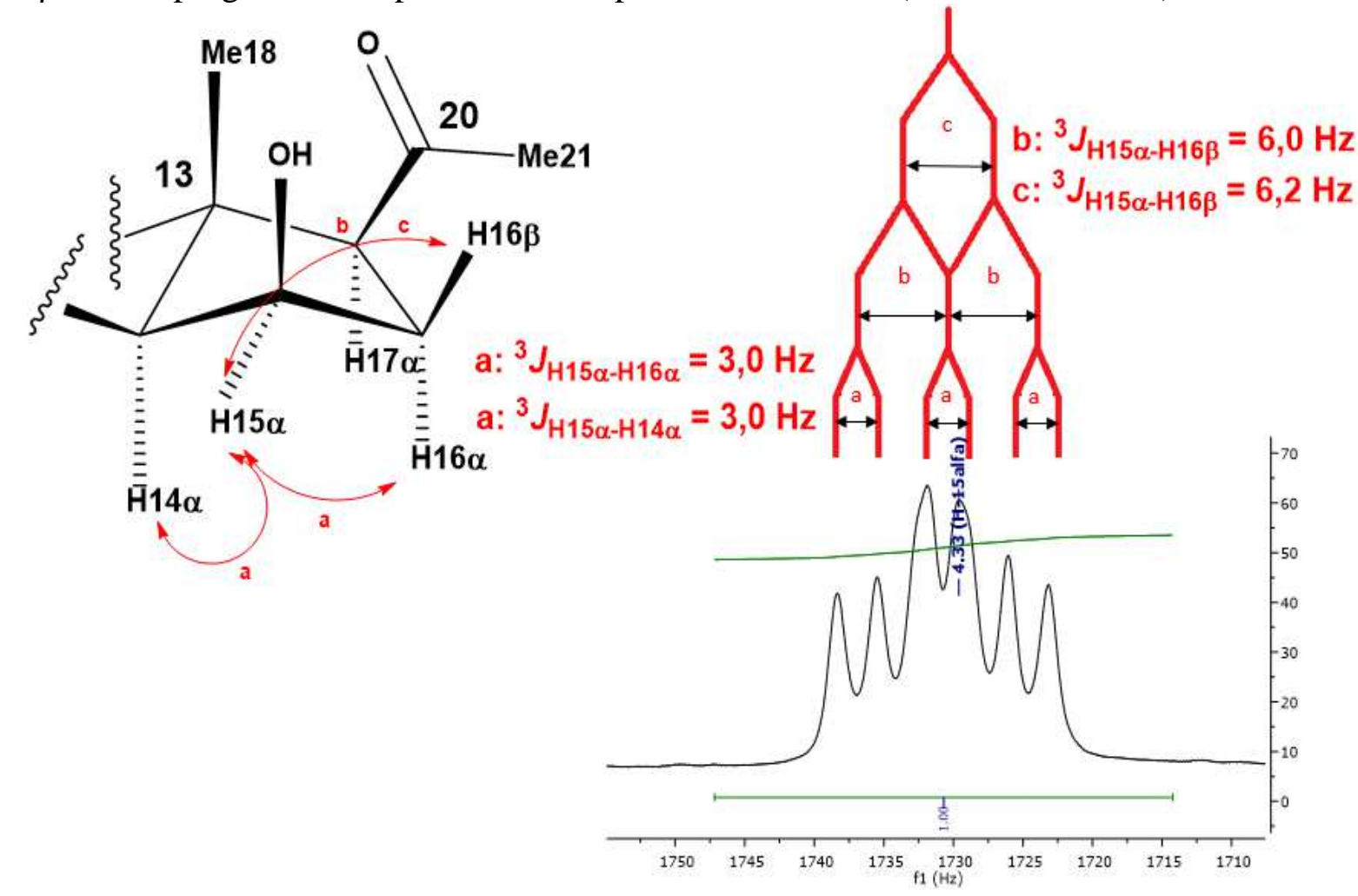

Espectro de EMAR - Modo positivo $\left({ }^{+} \mathrm{H}\right)$ - Full Scan da 15ß-hidroxiprogesterona.

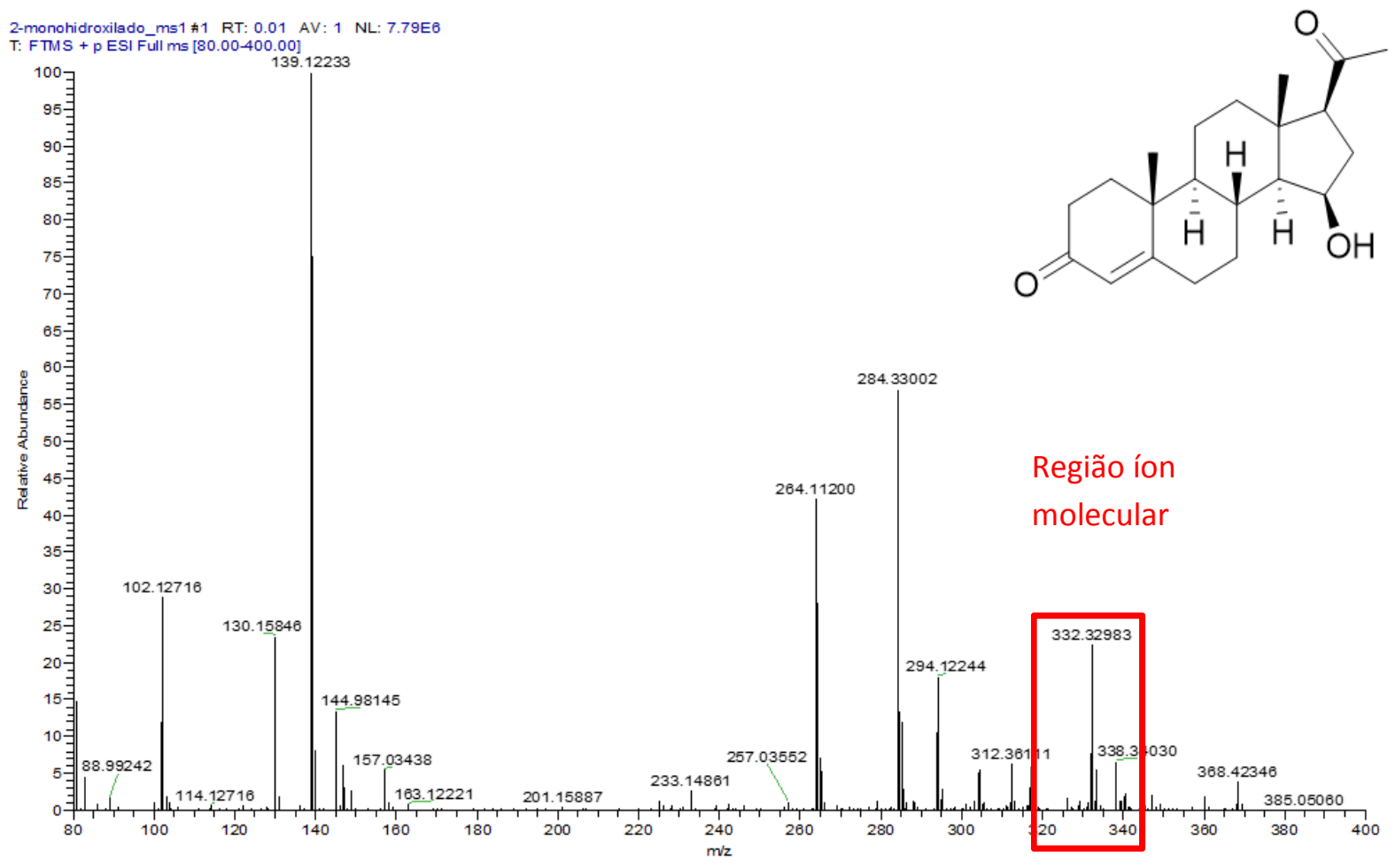


Espectro de EMAR - Modo positivo $\left({ }^{+} \mathrm{H}\right)$ - Full Scan da 15 $\beta$-hidroxiprogesterona. Ampliação da região do íon molecular e pico teórico do íon molecular.

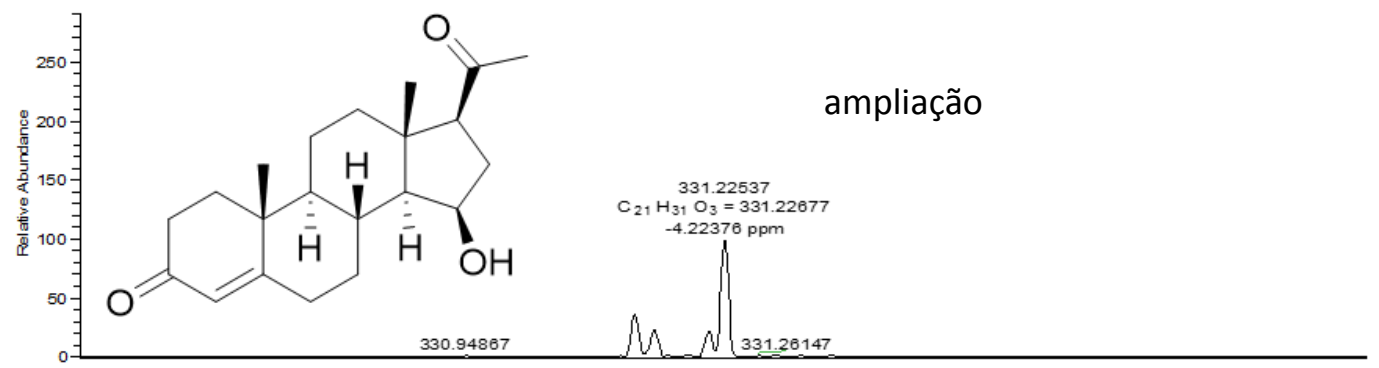
NL:
$7.76 E 4$ 2 monohidroxilado $\mathrm{ms}$
1\#1 RT: $0.01 \mathrm{AV}: 1$ T: FTMS + p ESIF ull ms $[80.00-400.00]$

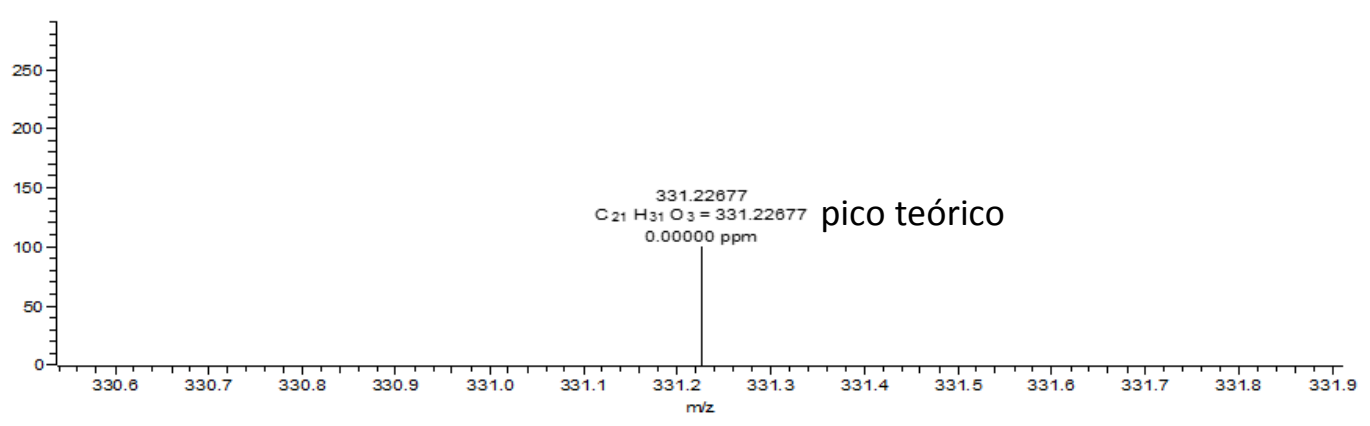

$\mathrm{C}_{21} \mathrm{~h}_{30} \mathrm{O}_{3}+\mathrm{H}$ pa Chrg 1

Espectro de RMN HMBC (100 MHz, $\left.400 \mathrm{MHz}, \mathrm{CDCl}_{3}\right)$ testosterona.
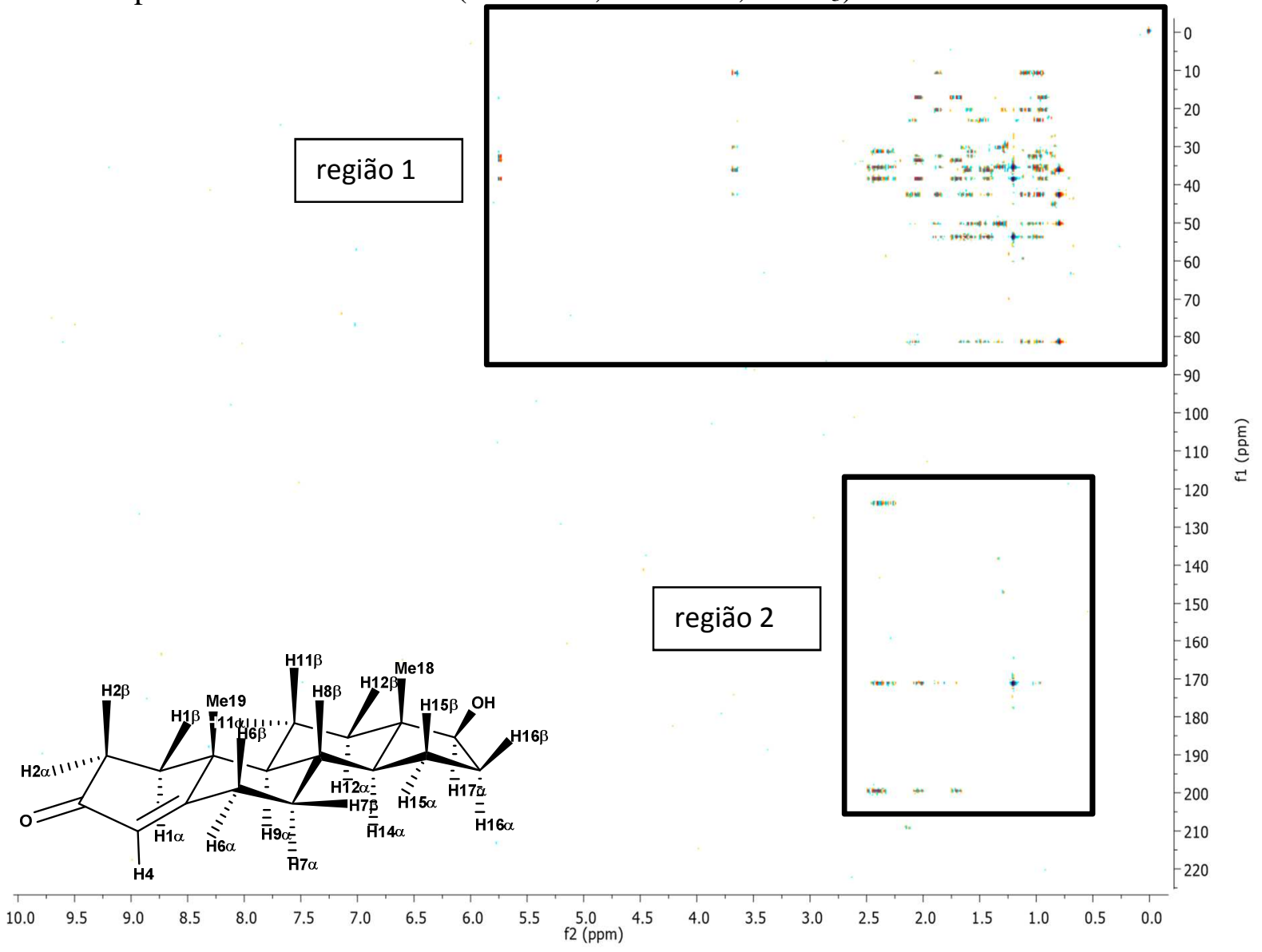
Espectro de RMN HMBC (100 MHz, $\left.400 \mathrm{MHz}, \mathrm{CDCl}_{3}\right)$ testosterona (região 1).
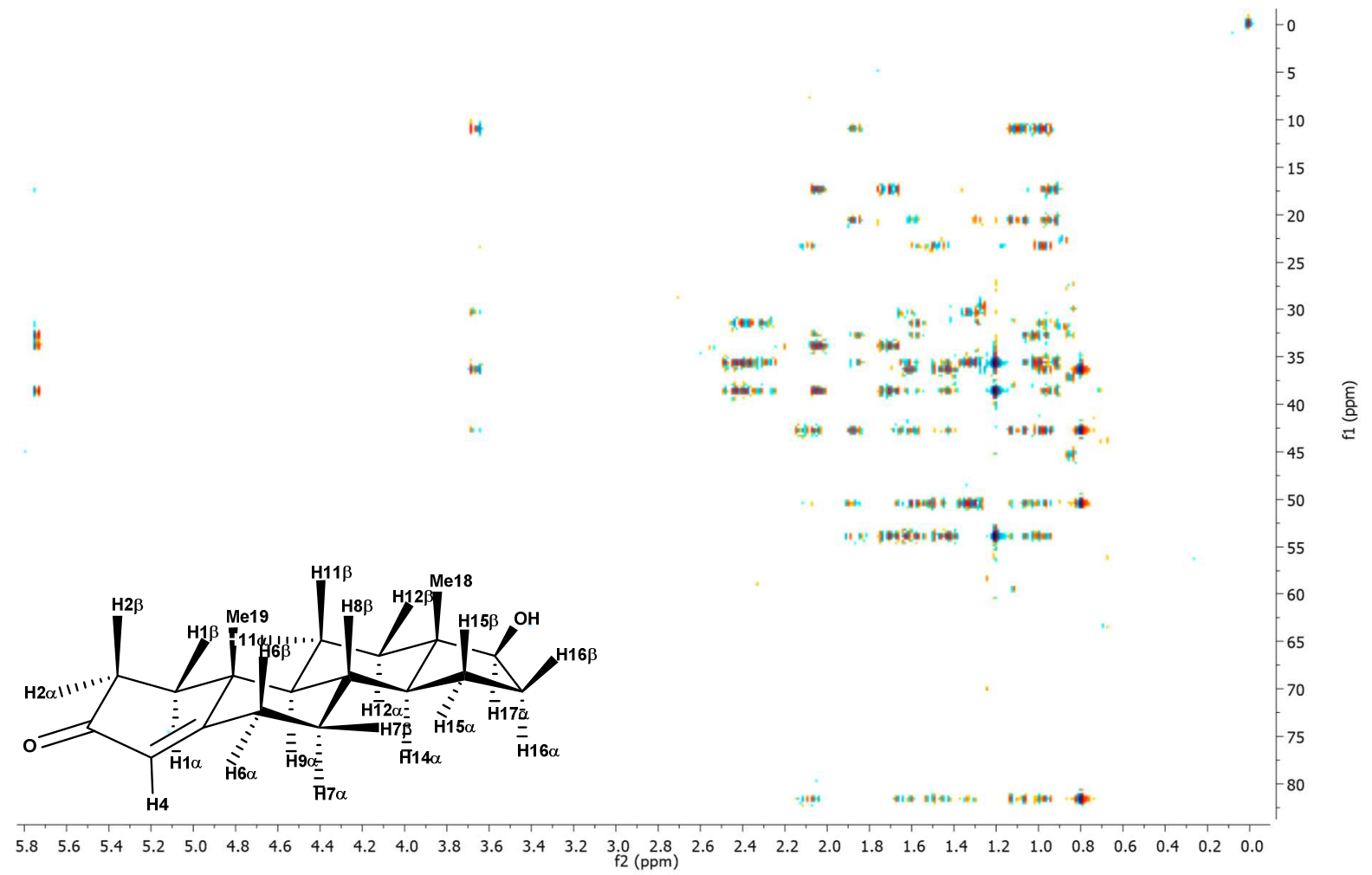

Espectro de RMN HMBC (100 MHz, $400 \mathrm{MHz}, \mathrm{CDCl}_{3}$ ) testosterona (região 2).

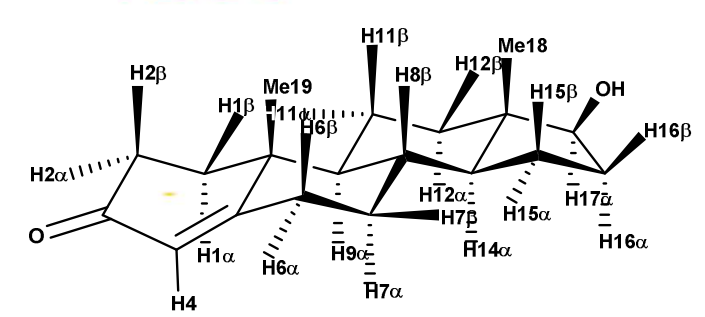


Espectro de RMN COSY (400 MHz, $\mathrm{CDCl}_{3}$ ) da testosterona.
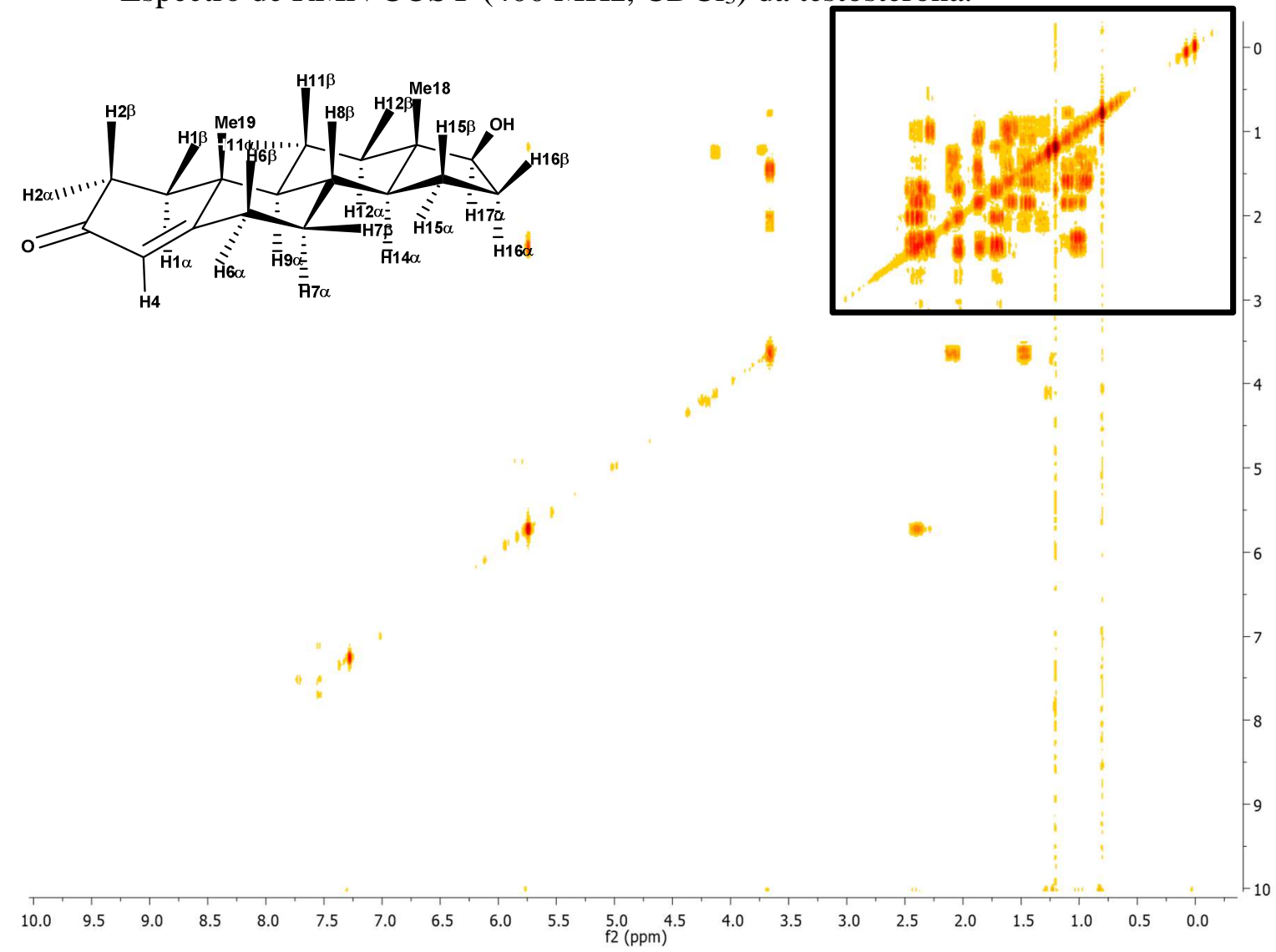

Espectro de RMN COSY (400 MHz, $\mathrm{CDCl}_{3}$ ) da testosterona (ampliação).
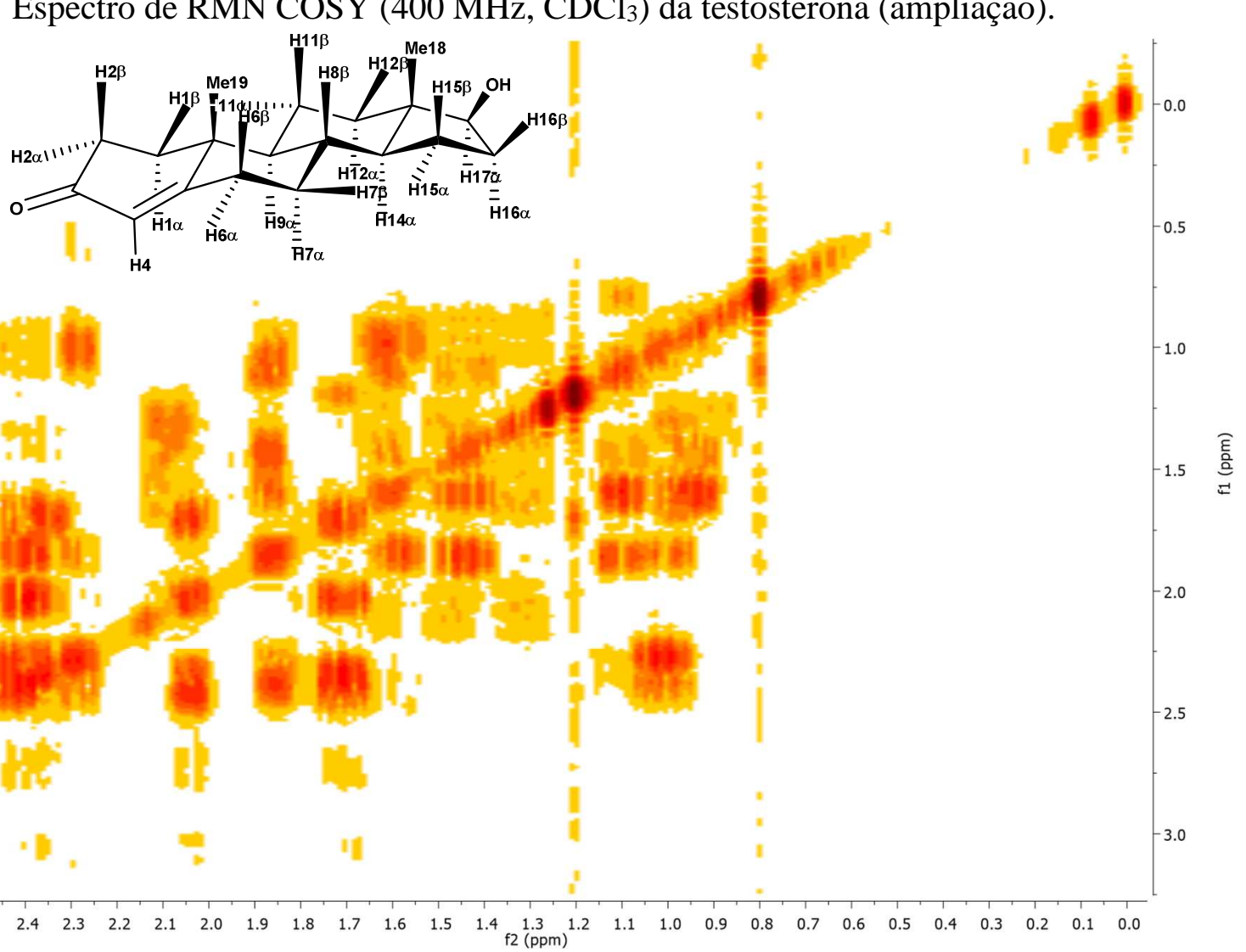

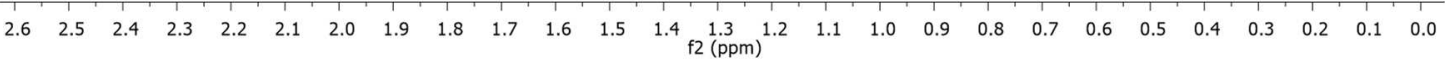



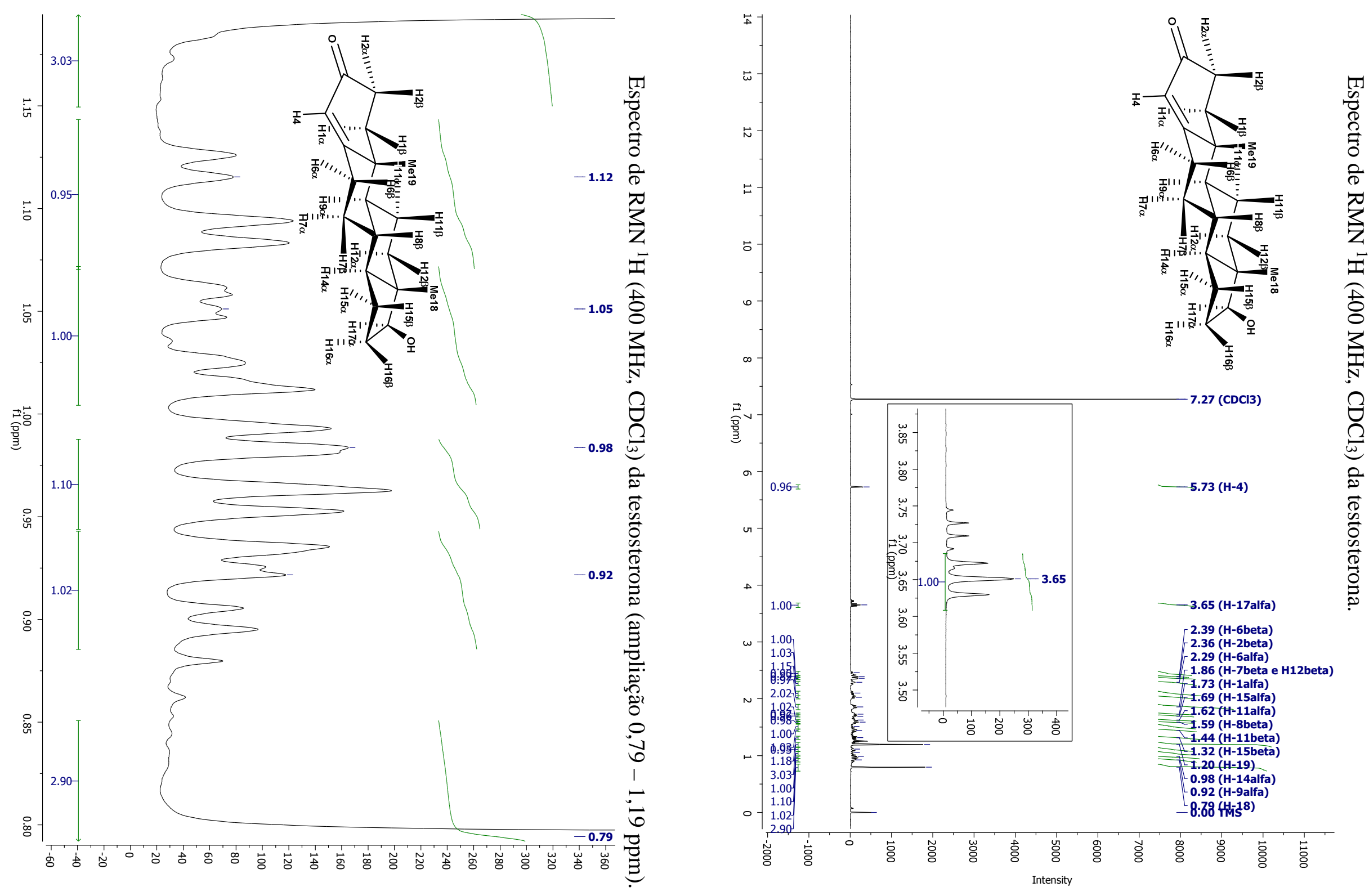
Espectro de $\mathrm{RMN}{ }^{1} \mathrm{H}\left(400 \mathrm{MHz}, \mathrm{CDCl}_{3}\right.$ ) da testosterona (ampliação 1,17 - 2,58 ppm). 帝
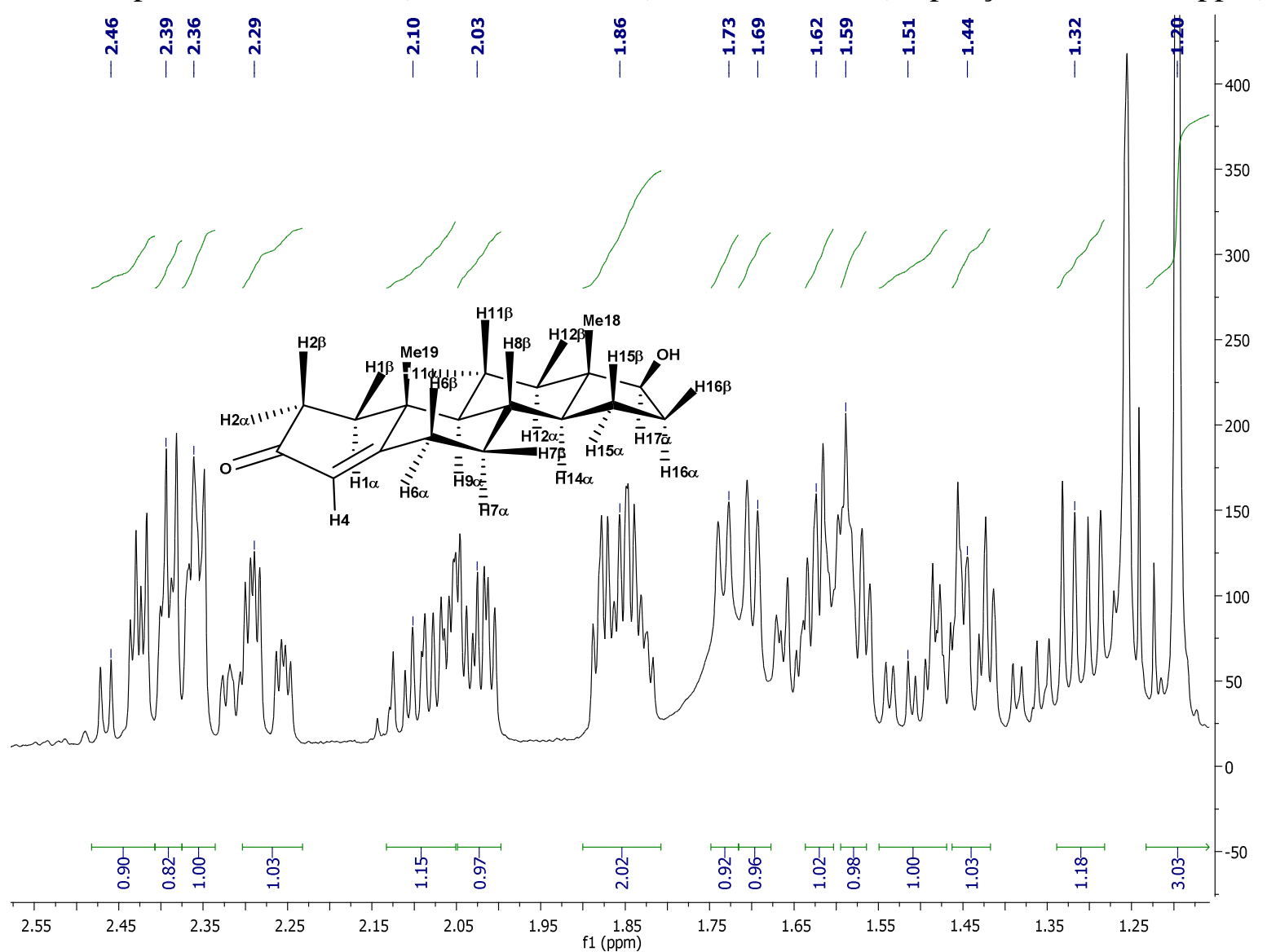

Constantes de acoplamento encontradas no sinal de multipleto do hidrogênio H-17 $\alpha$ da testosterona a partir do seu espectro de $\mathrm{RMN}^{1} \mathrm{H}\left(400 \mathrm{MHz}, \mathrm{CDCl}_{3}\right)$.

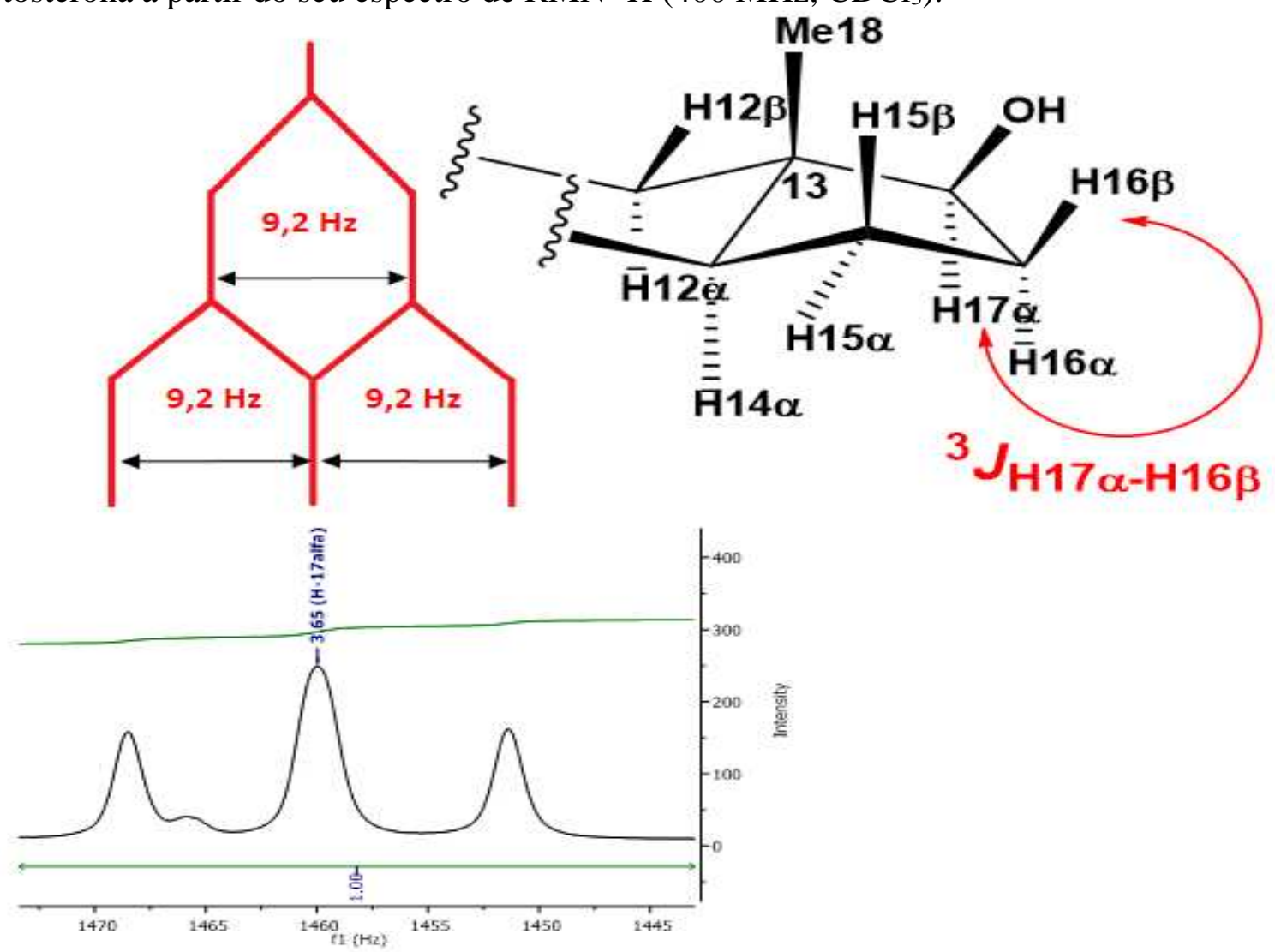


Espectro de RMN HMBC (100 MHz, $\left.400 \mathrm{MHz}, \mathrm{CDCl}_{3}\right)$ testololactona.

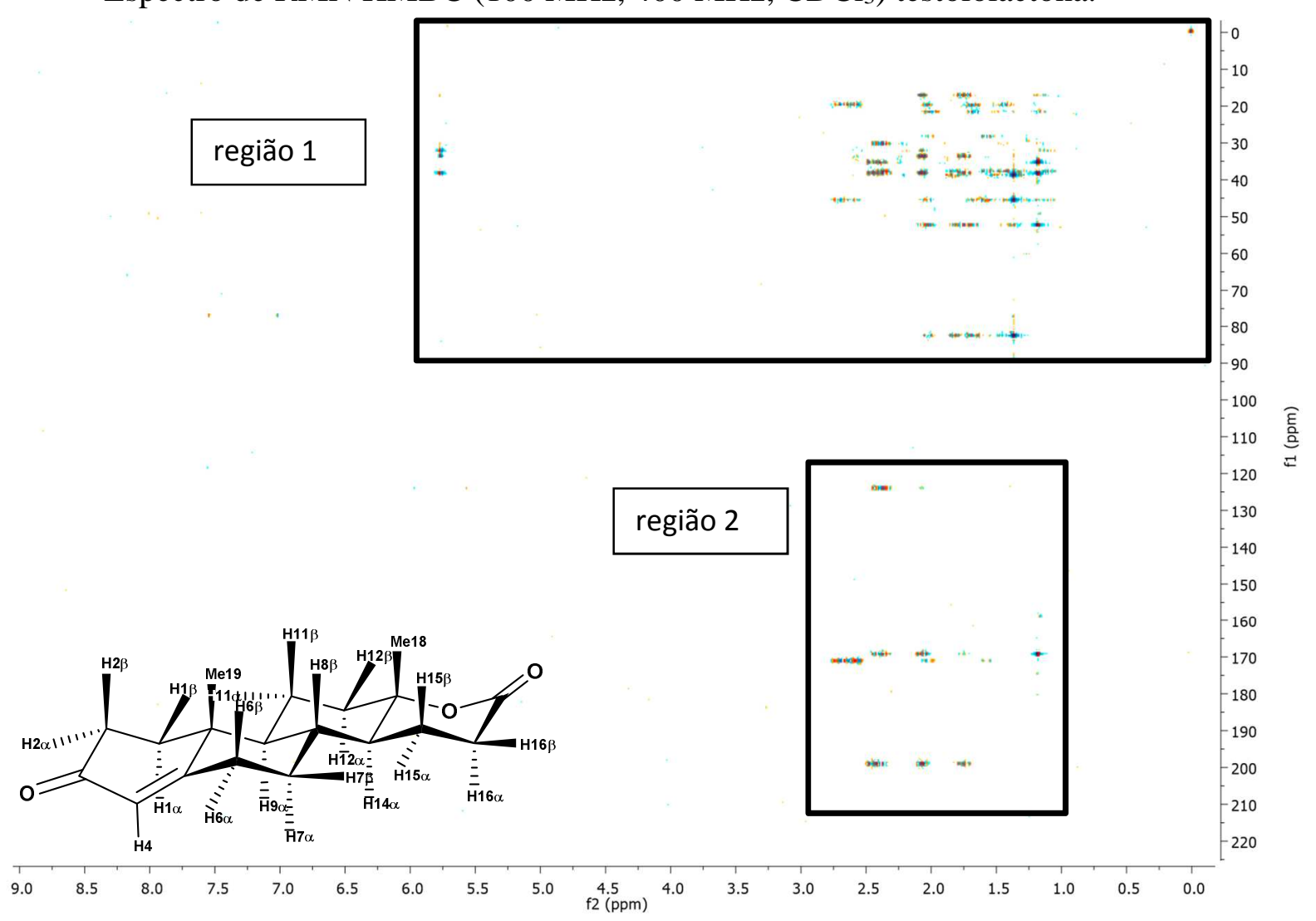

Espectro de RMN HMBC (100 MHz, $400 \mathrm{MHz}, \mathrm{CDCl}_{3}$ ) testololactona (região 1).

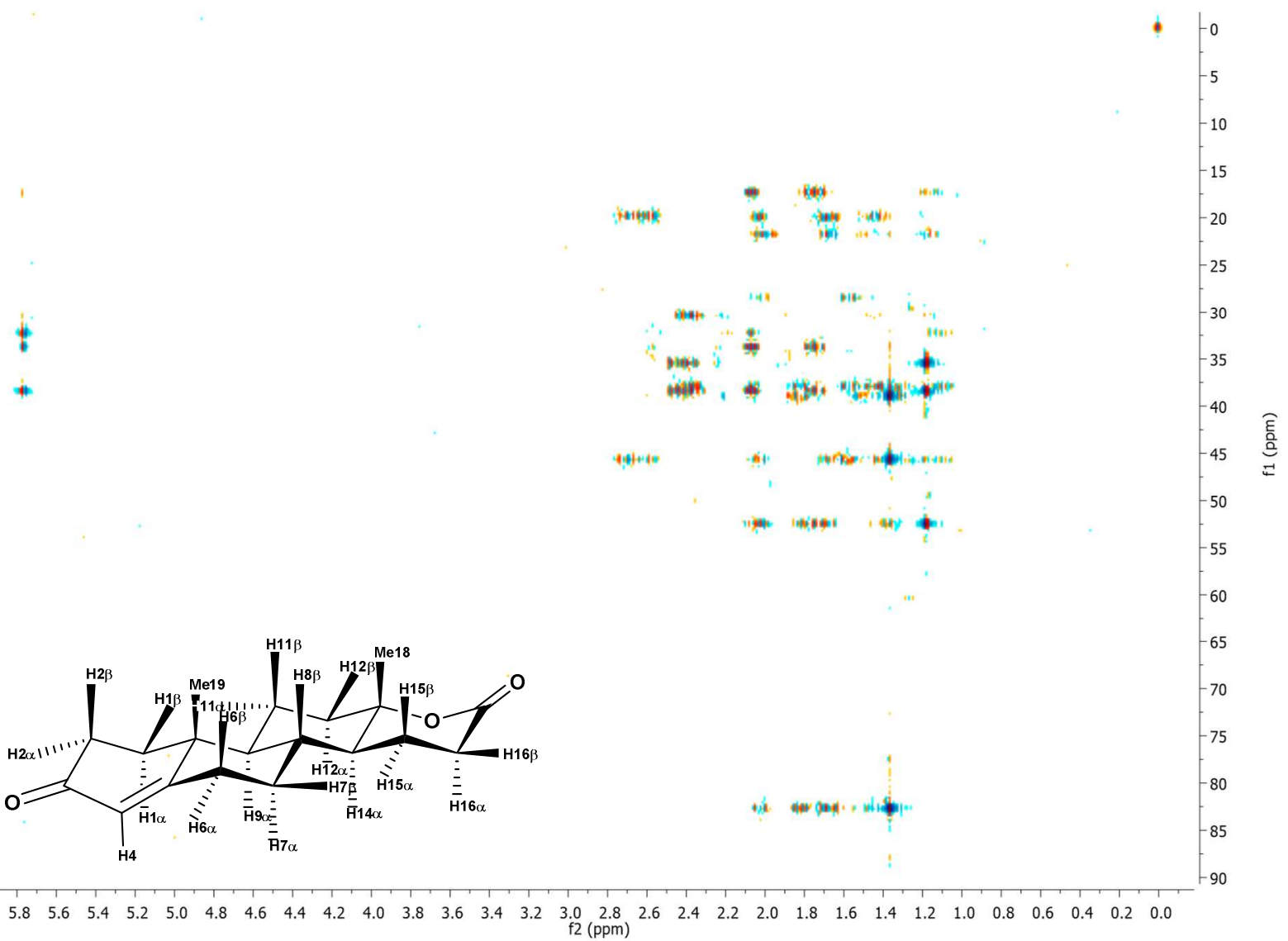


Espectro de RMN HMBC (100 MHz, $\left.400 \mathrm{MHz}, \mathrm{CDCl}_{3}\right)$ testololactona (região 2).

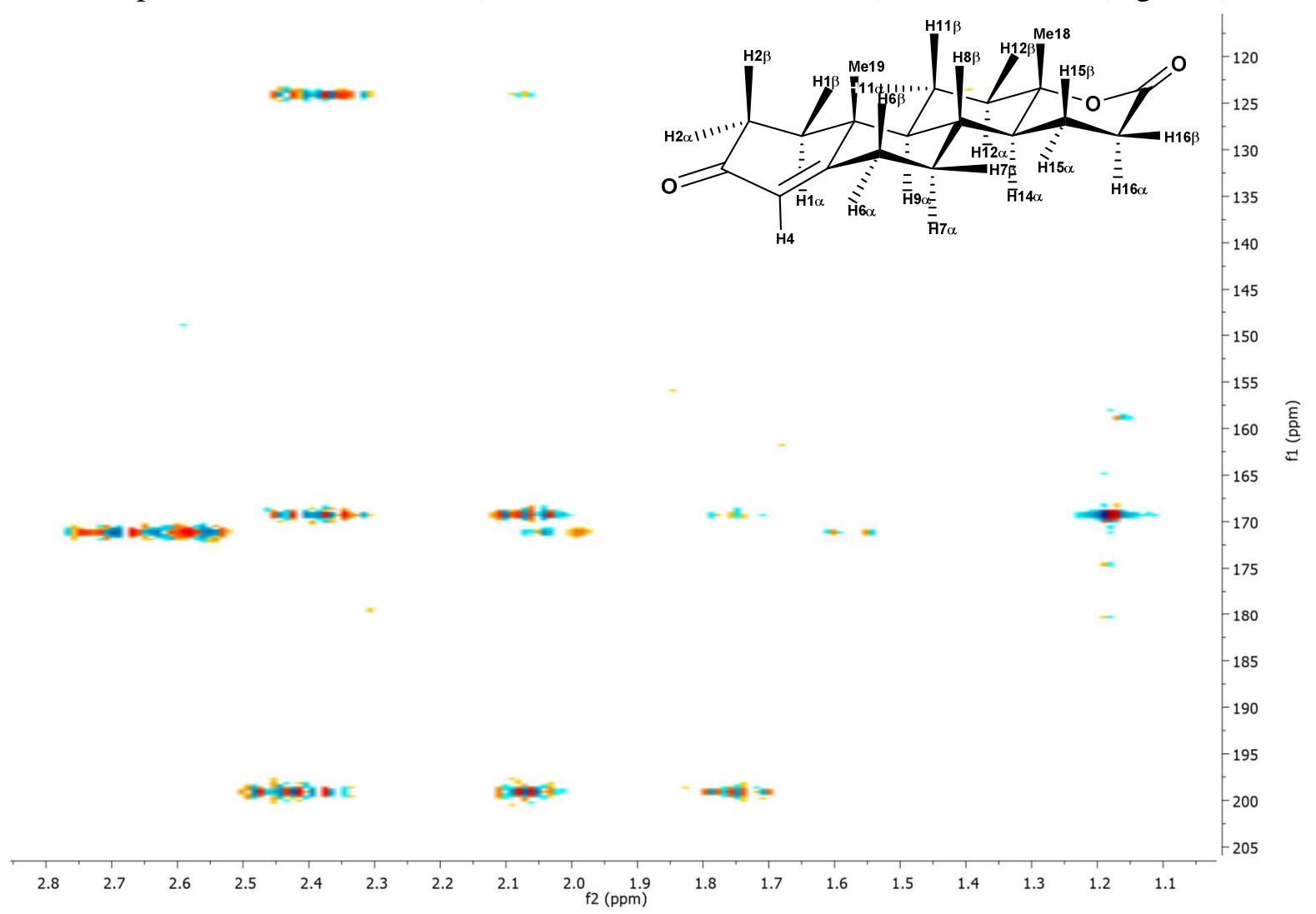

Espectro de RMN COSY (400 MHz, $\left.\mathrm{CDCl}_{3}\right)$ da testololactona.
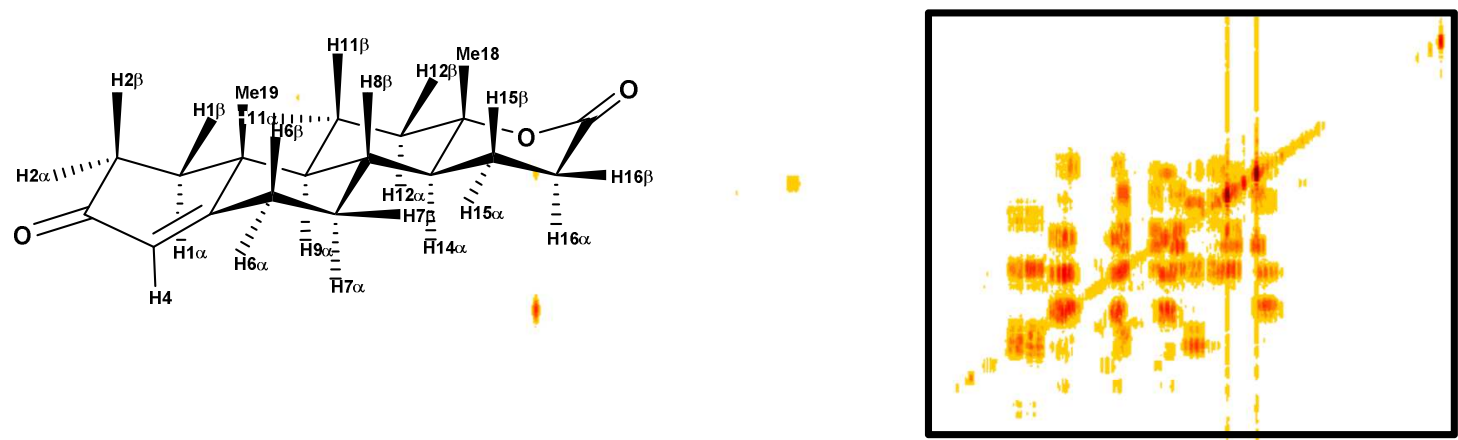

$-0.0$

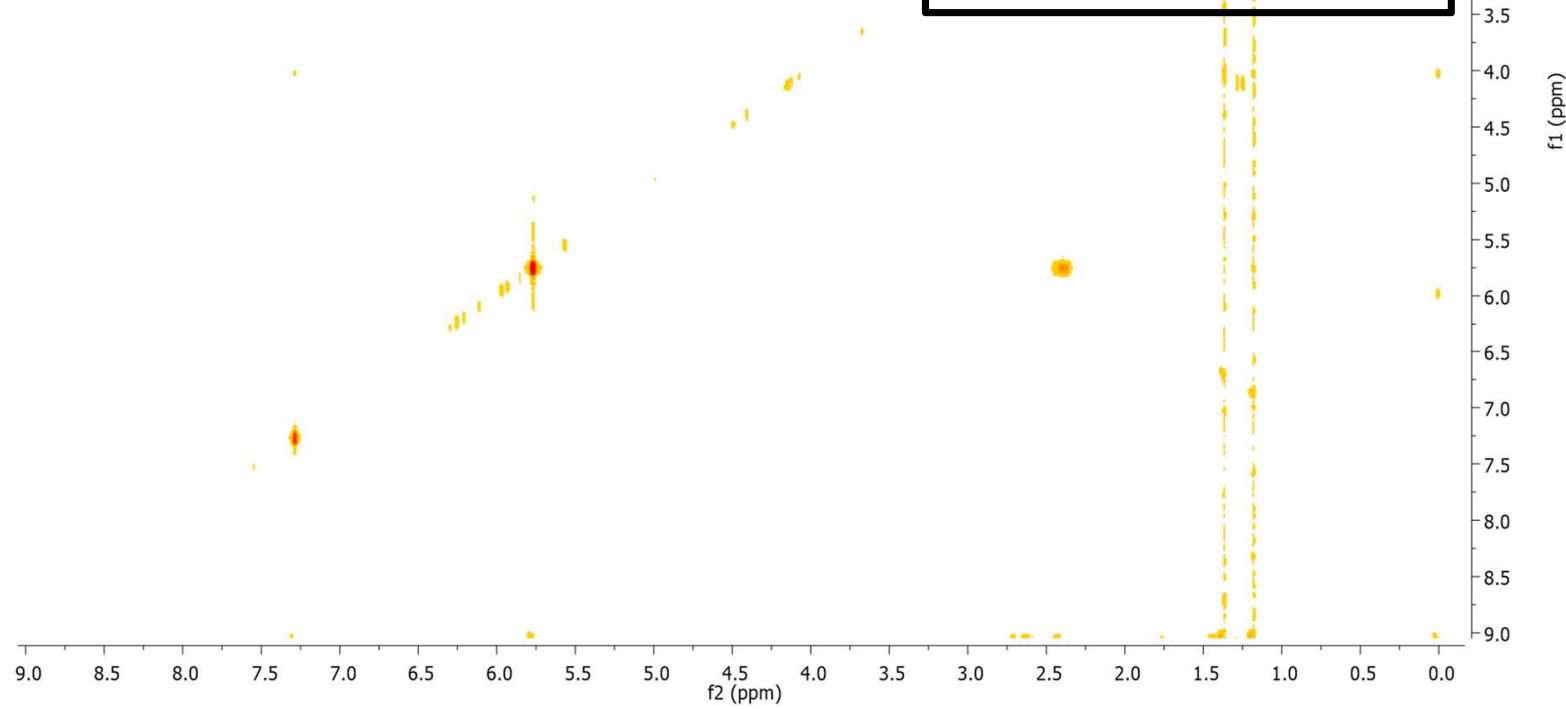



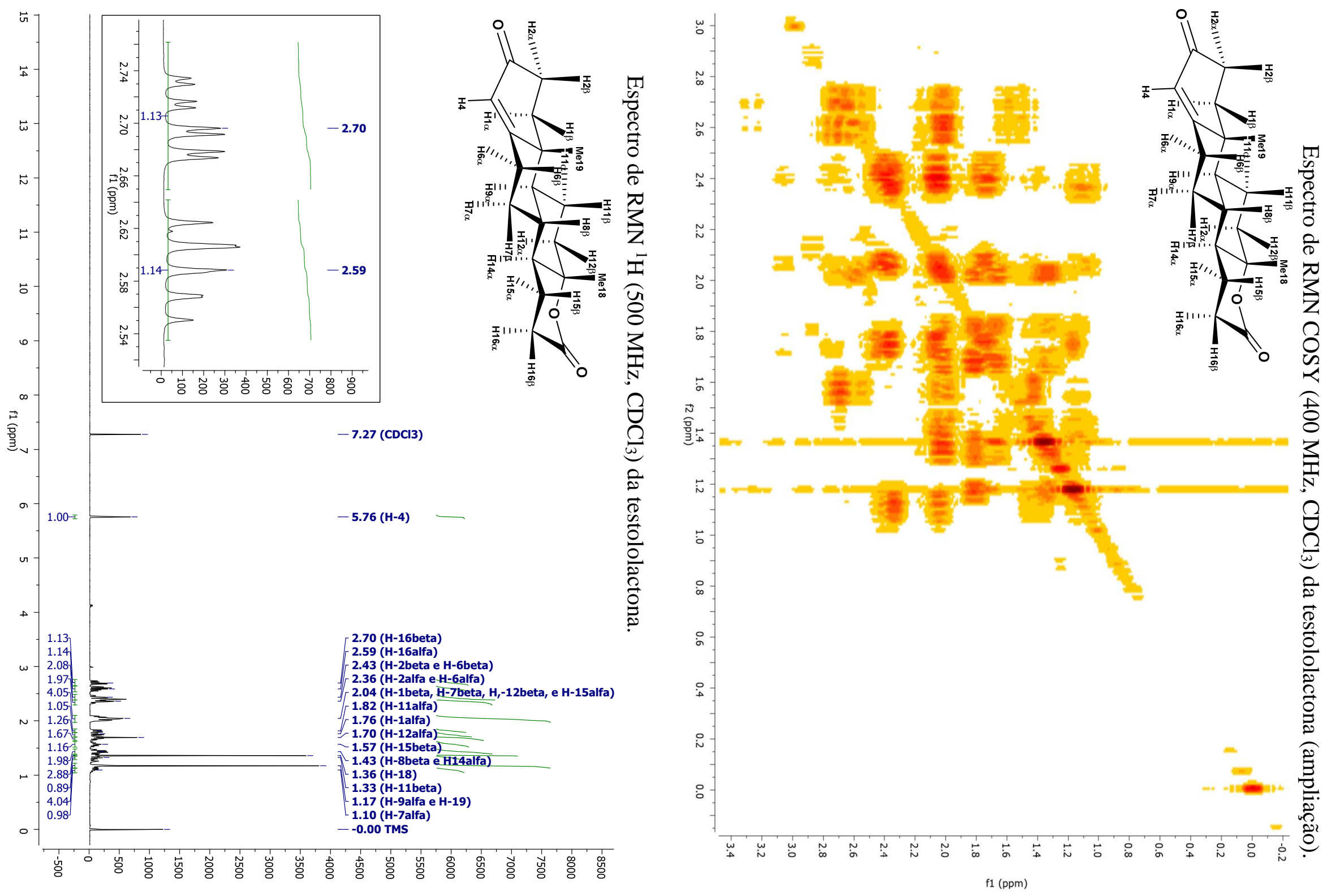
Espectro de $\mathrm{RMN}{ }^{1} \mathrm{H}\left(500 \mathrm{MHz}, \mathrm{CDCl}_{3}\right)$ testololactona (ampliação 1,03 - 1,23 ppm).

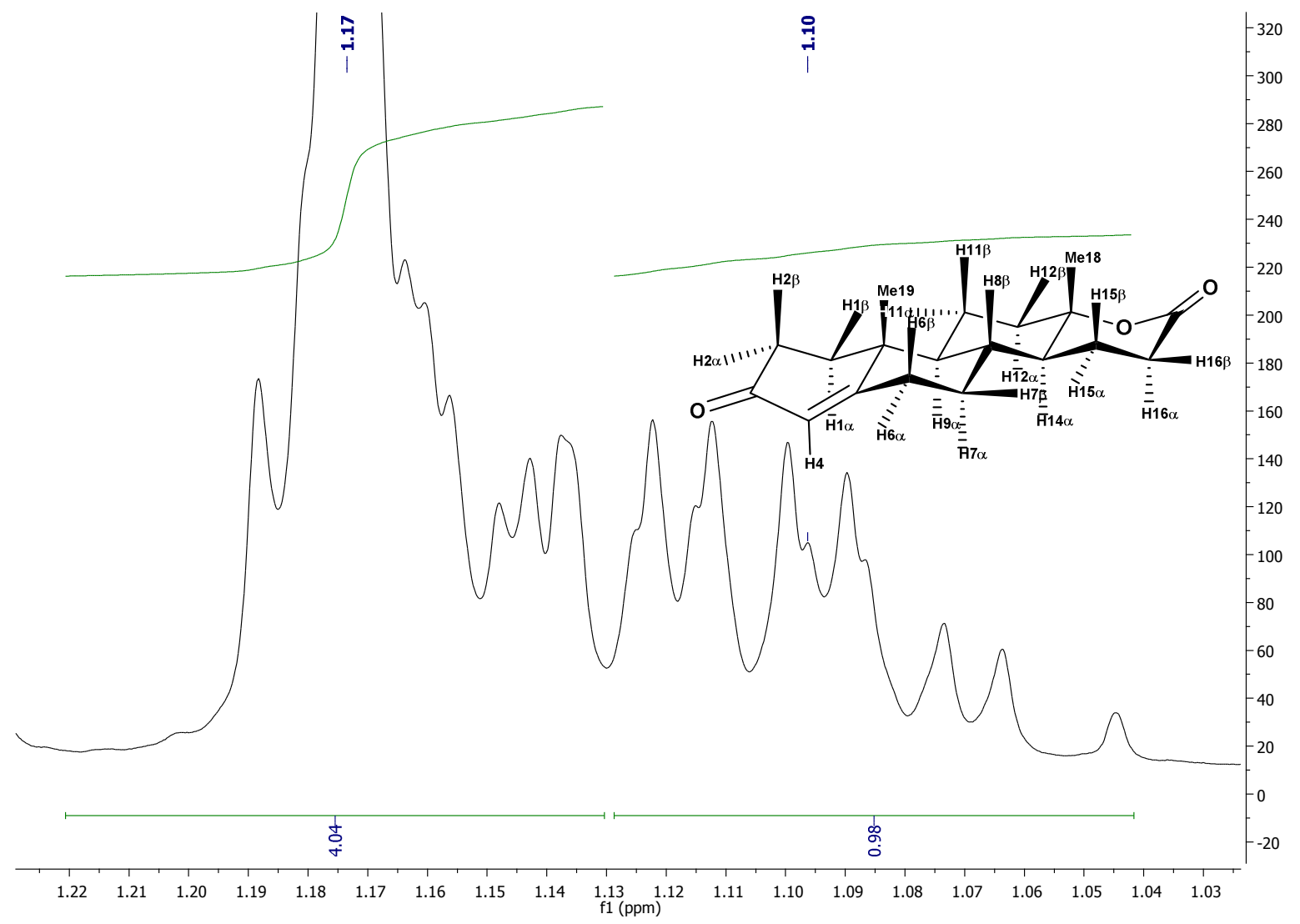

Espectro de RMN ${ }^{1} \mathrm{H}\left(500 \mathrm{MHz}, \mathrm{CDCl}_{3}\right.$ ) testololactona (ampliação 1,22 - 1,50 ppm).
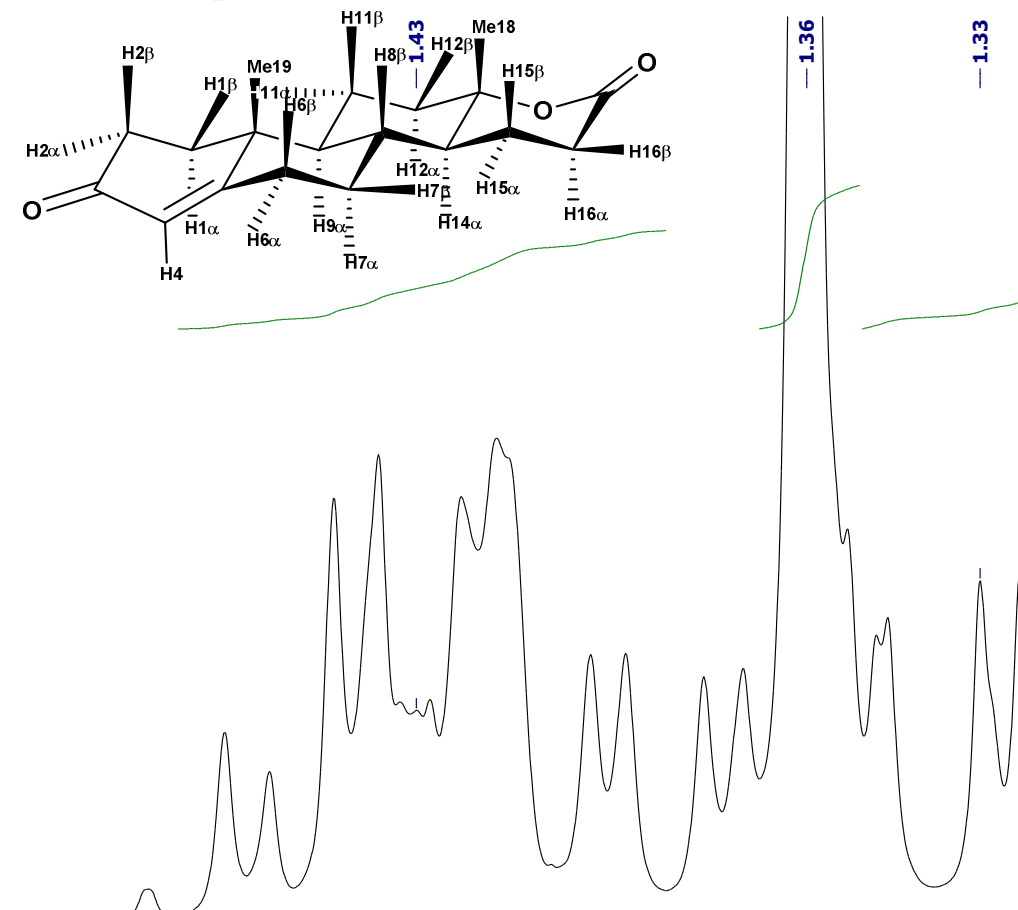

?

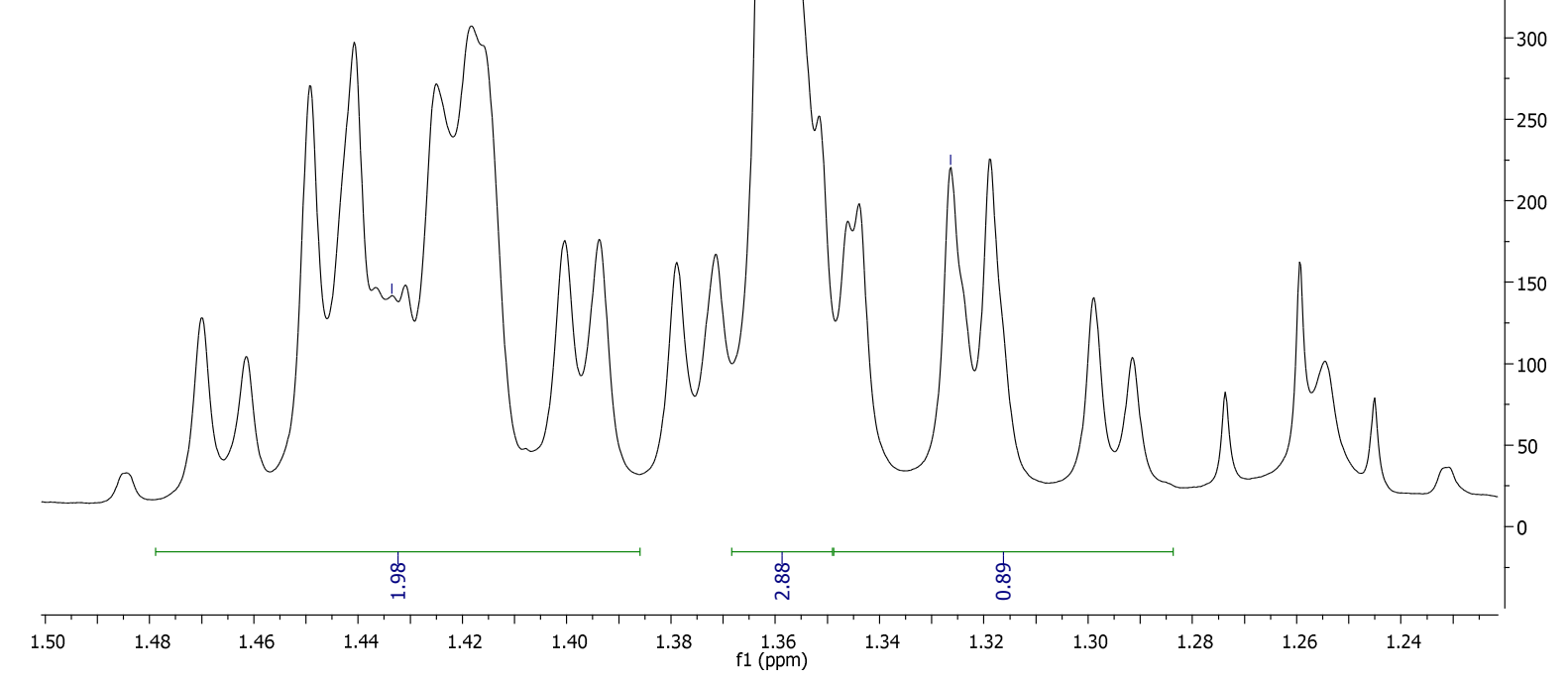


Espectro de $\mathrm{RMN}{ }^{1} \mathrm{H}\left(500 \mathrm{MHz}, \mathrm{CDCl}_{3}\right)$ testololactona (ampliação 1,51 - 1,87 ppm).

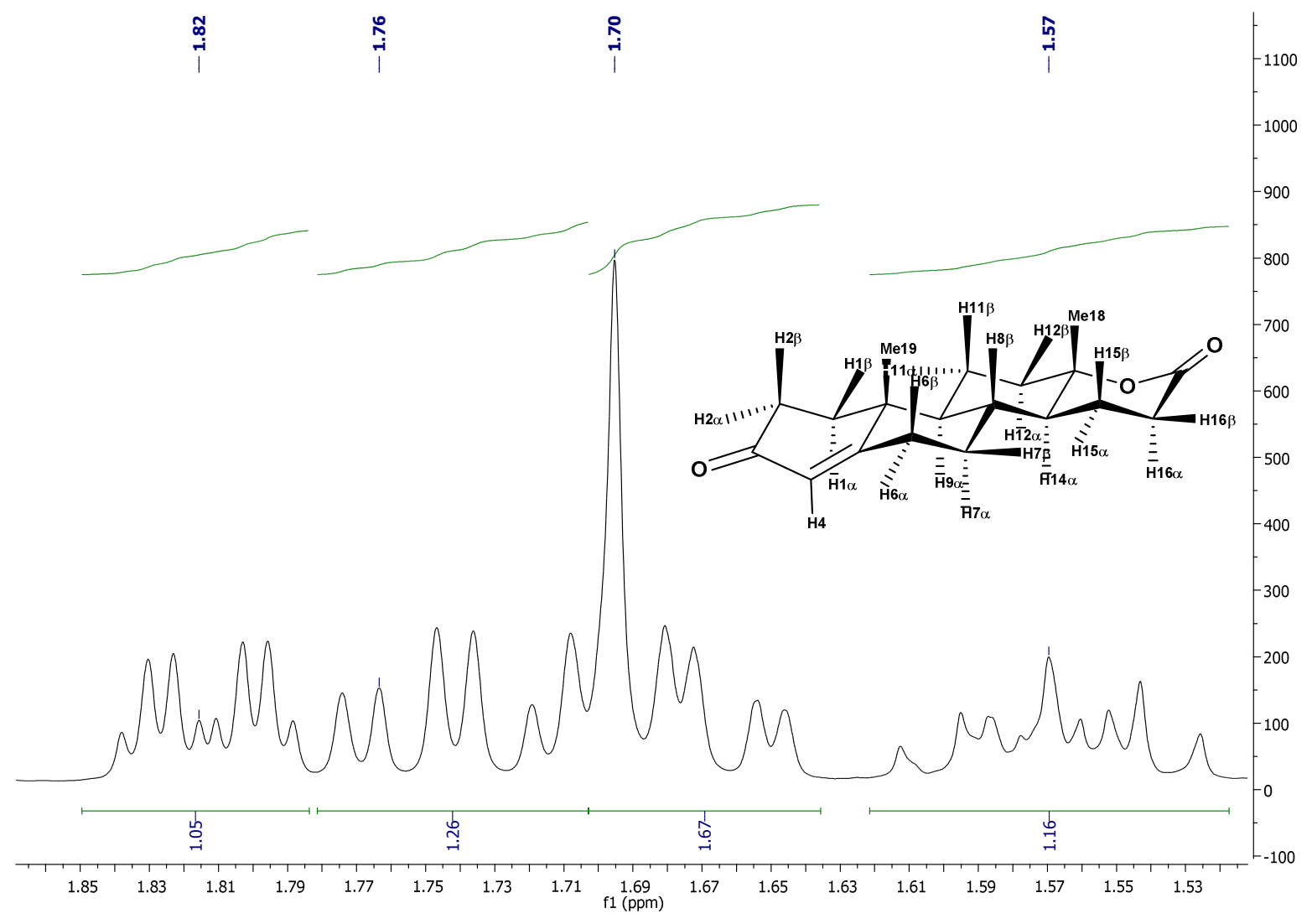

Espectro de $\mathrm{RMN}{ }^{1} \mathrm{H}\left(500 \mathrm{MHz}, \mathrm{CDCl}_{3}\right)$ testololactona (ampliação 1,96 - 2,50 ppm).

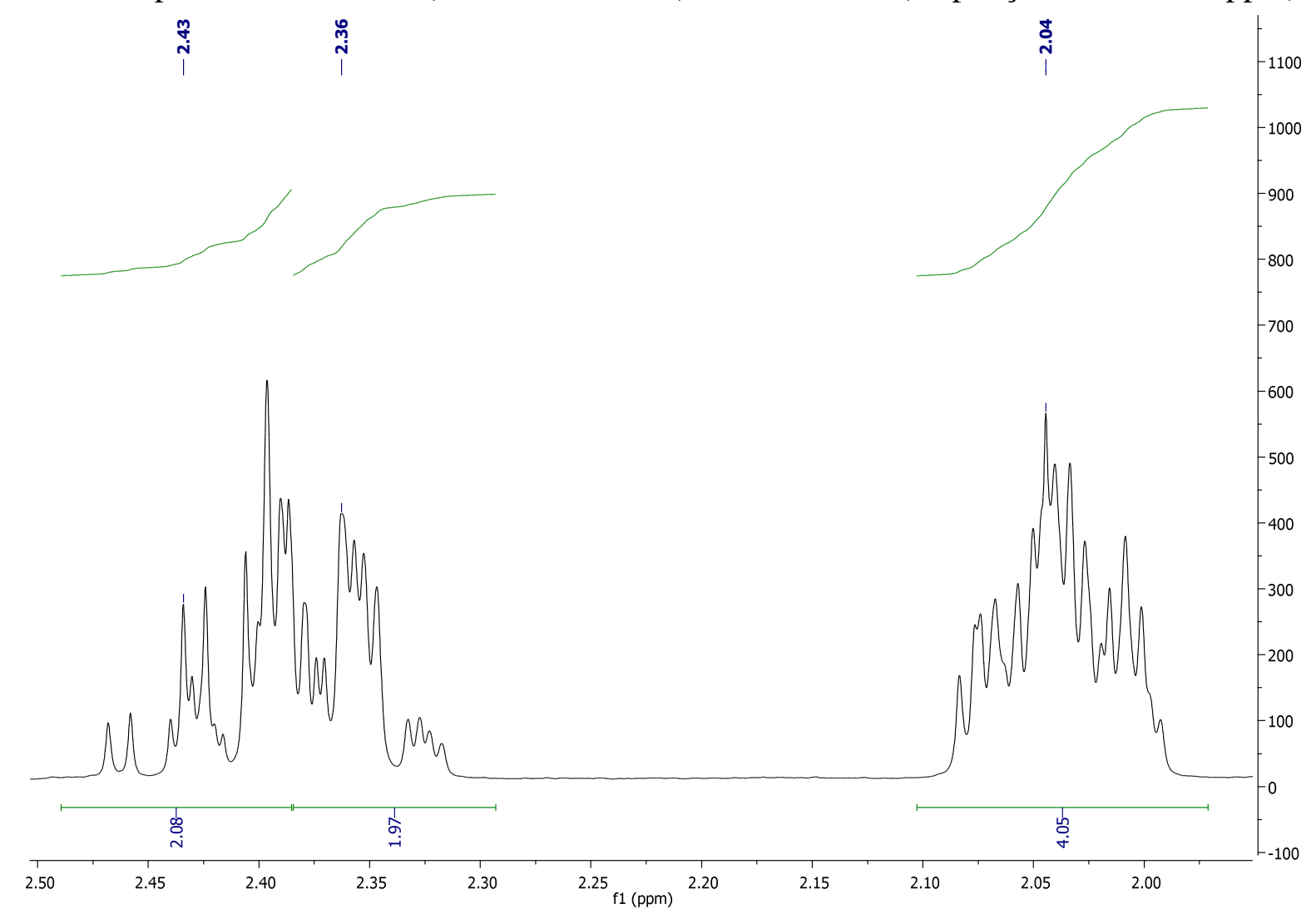


Constantes de acoplamento encontradas nos sinais dos multipletos dos hidrogênios H$16 \alpha$ e H-16 $\beta$ da testololactona a partir do seu espectro de $\mathrm{RMN}{ }^{1} \mathrm{H}\left(500 \mathrm{MHz}, \mathrm{CDCl}_{3}\right)$.

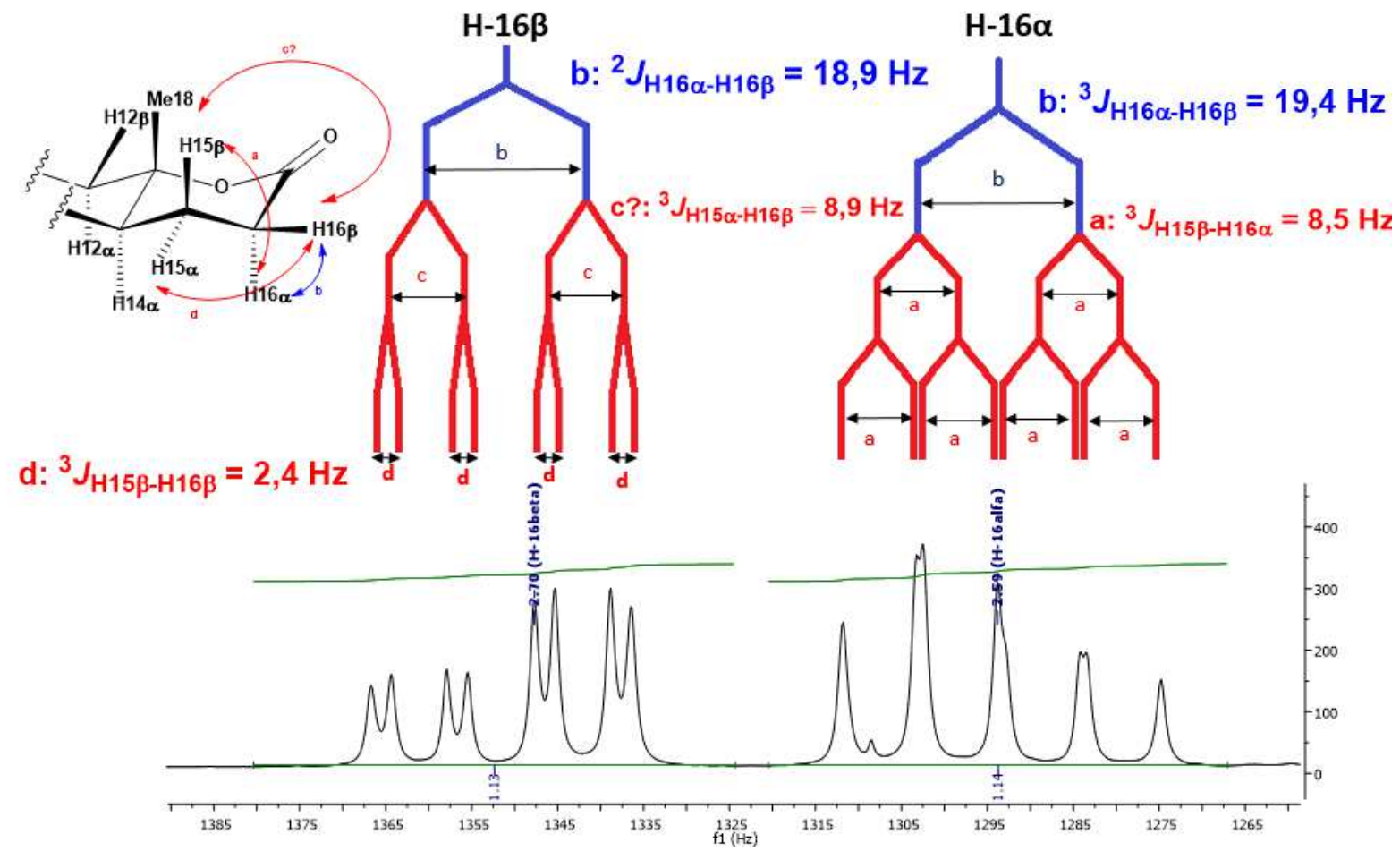

Espectro de EMAR - Modo positivo $\left({ }^{+} \mathrm{H}\right)$ - Full Scan da testololactona e ampliação do pico teórico do íon molecular.

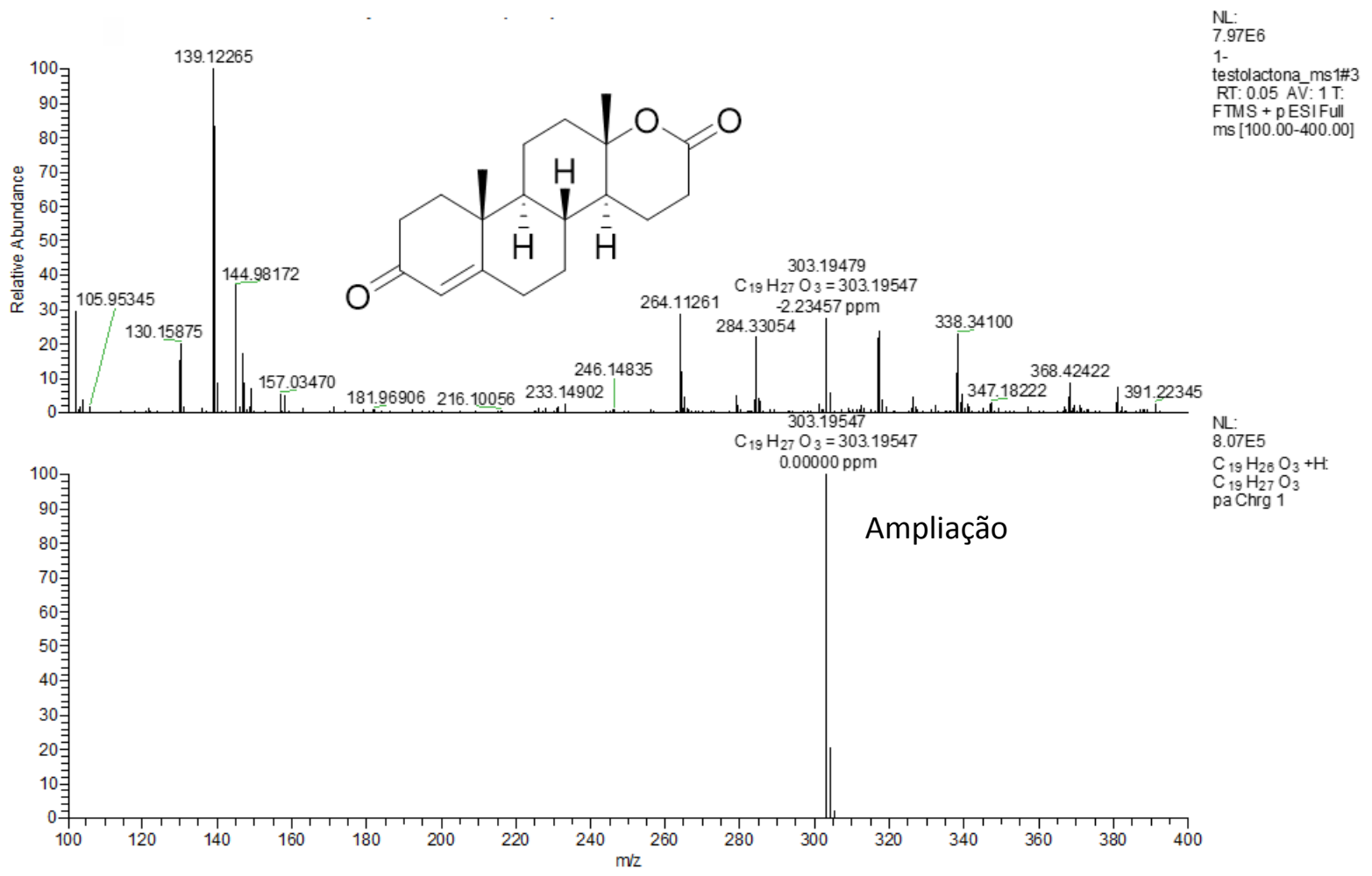

